\title{
Hanford Personnel Dosimeter Supporting Studies FY-1980
}

J. J. Fix, Program Manager

G. W. R. Endres

(Study 1)

F. M. Cummings

(Study 2)

F. M. Cummings

(Study 3)

J. M. Aldrich

(Study 4)

M. R. Thorson

(Study 5)

F. M. Cummings

(Study 6)

R. L. Kathren

(Study 7)

M. R. Thorson

(Study 8)

February 1981

Prepared for the U.S. Department of Energy under Contract DE-AC06-76RLO 1830

Pacific Northwest Laboratory

Operated for the U.S. Department of Energy by Battelle Memorial Institute 


\title{
NOTICE
}

This report was prepared as an account of work sponsored by the United States Government. Neither the United States nor the Department of Energy, nor any of their employees, nor any of their contractors, subcontractors, or their employees, makes any warranty, express or implied, or assumes any legal liability or responsibility for the accuracy, completeness or usefulness of any information, apparatus, product or process disclosed, or represents that its use would not infringe privately owned rights.

The views, opinions and conclusions contained in this report are those of the contractor and do not necessarily represent those of the United States Government or the United States Department of Energy.

\author{
PACIFIC NORTHWEST LABORATORY \\ operated by \\ BATTELLE \\ for the \\ UNITED STATES DEPARTMENT OF ENERGY \\ Under Contract EY-76-C-06-1830
}

\author{
Printed in the United States of America \\ Available from \\ National Technical Information Service \\ United States Department of Commerce \\ 5285 Port Royal Road \\ Springfield, Virginia 22151 \\ Price: Printed Copy $\$ \_$_ : Microfiche $\$ \mathbf{\$ 3} .00$ \\ NTIS \\ - Pages Selling Price \\ 001-025 $\$ 4.00$ \\ 026-050 \$4.50 \\ 051-075 \$5.25 \\ 076-100 \$6.00 \\ $101-125 \quad \$ 6.50$ \\ $126-150 \quad \$ 7.25$ \\ $151-175 \quad \$ 8.00$ \\ $176-200 \quad \$ 9.00$ \\ 201-225 $\$ \$ 9.25$ \\ $226-250 \quad \$ 9.50$ \\ $251.275 \quad \$ 10.75$ \\ 276-300 $\$ \$ 11.00$
}




\section{3}

HANFORD PERSONNEL DOSIMETER

SUPPORTING STUDIES FY-1980

Coordinator: J. J. Fix, Program Manager

Primary Authors:

G. W. R. Endres

F. M. Cummings

F. M. Cummings

J. M. Aldrich

M. R. Thorson

F. M. Cummings

R. L. Kathren

M. R. Thorson

(Study 1)

(Study 2)

(Study 3)

(Study 4)

(Study 5)

(Study 6)

(Study 7)

(Study 8)

Contributing Authors:

J. J. Fix

R. C. Yoder

G. W. R. Endres

L. L. Nichols

M. R. Thorson

D. L. Haggard

J. M. Aldrich

M. K. Winegardner

February 1981

Prepared for

the U.S. Department of Energy

under Contract DE-AC06-76RLO 1830

Pacific Northwest Laboratory

Richland, Washington 99352 


\section{FOREWORD}

DOE-Richland Operations funded eight specific studies during FY-1980 intended to better characterize the response of the 4-chip and 5-chip Hanford multipurpose dosimeters to current field conditions and expected future field conditions resulting from probable projects at Hanford (i.e., FMIT, Thorium Fuel Studies, etc.). These studies complement similar work conducted in the latter 1960s related to the design and implementation of the albedo thermoluminescent type dosimetry at Hanford. Studies funded during FY-1980 and included in this report are as follows:

1. Neutron Response

2. High Energy Photon Response

3. Beta and Low Energy Photon Response

4. Evaluate Existing Radiation Fields

5. Phantom Position Dependence

6. Environmental Factors

7. Extremity Dosimeter

8. Statistical and Low Dose Response.

The diversity of potential operations at Hanford and the uncertainty of future methods of neutron dose assessment have led to the need to re-examine the Hanford Personnel Dosimetry program to insure continued routine personnel dosimetry consistent with the best practices realistically available. Studies supporting different aspects of the dosimetry program including field radiation measurements, calibration sources and methods, dosimeter design, and dose interpretation, as well as characteristics of the reader will be documented during the coming years. These studies will provide strong technical documentation for the Hanford Personnel Dosimetry Program and allow a bas is for any program changes needed in the forseeable future. 


\section{SUMMARY}

The studies included in this report describe fundamental characteristics of the Hanford multipurpose personnel dosimeter (HMPD). Use of the data contained herein to determine dosimeter response from mixed field irradiation must be done with caution. Several observations, explained in greater detail in the appropriate study, can be made regarding the response of the HMPD, as follows:

- Dose Detection Leve1. For laboratory exposure to a single radiation source, the minimum significant detection levels are:

- 11 mrem for a strontium source,

- 3-4 mrem for photon irradiation greater than $100 \mathrm{kev}$,

- 0.2 mrem for thermal neutron irradiation for the PuBe: $\mathrm{D}_{2} \mathrm{O}$ source, and

- 10 mrem for fast neutron irradiation from a ${ }^{252} \mathrm{Cf}$ source.

The minimum significant detection level is determined when the calculated dose and standard deviation are equal to each other.

- Precision of Dose Estimates. For laboratory dosimeter exposures, the best calculated precision $( \pm 1 \sigma)$ was

- $\pm 7 \%$ for strontium calibration at a dose $>300 \mathrm{mrad}$

- $\pm 8 \%$ for photon calibration $\left({ }^{60} \mathrm{Co}\right)$ at a dose $\geq 150 \mathrm{mrad}$

- $\pm 13 \%$ for thermal neutron calibration using the PuBe: $D_{2} 0$ source at a dose equivalent $\geq 5$ mrem

- $\pm 60 \%$ for fast neutron calibration using the ${ }^{252} \mathrm{Cf}$ source at a dose equivalent $\geq 20 \mathrm{mrem}$.

- Energy Response. The response of the HMPD is known (and expected) to be energy dependent to beta, gamma, and neutron radiation. Studies 1, 2, and 3 quantify the energy response for each radiation type. For personnel dosimetry, it is important that the calibration and field spectra are similar allowing a good estimation of the dose received. Study 4 describes several methods used to measure radiation fields and in appendices data collected at specific Hanford locations. 


\section{ACKNOWLEDGMENT}

Several organizations within PNL, such as graphics, duplicating, and photography, provided their talents in the preparation of this document. Special acknowledgment is due Fred Eichner, Virginia Tews, and Mark Johnson for preparing and reading the many dosimeters used in the various studies as well as compiling all of the initial data. Marianna Cross provided much of the technical typing as well as coordinating the compilation of the document with the various authors. 
Additional locations will be studied during 1981. In general, the data collected to date indicate penetrating photon radiation and average neutron energies of a few hundred keV. The dosimeter interpreted dose for these conditions is consistent with field measurments for both photon and neutron radiation. No significant low level beta radiation was observed at the locations monitored (Study 4).

A potentially significant field consideration was observed regarding the narrow field of view for the dosimeter response in that only neutron radiation incident on the front of the body (and dosimeter) is significantly detected. Neutron radiation incident on the back or side of the body will result in a much lower dosimeter response relative to an instrument response. Most instruments have a wide field of view and the multisphere system has a full $360^{\circ}$ response.

- Environmental Sensitivity. The HMPD is generally insensitive to most environmental factors encountered in the work place. The effect of temperature and/or humidity is apparently negligible over the range of $19^{\circ}$ to $50^{\circ} \mathrm{C}$ and $10 \%$ to $95 \%$ relative humidity, respectively. Any effect from mechanical shock or microwave radiation was not discernable. Certain chemical contaminants, such as talc or hand cream, can cause significant thermoluminescence (interpreted as radiation dose received) if present on the dosimeter card (teflon over chip). 


\section{CONTENTS}

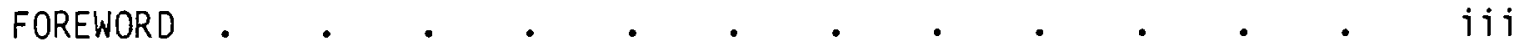

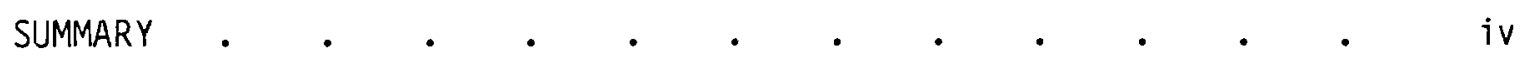

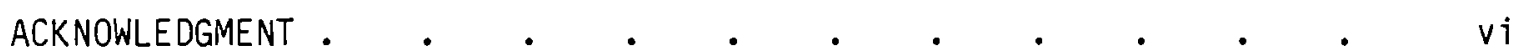

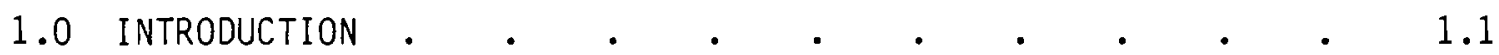

NONPENETRATING RADIATION RESPONSE • $\quad . \quad \ldots \quad$. $\quad . \quad$. $\quad 1.3$

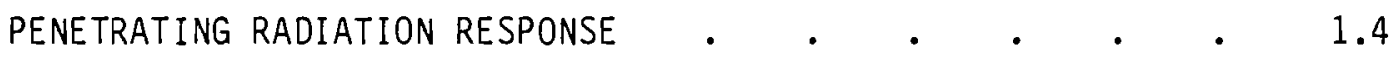

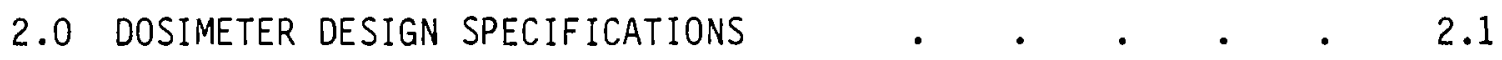

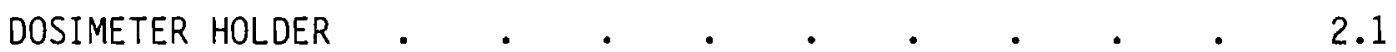

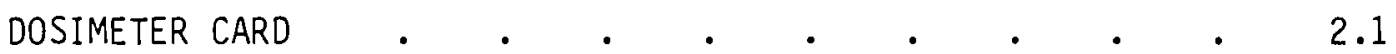

3.0 STUDY 1 - NEUTRON RESPONSE STUDY

G. W. R. Endres, J. J. Fix, M. R. Thorson,

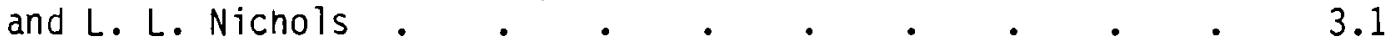

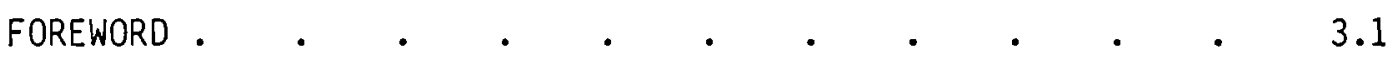

SUMMARY

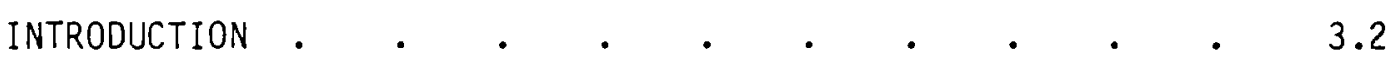

THEORY

Thermoluminescence-Albedo Dosimeters . . . . . 3.4

Energy Response Problems of Thermoluminescent-Albedo

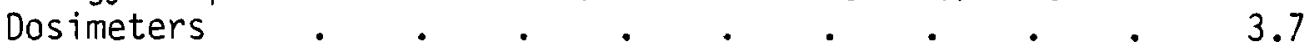

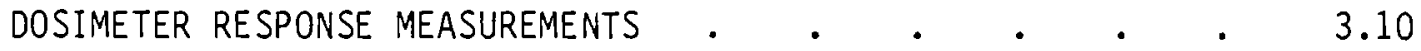

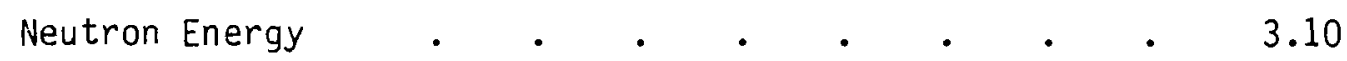

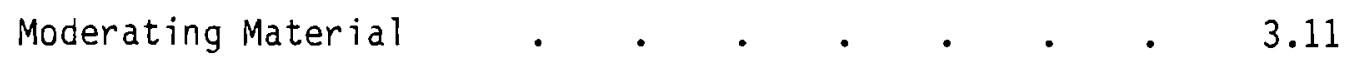

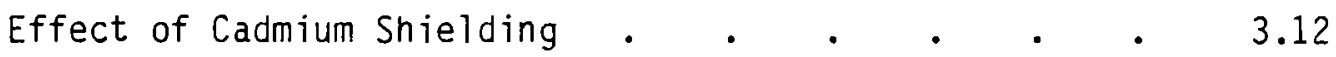

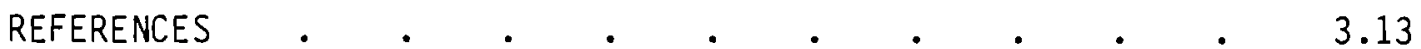


4.0 STUDY 2 - HIGH ENERGY PHOTON RESPONSE

F. M. Cummings, R. C. Yoder, G.W. R. Endres, and R.L. Kathren . . . . . .

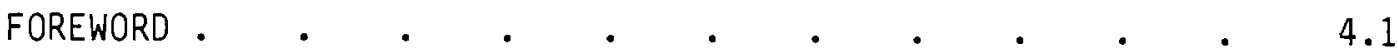

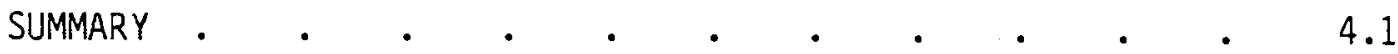

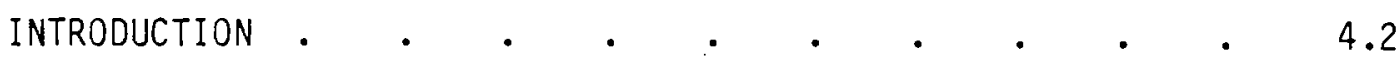

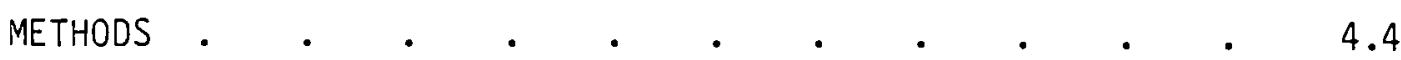

RESULTS

DISCUSSION

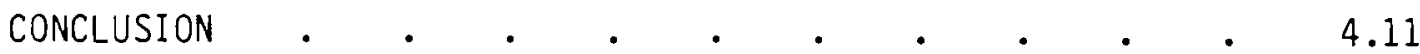

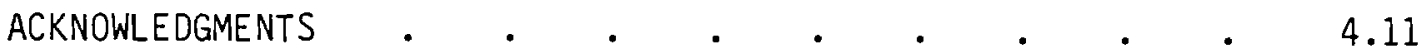

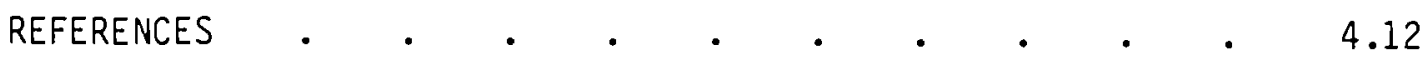

5.0 STUDY 3 - BETA AND LOW ENERGY PHOTON RESPONSE

F. M. Cummings and R. C. Yoder . . . . . . 5.1

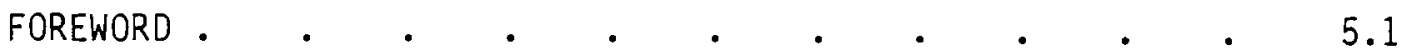

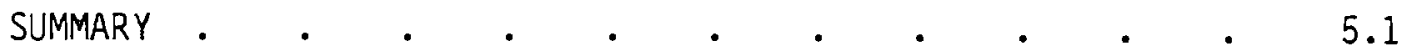

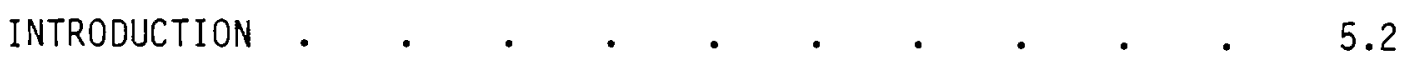

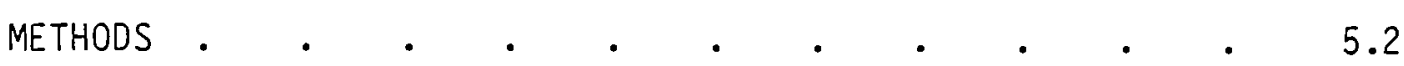

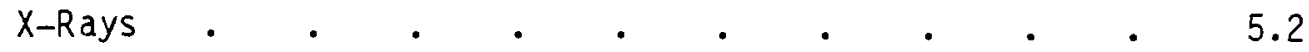

Beta Irradiations $\quad . \quad$. $\quad . \quad$. $\quad . \quad .5 .3$

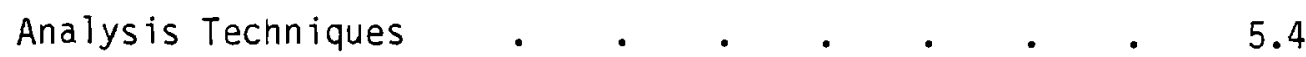

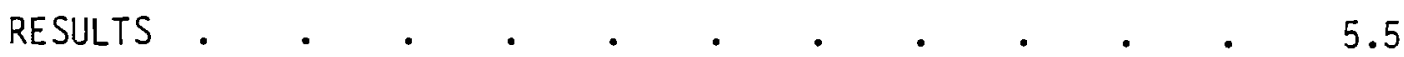

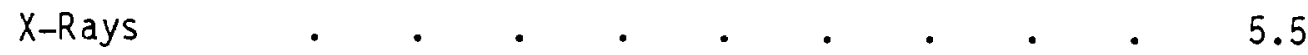

Dosimeters with Credentials . $\quad$. $\quad$. 5.5

Dosimeters Without Credentials . . . . 5.6 


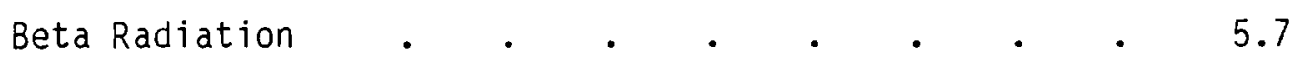

Dosimeters with Credentials . $\quad$ • $\quad$. 5.7

Dosimeters Without Credentials . . . . 5.8

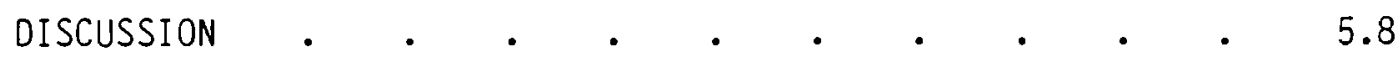

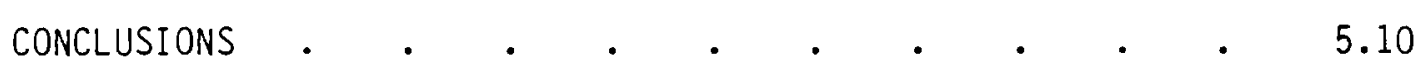

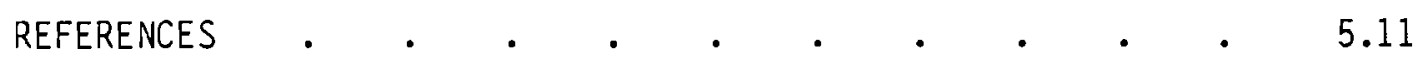

6.0 STUDY 4 - EVALUATE EXISTING RADIATION FIELDS

J. M. Aldrich, D. L. Haggard, G. W. R. Endres,

and J.J.Fix. . . . . . . . . . . 6.1

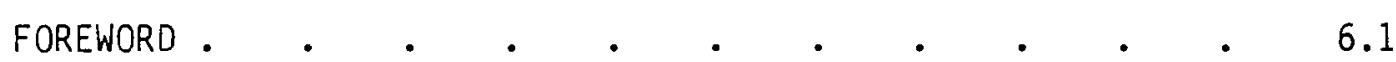

SUMMARY

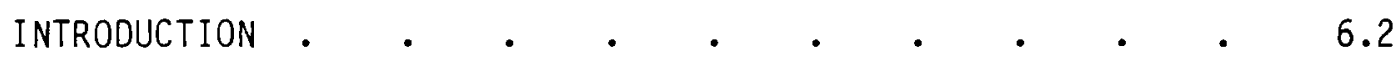

MATERIALS AND METHODS $. \quad . \quad . \quad . \quad . \quad . \quad . \quad 6.3$

Multisphere Spectrometer System . $\quad$. $\quad$. $\quad 6.3$

Tissue Equivalent Proportional Counter (TEPC) . $\quad$. 6.9

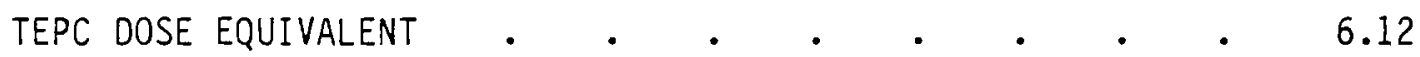

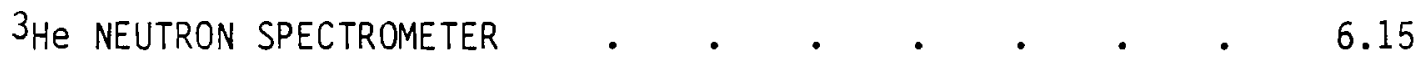

Theory of Operation . . . . . . . . . 6.15

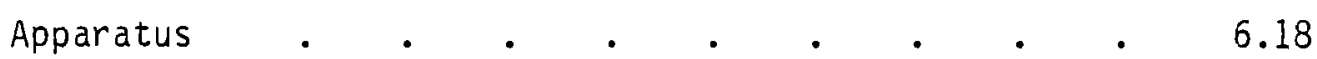

Calibration and Test Performance . . . . . . . 6.21

9" to 3" Sphere Ratios . . . . . . . . . 6.21

GAMMA SPECTROSCOPY .

Field Instrument System . . . . . . . 6.24

Data Collection and Analysis . . . . . . . . . 6.25

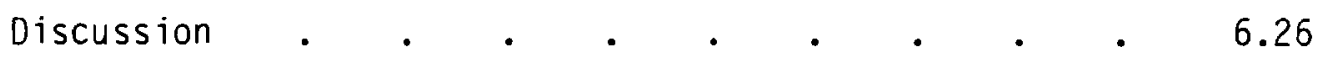

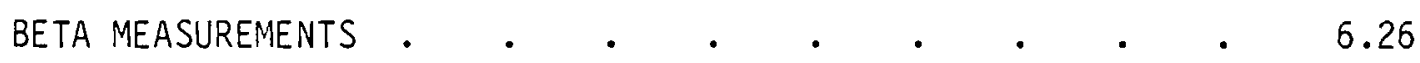

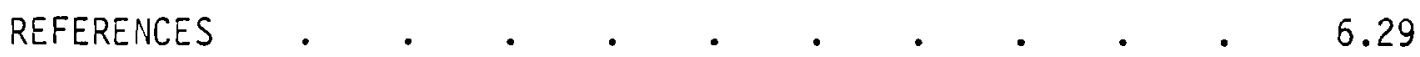




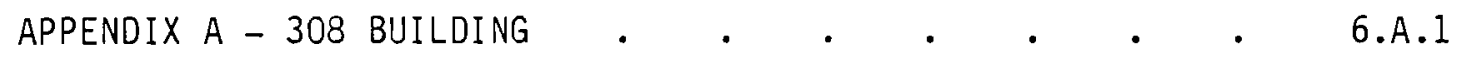

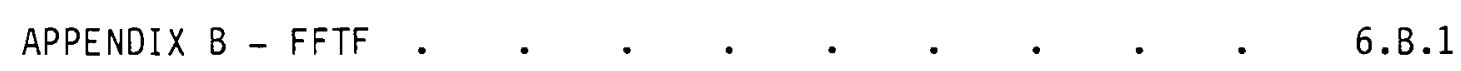

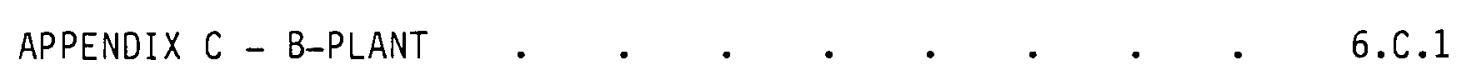

$$
\begin{aligned}
& \text { APPENDIX D - } 200 \text { WEST PLUTONIUM FACILITIES • • • • • } \quad \text { 6.D.1 }
\end{aligned}
$$

7.0 STUDY 5 - PHANTOM POSITION DEPENDENCE

M. R. Thorson and G.W.R. Endres . . . . . . . 7.1

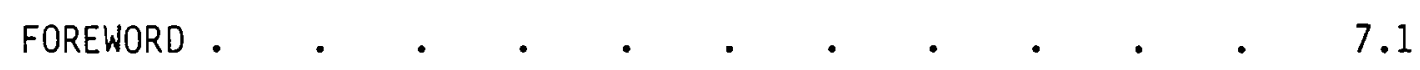

SUMMARY $\quad . \quad$ •

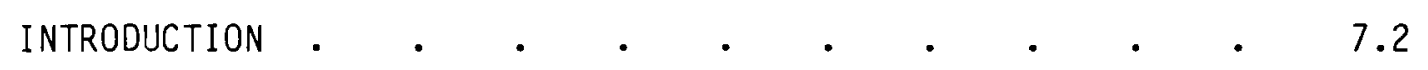

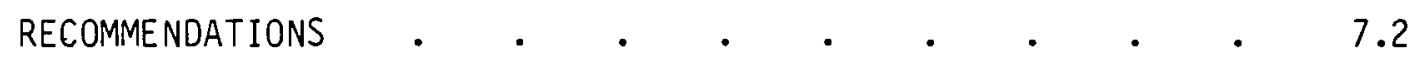

CONCEPT OF POSITIONAL DEPENDENCE, ANGLE DEPENDENCE
AND DISTANCE DEPENDENCE OF NEUTRON RESPONSES $\bullet . \quad \bullet \quad \bullet \quad 7.3$

POSITIONAL DEPENDENCE TO A 252Cf SPECTRUM . . . . . . 7.3

Evidence for Positional Dependence $\quad$. $\quad$ • $\quad$. $\quad$ e 7.4

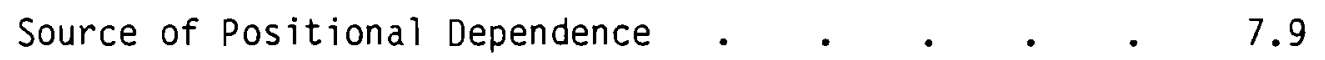

\begin{tabular}{l} 
Sources of Thermoluminescence of Chips 3 and 4 \\
on the Rando Phantom \\
\hline
\end{tabular}

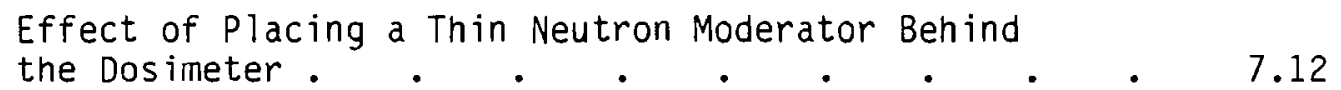

Rotating the Rando Phantom . . . . . . 7.15

Quantification of Positional Dependence for 252 Cf . 7.15

POSITIONAL DEPENDENCE AS A FUNCTION OF ENERGY • • • • $\quad 7.16$

POSITIONAL DEPENDENCE TO BARE PUBE AND BARE PUF 4 _ . $\quad 7.19$

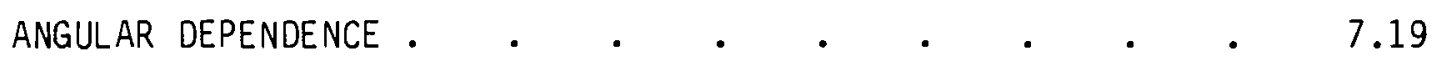

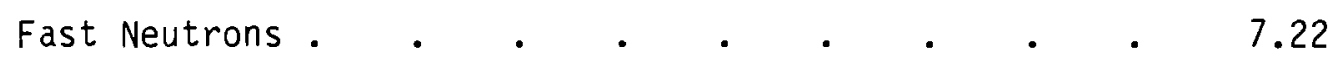

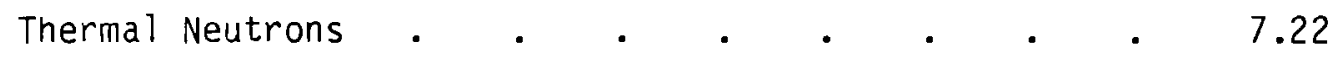


APPENDIX A - ENERGY SPECTRA AND CROSS SECTIONS • • • $\quad$ 7.A.1

APPENDIX B - DOSIMETER WITH PLEXIGLAS ATTACHED TO BACK • 7.8 .1

8.0 STUDY 6 - ENVIRONMENTAL EFFEFTS ON THE HANFORD

MULTIPURPOSE PERSONNEL DOSIMETER

F. M. Cummings

8.1

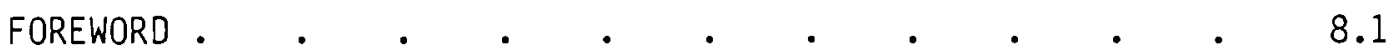

SUMMARY

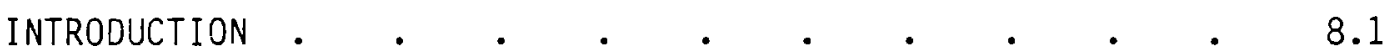

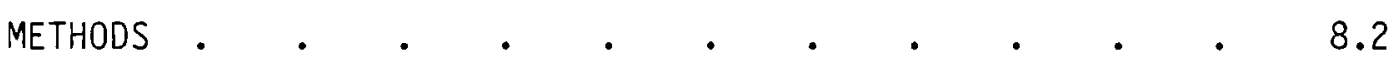

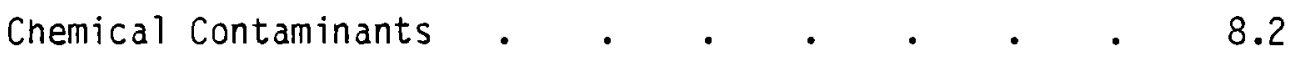

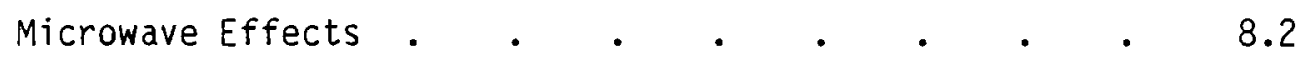

Mechanical Shock $\quad . \quad$. $\quad . \quad$.

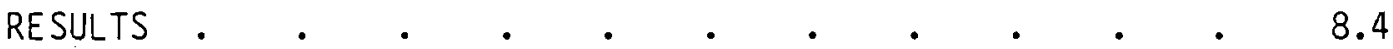

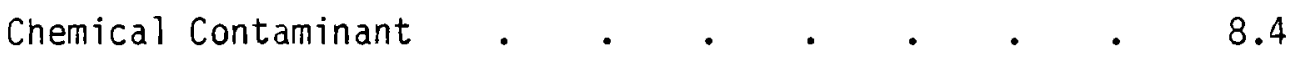

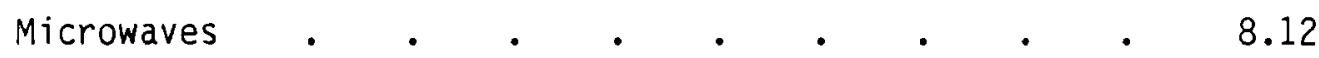

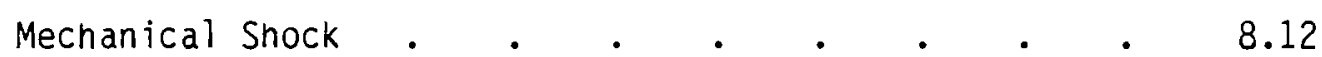

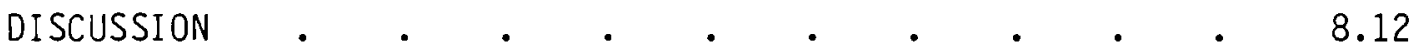

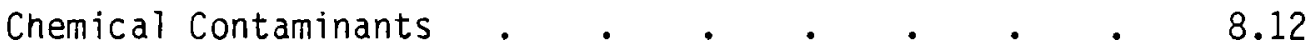

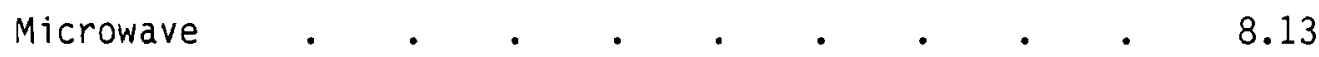

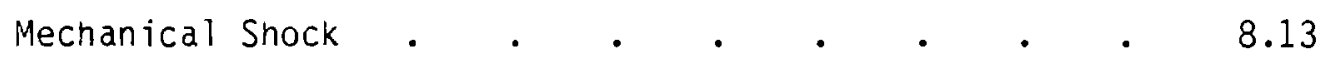

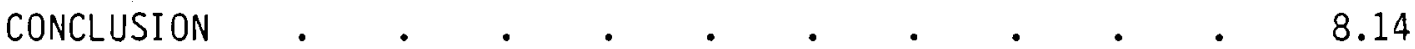

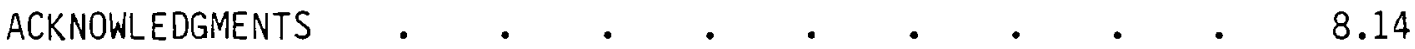

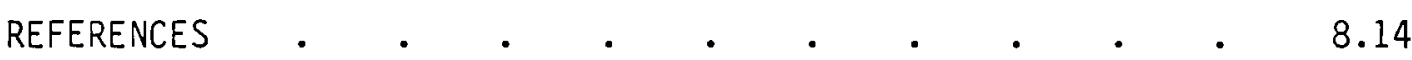

9.0 STUDY 7 - EXTREMITY DOSIMETER STUDIES

R. L. Kathren, J. W. Aldrich, G. W. R. Endres

and M. K. Winegardner . . . . . . . . . . . 9.1

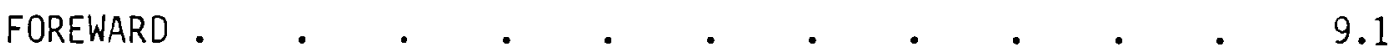

SUMMARY 


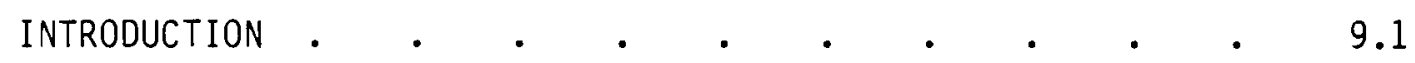

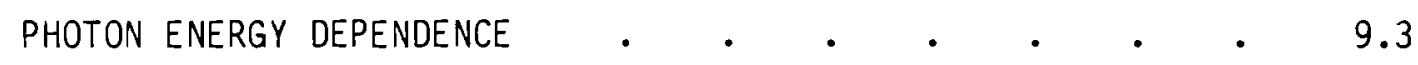

BETA RESPONSE •

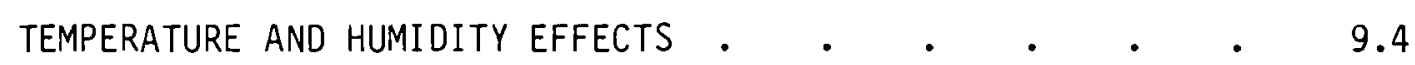

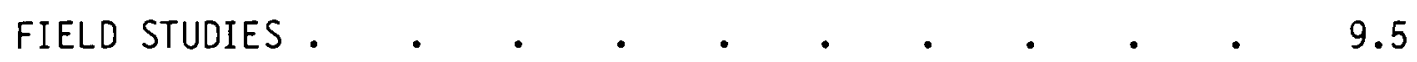

HUMAN FACTORS •

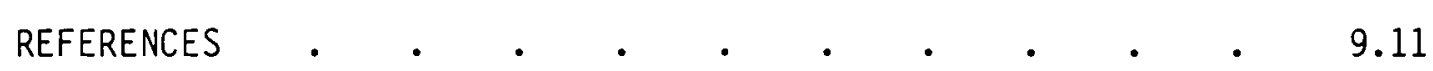

10.0 STUDY 8 - STATISTICAL AND LOW DOSE RESPONSE
M. R. Thorson and G. W. R. Endres • • • • • • . . 10.1

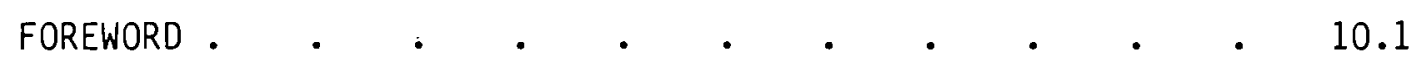

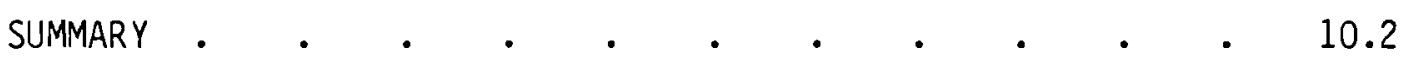

RECOMMENDATIONS $\quad . \quad$.

INTRODUCTION

IMPORTANCE OF STANDARD DEVIATION

SOURCES OF CALCULATING STANDARD DEVIATIONS $\quad \cdot \quad \cdot \quad \cdot \quad 10.9$

COMBINING SOURCES OF VARIANCE $\quad$. $\quad . \quad \ldots \quad . \quad$. 10.11

DISCUSSION

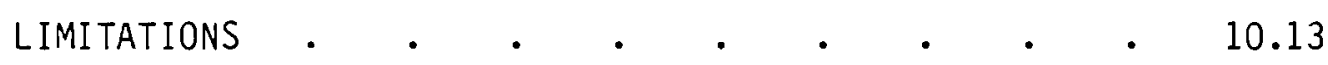

USE OF DATA IN TABLES AND FIGURES • • • • • • • 10.14

DESCRIPTION OF PRECISION, PROBLEMS, AND DETERMINATE ERROR 10.19

EFFECT OF "ZEROING" ALL NEGATIVE VALUES • • • • 10.23

THEORY AND EQUATIONS

ASSUMPTIONS $\quad . \quad$.

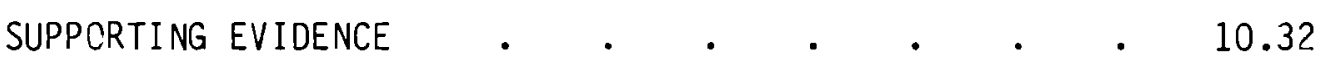




\begin{tabular}{|c|c|c|c|c|c|}
\hline \multicolumn{2}{|l|}{ EXPERIMENTAL AND CALCULATION METHOD } & - & • & • & 10.37 \\
\hline \multicolumn{2}{|l|}{ GENERAL HMPD RESPONSE AND VARIABILITY } & - & - & - & 10.37 \\
\hline \multicolumn{2}{|l|}{ LiF--READER BACKGROUND VARIABILITY } & - & - & - & 10.44 \\
\hline \multicolumn{3}{|c|}{ CALIBRATION DOSIMETER RESPONSE AND VARIABILITY } & - & - & 10.44 \\
\hline CALIBRATION EXPOSURE VARIABILITY & - & - & - & • & 10.48 \\
\hline READER RESPONSE VARIABILITY & - & $\cdot$ & $\cdot$ & • & 10.50 \\
\hline \multicolumn{5}{|c|}{ VERIFICATION OF STANDARD DEVIATION EQUATIONS AND } & 10.52 \\
\hline REFERENCES & - & - & - & - & 10.56 \\
\hline \multicolumn{6}{|c|}{$\begin{array}{l}\text { APPENDIX A - TABLE A.10.1. } \\
\text { CALCULATED STANDARD DEVIATIONS FOR } 100 \text { MREM }\end{array}$} \\
\hline APPENDIX B - CALCULATIONS FOR TABLE 10. & 4. & - & - & $\cdot$ & 10.8 .1 \\
\hline
\end{tabular}




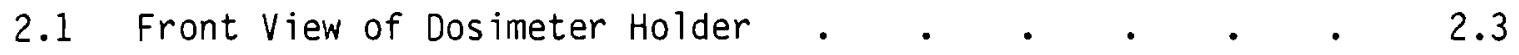

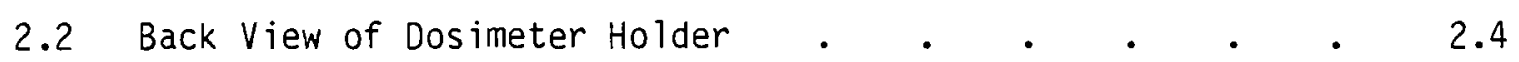

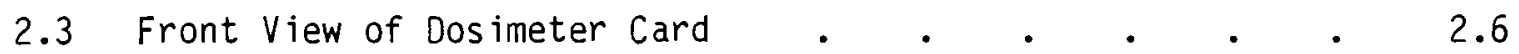

3.1 Hydrogen Scattering Cross Section as a Function of Neutron

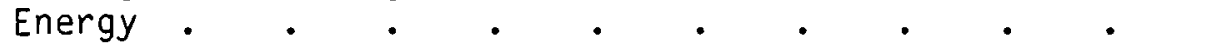

3.2 6 Lif Absorption Cross Section as a Function of Neutron

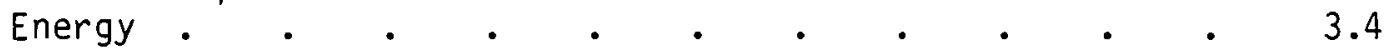

3.3 Basic Concept of TLD-Albedo Dosimeter . . . . . . $\quad 3.6$

3.4 Energy Dependence of Various Albedo Dosimeters . $\quad$ • $\quad 3.8$

3.5 Design of Karlsruhe TLD-Albedo Dosimeter $\quad . \quad \ldots \quad$ e $\quad 3.9$

3.6 Relative Neutron Energy Response of Hanford 3.11

3.7 Relative Neutron Energy Response of Hanford
Dosimeter Exposed on a Rando Phantom . . . . . . 3.12

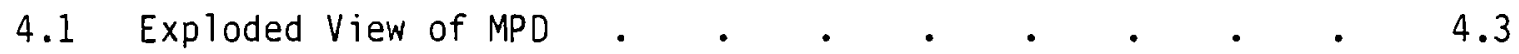

5.0 Spectrum From $16.1 \mathrm{keV}$ X-Ray $\quad . \quad$. $\quad . \quad$. $\quad . \quad$. 5.23

5.1 Spectrum From $23.7 \mathrm{keV} \mathrm{X-Ray} \quad$. $\quad$. $\quad . \quad$. $\quad . \quad$. 5.23

5.2 Spectrum from $34.3 \mathrm{keV} \mathrm{X-Ray} \quad$. $\quad . \quad$. $\quad . \quad$. 5.24

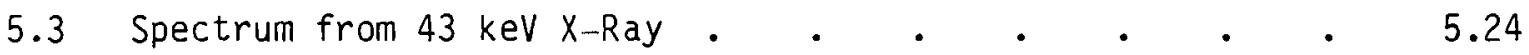

5.4 Spectrum from $58 \mathrm{keV} \mathrm{X-Ray} \mathrm{.} \quad$. $\quad$. $\quad$. $\quad$. 5.25

5.5 Spectrum from $78 \mathrm{keV} \mathrm{X-Ray} \mathrm{.} \mathrm{.} \mathrm{.} \mathrm{.} \mathrm{.} \mathrm{.} \mathrm{.} \mathrm{.} \mathrm{.} 5.25$

5.6 Response of Unfiltered TLD Chip . . . . . . . 5.26

5.7 Dose Response of Unfiltered TLO . . . . . . . 5.27

5.8 Ratio of Light Outputs of Unfiltered TLD Chip to Al $\quad 5.28$

5.9 Calculated Nonpenetrating Dose Response Function, X-rays . 5.29

5.10 Reported Skin Dose Response Function, X-rays . $\quad$. $\quad 5.30$ 
5.11 Ratio of Raw Count to Skin Dose, Beta . . . . . . 5.31

5.12 Calculated Dose Response Function, Beta $\quad$. $\quad$ • 5.32

5.13 Reported Dose Response Function, Beta . $\quad$. $\quad$. 5.33

6.1 Block Diagram of the Multisphere System . . . . 6.3

6.2 Multisphere Spectrometer and TEPC Systems . $\quad . \quad$. $\quad 6.10$

6.3 B lock Diagram of TEPC System $\quad . \quad \ldots \quad$. $\quad . \quad$. $\quad . \quad 6.11$

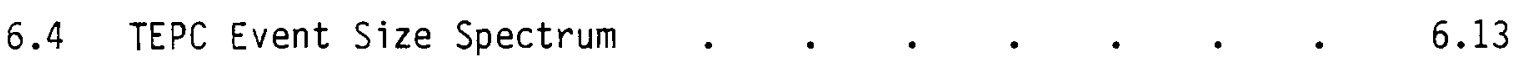

6.5 3He Cross Sections for Neutron Induced Charged

Particle Reactions as a Function of Neutron Energy . $\quad 6.16$

6.6 Block Diagram of the Electronic Equipment Used to

Construct the 3He Neutron Spectrometer . . . . 6.19

6.7 Effect of Cadmium Covering and Electronic Pulse Pile-Up

Rejection Circuitry in Reducing the Amount of Pulse

Pile-Up in High Dose Rate Neutron Fields . . . . 6.20

6.8 Results Obtained by Exposing the 3He Neutron Spectrometer to $144 \mathrm{keV}$ Moncenergetic Neutrons at the Filtered Neutron Beam

Facility at the U.S. National Bureau of Standards . $\quad 6.22$

6.9 Results Obtained by Exposing the ${ }^{3}$ He Neutron Spectrometer to $25 \mathrm{keV}$ Monoenergetic Neutrons at the Filtered Neutron Beam Facility at the U.S. National Bureau of Standards . .

6.10 Effective Neutron Energy as a Function of the Ratio of 23-cm to 6.76-cm Polyethylene Sphere Responses . . . 6.24

6.11 Simplified Layout of Equipment Used for Taking Gamma Spectrum Measurements . $. \quad . \quad . \quad . \quad . \quad . \quad . \quad .6 .25$

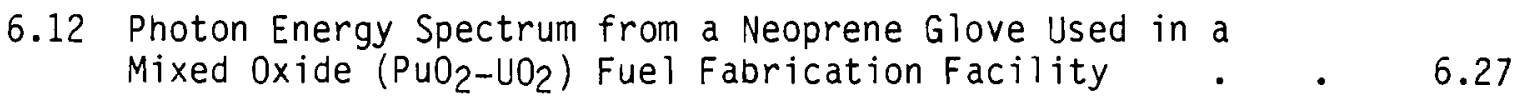

6.13 Modified Hanford Dosimeter for Beta Measurements . $\quad 6.28$

6.A.1 Neutron Spectra Measured by a Multisphere Spectrometer
at a Plutonium Fuel Fabrication Facility . . . . 6.A.2 
6.A.2 Photon Energy Spectrum of General Room Background in the

Fuel Fabrication Facility . . . . . . . 6.A.5

6.A.3 Photon Energy Spectrum Thru Bottom of Grinder Hood in a Mixed Oxide $\left(\mathrm{PuO}_{2}-\mathrm{UO}_{2} \mathrm{O}\right)$ Fuel Fabrication Facility 6.A.6

6.A.4 Photon Energy Spectrum From a Neoprene Glove Used in a Mixed Oxide $\left(\mathrm{PuO}_{2}-\mathrm{UO}_{2} \mathrm{O}\right)$ Fuel Fabrication Facility

6.A.5 Spectrum of General Room Background at Room Entry Near A-Cell. 327 Building . . . . . . . . 6.A.8

6.A.6 Spectrum of G-Cell-Open Portal. 327 Building . . . $\quad$ 6.A.9

6.B.1 Spectrum Taken Near 241-TX-302-C Catch Tank . 6. B. .

6.B.2 Spectrum Taken Outside Near 242-S Evaporator Building 200 West Area . . . . . . . . . 6.8.3

6.B.3 Spectrum Taken Near 152-U Diversion Box

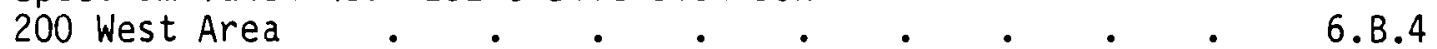

6.B.4 Plots of Radiation Penetration Through Increasing Filtration Using Modified Hanford Dosimeter . . . . 6.B.5

6.C.1 General Room Spectrum Taken Across Operating Gallery From Cell Fronts - 225-B Building

6.C.2 Spectrum Taken at Front Face of A Cell - 225-B Building • 6.C.3

6.C.3 Spectrum Taken at Front Face Between B-C Cells 225-B Building . . . . . . . . . . 6.C.4

6.C.4 Spectrum Taken at Front Face Between D-E Cell 225-B Building . . . . . . . . . 6.C.5

6.C.5 Spectrum Taken at Front Face of F Cell-225-Building . 6.C.6

6.D.1 234-5 Glovebox Neutron Measurements . . . . . . 6.D.3

6.D.2 234-5 Glovebox Spectra Measurements . . . . . . 6.0.3

6.D.3 HMPD Energy Response Curve, 3":9" Sphere Ratios, and
HMPD Neutron Energy Response Correction Factors . . 6.D.6

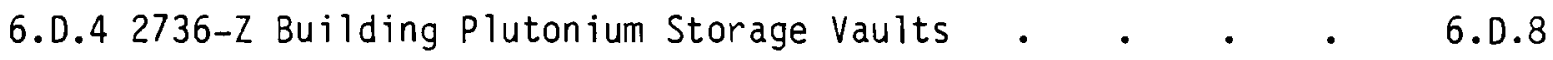


6.0 .5 2736-Z Vault Neutron Measurements . . . . . . 6.0.8

6.0.6 Neutron Critcality Detector Measurement Set-Up . . . 6.0.9

6.0.7 Normal Operation for Inventoring and Placement of $\mathrm{PuO}_{2}$ into the Storage Cubicles . $\quad . \quad$. $\quad$. 6.D.17

7.1a Rando Phantom with Dosimeter Placement Around ThoraxAnterior . . . . . . . . . . 7.5

7.1D Rando Phantom with Dosimeter Placement Around ThoraxPosterior $. \quad . \quad . \quad . \quad . \quad . \quad . \quad . \quad . \quad .7 .6$

7.2 HMPD Response with Position on the Water Jug Phantom • . 7.7

7.3 HMPD Response with Position on the Rando Phantom $\quad 7.8$

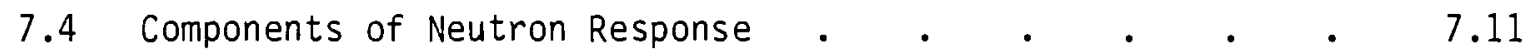

7.5 HMPD Response with 3/8-Inch Plexiglas Between Dosimeter and Rando Phantom . . . . . . . . 7.13

7.6 Rando Phantom Rotated . . . . . . . . . . . . 7.14

7.7 Dosimeter Placement for Van de Graaff Exposures . $\quad$ • $\quad 7.17$

7.8 Positional Dependence as a Function of Energy . . . . 7.18

7.9 HMPD Response with Position on the Rando Phantom to PuBe . 7.20

7.10 HMPD Response with Position on the Rando Phantom to PuF $4 \quad 7.21$

7.11 HMPD Response to Fast Neutrons as a Function of Angle

7.12 HMPD Response to $252 \mathrm{Cf}$ as a Function of Angle
Between Dosimeter and Phantom . . . . . . . 7.24

7.13 HMPD Response to Thermal Neutrons As a Function of Angle
Between Dosimeter and Phantom . . . . . . . . .

7.14 Response to ${ }^{252} \mathrm{Cf}$ as a Function of Distance Between 7.26

7.A.1 Neutron Energy Spectrum of $252 \mathrm{Cf} \quad$. $\quad . \quad$. $\quad . \quad$. $7 . \mathrm{A} .1$

7.A.2 Neutron Energy Spectrum of PuBe . . . . . . . 7. A.2

7.A.3 Neutron Energy Spectrum of PuF 4 . . . . . . . . . . . . 
7.A.4 Hydrogen Cross Section . . . . . . . . . . 7.4 .4

7.B.1 Dosimeter with 3/8-Inch Plexiglas Attached to Back $7 . B .1$

8.1 Glow Curve from an Unirradiated Control TLD-700's . $\quad 8.7$

8.2 Glow Curve from an Irradiated $(137 \mathrm{Cs})$ Control TLD-700 $\quad 8.7$

8.3 Glow Curve from Irradiated and Unirradiated TLD-700's
Contaminated with Spray Perfume . . . . . . 8.8

8.4 Glow Curve from Irradiated TLD-700 Contaminated with

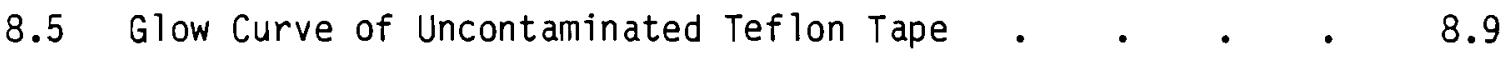

8.6 Glowing Curve of Teflon Tape Contaminated with Talc $\quad$ - 8.9

8.7 Glowing Curve of Teflon Tape Contaminated with

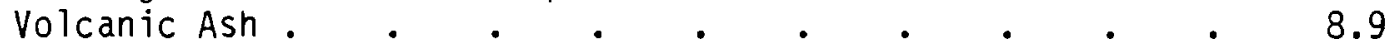

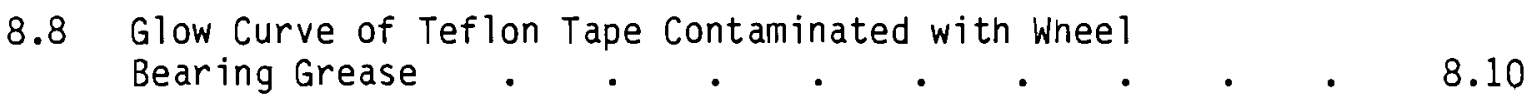

8.9 Glow Curve of Teflon Tape Contaminated with Wheel
Bearing Grease Analys is $\# 1$. 8.10

8.10 Glow Curve of Teflon Tape Contaminated with Wheel
Bearing Grease Analysis \#2 ..$\quad$. . . . . 8.11

8.11 Glow Curve of Teflon Tape Contaminated with Wheel
Bearing Grease Analysis \#3

8.12 Glow Curve of Teflon Tape Contaminated with Wheel
Bearing Grease Unirradiated by UV
.

9.1 Photon Energy Dependence of TLD Rings $\quad$ • $\quad$ e $\quad$ e $\quad$ e $\quad$ e 9.2

9.2 Comparison of Weekly and Monthly Ring Readings . $\quad$ • $\quad 9.6$

9.3 TLD Glow Curves for Different Annealing Procedures • $\quad 9.10$

10.1 a Modified Dosimeter Construction and Snielding . $\quad$ • 10.5

10.1D Current HMP Dosimeter Construction and Shielding $\quad 10.6$

10.2 Schematic for Calculating Dose Standard Deviations 10.12

10.3 Effect of Each Type of Radiation on Calculated
Penetrating Stanciard Deviation . . . . . . . . 10.16 
10.4 Effect of Each Type of Radiation on Calculated Thermal Neutron Standard Deviation

10.5 Effect of Each Type of Radiation on Calculated Fast Neutron Standard Deviation . . . . . . . 10.18

10.6 Effect of Each Type of Radiation on Calculated Nonpenetrating Standard Deviation. . . . . . 10.19

10.7 Effect of Thermal Neutron Exposure on Calculated Fast Neutron Standard Deviation . . . . . . . 10.21

10.8a Normal Frequency Distribution for a Calculated

Dose of $0 \pm 100 \mathrm{mrem} . \quad . \quad . \quad . \quad . \quad . \quad 10.24$

10.8b Effect of "Zeroing" All Negative Values . . . . 10.24

10.9 Low Dose Statistics of LiF, Batch A . . . . . . 10.33

10.10 High Dose Statistics of LiF, Batch B . . . . . . 10.34

10.11 Mixed Field Statistics of LiF, Batch C $\quad$. 10.36

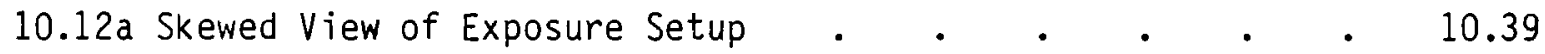

10.12b Side View of Exposure Setup . . . . . . . . . 10.40

10.12c Front-End View of Exposure Setup . . . . . . . 10.41

10.13 Top and Side View of Thermal Neutron Exposure . . . 10.42 


\section{$\underline{\text { TABLES }}$}

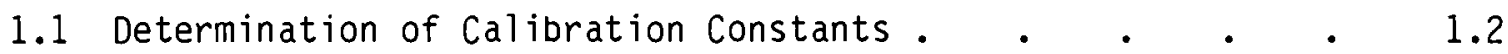

2.1 Filtration by Position for Hanford Personnel Dosimeter $\quad 2.5$

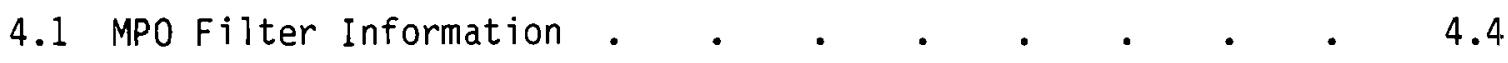

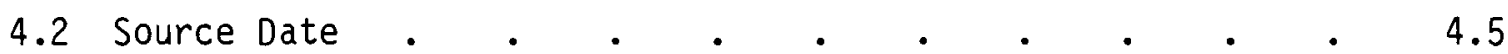

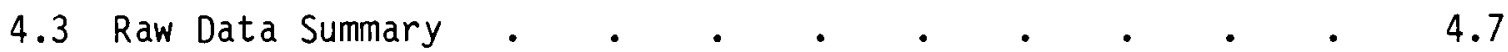

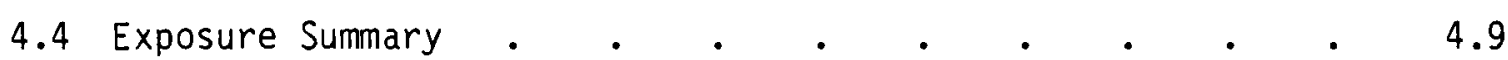

4.5 Dose Data Comparison Summary . . . . . . . . . 4.10

5.1 X-Ray Irradiation Data for Dosimeters Exposed With Credentials 5.12

5.2 Dose Equivalents and Delivered Dose $\quad$. 5.13

5.3 Raw Data Summary for Dosimeters Exposed With Credentials . 5.14

5.4 Chip 1 Response Data for Dosimeters Exposed With Credentials $\quad 5.15$

5.5 Dose Comparison Data for Dosimeters Exposed with Credentials $\quad 5.15$

5.6 Raw Data Summary for Dosimeters Exposed Without Security Credentials $. \quad . \quad . \quad . \quad . \quad . \quad . \quad . \quad . \quad 5.16$

5.7 Chip 1 Response Data for Dosimeters Exposed Without Credentials . $. . \quad . \quad . \quad . \quad . \quad . \quad 5.17$

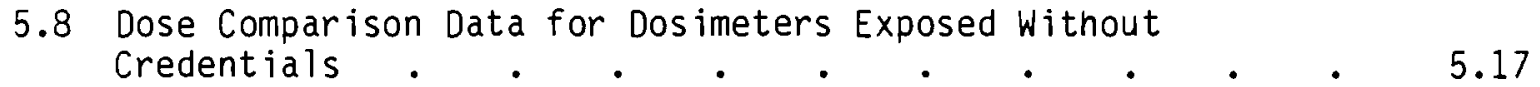

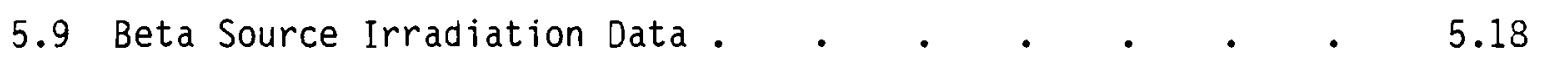

5.10 Beta Radiation Reference Energy . $\quad$. $\quad$. $\quad$. 5.18

5.11 Raw Data Summary for Dosimeters Exposed With Credentials $\quad 5.19$

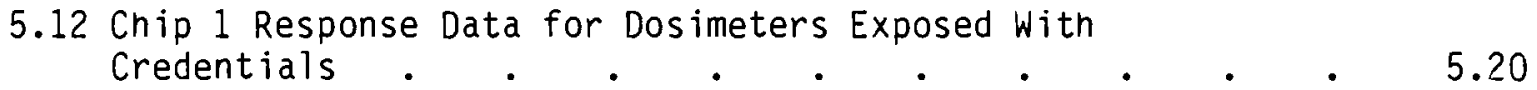

\begin{tabular}{l}
5.13 Dose Comparison Data for Dosimeters Exposed With \\
Credentials \\
\hline
\end{tabular}

5.14 Raw Data Summary for Dosimeters Exposed Without Credentials $\quad 5.21$ 
5.15 Chip 1 Response Data for Dosimeters Exposed Without

Credentials . $. \quad . \quad . \quad . \quad . \quad . \quad$.

5.16 Dose Comparison Data for Dosimeters Exposed Without

Credentials

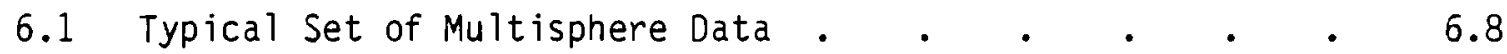

6.2 Materials Used in Dosimeter Construction . . . . . 6.28

6.A.1 Comparison of Various Neutron Dosimeters . . . . . 6.A.3

6.D.1 Neutron Measurements Data from $234-5$ and $2736-2$ Buildings . 6.D.2

6.0.2 234-5 Rm 232-A Glovebox H-9A $\quad$. $\quad . \quad$. $\quad . \quad$. $\quad . \quad 6.0 .4$

$6.0 .3234-5 \mathrm{Rm} 228$ Glovebox HC-9B . . . . . . . . . . 6.0 .5

$6.0 .42736-Z$ Vault 3 3CE-3DE . . . . . . . . . . . . 6.0.10

6.D.5 2736-Z Vault 3 3EE-3FE . . . . . . . . . . . 6.0.11

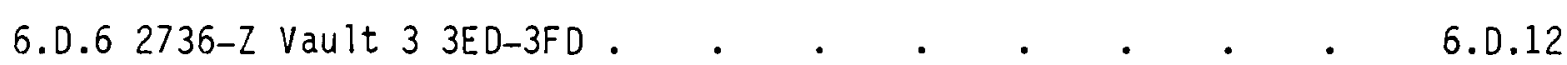

$6.0 .72736-Z$ Vault 43 GE-3HE . . . . . . . . . . . 6.0.13

6.0.8 2736-Z Hallway by Air Sampler . . . . . . . . . 6.0.14

6.D.9 Neutron Criticality Detector Spectrum Measurement . • 6.0.15

8.1 Light Output from Chemically Contaminated Teflon
TFE Tape and Irradiated TLD-700s . . . . . . . 8.3

8.2 Re-read Test Data on Telfon Tape Contaminated with
Wheel Bearing Grease . . . . . . . . . 8.5

8.3 Light Output from Unirradiated and Irradiated TLD-700's
Exposed to Microwave . . . . . . . . . $\quad 8.5$

8.4 Effects of Mechanical Shock on the Hanford

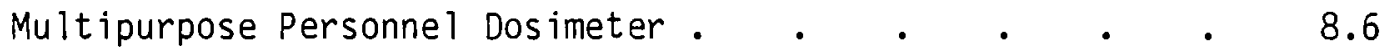

9.1 Response of Hanford TLD Rings to Beta Radiation . $\quad$ • $\quad 9.4$

9.2 Light Ouput of TLD-700 Following Various Annealing Procedures 9.9

10.1 Statistical Comparison of Current Dosimeter with Modified Dosimeter . . . . . . . . . . . 10.7

10.2 Equations Used in Calculating Dose Equivalent . . 10.26 
10.3 Equations Used in Calculating Standard Deviations of Calculated Exposure Due to Independent Chip Variability . 10.28

10.4 Values Used in Calculating Standard Deviations . $\quad$ • 10.38

10.5 Verification of Standard Deviation Equations . . . 10.53

10.6 Comparison of Predicted General HMPD Standard Deviations with Actual Calibrations HMPD Standard Deviations • • 10.54

10.7 Comparison of Predicted General HMPD Standard Deviations with Actual Control HMPD Standard Deviations . . . 10.55 


\subsection{INTRODUCTION}

Studies included in this document illustrate the importance of designing and calibrating the personnel dosimeter based on field conditions. The current personnel dosimeter and calibration techniques were developed to be especially sensitive to the low energy photon and thermal neutron irradiation received during plutonium separation; the major radiation exposure activity at Hanford during the late 1960s and the early 1970s (Purex operations stopped in 1972).

The Hanford dosimeter consists of either a 4-chip dosimeter as follows:

Chip 1. TLD-700 (non-pentrating dose, $88 \mathrm{mg} / \mathrm{cm}^{2}$ filtration)

Chip 2. TLD-700 (penetrating dose, $356 \mathrm{mg} / \mathrm{cm}^{2}$ filtration)

Chip 3. TLD-600 (slow neutron, No Cd filter, $902 \mathrm{mg} / \mathrm{cm}^{2}$ filtration)

Chip 4. TLD-600 (fast neutron, $C d$ filter, $991 \mathrm{mg} / \mathrm{cm}^{2}$ filtration)

or a 5-chip dosimeter with an additional chip as follows:

Chip 5. TLD-700 (gamma compensation, $901 \mathrm{mg} / \mathrm{cm}^{2}$ filtration)

The dosimeter design is described in detail in Section 2 entitled "Dosimeter Design Specifications."

Calibration sources used since the inception of the albedo thermoluminescent dosimeter for each radiation type are:

Non-Penetrating--Several aged uranium disk sources are used each equipped with a specially designed exposure jig. The response of the dosimeter to the uranium source is assumed to be equal to onehalf the response to an aged strontium-90 source encapsulated in $10 \mathrm{mil}$ aluminum (Study 3 ). To calibrate the dosimeter readout, 10 dosimeters are exposed to 4 rads each on the uranium sources (equal to 2 rads of Sr-90).

Penetrating-For the past few years, a cesium-137 source has usually been used although a cobalt-60 source has been used occasionally. Originally, a radium source was used. Ten dosimeters are exposed in air to calibrate the readout of personnel dosimeters. 
Slow Neutron--A graphite moderated sigma pile is used. Six personnel dosimeters are simultaneously exposed in a reproducible geometry for calibration.

Fast Neutron--A PuF 4 source is used. Six dosimeters are exposed on a polyethylene phantom for calibration.

At the beginning of each routine processing of Hanford personnel dosimeters, a set of calibration dosimeters is read through the automated reader. The results of these dosimeters are used to interpret the readout from the personnel dosimeters in terms of dose equivalent.

The results of the calibration dosimeters are used to determine several calibration constants ( $C 1$ through $\mathrm{C} 7$ ) as shown in Table 1.1 .

TABLE 1.1. Determination of Calibration Constants(a)

\begin{tabular}{|c|c|c|c|}
\hline $\begin{array}{l}\text { Nonpenetrating } \\
\text { Calibration } \\
\end{array}$ & $\begin{array}{l}\text { Penetrating } \\
\text { Calibration }\end{array}$ & $\begin{array}{r}\text { Slow Neutron } \\
\text { Calibration } \\
\end{array}$ & $\begin{array}{r}\text { Fast Neutron } \\
\text { Calibration } \\
\end{array}$ \\
\hline $\mathrm{R} 1=$ & $\mathrm{R} 1=$ & $\mathrm{R} 2=$ & $R 2=$ \\
\hline $\mathrm{R} 2=$ & $\mathrm{R} 2=$ & $\mathrm{R} 3=$ & $R 3=$ \\
\hline & $\mathrm{R} 4=$ & $R 4=$ & $R 4=$ \\
\hline$C 2=\frac{2000}{(R 1-K 2 R 2)}$ & $\mathrm{Cl}=\frac{1000}{\mathrm{R} 2}$ & $C 4=\frac{50}{(R 3-R 4)}(b)$ & $K 7=\frac{R 4-K 6 R 2-K 5(R 3-R 4)}{1000}(c)$ \\
\hline $\mathrm{C} 2=$ & $\mathrm{C} 1=$ & $C 4=$ & $\mathrm{K} 7=$ \\
\hline$C 3=C 2 \times K 2$ & $K 2=\frac{R L}{R 2}$ & $K 5=\frac{R 4-K 6 R 2}{R 3-R 4}(C)$ & $C 5=\frac{1}{k 7}$ \\
\hline $\mathrm{C} 3=$ & $\mathrm{K} 2=$ & $\mathrm{K} 5=$ & $C 5=$ \\
\hline & $\begin{array}{l}K 6=\frac{R 4}{R 2}(c) \\
K 6=\end{array}$ & & $\begin{array}{l}\mathrm{C6}=\mathrm{K} 6 \times \mathrm{C5} \\
\mathrm{C6}= \\
\mathrm{C7}=\mathrm{K} 5 \times \mathrm{C5} \\
\mathrm{C7}=\end{array}$ \\
\hline
\end{tabular}

(a) $\mathrm{Ri}$ where $\mathrm{i}=1,2,3,4$ or 5 refers to chip position reading minus the respective background count for each position.

(b) Calibration exposures: Nonpenetrating $=2000 \mathrm{mr}$ ad (4000 $\mathrm{mrad}$ Uranium)

Penetrating $=1000 \mathrm{mrad}$

Slow Neutron $=50 \mathrm{mrem}$

Fast Neutron $=1000 \mathrm{mrem}$.

(c) For 5-chip dosimeters, R5 would be used in place of R2. 
These calibration constants are used to interpret the readout of each of the chips in terms of dose using the following dose algorithms:

Nonpenetrating (NP)

$$
N P=(R 1 * C 2)-(R 2 * C 3) \mathrm{mrad}
$$

Penetrating $(P)$

$$
P=R 2 * C 1 \text { mrem }
$$

Slow Neutron (SN)

$$
S N=(R 3-R 4) * C 4 \text { mrem }
$$

Fast Neutron (FN) (a)

$$
F N=(R 4 * C 5)-(R 2 * C 6)-[(R 3-R 4] \star C 7) \text { mrem }
$$

Several observations can be made regarding the dose calculation methodology of the Hanford dosimeter considering its design as described in Section 2 .

NONPENETRATING RADIATION RESPONSE

Several considerations are important to accurately measure nonpenetrating radiation dose with the Hanford dosimeter. Fundamentally the dose is determined from the following expression (refer to Table 1.1 and dose algorithm):

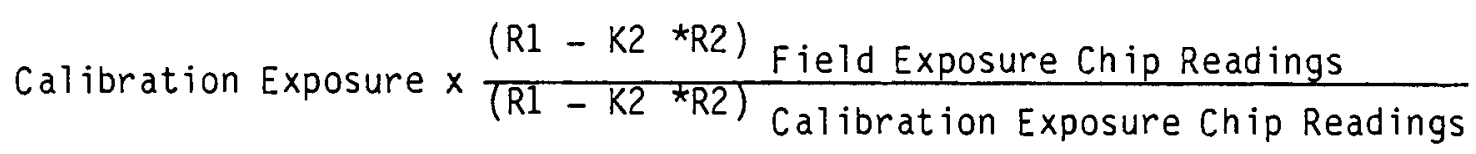

where R1 and R2 are the net readings of chips 1 and 2 after subtracting their respective chip background, and $K 2$ is a constant nearly equal to 1.0

(a) $\mathrm{R} 5$ replaces $\mathrm{R} 2$ in second parentheses for 5-chip dosimeter. 
representing the differences in Cs photon response between $R 1$ and $R 2$. It is apparent from the expression that the calculation of nonpenetrating dose depends on the relative magnitudes of both R1 and R2. Beta particle energies of at least $350 \mathrm{keV}$ and $900 \mathrm{keV}$, respectively, are necessary to penetrate the filtration over chips 1 and 2 .

\section{PENETRATING RADIATION RESPONSE}

The penetrating radiation dose calculation has two components being 1) penetrating beta-photon radiation and 2) neutron radiation.

1) Beta-Photon Components. The penetrating beta-photon dose calculation is the most direct for the Hanford dosimeter depending only on the net response of chip 2 relative to the calibration response. Chip 2 responds to photon radiation and energetic beta radiation $>900 \mathrm{keV}$. The response of chip 2 to low energy photon radiation falls rapidly below about $40 \mathrm{keV}$; however, chip 1 continues to respond indicating a nonpenetrating exposure.

2) Neutron Component. The neutron component is composed of a thermal neutron and a fast neutron dose estimate. The thermal neutron dose calculation is the most direct being a simple comparison of the difference between chips 3 and 4 for a field exposure with the difference for the calibration exposure as follows:

$$
\text { Calibration Exposure } \times \frac{(R 3-R 4) \text { Field Exposure Chip Readings }}{(R 3-R 4) \text { Calibration Exposure Chip Readings }}
$$

This method of calculation eliminates any separate consideration of photon contribution since chips 3 and 4 should have a nearly identical photon response.

The fast neutron dose estimate is determined from the net response of chip 4 relative to the calibration exposure minus contributions attributable to photon and/or thermal neutron radiation as follows: 


$$
\begin{aligned}
& \text { Calibration Exposure } \times \frac{(R 4) \text { Field Exposure Chip Readings }}{(R 4) \text { Calibration Exposure Chip Readings }} \\
& \text { - Photon Contribution - Thermal Neutron Contribution }
\end{aligned}
$$

The fast neutron dose estimate is the least precise because it is effected by the uncertainties of the photon and the thermal neutron contributions. Also, the chip response per unit dose is relatively low compared with the chip response for thermal neutrons. 



\subsection{DOSIMETER DESIGN SPECIFICATIONS}

The combination dosimeter and security credential holder was developed as part of the effort involved to provide an automated readout and thermoluminescent dosimetry capability at Hanford. The holder is designed to accommodate the thermoluminescent dosimeter card, appropriate filters, the security credential and a snap type clip. The body of the nolder is "ABS" plastic (acrylontrile-butadiene-styrene). The dosimeter holder and card is mold casted providing uniformity of construction.

DOSIMETER HOLDER

Figures 2.1 and 2.2 show the front and back view of the dosimeter holder, respectively. Table 2.1 summarizes the filtration over each of the 5 TLD positions from the front and from the back (Ref TLD Log Book 1, pp. 117, 118). It is apparent that the filtration for each position is different. For each position, the filtration in Table 2.1 is listed from the outside of the dosimeter holder towards the TL chip.

Historically, the filters are required to be within \pm 5 mils. Filter 2 consists of 2024-T4 aluminum which has the following composition:

$\sim 90 \% \mathrm{Al}$

$\sim 4 \% \mathrm{Cu}$

$\sim 1 \% \mathrm{Mg}$

$\sim 1 \% \mathrm{Mn}$

$\sim 4$ Other trace elements

During September 1980, the dosimeter manufacturer requested and was granted permisson to use 3003 aluminum which has the following composition:

$\sim 97 \%$ Al

$\sim 3 \%$ Trace elements.

\section{DOSIMETER CARD}

The dosimeter card is shown in Figure 2.3. Each of the TL chips measures 1/8-in. square by 0.035-in. thick. Transparent teflon $2 \mathrm{mils}$ thick is used to hold the chips in place. The chips are placed in a 3/8-in. hole in a 5-mil 
teflon spacer. As shown in Figure 2.3, two TLD-600s and two (or three) TLD-700s are used in the Hanford dosimeter. The slanted edge on the card corresponds to a slanted edge in the dosimeter holder providing one way only insert. 


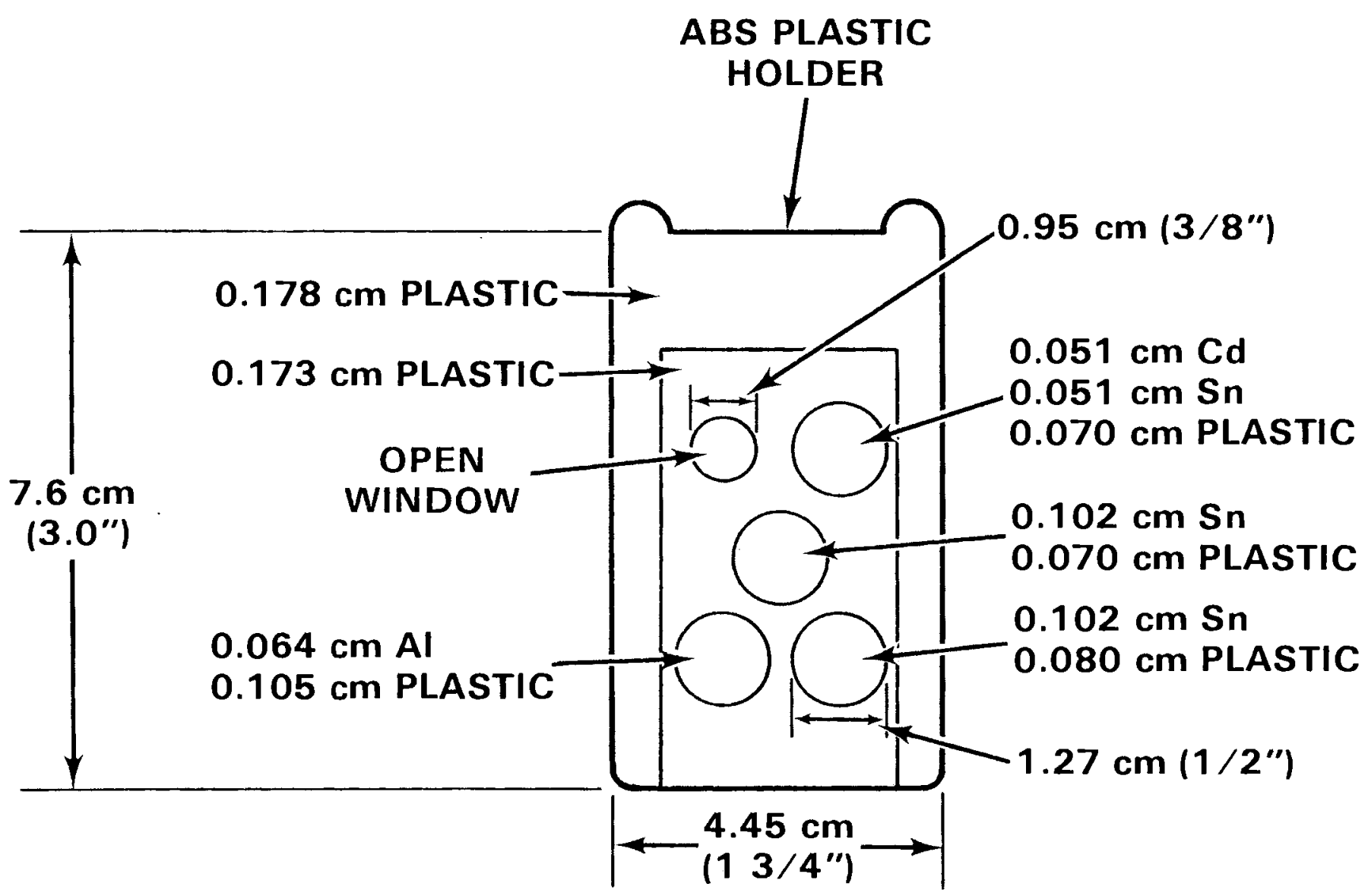

FIGURE 2.1. Front View of Dosimeter Holder (actual size) 


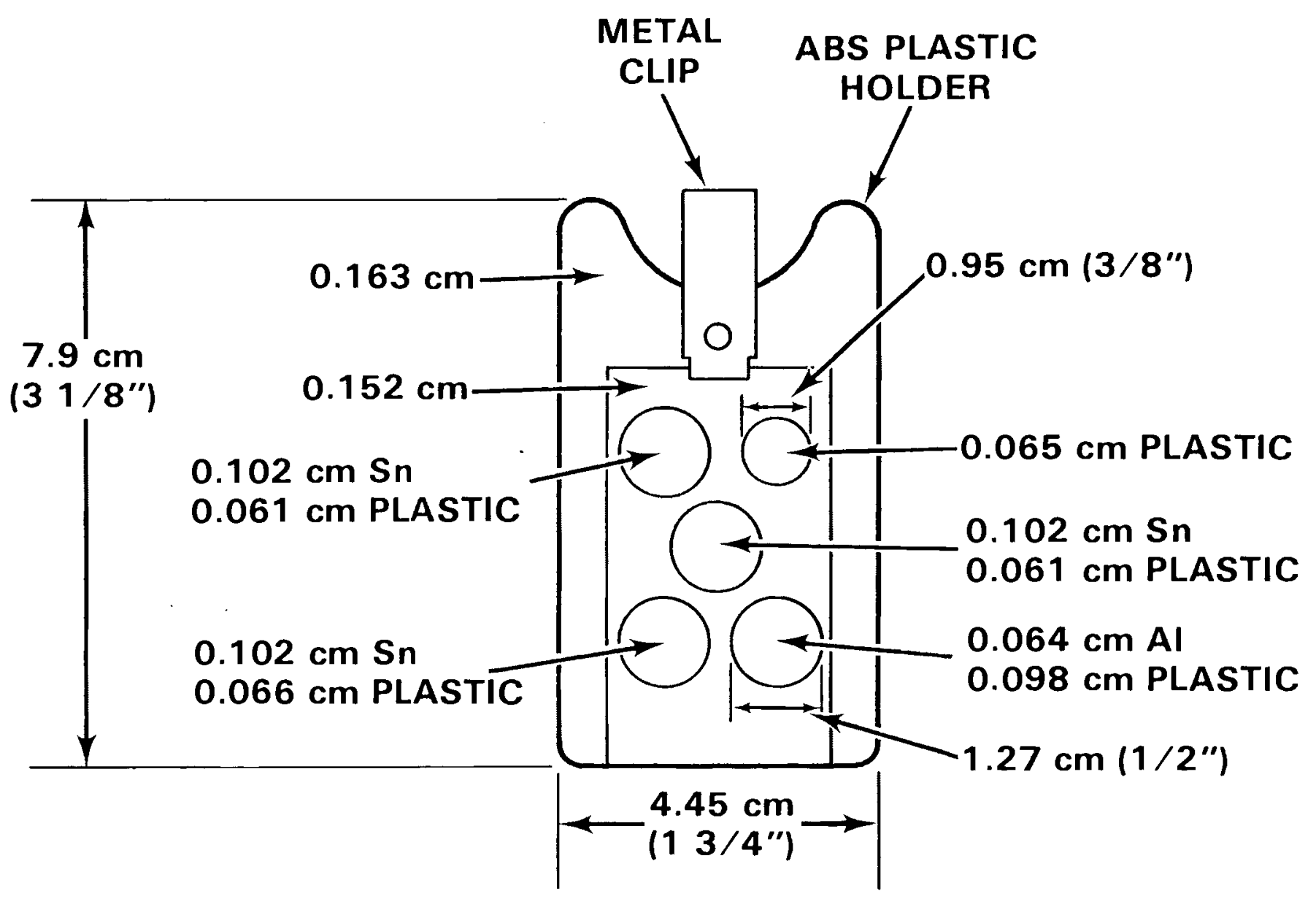

FIGURE 2.2. Back View of Dosimeter Holder (actual size) 
TABLE 2.1. Filtration by Position for Hanford Personnel Dosimeter

\begin{tabular}{|c|c|c|}
\hline \multirow{2}{*}{ 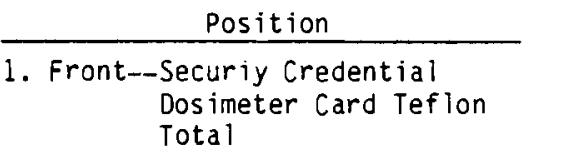 } & \multicolumn{2}{|c|}{ Thickness } \\
\hline & $\begin{array}{c}32.6 \mathrm{mil} \\
2.0\end{array}$ & $\begin{array}{l}83 \mathrm{mg} / \mathrm{cm}^{2} \\
\frac{5}{88}\end{array}$ \\
\hline $\begin{array}{l}\text { Back--Badge Holder } \\
\text { Dosimeter Card Teflon } \\
\text { Total }\end{array}$ & $\begin{array}{l}7.1 \mathrm{mil} \\
2.0\end{array}$ & $\begin{array}{r}56 \\
5 \\
61\end{array}$ \\
\hline $\begin{array}{l}\text { 2. Front--Security Credential } \\
\text { Badge Holder } \\
\text { Aluminum Filter } \\
\text { Dosimeter Card Teflon } \\
\text { Total }\end{array}$ & $\begin{array}{l}33.0 \mathrm{mil} \\
41.0 \\
26.6 \\
2.0\end{array}$ & $\begin{array}{r}84 \mathrm{mg} / \mathrm{cm}^{2} \\
85 \\
182 \\
5 \\
356\end{array}$ \\
\hline $\begin{array}{l}\text { Back--Badge Holder } \\
\text { Aluminum Filter } \\
\text { Dosimeter Card Teflon } \\
\text { Total }\end{array}$ & $\begin{array}{r}40.6 \\
27.3 \\
2.0\end{array}$ & $\begin{array}{r}85 \\
187 \\
5 \\
277\end{array}$ \\
\hline $\begin{array}{l}\text { 3. Front-- Security Credential } \\
\text { Badge Holder } \\
\text { Tin Filter } \\
\text { Dosimeter Card Teflon } \\
\text { Total }\end{array}$ & $\begin{array}{r}33.0 \mathrm{mil} \\
25.6 \\
41.0 \\
2.0\end{array}$ & $\begin{array}{l}84 \mathrm{mg} / \mathrm{cm}^{2} \\
53 \\
760 \\
\frac{5}{902}\end{array}$ \\
\hline $\begin{array}{l}\text { Back--Badge Holder } \\
\text { Tin Filter } \\
\text { Dosimeter Card Teflon } \\
\text { Total }\end{array}$ & $\begin{array}{r}28.5 \\
41.3 \\
2.0\end{array}$ & $\begin{array}{r}59 \\
766 \\
5 \\
830\end{array}$ \\
\hline $\begin{array}{l}\text { 4. Front---Security Credential } \\
\text { Badge Holder } \\
\text { Cadmium Filter } \\
\text { Tin Filter } \\
\text { Dosimeter Card Teflon } \\
\text { Total }\end{array}$ & $\begin{array}{r}33.0 \\
25.8 \\
20.8 \\
21.1 \\
2.0\end{array}$ & $\begin{array}{r}84 \mathrm{mg} / \mathrm{cm}^{2} \\
54 \\
457 \\
391 \\
5 \\
991\end{array}$ \\
\hline $\begin{array}{l}\text { Back--Badge Holder } \\
\text { Tin Filter } \\
\text { Dosimeter Card Teflon } \\
\text { Total }\end{array}$ & $\begin{array}{r}25.8 \\
41.0 \\
2.0\end{array}$ & $\begin{array}{r}54 \\
760 \\
5 \\
819\end{array}$ \\
\hline $\begin{array}{l}\text { 5. Front--Security Credential } \\
\text { Badge Holder } \\
\text { Tin Filter } \\
\text { Dosimeter Card Teflon } \\
\text { Total }\end{array}$ & $\begin{array}{l}33.0 \mathrm{mil} \\
25.8 \\
40.9 \\
2.0\end{array}$ & $\begin{array}{l}84 \mathrm{mg} / \mathrm{cm}^{2} \\
54 \\
758 \\
5 \\
901\end{array}$ \\
\hline $\begin{array}{l}\text { Back--Badge Holder } \\
\text { Tin Filter } \\
\text { Dosimeter Card Teflon } \\
\text { Total }\end{array}$ & $\begin{array}{r}25.0 \\
41.4 \\
2.0\end{array}$ & $\begin{array}{r}52 \\
768 \\
5 \\
825\end{array}$ \\
\hline $\begin{array}{ll}\text { NOTE: } & \text { Densities used in calculations } \\
\text { Teflon } & \rho=1.0 \mathrm{~g} / \mathrm{cm}^{3} \\
\text { ABS Plastic } & 0=0.82 \\
\text { Al } & \rho=2.70 \\
\text { Cd } & \rho=8.65 \\
\text { Sn } & \rho=7.30\end{array}$ & are: & \\
\hline
\end{tabular}




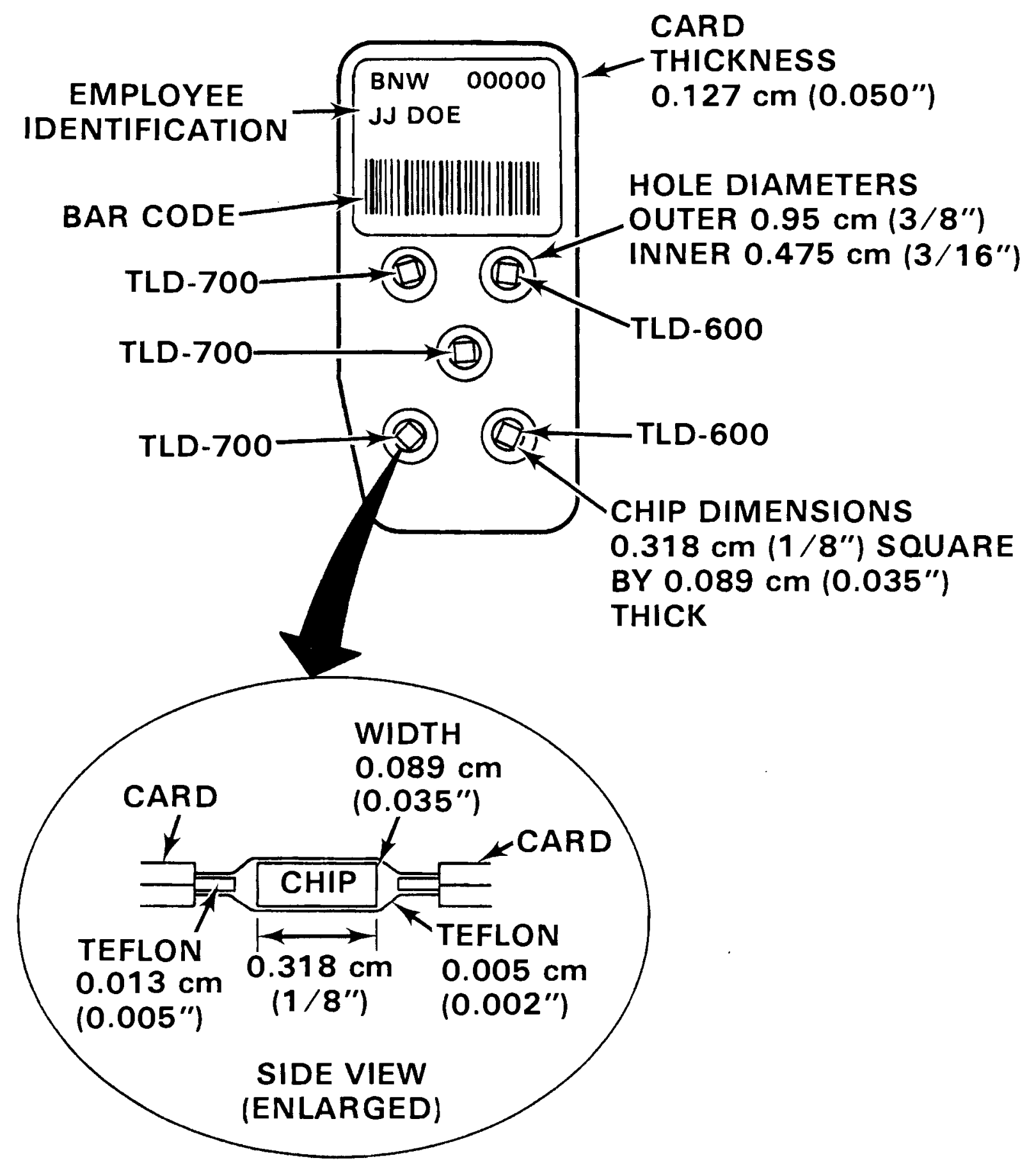

FIGURE 2.3. Front View of Dosimeter Card (actual size) 


\subsection{STUDY 1 - NEUTRON RESPONSE STUDY}

G. W. R. Endres, J. J. Fix, M. R. Thorson, and L. L. Nichols

\section{FOREWORD}

Neutron response of the albedo type dosimeter is strongly dependent on the energy of the incident neutrons as well as the moderating material on the backside of the dosimeter. This study characterizes the response of the Hanford dosimeter for a variety of neutron energies for both a water and Rando phantom. (a)

SUMMARY

The Hanford dosimeter response to neutrons of different energies is typical of albedo type dosimeters. An approximate two orders of magnitude difference in response is observed between neutron energies of $100 \mathrm{keV}$ and $10 \mathrm{MeV}$. Historically, the Hanford dosimeter has been calibrated at about $1 \mathrm{MeV}$ using a $\mathrm{PuF}_{4}$ source. During the past several years a ${ }^{252} \mathrm{Cf}$ source has often been used which has an average energy of about $1 \mathrm{MeV}$ when weighted by Hanford dosimeter response.

The Hanford dosimeter has shown differences in response by as much as a factor of 2 when calibrated with ${ }^{252} \mathrm{Cf}$ sources at different facilities. This is attributed to the contribution of room-scattered neutrons to the dosimeter response. The magnitude of the contribution is unique to the irradiation geometry at each facility. Little difference in dosimeter response was observed for dosimeters irradiated on a polyethylene phantom, water phantom, or on the centerline position of a Rando phantom (Study 5 describes response of dosimeter for different positions on Rando phantom).

(a) Simulated human body (trunk and head) consisting of an actual human skeleton with molded plastic for body muscle and certain organs. High density polyethylene is used to simulate muscle tissue and low density polyethylene is used to simulate lung tissue. 
Methods were described to compensate for the difference in dosimeter response between a laboratory neutron spectrum and the different spectra encountered at various facilities in the field. Generally, substantial field support is necessary for accurate neutron dosimetry.

\section{INTRODUCTION}

The neutron response of the Hanford albedo dosimeter is dependent, primarily, on three parameters as follows:

1. Energy of incident neutrons,

2. Type and distance of moderating material on the backside of the dosimeter, and

3. Angular position of dosimeter relative to the neutron source.

Other parameters include dose, which is discussed in Study 8 . The positional dependence is discussed in Study 5.

Albedo dosimeters are inherently highly energy dependent. The absorption cross-section of ${ }^{6}$ LiF (TLD-600) and the scattering cross-section of nuclei in the body are both extremely energy dependent and decrease with increasing neutron energy. The scattering cross-section of hydrogen in the body is shown in Figure 3.1 and the ${ }^{6} \operatorname{LiF}(n, a)$ cross-section is shown in Figure 3.2 .

The response of the Hanford dosimeter to several neutron energies has been measured. The Van de Graaff accelerator in the 3745B Building was used to generate neutrons of several energies. Dosimeters were also exposed to the 2, 24, and $144 \mathrm{keV}$ filtered neutron beams at the National Bureau of Standards (NBS) as well as to the National Bureau of Standards (NBS) ${ }^{252} \mathrm{Cf}$ source. Exposures were conducted using the $\mathrm{PuF}_{4}$ calibration source and the bare ${ }^{252} \mathrm{Cf}$ source in the $3745 \mathrm{~A}$ building.

The effect of moderating material was examined by comparing the response of the dosimeter on a $30 \mathrm{~cm}$ diameter water jug and a "Rando" phantom. The Rando phantom simulates the response expected from the human body in that it consists of an actual human skeleton with molded plastic for body-muscle and 


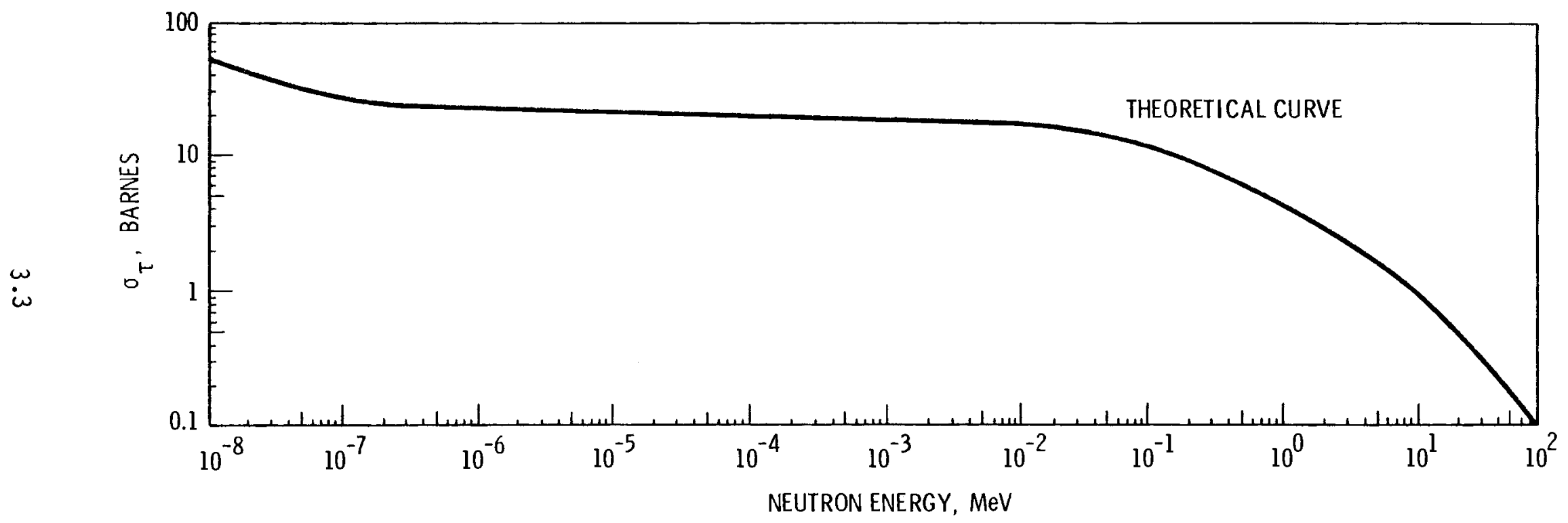

FIGURE 3.1. Hydrogen Scattering Cross Section as a Function of Neutron Energy. 


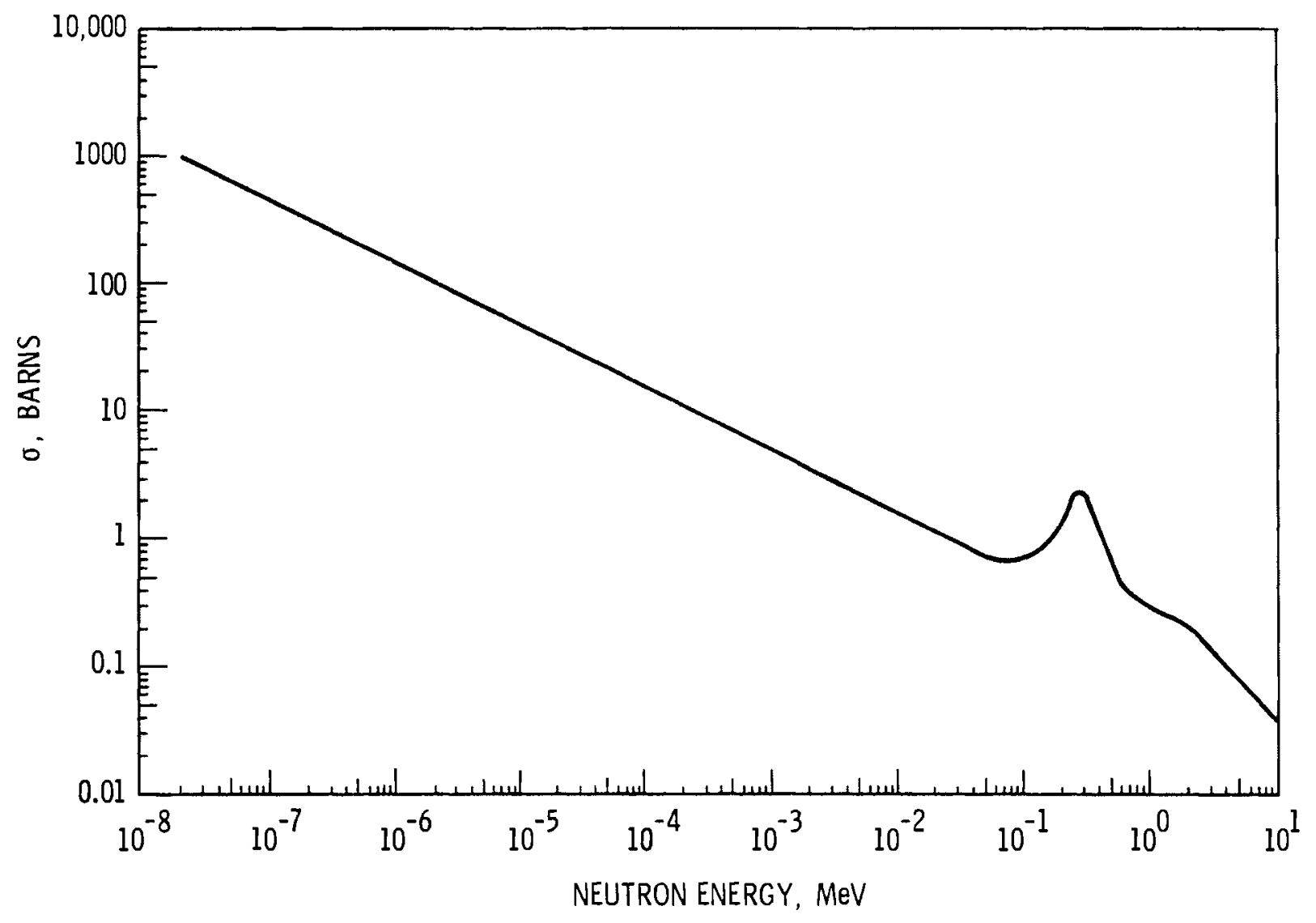

FIGURE 3.2. 6L iF Absorption Cross Section as a Function of Neutron Energy.

certain organs. Low density polyethylene is used to simulate the lungs whereas high density polyethylene is used to simulate muscle.

\section{THEORY}

Thermoluminescence-A lbedo Dosimeters

The neutron dosimetry technique most widely used at DOE facilities in the United States is the TLD-albedo system, which uses the ${ }^{6} L i(n, a)^{3} H$ reaction or ${ }^{10_{B}}(n, a)^{7} L$ i reaction in thermoluminescent materials to detect neutrons. Thermoluminescence-albedo dosimeters must be worn on the body. Incident fast neutrons enter the body and are moderated, and slow neutrons (thermal plus epithermal) are reflected back to the dosimeter (hence the term albedo, from 
the reflected neutrons). Slow neutrons interact with the thermoluminescent material, usually through ${ }^{6} L i(n, \alpha)^{3} H$ or ${ }^{10_{B}}(n, \alpha)^{7} L i$ reaction, and the charged particles then excite the thermoluminescent material. When heated, the phosphor emits light in quantities proportional to the energy deposited in the material. The energy deposited depends on the number of interactions which occur in the sensitive material.

The thermoluminescent material is sensitive to both neutrons and photons, so a correction must be made for photon response by using matched pairs of TL chips. One pair is made from ${ }^{6} L$ if or a boron crystal, which detects neutrons and photons, and the other is made from fully enriched ${ }^{7} \mathrm{~L} i F$, or some other neutron insensitive material which detects mostly photons. The neutron response is found by subtracting the photon response from the ${ }^{6} L$ if or boron crystal response. The Hanford multipurpose dosimeter uses a system of ${ }^{6} L i F$ and ${ }^{7} L i F$.

The basic concepts of the TLD-albedo dosimeter are shown in Figure 3.3. pairs of ${ }^{6} L i F$ and ${ }^{7} L i F$ TL chips are placed on each side of a cadmium shield, which is used to differentiate incident thermal neutrons from the albedo neutrons reflected from the body. The top pair measure the incident thermal neutron dose; the bottom pair measure the albedo neutrons from which the incident fast neutron dose is inferred. The cadmium foil is usually between 0.4 and $1.5 \mathrm{~mm}(0.015$ and $0.060 \mathrm{in.})$ thick. Thinner foils allow too many thermal neutrons to pass through. The cadmium foil should be as large as practical to prevent thermal neutrons from diffusing around the foil to the bottom TL chips; the smallest useful diameter for the cadmium foil is about $1 \mathrm{~cm}(0.39 \mathrm{in.})$ (Hankins 1972). Cadmium emits gamma rays when it captures a neutron, so gamma shields are sometimes placed between the cadmium and the TL chips. Boron or boron-loaded plastic can also be used in place of cadmium, but a much thicker shield is required because of boron's lower absorption cross section and density. The material is often enriched in $10_{B}$, but this is expensive.

The TLD-albedo dosimeter must be worn close to the body to function properly. As it is moved away from the body, its sensitivity to fast neutrons decreases and its sensitivity to thermal neutrons increases. Wearing a dosimeter loosely clipped on a pocket containing a pack of cigarettes can cause 


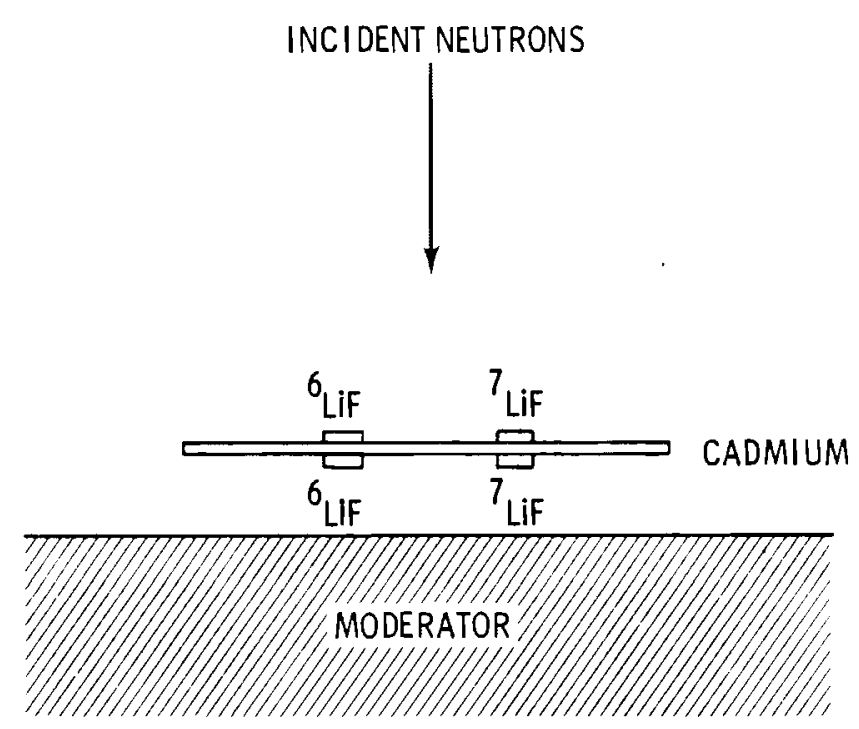

FIGURE 3.3. Basic Concept of TLD-Albedo Dosimeter

inaccurate readings as well as the movement of the dosimeter away from the body while a person is bending over will cause erroneous results. The Hanford dosimeter does not function at all for fast neutron measurements if it is worn backwards clipped to the inside of a pocket or loosely held on a necklace. Hankins has developed a symmetric dosimeter that can be worn in either direction (Hankins 1973). This dosimeter sacrifices sensitivity in order to achieve the symmetrical response.

There are several advantages to TLD-albedo dosimeters:

- They always give some indication when exposed to a significant neutron dose.

- They are relatively inexpensive and can be reused many times.

- They are simple to fabricate and are usually lightweight and easy to wear.

- Readout is relatively simple and can be automated. It is possible to process several thousand dosimeters with relative ease.

- They are insensitive to humidity and moderate mechanical shock. 
There are also several disadvantages to using TLD-albedo dosimeters:

- The single most important disadvantage of TLD-albedo dosimeters is that their sensitivity is nighly dependent upon the energy of the incident neutron. The dose equivalent indicated by the dosimeter can be in error by an order of magnitude if the dosimeter is not properly calibrated.

- The TLD-albedo dosimeter is also gamma sensitive. In mixed radiation fields, care must be taken to properly subtract out the photon response of the neutron sensitive TLD.

- The Hanford TLD-albedo dosimeters must be worn properly (i.e., close to the body) or serious errors can result.

- Most TLD-albedo dosimeters worn flat against the body exhibit some angular dependence, but the effect is small compared to that for observed beta-photon radiation.

- Thermoluminescence dosimeters do not give a permanent record, as film or track etch dosimeters do. If the TLD reader malfunctions, the reading may be lost.

- Thermoluminescence dosimeters must be carefully annealed to preserve the accuracy of their calibration.

- Some TLDs exhibit fading. The fading problem in TLD-600s and TLD-700s can be overcome by waiting 1 day before reading the TLDS out and by various preread annealing techniques. High temperatures can cause fading problems; especially if the time period is extended.

Energy Response Problems of Thermoluminescence-Albedo Dosimeters

Thermoluminescence-albedo dosimeters have a severe energy response problem, as demonstrated in Figure 3.4. A simplistic explanation of this variation in the response to neutrons of various energies is that the mean free path for high-energy neutrons is greater than that for low-energy neutrons, and the fast neutrons penetrate farther into the body because cross sections 


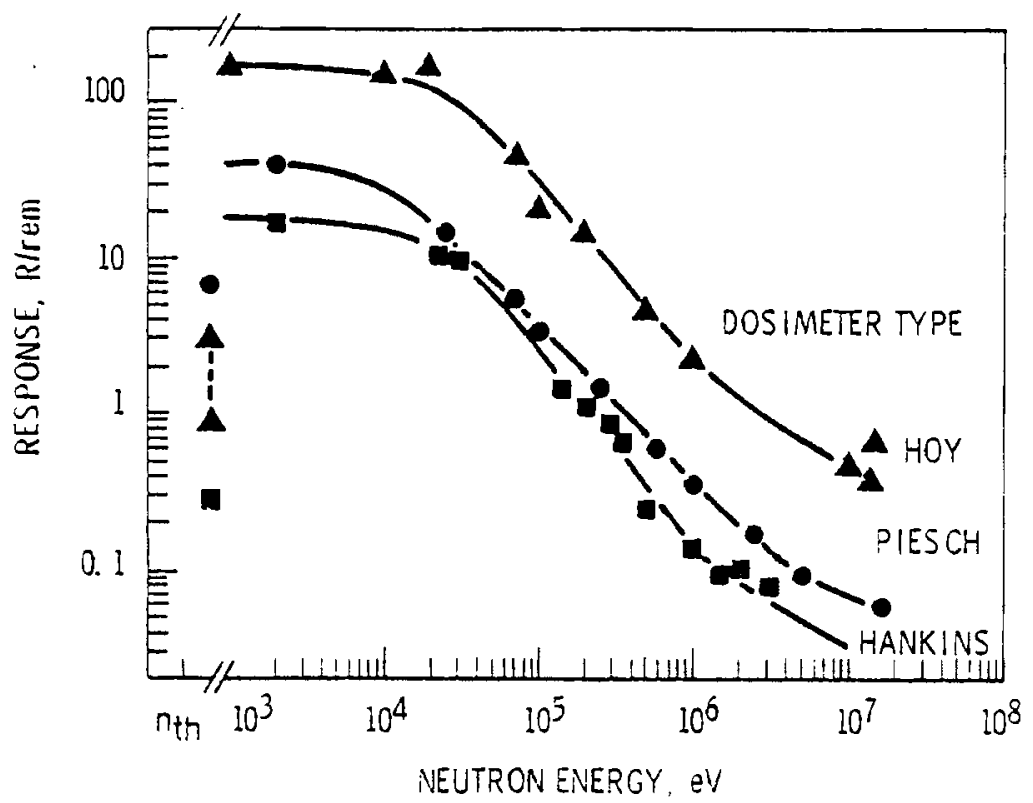

FIGURE 3.4. Energy Dependence of Various Albedo Dosimeters (Piesch and Bergkhardt 19780).

are small before interacting and becoming thermalized. The thermal neutrons must then migrate a farther distance back to the surface of the body, and many are absorbed before reaching the TLDs on the surface. It also requires fewer high energy neutronis to produce a given dose. Thus the sensitivity of the TLD-albedo dosimeter decreases with increasing neutron energy and the decrease is greater than the slope of the curve in Figure 3.1 for high energy neutrons.

Several methods can be used to overcome the energy dependence problem. If, TLD-albedo dosimeters are used in facilities in which the neutron energy spectrum is almost constant, a single calibration is then sufficient. Second, the TLD-albedo dosimeter can be designed to compensate for spectral differences. However, this solution is difficult to achieve in practice. Figure 3.5 shows a schmatic diagram of the Karlsruhe dosimeters (Piesch and Bergkhardt 1978a), a multicomponent dosimeter that provides information about variations in the neutron energy spectrum in work areas. The Karlsruhe dosimeter uses three pairs of TL chips inside a capsule of boron-loaded plastic, which is held to the body by a belt worn about the waist. One of the front chips, designated " $a$ " in Figure 3.5, measures the incicent thermal neutrons; a middle 


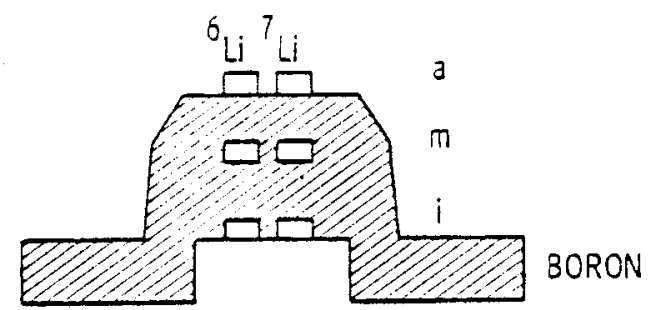

\section{FIGURE 3.5. Design of Karlsruhe TLD-Albedo Dosimeter (Piesch and Bergkhardt 1978a).}

chip, designated "m", measures mostly epithermal neutrons; and a bottom chip closest to the body, designated " $i$ ", measures mostly albedo neutrons. The use of the dosimeter to analyze the incident neutron spectrum is described in two papers (Piesch and Bergkhardt 1978a; Piesch and Bergkhardt 1978b). The dosimeter must be calibrated in work areas where it is worn, not in laboratories or by monoenergetic neutron exposures. Piesch introduces a method by which the dose equivalent can be separated into fractions corresponding to thermal and fast neutrons with an effective average energy, which can be related to field measurements and the ratio i/a of the response of the TL chips (Piesch and Bergkhardt 1978a). In this way, corrections are made for the dosimeter's greater response to the neutrons of thermal and intermediate energies that result from the high-scatter situations typical of work locations.

A third method of correcting for energy response (Hankins 1975) uses the ratio of the thermal neutron flux inside a 23-cm-dia (9-in.-dia) spherical "rem meter" to the flux inside a 7.6-cm-dia (3-in.-dia) sphere covered with a $0.025-\mathrm{cm}(0.010-$ in.) layer of cadmium. Measurements are usually made with a small $\mathrm{BF}_{3}$ counter inside the polyethylene spheres, and a calioration factor is determined from the ratio of the spheres' responses. The calibration factor will vary depending upon the sensitivity of the ${ }^{6} L i F T L$ chips and the type of albedo dosimeter used, but the response functions will approximate a straight line and have the same slope on log-log graphs. This method can be somewhat cumbersome because measurements must be made at several work locations and records kept of which dosimeters were used at these work locations. In many instances, the calibration factors for a single facility may not vary 
by more than $20 \%$ to $30 \%$ (Hankins 1975). Somewhat similar calibration factors have been obtained using the ratio of Bonner sphere measurements. The ratio of $30-\mathrm{cm}$ to $5-\mathrm{cm}(12-i n$. to $2-i n$.$) spheres has been used (Piesch and Bergkhardt$ $1978 \mathrm{~b})$, as has the ratio of $25-\mathrm{cm}$ to $7.6-\mathrm{cm}$ (10-in. to $3-\mathrm{in}$.$) spheres (Ander-$ son and Crain 1977).

\section{DOSIMETER RESPONSE MEASUREMENTS}

\section{Neutron Energy}

The neutron energy response of the dosimeter was determined by exposing the dosimeter to several sources of neutrons as follows:

- Approximately $100 \mathrm{keV}$ to $17 \mathrm{MeV}$ monoenergetic neutrons from the Van de Graaff accelerator in 3745B Building.

- Monoenergetic Deams of 2, 24, and $144 \mathrm{keV}$ at the National Bureau of Standards.

- Bare and moderated ${ }^{252} \mathrm{Cf}$ source at the National Bureau of Standards.

- Sigma pile, PuBe- $D_{2} 0, P_{4} F_{4}, P u B e$, and ${ }^{252} \mathrm{Cf}$ sources at the 3745 Building.

- ${ }^{252} \mathrm{Cf}$ source at 3708 Building.

Approximately 10 decades exist between thermal neutron energies $(0.025 \mathrm{eV})$ and fast neutron energies ( $50 \mathrm{MeV}$ ) potentially encountered at Hanford. The dosimeter response has been measured over much of this range.

The neutron response curves determined are shown in Figures 3.6 and 3.7 for the water phantom and Rando phantom, respectively. All data in the figure are normalized to the calibration data obtained at Hanford (i.e., bare ${ }^{252} \mathrm{Cf}$, Sigma pile, ${ }^{137} \mathrm{Cs}$, uranium slab) for dosimeters placed on a polyethylene phantom. An approximate factor of 2 difference is observed between the dosimeter response on a water phantom exposed to the $\mathrm{NBS}{ }^{252} \mathrm{Cf}$ source and the dosimeter response on a polyethylene phantom exposed to the Hanford ${ }^{252} \mathrm{Cf}$ source at 3745A Building. The expected cause is the contribution of roomscattered neutrons to the dosimeter response. The exposure geometry at the 


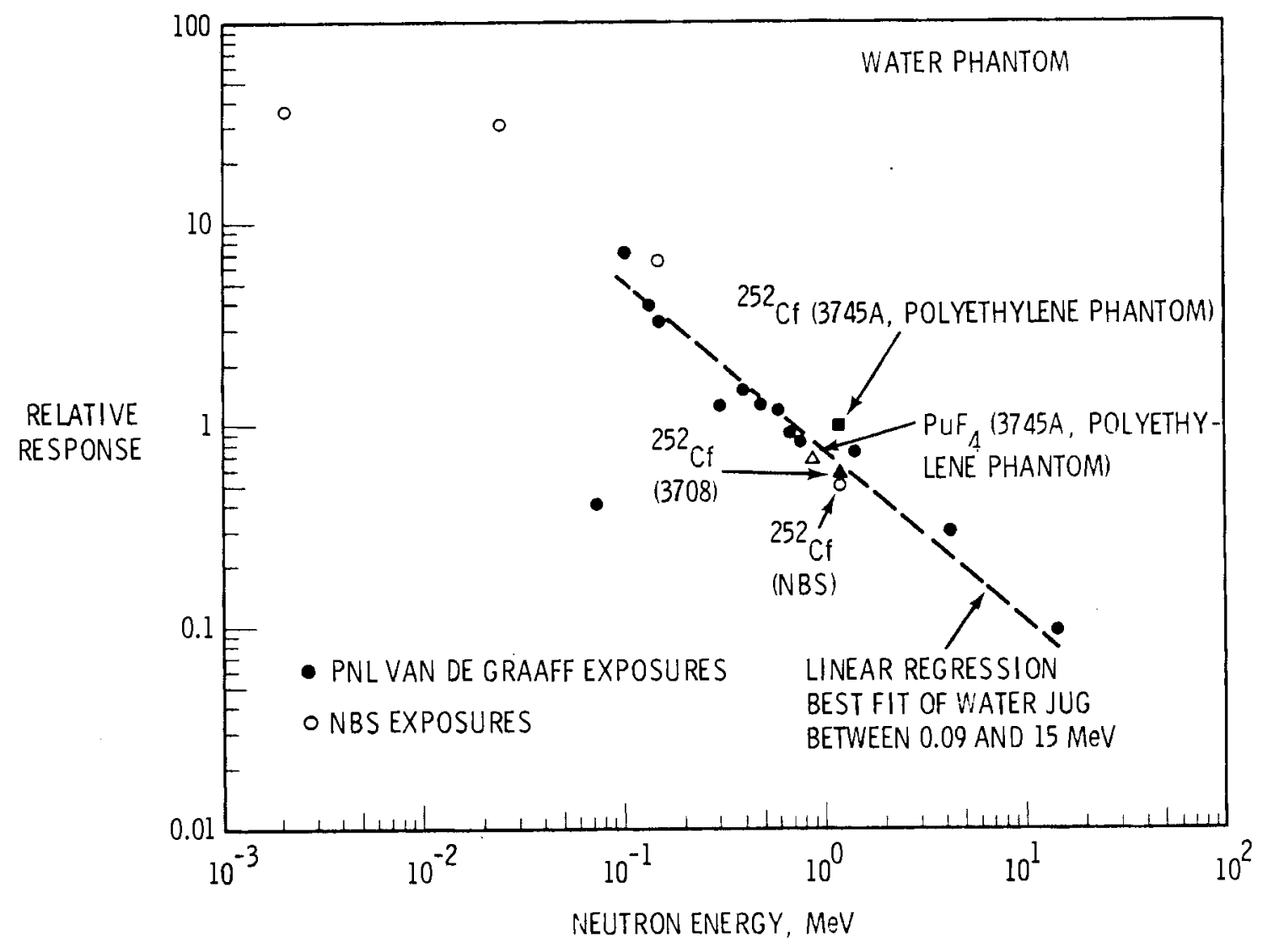

FIGURE 3.6. Relative Neutron Energy Response of Hanford Dosimeter Exposed on a Water Phantom.

3745 A Building involves a room much smaller than at the NBS and, as such, a greater percentage of room scattered neutrons.

These response curves are typical of albedo neutron dosimeters. The apparent linearity of the dosimeter response with neutron energies between about $100 \mathrm{keV}$ and $10 \mathrm{MeV}$ as well as the relative decrease in dosimeter response below about $100 \mathrm{keV}$ is consistent with the hydrogen cross section shown in Figure 3.1 .

\section{Moderating Material}

It is apparent in Figures 3.6 and 3.7 that the dosimeter response has nearly the same energy response characteristics and magnitude whether exposed on the Rando or water jug phantom. Study 5 analyzes the significant effect of dosimeter position on and distance from the phantom. The differences observed 


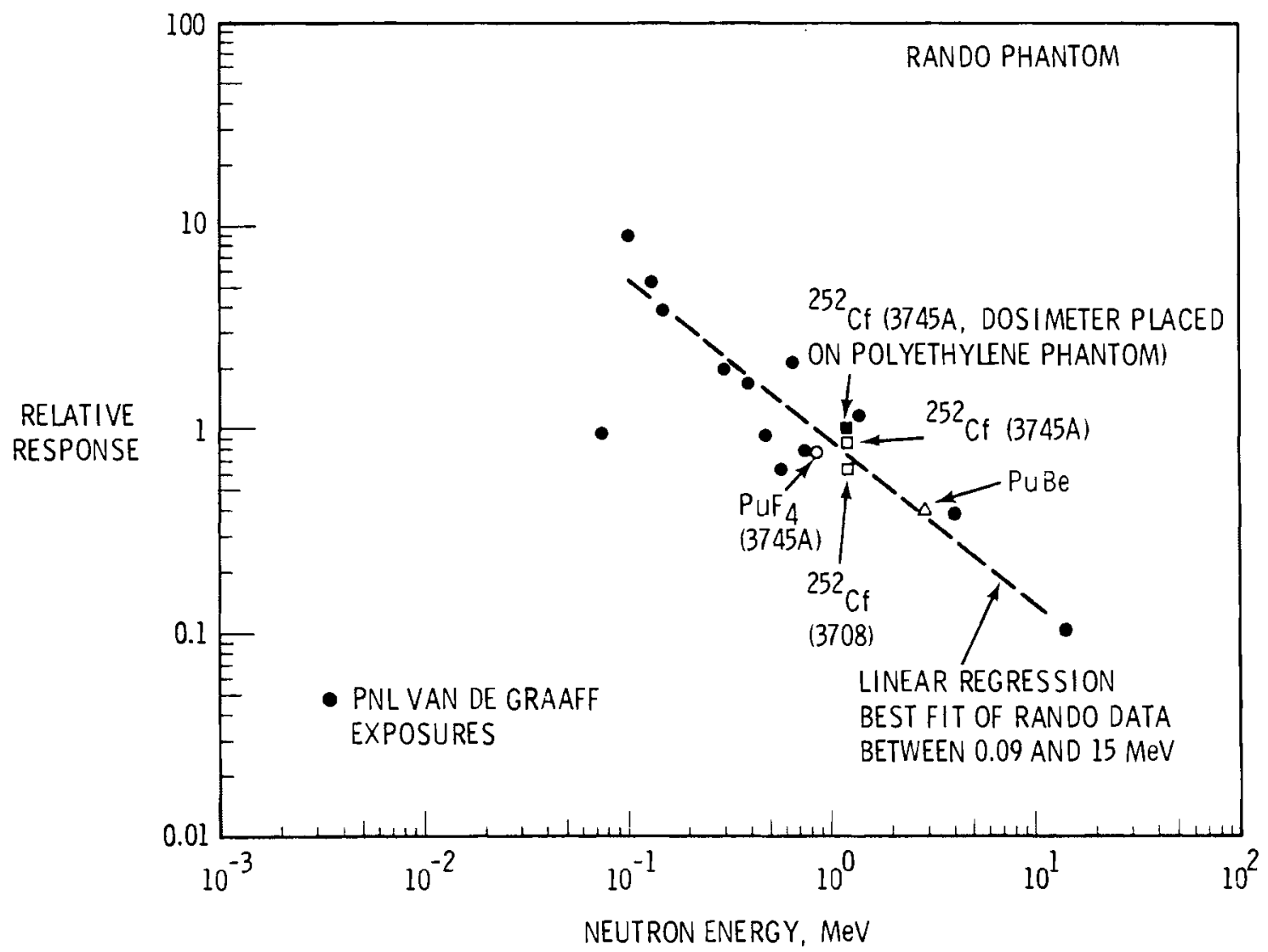

FIGURE 3.7. Relative Neutron Energy Response of Hanford Dosimeter Exposed on a Rando Phantom (centerline position only).

for dosimeter response on similar phantoms for ${ }^{252} \mathrm{Cf}$ sources are expected to be caused by differences in the intensity and energy cf scattered neutrons. Effect of Cadmium Shielding

Thermal neutrons which are absorbed by the cadmium shielding cause secondary radiation to be generated. By placing both TLD-600s and TLO-700s within a cadmium enclosure and exposing to a thermal neutron flux, this secondary radiation was measured. Between 2 and $3 \%$ of the reduced TLD-600 response due to cadmium thermal neutron capture was transferred into ionizing radiation (mostly gamma) measured by both TLD-600 and TLD-700 chips. 


\section{REFERENCES}

Anderson, M. E., and S. L. Crain. 1977. "A Combination TL-Film Personnel Neutron Dosimeter." In Sixth ERDA Workshop on Personnel Neutron Dosimetry. PNL-2449, Pacific Northwest Laboratory, Richland, Washington.

Hankins, D. E. 1972. Factors Affecting the Design of Albedo Neutron Dosimeters Containing $L$ ithium Fluoride Thermoluminescent Dosimeters. LA-4832, Los Alamos Scientific Laboratory, Los Alamos, New Mexico.

Hankins, D. E. 1973. A Small, Inexpensive Albedo-Neutron Dosimeter. LA-5261, Los Alamos Scientific Laboratory, L'OS Alamos, New Mexico.

Hankins, D. E. 1975. "The Effect of Energy Dependence on the Evaluations of Albedo Neutron Dosimeters." In Proceedings of the Ninth Midyear Topical Symposium. Health Physics Society, Denver, Colorado.

Piesch, E., and B. Bergkhardt. 1978a. "Advances in Albedo Neutron Dosimetry." In Advances in Radiation Protection Monitoring: Proceedings of a Symposium. IAEA-SM-229/5, International Atomic Energy Agency, Vienna, Austria.

Piesch, E., and B. Bergkhardt. 1978b. "The Role of an Analyzer Type Albedo Dosimeter in Routine Monitoring and the Current Situation for the Calibration Technique." In Seventh DOE Workshop on Personnel Neutron Dosimetry. PNL-2807, Pacific Northwest Laboratory, Richland, Washington. 
. 


\subsection{STUDY 2 - HIGH ENERGY PHOTON RESPONSE}

F. M. Cummings, R. C. Yoder, G. W. R. Endres, and R. L. Kathren

\section{FOREWORD}

This study examines the response of the Hanford 4-chip and 5-ch ip dosimeter to high energy photons. Of particular interest was the response to ${ }^{24} \mathrm{Na}$ because of FFTF operations and photons near $7 \mathrm{MeV}$ because of the presence of $16_{\mathrm{N}}$ at $\mathrm{N}$-Reactor. Obtaining calibrated photon beams with the desired energies is difficult. To characterize the response, calibrations were performed at the high energy electron accelerator (LINAC) at the University of Indiana.

SUMMARY

The dose response of the Hanford Multipurpose Personnel Dosimeter (HMPD) to photons with energies greater than $0.65 \mathrm{MeV}$ has been evaluated relative to the dose produced by photons from a ${ }^{60}$ Co source. The penetrating dose determined with the HMPD (chip 2, filtration $0.064 \mathrm{~cm}$ of Al) is compared to the $1 \mathrm{~cm}$ depth dose in tissue measured with an extrapolation chamber. The results of the study indicate that the HMPD can be used to estimate the $1 \mathrm{~cm}$ depth dose in tissue from photons with energies between $0.65 \mathrm{MeV}$ and $3.0 \mathrm{MeV}$ to with in an accuracy of $15 \%$. However, the $1 \mathrm{~cm}$ depth dose is underestimated by $38 \%$ when the dosimeter is irradiated in a beam of very high energy photons (average energy $=8 \mathrm{MeV}$ ) produced by bombarding a tungsten target with $25 \mathrm{MeV}$ electrons.

Two additional comparisons were performed. The first is a comparison penetrating dose determined by the HMPD using chip $510.102 \mathrm{~cm}$ of tin filtration) instead of chip 2 to the $5 \mathrm{~cm}$ depth dose in tissue measured with an extrapolation chamber for several different irradiations. The results indicate that this method of dose estimation is accurate to $5 \%$ over the range of photon energies tested $(0.662 \mathrm{MeV}-8 \mathrm{MeV})$. The second is a comparison of the penetrating dose determined by the HMPD using chip 5 to the $1 \mathrm{~cm}$ depth dose in tissue measured using an extrapolation chamber. The results of this study 
indicate that the comparison of 1 ight outputs from chips $1\left(89 \mathrm{mg} / \mathrm{cm}^{2} \mathrm{filtra-}\right.$ tion), $2\left(348 \mathrm{mg} / \mathrm{cm}^{2}\right)$, and $5\left(892 \mathrm{mg} / \mathrm{cm}^{2}\right.$ filtration) could possibly be used to arrive at a more accurate determination of dose at either the $1 \mathrm{~cm}$ or $5 \mathrm{~cm}$ depth in tissue.

\section{INTRODUCTION}

The Multipurpose Personnel Dosimeter (MPD) estimate of penetrating dose from photons with energies greater than $1.332 \mathrm{MeV}$ has not been fully documented in the past. New research at Hanford involving LMFBR's, particle accelerators, and fusion technology will produce photons with energies as high as $25 \mathrm{MeV}$. The dosimeter response must be characterized for these photon energies in order to make adequate estimates of dose to personnel. This study focuses on comparing the penetrating dose estimated with the MPD and the corresponding $1 \mathrm{~cm}$ and $5 \mathrm{~cm}$ tissue depth doses measured with an extrapolation chamber.

The current MPD is a four-element dosimeter which uses the light output of a filtered thermoluminescent chip (TLD-700) to determine the penetrating tissue dose. During the study, an additional TLD-700 chip was placed in the center of the dosimeter (position 5) and used to determine the penetrating dose (Figure 4.1). This dose was compared to the $5 \mathrm{~cm}$ and the $1 \mathrm{~cm}$ depth dose in tissue. The respective filters for the two chips are listed in Table 4.1. The detailed discussion of the dosimeter and its applications to photon dosimetry as well as the rationale for. the choice of filter material and thickness can be found in BNWL-SA-3955 (Kocher et al. 1971).

The penetrating dose calculated by the MPD for the different photon irradiations was based on a calibration exposure to ${ }^{60} \mathrm{Co}$. Penetrating dose was calculated as usual using the light output of chip 2 and also using the light output of chip 5. The calculated doses were compared to the measured $1 \mathrm{~cm}$ and $5 \mathrm{~cm}$ depth dose in tissue. 


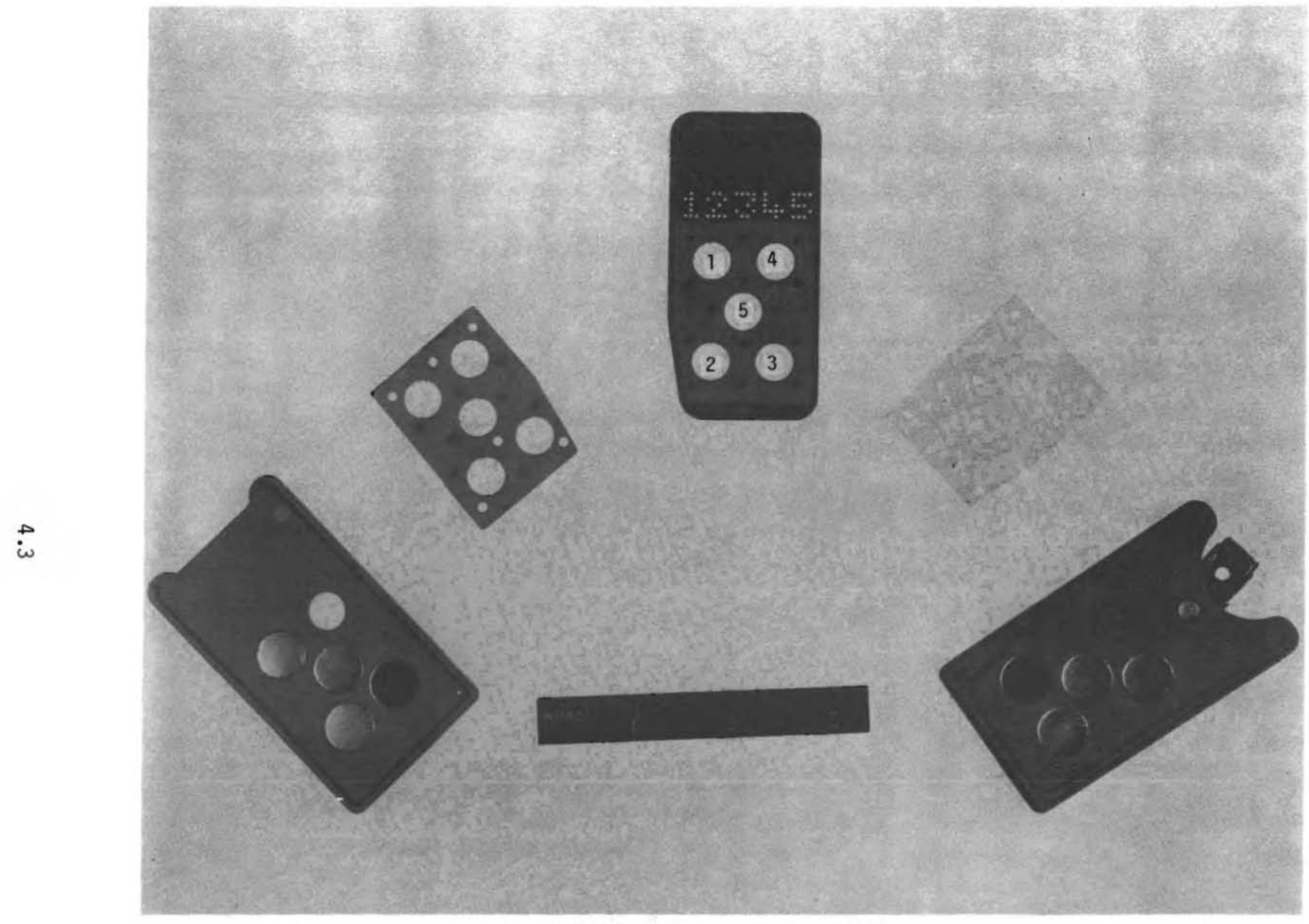

FIGURE 4.1. Exploded View of MPD 
TABLE 4.1. MPD Filter Information

Chip

2

5
Filter

Security Credential

$0.089 \mathrm{~cm}$ ABS Plastic

$0.064 \mathrm{~cm}$ Aluminum

Teflon Tape

Security Credential

$0.051 \mathrm{~cm}$ ABS Plastic

$0.102 \mathrm{~cm} \mathrm{Tin}$

Teflon Tape

METHODS

Dosimeters were exposed to various sources of photon radiations. These sources are listed in Table 4.2 along with the principal photons. Note that the clinical accelerator produced a photon spectrum by bombarding a tungsten target with $25 \mathrm{MeV}$ electrons. While the maximum photon energy produced was $25 \mathrm{MeV}$, the average energy was $8 \mathrm{MeV}$.

For each irradiation, five dosimeters were placed in an array on one of two phantoms: 1) a lucite based plastic and 2) a urethane based plastic. Both phantoms were $30 \mathrm{~cm} \times 30 \mathrm{~cm} \times 15 \mathrm{~cm}$ thick. The urethane phantom contained the extrapolation chamber used to measure absorbed dose in tissue at varying depths. The theory and application of the extrapolation chamber to photon dosimetry is found in PNL-3219 (Yoder et al. 1979).

With the exception of the accelerator exposures, all dosimeters were placed such that the distance between the source and the center of the phantom face was $1.0 \mathrm{~m}$. The phantoms were placed normal to the beam. During the accelerator exposures, encountered dose rates were so high that the phantom was placed $3 \mathrm{~m}$ from the source. With the exception of the accelerator exposures, irradiation times were estimated so as to deliver roughly $200 \mathrm{mrad}$ at $1 \mathrm{~cm}$ in tissue. The accelerator irradiation was set to deliver roughly 2 rads at $3.5 \mathrm{~cm}$ of tissue (maximum dose depth). 
TABLE 4.2. Source Data

\begin{tabular}{|c|c|c|}
\hline $\begin{array}{l}\text { Photon } \\
\text { Source } \\
\end{array}$ & $\begin{array}{c}\text { Principal } \\
\text { Photon Energies } \\
\text { (MeV) }\end{array}$ & $\begin{array}{c}Y \text { ield } \\
(\%) \\
\end{array}$ \\
\hline${ }^{137} \mathrm{Cs}$ & 0.662 & 85 \\
\hline $60 \mathrm{co}$ & $\begin{array}{l}1.173 \\
1.332\end{array}$ & $\begin{array}{l}100 \\
100\end{array}$ \\
\hline $233 U$ & $\begin{array}{l}0.583 \\
2.614\end{array}$ & $\begin{array}{r}86 \\
100\end{array}$ \\
\hline $24 \mathrm{Na}$ & $\begin{array}{l}1.369 \\
2.754\end{array}$ & $\begin{array}{l}100 \\
100\end{array}$ \\
\hline $\begin{array}{l}\text { Linear } \\
\text { Accelerator }\end{array}$ & $\begin{array}{l}\text { Bremsstrahlun } \\
\text { Maximum Energ } \\
\text { Average Energ }\end{array}$ & $\begin{array}{l}\text { Spectrum } \\
=25 \mathrm{MeV} \\
=8 \mathrm{MeV}\end{array}$ \\
\hline
\end{tabular}

Following each exposure, individual chips were analyzed on a Harshaw-2000 TLD reader and the light output per measured dose in tissue was compared to the light output per measured dose in tissue of the ${ }^{60}$ Co exposures.

A discussion of the pre-exposure annealing and TL chip analysis follows. $7_{L}$ if $(T L-700)$ chips were supplied by Harshaw Chemical Supply. The average light output expressed as reader current of the bare chips to a $200 \mathrm{mR}$ exposure to photons from ${ }^{137} \mathrm{Cs}$ was found to be $111.0 \pm 8.9$ nanocoulombs (1 standard deviation). The TL chips were each annealed for 1 hour at $400^{\circ} \mathrm{C}$ and 2 hours at $100^{\circ} \mathrm{C}$ in a vicor glass dish. All the chips had received previous exposures to photons of various energies and the average response over their life times was not found to be significantly different from the initial response. Following the annealing, the chips were loaded into dosimeters and exposed. The analysis procedure included removing the chips from each dosimeter and individually heating them to $250^{\circ} \mathrm{C}$ on a heat ramp of $5^{\circ} \mathrm{C} / \mathrm{sec}$ from a base temperature of $50^{\circ} \mathrm{C}$. 
Raw data from each exposure group were averaged and tabulated in Table 4.3. The HMD penetrating was calculated as:

$$
D=A j \times R i
$$

where:

$$
D=\text { the penetrating dose }
$$

$A j=$ the calibration constant derived from the response of TLD's to ${ }^{60} \mathrm{Co}$

$\mathrm{Ri}=$ the net 1 ight output from chips 2 or 5 in the irradiated dosimeter.

Note: $\quad A 1=$ The calibration constant derived using the light output of the Al filtered chip (chip 2) in a dosimeter irradiated using ${ }^{60} \mathrm{Co}$.

$A 2$ = The calibration constant derived using the light output of the $S n$ filtered chip (chip 5) in a dosimeter irradiated using ${ }^{60} \mathrm{Co}$.

$A 5=$ The calibration constant, used to evaluate the $5 \mathrm{~cm}$ depth dose, derived using the light output of the Sn filtered chip (chip 5) in a dosimeter irradiated using ${ }^{60} \mathrm{Co}$.

These constants were combined as follows to estimate penetrating dose with the MPD:

$$
\begin{array}{ll}
D=A 1 \times R 2 & \text { (equation } 4.1 \text { ) } \\
D=A 2 \times R 5 & \text { (equation } 4.2 \text { ) } \\
D=A 5 \times R 5 & \text { (equation } 4.3 \text { ) }
\end{array}
$$

\section{RESULTS}

Table 4.3 gives a summary of net light output compared to dose. The average ratio of net light output expressed in $\mathrm{nc}$ to millirads of absorbed dose measured at the $1 \mathrm{~cm}$ depth in tissue for all sources but the LINAC is 


\section{TABLE 4.3. Raw Data Summary}

\begin{tabular}{|c|c|c|c|c|c|c|c|}
\hline $\begin{array}{l}\text { Photon } \\
\text { Source }\end{array}$ & $\begin{array}{l}1 \mathrm{~cm}(\mathrm{a}) \\
\text { Depth Dose } \\
(\mathrm{mrad}) \\
\end{array}$ & $\begin{array}{l}\text { Net Light } \\
\text { Output-Chip } 2 \\
\text { (nC) } \\
\end{array}$ & $\begin{array}{c}1 \mathrm{~cm} / \mathrm{Chip} 2^{(\mathrm{c})} \\
\text { Ratio } \\
\end{array}$ & $\begin{array}{l}5 \mathrm{~cm}(\mathrm{a}) \\
\text { Depth Dose } \\
\text { (mrad) }\end{array}$ & $\begin{array}{l}\text { Net Light (b) } \\
\text { Output-Chip } 5 \\
(n C) \\
\end{array}$ & $\begin{array}{l}5 \mathrm{~cm} / \mathrm{Cnip} 5^{(\mathrm{c})} \\
\text { Ratio } \\
\end{array}$ & $\begin{array}{l}1 \mathrm{~cm} / \mathrm{Cnip} 5^{(\mathrm{c})} \\
\text { Ratio } \\
\end{array}$ \\
\hline${ }^{137} \mathrm{Cs}$ & 206 & $110.57 \pm 8.51$ & 0.54 & 183 & $107.57 \pm 7.68$ & 0.59 & 0.52 \\
\hline${ }^{60} \mathrm{Co}$ & 202 & $114.61 \pm 7.05$ & 0.57 & 182 & $105.39 \pm 5.40$ & 0.58 & 0.52 \\
\hline $233 \mathrm{U}$ & 268 & $138.45 \pm 3.87$ & 0.52 & 224 & $128.47 \pm 6.01$ & 0.57 & 0.48 \\
\hline${ }^{24} \mathrm{Na}$ & 205 & $98.93 \pm 6.32$ & 0.48 & 166 & $92.00 \pm 2.02$ & 0.55 & 0.45 \\
\hline LINAC & 1510 & $529.77 \pm 29.32$ & 0.35 & 2100 & $1074.9 \pm 71.7$ & 0.51 & 0.71 \\
\hline
\end{tabular}

(a) Measured with extrapolation chamber.

(b) Expressed as nanocoulombs of reader current.

(c) Ratio determined by dividing dose into light output. 
$0.53 \pm 0.04(1 \sigma)$ for the TL chip behind the Al filter (chip 2). That ratio decreases to 0.35 for the irradiation performed on the LINAC. Similarly, the average ratio of net light output to dose at the $5 \mathrm{~cm}$ depth in tissue is $0.57 \pm 0.02(1 \sigma)$ for the TL chip behind the tin filter (chip 5). That ratio decreases to 0.51 for the LINAC irradiation. Similarly, the average ratio of the net light output from chip 5 to the measured $1 \mathrm{~cm}$ depth dose is $0.49 \pm 0.03$, for all the photon sources with the exception of the LINAC. That ratio increases to 0.71 for the LINAC exposure.

Table 4.4 illustrates exposure conditions, estimated dose and measured doses. The measured $1 \mathrm{~cm}$ depth doses ranged from $202 \mathrm{mrad}$ for the ${ }^{60} \mathrm{Co}$ irradiation to $1510 \mathrm{mrad}$ for the LINAC exposure while the estimated doses ranged from $175 \mathrm{mrad}$ for the ${ }^{24} \mathrm{Na}$ irradiation to $934 \mathrm{mrad}$ for the LINAC irradiation. The measured $5 \mathrm{~cm}$ doses range from $182 \mathrm{mrad}$ for the ${ }^{60} \mathrm{Co}$ irradiation to $2100 \mathrm{mrad}$ for the LINAC irradiation while the estimated $5 \mathrm{~cm}$ doses range from $160 \mathrm{mrad}$ for the ${ }^{24} \mathrm{Na}$ irradiation to $1856 \mathrm{mrad}$ for the LINAC irradiation. Additionally, $1 \mathrm{~cm}$ depth doses estimated by evaluating the net light output from the tin filtered $T L$ chip range from 176 mrad for the ${ }^{24} \mathrm{Na}$ irradiation to $2060 \mathrm{mrad}$ for the LINAC irradiation.

Table 4.5 summarizes the ratio of estimated penetrating dose calculated by the MPD using equations $4.1,4.2$, or 4.3 to measured doses. The $1 \mathrm{~cm}$ dose ratio estimated using equation 4.1 to calculate the penetrating dose compared to the measured $1 \mathrm{~cm}$ dose ranged from 1.00 for ${ }^{60} \mathrm{Co}$ to 0.62 for the LINAC irradiation. The $5 \mathrm{~cm}$ dose ratio (equation 4.3 ) ranged from 1.0 for the ${ }^{60}$ Co irradiation to 0.88 for the LINAC irradiation. The $1 \mathrm{~cm}$ dose ratio using the equation 4.2 ranged from 0.86 for ${ }^{24} \mathrm{Na}$ irradiations to 1.36 for the LINAC irradiations.

\section{DISCUSSION}

The response of the MPD is a complex function based on the ability of TL material to interact with the primary radiation, the interaction of the filter material with the primary radiation and the ability of the TL material to interact with secondary radiations produced in the filters. 
TABLE 4.4. Exposure Summary

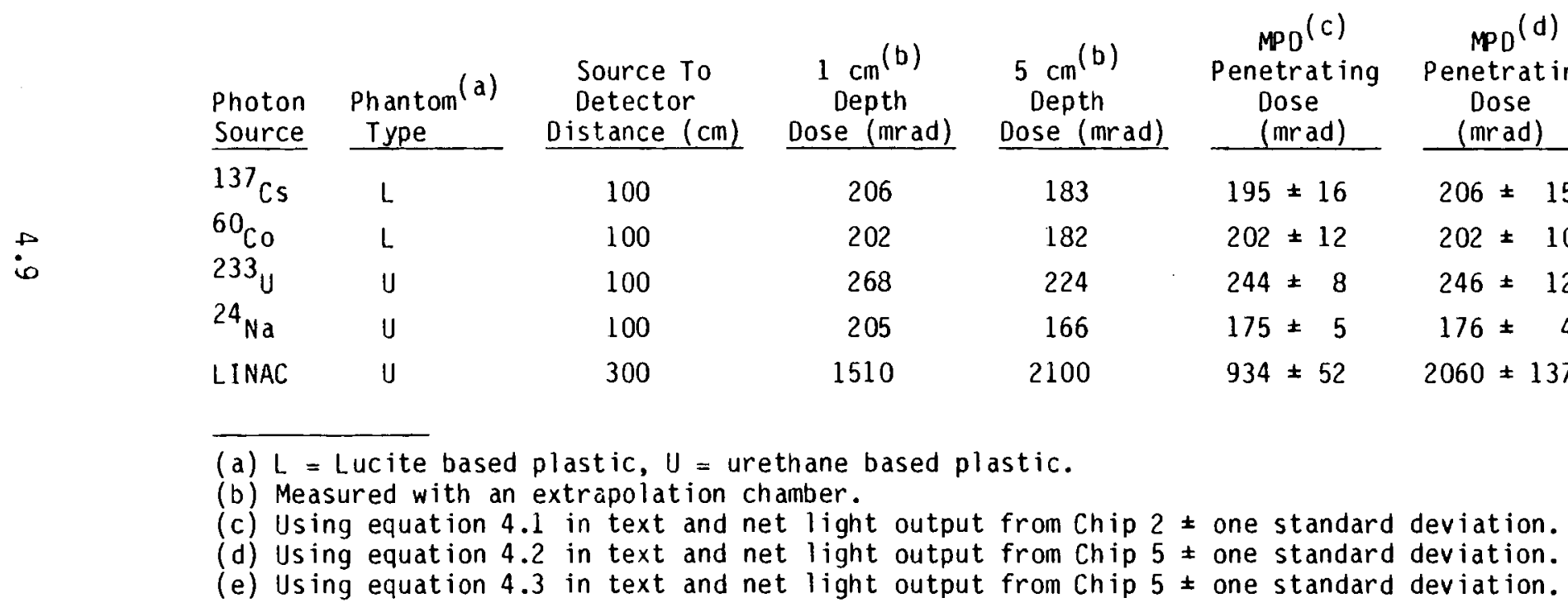


TABLE 4.5. Dose Data Comparison Summary

\begin{tabular}{|c|c|c|c|c|c|c|}
\hline \multirow{2}{*}{$\begin{array}{l}\text { Photon } \\
\text { Source }\end{array}$} & \multicolumn{2}{|c|}{$1 \mathrm{~cm}$ Dose ${ }^{(a)}$} & \multicolumn{2}{|c|}{$1 \mathrm{~cm}$ Dose $\mathrm{b}^{(\mathrm{b})}$} & \multicolumn{2}{|c|}{$5 \mathrm{~cm}$ Dose $(\mathrm{c})$} \\
\hline & Ratio & $1 \sigma$ & Ratio & $1 \sigma$ & Ratio & $1 \sigma$ \\
\hline${ }^{137} \mathrm{Cs}$ & 0.95 & 0.08 & 1.00 & \pm 0.07 & 1.02 & 0.07 \\
\hline${ }^{60} \mathrm{CO}$ & 1.00 & 0.06 & 1.00 & \pm 0.05 & 1.00 & 0.05 \\
\hline 233 & 0.91 & 0.03 & 0.92 & 0.04 & 0.99 & 0.03 \\
\hline${ }^{24} \mathrm{Na}$ & 0.85 & 0.02 & 0.86 & 0.02 & 0.96 & 0.02 \\
\hline LINAC & 0.62 & 0.03 & 1.36 & \pm 0.13 & 0.88 & 0.06 \\
\hline
\end{tabular}

(a) Ratio of penetrating dose estimated with the MPD (equation 4.1 in text) to the $1 \mathrm{~cm}$ tissue dose measured using an extrapolation chamber.

(b) Ratio of penetrating dose estimated with the MPD (equation 4.2 in text) to the $1 \mathrm{~cm}$ tissue dose measured using an extrapolation chamber.

(c) Ratio of penetrating dose estimated with the MPD (equation 4.3 in text) to the $5 \mathrm{~cm}$ tissue dose measured using an extrapolation chamber.

The complicated picture of interactions of the $T L$ chip and aluminum filter with photon radiation is demonstrated by considering the light output to dose ratios in Table 4.3. Where the dosimeter has been irradiated using sources which produce spectra with average photon energy less than $3.0 \mathrm{MeV}$, the light output to dose ratio remains fairly constant around 0.5 (1 cm depth dose). The change in the energy deposition distribution from higher energy photons is demonstrated by the lower ratio produced at the $8 \mathrm{MeV}$ point using the 1 ight output from the aluminum filtered chip. This situation can be further demonstrated by considering the ratio of light output to dose for the $5 \mathrm{~cm}$ depth. The dose deposited at that depth is more slowly varying as: 1) $5 \mathrm{~cm}$ lies beyond the maximum dose buildup depth in tissue for all the energies tested and 2) some additional energy is deposited in the TL chip as a result of pair production in the tin filter. Note that pair production is more important in $t$ in than in aluminum due to the difference in atomic number ( $z$ of $t$ in $=50$, $Z$ of aluminum $=13$ ) as evidenced by the 1.36 ratio of light output to absorbed 
dose at the $1 \mathrm{~cm}$ depth using the light output from the tin filtered chip compared with the 0.71 ratio using the light output from the Al filtered chip.

Historically, for photon radiations, the dosimeter was designed to estimate a nonpenetrating and a penetrating dose in tissue. Analys is of the interaction of tissue to a source of photons with energy equal to $3.5 \mathrm{MeV}$ would involve the possible production of an electron with a maximum energy of 2.1 MeV and a range in tissue of $1 \mathrm{~cm}$. The depth of maximum dose deposition in tissue from the LINAC ( $8 \mathrm{MeV}$ average energy) is $3.5 \mathrm{~cm}$. Hence, an accurate estimate of the $1 \mathrm{~cm}$ depth dose is less than the maximum absorbed dose in tissue for photons of energy greater than $3.5 \mathrm{MeV}$.

CONCLUSION

For photons with energies between 0.65 and $3.0 \mathrm{MeV}$, the dosimeter approximates closely the $1 \mathrm{~cm}$ depth dose in tissue. At higher energies this is not the case, so several alternatives may need to be considered. Those alternatives would include but not be limited to: 1) calibrating the dosimeter at higher energies using an extrapolation chamber, for those individuals working in the proximity of high energy photon sources and 2) place a TL chip in position 5 and compare its light output to the TL chips in positions 1 and 2 to arrive at an approximate spectral calibration and, hence, a more accurate determination of 1 and $5 \mathrm{~cm}$ depth doses in tissue.

If the five-element dosimeter is to be used for future dosimetry, it is recommended that a study be performed investigating the relative 1 ight outputs per dose for all three chips over a wide range of energies.

\section{ACKNOWLEDGMENTS}

We wish to express our gratitude to the people who spent so much time and effort in support of this task. Jack Courtney, Claude Hooker, and Becky Hogan performed irradiations using the ${ }^{208} \mathrm{Tl}$ and ${ }^{24} \mathrm{Na}$ sources and Margaret Kress

performed the ${ }^{137} \mathrm{Cs}$ and ${ }^{60} \mathrm{Co}$ exposures. A special thanks goes to Fred Eichner and Virginia Tews for preparing the dosimeters and reading approximately 1000 TL chips. Thanks also to Karen Mills who typed and proofread the report. 


\section{REFERENCES}

Kocher, L.F., et al. 1971. "The Hanford Thermoluminescent Multipurpose Dosimeter", pp. 8-12, BNWL-SA-3955, Pacific Northwest Laboratory, Richland, Washington.

Yoder, R. C., et al. 1979. "Conf irmation of Conversion Factors Relating Exposure and Dose Equivalent Index Presented in ANSI 13.11", PNL-3219, Pacific Northwest Laboratory, Richland, Washington. 


\title{
5.0 STUDY 3 - BETA AND LOW ENERGY PHOTON RESPONSE
}

\author{
F. M. Cummings and R. C. Yoder
}

\section{FOREWORD}

The response of the Hanford dosimeter to beta and low energy photon radiation is complicated. The response ranges from zero at some lower threshold energy and increases with increasing energy. For photon irradiation, a maximum dosimeter response is observed between 30 and $40 \mathrm{keV}$.

This study quantifies the observed dosimeter response for a variety of beta and photon energies. The reportable skin dose is also included in the discussion. Presently, the reportable skin dose is determined by adding the nonpenetrating and penetrating dose components together.

SUMMARY

The scheme presently used to estimate the nonpenetrating dose component for personnel at Hanford utilizes the difference in light outputs of a TLD-700 chip filtered only by the security credential (total of $88 \mathrm{mg} / \mathrm{cm}^{2}$ ) and a TLD-700 chip filtered by a $0.064 \mathrm{~cm}$ thick aluminum filter as well as the credential. The study indicates that a maximum chip response (reader current/ delivered skin dose) occurs in the range of photon energies between $30 \mathrm{keV}$ and $40 \mathrm{keV}$ and results in an overestimation of the calculated nonpenetrating dose by a factor of approximately 2. The reportable skin dose is overestimated by a factor of approximately 2.5 following adding the nonpenetrating and penetrating dose components. The effect of removing the security credential is slight and tends to increase the steepness of slope in the photon response curve.

The beta response curve for the Hanford dosimeter was observed to decrease with decreasing beta energy as expected. The calculated nonpenetrating dose is underestimated, relative to the delivered dose at $7 \mathrm{mg} / \mathrm{cm}^{2}$, by a factor of 2 at $1.0 \mathrm{MeV}$ (maximum energy of isotopic beta radiation). The response of the Hanford dosimeter became nonexistent to beta radiation less 
than about $0.6 \mathrm{MeV}$. The skin dose that is reported for an individual at Hanford is the sum of the nonpenetrating and penentrating components. While the lower energy beta radiations ( $<2 \mathrm{MeV}$ ) result in an underestimate of the skin dose, the lower energy photons ( $<80 \mathrm{keV})$ result in an overestimate of the skin dose by adding in the penetrating component.

\section{INTRODUCTION}

In this study, the response of the Hanford dosimeter to photons with energies between $16 \mathrm{keV}$ and $78 \mathrm{keV}$ and to beta spectra with maximum energies up to $3.54 \mathrm{MeV}$ is investigated. The light output from the TLD chip in position 1 is compared to the respective light output from the chip in position 2 . The exposure to which multipurpose dosimeters were irradiated and the corresponding measured skin dose are compared as are calculated and reported skin doses relative to delivered doses.

Additionally, comparisons are made for the above mentioned quantities for dosimeters with the security credential and without the security credential.

METHODS

$\underline{X-R a y s}$

K-fluorescence $x$-ray sources were used to produce essentially monoenergetic photons with energies in the range of $16.1 \mathrm{keV}$ to $78 \mathrm{keV}$. Dosimeters were irradiated on a tissue equivalent extrapolation chamber which served as the phantom. After irradiation, dosimeters were annezled and the raw data analyzed to accurately characterize the dependence on photon energy of the dose response function and the relative light output response of the "unfiltered" chip. Dosimeter irradiations were performed in the 318 Building $x$-ray room, which has been specifically designed to minimize scatter. The $x-r a y$ tube control system and $x-r$ ay production were constantly monitored throughout the experiment (Yoder et a 1. 1979).

The tube and x-ray production methods are described in detail in PNL-3219 (Yoder et al. 1979). Briefly, however, X-rays are directed toward "K" 
irradiator targets, exciting the electrons in the $\mathrm{k}$ orbitals. As these electrons "fall" back to lower energy levels they emit monoenergetic photons (see Figures 5.0 through 5.5). Irradiation targets are listed in Table 5.1 containing the corresponding $K$-fluorescence $x$-ray energies, the primary $x-r a y$ tube potential and current and the distance between the source (target) and the phantom face. The exposure-to-absorbed dose conversion factors, the delivered exposures and the corresponding skin doses are listed in Table 5.2.

Two dosimeters were placed on a tissue equivalent phantom such that their TLD chips in position 1 were adjacent. They were aligned with a laser beam such that the center of the beam was directly between the two adjacent dosimeters and directly between the chips in position 1 of each dosimeter. The standard holders were modified by removing the personnel clip so they might be placed flat on the phantom.

Dosimeters were thus irradiated in pairs. Separate irradiations were made for dosimeters containing security credentials and dosimeters without security credentials. Following irradiation, dosimeters were analyzed chipwise and the raw data averaged and tabulated in Tables 5.3 to 5.8. A discussion of the TLD-700 handling and analys is procedure may be found in Study 2 of this report (Cummings 1980).

Beta Irradiations

Dosimeters were irradiated using various beta emitting radionuclides. These sources are summarized in Table 5.9. The ${ }^{85_{\mathrm{Kr}} \text { source }}{ }^{90_{\mathrm{Sr} /}}{ }^{90_{\mathrm{Y}}}$ 2 source and the ${ }^{106} \mathrm{Rh}$ source are special button sources mounted on wood holders and stored in 318. All irradiations using these sources were performed on the urethane based plastic extrapolation chamber that was used to measure the delivered dose. The ${ }^{238} \cup 1$ and 2 are the same being the aged uranium slab stored in 3745. However, irradiations using $238_{U} 2$ were made by laying dosimeters face down on the slab and covering them with a 1" thick slab of lucite. The source ${ }^{238} \mathrm{U} 3$ is the source used to calibrate the Hanford MPD and was utilized mainly for irradiating dosimeters that lacked the presence of a security card. The ${ }^{90} \mathrm{Sr}-{ }^{90} \mathrm{Y} 1$ and 4 are the same source and are 
differentiated only in that 4 was used to irradiate dosimeters lacking the presence of the security credential.

To graphically illustrate the difference in data, a "reference" energy was devised. The derivation of that energy lies in averaging weighted maximum beta radiations. The reference energy is used for graphical display only and not intended to be used for technical comparison of sources. Additionally, one must be warned against a strict comparison of the $U$ data with the other sources due to the extreme differences in irradiation geometries. In the case of the $\mathrm{Sr} / \mathrm{Y}$ and $\mathrm{Kr}$ sources it was felt that the reference energy would be the maximum energy of the beta particle emitted by $90 \mathrm{Y}$ as the source encapsulation would effectively absorb the lower energy beta particle emitted by those sources. Table 5.10 summarized the source data used in this study. Analysis Techniques

The net light output is expressed in nanocoulombs (nc) of reader current and is the difference between the average light output for a chip in a particular position of similarly irradiated dosimeters minus the average light output from the corresponding chip in unirradiated dosimeters. The standard deviation is defined as the square root of the sum of the squares of the individual standard deviations. Where average values are divided one into another, the standard deviation of the ratio is defined as:

$$
S D=\sqrt{\left(\frac{S 1}{R 1}\right)^{2}+\left(\frac{S 2}{R 2}\right)^{2}}
$$

where

$$
\begin{aligned}
S D= & \text { the standard deviation of the ratio } R 1 / R 2 . \\
S i= & \text { the standard deviation of the group of chips in position } i \text { for a } \\
& \text { particular irradiation. } \\
\mathrm{Ri}= & \text { the average net light output of the chips in position } i \text { for a } \\
& \text { particular irradiation. }
\end{aligned}
$$


RESULTS

$\underline{X-R a y s}$

Dosimeters with Credentiais

As is noted in Table 5.3, the average net light output from the chip in Position 1 ranges from $103.88 \mathrm{nc}$ at $16.1 \mathrm{keV}$ to $110.87 \mathrm{nc}$ at $662 \mathrm{keV}\left({ }^{137} \mathrm{Cs}\right)$ with a maximum of $201.15 \mathrm{nc}$ at $43 \mathrm{keV}$. The average values for the chip in position 2 behave similarly ranging from $20.73 \mathrm{nc}$ at $16.1 \mathrm{keV}$ to $110.19 \mathrm{nc}$ at $662 \mathrm{keV}$ with a maximum of $174.40 \mathrm{nc}$ at $58 \mathrm{keV}$. The ratio of average light outputs from chips in positions 1 and 2 are shown to decrease from 5.01 at $16.1 \mathrm{keV}$ to 1.01 at $662 \mathrm{keV}$. Note that K2, defined as R1/R2 from a dosimeter irradiated using ${ }^{137} \mathrm{Cs}$, is approached asymptotically with increasing energy.

Table 5.4 contains the response data for the irradiated dosimeters. The response is defined as the net light output from the chip in position 1 divided by the noted quantity (either measured skin dose or exposure). The dose response ranges from $0.48 \mathrm{nc} / \mathrm{mr}$ ad at $16.1 \mathrm{keV}$ to $0.52 \mathrm{nc} / \mathrm{mr}$ ad at $662 \mathrm{keV}$ with a maximum value of $0.87 \mathrm{nc} / \mathrm{mr}$ ad at $34.3 \mathrm{keV}$. The exposure response can be considered as the TLD response to filtered (credential) x-rays and varies from $0.52 \mathrm{nc} / \mathrm{mR}$ at $16.1 \mathrm{keV}$ to $0.55 \mathrm{nc} / \mathrm{mR}$ at $662 \mathrm{keV}$ with a maximum value of $1.01 \mathrm{nc} / \mathrm{mR}$ at $43 \mathrm{keV}$.

Table 5.5 illustrates the comparison of dose estimation techniques. The calculated skin (nonpenetrating) dose is evaluated from dosimeter data by the following:

$$
D=A \times(R i-K 2 R 2)
$$

where

$$
\begin{aligned}
D= & \text { the skin dose estimate. } \\
A= & \text { a calibration constant derived from a }{ }^{90} \mathrm{Sr}_{-}{ }^{90} \mathrm{Y} \text { exposure and } \\
& \text { equals } 4.9637 \mathrm{mrad} / \mathrm{nc} \\
\mathrm{Ri}= & \text { the } 1 \text { ight output from the } \mathrm{i}^{\text {th }} \text { chip } \\
\mathrm{K} 2= & \text { the ratio of } \mathrm{R} 1 / \mathrm{R} 2 \text { from a dosimeter irradiated using }{ }^{137} \mathrm{Cs} \\
& \text { and equals } 1.0062 .
\end{aligned}
$$


The calculated $1 \mathrm{~cm}$ (penetrating) dose is evaluated as follows:

$$
D 1=A 1 \times R 2
$$

where

$$
\begin{aligned}
D 1= & \text { the } 1 \mathrm{~cm} \text { depth dose estimate } \\
\mathrm{A1}= & \text { a calibration constant derived from a }{ }^{137} \mathrm{Cs} \text { exposure and } \\
& \text { equals } 1.7588 \mathrm{mrad} / \mathrm{nc} \\
\mathrm{R} 2= & \text { the net light output from chip } 2 .
\end{aligned}
$$

The calculated skin dose, defined above, differs from the skin dose normally reported to an individual's personal dose history record. The reported dose is defined as the sum of skin dose equivalent (nonpenetrating), the $1 \mathrm{~cm}$ depth dose equivalent (penetrating) and the dose equivalent a person receives when exposed to neutrons. The neutron dose is zero in these irradiations, so the reported dose for this study is defined as the sum of the skin and $1 \mathrm{~cm}$ depth doses. The calculated dose ratio, defined as the calculated skin dose divided by the delivered skin dose, ranges from a maximum of 1.91 at $16.1 \mathrm{keV}$ to 0.00 at $662 \mathrm{keV}$. The reported dose ratio, defined as the reported skin dose divided by the delivered skin dose ranges from 1.08 at $16.1 \mathrm{keV}$ to 0.92 at $662 \mathrm{keV}$ with a maximum of 2.47 at $23.7 \mathrm{keV}$.

\section{Dosimeters Without Credentials}

Table 5.6 contains the raw data for dosimeters irradiated without the standard security credential in front of them. The pattern of net light output is the same as for the irradiations made with the security credential. The net light output from the chip in position 1 ranges from $99.58 \mathrm{nc}$ at $16.1 \mathrm{keV}$ to $210.83 \mathrm{nc}$ at $78 \mathrm{keV}$ with a maximum of $225.63 \mathrm{nc}$ at $58 \mathrm{keV}$. The corresponding data from chip 2 ranges from $16.02 \mathrm{nc}$ at $16.1 \mathrm{keV}$ to $204.27 \mathrm{nc}$ to $78 \mathrm{keV}$ with a maximum of $214.67 \mathrm{nc}$ at $58 \mathrm{keV}$. The ratio of light outputs from Chips 1 and 2 decreases asymptotically from 6.62 at $16.1 \mathrm{keV}$ to 1.03 at $78 \mathrm{keV}$ approaching 1.01 , the value of $\mathrm{K} 2$.

The response data for chip 1 is contained in Table 5.7. The count-to-skin dose ratio ranges from $0.46 \mathrm{nc} / \mathrm{mrad}$ at $16.1 \mathrm{keV}$ to $0.65 \mathrm{nc} / \mathrm{mrad}$ at $78 \mathrm{keV}$ with 
a maximum ratio of $0.91 \mathrm{nc} / \mathrm{mr}$ ad at $34.3 \mathrm{keV}$. Likewise, the count-to-exposure ratio ranges from $0.5 \mathrm{nc} / \mathrm{mR}$ at $16.1 \mathrm{keV}$ to $1.05 \mathrm{nc} / \mathrm{mR}$ at $78 \mathrm{keV}$ with a maximum of $1.13 \mathrm{nc} / \mathrm{mR}$ at $58 \mathrm{keV}$. This response can be thought of as the TLD response function to $x$-rays mentioned in the literature.

Table 5.8 compares the different dose estimates as previously noted. The calculated skin dose ratio decreases from 1.92 at $16.1 \mathrm{keV}$ to 0.08 at $78 \mathrm{keV}$ while the reported dose ratio ranges from 2.05 at $16.1 \mathrm{keV}$ to 1.20 at $78 \mathrm{keV}$ with a maximum of 2.30 at $34.3 \mathrm{keV}$.

Beta Radiation

Dosimeters with Credentials

Table 5.11 contains the raw data summary for dosimeters irradiated with the security credential (taken as $89 \mathrm{mg} / \mathrm{cm}^{2}$ ) in place. The ratio of the light outputs from chips in positions 1 and 2 varies from $4.36 \pm 0.17$ at ${ }^{238_{U}}$ to $1.99 \pm 0.16$ at ${ }^{106} \mathrm{Rh}$ with a maximum of $5.11 \pm 0.06$ using the Sr button at 3745. It was not possible to define a chip ratio for the irradiations using $85 \mathrm{Kr}$ due to the absorption of the beta rays in the security credential. Also, for graphical purposes the ratios from similar sources were averaged to produce values of 4.52 using ${ }^{238} \mathrm{U}$ and 4.65 using ${ }^{90} \mathrm{Sr} /{ }^{90} \mathrm{Y}$.

Table 5.12 summarized dose response data which ranges from $0.00 \mathrm{nc} / \mathrm{mrad}$ using the ${ }^{85} \mathrm{Kr}$ to $0.40 \mathrm{nc} / \mathrm{mr}$ ad using the ${ }^{106} \mathrm{Rh}$. Again, for graphical purposes the ratios from similar sources were averaged to produce $0.145 \mathrm{nc} / \mathrm{mr}$ ad using $238 \mathrm{U}$ and $0.243 \mathrm{nc} / \mathrm{mr}$ ad using ${ }^{90} \mathrm{Sr} /{ }^{90} \mathrm{Y}$.

Table 5.13 presents a dose comparison summary using the various sources. The calculated skin dose is evaluated using the previous algorithm of $D=$ $A x-(R 1-K 2 R 2)$ and the $1 \mathrm{~cm}$ depth dose is evaluated by $D=A 1 \times R 2$. The ratio of the calculated skin dose using dosimeter data to the delivered skin dose ranges from 0.02 at ${ }^{85} \mathrm{Kr}$ to 0.98 at ${ }^{106} \mathrm{Rh}$ with a maximum of 1.3 at ${ }^{90} \mathrm{Sr} /{ }^{90} \mathrm{Y}$. The reported dose, defined as the sum of calculated skin and $1 \mathrm{~cm}$ doses, to delivered dose ratio ranges from 0.02 at ${ }^{85} \mathrm{Kr}$ to 1.33 at ${ }^{106} \mathrm{Rh}$ with a maximum of 1.42 at ${ }^{90} \mathrm{Sr}-{ }^{90} \mathrm{Y}$. 


\section{Dosimeters Without Credentials}

Table 5.14 lists raw data for dosimeters irradiated without the security credential. Those ratios range from $22.04 \pm 0.07$ at ${ }^{238} \mathrm{U}$ to $1.96 \pm 0.14$ at $106_{\text {Rh. }}$

Table 5.15 summarizes the response data for the dosimeters irradiated without the credential. The ratio of net light output to skin dose ranges from $0.10 \mathrm{nc} / \mathrm{mr}$ ad at ${ }^{85} \mathrm{Kr}$ to $0.47 \mathrm{nc} / \mathrm{mr}$ ad at ${ }^{106} \mathrm{Rh}$.

The dose comparison data for dosimeters irradiated without the credential is presented in Table 5.16. The calculated skin dose ratio ranges from 0.51 at ${ }^{85} \mathrm{Kr}$ to 1.13 at ${ }^{106} \mathrm{Rh}$ with a maximum of 1.64 using ${ }^{90} \mathrm{Sr} /{ }^{90} \mathrm{Y}$ while the reported skin dose ratio varies from 0.51 at ${ }^{85_{\mathrm{Kr}}}$ to 1.55 at ${ }^{106} \mathrm{Rh}$ with a maximum of 1.85 at ${ }^{90} \mathrm{Sr} /{ }^{90} \mathrm{Y}$.

\section{DISCUSSION}

Figure 5.6 illustrates the response function of TLD-700 to $x$-rays. The shape of the response curve of the TLD chip behind the security credential has been reported by Endres (1965) and Kocher et al. (1967). The noted peak occurs at roughly $60 \mathrm{keV}$ in this report. The difference lies in the sources of $x$-rays and in the fact that dosimeters in this study were exposed on a phantom which contributes a scatter component to the $x$-ray spectrum. While K-fluorescence, producing a sharp peak of roughly monoenergetic photons, was employed in this study, previous studies used filtered $x$-rays which have broader spectra. The two curves in Figure 5.6 represent the response of an unfiltered chip and the response of a chip which is filtered by the security credential. The difference of the positions of the maxima could be due to spectral hardening by the credential. It is felt that statistical problems at the low energy ends of the curves contribute to their intersection at about $25 \mathrm{keV}$.

As was noted in Table 5.2, the conversion from exposure to absorbed dose in the range of 10-100 keV is a varying function which is maximized at $80 \mathrm{keV}$. 
Coupling this effect with that of the TLD response produces the curve in Figure 5.7, which is the response of the TLD relative to skin dose. Note that the curve asymptotically approaches 0.5 which is fairly constant above $80 \mathrm{keV}$.

Figure 5.8 illustrates the difference in response of the "open window" chip and the chip behind the aluminum filter. The ratio approaches the value of $\mathrm{K} 2$ (1.01) at roughly $45 \mathrm{keV}$ and is fairly constant to $662 \mathrm{keV}$ and beyond. This fact demonstrates that dose deposited by photons with higher energies than $45 \mathrm{keV}$ is defined as totally "penetrating". That situation is further illustrated by Figure 5.9 as the calculated skin dose (nonpenetrating) decreases rapidly for photons with energies between $10 \mathrm{keV}$ and $45 \mathrm{keV}$, tapering off to a very small fraction of the delivered dose.

The skin dose that is reported for an individual at Hanford is the sum of penetrating and nonpenetrating. In the range of $10 \mathrm{keV}$ to $80 \mathrm{keV}$ that dose is overestimated as shown in Figure 5.10. Hence the underestimation of skin dose based on the difference between an unfiltered and a filtered chip is countered by a conservative philosophy which includes the $1 \mathrm{~cm}$ depth (penetrating) dose in the skin dose estimate.

For low energy photons, the effect of introducing the security credential acts as a smoothing mechanism for the response curves. There is no appreciable difference in sensitivity between the two situations.

For the beta emitting sources studied, the amount of light output per unit dose increases as a function of the energy of the incident beta particle as shown in Figure 5.11. This phenomenon is a result of the dose distribution in tissue, in the LiF chip and in the materials surrounding the LiF crystal. Bremmstrahlung radiations caused by the interaction of the more energetic beta particles with the credential and surrounding dosimeter mate- rials most certainly account for some of the increase, especially since the bremmstrahlung photons are less energetic which produces an over response in the light output of the chip (Figure 5.7).

Figures 5.12 and 5.13 illustrate the fact that the dosimeter may be used to assess skin doses fairly accurately for beta radiations with reference energies above $-2.0 \mathrm{MeV}$. 
Comparison of Figures 5.10 and 5.13 present the main flaw with using the Hanford MPD in beta dosimetry. While the lower energy x-rays produce an overestimation of the skin dose to the individual, the lower energy beta radiations produce a gross underestimation of skin dose to the individual. Both these types of radiations are pooled together into a NON-PEN category, which has the effect of philosophically stating that the dosimeter has equal propensity for estimating skin dose from these radiations. As is seen from Figures 5.10 and 5.13 that is certainly not the case.

Additionally, while there are slight to negligible differences in the dosimeter response to low energy x-rays, that situation is not identical for beta particles. Hence, any absorber between the source of beta radiations and the Lif crystal has the effect of lowering response and underestimating skin dose.

\section{CONCLUSIONS}

The estimation of skin dose using the MPD is conservatively high for photons with energies between $10 \mathrm{keV}$ and $80 \mathrm{keV}$. This situation is most pronounced between $30 \mathrm{keV}$ and $60 \mathrm{keV}$ where the dose estimate is approximately twice the corresponding delivered dose. Response and estimate functions tend to stabilize at $80 \mathrm{keV}$ and remain fairly constant through energies of $1250 \mathrm{keV}$ $\left({ }^{60} \mathrm{Co}\right)$.

It is recommended that in order to obtain a more accurate measure of skin dose, a system of filtered chips be used. The estimation should not be based on the difference of light outputs from an unfiltered chip and a filtered chip only, but rather on the interrelationships between the response of several TLDs behind various types of filter material. Study should be undertaken to determine appropriate filters and respective response functions to arrive at an estimate of dose based on spectral measurements of photon fields.

It is further recommended that, in light of the over-response of TLDS to low energy photons and the extreme difference in filtering between the chips in positions 2 and 5 , the chip in position 2 not be used as a gamma compensation technique for estimation of neutron dose. 
The estimation of skin dose from beta radiations using a multipurpose dosimeter is highly dependent upon the energy of the incident beta particle. Hence, it should be employed with great caution and a calibration made for each spectrum of beta radiations to which the dosimeter is exposed. Furthermore, that calibration should be applied in dose estimation and administrative controls should be established to inhibit the use of the dosimeter in fields of mixed beta and photon radiations.

\section{REFERENCES}

Cummings, F. M., et a1. 1980. "Final Report - Study 2: High Energy Photon Reponse," PNL-3536, Pacific Northwest Laboratory, Richland, Washington.

Endres, G. W. R. 1965. "Thermoluminescence Dosimetry Studies at Hanford," Luminescence Dosimetry, CONF-650637.

Kocher, L.F., et al. 1971. "The Hanford Thermoluminescent Multipurpose Dosimeter," BNWL-SA-3955, Pac if ic Northwest Laboratory, Richland, Washington.

Yoder, R. C., et al. 1979. "Confirmation of Conversion Factors Relating Exposure and Dose Equivalent Index Presented in ANSI 13.11," PNL-3219, Pacific Northwest Laboratory, Richland, Washington. 
TABLE 5.1. X-Ray Irradiation Data for Dosimeters Exposed with Credentials

\begin{tabular}{|c|c|c|c|c|c|c|}
\hline $\begin{array}{l}\text { Photon } \\
\text { Energy } \\
\text { (keV) } \\
\end{array}$ & $\begin{array}{c}\text { Target } \\
\text { Irradiator }\end{array}$ & $\begin{array}{c}\text { K X-Ray Beam } \\
\text { Filtration } \\
(\mathrm{mm}) \\
\end{array}$ & $\begin{array}{l}\text { Tube } \\
\text { Potential } \\
(\mathrm{kV}) \\
\end{array}$ & $\begin{array}{l}\text { Tube } \\
\text { Current } \\
\text { (ma) }\end{array}$ & $\begin{array}{c}\text { Source-to-Phantom } \\
\text { Distance } \\
(\mathrm{cm}) \\
\end{array}$ & $\begin{array}{c}\text { Exposure }_{(\mathrm{mR})}^{(a)} \\
\end{array}$ \\
\hline 16.1 & $\mathrm{Zr}$ & None & 80 & 24 & 50 & 200 \\
\hline 23.7 & $\mathrm{Cd}$ & None & 95 & 27.5 & 50 & 200 \\
\hline 34.3 & La & None & 115 & 24 & 50 & 200 \\
\hline 43 & $S m-G d$ & $0.8 \mathrm{Al}$ & 125 & 24 & 50 & 200 \\
\hline 58 & $\mathrm{Ta}$ & $0.8 \mathrm{Al}$ & 145 & 20 & 50 & 200 \\
\hline 78 & $\mathrm{~Pb}$ & $\begin{array}{l}2.4 \mathrm{Al} \\
0.08 \mathrm{Cu}\end{array}$ & 165 & 20 & 50 & 200 \\
\hline
\end{tabular}

(a) Measured using a free air ionization chamber. 
TABLE 5.2. Dose Equivalents and Delivered Dose(a)

\begin{tabular}{|c|c|c|c|}
\hline $\begin{array}{l}\text { Photon } \\
\text { Energy } \\
\text { (keV) } \\
\end{array}$ & $\begin{array}{r}0.07 \mathrm{~cm} \\
\mathrm{DEI} \\
(\mathrm{rad} / \mathrm{R}) \\
\end{array}$ & $\begin{array}{c}\text { Exposure } \\
(\mathrm{mR}) \\
\end{array}$ & $\begin{array}{l}\text { Sk in Dose } \\
0.007 \mathrm{~cm} \\
\text { (mrad) }\end{array}$ \\
\hline 16.1 & 1.08 & 200 & 216 \\
\hline 23.7 & 1.07 & 200 & 214 \\
\hline 34.3 & 1.07 & 200 & 214 \\
\hline 43 & 1.28 & 200 & 256 \\
\hline 58 & 1.47 & 200 & 294 \\
\hline 78 & 1.61 & 200 & 322 \\
\hline $100^{(b)}$ & 1.50 & & \\
\hline
\end{tabular}

(a) From Yoder et al. 1979.
(b) Used for reference. 
TABLE 5.3. Raw Data Summary for Dosimeters Exposed with Credentials

\begin{tabular}{|c|c|c|c|c|c|c|c|c|c|}
\hline $\begin{array}{l}\text { Photon } \\
\text { Energy } \\
\text { (kev) }\end{array}$ & $\begin{array}{c}\text { Net } \\
\text { Raw Data } \\
\text { Ch ip } 1 \\
\text { (nc) } \\
\end{array}$ & $1 \mathrm{SO}{ }^{(\mathrm{a})}$ & $\begin{array}{c}\text { Net } \\
\text { Raw Data } \\
\text { Ch ip } 2 \\
(n c) \\
\end{array}$ & & $1 S D^{(a)}$ & $\begin{array}{l}\text { Ratio } \\
\text { R1/R2 } \\
\end{array}$ & & $\underline{1 S D}{ }^{(a)}$ & $\begin{array}{c}\text { Exposure }^{(b)}(\mathrm{mR}) \\
\end{array}$ \\
\hline 16.1 & 103.88 & 5.91 & 20.73 & $+1-$ & 2.45 & 5.01 & $+1-$ & 0.13 & 200 \\
\hline 23.7 & 158.20 & $+/-\quad 6.30$ & 81.18 & $+1-$ & 4.38 & 1.95 & $+1-$ & 0.07 & 200 \\
\hline 34.3 & 186.33 & $+/-\quad 15.67$ & 146.03 & $+1-$ & 5.71 & 1.28 & $+1-$ & 0.09 & 200 \\
\hline 43 & 201.15 & $+1-10.82$ & 173.25 & $+1-$ & 12.33 & 1.16 & $+1-$ & 0.09 & 200 \\
\hline 58 & 197.15 & 8.41 & 174.40 & $+1-$ & 10.41 & 1.13 & $+1-$ & 0.07 & 200 \\
\hline 78 & 179.28 & 6.22 & 166.58 & $+1-$ & 8.42 & 1.08 & $+1-$ & 0.06 & 200 \\
\hline $662\left({ }^{137} \mathrm{Cs}\right)$ & 110.87 & 8.86 & 110.19 & $+1-$ & 8.51 & 1.01 & $+1-$ & 0.11 & 200 \\
\hline $1250^{(\mathrm{c})}\left({ }^{60} \mathrm{Co}\right)$ & 120.05 & 6.31 & 114.21 & $+1-$ & 7.05 & 1.05 & $+1-$ & 0.08 & 200 \\
\hline Background & 4.75 & 0.37 & 4.80 & $+1-$ & 0.12 & 0.99 & $+1-$ & 0.08 & 0 \\
\hline
\end{tabular}

\footnotetext{
(a) One standard deviation.

(b) Measured with free air ionization chamber.

(c) Used for reference only.
} 
TABLE 5.4. Chip 1 Response Data for Dosimeters Exposed with Credential

\begin{tabular}{|c|c|c|c|c|}
\hline $\begin{array}{l}\text { Photon } \\
\text { Energy } \\
\text { (keV) }\end{array}$ & $\begin{array}{c}\text { Net } \\
\text { Raw Data } \\
\text { Chip } 1 \\
(n c) \\
\end{array}$ & $\begin{array}{c}\text { Given } \\
\text { Sk in Dose } \\
\text { (mrad) } \\
\end{array}$ & $\begin{array}{l}\text { Raw Count to } \\
\text { Skin Dose } \\
\text { Ratio } \\
\text { (nc/mrad) } \\
\end{array}$ & $\begin{array}{l}\text { Raw Count to }(a) \\
\text { Exposure } \\
\text { Ratio } \\
\text { (nc/mR) } \\
\end{array}$ \\
\hline 16.1 & 103.88 & 216 & 0.48 & 0.52 \\
\hline 23.7 & 158.20 & 214 & 0.74 & 0.79 \\
\hline 34.3 & 186.33 & 214 & 0.87 & 0.93 \\
\hline 43 & 201.15 & 256 & 0.79 & 1.01 \\
\hline 58 & 197.15 & 294 & 0.67 & 0.99 \\
\hline 78 & 179.21 & 322 & 0.56 & 0.90 \\
\hline $662\left({ }^{137} \mathrm{Cs}\right)$ & 110.87 & 212 & 0.52 & 0.55 \\
\hline $1250^{(b)}\left({ }^{60} \mathrm{Co}\right)$ & 120.06 & 212 & 0.57 & 0.60 \\
\hline
\end{tabular}

(a) Exposure $=200 \mathrm{mR}$ in all cases.

(b) For reference only.

TABLE 5.5. Dose Comparison Data for Dosimeters Exposed with Credential

\begin{tabular}{|c|c|c|c|c|c|}
\hline $\begin{array}{l}\text { Photon } \\
\text { Energy } \\
\text { (kev) }\end{array}$ & $\begin{array}{l}\text { Calculated } \\
\text { Sk in Dose } \\
\text { (mrad) } \\
\end{array}$ & $\begin{array}{l}\text { Calculated } \\
1 \text { cm Dose } \\
\text { (mrad) } \\
\end{array}$ & $\begin{array}{c}\text { Given } \\
\text { Skin Dose } \\
\text { (mrad) } \\
\end{array}$ & $\begin{array}{l}\text { Calculated } \\
\text { Skin Dose } \\
\text { Ratio } \\
\end{array}$ & $\begin{array}{l}\text { Reportable(a } \\
\text { Skin Dose } \\
\text { Ratio }\end{array}$ \\
\hline 16.1 & 412 & 38 & 216 & 1.91 & 2.08 \\
\hline 23.7 & 380 & 148 & 214 & 1.78 & 2.47 \\
\hline 34.3 & 196 & 266 & 214 & 0.92 & 2.16 \\
\hline 43 & 133 & 316 & 256 & 0.52 & 1.75 \\
\hline 58 & 108 & 318 & 294 & 0.37 & 1.45 \\
\hline 78 & 58 & 304 & 322 & 0.18 & 1.12 \\
\hline 100 & & & 300 & & \\
\hline $662\left({ }^{137} \mathrm{Cs}\right)$ & 0 & 195 & 212 & -- & 0.92 \\
\hline $1250^{(\mathrm{b})}\left({ }^{60} \mathrm{Co}\right)$ & 0 & 202 & 212 & - & 0.95 \\
\hline
\end{tabular}

(a) Reportable skin dose ratio equal to calculated skin (nonpentrating) dose (column 2) plus penetrating dose (column 3) divided by given skin $\left(7 \mathrm{mg} / \mathrm{cm}^{2}\right.$ ) dose (column 4$)$.

(b) For reference only. 
TABLE 5.6. Raw Data Summary for Dosimeters Exposed Without Security Credential

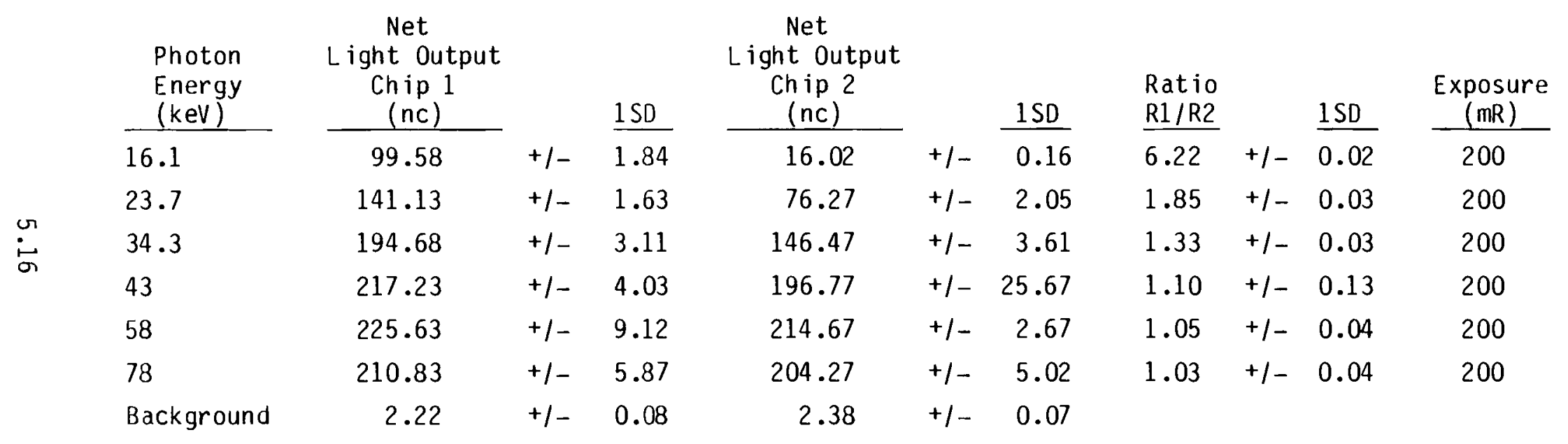


TABLE 5.7. Chip 1 Response Data for Dosimeters Exposed Without Security Credential

\begin{tabular}{|c|c|c|c|c|}
\hline $\begin{array}{l}\text { Photon } \\
\text { Energy } \\
\text { (kev) } \\
\end{array}$ & $\begin{array}{c}\text { Net } \\
\text { Raw Data } \\
\text { Chip } 1 \\
\text { (nc) } \\
\end{array}$ & $\begin{array}{c}\text { Given } \\
\text { Sk in Dose } \\
\text { (mrad) } \\
\end{array}$ & $\begin{array}{l}\text { Raw Count to } \\
\text { Sk in Dose } \\
\text { Ratio } \\
\text { (nc/mrad) } \\
\end{array}$ & $\begin{array}{c}\text { Raw Count to (a) } \\
\text { Exposure } \\
\text { Ratio } \\
\text { (nc/mrad) } \\
\end{array}$ \\
\hline 16.1 & 99.58 & 216 & 0.46 & 0.50 \\
\hline 23.7 & 141.13 & 214 & 0.66 & 0.71 \\
\hline 34.3 & 194.68 & 214 & 0.91 & 0.97 \\
\hline 43 & 217.23 & 256 & 0.85 & 1.09 \\
\hline 58 & 225.63 & 294 & 0.77 & 1.13 \\
\hline 78 & 210.83 & 322 & 0.65 & 1.05 \\
\hline
\end{tabular}

(a) Exposure $=200 \mathrm{mR}$ in all cases.

TABLE 5.8. Dose Comparison Data for Dosimeters Exposed Without Credentials

\begin{tabular}{|c|c|c|c|c|c|}
\hline $\begin{array}{l}\text { Photon } \\
\text { Energy } \\
\text { (kev) } \\
\end{array}$ & $\begin{array}{l}\text { Calculated } \\
\text { Skin Dose } \\
\quad \text { (mrad) } \\
\end{array}$ & $\begin{array}{l}\text { Calculated } \\
1 \text { cm Dose } \\
\text { (mrad) } \\
\end{array}$ & $\begin{array}{c}\text { Given } \\
\text { Sk in Dose } \\
\text { (mrad) } \\
\end{array}$ & $\begin{array}{c}\text { Calculated }(a) \\
\text { Skin Dose } \\
\text { Ratio } \\
\end{array}$ & $\begin{array}{c}\text { Reported }(b) \\
\text { Sk in Dose } \\
\text { Ratio } \\
\end{array}$ \\
\hline 16.1 & 414 & 28 & 216 & 1.92 & 2.05 \\
\hline 23.7 & 320 & 134 & 214 & 1.50 & 2.12 \\
\hline 34.3 & 235 & 258 & 214 & 1.10 & 2.30 \\
\hline 43 & 96 & 346 & 256 & 0.38 & 1.73 \\
\hline 58 & 48 & 378 & 294 & 0.16 & 1.45 \\
\hline 78 & 26 & 359 & 322 & 0.08 & 1.20 \\
\hline
\end{tabular}

(a) Calculated skin dose ratio equal to calculated skin (nonpenetrating) dose (column 2) divided by given sk in $\left(7 \mathrm{mg} / \mathrm{cm}^{2}\right.$ ) dose (column 4 ).

(b) Reported skin dose ratio equal to calculated skin (nonpenetrating) dose (column 2) plus calculated $1 \mathrm{~cm}$ (penetrating) dose (column 3 ) divided by given skin $\left(7 \mathrm{mg} / \mathrm{cm}^{2}\right)$ dose (column 4$)$. 
TABLE 5.9. Beta Source Irradiation Data

\begin{tabular}{|c|c|c|c|c|}
\hline Source & $\begin{array}{c}\text { Source } \\
\text { Geometry }\end{array}$ & $\begin{array}{l}\text { Emax } \\
(\mathrm{MeV}) \\
\end{array}$ & $\begin{array}{l}\text { Source-to-Phantom } \\
\text { Distance } \\
(\mathrm{cm}) \\
\end{array}$ & $\begin{array}{c}\text { Sk in Dose } \\
\left(\begin{array}{c}7 \mathrm{~mm}, \mathrm{t} \text { issue }) \\
\text { (mrad) }\end{array}\right.\end{array}$ \\
\hline $85_{\mathrm{Kr}}$ & $\overline{\text { Button }}$ & 0.67 & 49 & 1010 \\
\hline $238 \cup 1$ & Slab & 2.29 & Contact & 1000 \\
\hline $238 \cup 2$ & Slab & 2.29 & Contact & 200 \\
\hline 238 U 3 & Disk & 2.29 & Contact & 4000 \\
\hline${ }^{90} \mathrm{Sr} /^{90_{\mathrm{Y}} 1}$ & Button & 2.27 & 50.5 & 1000 \\
\hline${ }^{90}{ }_{S r / 1} 90_{Y} 2$ & Button & 2.27 & 34 & 261 \\
\hline${ }^{90} \mathrm{Sr} /{ }^{90} \mathrm{Y} 3$ & Sphere & 2.27 & 50 & 220 \\
\hline${ }^{90}{ }_{S r / 1} 90_{Y} 4$ & Button & 2.27 & 50.5 & 2000 \\
\hline${ }^{106} \mathrm{Rh}$ & Button & 3.54 & 49 & 242 \\
\hline
\end{tabular}

TABLE 5.10. Beta Radiation Reference Energy

$\begin{array}{lll}\text { Source } & & \begin{array}{c}\text { Maximum Energy and } \\ \text { Abundance of } \\ \text { Principal Beta } \\ \text { Radiat ions } \\ \text { (MeV [\%]) }\end{array}\end{array}$

(a) To be used for illustration only.

(b) Encapsulation assumed to absorb lower energy radiation. 
TABLE 5.11. Raw Data Summary for Dosimeters Exposed with Credentials

Net

Light output

Ch ip 1

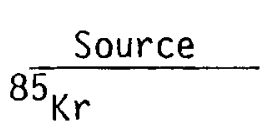

$238_{U}(2) \quad 1$

$238_{Y}(2) 2$

${ }^{90} \mathrm{Sr}_{\mathrm{Y}-}{ }^{90} \mathrm{Y} \quad 1$

${ }^{90} \mathrm{Sr}_{\mathrm{S}-}{ }^{90} \mathrm{O}_{\mathrm{Y}} 2$

$90_{\mathrm{Sr}-} 90_{\mathrm{Y}} 3$

${ }^{106} \mathrm{Ru}-{ }^{106} \mathrm{Rh}$

\begin{tabular}{rlr}
$\begin{array}{rr}\text { Chip } 1 \\
(\mathrm{nC})\end{array}$ & & $\frac{1 \mathrm{SD}(\mathrm{a})}{0.94}$ \\
\cline { 1 - 1 } 4.07 & $+/-$ & 0.94 \\
134.68 & $+/-$ & 8.06 \\
29.14 & $+/-$ & 3.16 \\
250.87 & $+/-$ & 10.54 \\
85.93 & $+/-$ & 3.40 \\
59.10 & $+/-$ & 6.01 \\
96.58 & $+/-$ & 1.71
\end{tabular}

\section{Light Output}

Ch ip 2

(nc)

$-0.043$

28.78

6.68

49.10

17.60

14.92

48.44

$\frac{15 D^{(a)}}{0.51}$
$+/-1.52$
$+/-1.87$
$+1-0.87$
$+1-2.33$
$+1-1.73$
$+1-1.98$
$+1-7.92$

Ratio
R1/R2

$4.68+/-0.08$

$4.36+1-0.17$

$5.11+/-0.06$

$4.88+/-0.11$

$3.96+1-0.17$

$1.99+/-0.16$

(a) One standard deviation $9 \% 238 U$ and daughters. 
TABLE 5.12. Chip 1 Response Data for Dosimeters Exposed with Credential

\begin{tabular}{|c|c|c|c|}
\hline Source & $\begin{array}{c}\text { Net } \\
\text { Light Output } \\
\text { Chip } 1 \\
\text { (nc) } \\
\end{array}$ & $\begin{array}{c}\text { Given } \\
\text { Sk in Dose } \\
\text { (mrad) } \\
\end{array}$ & $\begin{array}{l}\text { Light Output to } \\
\text { Sk in Dose Rat io } \\
\text { (nc/mrad) }\end{array}$ \\
\hline $85_{K r}$ & 4.07 & 1010 & 0.00 \\
\hline $238 \cup 1$ & 134.68 & 1000 & 0.14 \\
\hline $238 \cup 2$ & 29.14 & 200 & 0.15 \\
\hline${ }^{90} S_{S r} 90_{Y} 1$ & 250.87 & 1000 & 0.25 \\
\hline${ }^{90}{ }_{S r} 90_{Y} 2$ & 85.93 & 261 & 0.33 \\
\hline${ }^{90} 0_{S r} 90_{Y} 3$ & 59.10 & 220 & 0.27 \\
\hline${ }^{106} \mathrm{Rh}$ & 96.58 & 242 & 0.40 \\
\hline
\end{tabular}

TABLE 5.13. Dose Comparison Data for Dosimeters Exposed With Credential

\begin{tabular}{|c|c|c|c|c|c|}
\hline Source & $\begin{array}{c}\text { Caiculated }(1) \\
\text { Sk in Dose } \\
(m r \neq d) \\
\end{array}$ & $\begin{array}{l}\text { Caiculated (a) } \\
1 \text { cm Jose } \\
\text { (mrad) }\end{array}$ & $\begin{array}{l}\text { De! ivered }(b) \\
\text { Sk in Dose } \\
\text { (mrad) }\end{array}$ & $\begin{array}{c}\text { Calculated }(c) \\
\text { Skin Dose } \\
\text { Ratio } \\
\end{array}$ & $\begin{array}{c}\text { Reportad }(d) \\
\text { Skin Dose } \\
\text { Ratio } \\
\end{array}$ \\
\hline $8 \overline{5_{k r}}$ & 20 & 0 & 1010 & 0.02 & 0.02 \\
\hline $238_{1] 1}$ & 525 & 51 & 1000 & 0.53 & 0.58 \\
\hline $233_{\mathrm{U}} ?$ & $11 i$ & 12 & 200 & 0.56 & 0.62 \\
\hline $90_{S r} 1$ & 1000 & 36 & 1000 & 1.00 & 1.09 \\
\hline${ }^{30} \mathrm{Sr} ?$ & 339 & 31 & 251 & 1.30 & 1.42 \\
\hline${ }^{90} \mathrm{Sr} 3$ & 219 & 25 & 220 & 1.00 & 1.11 \\
\hline${ }^{106} R \mathrm{R}$ & 237 & 35 & 212 & 0.98 & 1.33 \\
\hline
\end{tabular}

(a) Using dosimeter data.

(b) Measured using an extrapolation chamoer.

(c) Calculacej skin Jose ratio equal to calculated skin (nonpenetrating) dose (column 2) divided oy given jkin $\left(7 \mathrm{mg} / \mathrm{cm}^{2}\right.$ ) Jose (column 4 ).

(d) Reported skin jose ratio equal to calculated skin (nonpenetrating) dose (column 2) olus caiculated $1 \mathrm{~cm}$ (penetrating) dose (column 3) divided by given skin $\left(7 \mathrm{ng} / \mathrm{cm}^{2}\right.$ ) dose (column 4 ). 
TABLE 5.14. Raw Data Summary for Dosimeters Exposed Without Credential Net

Light Output

$\frac{\text { Source }}{{ }^{85} \mathrm{Kr}}$
${ }^{238} \mathrm{U}$
${ }^{90} \mathrm{Sr} 1$
${ }^{90} \mathrm{Sr} 2$
${ }^{90} \mathrm{Sr} 3$
$106 \mathrm{Rh}$

Chip 1 (nc)

104.80

817.79

781.47

117.75

79.64

113.23

$\begin{array}{cc} & \frac{1 S D}{1 S} \\ +/- & 2.34 \\ +/- & 19.42 \\ +/- & 27.53 \\ +/- & 5.26 \\ +/- & 8.49 \\ +/- & 12.85\end{array}$

Net

Light Output

Chip 2

Chip 2

$-0.31$

37.10

268.98

31.07

23.07

57.82

$+\frac{1 S D^{(1)}}{0.82}$

$+1-0.82$

$+1-2.52$

$+/-6.61$

$+1-1.11$

$+1-1.91$

$+1-4.92$

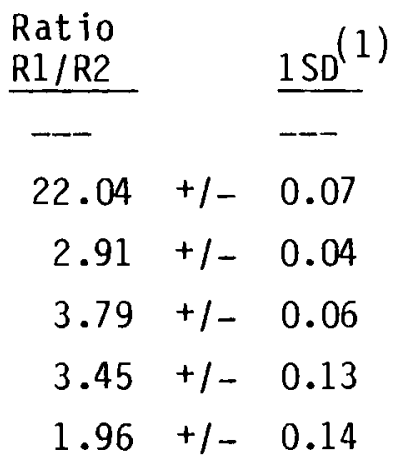

(a) One standard deviation. 
TABLE 5.15. Chip 1 Response Data for Dosimeters Exposed Without Credential Net

\begin{tabular}{|c|c|c|}
\hline $\begin{array}{l}\text { Light Output } \\
\text { Chip } 1 \\
\text { (nc) } \\
\end{array}$ & $\begin{array}{c}\text { Given } \\
\text { Sk in Dose } \\
\text { (mrad) } \\
\end{array}$ & $\begin{array}{l}\text { Light Output to } \\
\text { Skin Dose Ratio } \\
\text { (nc/mrad) }\end{array}$ \\
\hline 104.80 & 1010 & 0.10 \\
\hline 817.79 & 4000 & 0.20 \\
\hline 781.47 & 2000 & 0.39 \\
\hline 117.75 & 261 & 0.45 \\
\hline 79.64 & 220 & 0.36 \\
\hline 113.23 & 242 & 0.47 \\
\hline
\end{tabular}

TABLE 5.16. Dose Comparison Data for Dosimeters Exposed Without Credential

\begin{tabular}{|c|c|c|c|c|c|}
\hline Source & $\begin{array}{c}\text { Calculated } \\
\text { Sk in Dose } \\
\text { (mrad) } \\
\end{array}$ & $\begin{array}{l}\text { Calculated } \\
1 \text { cm Dose } \\
\text { (mrad) } \\
\end{array}$ & $\begin{array}{c}\text { Given } \\
\text { Sk in Dose } \\
\text { (mrad) } \\
\end{array}$ & $\begin{array}{c}\text { Calculated }(a) \\
\text { Skin Dose } \\
\text { Ratio } \\
\end{array}$ & $\begin{array}{c}\text { Reported (b) } \\
\text { Skin Dose } \\
\text { Ratio } \\
\end{array}$ \\
\hline & 519 & 1 & 1010 & 0.51 & 0.51 \\
\hline $238 U$ & 3874 & 65 & 4000 & 0.97 & 0.98 \\
\hline${ }^{90} \mathrm{Sr} \quad 1$ & 2536 & 473 & 2000 & 1.27 & 1.50 \\
\hline${ }^{90} \mathrm{Sr} \quad 2$ & 429 & 55 & 261 & 1.64 & 1.85 \\
\hline${ }^{90} \mathrm{Sr} 3$ & 280 & 41 & 220 & 1.27 & 1.46 \\
\hline${ }^{106} \mathrm{Rh}$ & 273 & 102 & 242 & 1.13 & 1.55 \\
\hline
\end{tabular}

(a) Calculated skin dose ratio equal to calculated skin (nonpenetrating) dose (column 2) divided by given skin $\left(7 \mathrm{mg} / \mathrm{cm}^{2}\right.$ ) dose (column 4 ).

(b) Reported skin dose ratio equal to calculated skin (nonpenetrating) dose (column 2) plus calculated $1 \mathrm{~cm}$ (penetrating) dose (column 3 ) divided by given skin $\left(7 \mathrm{mg} / \mathrm{cm}^{2}\right)$ dose (column 4$)$. 


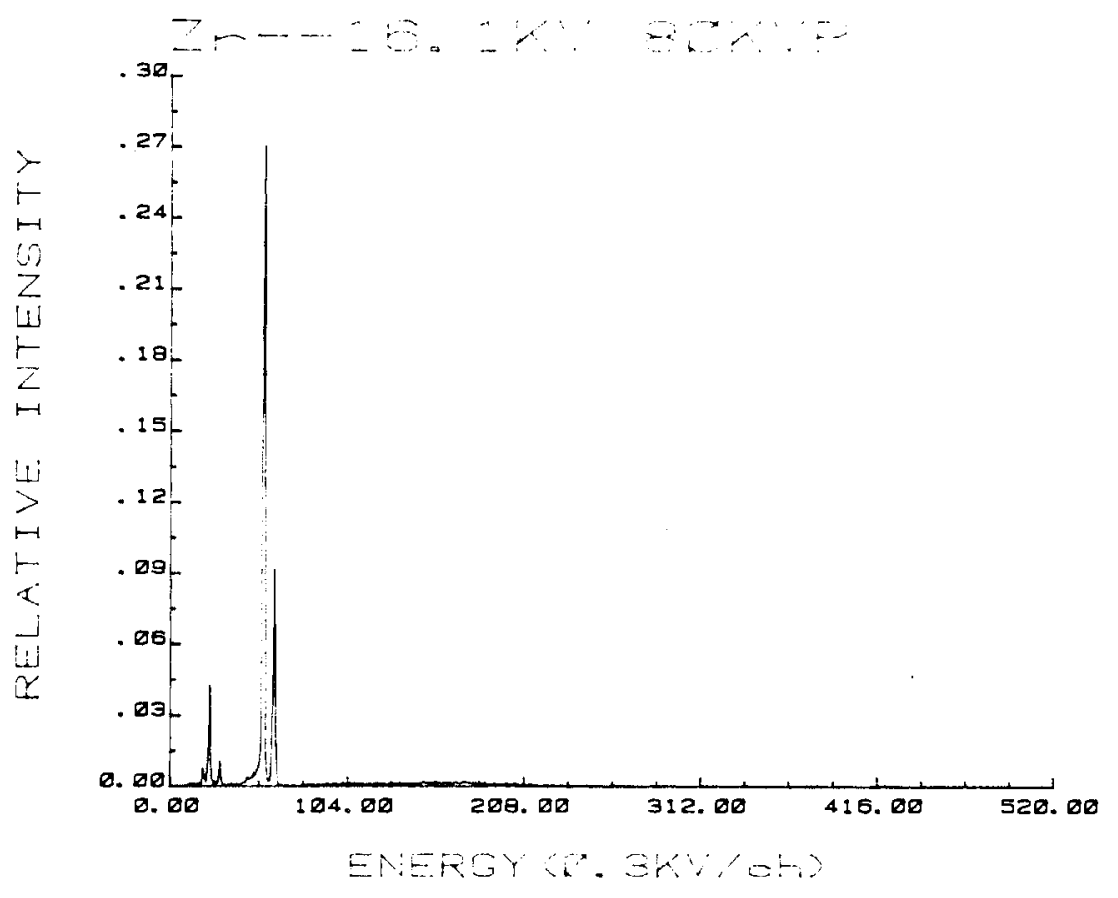

FIGURE 5.0. Spectrum From $16.1 \mathrm{keV} X$-Ray (Yoder et al 1967).

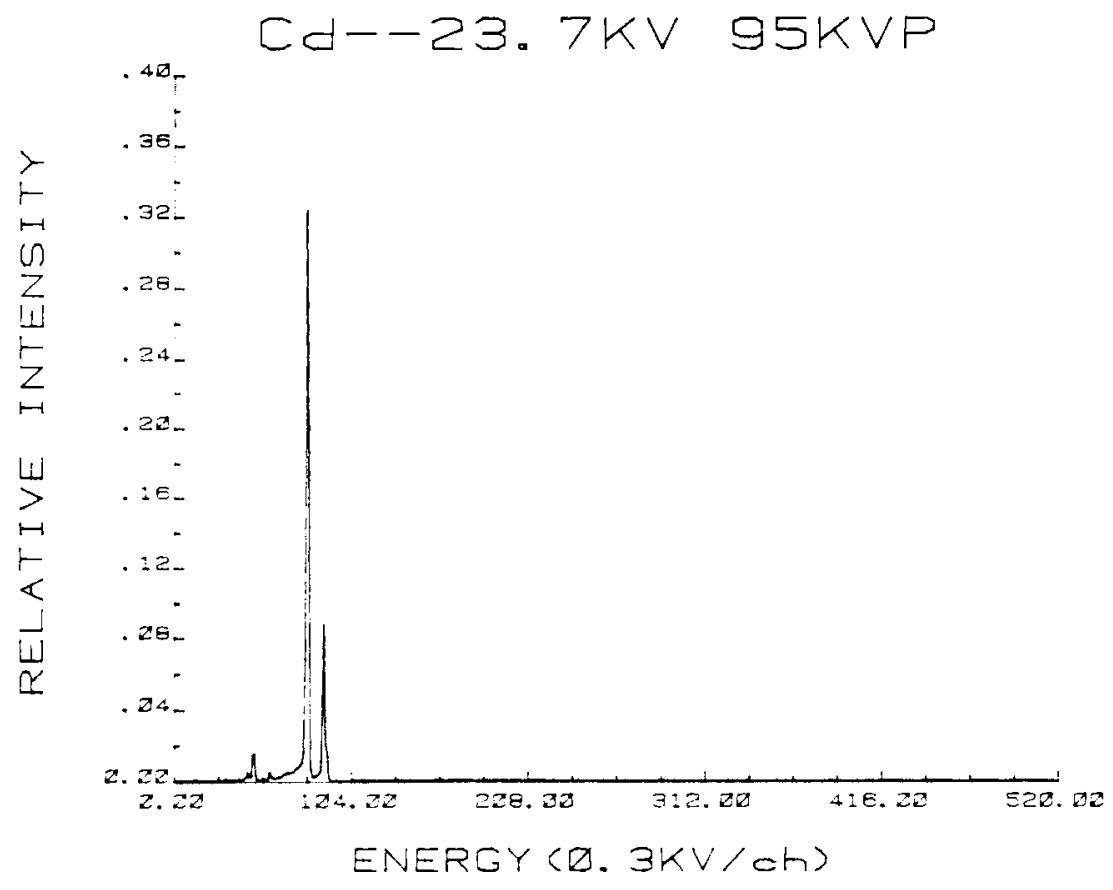

FIGURE 5.1. Spectrum from $23.7 \mathrm{keV} X$-Ray (Yoder et al 1979). 


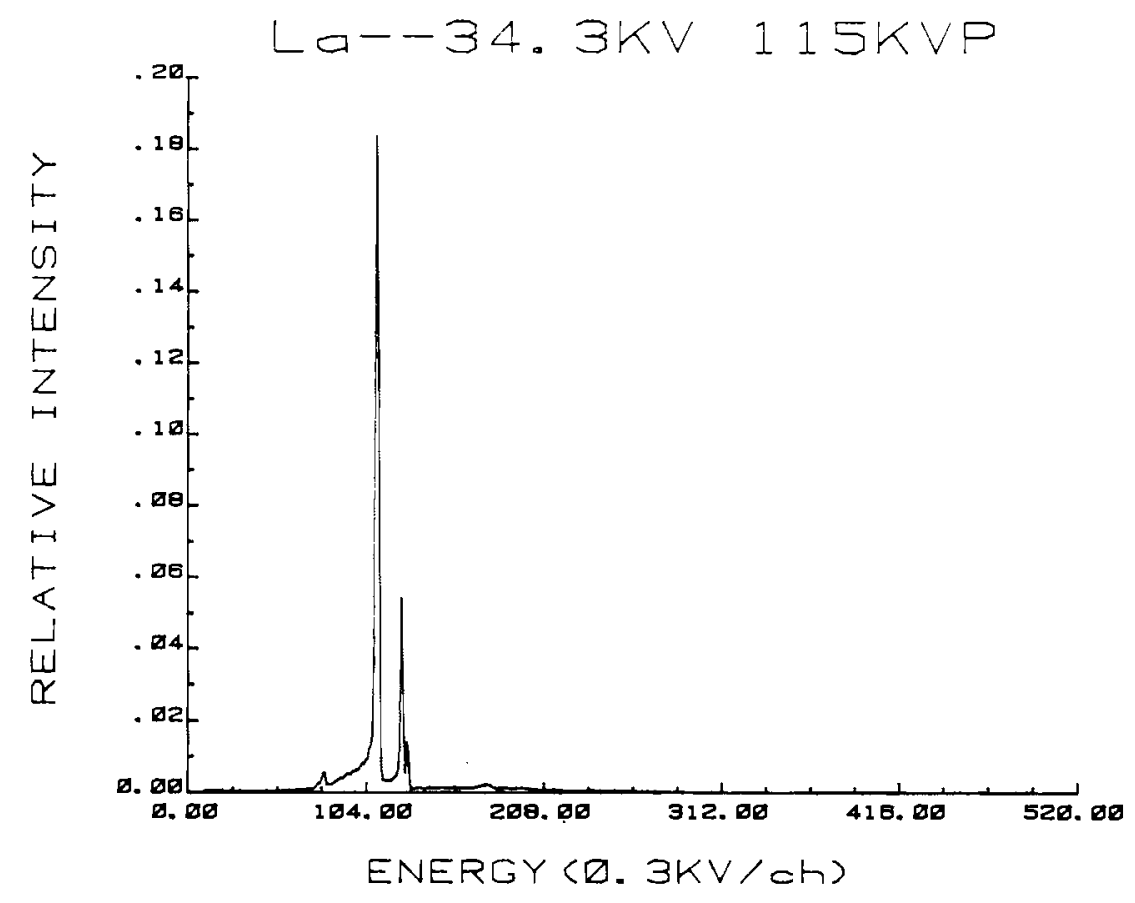

FIGURE 5.2. Spectrum from $34.3 \mathrm{keV} X$-Ray (Yoder et al 1976).

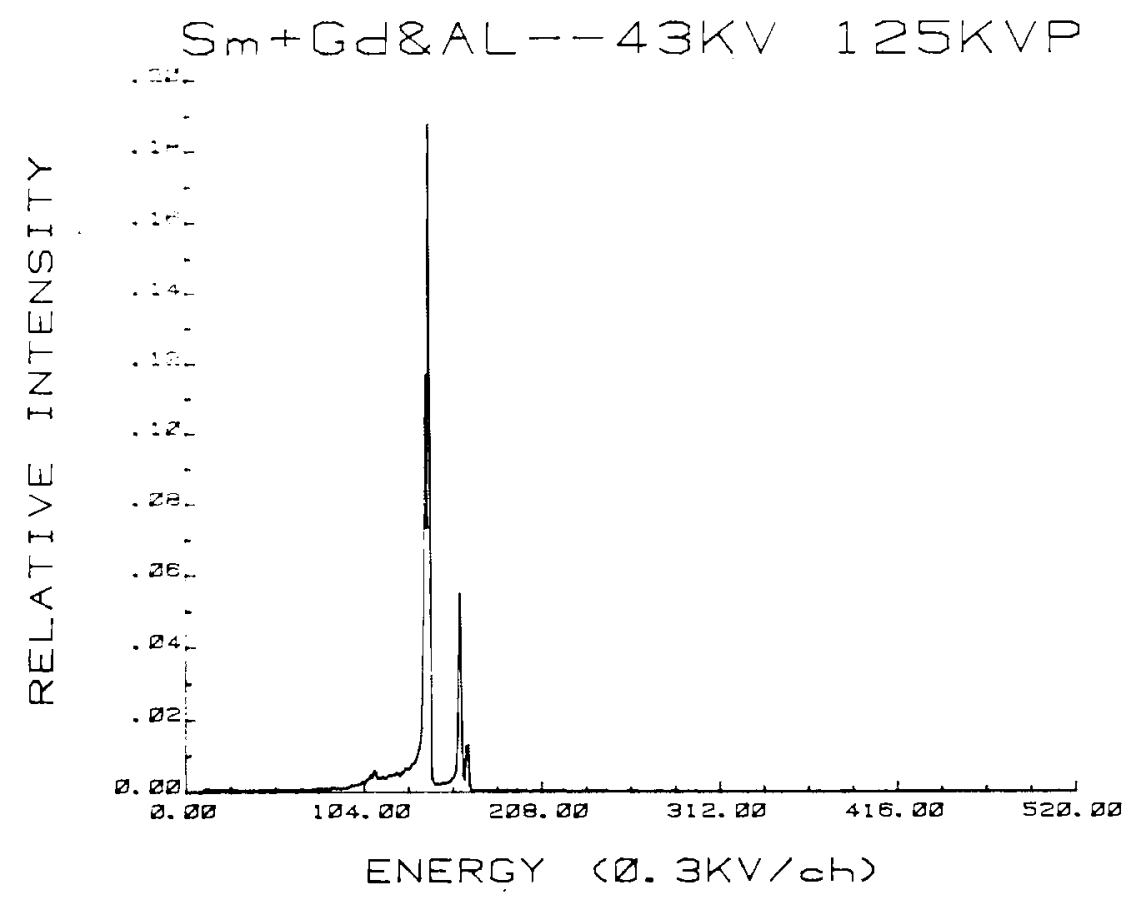

FIGURE 5.3. Spectrum from $43 \mathrm{keV} X$-Ray (Yoder et al. 1979). 


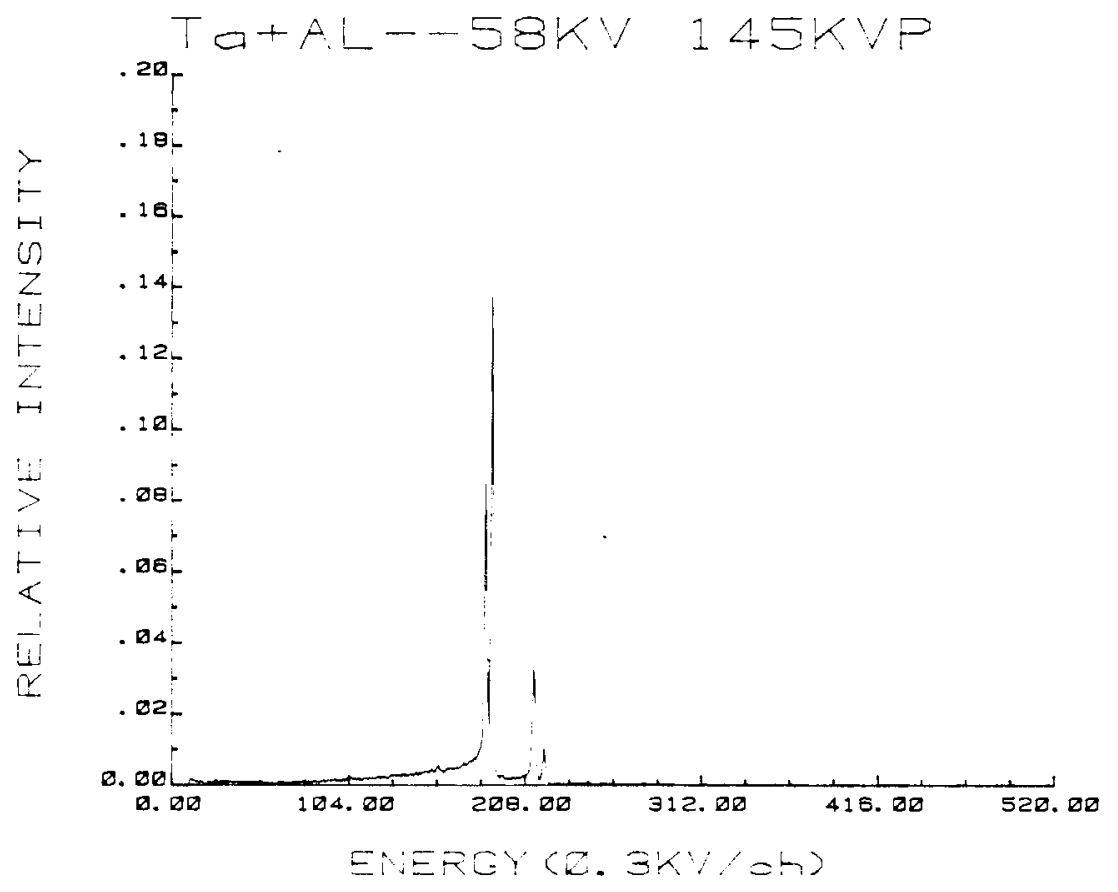

FIGURE 5.4. Spectrum from $58 \mathrm{keV} X$-Ray (Yoder et al. 1979).

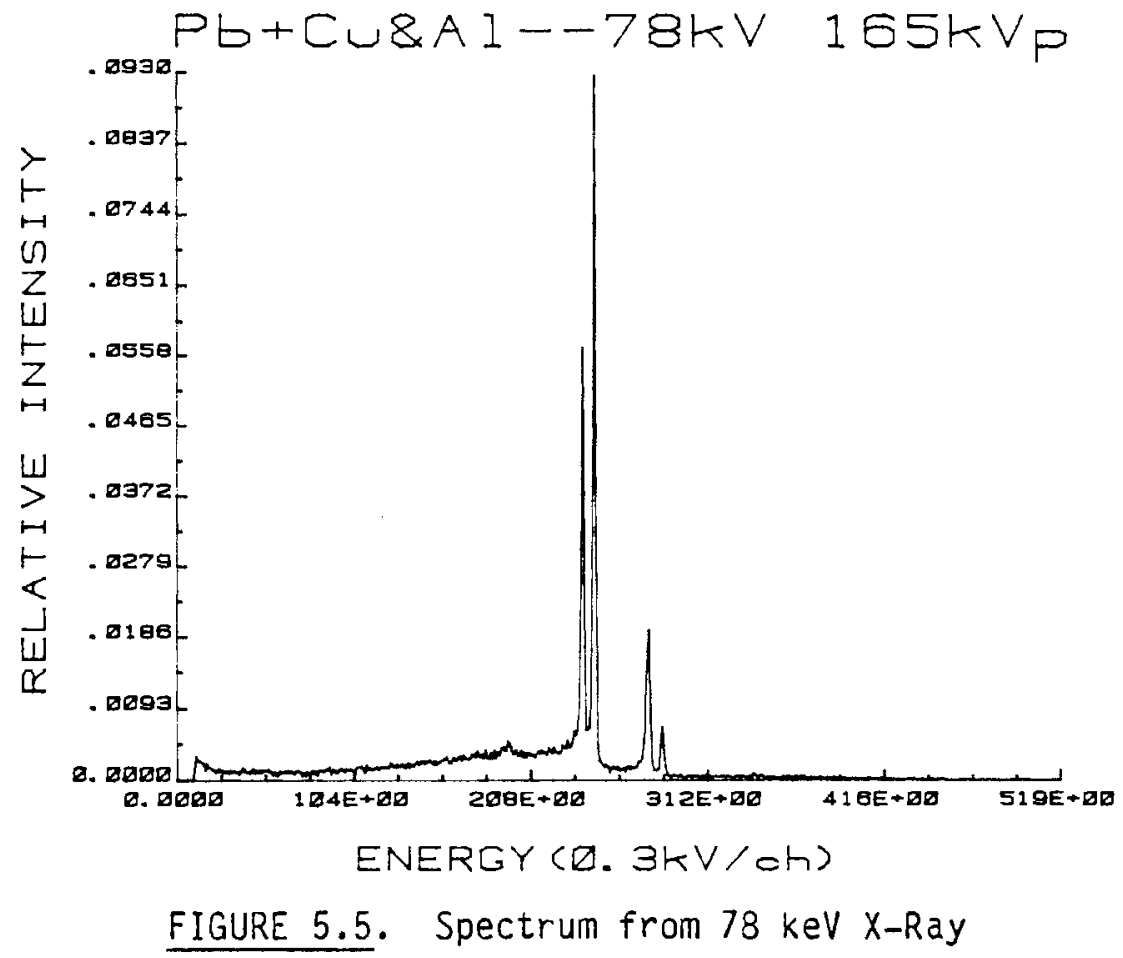




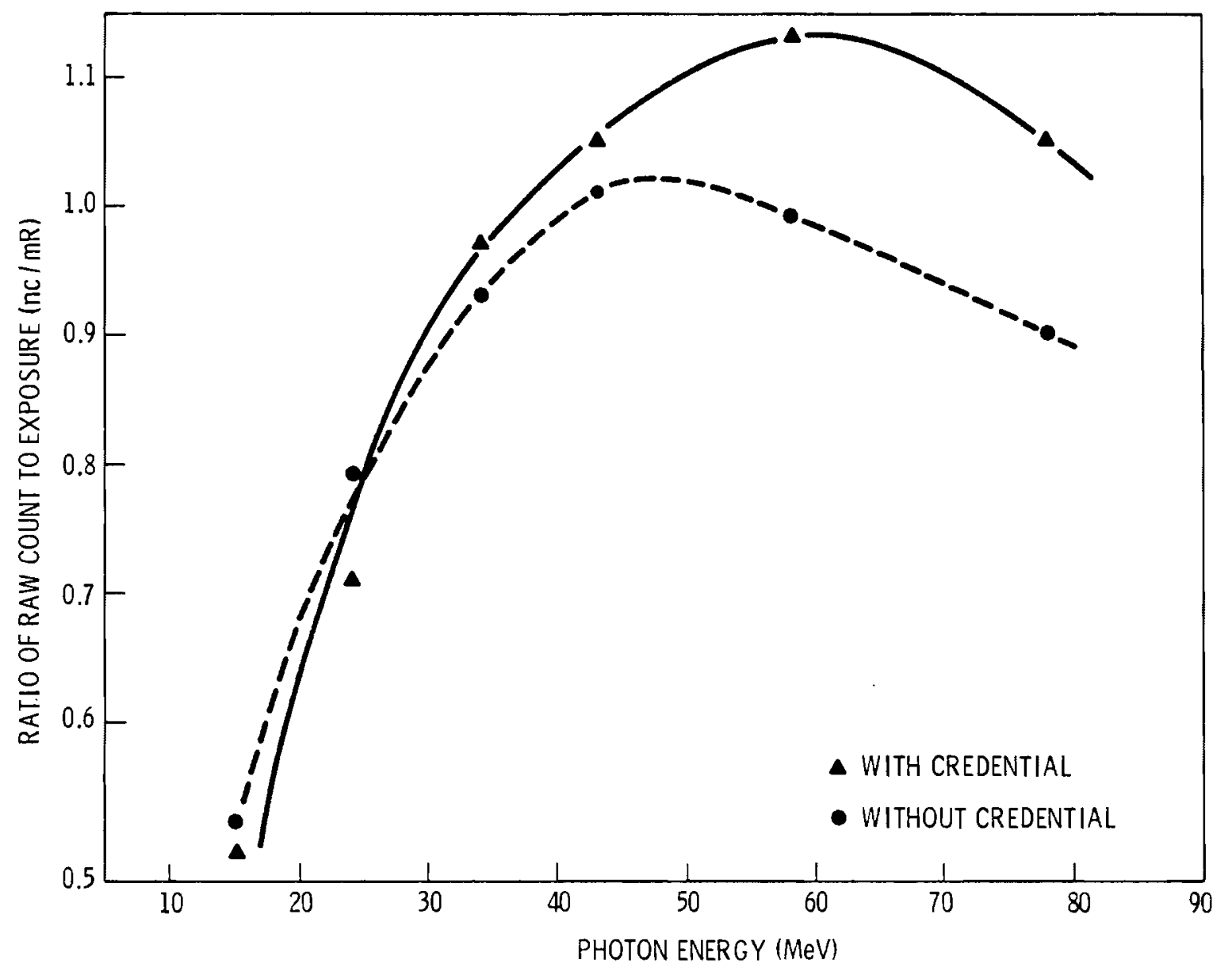

FIGURE 5.6. Response of Unfiltered TLD Chip (Chip 1) 


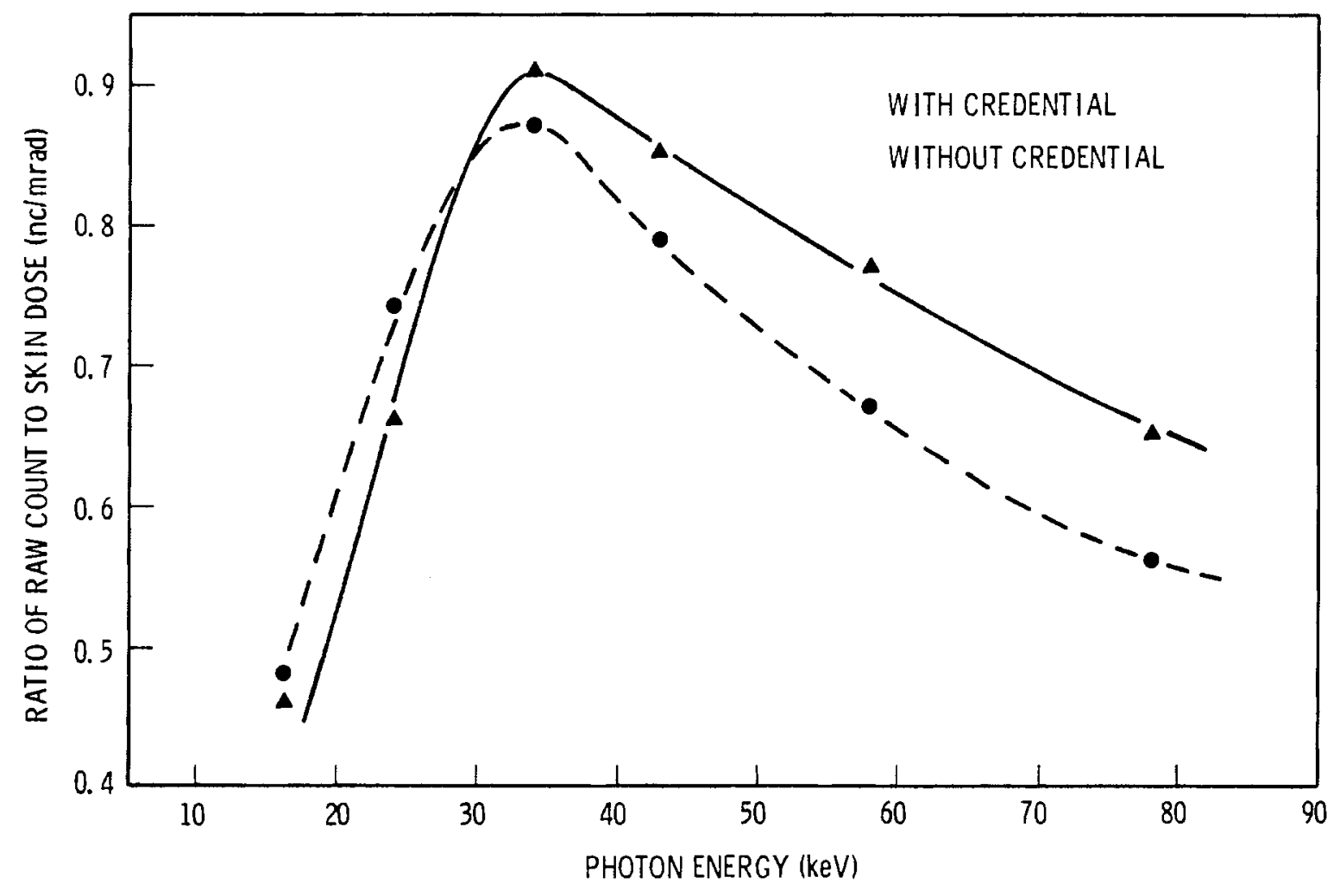

FIGURE 5.7. Dose Response of Unfiltered TLD (Chip 1) 


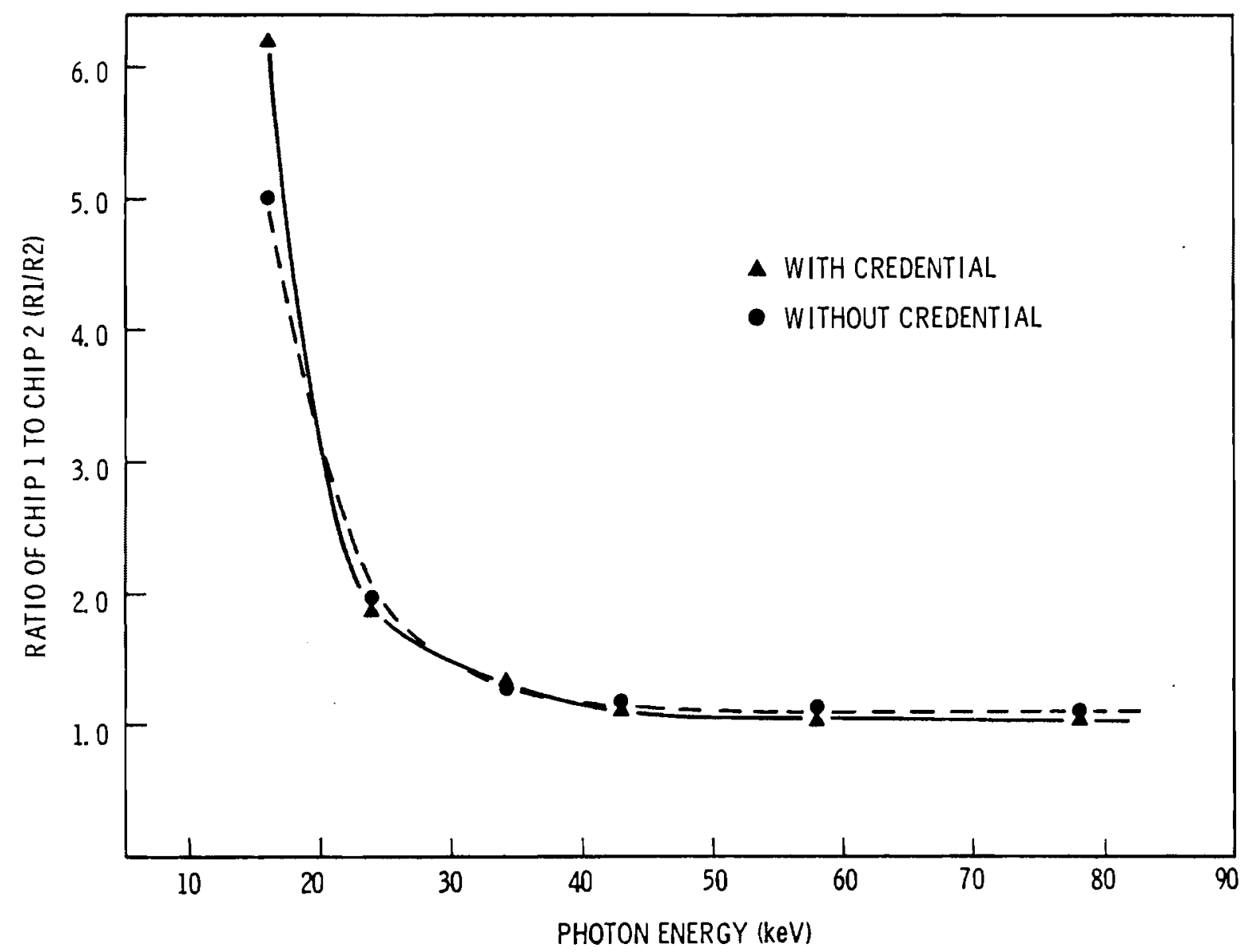

FIGURE 5.8. Ratio of Light Outputs of Unfiltered TLD Chip (Chip 1) to Al Filtered TLD Chip(Chip 2) 


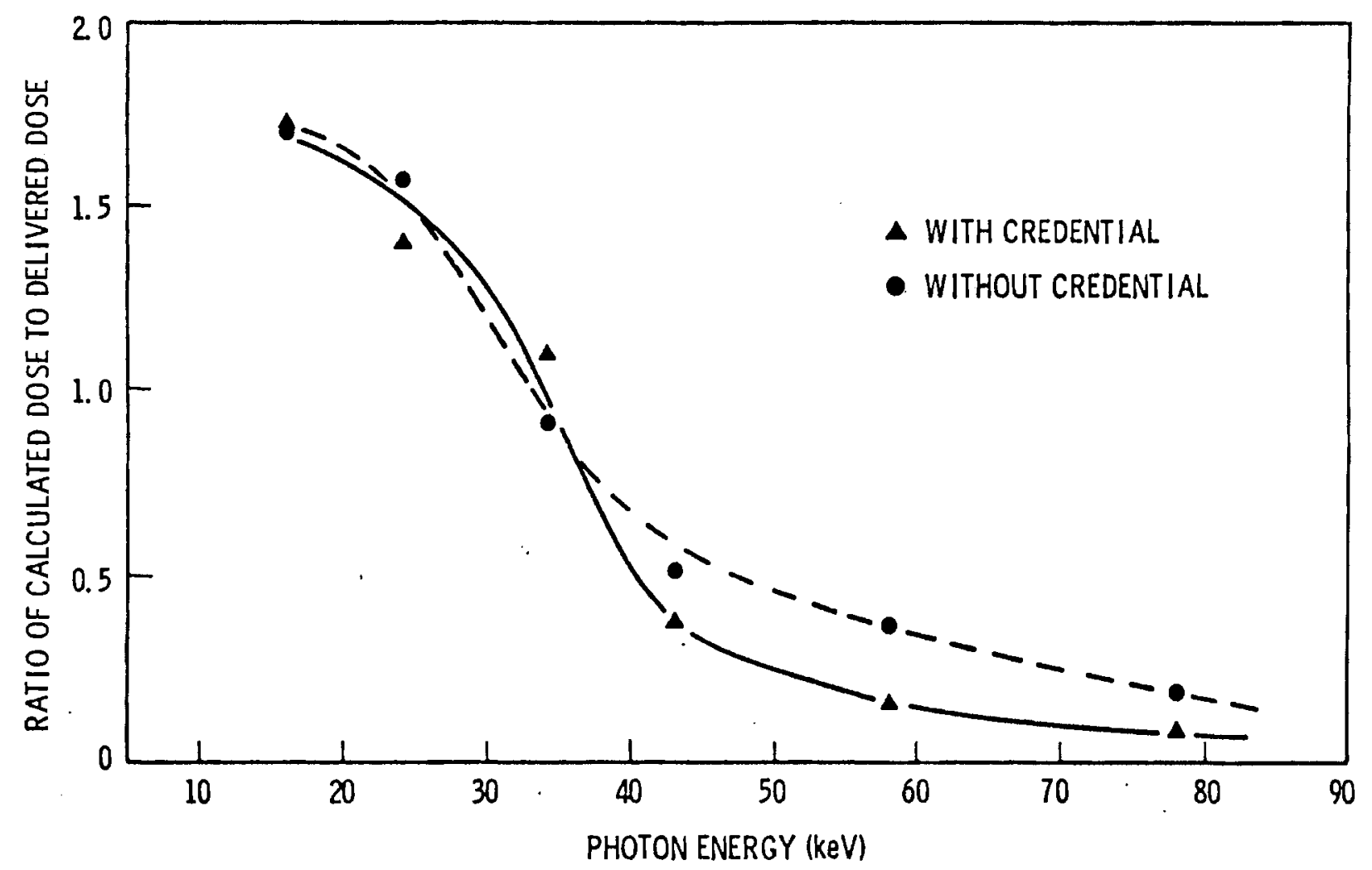

FIGURE 5.9. Calculated Nonpenetrating Dose Response Function, X-rays 


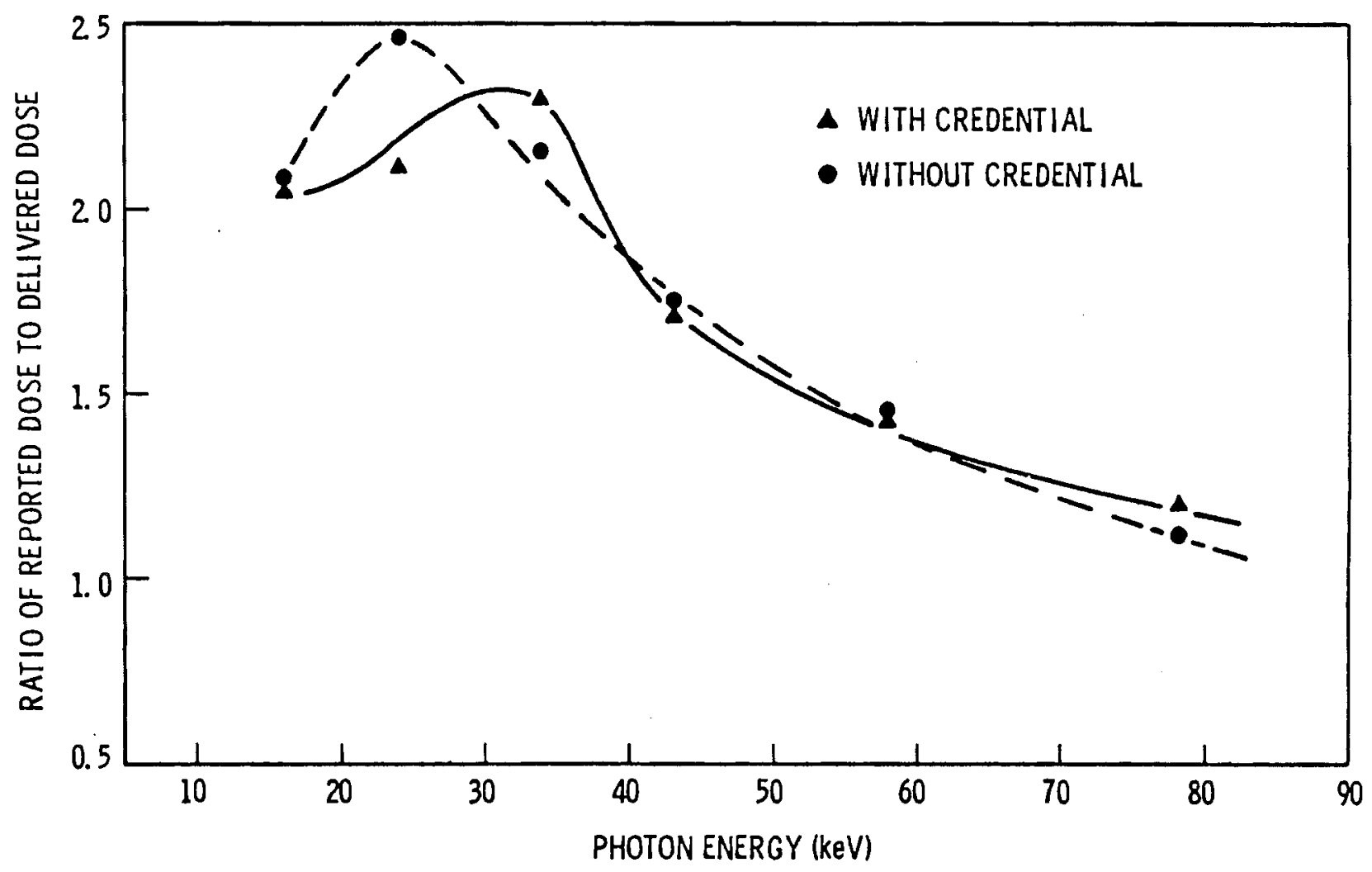

FIGURE 5.10. Reported Skin Dose Response Function, X-rays 


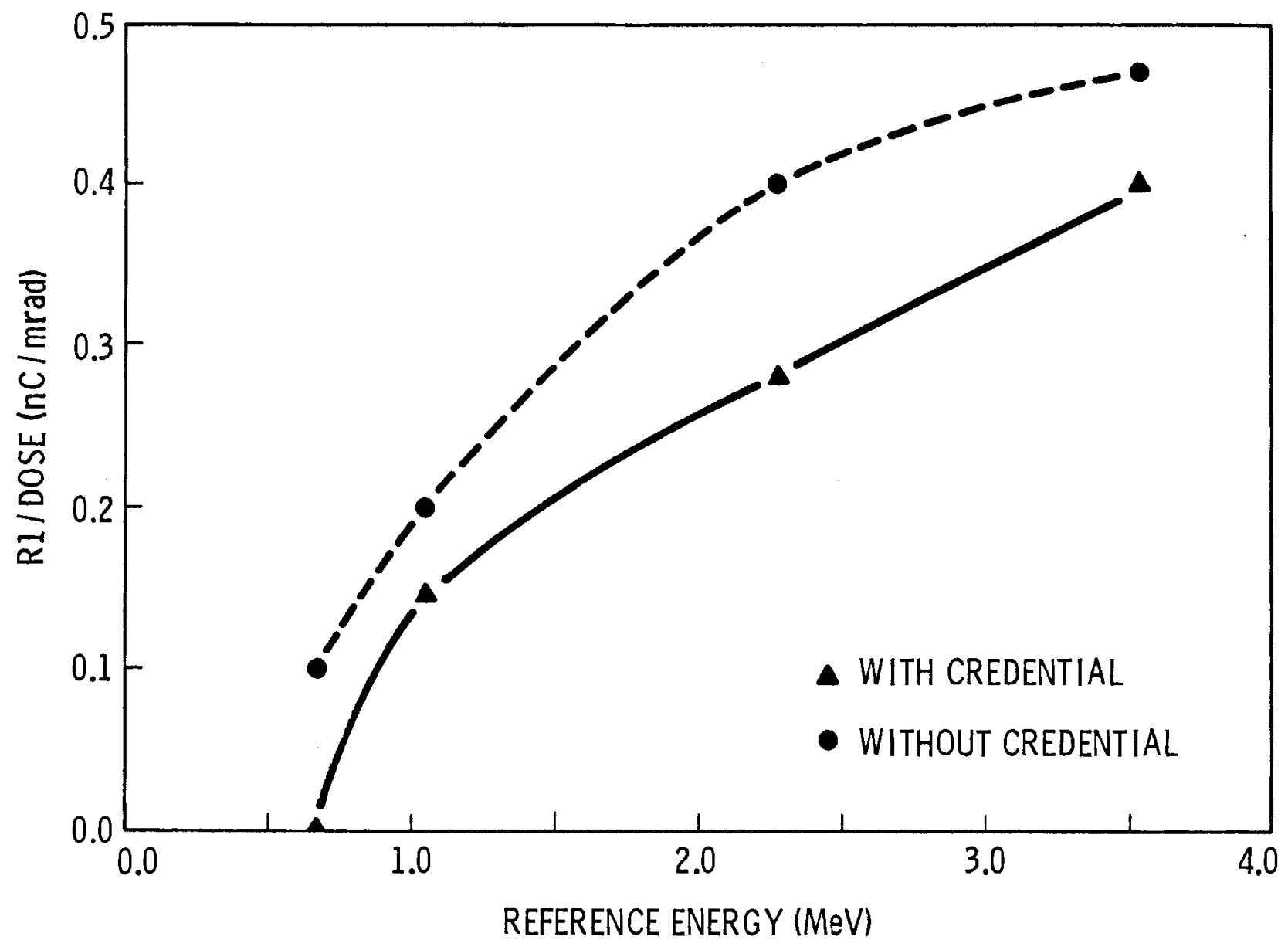

FIGURE 5.11. Ratio of Raw Count to Sk in Dose, Beta 


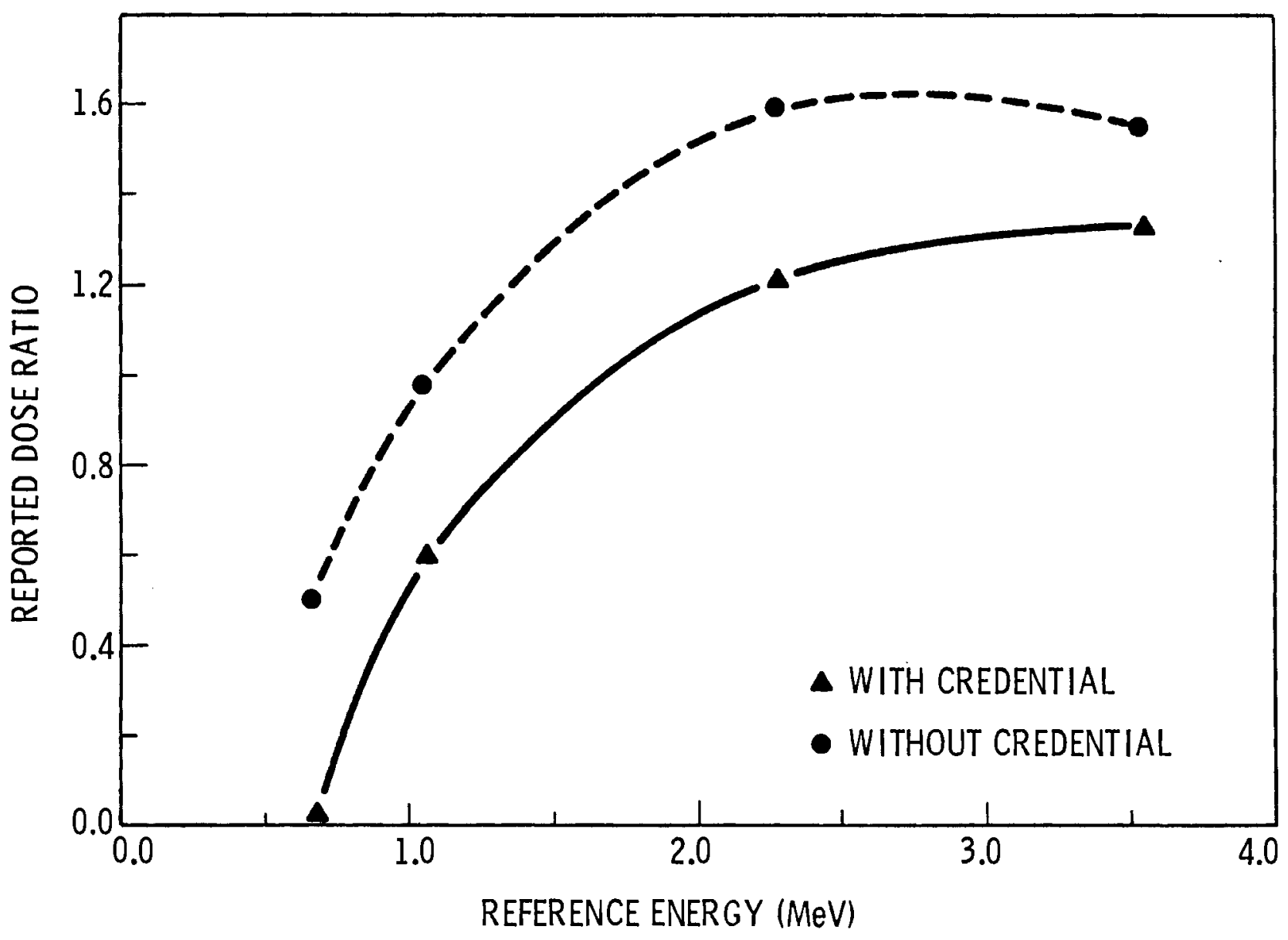

FIGURE 5.12. Calculated Nonpenetrating Dose Response Function, Beta 


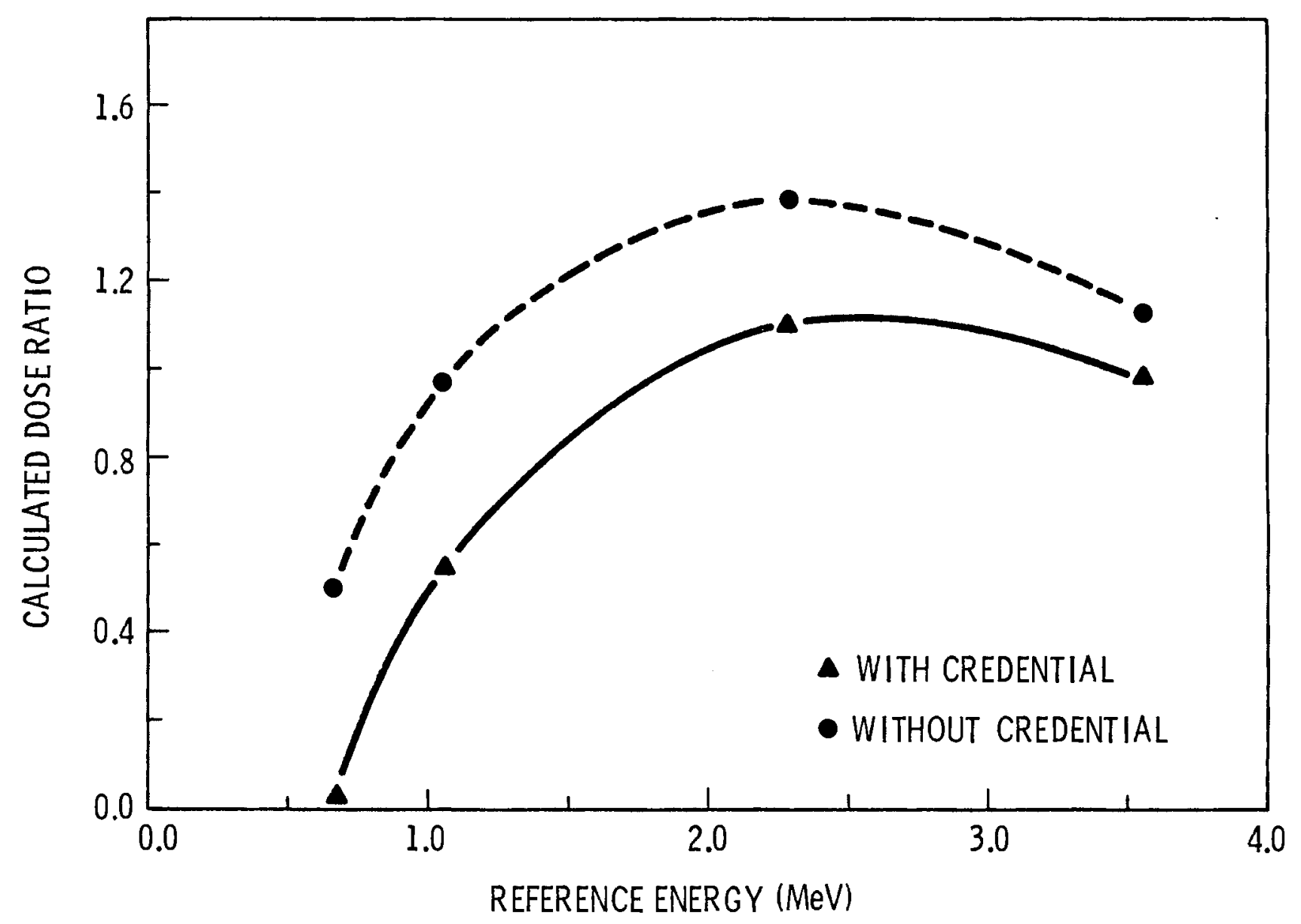

FIGURE 5.13. Reported Sk in Dose Response Function, Beta 



\subsection{STUDY 4 - EVALUATE EXISTING RADIATION FIELDS}

J. M. Aldrich, D. L. Haggard, G. W. R. Endres, and J. J. Fix

\section{FOREWORD}

Knowledge of the spectrum of energies for beta, gamma, and neutron radiation experienced in the field is crucial to the proper interpretation of personnel dose. Calibration sources and techniques are determined on the basis of their relationship to field exposures. This study describes the measurement techniques used, particularly for neutrons, and, in appendices, the data obtained for several locations at Hanford during FY-1981.

SUMMARY

During FY-1980, field measurements were taken at the following locations:

\begin{tabular}{|c|c|c|}
\hline & & Measurements $(a)$ \\
\hline 308 Building & $\begin{array}{l}\text { Fuel Storage Pit Area } \\
\text { Plutonium Storage Vault } \\
\text { Fuel Pin Storage Box Area } \\
\text { Bare Fuel Subassembly } \\
\text { Room Background } \\
\text { Grinder Hood Bottom } \\
\text { Pellet Pressina Station }\end{array}$ & $\begin{array}{l}\text { MS, TEPC, RASCAL, HMPD } \\
\text { MS, TEPC, RASCAL } \\
\text { MS, TEPC, RASCAL } \\
\text { MS, TEPC, RASCAL, HMPD } \\
\text { Gamma } \\
\text { Gamma } \\
\text { Gamma }\end{array}$ \\
\hline 327 Building & $\begin{array}{l}\text { Background - A Cell } \\
\text { Background - G Cell }\end{array}$ & $\begin{array}{l}\text { Gamma } \\
\text { Gamma }\end{array}$ \\
\hline $2425-200 \mathrm{~W}$ & $\begin{array}{l}\text { Evaporator Building - NE } \\
\text { Corner }\end{array}$ & Gamma \\
\hline 200 W-Diversion Boxes & $\begin{array}{l}241-T X-302-C \text { Catch Tank } \\
\text { K2U }\end{array}$ & Gamma \\
\hline B-Plant & $\begin{array}{l}\text { Rigging Crew } \\
\text { A Cell }\end{array}$ & $\begin{array}{l}\text { Beta } \\
\text { Gamma }\end{array}$ \\
\hline (225 Building) & $\begin{array}{l}\text { Between B-C Cells } \\
\text { Between D-E Cells } \\
\text { F Cell } \\
\text { Room Background }\end{array}$ & $\begin{array}{l}\text { Gamma } \\
\text { Gamma } \\
\text { Gamma } \\
\text { Gamma }\end{array}$ \\
\hline $271 B$ & Pipe Gallery - Cell 9 & Beta \\
\hline $234-5$ & $\begin{array}{l}\text { Glovebox } H-9 A \\
\text { Glovebox } H C-9 B\end{array}$ & $\begin{array}{l}\text { MS, TEPC, SNOOPY, HMPD } \\
\text { MS, TEPC, SNOOPY, HMPD }\end{array}$ \\
\hline $2736-z$ & Six locations in building & MS, TEPC, SNOOPY, HMPD \\
\hline
\end{tabular}

(a) MS - multisphere system, TEPC - tissue equivalent pruportional counter, HMPD - Hanford multipurpose personnel dosimeter. 
Generally neutron dose equivalent rate measurements with the multisphere system, TEPC, and SNOOPY were consistent with each other. The RASCAL indicated dose equivalent rates about a factor of two higher. Dose equivalent rates were generally very low resulting in uncertainties in the small integral doses recorded by the Hanford dosimeters. Average neutron energies for different locations were observed from about $150 \mathrm{keV}$ (hallway in 2736-Z Building) to $1.5 \mathrm{MeV}$ (midpoint of the bare fuel subsassembly in 308 Building). Gamma measurements showed ${ }^{137} \mathrm{Cs}$ to be the predominate nuclide at B-Plant and at the 200 West Diversion box. At the 308 Building, ${ }^{241}$ Am was the predominant gamma emitting nuclide observed. At $327,{ }^{137} \mathrm{Cs},{ }^{54} \mathrm{Mn}$, and ${ }^{60} \mathrm{Co}$ were observed. Beta measurements obtained using a modified Hanford dosimeter worn by a rigging crew in the 200 Area showed generally penetrating radiation only. Beta measurements collected in the 271B pipe gallery and a diversion box showed a low energy beta component.

An observation of significance for proper field use of the personnel dosimeter is the reduced response of the dosimeter to neutrons incident to the side of the dosimeter or to the back of the phantom (or person) relative to an instrument response which has an effective full $360^{\circ}$ response. Whenever a significant neutron flux is incident on a person wearing a dosimeter from any direction other than in front, the dosimeter will underresponse. Countering this effect is the overresponse of the dosimeter for neutrons less than the calibration neutron spectrum (mean energy about $1 \mathrm{MeV}$ ).

\section{INTRODUCTION}

Selected techniques were used to obtain neutron, photon, and beta energy spectra data at several Hanford locations. Four neutron energy spectra and dose measurement methods were used:

1. Multisphere spectrometer system

2. Tissue equivalent proportional counter (TEPC)

3. RASCAL (a) (9" to 3" sphere ratios)

4. Helium-3 neutron spectrometer.

(a) Portable neutron rem counter manufactured $b_{j}$ Eberline, Santa Fe, New Mexico. 
Gamma spectroscopy was done using standard techniques. A specially designed TLD dosimeter was used to obtain beta spectrum measurements.

The design and use of each of these instruments is described in the body of this report. Data collected and analyzed for each of the Hanford locations are included in appendices for each location.

\section{MATERIALS AND METHODS}

Measurement systems employed during this study were selected to characterize the energy spectrum of the predominate radiation type(s) at each location. Complementary neutron instrumentation was used to better characterize the neutron radiation at several locations. Gamma fields were characterized according to predominant radionuclides. An approximation of the beta field energy was obtained using a multifiltered TLD dosimeter. There is no convenient field instrument to characterize beta energies.

Multisphere Spectrometer System

The multisphere neutron system (Awschalom 1966) and specific instrument settings used in this work are shown in the block diagram in Figure 6.1 . Multispheres are the best available commercial system for measuring intermediate neutron energy spectra (1 keV to $1 \mathrm{MeV}$ ) (Griffith and Fisher 1976) and are also capable of detecting neutrons in the thermal to $1 \mathrm{keV}$ energy range. When the multisphere system is used with a spectrum unfolding code such as

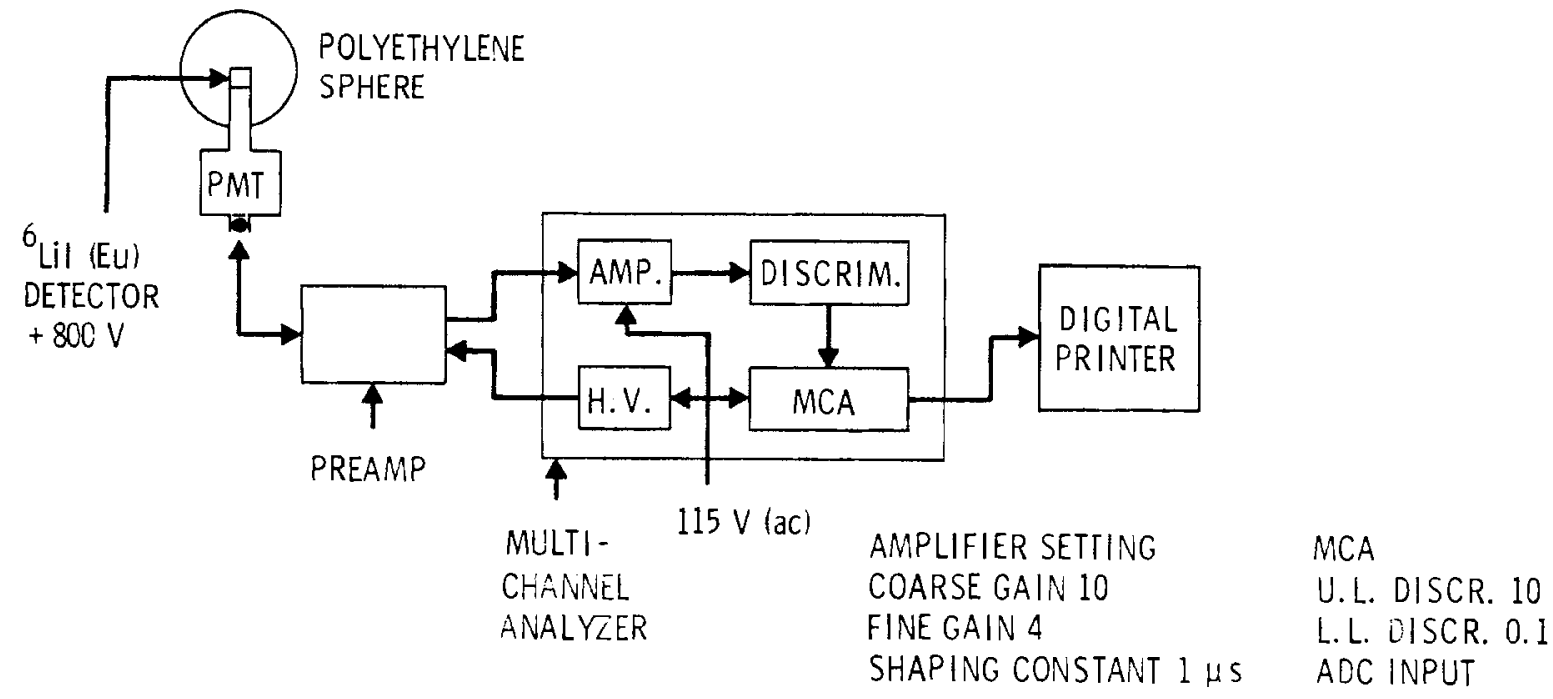

FIGURE 6.1. Block Diagram of the Multisphere System 
LOUHI (Routti and Sandberg 1978), the average neutron energy, dose equivalent rate, total flux, kerma, and graphical plots of differential flux versus energy, flux per unit lethargy versus energy, and flux versus energy can be obtained. The detector is a cylindrical ${ }^{6} \mathrm{LiI}(E \mathrm{U})$ scintillation crystal, $1.27 \mathrm{~cm}$ in diameter by $1.27 \mathrm{~cm}$ long, optically coupled to a $20.32 \mathrm{~cm}$ light pipe which in turn is optically coupled to a photomultipler tube (PMT). The detector and its integral components are hermetically sealed in an aluminum tube with walls $0.16 \mathrm{~cm}$ thick. The PMT is surrounded by a brass sleeve for protection and support for cable connectors. A single cable carries both the high voltage and output signals, connecting the detector to a preamplifier which decouples the signals and feeds them into the multichannel analyzer (MCA). This analyzer has three built-in systems as intergral parts: amplifer, high voltage power supply, and discriminators. The unanalyzed data is directly obtained from the MCA and fed to a digital printer for hard copy. The neutron detection mechanism exhibited by the ${ }^{6}$ LiI (Eu) crystal is the ${ }^{6} i(n, \alpha)^{3} H$ reaction for thermal neutrons. This reaction is exoergic and deposits an equivalent electron energy of $4.8 \mathrm{MeV}$ in the scintillator, producing a distinct peak in the pulse height spectrum shown on the MCA. There are no other competing peaks in the spectrum. An exponential background continuum is subtracted from the full width peak area.

Unanalyzed data for the neutron energy spectrum are obtained by taking counts with the scintillation crystal unshielded (bare), with the crystal in a cadmiun she $11(0.051 \mathrm{~cm}$ thick), and with the crystal moderated by spheres of high density polyethylene $(7.6,12.7,20.3,25.5$, and $30.5 \mathrm{~cm}$ in diameter). The fast neutron response of this sytem increases with sphere size because the larger polyethylene spheres remove low energy neutrons by scattering and moderate the fast neutrons to lower energies where they are then detected with a greater probability by the ${ }^{6}$ LII(EU) scintillator. Cadmium shells placed around the 7.6 and 12.7 spheres suppress response to external thermal neutron fields which improves the detectability of the system to moderated fast neutrons above cadmium cutoff $(0.4 \mathrm{eV})$ (Hankins and Griffith 1979). 
Using the responses from the seven detector configurations (bare, cadmium covered, $7.6,12.7,20.3,25.5$, and $30.5 \mathrm{~cm}$ moderators) the spectrum is unfolded with the aid of the LOUHI computer code. LOUHI is a FORTRAN program written to solve Fredholm integral equations of the first kind by using a generalized least-squares procedure with non-negative solutions. With LOUHI, the spectral solution is not dependent on the choice of initial approximation. Through prior knowledge of the flux in a particular part of the spectrum, the solution in the appropriate energy bin can be "tied" to that point (Hajnal 1979). The energy bin referred to is the $26^{\text {th }}$ bin or upper limit of the energy range over which the spectrum is to be calculated. This becomes the "tied" point and is based on the response of the $12.7 \mathrm{~cm}$ sphere. For this study, this feature is used to place the high energy bin at a realistic value which reflects the general lack of source neutrons above $14 \mathrm{MeV}$ (Hankins and Griffith 1979; Hajnal 1979).

Neutron energy response functions calculated by Sanna (1973) are used as input for the unfolding process. Sanna's calculations are based on one dimensional spherical geometries and were verified empirically in the energy range $100 \mathrm{keV}$ to $20 \mathrm{MeV}$ (Griffith and Fisher 1976). To make the sphere responses equal to Sanna's calculations in this energy range, density corrections for the spheres are performed by the LOUHI code.

Essentially, the basic equations of LOUHI solve for neutron flux, absorbed dose, average neutron energy, and dose equivalent rate. LOUHI uses equation (1) to determine neutron flux in the $j^{\text {th }}$ energy band, $\phi_{j}$ :

$$
A_{i}=\sum_{j=1}^{26} R_{i j} \phi_{j}
$$

where: $\quad A_{i}=$ the count rate with the $i^{\text {th }}$ detector configuration, and is obtained by integrating under the peak using a log background subtraction continuum and dividing that value by the count time for each individual detector configuration, and

$R_{i j}=$ the response function of the $i^{\text {th }}$ detector in the $j^{\text {th }}$ energy band calculated by Sanna (1973), and is directly available from his tabulations. 
The average neutron energy calculation incorporates a weighting function shown in equation (2):

$$
E a v=\sum_{j=1}^{n} w_{j} \cdot E_{j} \cdot F_{j} \cdot F_{s}^{-1}
$$

where: $\quad E a v=$ average neutron energy

$$
\begin{aligned}
j & =\text { energy band }(1-26) \\
n & =\text { total number of energy bands }(26) \\
w_{j} & =\text { weighting function of } j \text { th energy band } \\
E_{j} & =\text { energy value at the } j \text { th point, in MeV } \\
F_{j} & =\text { the solution at point } j \\
F_{s} & =\text { total flux }
\end{aligned}
$$

The dose equivalent rate equation uses a weighting function and a precalculated neutron flux to dose equivalent conversion ratio as shown in equation (3):

$$
D S=\sum_{j=1}^{n} \cdot w_{j} \cdot d_{j} \cdot F_{j}
$$

where: $\quad$ DS $=$ dose equivalent rate

$$
\begin{aligned}
n, j, w_{j}, \text { and } F_{j} & =\text { are the same as equation }(2) \\
d_{j} & =\text { neutron flux to dose equivalent conversion factor. }
\end{aligned}
$$

Flux-to-dose equivalent conversion factors are compiled as a subroutine in the LOUHI program and have been taken directly from tables in ICRP 21 (1971). Absorbed dose calculations are performed in a subroutine called element 57 dose rate, developed at Oak Ridge National Laboratory. This mode 1 is used to estimate the dose in various regions of a homogenous anthropomorphic phantom, which was taken as a right cylinder with a radius of $15 \mathrm{~cm}$ and a height of $60 \mathrm{~cm}$. Composition of the phantom was assumed to be $H, C, N$, and 0 in the proportions of standard man. The cylindrical volume was divided into 150 numbered volume elements and the average dose per neutron flux in the incident beam was computed for each volume element. The neutron beam was assumed to be broad enough to irradiate the whole phantom and to be monoenergetic and monodirectional with velocity vector parallel to the base of the 
cylinder (Auxier, Snyder, and Jones 1968). The maximum dose rate, in this scheme, is to Element 57 . Thus, the Element 57 dose rate is considered to be the best estimate for depth dose rate at the energy levels measured in reactors.

Quality factors are not directly calculated by the LOUHI unfolding code but can be easily determined by dividing the dose equivalent rate by the Element 57 absorbed dose rate. A QF value determined by this method will not be the same as the QF value calculated by the TEPC. The significance of this point will become more apparent as it is shown that both systems derive dose equivalent rates and $Q F^{\prime}$ 's from different methodologies. Further detailed discussion of the LOUHI program is readily available in the literature (Awschalom 1966; Routti and Sandberg 1978; Bramblett, Ewing and Bonner 1960).

There are two sphere sizes sometimes associated with the multisphere which were not used in this study; they are the $5.08 \mathrm{~cm}$ and $45.7 \mathrm{~cm}$ diameter spheres. The smaller of the two, the $5.08 \mathrm{~cm}$ sphere, produces a response very nearly equal to that of the cadmium shielded detector. Because of the size of the hole bored into the sphere, to accommodate the detector, it is not known whether the response is valid in this system. Therefore, a well-defined cadmium cutoff point of $0.4 \mathrm{eV}$ is established as the next to lowest energy band (the response of the bare detector being the lowest). The larger sphere 45.7 $\mathrm{cm}$, would normally be used to provide a response in the energy range of $>3 \mathrm{MeV}$. Since the responses of the $30.5 \mathrm{~cm}$ diameter sphere and the $45.7 \mathrm{~m}$ diameter sphere are nearly identical for the spectra of concern, the larger sphere was not used.

A typical multisphere data table generated by the LOUHI code shows the calculated fluxes, energies, and integral dose equivalents over the 26 points with the final results compiled at the bottom of the table (see Table 6.1). Two of the plots developed from the data table are a differential spectrum versus energy and flux per unit lethargy versus energy spectrum. 
Table $f_{.} .1$. Typical Set of Multisphere Data

\begin{tabular}{|c|c|c|c|c|c|c|}
\hline & $\frac{\mathrm{E}(1)}{\mathrm{MeV}}$ & $\frac{\text { DIFFERENTIAL FLUX }}{\left(\mathrm{n} / \mathrm{cm}^{2}-\mathrm{MeV}-\mathrm{sec}\right)}$ & INTEGRAL FLUX & $\begin{array}{c}\text { INTEGRAL } \\
\text { DOSE EQUIVALENT }\end{array}$ & $\frac{\text { ENERGY BAND }}{(\mathrm{MeV})}$ & $\frac{F L U X}{\left(n / \mathrm{cm}^{2}-\mathrm{sec}\right)}$ \\
\hline $\begin{array}{l}1 \\
2 \\
3 \\
4 \\
5\end{array}$ & $\begin{array}{l}2.07 E-07 \\
5.32 E-07 \\
9.93 E-07 \\
2.10 E-06 \\
4.45 E-06\end{array}$ & $\begin{array}{l}3.77 E+08 \\
5.16 E+07 \\
8.52 E+06 \\
1.83 E+06 \\
5.14 E+05\end{array}$ & $\begin{array}{l}1.00 E+00 \\
8.03 E-01 \\
7.85 E-01 \\
7.76 E-01 \\
7.72 E-01\end{array}$ & $\begin{array}{l}1.00 E+00 \\
9.28 E-01 \\
9.20 E-01 \\
9.17 E-01 \\
9.15 E-01\end{array}$ & $\begin{array}{l}3.89 E-07 \\
2.69 E-07 \\
7.63 E-07 \\
1.61 E-06 \\
3.42 E-06\end{array}$ & $\begin{array}{l}1.47 E+02 \\
1.39 E+01 \\
6.50 E+\infty \\
2.95 E+\infty \\
1.76 E+\infty\end{array}$ \\
\hline $\begin{array}{r}6 \\
7 \\
8 \\
9 \\
10\end{array}$ & $\begin{array}{l}9.42 E-01 \\
2.00 E-05 \\
4.22 E-05 \\
8.94 E-05 \\
1.89 E-04\end{array}$ & $\begin{array}{l}1.88 E+05 \\
8.73 E+04 \\
4.99 E+04 \\
3.40 E+04 \\
2.65 E+04\end{array}$ & $\begin{array}{l}7.70 E-01 \\
7.68 E-01 \\
7.66 E-01 \\
7.64 E-01 \\
7.61 E-01\end{array}$ & $\begin{array}{l}9.15 E-01 \\
9.14 E-01 \\
9.13 E-01 \\
9.12 E-01 \\
9.11 E-01\end{array}$ & $\begin{array}{l}7.22 E-06 \\
1.53 E-05 \\
3.23 E-05 \\
6.89 E-05 \\
1.45 E-04\end{array}$ & $\begin{array}{l}1.36 E+\infty 0 \\
1.34 E+\infty 0 \\
1.61 E+\infty 0 \\
2.34 E+\infty 0 \\
3.84 E+\infty 0\end{array}$ \\
\hline $\begin{array}{l}11 \\
12 \\
13 \\
14 \\
15\end{array}$ & $\begin{array}{l}4.04 E-04 \\
8.55 E-04 \\
1.80 E-03 \\
3.80 E-03 \\
8.05 E-03\end{array}$ & $\begin{array}{l}2.27 E+04 \\
2.03 E+04 \\
1.82 E+04 \\
1.54 E+04 \\
1.17 E+04\end{array}$ & $\begin{array}{l}7.55 E-01 \\
7.46 E-01 \\
7.28 E-01 \\
6.95 E-01 \\
6.34 E-01\end{array}$ & $\begin{array}{l}9.10 E-01 \\
9.06 E-01 \\
9.01 E-01 \\
8.90 E-01 \\
8.70 E-01\end{array}$ & $\begin{array}{l}3.18 E-04 \\
6.40 E-04 \\
1.38 E-03 \\
2.91 E-03 \\
6.20 E-03\end{array}$ & $\begin{array}{l}7.22 E+00 \\
1.30 E+01 \\
2.51 E+01 \\
4.48 E+01 \\
7.25 E+01\end{array}$ \\
\hline $\begin{array}{l}16 \\
17 \\
18 \\
19 \\
20\end{array}$ & $\begin{array}{l}1.70 E-02 \\
3.61 E-02 \\
7.64 E-02 \\
1.58 E-01 \\
3.18 E-01\end{array}$ & $\begin{array}{l}7.64 E+03 \\
4.04 E+03 \\
1.65 E+03 \\
5.00 E+02 \\
1.10 E+02\end{array}$ & $\begin{array}{l}5.37 E-01 \\
4.03 E-01 \\
2.53 E-01 \\
1.23 E-01 \\
4.74 E-02\end{array}$ & $\begin{array}{l}8.40 E-01 \\
7.75 E-01 \\
6.48 E-01 \\
4.54 E-01 \\
2.60 E-01\end{array}$ & $\begin{array}{l}1.30 E-02 \\
2.77 E-02 \\
5.86 E-C_{c} \\
1.13 E-01 \\
2.27 E-01\end{array}$ & $\begin{array}{l}9.93 E+01 \\
1.12 E+02 \\
9.67 E+01 \\
5.56 E+01 \\
2.50 E+01\end{array}$ \\
\hline $\begin{array}{l}21 \\
22 \\
23 \\
24 \\
25 \\
26\end{array}$ & $\begin{array}{l}6.40 E-01 \\
1.29 E+00 \\
2.59 E+00 \\
5.22 E+00 \\
1.05 E+01 \\
1.96 E+01\end{array}$ & $\begin{array}{l}1.75 E+01 \\
2.12 E+00 \\
2.05 E-01 \\
1.68 E-02 \\
1.23 E-03 \\
8.56 E-05\end{array}$ & $\begin{array}{l}1.39 E-02 \\
3.22 E-03 \\
6.06 E-04 \\
9.76 E-05 \\
1.37 E-05 \\
1.25 E-06\end{array}$ & $\begin{array}{l}1.15 E-01 \\
3.61 E-02 \\
7.17 E-03 \\
1.22 E-03 \\
1.79 E-04 \\
1.72 E-05\end{array}$ & $\begin{array}{l}4.56 E-01 \\
9.20 E-01 \\
1.85 E+\infty 0 \\
3.73 E+\infty 0 \\
7.50 E+00 \\
1.09 E+01\end{array}$ & $\begin{array}{l}7.98 E+00 \\
1.95 E+00 \\
3.79 E-01 \\
6.27 E-02 \\
9.23 E-03 \\
9.33 E-04\end{array}$ \\
\hline
\end{tabular}

TOTAL FLUX $=7.4477 \mathrm{E}+02$ NEUTRONS/ SQ. Cm. $/ \mathrm{SEC}$. DOSE EQUIVALENT RATE $=8.5643 \mathrm{E}+00 \mathrm{Mrem} / \mathrm{HOUR}$ ELEMENT 57 DOSE RATE $=1.6681 \mathrm{E}-03$ RADS $/$ HOUR AVERAGE ENERG $Y=5.3385 \mathrm{E}-02 \mathrm{MeV}$ 
Tissue Equivalent Proportional Counter (TEPC)

The tissue equivalent proportional counter (TEPC) system measures the absorbed dose and the TEPC computer code calculates the dose distribution as a function of event size and LET. The TEPC computer code also calculates a quality factor by using the Rossi analysis (Rossi 1968) and several approximations derived by Brackenbush, Endres and Faust (date). A block diagram of the TEPC system and instrumentation settings is shown in Figure 6.2 The electronic system components include detector, preamplifer, amplifier, and high voltage power supply. The multichannel analyzer (MCA) used with the TEPC has a log display. This log display greatly assists in the preliminary interpretation of the unanalyzed data. Figure 6.3 shows the multisphere, TEPC, and associated electronic systems.

The TEPC is a hollow sphere of tissue equivalent plastic (Shonka A150 muscle equivalent plastic with the walls $3.2 \mathrm{~mm}$ thick) filled with methanebased tissue equivalent gas. Details of plastic and gas composition and methods of construction can be found in ICRU Report 26 (1977). This form of TEPC, called a Rossi counter, has a helical grid around the central anode wire. The helical grid establishes uniform lines of force along the entire length of the anode. This produces the needed uniformity in gas amplification at all points along the anode for proper pulse height analysis. The plastic sphere is contained inside a metal pressure vessel with a valve for admitting tissue equivalent gas. The gas pressure is maintained at a low pressure of $5.6 \mathrm{~mm} \mathrm{Hg}$ absolute so that charged particles crossing the cavity lose only a small amount of energy as they transverse the counter. Energy deposited in the cavity is then equal to the linear energy transfer of the particle times the path length. At these low pressures the gas-filled cavity has the same mass stopping power as a sphere of tissue $\left(\rho=1 \mathrm{gm} / \mathrm{cm}^{3}\right)$ with a diameter of about one micrometer and is said to have an "equivalent diameter" of one micrometer.

The TEPC becomes self-calibrating when the proton drop point is identified. A proton drop point corresponds to a slow proton recoil having the highest linear energy transfer or transversing the diameter of the spherical cavity and is independent of the initial energy of the neutron producing the 


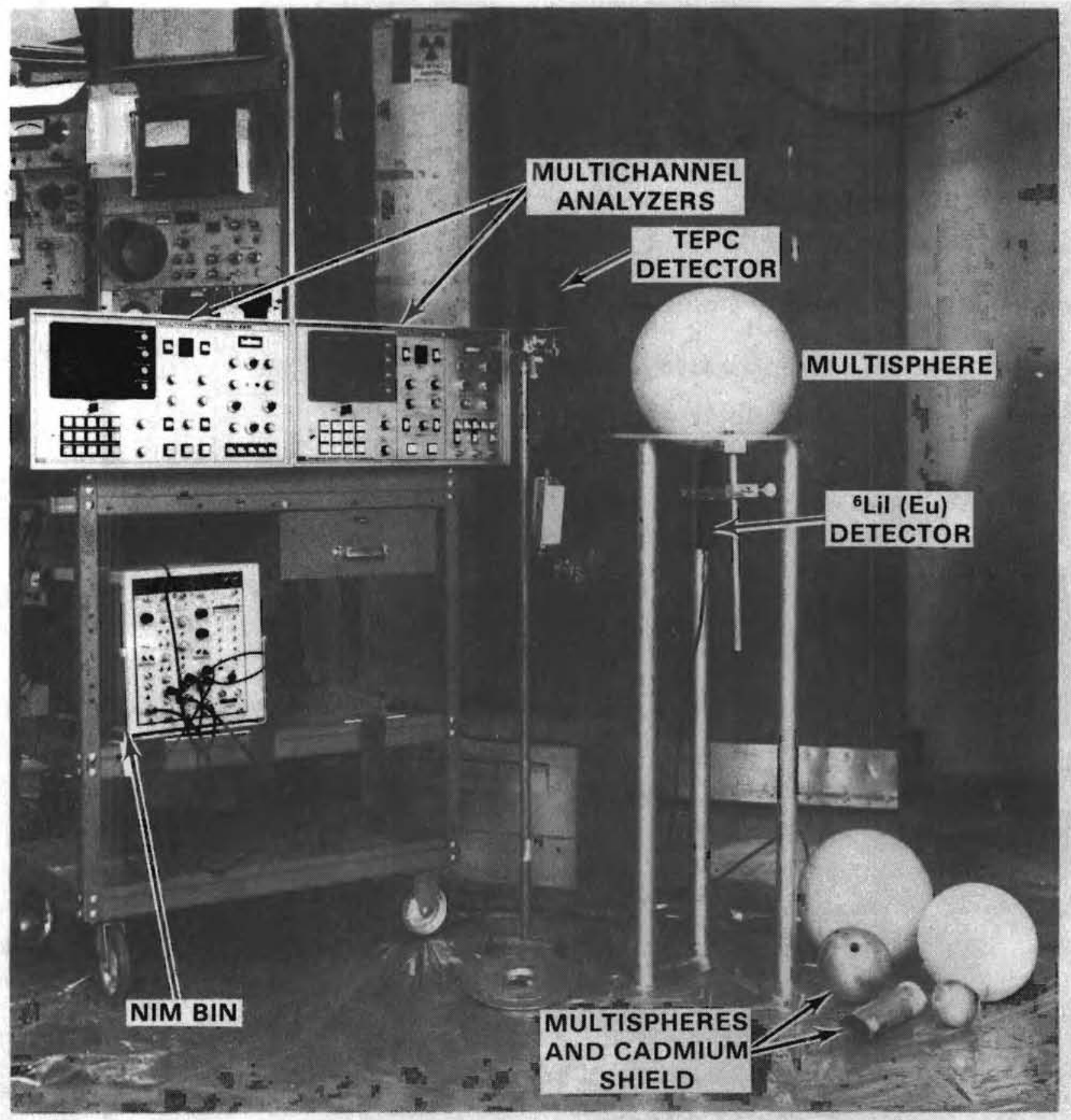

FIGURE 6.2. Multisphere Spectrometer and TEPC Systems 


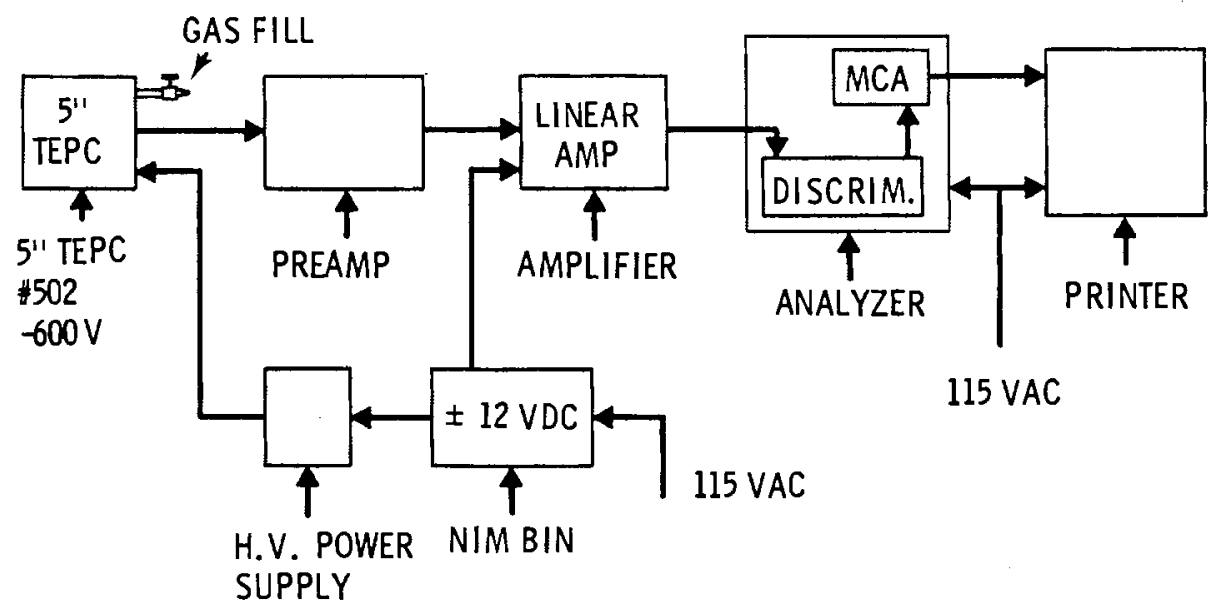

LINEAR AMP SETTINGS
COARSE GAIN 10
FINE GAIN 6.0
SHAPING CONSTANT $1 \mu \mathrm{SEC}$
BASE LINE RESTORER BLR
1) ASYMMETRY - XI
2) RATE - HIGH
3) GATE - IN
UNIPOLAR OUTPUT - POSITIVE

MCA

LOG SCALE

ZERO SETTING 2.65

U.L. DISCR. 10

L.L DISCR. 0

ACQ (ACQUIRE MODE) DIRECT

OFF

INPUT IS IN DIRECT

FIGURE 6.3. Block Diagram of TEPC System

event. According to the data of Glass and Samsky (1967), this point occurs at about $100 \mathrm{keV} / \mathrm{\mu m}$ and is a slowly varying function of tissue-equivalent gas pressure.

Multiplying the number of events of a given size by the energy of the event gives the absorbed energy distribution in the TE gas, which is a direct measure of absorbed dose. Following the nomenclature in ICRU 26 (1977), this is stated in equation (4):

$$
D=1.602 \times 10^{-8} \sum_{h_{1}}^{h_{2}} k \cdot h \cdot N(h) \cdot v^{-1} \cdot o^{-1}
$$


where:

$$
\begin{aligned}
D= & \text { absorbed dose ( } r \text { ad) } \\
h= & \text { the measured pulse height expressed as channel number } \\
N(h)= & \text { the number of pulses accumulated in channel } h, h_{1} \text {, and } \\
& h_{2} \text { are the limits in pulse height between which the } \\
& \text { absorbed dose is to be determined } \\
\rho= & \text { the gas density, in } \mathrm{gm}^{-3} \\
V= & \text { the sensitive volume of the cavity in } \mathrm{cm}^{3} \\
k= & \text { the calibration relating energy to channel number, which } \\
& \text { was determined from the proton drop point (keV/channel } \\
& \text { number). }
\end{aligned}
$$

For calculational purposes: $h_{1}$, the lower limit of event size, is defined as the minimum between photon and neutron induced events which occurs at an event size of about $15 \mathrm{keV} / \mu \mathrm{m}$, and $h_{2}$ is the upper limit of the event size spectrum. The summation over $N(h)$ between $h_{1}$ and $h_{2}$, as shown in equation (4), is the total energy absorbed in the gas cavity due to high LET events. The measured neutron dose, $D$, is the energy absorbed in the gas cavity divided by the mass of TE gas inside the sphere.

The TEPC event spectrum (Figure 6.4) shows the number of events per channel, commonly referred to as the energy deposited per channel or event size spectrum. Also shown in Figure 6.4 are the three parameters needed to analyze TEPC data: $h_{1}$, the lower limit; $h_{2}$, the upper limit; and the proton drop point.

\section{TEPC DOSE EQUIVALENT}

The only general method that has been developed for the measurement of the distribution of dose in LET is based on an analysis of the frequency distribution of the event size due to individual particles in a spherical volume of tissue, that is, the $N(y)$ distribution. Actual distributions are different from those derived with the assumptions that energy loss is continuous and that particles travel in straight lines and have a range that is infinitely long compared with cavity diameter. These same assumptions are made in the derivation of the LET spectrum from event-size spectrum; it is evident that error is introduced. Also $X$-rays, electrons, $H(n, \gamma) D$ reactions, and positrons 


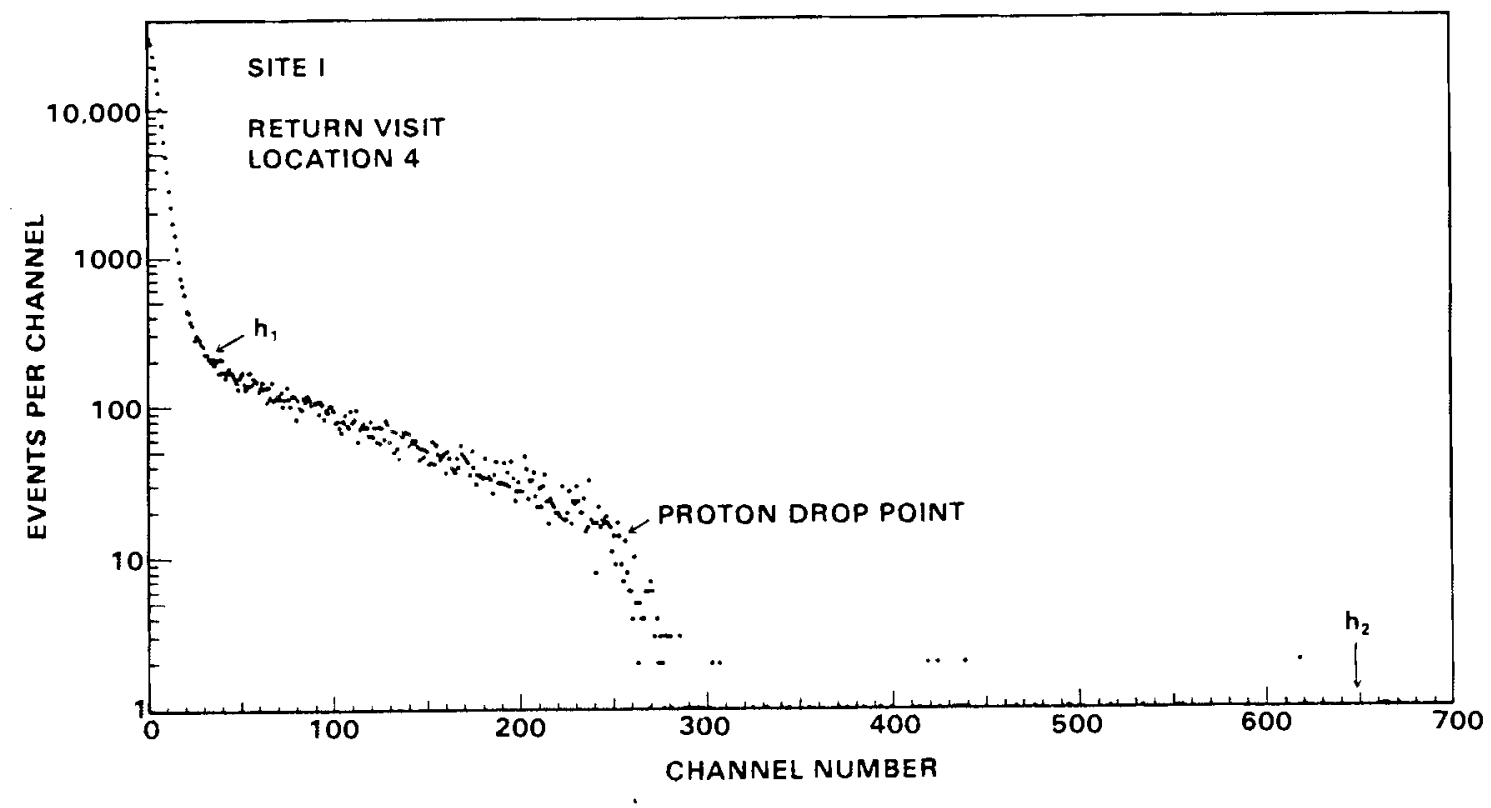

FIGURE 6.4. TEPC Event Size Spectrum

are assigned a QF of 1 , which does not add significantly (<0.1) to the calculated dose equivalent. Most of these events are below the lower limit $\left(h_{1}\right)$ used in spectral analysis. However, discrepancies between experimental and theoretical spectra are usually sufficiently small so as to be acceptable for purposes of radiation protection. It has been Rossi's development of this technique, using the above assumptions, that has led to a determination of dose equivalent rates by calculating absorbed dose as a function of LET and by using QF as a function of LET described in ICRU 20 and ICRU $26(1977 ; 1976)$.

H. H. Rossi devised a relatively simple model to determine the absorbed dose distribution as a function of linear energy transfer (Rossi 1968). In ICRU 26, QFs are defined in terms of LET which makes it possible to determine dose equivalent rates and QFS from a single TEPC measurement. The Rossi model employs a spherical counter with neutron recoils arising within the walls and assumes the recoil have a constant, uniform energy loss along a straight line and completely cross the cavity. Under these assumptions, the absorbed dose distribution within the cavity as a function of LET, $O(L)$ can be calculated by equation (5) (Rossi 1968). 


$$
D(L)=\frac{k}{r^{2}}\left[y N(y)-y^{2} \frac{d N}{d y}\right]_{y=L}
$$

where: $\quad k=a$ constant of proprtionality, and

$$
\begin{aligned}
r= & \text { the radius of a sphere of tissue in } \mathrm{cm} \text { having the same } \\
& \text { mass stopping power as the tissue equivalent gas in the } \\
& \text { cavity } \\
y= & \text { the lineal energy; the quotient of the mean energy } \\
& \text { imparted to the volume divided by the mean chord length in } \\
& \text { the cavity, referred to as mean event size } \\
N(y)= & \text { the event size distribution as a function of lineal energy } \\
\frac{d N}{d y}= & \text { the derivative of the event size distribution evaluated at } \\
& \text { the point where linear energy transfer and lineal energy } \\
& \text { are equal ( } y=L) \text {. }
\end{aligned}
$$

A computer code, "TEPC", performs the above calculations by evaluating the derivative using digital filter techniques to smooth the data and compute a QF.

It is not possible to distinguish between photons originating from $H(n, y) D$ reactions in a phantom or tissue equivalent plastic counter and photons originating from external sources so a 11 photon events below the lower limit $\left(h_{1}\right)$ described in equation (4) are excluded in this analysis. The Rossi model also neglects energy loss effects (energy entering and leaving the counter without being detected) from very low energy neutrons, scattering, delta rays, and variation of LET along the particle track. In spite of these limitations, the Rossi model seems to be sufficiently accurate to determine QFs with in one integer value, which is generally adequate for health physics purposes for neutrons with energies from $200 \mathrm{keV}$ to about $10 \mathrm{MeV}$. In low energy neutron spectra such as those found inside reactor containment, the Rossi assumption encompassing low energy neutrons cannot be met. Therefore, calibration, operation, and analys is of TEPC data using the $h_{1}$ reference point actually remove a part of the low energy proton recoils and some $(n, y)$ events which then results in a higher QF than is expected. These errors tend 
to compensate each other since photon events are excluded from the QF analysis, Rossi's method yields a high QF for neutron energies below about $200 \mathrm{keV}$ where $H(n, y) D$ reactions with in a phantom contribute significantly to the dose and to the effective QF Brackenbush, Endres and Faust 1978).

${ }^{3}$ He NEUTRON SPECTROMETER (LuCas 1979)

This section deals with the theory of operation of the ${ }^{3}$ He neutron spectrometer, and its construction, calibration, and operation. Results of measurements of monoenergetic neutron beams and measurements inside PWR reactor containment are also discussed.

Theory of Operation

Neutrons interact with ${ }^{3}$ He to produce a triton and a proton which are easily detected in a proportional counter. If the proton and triton are absorbed in the sensitive volume of a proportional counter, the resultant pulse height is proportional to the neutron energy plus $764 \mathrm{keV}$, the Q value of the ${ }^{3} \mathrm{He}(n, p) T$ reaction. Thermal neutrons produce events with an energy of $764 \mathrm{keV}$, which is convenient for energy calibration. The additional energy released by the reaction makes it easy to differentiate neutron induced events from gamma ray events. Unfortunately, there are competing nuclear reactions to confuse data analysis. The cross sections for these reactions as a function of neutron energy are shown in Figure 6.5. From conservation of energy and momentum it can be shown that an elastically scattered neutron [a ${ }^{3} \mathrm{He}\left(n, n^{\prime}\right)^{3} \mathrm{He}$ reaction] can deposit a maximum of $75 \%$ of its energy to the elasticaily scattered ${ }^{3}$ He recoil. This recoil deposits $764 \mathrm{keV}$ of energy if the original neutron has an energy of $1.02 \mathrm{MeV}$. Hence, neutrons with energies above $1 \mathrm{MeV}$ can produce ${ }^{3}$ He recoils which can be confused with events from the ${ }^{3} \mathrm{He}(n, p) T$ reaction. Above 4 Mev ${ }^{3} \mathrm{He}(n, d) \mathrm{D}$ reactions occur which can also be confused with the ${ }^{3} \mathrm{He}(n, p) T$ reactions. Fortunately, many of these competing events can be eliminated on the basis of pulse rise time or pulse shape. The deuterons and ${ }^{3} \mathrm{He}$ recoils have linear energy transfer values higher than that of protons or tritons. Hence, for the same energy deposited in the proportional counter, the deuterons and ${ }^{3}$ He recoils have 


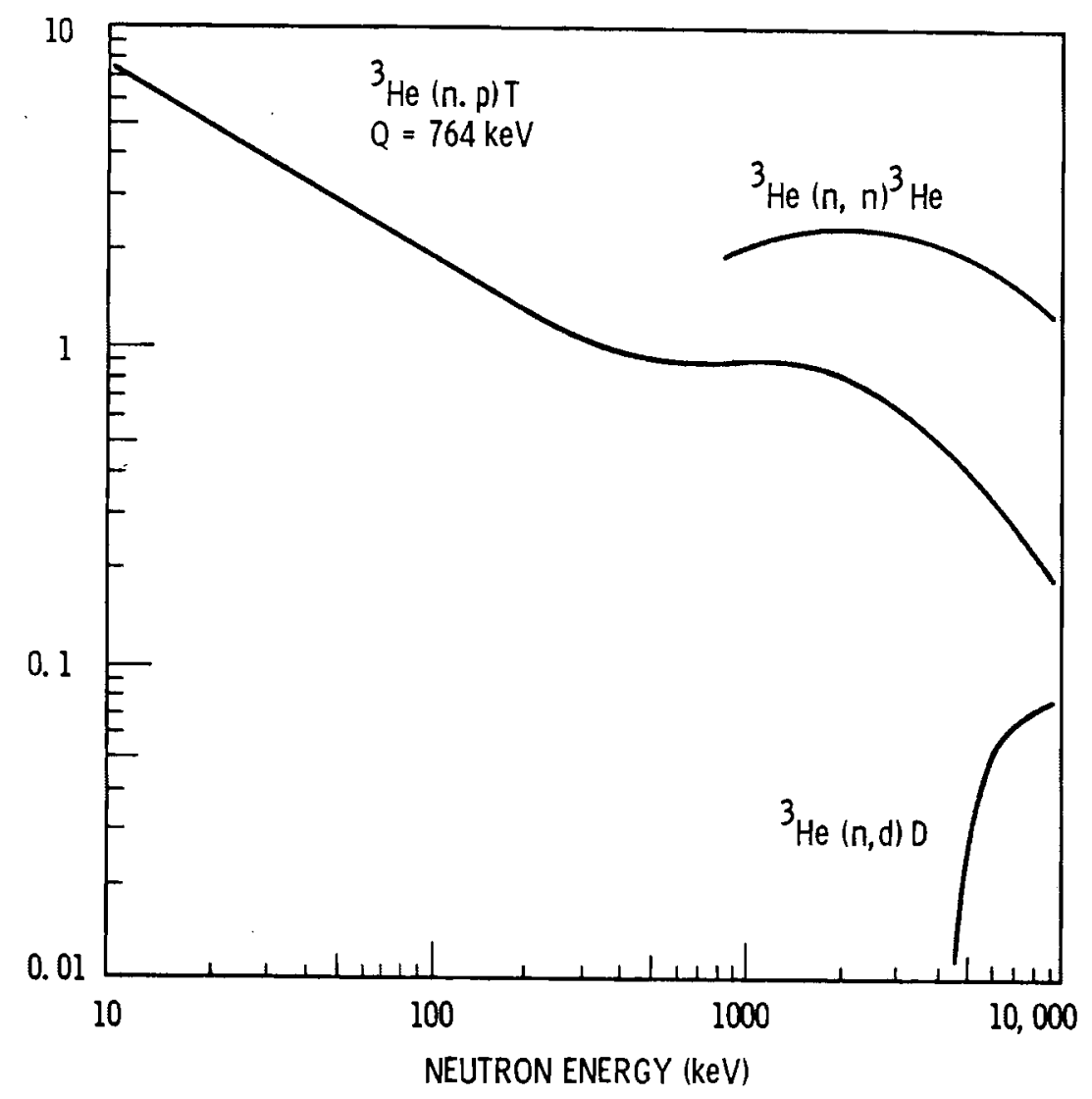

FIGURE 6.5. 3He Cross Sections for Neutron Induced Charged Particle Reactions as a Function of Neutron Energy

shorter tracks. The ions produced by these shorter tracks migrate to the anode of the proportional counter in less time and produce pulses with faster risetimes. Unfortunately, if the tracks are parallel to the anode wire the pulse risetime discrimination technique does not work.

There are several properties which limit the usefulness of the ${ }^{3} \mathrm{He}$ spectrometer:

- The ${ }^{3} \mathrm{He}(n, p) T$ cross section for thermal neutrons is about 5000 barns, while that for fast neutrons is only a few barns. Thus, the detector is very sensitive to low energy neutrons and cadmium or boron absorbers and pulse pile-up circuitry must be used to prevent distortion of the measured spectrum. 
- The lowest detectable energy is determined by the resolution of the proportional counter and by the peak produced by thermal neutrons, which overlaps very low energy neutron events. Some commercial ${ }^{3} \mathrm{He}$ proportional counters have a resolution of $2.5 \%$, which corresponds to a full width half maximum energy of $19 \mathrm{keV}$. The practical lower energy limit for these tubes is 25 to $30 \mathrm{keV}$.

- At energies above $1.02 \mathrm{MeV}$ there are competing nuclear reaction which produce pulses that can be confused with the desired $3_{\mathrm{He}}(\mathrm{n}, \mathrm{p}) \mathrm{T}$ reaction and complicate the proper interpretation of spectral data. Some of these competing reactions can be rejected by rise time or pulse shape analysis.

- Some neutron induced events occur near the wall or end of the counter. Charged particles striking the walls may not deposit all their energy in the sensitive volume of the proportional counter. At low neutron energies almost all of the events will deposit all their energy with in the sensitive volume of the counter; a serious wall effect problem occurs at $h$ igh neutron energies where the particle path lengths are about the same as the diameter of the proportional counter. To reduce wall effects, a high atom number inert gas having a greater mass stopping power, such as argon or krypton, is often added to the detector.

In spite of these apparent limitations the ${ }^{3}$ He proportional counter spectrometer offers some real advantages:

- The ${ }^{3} \mathrm{He}$ detectors are very sensitive to low energy neutrons from thermal energies to $1 \mathrm{MeV}$. Few other types of spectrometers operate in this energy region.

- The data analysis of the ${ }^{3}$ He proportional counter is straight forward and much less complicated than in other types of spectrometers.

- The components necessary to construct a ${ }^{3}$ He spectrometer are commercially available, moderately expensive, and perhaps more rugged than those of other types of spectrometers. 
- The ${ }^{3} \mathrm{He}$ spectrometer is self calibrating by using the $764 \mathrm{keV}$ peak produced by thermal neutrons.

- The ${ }^{3}$ He spectrometer is well suited to neutron spectrum measurements at nuclear reactors where almost all of the neutrons have energies below $1 \mathrm{MeV}$, so that competing nuclear reactions are not a problem.

\section{Apparatus}

Figure 6.6 shows a block diagram of the electronics used with the neutron spectrometer. The neutrons are detected with a one-inch diamter ${ }^{3} \mathrm{He}$ proportional counter. Signals pass through the preamp and are split into two paths. For the signal path, the pulses pass through an amplifier with 2 microsecond time constants and a pulse pile-up rejector. If two pulses occur within 12 microseconds of one another, an inhibit signal is sent to a linear gate to block the signal. Pulses are also routed along a second path through a linear amplifier with 0.5 microsecond time constants and to a pulse shape analyzer. This analyzer is adjusted to accept pulses in a narrow rise time "window," which corresponds to ${ }^{3} \mathrm{He}(n, p) T$ reactions. A signal is sent to a second linear gate to accept that pulse if it has the correct risetime. In the spectrometer which is used for field measurements, acceptable pulses are then routed to a multichannel analyzer. In laboratory situations the output of the pulse shape analyzer could be routed to a dual parameter analyzer to provide energy versus pulse rise time data to allow better separation of the desired ${ }^{3} \mathrm{He}(n, p) T$ events from competing events.

Figure 6.7 shows the importance of th is electronic circuitry. To demonstrate this fact a ${ }^{3}$ He proportional counter was exposed in a $h$ igh dose rate field from a ${ }^{252} \mathrm{Cf}$ source. The top curve shows the results obtained without a $C d$ shield to eliminate thermal neutrons. At least 2 sum peaks are evident from thermal neutron events occurring almost simultaneously in the counter. The middle curve shows the effect of adding a 40-mil thick cadmium cover, wh ion 


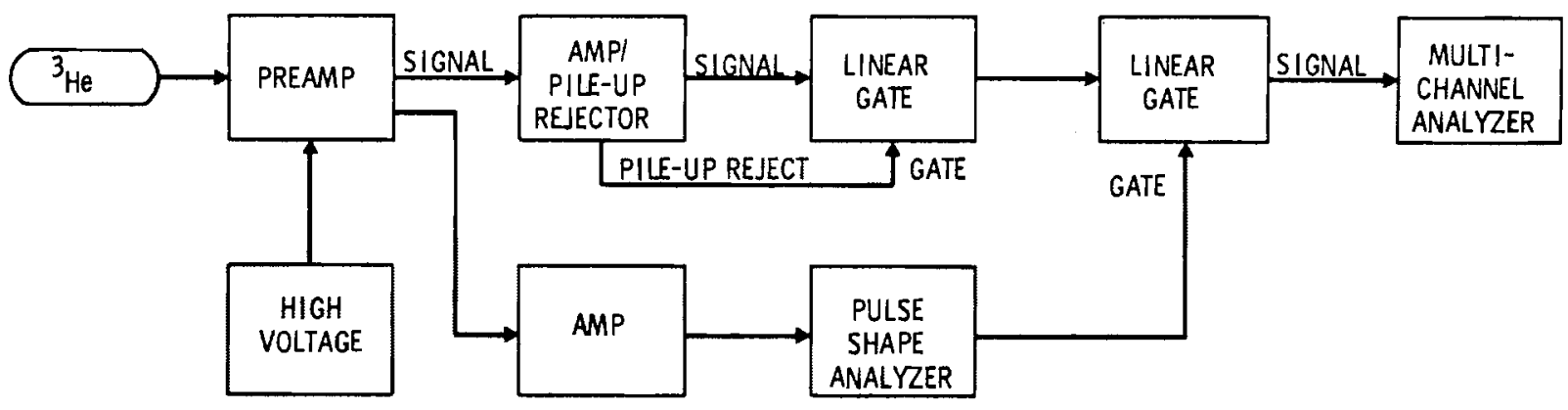

FIGURE 6.6. Block Diagram of the Electronic Equipment Used to Construct the 3He Neutron Spectrometer

eliminates almost all neutrons with energies below about $0.4 \mathrm{eV}$. Some summing and pulse pile-up is still evident. The bottom curve shows the results obtained with a cadmium cover and pulse pile-up rejection and pulse shape analysis in use. Note the lack of sum peaks and virtual elimination of pulse pile-up.

The resolution and sensitivity of the ${ }^{3}$ He proportional counter depends upon its physical size as well as the filling gas and fill pressure. Five to ten years ago commercially available ${ }^{3}$ He proportional counters had full width half maximum (FWHM) thermal neutron peak resolutions of 8 to $15 \%$. At the present time (1980) it is possible to purchase ${ }^{3}$ He proportional counters which have resolutions of 2.3 to $3 \%$ for about $\$ 300$. These improvements are due to better gas fillings and improved construction techniques. Improved resolutions can be obtained with mixtures of ${ }^{3}$ He and argon gas with small amounts of carbon dioxide added. Companies making proportional counters are cleaning and outgassing the components and using center wires which are smoother, thus providing a more uniform gas gain along the length of the wire.

Neutron spectrometers used for measurements at work locations in nuclear plants must make compromises between sensitivity, or counting times and energy resolution. A 1 -inch $(2.5 \mathrm{~cm})$ diameter tube with a 12 inch $(30 \mathrm{~cm})$ long active region filled with $4 \mathrm{psi}^{3} \mathrm{He}, 28 \mathrm{psi} \mathrm{Ar}$ and a trace of $\mathrm{CO}_{2}$ seems to be a reasonable compromise with reasonable sensitivity and FWHM resolution of $20 \mathrm{keV}$ or better. 


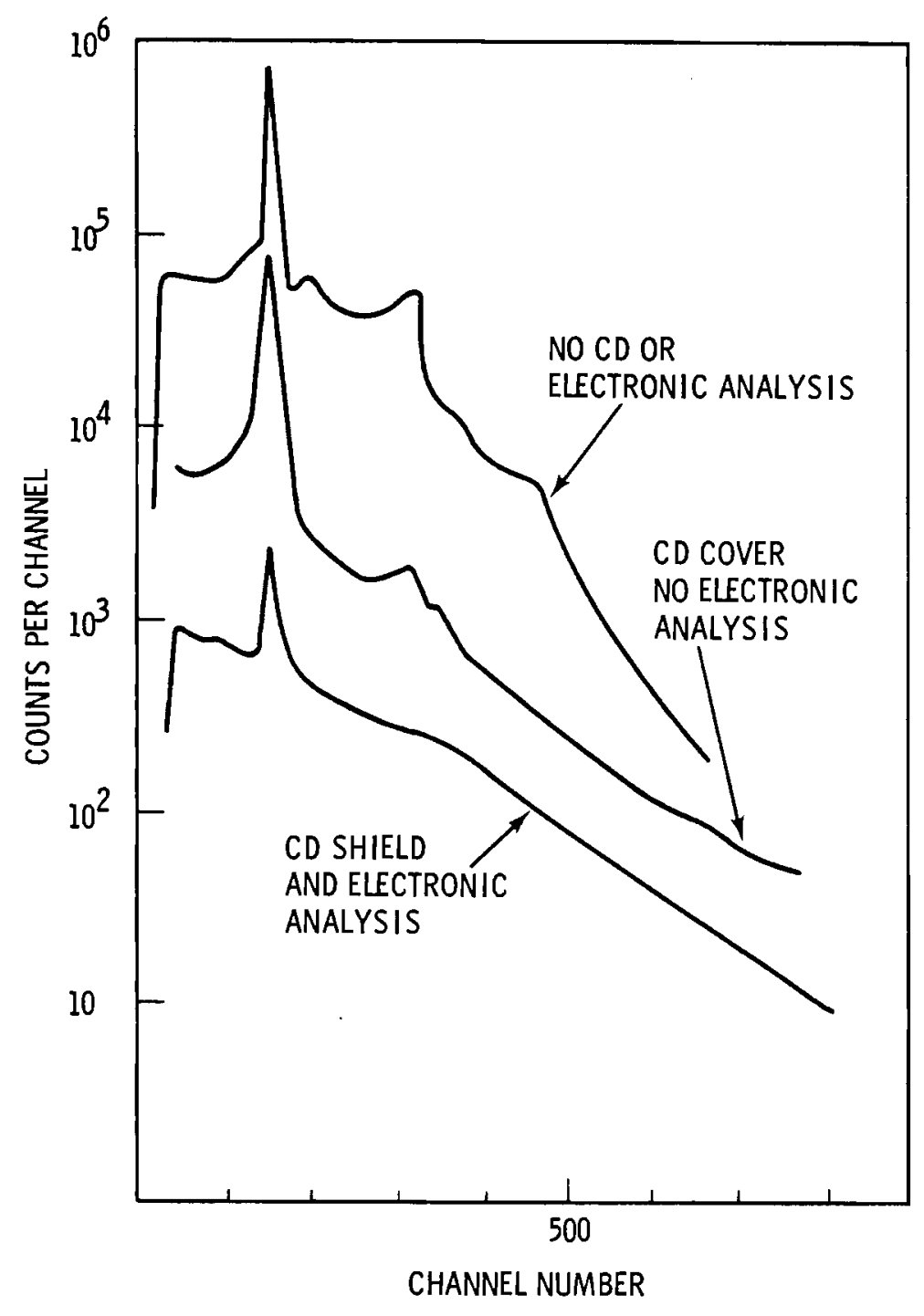

FIGURE 6.7. Effect of Cadmium Covering and Electronic Pulse Pile-Up Rejection Circuitry in Reducing the Amount of Pulse Pile-Up in High Dose Rate Neutron Fields 
Calibration and Test Performance

As mentioned previously the energy calibration of the ${ }^{3}$ He spectrometer is very simple. Exposing the counter to thermal neutrons produces a peak which corresponds to $764 \mathrm{keV}$. If the multichannel analyzer used to collect data is adjusted so that channel zero corresponds to zero pulse height, the keV per channel is simply $764 \mathrm{keV}$ divided by the channel number of the centroid of the thermal neutron peak.

A very simple computer program called HESPEC has been written to analyze

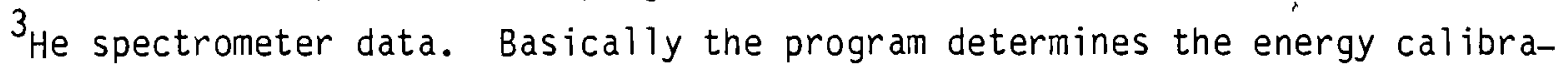
tion, i.e., the keV per channel from the thermal peak. From this information the program divides the raw data up into energy groups which have a "bin width" approximately equal to the resolution of the proportional counter used. A correction factor is then applied for the variation in cross-section with neutron energy to determine the relative neutron flux as a function of neutron energy. At the present time the program ignores wall and end effects.

The ${ }^{3}$ He spectrometer system was exposed to beams of monoenergetic neutrons to check the proper operation of the system, i.e., if the experimental measurments would indeed give monoenergetic neutrons. The filtered neutron beam facility at the National Bureau of Standards was utilized for these measurements. Figure 6.8 shows the response of the spectrometer to $144 \mathrm{keV}$ neutrons. A distinct peak was recorded for the $144 \mathrm{keV}$ neutrons, and the small peak corresponds to $51 \mathrm{keV}$ neutrons which are also present. The upper curve was obtained by correcting the data for the change in the cross section of the ${ }^{3} \mathrm{He}(n, p) T$ reaction with energy. The full width half maximum (FWHM) resolution of the spectrometer was determined to be about $18 \mathrm{keV}$, therefore, the next step was to expose the spectrometer to a $25 \mathrm{keV}$ neutron beam to determine whether it could resolve neutrons at this lower energy. Figure 6.9 shows that indeed it is possible to resolve $25 \mathrm{keV}$ neutrons under ideal conditions.

9" to 3" Sphere Ratios

One method of correcting TLD albedo dosimeter neutron response for different neutron energies involves a survey of work areas to determine an 

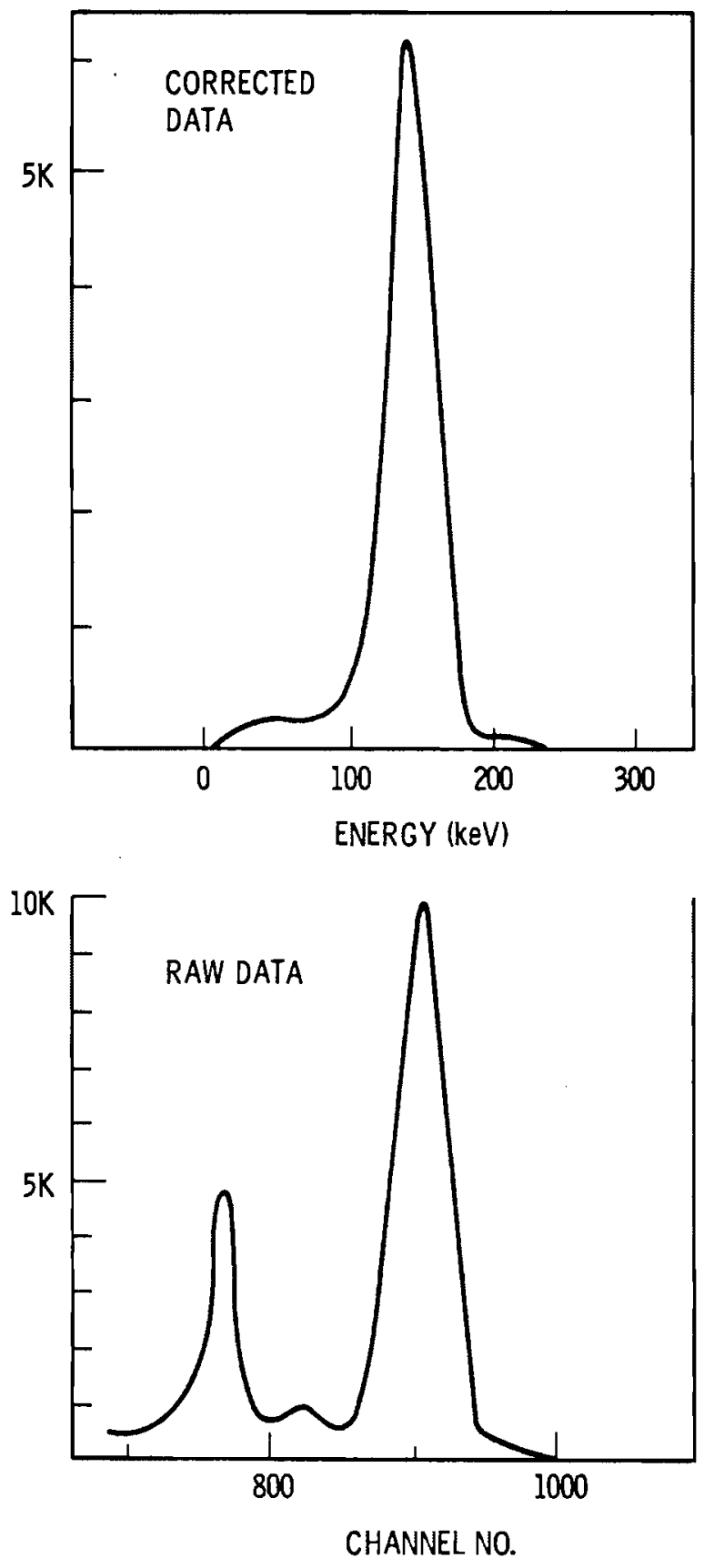

FIGURE 6.8. Results Obtained by Exposing the 3He neutron spectrometer to $144 \mathrm{keV}$ Monoenergetic Neutrons at the Filtered Neutron Beam Facility at the U.S. National Bureau of Standards 


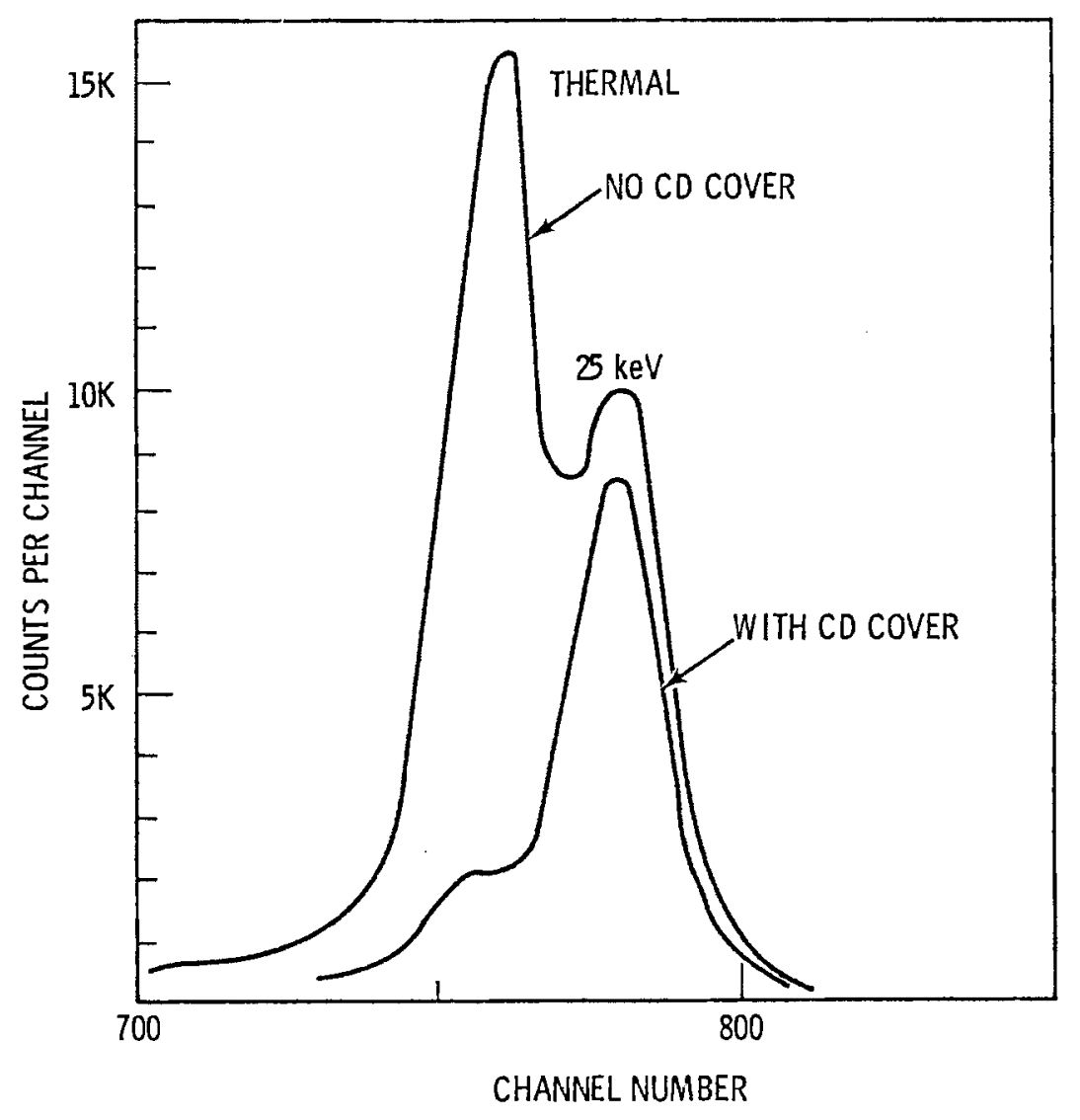

FIGURE 6.9. Results Obtained by Exposing the 3 He neutron Spectrometer to $25 \mathrm{keV}$ Monoenergetic Neutrons at the Filtered Neutron Beam Facility at the U.S. National Bureau of Standards

appropriate calibration factor. The thermal neutron flux in a 23-cm-diameter (9") sphere of polyehtylene and in a 7.6-cm-diameter (3") cadmium-covered sphere of polyehtylene is determined using a $\mathrm{BF}_{3}$ proportional counter and a commercially available survey meter. The effective TLD calibration factor can be determined from the ratio of the responses of the two spheres using Figure 6.10, which is derived from a graph presented by Griffith et al. (1979). A similar method of field measurements is reported by Rei1, Scofield, and Woo (1979). This method provides correction factors which are usually accurate to within $\pm 25 \%$. The ratios however, can not be used to measure the average energy of the neutron spectrum because of the many uncertainties involved. 


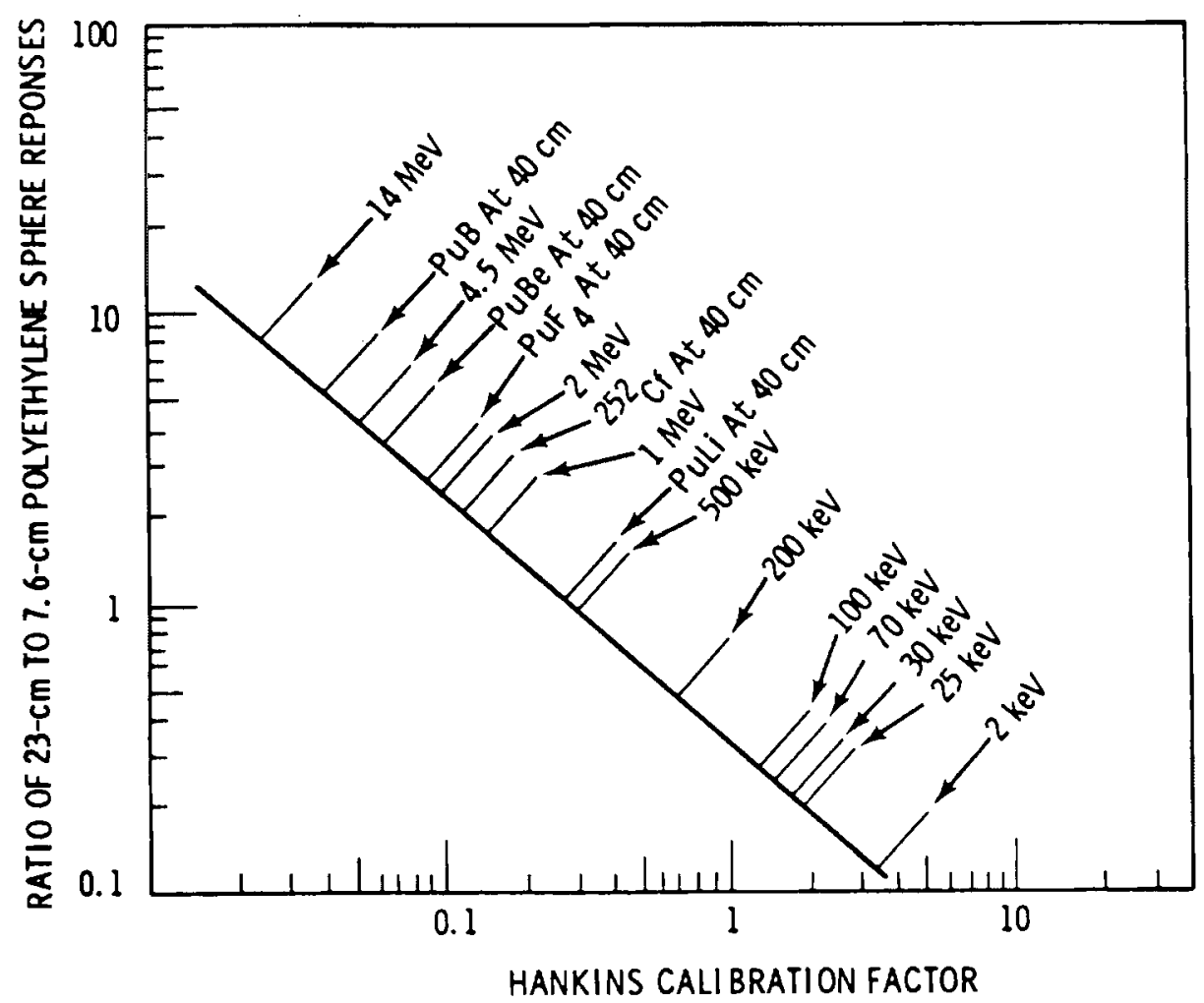

FIGURE 6.10. Effective Neutron Energy as a Function of the Ratio of 23-cm to $6.76-\mathrm{cm}$ Polyethylene Sphere Responses (Griffith et al. 1979)

\section{GAMMA SPECTROSCOPY}

\section{Field Instrument System}

The major equipment used to make the gamma measurements is shown in block diagram form presented in Figure 6.11. Two types of germainium detectors were used. A $70 \mathrm{cc}, 13 \%$ efficient lithium drifted germainium diode [Ge(Li)] having $2.20 \mathrm{keV}$ full width half maximum (FWHM) resolution for the $1332 \mathrm{keV}{ }^{60} \mathrm{Co}$ gamma was used to take the high energy (200 keV-4 Mev) gamma measurements. A smaller intrinsic germainium $(0.7 \mathrm{cC})$ with very high resolution, 202 eV FWHM at $5.9 \mathrm{keV}$ and $479 \mathrm{eV}$ FWHM at $122 \mathrm{keV}\left({ }^{57} \mathrm{Co}\right)$, was used for low energy $(0-400 \mathrm{keV})$ measurements in the 308 Building. A preamplifier is connected directly to the detector output. Preamplifier power and output pulses are fed to a spectroscopy amplifier through a series of coaxial cables. The amplifier and shaped pulses are then fed to a 4096 multichannel analyzer. The spectral 


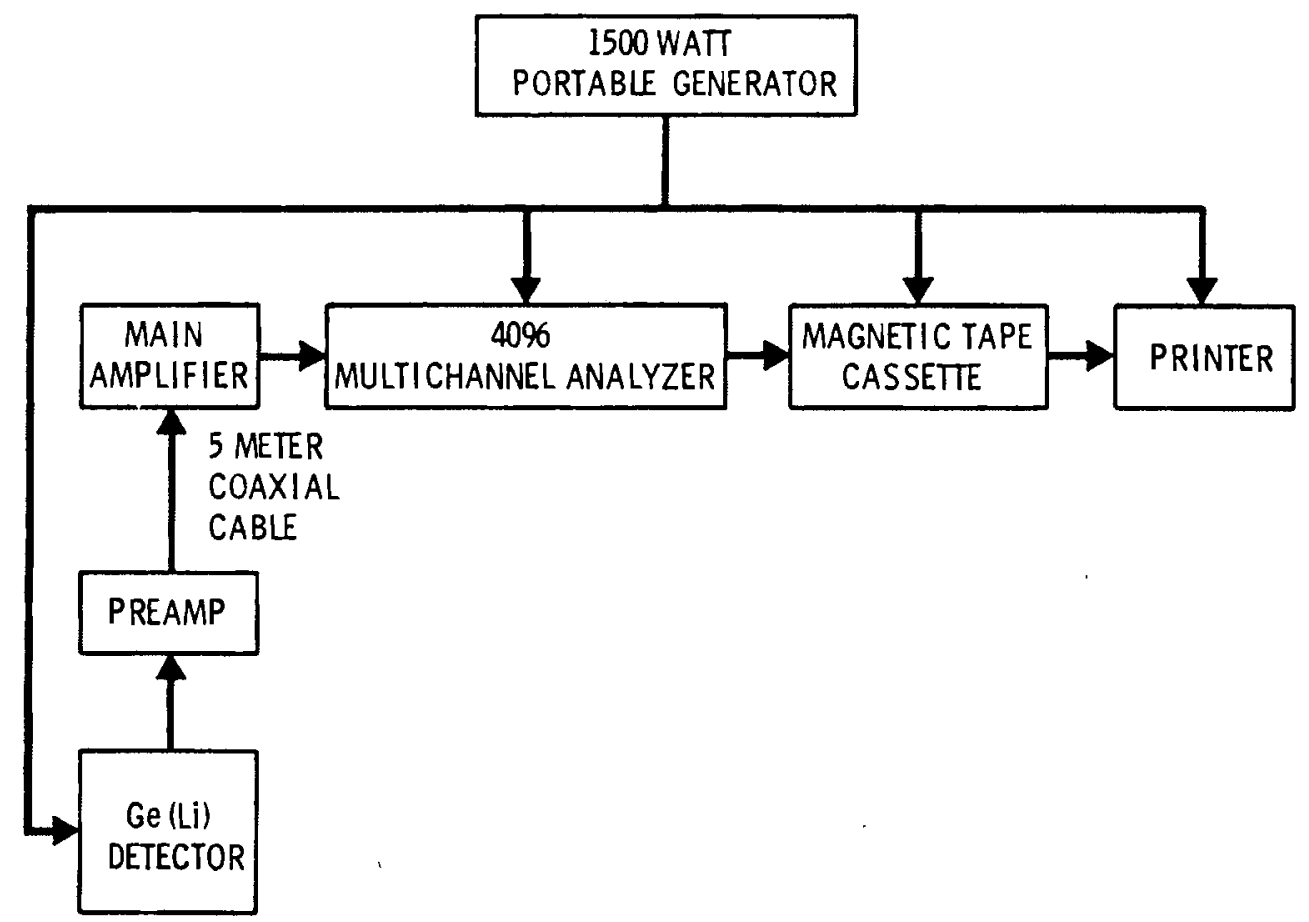

FIGURE 6.11. Simplified Layout of Equipment Used for Taking Gamma Spectrum Measurements

data are recorded on magnetic tape cassette and printed simultaneously. Power for outdoor measurements (200 West diversion box) is provided by a 1500 watt portable generator.

Data Collection and Analysis

Data analysis is done by a microprocessor based software package included in the multichannel analyzer (Canberra Model $8180, P / Q$ \& II User's Guide). The pushbutton (hardwired) programs are used to determine energies, photopeak areas, and statistical infomration on resolved peaks. Also included is a radioisotope identification library which uses the energy of a photopeak to determine the identification of a particular radionuclide. Energy calibration is accomplished by using known radioisotope standards, such as ${ }^{137} \mathrm{Cs},{ }^{57} \mathrm{Co}$, and ${ }^{60} \mathrm{Co}$, whose energies and abundances are well documented (ORNL/NUREG/TM-102 1977). 
Discussion

In situ field spectrometry is very useful in identifying radionuclides in the areas around diversion boxes, process lines, holding tanks, and other work areas where the actual fission and activation products need to be identified. Qualitative analysis of room/building spectra by direct counting will provide information regarding the energy spectrum at various work locations throughout the project. Figure 6.12 is typical of the data collected (actually a gamma spectrum of a hood glove in 308 Building). Results obtained for each facility are included in their respective appendix.

\section{BETA MEASUREMENTS}

A convenient field instrument for making field beta spectra measurements does not currently exist. A specially fabricated TLD dosimeter was used to obtain an estimate of beta and photon radiation penetration at the following deptns:

$$
\begin{array}{r}
6 \mathrm{mg} / \mathrm{cm}^{2} \\
30 \mathrm{mg} / \mathrm{cm}^{2} \\
55 \mathrm{mg} / \mathrm{cm}^{2} \\
89 \mathrm{mg} / \mathrm{cm}^{2} \\
900 \mathrm{mg} / \mathrm{cm}^{2}
\end{array}
$$

Figure 6.13 shows the actual dosimeter construction and Table 6.2 indicates the filtration for each dosimeter position. Two TLD-700 chips were placed in each dosimeter card position.

Position 2 corresponds to the current "open window" filtration $\left(89 \mathrm{mg} / \mathrm{cm}^{2}\right)$ for the Hanford dosimeter and position 3 corresponds to positions 3 , 4 , or 5 of the Hanford dosimeter. A beta particle of energy nearly $2 \mathrm{MeV}$ is necessary to penetrate position 3. As such, position 3 is used to photon compensate the data from the other positions. To calibrate the dosimeter data, dosimeters were exposed to the uranium slab and strontium calibration sources. 


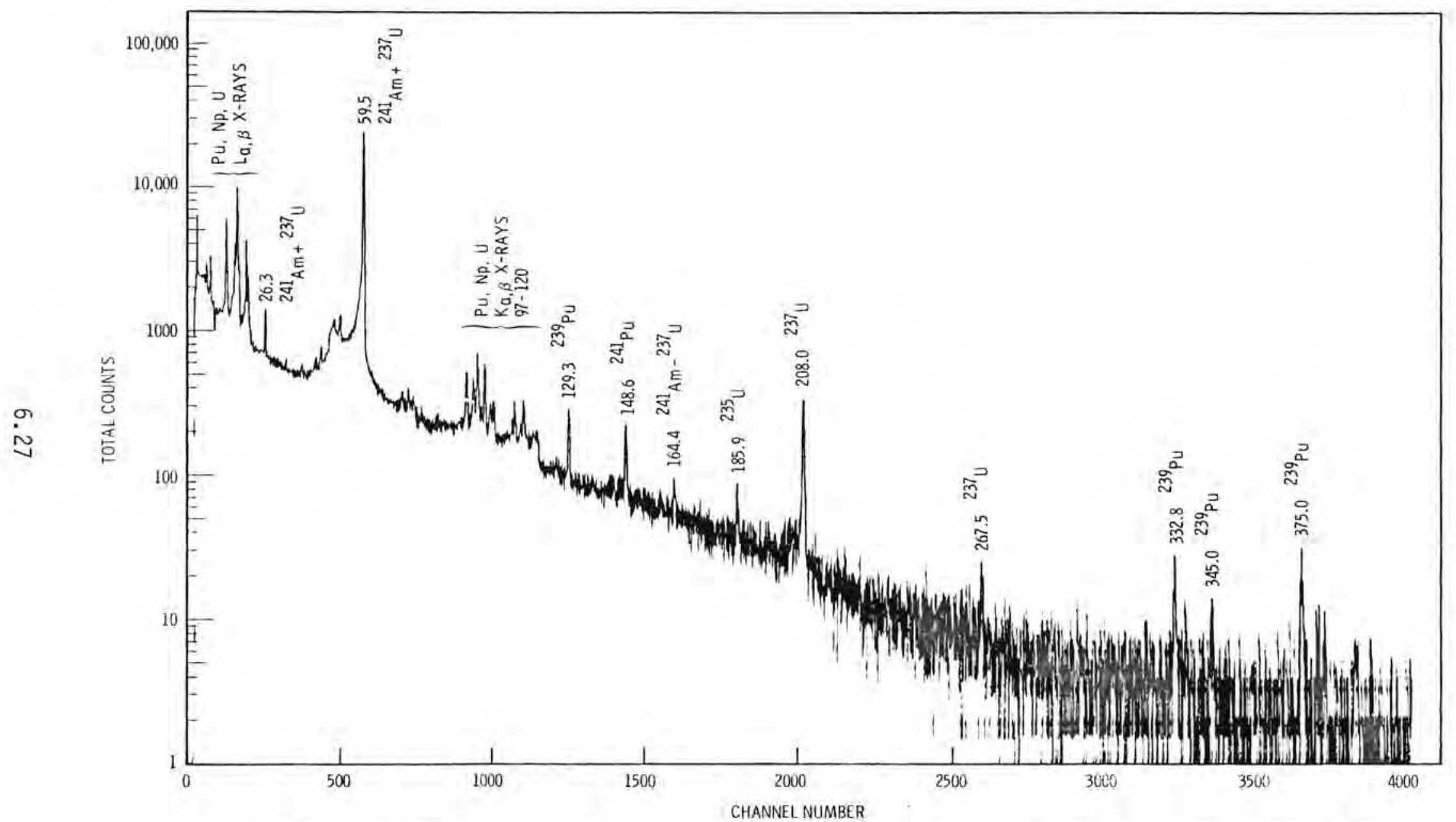

FIGURE 6.12. Photon Energy Spectrum from a Neoprene Glove Used in a Mixed Oxide $\left(\mathrm{PuO}_{2}-\mathrm{UO}_{2}\right)$ Fuel Fabrication Facility 


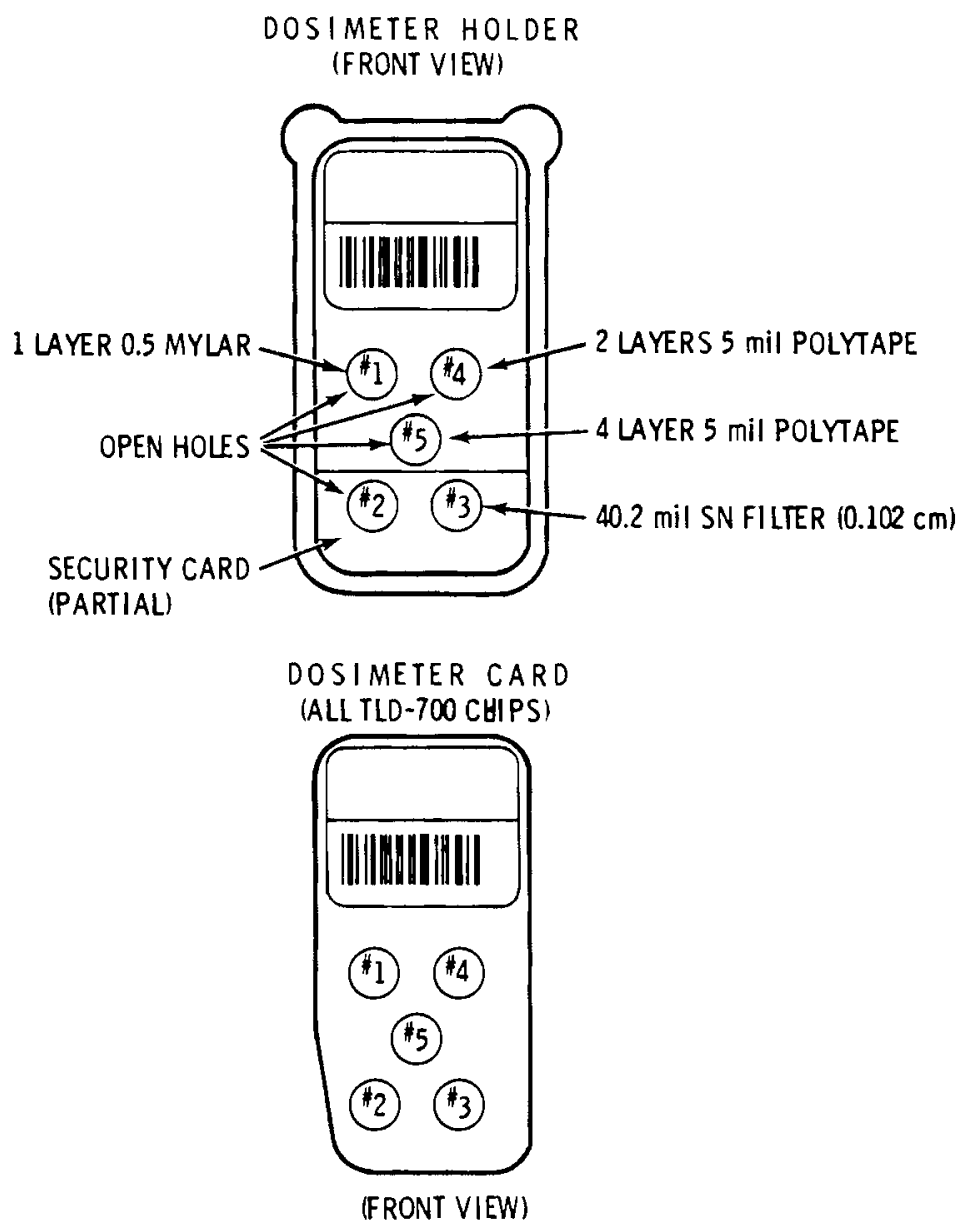

FIGURE 6.13. Modified Hanford Dosimeter for Beta Measurements

TABLE 6.2. Materials Used in Dosimeter Construction

\begin{tabular}{|c|c|c|c|c|c|}
\hline $\begin{array}{l}\text { Position } \\
\text { Number } \\
\end{array}$ & $\begin{array}{c}\text { Dos imetry } \\
\text { Card }\end{array}$ & $\begin{array}{c}\text { Dosimeter } \\
\text { Holder }\end{array}$ & $\begin{array}{c}\text { Security } \\
\text { Credential } \\
\end{array}$ & Filtration & $\begin{array}{r}\text { Effective } \\
\text { Filtration } \\
\end{array}$ \\
\hline 1 & 2 mil teflon & - & & $0.5 \mathrm{mil}$ mylar & $\sim 6 \mathrm{mg} / \mathrm{cm}^{2}$ \\
\hline 2 & 2 mil teflon & - & $33 \mathrm{mil}$ & - & 89 \\
\hline 3 & 2 mil teflon & $31.5 \mathrm{mil}$ & $33 \mathrm{mil}$ & $40.2 \mathrm{mil} \mathrm{Sn}$ & 900 \\
\hline 4 & 2 mil teflon & - & - & 10 mil poly tape & 30 \\
\hline 5 & 2 mil teflon & - & - & 20 mil poly tape & 55 \\
\hline
\end{tabular}




\section{REFERENCES}

Auxier, J. A., W. S. Snyder, and T. D. Jones. 1968. "Neutron Interactions and Penetration in Tissue." Radiation Dosimetry, Vol. 1, eds. F. H. Attix, W. C. Roesch, and E. Tochlin, (publisher, city, state).

Awschalom, M. 1966. "Use of the Multisphere Neutron Detector for Dosimetry of Mixed Radiation Fields." In: Neutron Monitoring Proceedings of a

Symposium I.A.E.A.

Brackenbush, L. W., G. W. R. Endres, and L. G. Faust. (date). "Experimentally Determined Quality Factors for Fast neutrons," BNWL-SA-4249, Pacific Northwest Laboratory, Richland, Washington.

Brackenbush, L.W., G. W. R. Endres, and L. G. Faust. 1978. "Measuring Neutron Dose and Quality Factors with Tissue EQuivalent Proportional Counters." IAEA-SM-229/52, 1-11.

Bramblett, R. L., R. I. Ewing, and T. W. Bonner. 1960. "A New Type of Neutron Spectrometer. Nucl. Instruments and Methods 9:1-13.

Canberra Model 8180, P/Q a II User's Guide, Canberra Industries, Inc., 45 Gravey Avenue, Meriden, Connecticut 06450.

Glass, W. A., D. N. Samsky. 1967. "Ionization in Thin Tissue-Like Gas Layers by Monoenergetic Protons," Radiation Research 32:138-148.

Griffith, R. V. and J. C. Fisher. 1976. "Measurement of the Responses of Multisphere Detectors with Monoenergetic Neutrons, 0.1 to $18.5 \mathrm{MeV} . "$ Lawrence Livermore Laboratory Hazards Control Progress Report No. 51, 29-41.

Griffith, R. V., D. E. Hankins, R. B. Gammage, L. Tommasino and

R. V. Wheeler. 1979. "Recent Developments in Personnel Neutron Dosimeters - A Review." Health Phys. 36:235-260.

ICRP Publication 21. 1971. "Data for protection Against Ionizing Radiation from External Sources," Supplement to ICRP Publication 15. 12, 55.

ICRU Report 20. 1976. Radiation Protection Instrumentation and Its Application. 1-8.

ICRU Report 26. 1977. Neutron Dosimetry for Biology and Medicine. 1-29

Hajnal, F. 1979. Stray Neutron Fields Inside the Containment of PWR's. IAEA-SM-242/24, International Atomic Energy Agency, Vienna, Austria.

Hankins, D. E., and R. V. Griffith. 1979. "A Survey of Neutrons Inside the Containment of a Pressurized Water Reactor." In Radiation Streaming in Power Reactors. ORNL/RSIC-43, Oak Ridge National Laboratory, Oak Ridge, Tennessee. 
Lucas, A. C. 1979. "The Use of Helium-3 Filled Proportional Counter as a Sensitive Dose or Dose Equivalent Meter." IEEE Trans. Nuc1. Sci. NS26:770.

Nuclear Decay Data for Radionuclides Occurring in Routine Releases from Nuclear Fuel Cycle Facilityies, ed. by D. C. Kocher, ORNL/NUREG/TM-102, 0ak Ridge National Laboratory, Oak Ridge, Tennessee (August 1977).

Reil, G., N. Scofield and K. Woo. 1979. "Measurements to Determine Field Calibrations for an Albedo Neutron Dosimeter." In Abstracts of the Twenty-Fourth Annual Meeting of the Health Physics Society, Philadelphia, Pennsylvania. Health Physics Society, Denver, Colorado.

Rossi, H. H. 1968. Microscopic Energy Distribution in Irradiated Mattter. Radiation Dosimetry, Vol. 1, eds. F. H. Attix, W. C. Roesch, and E. Tochlin, (publisher, city, state).

Routti, J. T., and J. V. Sandberg. 1978. "General Purpose Unfolding Program LOUHI 78 with Linear and Non-Linear Regularization." Helsinki University of Technology, Department of Technical Physics, Report TKK-A359, 1-51.

Sanna, R. S. 1973. "Thirty One Group Response Matrices for the Multisphere Neutron Spectrometer Over the Energy Range Thermal to $400 \mathrm{MeV}, "$ HASL-267, $1-37$. 
APPENDIX A

308 BUILDING 
APPENDIX A

308 BUILDING

Five separate locations were measured using the multisphere system, RASCAL, and TEPC systems. Dosimeters were mounted on water phantoms at two of these locations. The neutron spectral data, as they are presented in Figure 6.A.1, are: the plutonium storage vault, the fuel storage pit, the pin storage pit, the fuel pin storage boxes, and the bare fuel subassembly.

As seen in Figure 6.A.1, there are relatively few low energy neutrons (thermal to $500 \mathrm{keV}$ ). The unmoderated and slightly moderated neutron fields produced high energy spectra ( $500 \mathrm{keV}$ to $1.5 \mathrm{MeV}$ ). In the two storage pits and vault there is a higher contribution of thermal and intermediate neutrons but the higher energy neutrons continue to dominate the spectra. This increased contribution of lower energy neutrons is indicative of increased shielding and room scatter. Average neutron energies, as calculated from the mult isphere computes program, are:

- $530 \mathrm{keV}$ in the fuel storage pit area

- $576 \mathrm{keV}$ in the plutonium storage vault

- $660 \mathrm{keV}$ in the fuel pin storage box area

- $1.1 \mathrm{MeV}$ in the pin storage area

- $1.5 \mathrm{MeV}$ at the mid point of a bare fuel subassembly.

Dose equivalent rates measured with the TEPC and multisphere systems compare very favorably. Their analys is varied by $\pm 20 \%$ (see Table 6.2). The RASCAL indicated dose equivalent rates much higher by factors ranging from 1.6 to 2.9 which are more in accordance with previous studies. The higher factor of 14.8 is probably an instrument malfunction, because in the fuel storage area the RASCAL failed to operate.

Dosimeters exposed to neutron fields in the fuel storage pit area and the pin storage pit area compared remarkably well. When the dosimters' adsorbed dose was converted to a dose equivalent $r$ ate the response varied by $\pm 30 \%$ of dose equivalent rates determined by the multisphere and TEPC systems (shown in Table 6.1). 


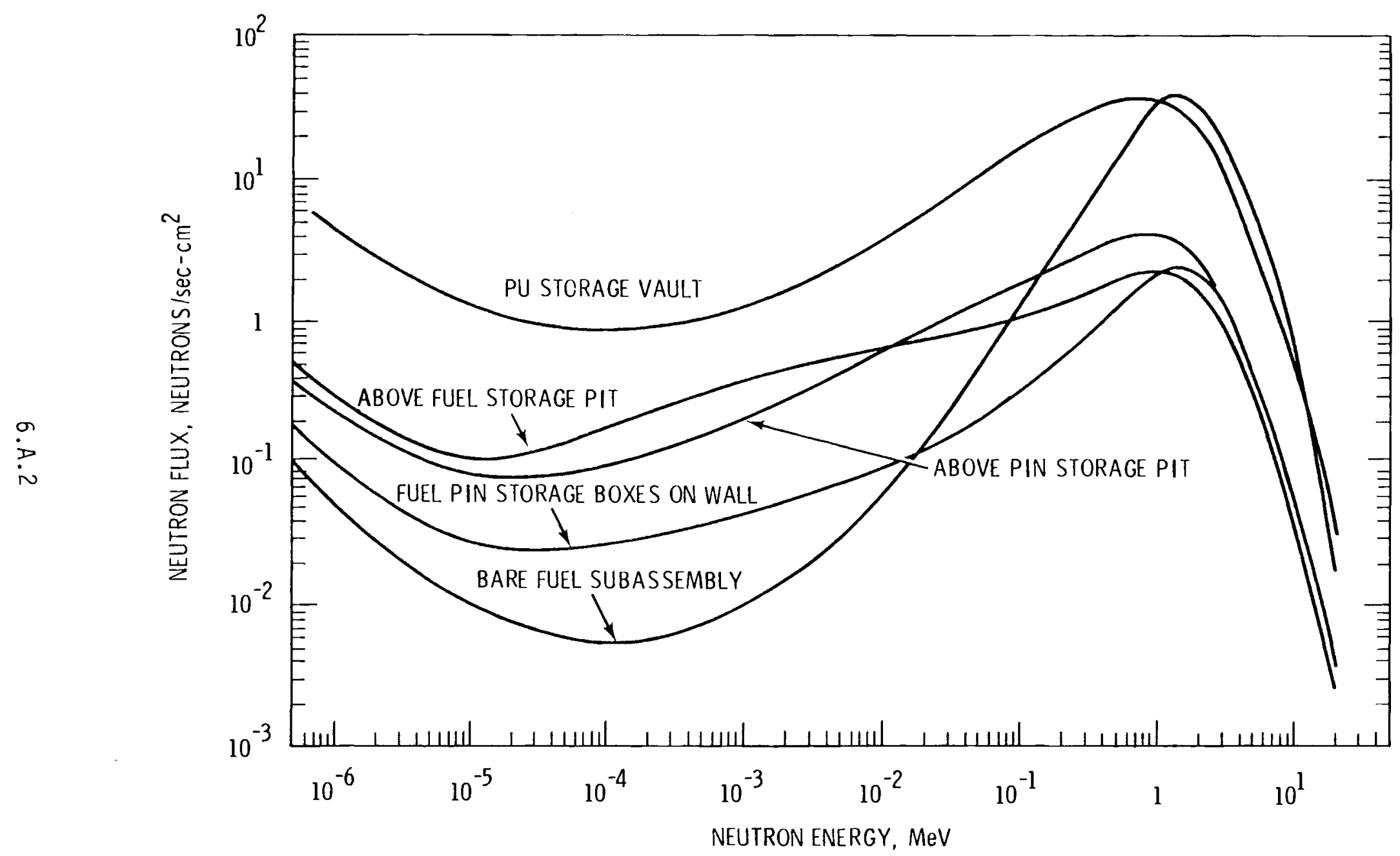

FIGURE 6.A.1. Neutron Spectra Measured by a Multisphere Spectrometer at a Plutonium Fuel Fabrication Facility 
TABLE 6.A.1. Comparison of Various Neutron Dosimeters

\begin{tabular}{|c|c|c|c|c|c|}
\hline Location & $\begin{array}{c}\text { RASCAL } \\
(\mathrm{mrem} / \mathrm{hr}) \\
\end{array}$ & $\begin{array}{l}\text { Mult isphere } \\
(\mathrm{mrem} / \mathrm{hr})\end{array}$ & $\begin{array}{c}\text { TEPC } \\
(\mathrm{mrem} / \mathrm{hr})\end{array}$ & $\begin{array}{l}\text { TLD-Albedo Dosimeter } \\
(\mathrm{mrem} / \mathrm{hr})\end{array}$ & $\begin{array}{c}\text { Average Neutron } \\
\text { Energy }\end{array}$ \\
\hline Pu storage vault & 17.7 & 1.2 & & & $576 \mathrm{keV}$ \\
\hline $\begin{array}{l}\text { Above fuel storage } \\
\text { pit }\end{array}$ & & 0.9 & 0.54 & 0.96 & $530 \mathrm{keV}$ \\
\hline Above pin sotrage pit & 2.0 & 0.8 & 1.3 & $\begin{array}{l}1.2 \\
0.46 \text { (phantom } \\
\text { on floor) }\end{array}$ & $1.1 \mathrm{MeV}$ \\
\hline $\begin{array}{l}\text { Fuel pin storage } \\
\text { boxes on wall }\end{array}$ & 4.1 & 1.4 & & & $660 \mathrm{keV}$ \\
\hline Bare fuel subassembly & 17.6 & 10.8 & 11 & & $1.5 \mathrm{MeV}$ \\
\hline
\end{tabular}


GAMMA MEASUREMENTS

Plots of gamma spectra measurements taken in the 308 and 327 Buildings are listed below with each building and location heading and the isotope identification and a corresponding column titled $\mathrm{r} / \mathrm{s}$ (gamma per second). The gamma/second column is merely an indicator as to the relative amount of each identified radionuclide.

\begin{tabular}{|c|c|c|c|}
\hline Building & Location/Type & Radionuclide & Activity $\mathrm{r} / \mathrm{s}$ \\
\hline \multirow[t]{3}{*}{308} & 1. General room background count & $241_{A m}$ & 36.3 \\
\hline & 2. Through bottom of grinder hood & $241_{A m}$ & 176.4 \\
\hline & $\begin{array}{l}\text { 3. Port glove at pellet pressing } \\
\text { station }\end{array}$ & $241_{A m}$ & 1075.8 \\
\hline \multirow[t]{6}{*}{327} & 1. Near A cell - room background & ${ }^{137} \mathrm{Cs}$ & 0.2 \\
\hline & & $54 M n$ & 0.2 \\
\hline & & $60 \mathrm{Co}$ & 2.2 \\
\hline & 2. Near $G$ cell with open port & ${ }^{137} \mathrm{Cs}$ & 11.9 \\
\hline & & $54 M n$ & 15.3 \\
\hline & & $60_{\mathrm{Co}}$ & 103.6 \\
\hline
\end{tabular}




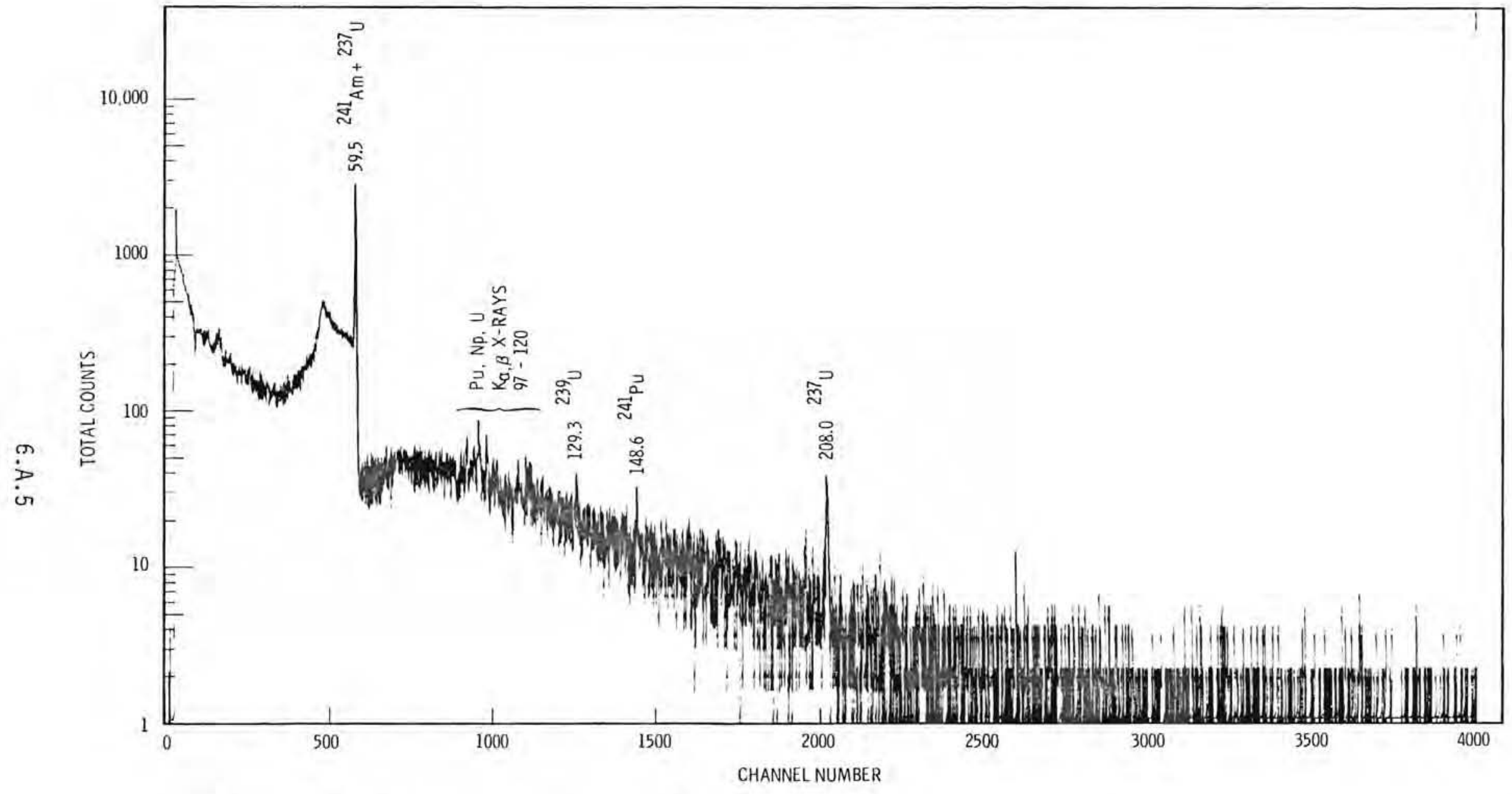

FIGURE 6.A.2. Photon Energy Spectrum of General Room Background in the Fuel Fabrication Facility 


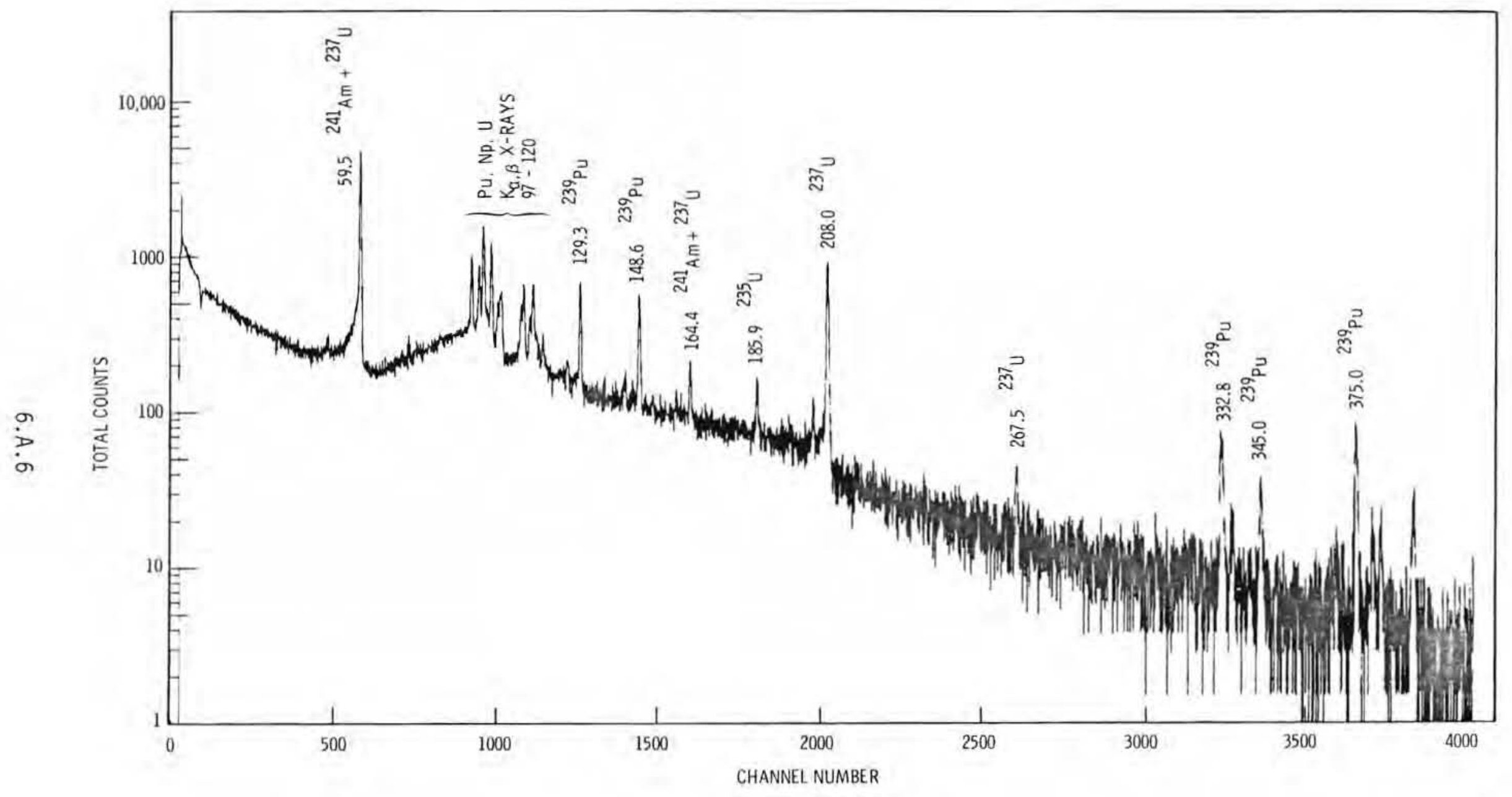
FIGURE 5.A.3. Photon Energy Spectrum Thru Bottom of Grinder Hood in a Mixed Oxide $\left(\mathrm{PuO}_{2}-\mathrm{UO}_{2}\right)$ Fue1
Fabrication Facility 


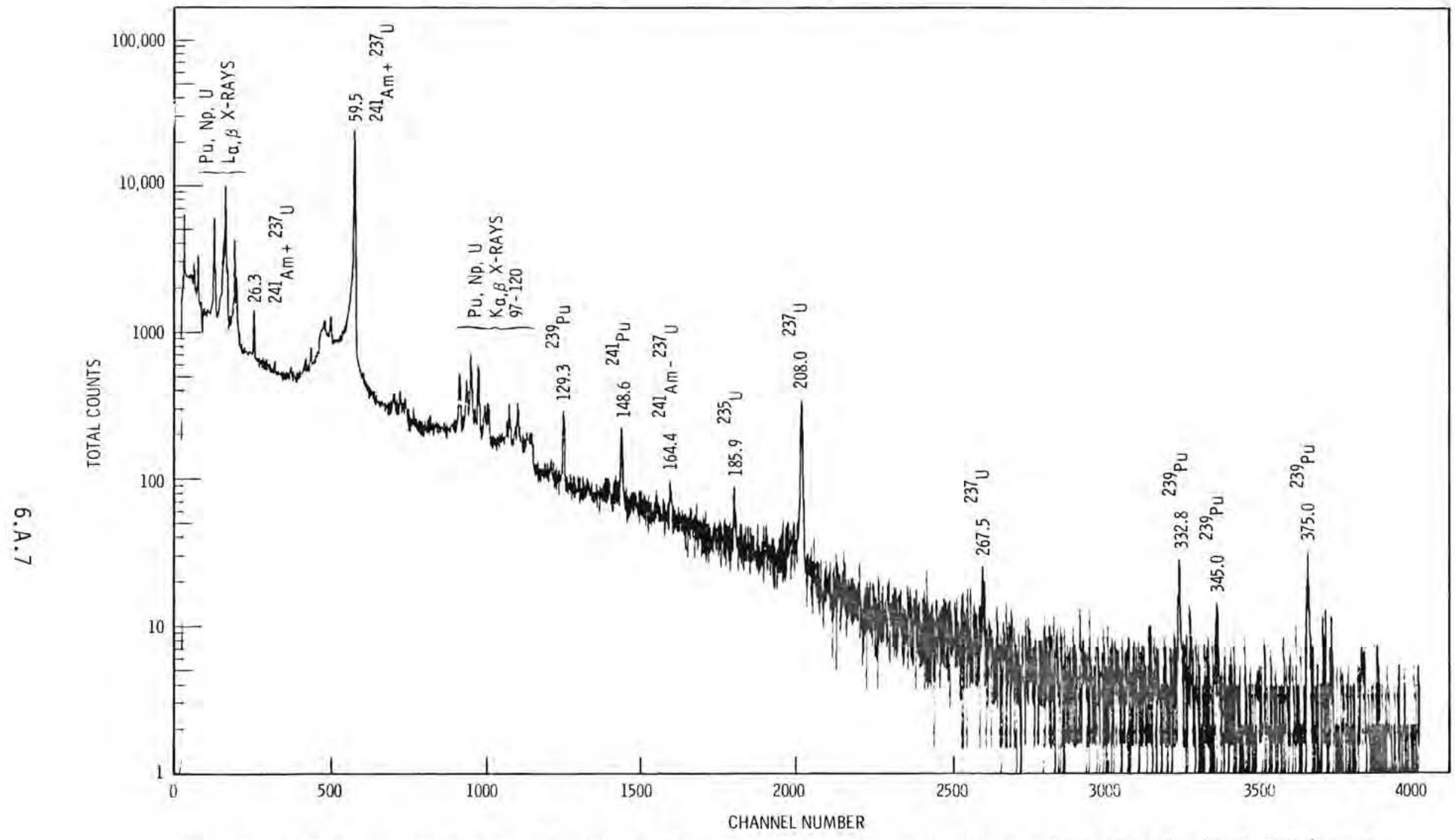

FIGURE 6.A.4. Photon Energy Spectrum From a Neoprene Glove Used in a Mixed Oxide $\left(\mathrm{PuO}_{2}-\mathrm{UO}_{2}\right) \mathrm{Fuel}$ Fabrication Facility 


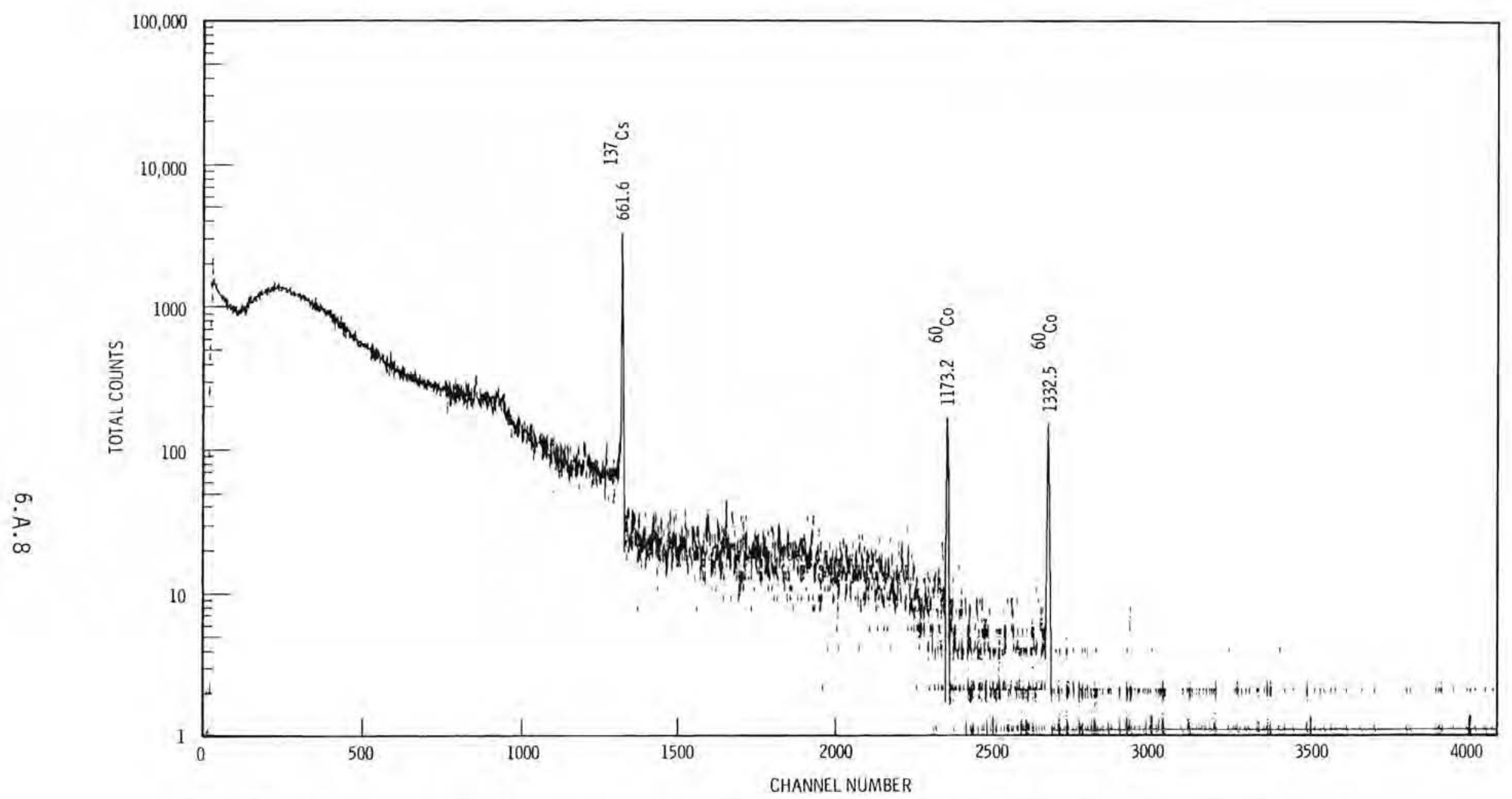

FIGURE 6.A.5. Spectrum of General Room Background at Room Entry Near A-Cell. 327 Building 


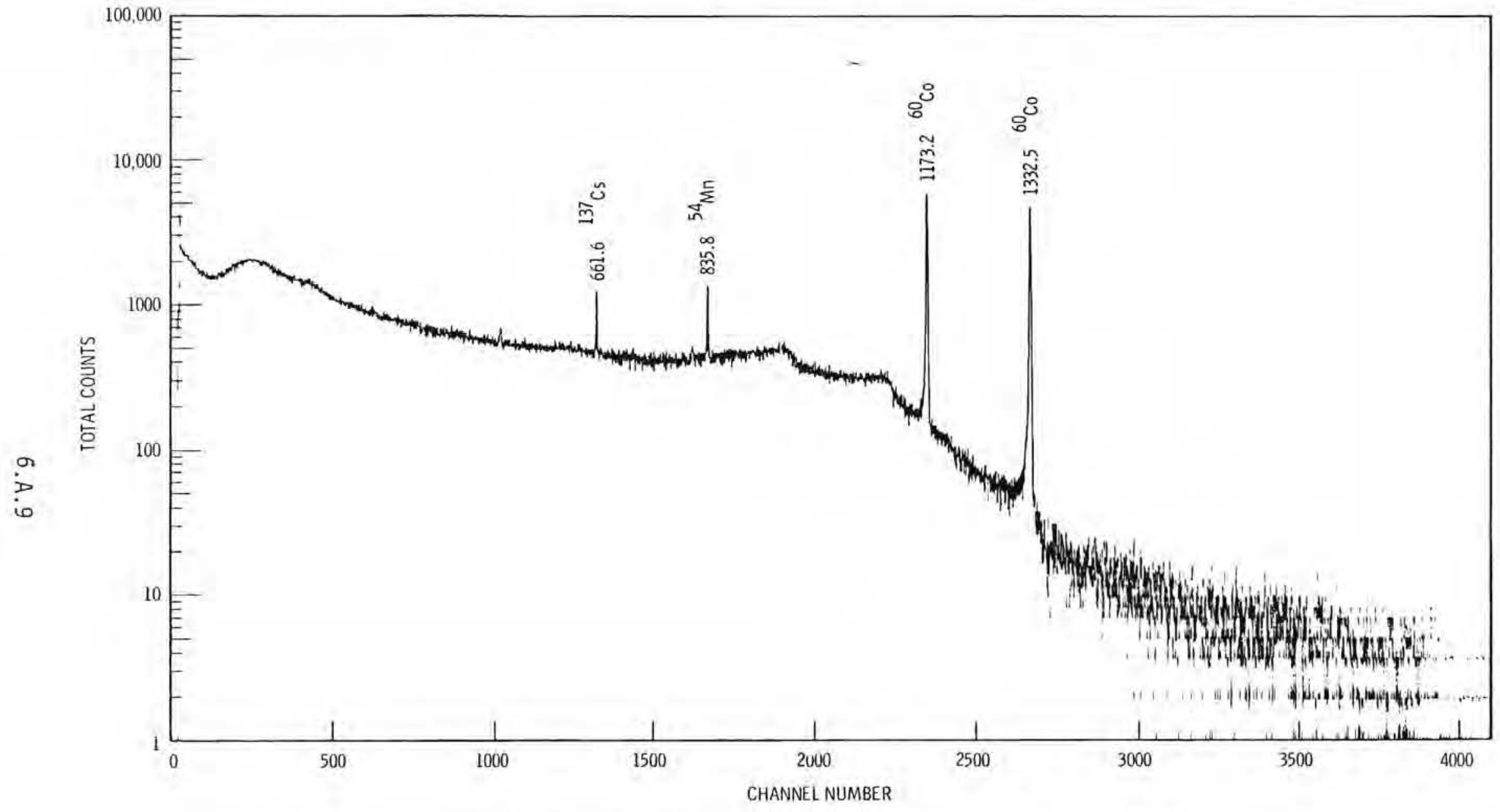

FIGURE 6.A.6. Spectrum of G-Cel1-0pen Portal. 327 Building 


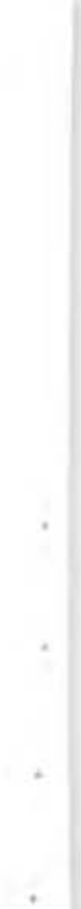


APPENDIX B

200 WEST DIVERSION BOX

\section{,}


APPENDIX B

200 WEST DIVERSION BOX

\section{GAMMA MEASUREMENTS}

Plots of gamma spectra measurements taken at the 200 West Diversion Box are listed below with each locations heading, isotope identification and a corresponding column titled $\gamma / \mathrm{s}$ (gamma/second). The gammas/second column is merely an indicator as to the relative amount of each identified radionuclide.

\begin{tabular}{|c|c|c|c|}
\hline Building & Location/Type & Radionuclide & Activity $Y / S$ \\
\hline $\begin{array}{l}242 S-200 w \\
\text { Evaporator } \\
\text { Building }\end{array}$ & 1. Outside near northeast corner & ${ }^{137} \mathrm{Cs}$ & 23.1 \\
\hline $\begin{array}{l}\text { Diversion } \\
\text { Boxes-200W }\end{array}$ & $\begin{array}{l}\text { 1. } 241-T X-302-C \text { catch tank } \\
\text { near } 222 T \text { Building }\end{array}$ & 137 Cs & 4.4 \\
\hline & 2. $152 \mathrm{U}$ diversion Box (closed) & ${ }^{137} \mathrm{Cs}$ & 4.4 \\
\hline
\end{tabular}

BETA MEASUREMENTS

Figure 5.B.1 is a plot of data collected with the specially fabricated dosimeters showing radiation penetration with increasing filter thickness. Plots 2 through 6 represent dosimeters worn by a rigging crew in the 200 west area. All of the data are charcteristics of penetrating photon raidation. Plot 1 represents a dosimeter placed near a contamination spec and shows a large component of soft beta radiation. Plot 7 represents a dosimeter placed in the pipe gallery of the $271 \mathrm{~B}$ building near cell 9. Calibration plots for the strontium and uranium sources are shown for reference. 


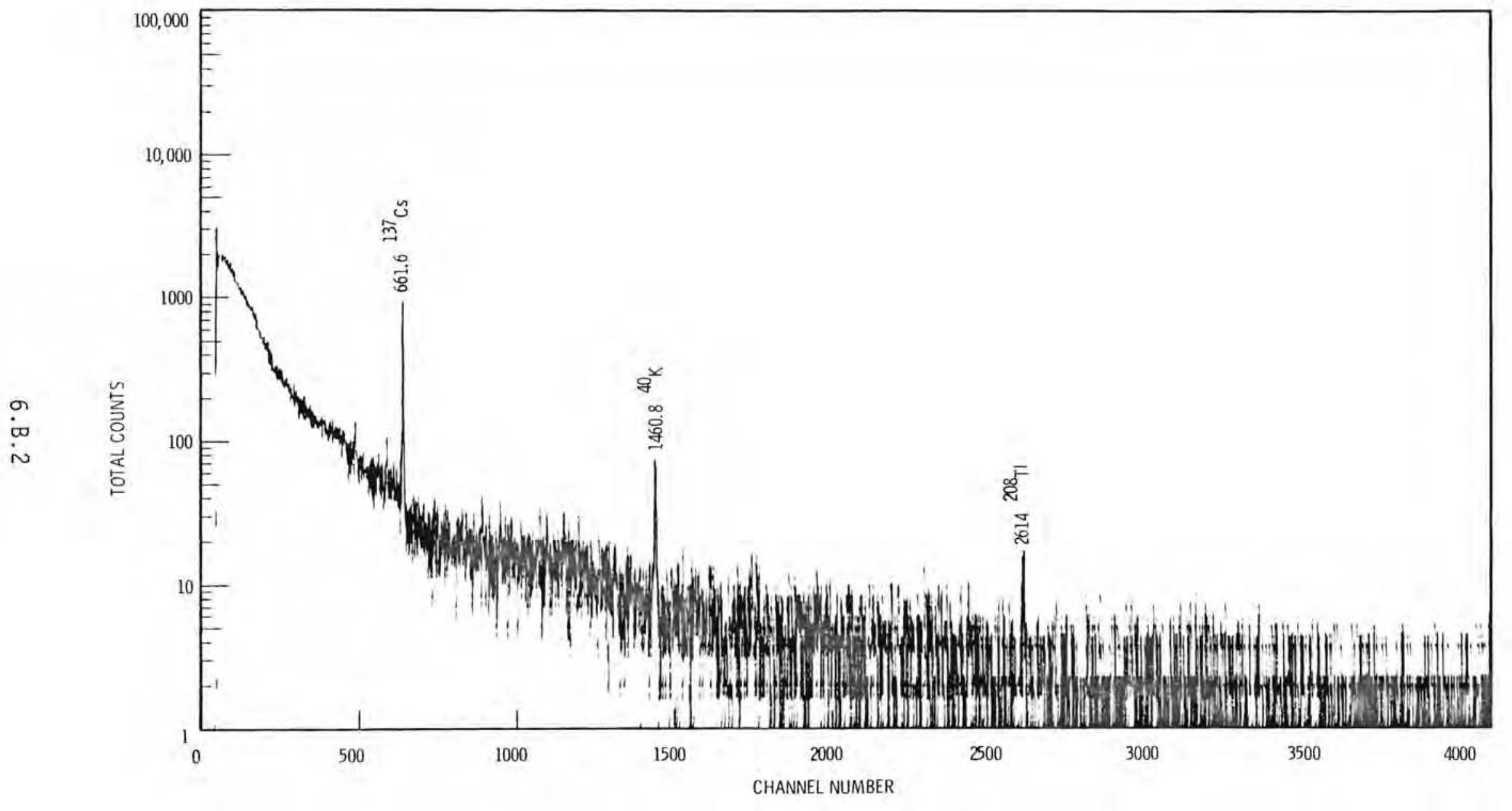

FIGURE 6.B.1. Spectrum Taken Near 241-TX-302-C Catch Tank 


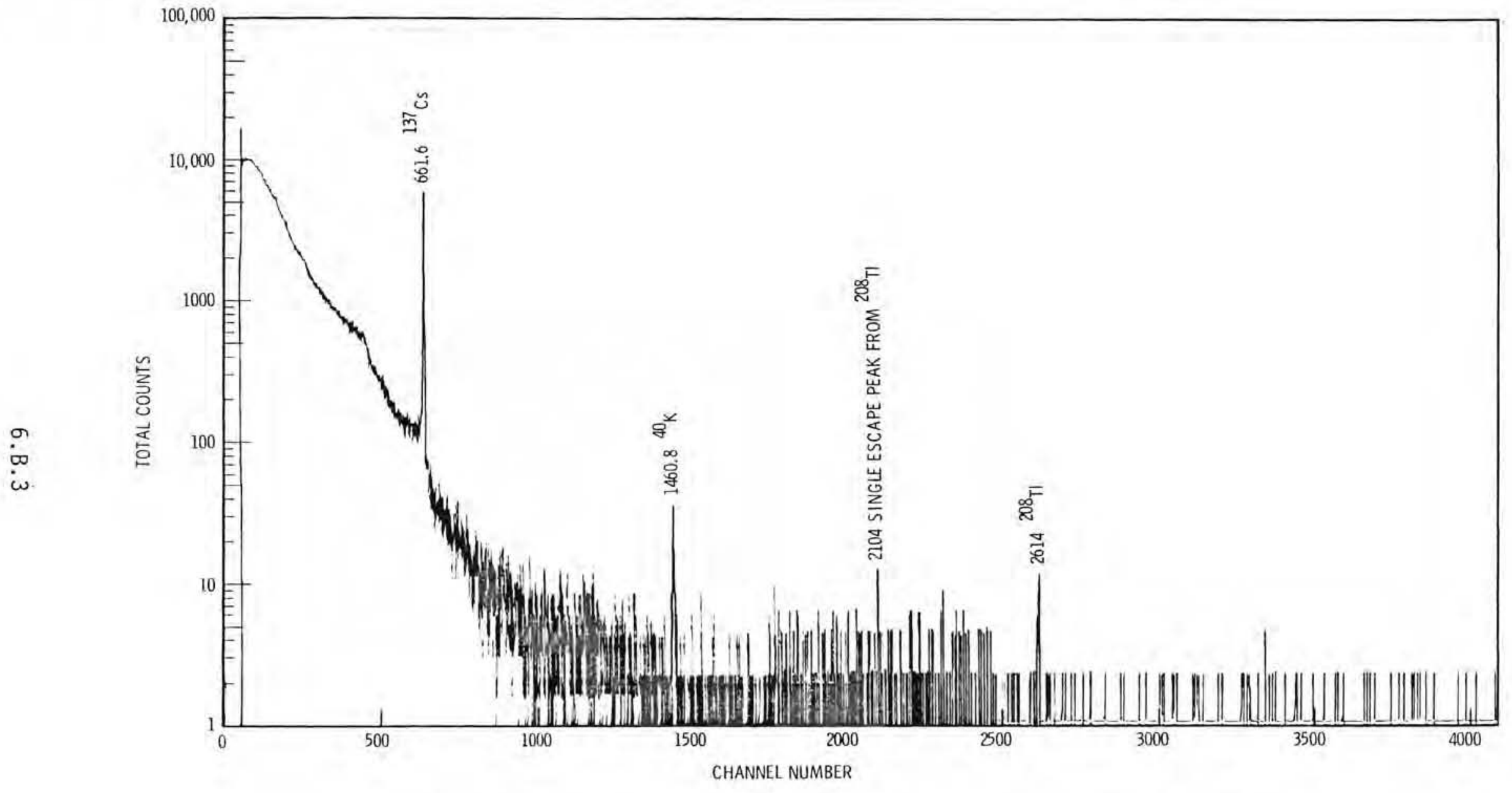

FIGURE 6.B.2. Spectrum Taken Outside Near 242-S Evaporator Building 200 West Area 


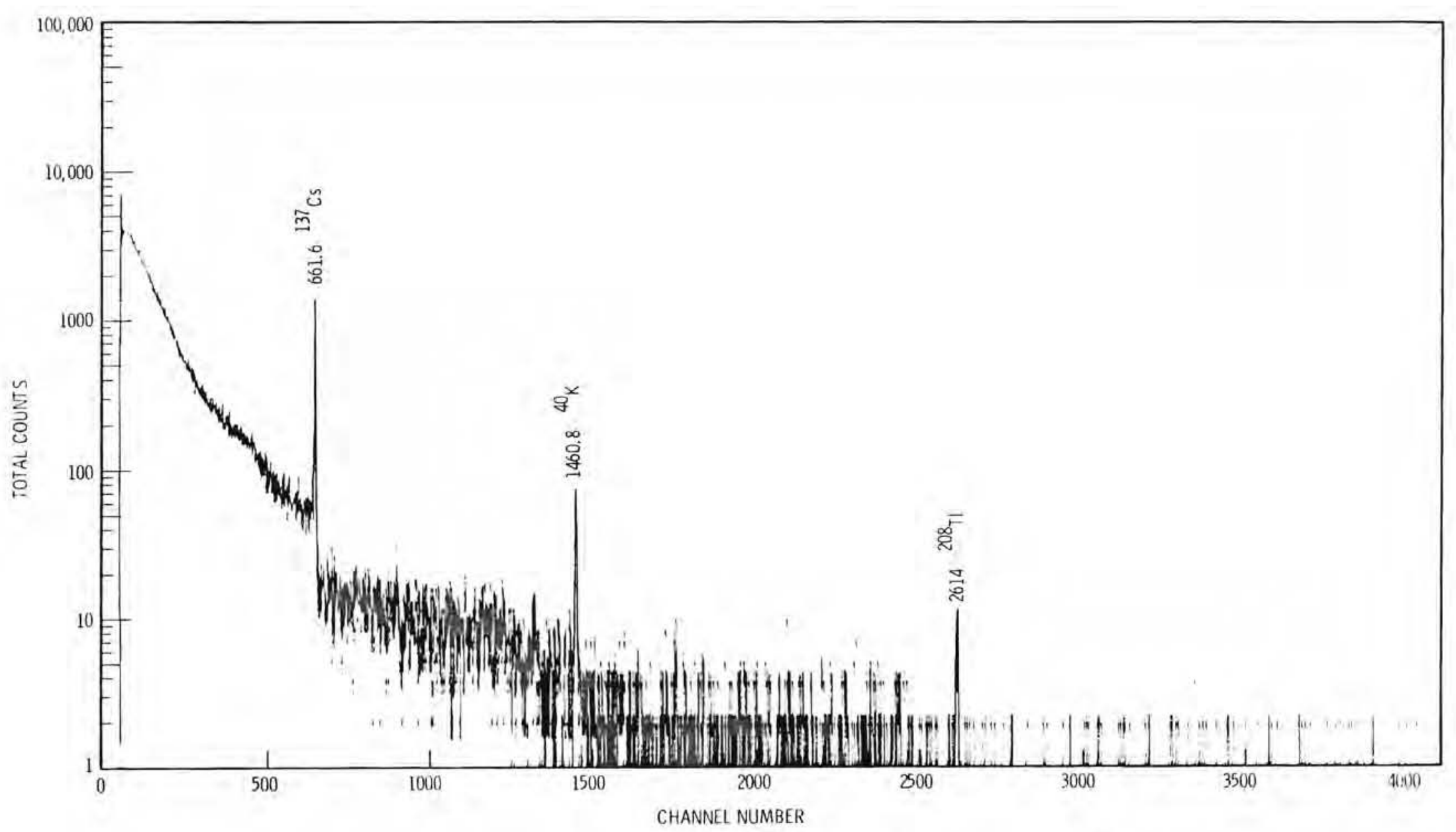

FIGURE 6.B.3. Spectrum Taken Near 152-U Diversion Box 200 West Area 


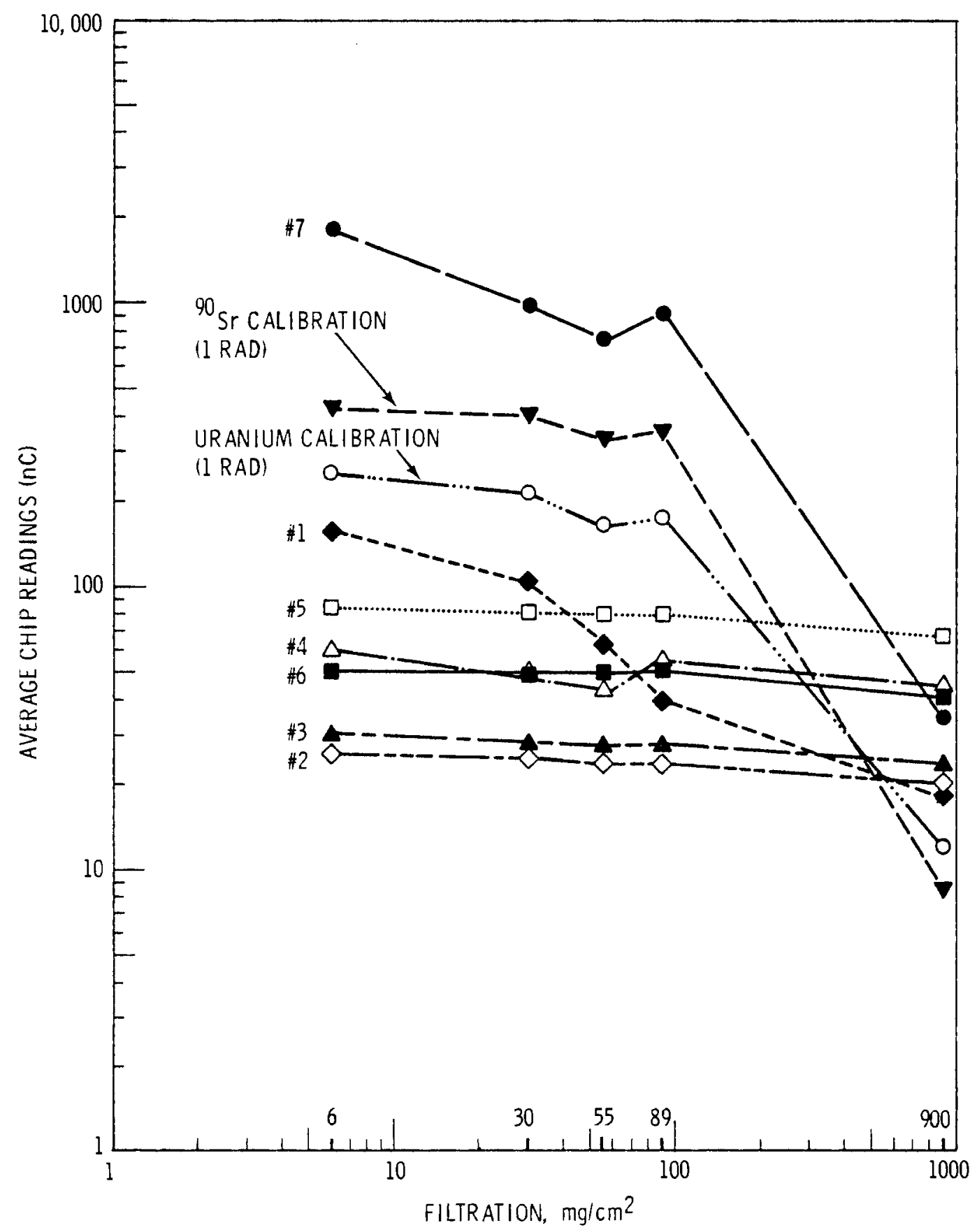

FIGURE 6.B.4. Plots of Radiation Penetration through Increasing Filtration Using Modified Hanford Dosimeter 
. 
APPENDIX C

B-PLANT 


\section{APPENDIX C}

B-PLANT

\section{GAMMA MEASUREMENTS}

Plots of gamma spectra measurements taken at the 225B Building are listed below with each locations heading, isotope identification and a corresponding column titled $\mathrm{r} / \mathrm{s}$ (gamma/second). The gammas/second column is merely an indicator as to the relative amount of each identified radionuclide.

\begin{tabular}{|c|c|c|c|}
\hline Building & Location/Type & Radionuclide & Activity $r / s$ \\
\hline \multirow{5}{*}{$\begin{array}{l}\text { 225B-200E } \\
\text { Encapsula- } \\
\text { tion } \\
\text { Building } \\
\text { rsion } \\
\text { Boxes-200w }\end{array}$} & 1. A cell & ${ }^{137} \mathrm{Cs}$ & 2.6 \\
\hline & 2. Between B-C cells & $137 \mathrm{Cs}$ & 9.9 \\
\hline & 3. Between D-E cells & ${ }^{137} \mathrm{Cs}$ & 60.1 \\
\hline & 4. F Cell & ${ }^{137} \mathrm{Cs}$ & 77.3 \\
\hline & $\begin{array}{l}\text { 5. General room background } \\
\text { across from cell fronts }\end{array}$ & ${ }^{137} \mathrm{Cs}$ & 24.1 \\
\hline
\end{tabular}




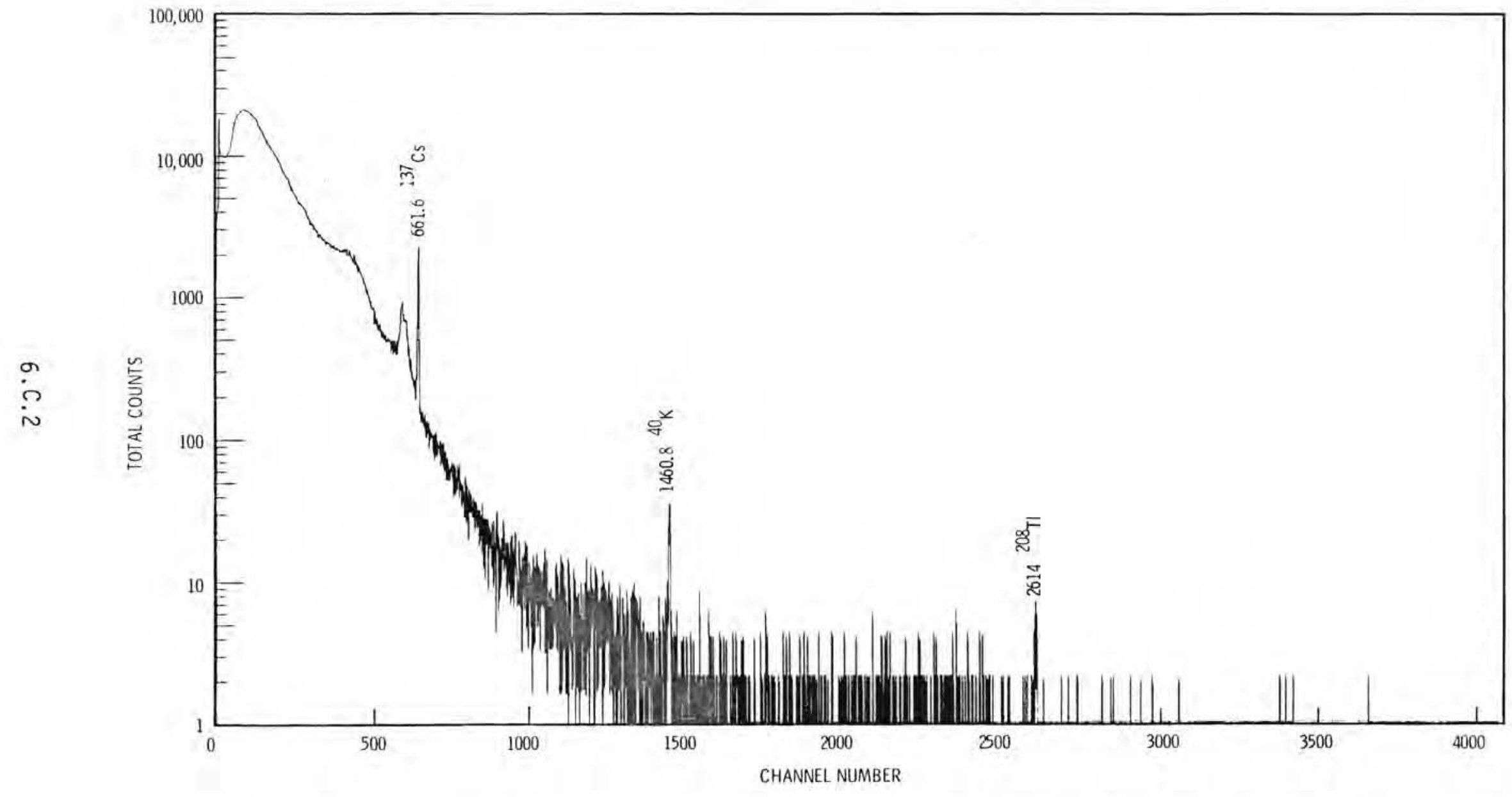

FIGURE E.C.1. General Room Spectrum Taken Across Operating Gallery From Cell Fronts - 225-B Building 


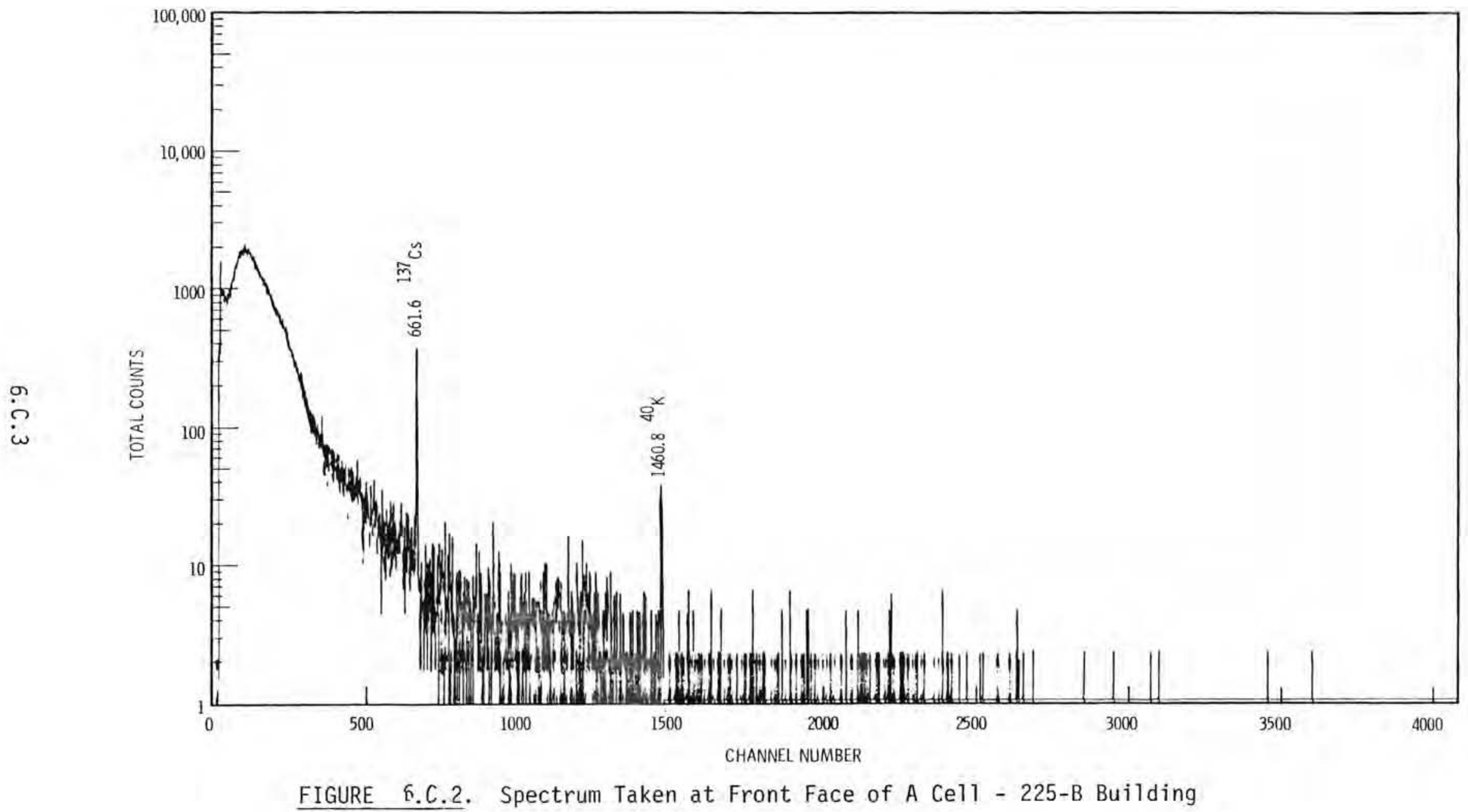




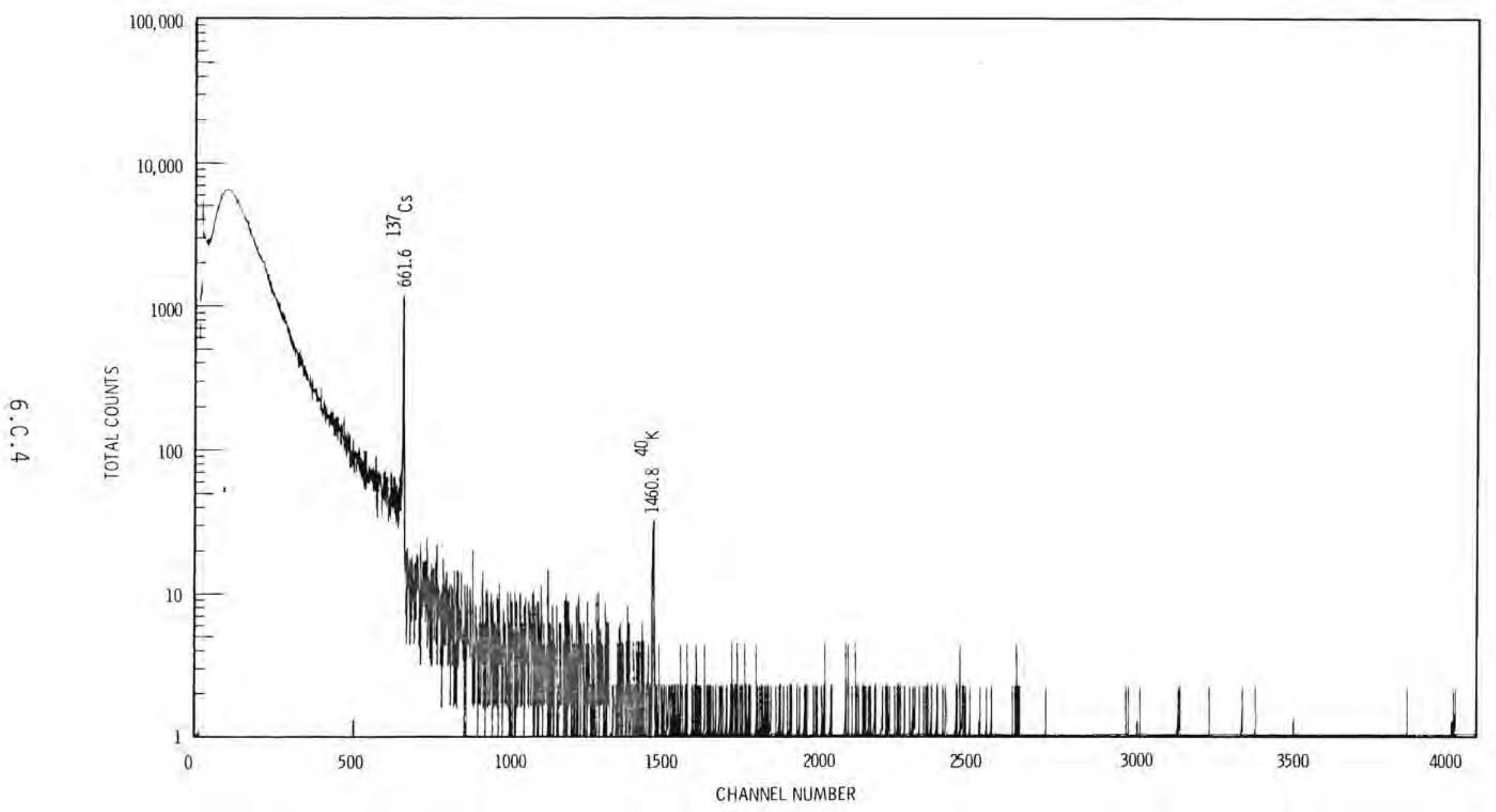

FIGURE 6.C.3. Spectrum Taken at Front Face Between B-C Cells - 225-B Building 


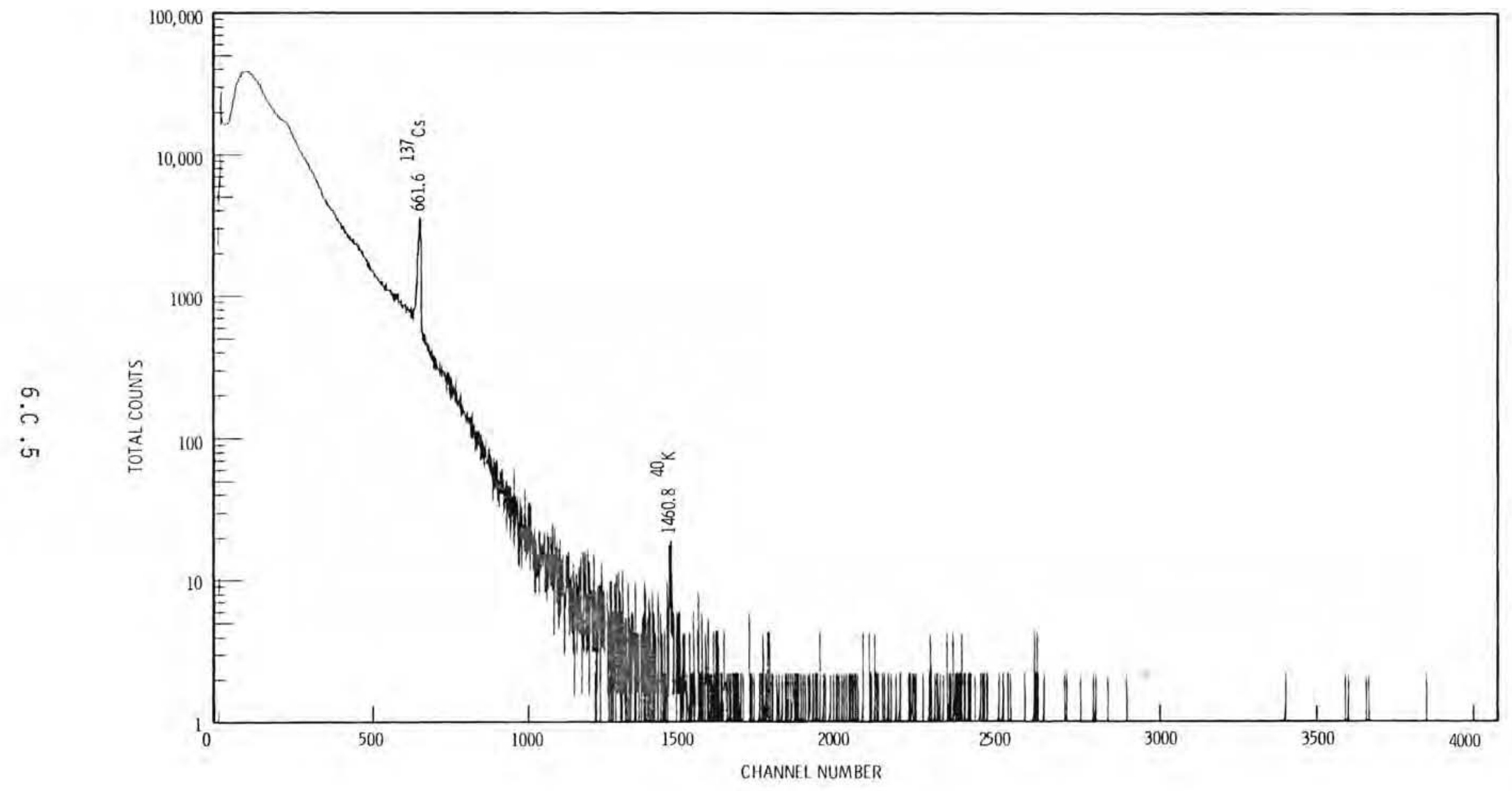

FIGURE '6.C.4. Spectrum Taken at Front Face Between D-E Cell - 225-B Building 


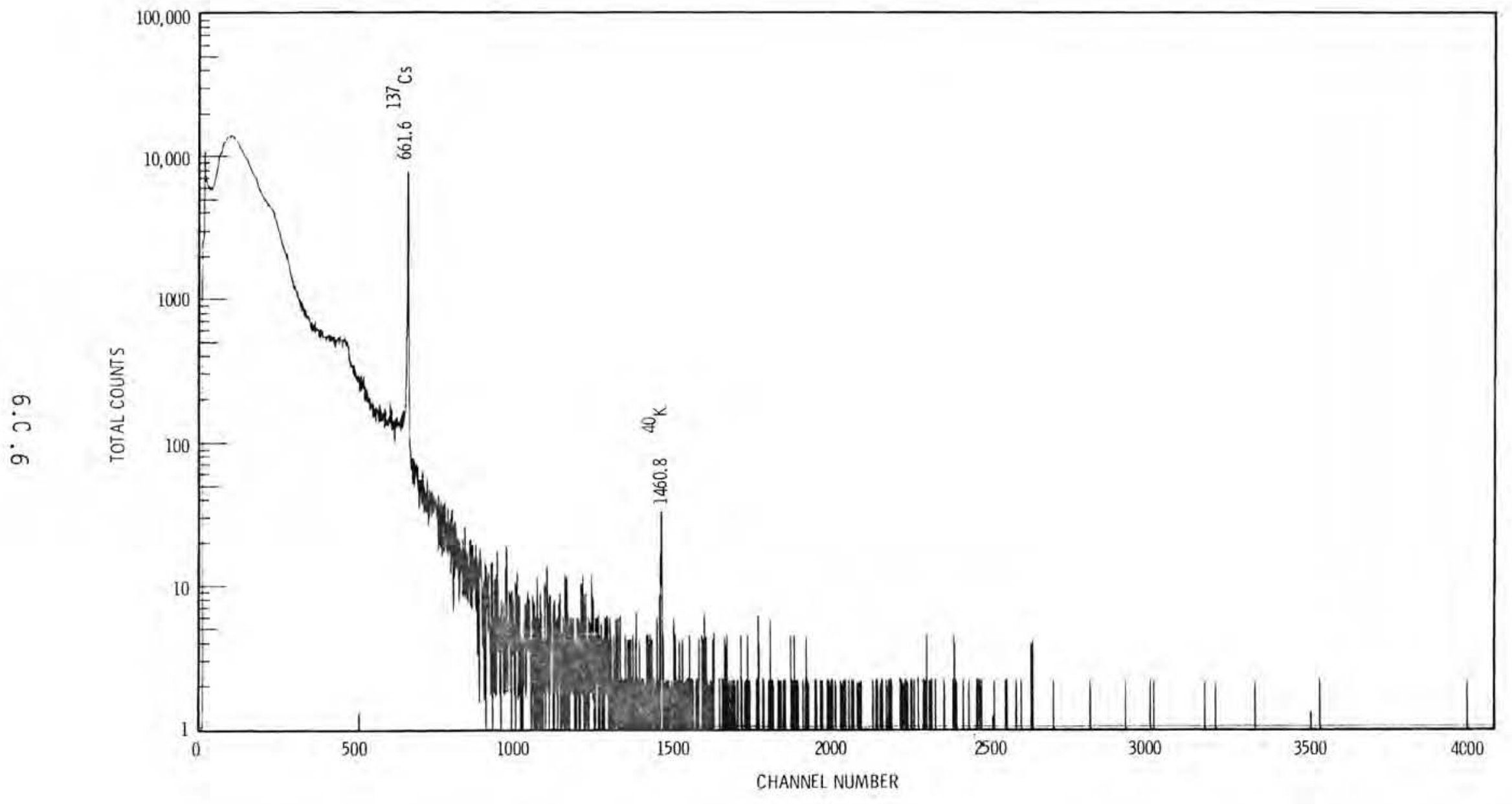

FIGURE 6.C.5. Spectrum Taken at Front Face of F Cell - 225-B Building 
APPENDIX D

200 WEST PLUTONIUM FACILITIES 
APPENDIX D

\section{WEST PLUTONIUM FACILITIES}

BUILDING 234-5

The neutron spectra and dosimeter responses were characterized around plutonium calcine gloveboxes $H-9 A$ and $H C-9 B$ in September, 1980. The data is tabulated in Table 6.0.1 and the instrumentation, dosimeters, and phantom positioning is shown in Figure 6.D.1. Neutron average energies, as determined by the multisphere system, were 390-395 kev. This energy is indicative of slightly moderated $\mathrm{PuO}_{2}$ fission neutrons but yet nearly four to five times lower than unmoderated spontaneous $240_{\mathrm{Pu}}$ fission neutron energies.

Dose equivalent rates, as measured by the multisphere sytem, TEPC, and a portable survey instrument, "SNOOPY", were in relatively close agreement at both locations ranging from \pm 9.5 to $\pm 15.0 \%$. Although $\pm 15 \%$ seems to be quite a large difference between instruments, it is insignificant in view of the very low dose equivalent rates. A difference of 1-3 $\mathrm{mrem} / \mathrm{hr}$ on a field instrument reading is not very significant and the same amount of error can be introduced in the interpretation of complex computer unfolding codes.

The LOUHI-78 spectral unfolding code, used with the multisphere system, produced curves of flux versus energy for each glovebox as shown in Figure 6.0.2. These curves indicate a much larger contribution of neutrons with energies between $10 \mathrm{keV}$ and $1 \mathrm{MeV}$. As mentioned earlier, the shielding on the gloveboxes produces slightly moderated spectra resulting in average neutron energies of $390-395 \mathrm{keV}$. The two data tables generated from the 26 point unfolded spectra are shown in Tables 6.0.2. and 6.0.3.

Two dosimeters were placed on each of two phantoms and then the phantoms were positioned near glovebox $H-9 A$ as shown in Figure 6.0.1. Of these four dosimeters only one dosimeter resulted in a positive response. Its response was considerably lower than the responses of the active measurement devices included in Table 6.D.1. After an energy response correction was applied to the dosimter response, using the energy response curve shown in Figure 6.0.3, the resultant dose equivalent rate was appreciably lower than the instrumentation results.

$$
6.0 .1
$$


TABLE 6.D.1. Neutron Measurements Data from 234-5 and 2736-Z Buildings

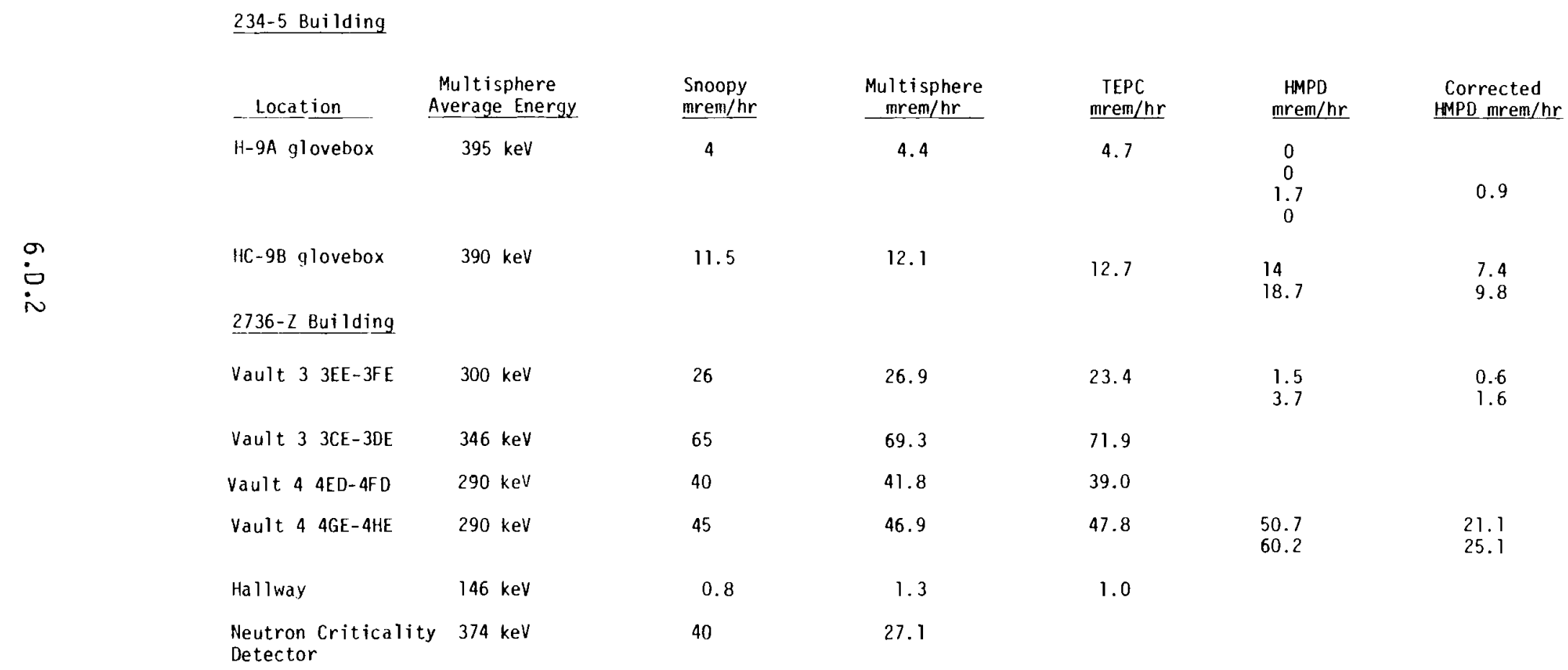



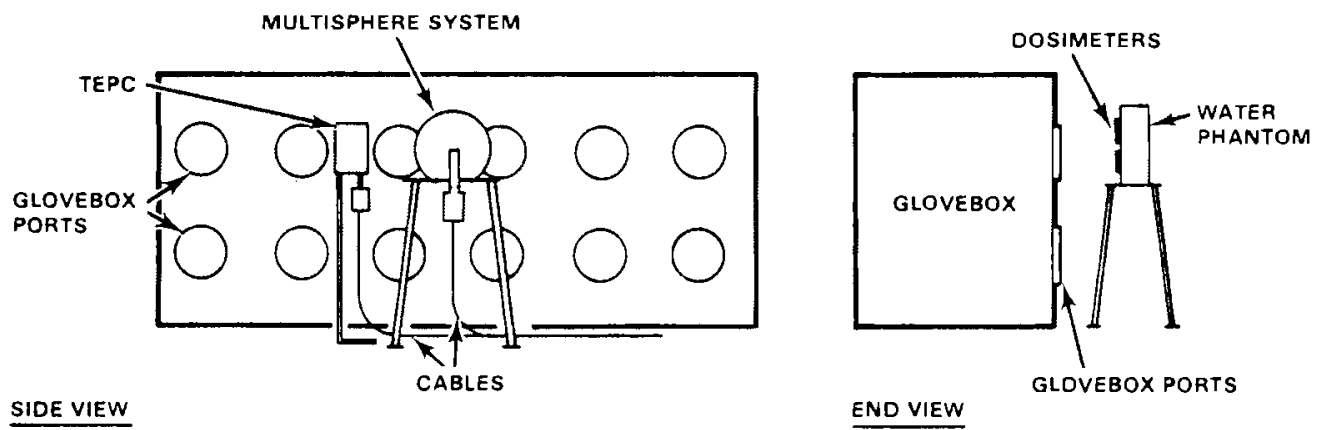

FIGURE 6.D.1. 234-5 Glovebox Neutron Measurements

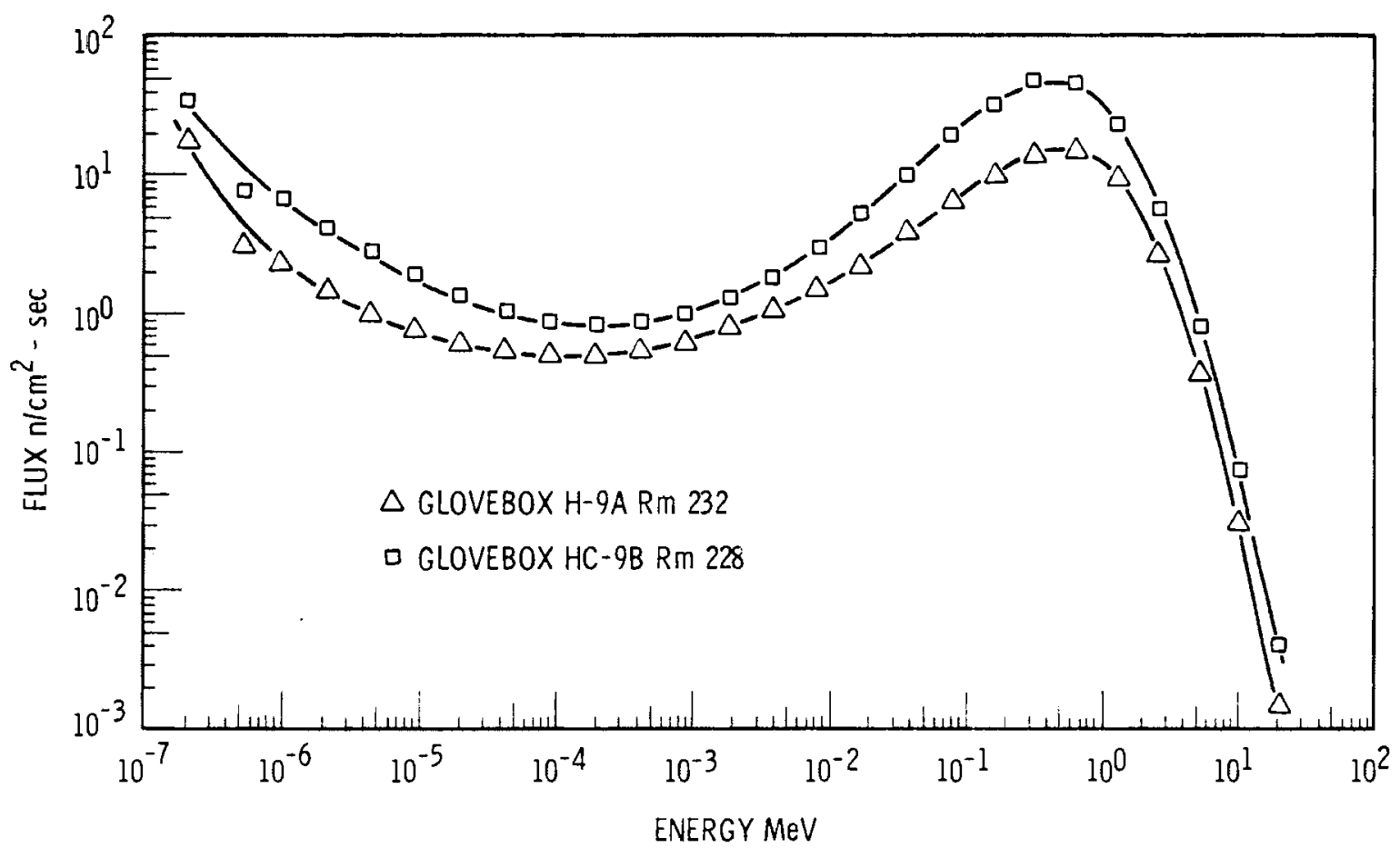

FIGURE 6.0.2. 234-5 Glovebox Spectra Measurements 
TABLE 6.D.2. 234-5 Rm 232-A Glovebox H-9A (9/17/80)

\begin{tabular}{|c|c|c|c|c|c|}
\hline$\frac{E(I)}{M e V}$ & $\frac{\text { DIFFERENTIAL FLUX }}{\left(\mathrm{n} / \mathrm{cm}^{2}-M \mathrm{eV}-\mathrm{s}\right)}$ & INTEGRAL FLUX & $\begin{array}{c}\text { INTEGRAL } \\
\text { DOSE EQUIVALENT }\end{array}$ & $\frac{\text { ENERGY BAND }}{(\mathrm{MeV})}$ & $\frac{F L U X}{\left(n / \mathrm{cm}^{2}-5\right)}$ \\
\hline $\begin{array}{l}2.07 \mathrm{E}-07 \\
5.32 \mathrm{E}-07 \\
9.93 \mathrm{E}-07 \\
2.10 \mathrm{E}-06 \\
4.45 \mathrm{E}-06\end{array}$ & $\begin{array}{l}4.53 E+07 \\
1.16 E+07 \\
3.15 E+06 \\
9.28 E+05 \\
2.99 E+05\end{array}$ & $\begin{array}{l}1.00 \mathrm{E}+00 \\
8.24 \mathrm{E}-01 \\
7.92 \mathrm{E}-01 \\
7.68 \mathrm{E}-01 \\
7.53 \mathrm{E}-01\end{array}$ & $\begin{array}{l}1.00 \mathrm{E}+00 \\
9.83 \mathrm{E}-01 \\
9.80 \mathrm{E}-01 \\
9.77 \mathrm{E}-01 \\
9.76 \mathrm{E}-01\end{array}$ & $\begin{array}{l}3.89 \mathrm{E}-07 \\
2.69 \mathrm{E}-07 \\
7.63 \mathrm{E}-07 \\
1.61 \mathrm{E}-06 \\
3.42 \mathrm{E}-06\end{array}$ & $\begin{array}{l}1.76 E+01 \\
3.12 E+00 \\
2.40 E+00 \\
1.49 E+00 \\
1.02 E+00\end{array}$ \\
\hline $\begin{array}{l}9.42 \mathrm{E}-06 \\
2.00 \mathrm{E}-05 \\
4.22 \mathrm{E}-05 \\
8.94 \mathrm{E}-05 \\
1.89 \mathrm{E}-04\end{array}$ & $\begin{array}{l}1.05 E+05 \\
4.02 E+04 \\
1.66 E+04 \\
7.41 E+03 \\
3.55 E+03\end{array}$ & $\begin{array}{l}7.43 \mathrm{E}-01 \\
7.36 \mathrm{E}-01 \\
7.29 \mathrm{E}-01 \\
7.24 \mathrm{E}-01 \\
7.19 \mathrm{E}-01\end{array}$ & $\begin{array}{l}9.75 \mathrm{E}-01 \\
9.74 \mathrm{E}-01 \\
9.73 \mathrm{E}-01 \\
9.73 \mathrm{E}-01 \\
9.73 \mathrm{E}-01\end{array}$ & $\begin{array}{l}7.22 \mathrm{E}-06 \\
1.53 \mathrm{E}-05 \\
3.23 \mathrm{E}-05 \\
6.89 \mathrm{E}-05 \\
1.45 \mathrm{E}-04\end{array}$ & $\begin{array}{l}7.58 \mathrm{E}-01 \\
6.15 \mathrm{E}-01 \\
5.36 \mathrm{E}-01 \\
5.11 \mathrm{E}-01 \\
5.15 \mathrm{E}-01\end{array}$ \\
\hline $\begin{array}{l}4.04 \mathrm{E}-04 \\
8.55 \mathrm{E}-04 \\
1.80 \mathrm{E}-03 \\
3.80 \mathrm{E}-03 \\
8.05 \mathrm{E}-03\end{array}$ & $\begin{array}{l}1.82 E+03 \\
1.00 E+03 \\
5.89 E+02 \\
3.71 E+02 \\
2.51 E+02\end{array}$ & $\begin{array}{l}7.14 \mathrm{E}-01 \\
7.08 \mathrm{E}-01 \\
7.02 \mathrm{E}-01 \\
6.93 \mathrm{E}-01 \\
6.83 \mathrm{E}-01\end{array}$ & $\begin{array}{l}9.72 \mathrm{E}-01 \\
9.72 \mathrm{E}-01 \\
9.71 \mathrm{E}-01 \\
9.70 \mathrm{E}-01 \\
9.69 \mathrm{E}-01\end{array}$ & $\begin{array}{l}3.18 \mathrm{E}-04 \\
6.40 \mathrm{E}-04 \\
1.38 \mathrm{E}-03 \\
2.91 \mathrm{E}-03 \\
6.20 \mathrm{E}-03\end{array}$ & $\begin{array}{l}5.79 \mathrm{E}-01 \\
6.40 \mathrm{E}-01 \\
8.13 \mathrm{E}-01 \\
1.08 \mathrm{E}+00 \\
1.56 \mathrm{E}+00\end{array}$ \\
\hline $\begin{array}{l}1.70 \mathrm{E}-02 \\
3.61 \mathrm{E}-02 \\
7.64 \mathrm{E}-02 \\
1.58 \mathrm{E}-01 \\
3.18 \mathrm{E}-01\end{array}$ & $\begin{array}{l}1.82 E+02 \\
1.39 E+02 \\
1.12 E+02 \\
8.92 E+01 \\
6.46[+01\end{array}$ & $\begin{array}{l}6.67 \mathrm{E}-01 \\
6.43 \mathrm{E}-01 \\
6.05 \mathrm{E}-01 \\
5.39 \mathrm{E}-01 \\
4.39 \mathrm{E}-01\end{array}$ & $\begin{array}{l}9.68 \mathrm{E}-01 \\
9.65 \mathrm{E}-01 \\
9.57 \mathrm{E}-01 \\
9.31 \mathrm{E}-01 \\
8.63 \mathrm{E}-01\end{array}$ & $\begin{array}{l}1.30 \mathrm{E}-02 \\
2.77 \mathrm{E}-02 \\
5.86 \mathrm{E}-02 \\
1 . \mathrm{i} 3 \mathrm{E}-01 \\
2.27 \mathrm{E}-01\end{array}$ & $\begin{array}{l}2.37 \mathrm{E}+00 \\
3.85 \mathrm{E}+00 \\
6.56 \mathrm{E}+00 \\
1.01 \mathrm{E}+01 \\
1.47 \mathrm{E}+01\end{array}$ \\
\hline $\begin{array}{l}6.40 \mathrm{E}-01 \\
1.29 \mathrm{E}+00 \\
2.59 \mathrm{E}+00 \\
5.22 \mathrm{E}+00 \\
1.05 \mathrm{E}+01 \\
1.96 \mathrm{E}+01\end{array}$ & $\begin{array}{l}3.52 E+01 \\
1.08 E+01 \\
1.49 E+00 \\
9.98 E-02 \\
4.04 E-03 \\
1.27 E-04\end{array}$ & $\begin{array}{l}2.92 \mathrm{E}-01 \\
1.31 \mathrm{E}-01 \\
3.17 \mathrm{E}-02 \\
4.04 \mathrm{E}-03 \\
3.17 \mathrm{E}-04 \\
1.39 \mathrm{E}-05\end{array}$ & $\begin{array}{l}6.96 \mathrm{E}-01 \\
3.87 \mathrm{E}-01 \\
9.80 \mathrm{E}-02 \\
1.31 \mathrm{E}-02 \\
1.09 \mathrm{E}-03 \\
4.98 \mathrm{E}-05\end{array}$ & $\begin{array}{l}4.56 \mathrm{E}-01 \\
9.20 \mathrm{E}-01 \\
1.85 \mathrm{E}+00 \\
3.73 \mathrm{E}+00 \\
7.50 \mathrm{E}+00 \\
1.09 \mathrm{E}+0)\end{array}$ & $\begin{array}{l}1.61 \mathrm{E}+01 \\
9.94 \mathrm{E}+00 \\
2.76 \mathrm{E}+00 \\
3.72 \mathrm{E}-01 \\
3.03 \mathrm{E}-02 \\
1.38 \mathrm{E}-03\end{array}$ \\
\hline
\end{tabular}

TOTAL FLUX $=9.9979 \mathrm{E}+01 \mathrm{n} 1 \mathrm{~cm} \mathrm{~cm}^{2}-5$

DOSE EQUIVALENT RATE $=4.3869 \mathrm{E}+00 \mathrm{mrem} / \mathrm{ar}$ KERMA RATE $=3.5893 \mathrm{E}-02 \mathrm{Erg} / \mathrm{g} / \mathrm{hr}$

ELEMENT 57 DOSE RATE $=5.0591 \mathrm{E}-04 \mathrm{Rad} / \mathrm{hr}$ AVERAGE ENERGY $=3.9498 \mathrm{E}-01 \mathrm{MeV}$ 
TABLE 6.D.3. 234-5 Rm 228 Glovebox HC-9B (9/17/80)

\begin{tabular}{|c|c|c|}
\hline & $\frac{E(I)}{M e V}$ & $\frac{\text { DIFFERFNTIAL FLUXX }}{\left(\mathrm{n} / \mathrm{cm}^{2}-\mathrm{MeV}-\mathrm{s}\right)}$ \\
\hline $\begin{array}{l}1 \\
2 \\
3 \\
4 \\
5\end{array}$ & $\begin{array}{l}2.07 \mathrm{E}-07 \\
5.32 \mathrm{E}-07 \\
9.93 \mathrm{E}-07 \\
2.10 \mathrm{E}-06 \\
4.45 \mathrm{E}-06\end{array}$ & $\begin{array}{l}9.38 E+07 \\
2.84 E+07 \\
8.59 E+06 \\
2.61 E+06 \\
8.10 E+05\end{array}$ \\
\hline $\begin{array}{r}6 \\
7 \\
8 \\
9 \\
10\end{array}$ & $\begin{array}{l}9.42 \mathrm{E}-06 \\
2.00 \mathrm{E}-05 \\
4.22 \mathrm{E}-05 \\
8.94 \mathrm{E}-05 \\
1.89 \mathrm{E}-04\end{array}$ & $\begin{array}{l}2.62 E+05 \\
8.95 E+04 \\
3.29 E+04 \\
1.32 E+04 \\
5.80 E+03\end{array}$ \\
\hline $\begin{array}{l}11 \\
12 \\
13 \\
14 \\
15\end{array}$ & $\begin{array}{l}4.04 \mathrm{E}-04 \\
8.55 \mathrm{E}-04 \\
1.80 \mathrm{E}-03 \\
3.80 \mathrm{E}-03 \\
8.05 \mathrm{E}-03\end{array}$ & $\begin{array}{l}2.84 E+03 \\
1.55 E+03 \\
9.44 E+02 \\
6.44 E+02 \\
4.89 E+02\end{array}$ \\
\hline $\begin{array}{l}16 \\
17 \\
18 \\
19 \\
20\end{array}$ & $\begin{array}{l}1.70 \mathrm{E}-02 \\
3.61 \mathrm{E}-02 \\
7.64 \mathrm{E}-02 \\
1.58 \mathrm{E}-01 \\
3.18 \mathrm{E}-01\end{array}$ & $\begin{array}{l}4.08 E+02 \\
3.66 E+02 \\
3.37 E+02 \\
2.96 E+02 \\
2.14 E+02\end{array}$ \\
\hline $\begin{array}{l}21 \\
22 \\
23 \\
24 \\
25 \\
26\end{array}$ & $\begin{array}{l}\text { 6. } 40 \mathrm{E}-01 \\
1.29 \mathrm{E}+00 \\
2.59 \mathrm{E}+00 \\
5.22 \mathrm{E}+00 \\
1.05 \mathrm{E}+01 \\
1.96 \mathrm{E}+01\end{array}$ & $\begin{array}{l}1.03 E+02 \\
2.60 E+01 \\
3.19 E+00 \\
2.17 E-01 \\
9.89 E-03 \\
3.69 E-04\end{array}$ \\
\hline \multicolumn{3}{|c|}{$\begin{array}{l}\text { TOTAL FLUX }=2.6680 \mathrm{E}+02 \mathrm{n} / \mathrm{cm}^{2}-\mathrm{s} \\
\text { DOSE EQUIVALENT RATE }=1.2126 \mathrm{E}+01 \mathrm{mrem} / \mathrm{hr} \\
\text { KERMA RATE }=1.0056 \mathrm{E}-01 \mathrm{Erg} / \mathrm{g} / \mathrm{hr} \\
\text { ELEMENT } 57 \text { DOSE RATE }=1.3768 \mathrm{E}-03 \mathrm{Rad} / \mathrm{hr} \\
\text { AVERAGE ENERGY }=3.8980 \mathrm{E}-01 \mathrm{MeV}\end{array}$} \\
\hline
\end{tabular}

INTEGRAL FLUX

$1.00 E+00$
$8.63 E-01$
$8.35 E-01$
$8.10 E-01$
$7.94 E-01$
$7.84 E-01$
$7.77 E-01$
$7.72 E-01$
$7.68 E-01$
$7.64 E-01$
$7.61 E-01$
$7.58 E-01$
$7.54 E-01$
$7.49 E-01$
$7.42 E-01$
$7.31 E-01$
$7.11 E-01$
$6.73 E-01$
$5.99 E-01$
$4.74 E-01$
$2.91 E-01$
$1.15 E-01$
$2.55 E-02$
$3.33 E-03$
$2.93 E-04$
$1.51 E-05$

\section{INTEGRAL}

DOSE EQUIVALENT

$1.00 \mathrm{E}+00$
$9.87 \mathrm{E}-01$
$9.84 \mathrm{E}-01$
$9.82 \mathrm{E}-01$
$9.80 \mathrm{E}-01$
$9.79 \mathrm{E}-01$
$9.79 \mathrm{E}-01$
$9.78 \mathrm{E}-01$
$9.78 \mathrm{E}-01$
$9.78 \mathrm{E}-01$
$9.77 \mathrm{E}-01$
$9.77 \mathrm{E}-01$
$9.77 \mathrm{E}-01$
$9.76 \mathrm{E}-01$
$9.76 \mathrm{E}-01$
$9.75 \mathrm{E}-01$
$9.75 \mathrm{E}-01$
$9.64 \mathrm{E}-01$
$9.36 \mathrm{E}-01$
$8.55 \mathrm{E}-01$
$6.55 \mathrm{E}-01$
$3.28 \mathrm{E}-01$
$7.61 \mathrm{E}-02$
$1.05 \mathrm{E}-02$
$9.70 \mathrm{E}-04$
$5.22 \mathrm{E}-05$

$\frac{\text { ENERGY BAND }}{(\mathrm{MeV})}$

2. $69 \mathrm{E}-07$

$7.63 \mathrm{E}-07$

1. $61 \mathrm{E}-06$
$3.42 \mathrm{E}-06$

$7.22 \mathrm{E}-06$

$1.53 \mathrm{E}-05$

3. $23 \mathrm{E}-05$
$6.89 \mathrm{E}-05$

$6.89 E-05$
$1.45 E-04$

$3.18 E-04$

6. $40 E-04$
$1.38 E-03$

1. $38 \mathrm{E}-03$
$2.91 \mathrm{E}-03$

6. $20 E-03$

1. $30 \mathrm{E}-02$

2. $77 \mathrm{E}-02$

5. $86 \mathrm{E}-02$

$1.13 \mathrm{E}-01$

$2.27 \mathrm{E}-01$

4. $56 \mathrm{E}-01$

$9.20 \mathrm{E}-01$

$1.85 \mathrm{E}+00$
$3.73 \mathrm{E}+00$

$3.73 \mathrm{E}+00$

$7.50 \mathrm{E}+00$
$1.09 \mathrm{E}+01$
$\frac{F L U X}{\left(n / c m^{2}-5\right)}$

$3.65 \mathrm{E}+01$

$6.55 E+00$

$6.55 \mathrm{E}+00$
$4.20 \mathrm{E}+00$

$2.77 \mathrm{E}+00$

1. $89 E+00$

$1.37 \mathrm{E}+00$

9.10E-01

$8.41 E-01$

$9.03 \mathrm{E}-01$

9.92E-01

1. $30 \mathrm{E}+00$

$1.87 \mathrm{E}+00$

$3.03 \mathrm{E}+00$

5. $30 \mathrm{E}+00$

$1.01 \mathrm{E}+01$

$1.97 E+01$

3. $34 E+01$

$4.86 \mathrm{E}+0$

4. $70 \mathrm{E}+01$

$2.40 \mathrm{E}+01$

5. $90 \mathrm{E}+00$

$8.09 E-01$

7. $42 \mathrm{E}-02$
$4.02 \mathrm{E}-03$

AVERAGE ENERGY $=3.8980 \mathrm{E}-01 \mathrm{MeV}$ 


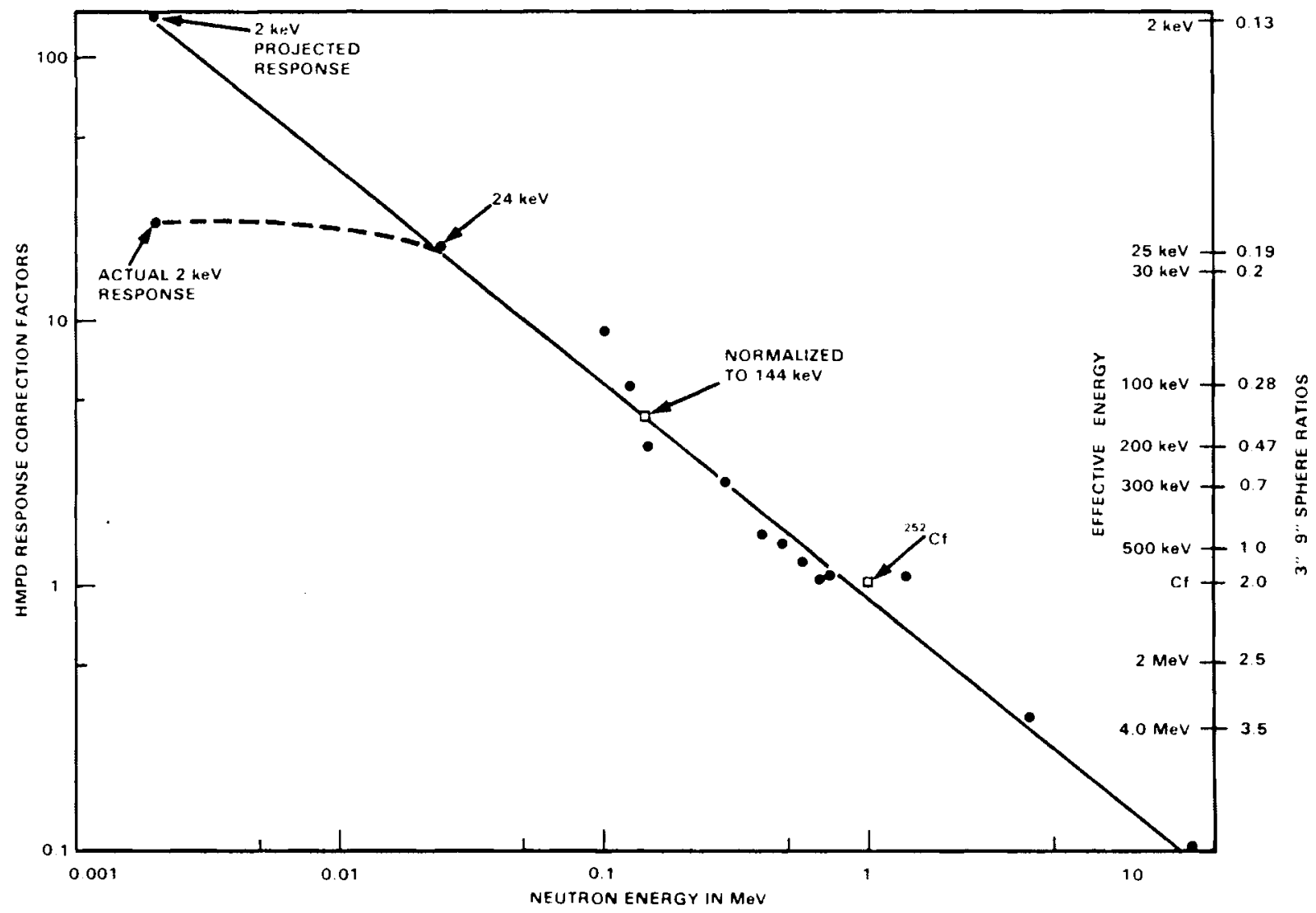

FIGURE 6.D.3. HMPD Energy Response Curve, 3":9" Sphere Ratios, and HMPD Neutron Energy Response Correction Factors

When similar measurements were taken at glovebox $\mathrm{HC}-9 \mathrm{~B}$ the results were in closer agreement. Prior to energy response corrections the two dosimeters used at glovebox $\mathrm{HC}-9 \mathrm{~B}$ indicated a higher dose equivalent rate than the instruments but after energy response corrections they were somewhat lower than the instruments. One of the suspected reasons for differences between dosimeters and instrumentation 1 ies in the very low dose equivalent rates received by the dosimeters. In the case of glovebox H-9A, the dosimeters were only in position for 1 hour. The low dose equivalent rates which were measured are near the lower level of sensitivity of the dosimeters and, as such, the dosimeters will not respond with great accuracy. 
BUILDING 2736-Z

For the six sets of measurements taken in three separate rooms within the $2736-2$ building, the average neutron energy ranged from $146 \mathrm{keV}$ to $374 \mathrm{keV}$, as shown in Table 6.D.1. The lowest energy was found in the main hallway as expected. Average energy levels along the passageways betwen storage cubicles were relatively consistant and ranged from 290 to $346 \mathrm{keV}$. This slight difference in energy is primarily related to the amount of shielding around the cans of $\mathrm{PuO}_{2}$ and secondarily to the age of the material. The highest average energy found in storage vault $3,374 \mathrm{keV}$, was near the ceiling next to the neutron criticality detectors. Although this energy is not as high as that found next to the gloveboxes in 234-5, it is indicative of the increased average energies found from streaming upwards towards the criticality detectors. This lack of shielding produces a more skewed spectrum that is found between the cubicles or at the gloveboxes (see Figure 6.0.4).

As shown in Figure 6.0.4, there are four spectra which are very similar. These spectra represent measurements taken betrween storage cubicles in the middle of each passageway (see Figure 6.D.5). The lower curve in Figure 6.0.4 represents the spectrum outside the vault in the hallway. Shielding provided by the vault walls contributed to the overall lower amplitude. Figure 6.0.6 shows the relative position of the multisphere system to the storage cubicles and neutron criticality detectors. The spectrum in this location, as shown in Figure 6.0.4, has very few low energy neutrons and those neutrons which were detected are essentially between $100 \mathrm{keV}$ and $1 \mathrm{MeV}$. Computed data, derived from the LOUHI-78 unfolding code, for these six measurements are shown in Tables 6.0.4 through 6.D.9.

Dose equivalent rate measurement comparisons between the multisphere system, TEPC, and SNOOPY indicate they were very consistent with each other, as shown in Table 6.D.1. An insignificant discrepancy was observed between the multisphere sytem and SNOOPY at the neutron criticality detector location. At present, the likely explanation for this discrepancy is based on the skewed spectrum. This particular spectrum is more skewed than those plotted in Figure 6.D.2. Even though the average energies are higher at the gloveboxes, their spectra still seefii to indicate a more moderated spectra than the criticality detector spsectrum.

\section{0 .7}




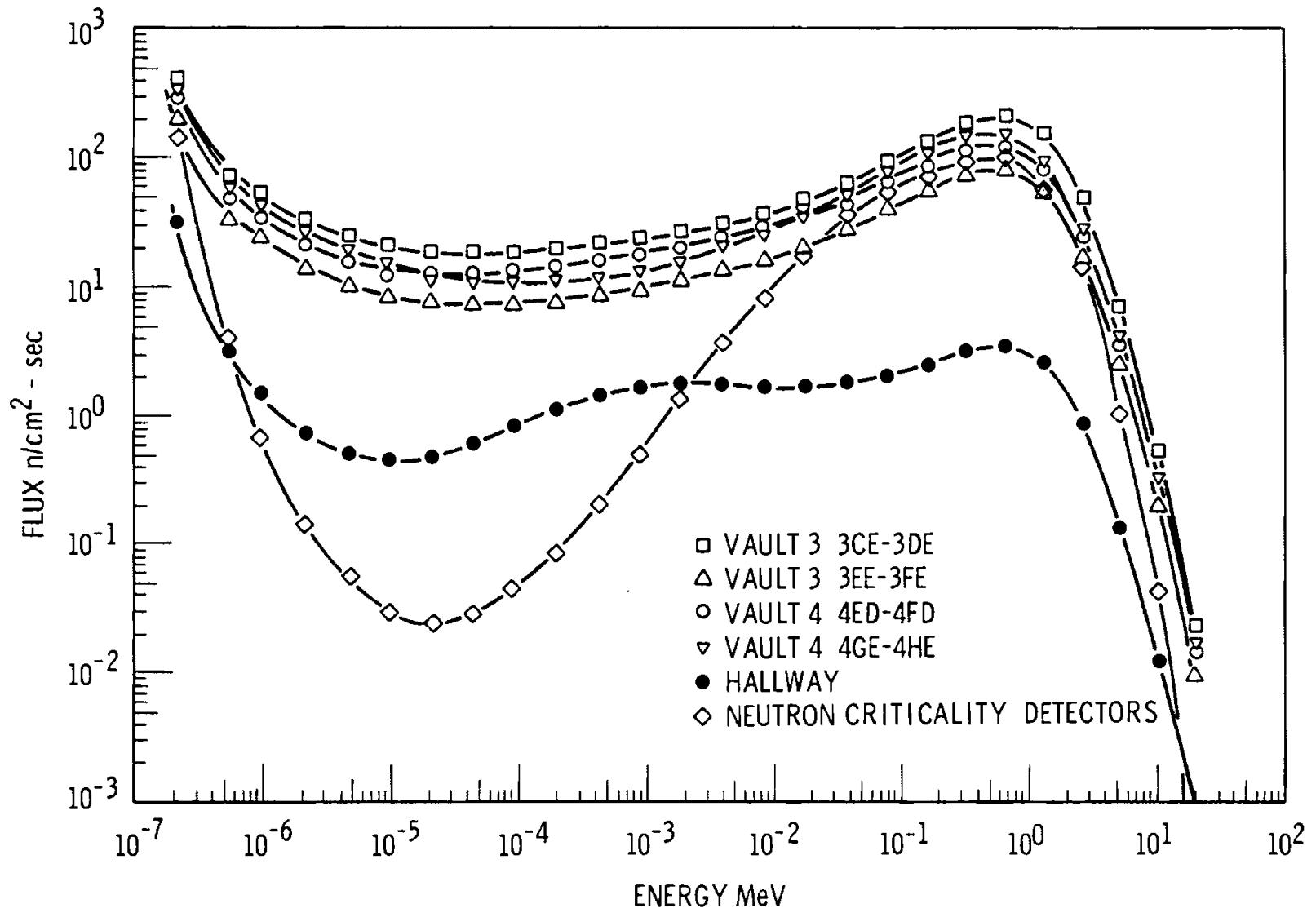

FIGURE 6.0.4 . 2736-Z Building Plutonium Storage Vaults
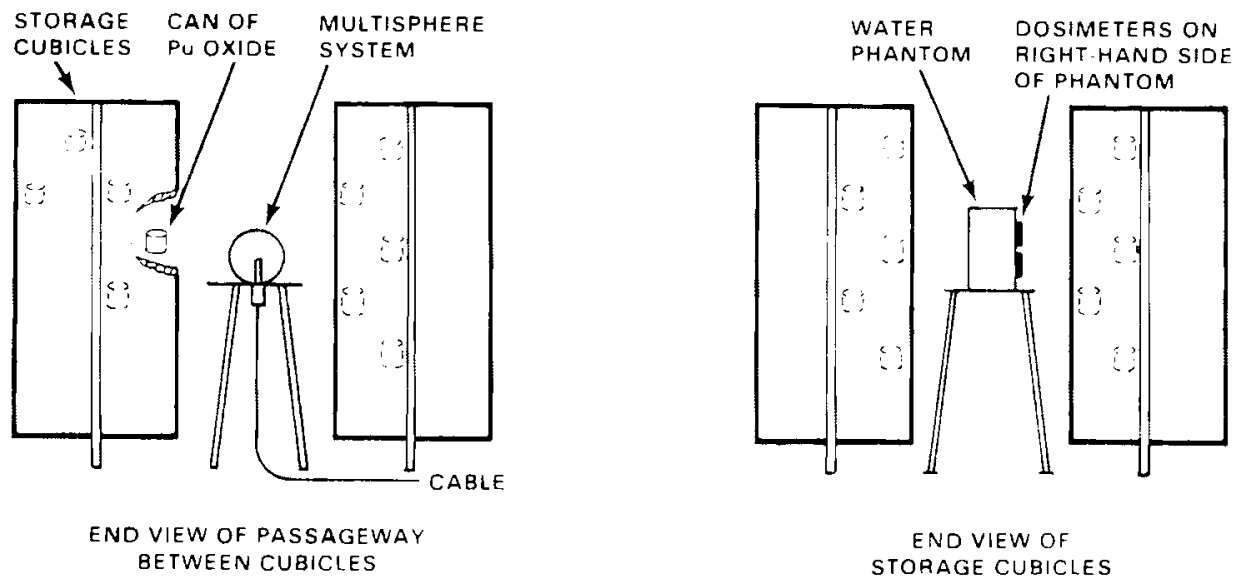

FIGURE 6.0.5. 2736-Z Vault Neutron Measurements 


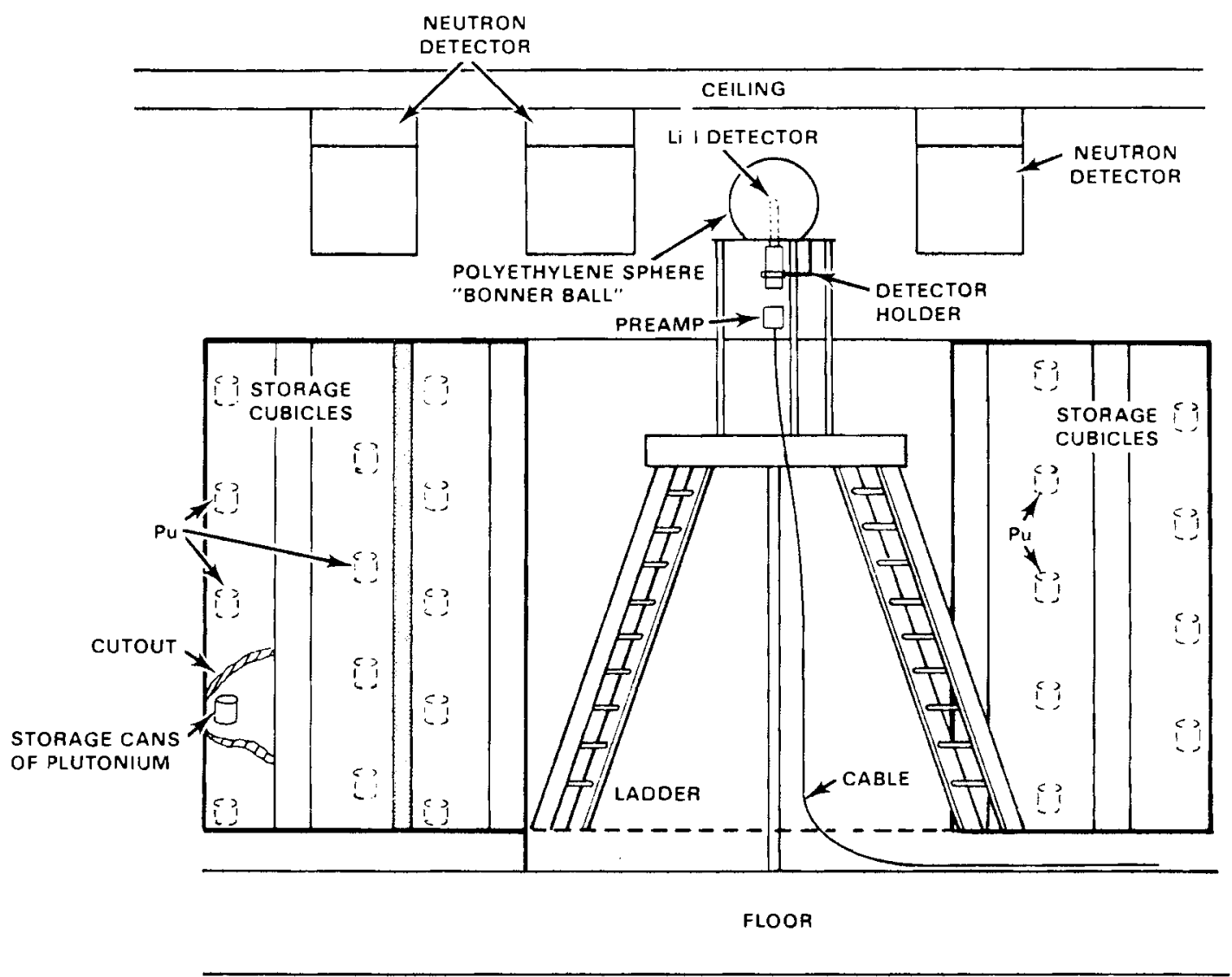

FIGURE 6.D.6. Neutron Criticality Detector Measurement Set-Up 
TABLE 6.0.4. 2736-Z Vault 3 3CE-3DE (9/18/80)

\begin{tabular}{|c|c|c|}
\hline & $\frac{E(I)}{M e V}-$ & $\frac{\text { DIFFERENTIAL FLUX }}{\left(\mathrm{n} / \mathrm{cm}^{2}-1 \mathrm{HeV}-\mathrm{s}\right)}$ \\
\hline $\begin{array}{l}1 \\
2 \\
3 \\
4 \\
5\end{array}$ & $\begin{array}{l}2.07 \mathrm{E}-07 \\
5.32 \mathrm{E}-07 \\
9.93 \mathrm{E}-1) 7 \\
2.10 \mathrm{E}-06 \\
4.45 \mathrm{E}-06\end{array}$ & $\begin{array}{l}1.10 \mathrm{E}+09 \\
2.65 \mathrm{E}+08 \\
7.03 \mathrm{E}+07 \\
2.14 \mathrm{E}+07 \\
7.47 \mathrm{E}+06\end{array}$ \\
\hline $\begin{array}{r}6 \\
7 \\
8 \\
9 \\
10\end{array}$ & $\begin{array}{l}9.42 E-06 \\
2.00 E-05 \\
4.22 E-05 \\
8.94 E-05 \\
1.89 E-04\end{array}$ & $\begin{array}{l}2.93 E+06 \\
1.26 E+06 \\
5.83 E+05 \\
2.82 E+05 \\
1.41 E+05\end{array}$ \\
\hline $\begin{array}{l}11 \\
12 \\
13 \\
14 \\
15\end{array}$ & $\begin{array}{l}4.04 E-04 \\
8.55 E-04 \\
1.80 E-03 \\
3.80 E-03 \\
8.05 E-03\end{array}$ & $\begin{array}{l}7.19 E+04 \\
3.73 E+04 \\
1.98 E+04 \\
1.08 E+04 \\
6.13 E+03\end{array}$ \\
\hline $\begin{array}{l}16 \\
17 \\
18 \\
19 \\
20\end{array}$ & $\begin{array}{l}1.70 \mathrm{E}-02 \\
3.61 \mathrm{E}-02 \\
7.64 \mathrm{E}-02 \\
1.58 \mathrm{E}-01 \\
3.18 \mathrm{E}-01\end{array}$ & $\begin{array}{l}3.69 \mathrm{~L}+03 \\
2.38 \mathrm{E}+03 \\
1.65 \mathrm{E}+03 \\
1.20 \mathrm{E}+03 \\
8.57 \mathrm{E}+02\end{array}$ \\
\hline $\begin{array}{l}21 \\
22 \\
23 \\
24 \\
25 \\
26\end{array}$ & $\begin{array}{l}6.40 E-01 \\
1.29 E+00 \\
2.59 E+00 \\
5.22 E+00 \\
1.05 E+01 \\
1.96 E+01\end{array}$ & $\begin{array}{l}5.09 \mathrm{E}+02 \\
1.84 \mathrm{E}+02 \\
2.87 \mathrm{E}+01 \\
1.96 \mathrm{E}+00 \\
7.48 \mathrm{E}-02 \\
2.12 \mathrm{E}-03\end{array}$ \\
\hline $\begin{array}{l}\text { TO1 } \\
\text { DOS } \\
\text { KEF } \\
\text { ELE } \\
\text { AVE }\end{array}$ & $\begin{array}{l}\text { TTE }=5.54 \\
57 \text { DOSE R } \\
\text { ENERGY = }\end{array}$ & 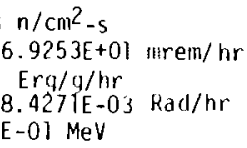 \\
\hline
\end{tabular}

INTEGRAL FLUX

7. $70 \mathrm{E}-01$

7. $03 \mathrm{E}-01$

$6.84 \mathrm{E}-01$

6. $70 \mathrm{E}-01$

6. $49 \mathrm{E}-01$

6. $49 \mathrm{E}-01$

$6.38 \mathrm{E}-01$
$6.28 \mathrm{E}-01$

6. $17 \mathrm{E}-01$

$6.05 \mathrm{E}-01$

5. $92 \mathrm{E}-01$

5. $77 \mathrm{E}-01$

5. $60 \mathrm{E}-01$

$5.40 E-01$

5. $14 E-01$

4. $78 \mathrm{E}-01$

$4.26 \mathrm{E}-01$
$3.54 \mathrm{E}-01$

$2.49 \mathrm{E}-0$

1. $24 \mathrm{E}-01$
3. $29 \mathrm{E}-02$

3. $29 \mathrm{E}-02$

3. $14 \mathrm{E}-04$

$1.25 \mathrm{E}-05$
INTEGRAL

DOSE EQUIVALENT

1. $00 E+00$

$9.74 E-0$

$9.66 E-01$

$9.62 \mathrm{E}-01$

$9.61 \mathrm{E}-01$

$9.59 \mathrm{E}-01$

$9.58 \mathrm{E}-01$

$9.57 \mathrm{E}-01$

9. $56 \mathrm{E}-01$

$9.55 \mathrm{E}-01$

$2.52 \mathrm{E}-0)$

9. $50 \mathrm{E}-0 \mathrm{I}$

9. $48 \mathrm{E}-01$

$9.45 \mathrm{E}-01$
9. $35 \mathrm{E}-01$
$9.11 \mathrm{E}-01$

9. $11 \mathrm{E}-01$

7. $13 E-01$

4. 30E-0I

$1.20 \mathrm{E}-01$

$1.63 \mathrm{E}-02$

1. $27 \mathrm{E}-03$
$5.26 \mathrm{E}-05$ $\frac{\text { ENERGY BAND }}{(\text { MeV })} \quad \frac{\text { FLUX }}{\left(n / \mathrm{Cl:}^{2}-\mathrm{s}\right)}-$

2. $69 \mathrm{E}-0$ ?

1. $61 \mathrm{E}-06$
3. $42 \mathrm{E}-06$

4. $28 \mathrm{E}+02$

5. $36 \mathrm{E}+01$

3. $45 \mathrm{E}+01$

$2.56 \mathrm{E}+01$

$7.22 \mathrm{E}-06$
1. $53 \mathrm{E}-05$

3. $23 \mathrm{E}-05$

$6.89 \mathrm{E}-05$

6. $89 \mathrm{E}-05$
$1.45 \mathrm{E}-04$

2. $12 \mathrm{E}+01$

$1.88 \mathrm{E}+01$

$1.94 E+01$

$2.04 E+01$

3. $18 \mathrm{E}-04$

6. $40 \mathrm{E}-04$

2. $91 E-03$
$6.20 E-03$

1. $30 \mathrm{E}-02$

2. $77 \mathrm{E}-02$

$5.86 \mathrm{E}-02$
$1.13 \mathrm{E}-01$

2. $27 \mathrm{E}-0$

4. $56 \mathrm{E}-01$

$9.20 \mathrm{E}-01$

1. $85 \mathrm{E}+00$

3. $73 \mathrm{E}+00$

7. $50 \mathrm{E}+00$

2. $29 E+01$

2. $39 \mathrm{E}+01$

3. $14 \mathrm{E}+01$

3. $80 \mathrm{E}+01$

4. $80 \mathrm{E}+01$

6. $60 E+01$

1. $36 E+02$

$1.95 \mathrm{E}+02$

2. $32 E+02$

1. $69 \mathrm{E}+02$

5. $31 E+01$

7. $31 \mathrm{E}+00$

$5.61 E-01$

2. 3IE-02 
TABLE 6.D.5. 2736-Z Vault 3 3EE-3FE $(9 / 18 / 80)$

\begin{tabular}{|c|c|c|}
\hline & $\frac{E(I)}{M e V}$ & $\frac{\text { DIFFEREMTIAL FLUX }}{\left(\mathrm{n} / \mathrm{cm}^{2}-\mathrm{k} \mathrm{eV}-\mathrm{s}\right)}$ \\
\hline $\begin{array}{l}1 \\
2 \\
3 \\
4 \\
5\end{array}$ & $\begin{array}{l}2.07 \mathrm{E}-07 \\
5.32 \mathrm{E}-07 \\
9.93 \mathrm{E}-07 \\
2.10 \mathrm{E}-06 \\
4.45 \mathrm{E}-06\end{array}$ & $\begin{array}{l}5.47 \mathrm{E}+08 \\
1.26 \mathrm{E}+08 \\
3.19 \mathrm{E}+07 \\
9.38 \mathrm{E}+06 \\
3.18 \mathrm{E}+06\end{array}$ \\
\hline $\begin{array}{r}6 \\
7 \\
8 \\
9 \\
10\end{array}$ & $\begin{array}{l}9.42 \mathrm{E}-06 \\
2.00 \mathrm{E}-05 \\
4.22 \mathrm{E}-05 \\
8.94 \mathrm{E}-05 \\
1.89 \mathrm{E}-04\end{array}$ & $\begin{array}{l}1.22 \mathrm{E}+06 \\
5.20 \mathrm{E}+35 \\
2.39 \mathrm{E}+05 \\
1.16 \mathrm{E}+05 \\
5.85 \mathrm{E}+04\end{array}$ \\
\hline $\begin{array}{l}11 \\
12 \\
13 \\
14 \\
15\end{array}$ & $\begin{array}{l}4.04 \mathrm{E}-04 \\
8.55 \mathrm{E}-04 \\
1.80 \mathrm{E}-03 \\
3.80 \mathrm{E}-03 \\
8.05 \mathrm{E}-03\end{array}$ & $\begin{array}{l}3.02 \mathrm{E}+04 \\
1.60 \mathrm{E}+04 \\
8.60 \mathrm{E}+03 \\
4.77 \mathrm{E}+03 \\
2.75 \mathrm{E}+03\end{array}$ \\
\hline $\begin{array}{l}16 \\
17 \\
18 \\
19 \\
20\end{array}$ & $\begin{array}{l}1.70 \mathrm{E}-02 \\
3.61 \mathrm{E}-02 \\
7.64 \mathrm{E}-02 \\
1.58 \mathrm{E}-01 \\
3.18 \mathrm{E}-01\end{array}$ & $\begin{array}{l}1.66 \mathrm{E}+03 \\
1.07 \mathrm{E}+03 \\
7.29 \mathrm{E}+02 \\
5.16 \mathrm{E}+02 \\
3.52 \mathrm{E}+02\end{array}$ \\
\hline $\begin{array}{l}21 \\
22 \\
23 \\
24 \\
25 \\
26\end{array}$ & $\begin{array}{l}6.40 E-01 \\
1.29 E+00 \\
2.59 E+00 \\
5.22 E+00 \\
1.05 E+01 \\
1.96 E+01\end{array}$ & $\begin{array}{l}1.97 \mathrm{E}+02 \\
6.71 \mathrm{E}+01 \\
1.03 \mathrm{E}+01 \\
7.16 \mathrm{E}-01 \\
2.87 \mathrm{E}-02 \\
8.74 \mathrm{E}-04\end{array}$ \\
\hline
\end{tabular}

INTEGRAL FLUX

$1.00 E+00$
$7.36 \mathrm{E}-01$
$6.94 \mathrm{E}-01$
$6.64 \mathrm{E}-01$
$6.45 \mathrm{E}-01$
$6.32 \mathrm{E}-01$
$6.21 \mathrm{E}-01$
$6.11 \mathrm{E}-01$
$6.01 \mathrm{E}-01$
$5.92 \mathrm{E}-01$
$5.81 \mathrm{E}-01$
$5.69 \mathrm{E}-01$
$5.56 \mathrm{E}-01$
$5.42 \mathrm{E}-01$
$5.24 \mathrm{E}-01$

$5.03 \mathrm{E}-01$
$4.76 \mathrm{E}-01$
$4.40 \mathrm{E}-01$
$3.87 \mathrm{E}-01$
$3.15 \mathrm{E}-01$

$2.15 \mathrm{E}-01$
$1.04 \mathrm{E}-01$
$2.72 \mathrm{E}-02$
$3.59 \mathrm{E}-03$
$2.79 \mathrm{E}-04$
$1.18 \mathrm{E}-05$

INTEGRAL

DOSE EQUIVALENT

$\begin{array}{cc}\frac{\text { ENERGY BAND }}{(M \mathrm{MeV})} & \frac{\text { FLUX }}{\left(1 / \mathrm{cm} \mathbf{2}^{2}-\mathrm{s}\right)} \\ 3.89 \mathrm{E}-07 & \\ 2.69 \mathrm{E}-07 & 3.13 \mathrm{E}+02 \\ 7.63 \mathrm{E}-07 & 2.49 \mathrm{E}+01 \\ 1.61 \mathrm{E}-06 & 1.51 \mathrm{E}+01 \\ 3.42 \mathrm{E}-06 & 1.09 \mathrm{E}+01 \\ 7.22 \mathrm{E}-06 & 8.81 \mathrm{E}+00 \\ 1.53 \mathrm{E}-05 & 7.96 \mathrm{E}+00 \\ 3.23 \mathrm{E}-05 & 7.72 \mathrm{E}+00 \\ 6.89 \mathrm{E}-05 & 7.99 \mathrm{E}+00 \\ 1.45 \mathrm{E}-04 & 8.48 \mathrm{E}+00 \\ & \\ 3.18 \mathrm{E}-04 & 9.60 \mathrm{E}+00 \\ 6.40 \mathrm{E}-04 & 1.02 \mathrm{E}+01 \\ 1.38 \mathrm{E}-03 & 1.19 \mathrm{E}+01 \\ 2.91 \mathrm{E}-03 & 1.39 \mathrm{E}+01 \\ 6.20 \mathrm{E}-03 & 1.71 \mathrm{E}+01 \\ & \\ 1.30 \mathrm{E}-02 & 2.16 \mathrm{E}+01 \\ 2.77 \mathrm{E}-02 & 2.96 \mathrm{E}+01 \\ 5.86 \mathrm{E}-02 & 4.27 \mathrm{E}+01 \\ 1.13 \mathrm{E}-01 & 5.83 \mathrm{E}+01 \\ 2.27 \mathrm{E}-01 & 7.99 \mathrm{E}+01 \\ & \\ 4.56 \mathrm{E}-01 & 8.98 \mathrm{E}+01 \\ 9.20 \mathrm{E}-01 & 6.17 \mathrm{E}+01 \\ 1.85 \mathrm{E}+00 & 1.91 \mathrm{E}+01 \\ 3.73 \mathrm{E}+00 & 2.67 \mathrm{E}+00 \\ 7.50 \mathrm{E}+00 & 2.15 \mathrm{E}-01 \\ 1.09 \mathrm{E}+01 & 9.53 \mathrm{E}-03\end{array}$

DOSE EQUIVALENT RATE $=2.6948 \mathrm{E}+01 \mathrm{mrem} / \mathrm{hr}$

KERMA RATE $=2.1467 \mathrm{E}-01 \mathrm{Era} / \mathrm{g} / \mathrm{hr}$

ELEMENT 57 DOSE RATE $=3.3884 \mathrm{E}-03 \mathrm{Rad} / \mathrm{hr}$

$1.00 \mathrm{E}+00$
$9.67 \mathrm{E}-01$
$9.61 \mathrm{E}-01$
$9.57 \mathrm{E}-01$
$9.54 \mathrm{E}-01$
$9.53 \mathrm{E}-01$
$9.51 \mathrm{E}-01$
$9.50 \mathrm{E}-01$
$9.49 \mathrm{E}-01$
$9.48 \mathrm{E}-01$
$9.46 \mathrm{E}-01$
$9.45 \mathrm{E}-01$
$9.44 \mathrm{E}-01$
$9.42 \mathrm{E}-01$
$9.40 \mathrm{E}-01$
$9.38 \mathrm{E}-01$
$9.33 \mathrm{E}-01$
$9.23 \mathrm{E}-01$
$8.95 \mathrm{E}-01$
$8.32 \mathrm{E}-01$

$6.84 \mathrm{E}-01$
$4.02 \mathrm{E}-01$
$1.10 \mathrm{E}-01$
$1.53 \mathrm{E}-02$
$1.26 \mathrm{E}-03$
$5.57 \mathrm{E}-05$

2. $13 \mathrm{E}+02$

$-39 \mathrm{E}+01$
$.43 \mathrm{E}+01$

. $09 \mathrm{E}+01$

$81 \mathrm{~B}+00$

$72 \mathrm{E}+00$

$48 \mathrm{E}+00$

$02 \mathrm{E}+01$

$19 \mathrm{E}+0$

$71 E+0$

$27 \mathrm{E}+0$

$.99 \mathrm{E}+01$ 
TABLE 6.D.6. 2736-Z Vault 3 3ED-3FD (9/18/80)

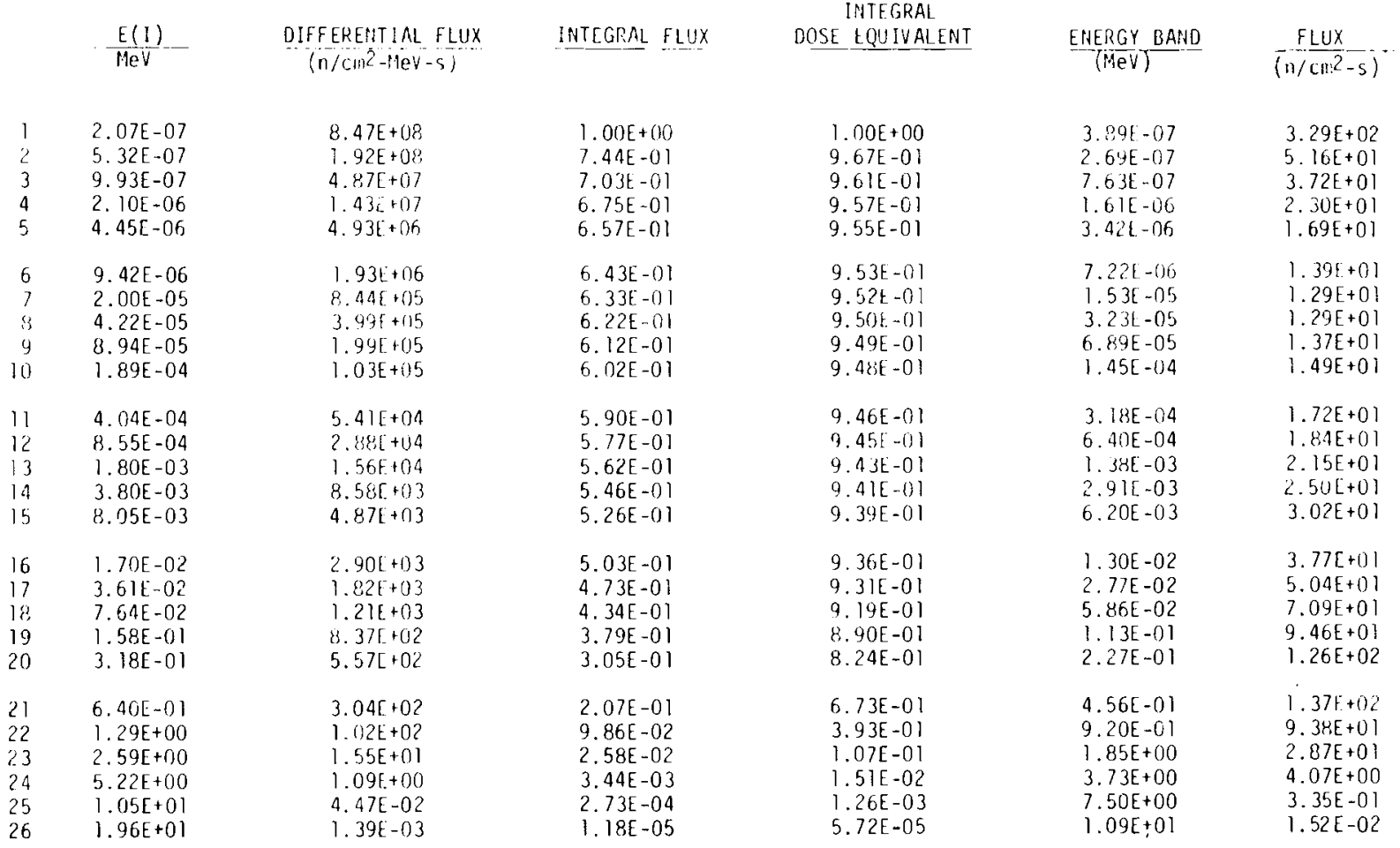

TOTAL FLUX $=1.2944 \mathrm{E}+03 \mathrm{n} / \mathrm{cm}^{2}-\mathrm{s}$

DOSE EQUIVALENT RATE $=4.1816 \mathrm{E}+01 \mathrm{~m} 1 \mathrm{rem} / \mathrm{hr}$ KERMA RATE $=3.3359 \mathrm{E}-01 \mathrm{Erq} / \mathrm{o} / \mathrm{hr}$

ELEMENT 57 DOSE RATE $=5.2957 \mathrm{E}-03 \mathrm{Rad} / \mathrm{hr}$

AVERAGE ENERGY $=2.8958 \mathrm{E}-01 \mathrm{MeV}$ 
TABLE 6.0.7. 2736-Z Vault 4 3GE-3HE (9/18/80)

\begin{tabular}{|c|c|c|c|}
\hline & $E(I)$ & DIFFERENT IAL FLUX & INTEGRAL FLU \\
\hline & $\mathrm{MeV}$ & $\left(\mathrm{n} / \mathrm{cm}^{2}-M e V-s\right)$ & \\
\hline 1 & $2.07 E-07$ & $9.05 E+08$ & $1.00 E+00$ \\
\hline 2 & $5.32 E-07$ & $2.19 \mathrm{E}+08$ & $7.48 \mathrm{E}-01$ \\
\hline 3 & $9.93 \mathrm{E}-07$ & $5.75 \mathrm{E}+07$ & 7.05E-01 \\
\hline 4 & $2.10 E-06$ & $1.69 E+07$ & $6.74 E-01$ \\
\hline 5 & $4.45 E-06$ & $5.59 E+06$ & $6.54 \mathrm{E}-01$ \\
\hline 6 & 9. $42 \mathrm{E}-06$ & $2.05 E+06$ & $6.41 E-01$ \\
\hline 7 & $2.00 E-05$ & $8.25 \mathrm{E}+05$ & $6.30 \mathrm{E}-01$ \\
\hline 8 & $4.22 \mathrm{E}-05$ & $3.57 \mathrm{E}+05$ & $6.21 E-01$ \\
\hline 9 & $8.94 \mathrm{E}-05$ & $1.64 E+05$ & $6.13 E-01$ \\
\hline 10 & $1.89 \mathrm{E}-04$ & $7.95 E+04$ & $6.05 \mathrm{E}-01$ \\
\hline ון & $4.04 E-04$ & $4.04[+04$ & $5.96 \mathrm{E}-0 \mathrm{I}$ \\
\hline 12 & $8.55 \mathrm{E}-04$ & 2. $14 E+04$ & $5.87 E-01$ \\
\hline 13 & $1.80 \mathrm{E}-03$ & $1.19 E+04$ & $5.77 \mathrm{E}-01$ \\
\hline 14 & $3.80 \mathrm{E}-03$ & $6.98 E+03$ & $5.66 \mathrm{E}-01$ \\
\hline 15 & $8.05 E-03$ & 4. $31 E+03$ & $5.51 E-01$ \\
\hline 16 & $1.70 \mathrm{E}-02$ & $2.82 E+03$ & 5. $32 \mathrm{E}-01$ \\
\hline 17 & $3.61 \mathrm{E}-02$ & $1.96 \mathrm{E}+03$ & $5.06 \mathrm{E}-01$ \\
\hline 18 & 7.64E-02 & 1. $42 E+03$ & $4.67 \mathrm{E}-01$ \\
\hline 19 & $1.58 \mathrm{E}-01$ & $1.04 E+03$ & $4.07 \mathrm{E}-01$ \\
\hline 20 & 3. $18 \mathrm{E}-01$ & $6.95 \mathrm{E}+02$ & $3.23 \mathrm{E}-01$ \\
\hline 21 & $6.40 E-01$ & $3.58 \mathrm{E}+02$ & $2.10 E-01$ \\
\hline 22 & $1.29 E+00$ & 1. $07 \mathrm{E}+02$ & $9.34 \mathrm{E}-02$ \\
\hline 23 & $2.59 E+00$ & 1. $50 \mathrm{E}+01$. & $2.29 \mathrm{E}-02$ \\
\hline 24 & $5.22 \mathrm{E}+00$ & $1.05 E+00$ & $3.05[-03$ \\
\hline 25 & $1.05 E+01$ & 4. $52 \mathrm{E}-02$ & $2.55 E-04$ \\
\hline 26 & $1.96 \mathrm{E}+01$ & $1.53 \mathrm{E}-03$ & $1.20 \mathrm{E}-05$ \\
\hline
\end{tabular}

INTEGRAL

DOSE EQUIVALENT

$1.00 \mathrm{E}+00$
$9.68 \mathrm{E}-01$

$9.68 \mathrm{E}-01$
$9.63 \mathrm{E}-01$
$9.58 \mathrm{E}-01$

$9.58 \mathrm{E}-01$

$9.56 \mathrm{E}-01$

9. $54 \mathrm{E}-01$

$9.53 \mathrm{E}-01$
$9.52 \mathrm{E}-01$

$9.52 \mathrm{E}-01$
$9.51 \mathrm{E}-01$

$9.50 \mathrm{E}-01$

$9.49 \mathrm{E}-01$

9. $48 \mathrm{E}-01$

$9.46 \mathrm{E}-0 \mathrm{~T}$

$9.44 \mathrm{E}-01$

9. $41 \mathrm{E}-01$

9. $37 \mathrm{E}-01$
$9.26 \mathrm{E}-01$

$8.95 \mathrm{E}-01$

6. $54 \mathrm{E}-01$

$9.26 \mathrm{E}-02$

$1.30 \mathrm{E}-02$

1. $14 \mathrm{E}-03$
$5.62 \mathrm{E}-05$ $\frac{\text { ENERGY BAND }}{(\mathrm{MeV})} \quad \frac{\text { FLUX }}{\left(\mathrm{n} / \mathrm{cm}^{2}-5\right)}$

3. $89 \mathrm{E}-07$

2. $69 \mathrm{E}-07$
7. $63 \mathrm{E}-07$

$1.61 \mathrm{E}-06$

$3.42 \mathrm{E}-06$
7.06

7. $22 \mathrm{E}-06$

1. $53 \mathrm{E}-05$

3. $23 \mathrm{E}-05$

$6.89 \mathrm{E}-05$

$1.45 \mathrm{E}-04$

3. $18 \mathrm{E}-04$

6. $40 \mathrm{E}-04$

$1.38 \mathrm{E}-03$

2.91E-03

1. $30 \mathrm{E}-02$

2. $30 \mathrm{E}-02$
2. $77 \mathrm{E}-02$

$1.13 \mathrm{E}-01$

$2.27 \mathrm{E}-01$

4. $56 \mathrm{E}-01$
$4.20 \mathrm{E}-01$

1. $85 \mathrm{E}+00$

$3.73 \mathrm{E}+00$

7. $50 \mathrm{E}+00$

$1.09 \mathrm{E}+01$
$3.52 \mathrm{E}+02$

5. $89 \mathrm{E}+01$

2. $72 \mathrm{E}+01$

1. $91 \mathrm{E}+01$

1. $48 \mathrm{E}+01$

1. $26 \mathrm{E}+01$

$1.15 \mathrm{E}+01$

1. $13 \mathrm{E}+01$

1. $15 \mathrm{E}+01$

1. $28 \mathrm{E}+01$

1. $37 \mathrm{E}+01$

$1.64 \mathrm{E}+01$

$2.03 \mathrm{E}+01$

$3.67 E+01$

5. $43 \mathrm{E}+01$

1. $18 \mathrm{E}+02$

1. $58 \mathrm{E}+02$

$1.63 \mathrm{E}+02$

$9.84 E+01$

$2.77 \mathrm{E}+01$

3. $92 \mathrm{E}+00$
3. $39 \mathrm{E}-01$

1. $67 \mathrm{E}-02$

TOTAL FLUX $=1.3953 E+03 \mathrm{n} / \mathrm{cm}^{2}-\mathrm{s}$

DOSE EQUIVALENT RATE $=4.6863 \mathrm{E}+01 \mathrm{mrem} / \mathrm{hr}$

KERIAA RATE $=3.7655 \mathrm{E}-01 \mathrm{Erg} / \mathrm{g} / \mathrm{hr}$

ELEMENT 57 DOSE RATE $=5.8604 \mathrm{E}-03 \mathrm{Rad} / \mathrm{hr}$

AVERAGE ENERGY $=2.9010 \mathrm{E}-01 \mathrm{MEV}$ 
TABLE 6.0.8. 2736-Z Hallway by Air Sampler (9/18/80)

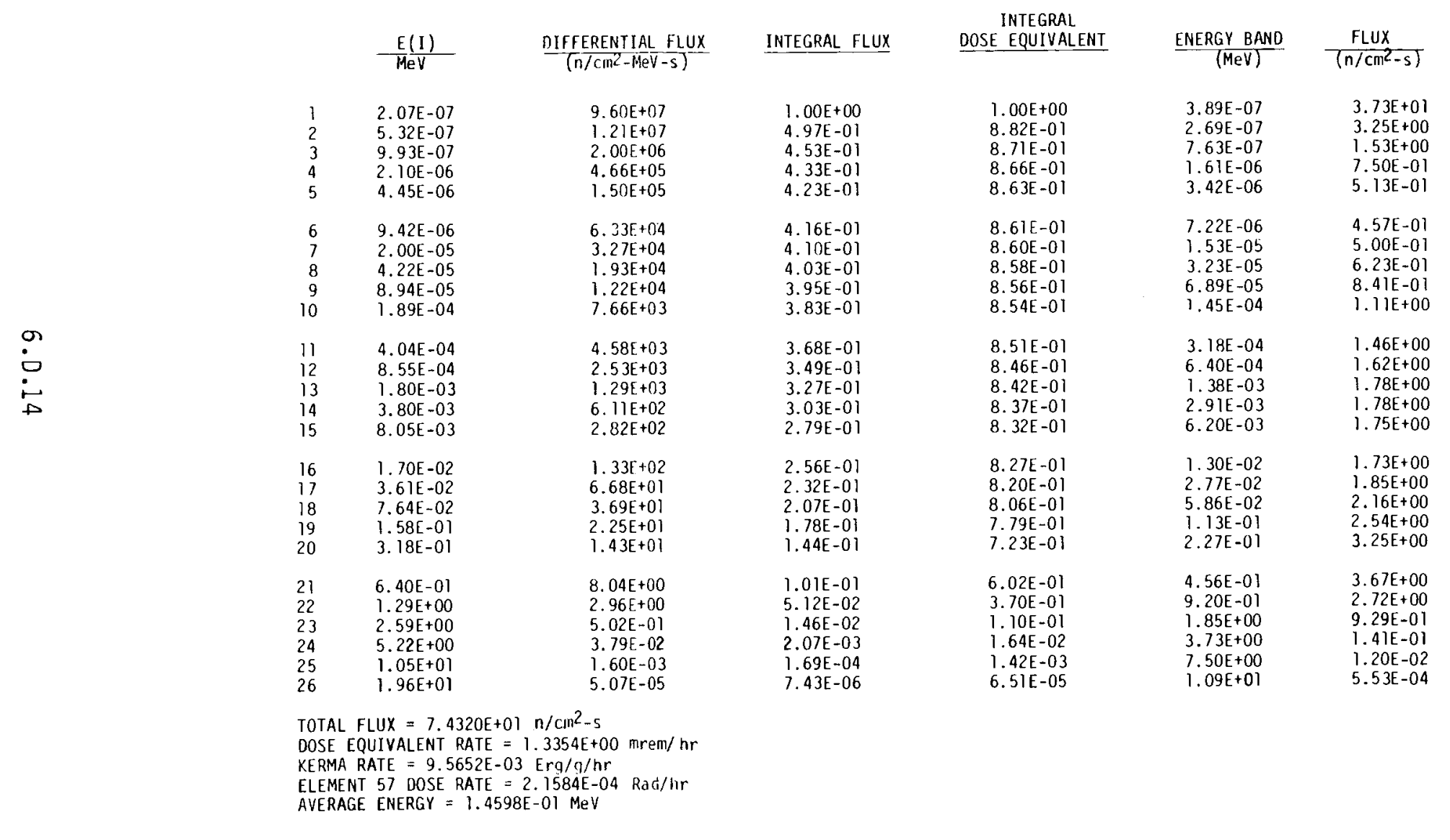


TABLE 6.0.9. Neutron Criticality Detector Spectrum Measurement

\begin{tabular}{|c|c|c|c|c|c|c|c|}
\hline & & $\frac{\mathrm{E}(\mathrm{I})}{\mathrm{MeV}}$ & 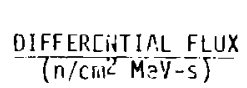 & INTEGRAL FLUX & $\begin{array}{c}\text { INTEGRAL } \\
\text { DOSE EQUIVALENT }\end{array}$ & $\frac{\text { ENERGY BAND }}{\text { (MeV) }}$ & $\frac{\text { FLUX }}{\left(\mathrm{n} / \mathrm{cm}^{2}-5\right)}$ \\
\hline & $\begin{array}{l}1 \\
2 \\
3 \\
4 \\
5\end{array}$ & $\begin{array}{l}2.07 \mathrm{E}-07 \\
5.32 \mathrm{E}-07 \\
9.93 \mathrm{E}-07 \\
2.10 \mathrm{E}-06 \\
4.45 \mathrm{E}-06\end{array}$ & $\begin{array}{l}3.76 \mathrm{E}+08 \\
1.45 \mathrm{E}+07 \\
8.94 \mathrm{E}+05 \\
9.26 \mathrm{E}+04 \\
1.57 \mathrm{E}+04\end{array}$ & $\begin{array}{l}1.00 \mathrm{E}+00 \\
7.64 \mathrm{E}-01 \\
7.57 \mathrm{E}-01 \\
7.56 \mathrm{E}-01 \\
7.56 \mathrm{E}-01\end{array}$ & $\begin{array}{l}1.00 \mathrm{E}+00 \\
9.77 \mathrm{E}-01 \\
9.77 \mathrm{E}-01 \\
9.76 \mathrm{E}-01 \\
9.76 \mathrm{E}-01\end{array}$ & $\begin{array}{l}3.89 \mathrm{E}-07 \\
2.69 \mathrm{E}-07 \\
7.63 \mathrm{E}-07 \\
1.61 \mathrm{E}-06 \\
3.42 \mathrm{E}-06\end{array}$ & $\begin{array}{l}1.46 \mathrm{E}+02 \\
3.90 \mathrm{E}+00 \\
6.82 \mathrm{E}-01 \\
1.49 \mathrm{E}-01 \\
5.37 \mathrm{E}-02\end{array}$ \\
\hline & $\begin{array}{r}6 \\
7 \\
8 \\
9 \\
10\end{array}$ & $\begin{array}{l}\text { 9. } 42 \mathrm{E}-06 \\
2.00 \mathrm{E}-05 \\
4.22 \mathrm{E}-05 \\
8.94 \mathrm{E}-05 \\
1.89 \mathrm{E}-04\end{array}$ & $\begin{array}{l}4.13 \mathrm{E}+03 \\
1.61 \mathrm{E}+03 \\
8.83 \mathrm{E}+02 \\
6.42 \mathrm{E}+02 \\
5.85 \mathrm{E}+02\end{array}$ & $\begin{array}{l}7.56 \mathrm{E}-01 \\
7.56 \mathrm{E}-01 \\
7.56 \mathrm{E}-01 \\
7.56 \mathrm{E}-01 \\
7.56 \mathrm{E}-01\end{array}$ & $\begin{array}{l}9.76 \mathrm{E}-01 \\
9.76 \mathrm{E}-01 \\
9.76 \mathrm{E}-01 \\
9.76 \mathrm{E}-01 \\
9.76 \mathrm{E}-01\end{array}$ & $\begin{array}{l}7.22 \mathrm{E}-06 \\
1.53 \mathrm{E}-05 \\
3.23 \mathrm{E}-05 \\
6.89 \mathrm{E}-05 \\
1.45 \mathrm{E}-04\end{array}$ & $\begin{array}{l}2.98 \mathrm{E}-02 \\
2.46 \mathrm{E}-02 \\
2.85 \mathrm{E}-02 \\
4.42 \mathrm{E}-02 \\
8.48 \mathrm{E}-02\end{array}$ \\
\hline $\begin{array}{l}\dot{\sigma} \\
\dot{G}\end{array}$ & $\begin{array}{l}11 \\
12 \\
13 \\
14 \\
15\end{array}$ & $\begin{array}{l}4.04 \mathrm{E}-04 \\
8.55 \mathrm{E}-04 \\
1.80 \mathrm{E}-03 \\
3.80 \mathrm{E}-03 \\
8.05 \mathrm{E}-03\end{array}$ & $\begin{array}{l}6.34 E+02 \\
7.68 E+02 \\
9.80 E+02 \\
1.24 E+03 \\
1.47 E+03\end{array}$ & $\begin{array}{l}7.55 \mathrm{E}-01 \\
7.55 \mathrm{E}-01 \\
7.54 \mathrm{E}-01 \\
7.52 \mathrm{E}-01 \\
7.46 \mathrm{E}-01\end{array}$ & $\begin{array}{l}9.76 \mathrm{E}-01 \\
9.76 \mathrm{E}-01 \\
9.76 \mathrm{E}-01 \\
9.76 \mathrm{E}-01 \\
9.76 \mathrm{E}-01\end{array}$ & $\begin{array}{l}3.18 E-04 \\
6.40 E-04 \\
1.38 E-03 \\
2.91 E-03 \\
6.20 E-03\end{array}$ & $\begin{array}{l}2.02 E-01 \\
4.92 E-01 \\
1.35 E+00 \\
3.61 E+00 \\
9.11 E+00\end{array}$ \\
\hline & $\begin{array}{l}16 \\
17 \\
18 \\
19 \\
20\end{array}$ & $\begin{array}{l}1.70 \mathrm{E}-02 \\
3.61 \mathrm{E}-02 \\
7.64 \mathrm{E}-02 \\
1.58 \mathrm{E}-01 \\
3.18 \mathrm{E}-01\end{array}$ & $\begin{array}{l}1.52 \mathrm{E}+03 \\
1.33 \mathrm{E}+03 \\
9.80 \mathrm{E}+02 \\
6.35 \mathrm{E}+02 \\
3.94 \mathrm{E}+02\end{array}$ & $\begin{array}{l}7.32 \mathrm{E}-01 \\
7.00 \mathrm{E}-01 \\
6.40 \mathrm{E}-01 \\
5.47 \mathrm{E}-01 \\
4.32 \mathrm{E}-01\end{array}$ & $\begin{array}{l}9.74 \mathrm{E}-01 \\
9.70 \mathrm{E}-01 \\
9.57 \mathrm{E}-01 \\
9.21 \mathrm{E}-01 \\
8.43 \mathrm{E}-01\end{array}$ & $\begin{array}{l}1.30 \mathrm{E}-02 \\
2.77 \mathrm{E}-02 \\
5.86 \mathrm{E}-02 \\
1.13 \mathrm{E}-01 \\
2.27 \mathrm{E}-01\end{array}$ & $\begin{array}{l}1.98 E+01 \\
3.68 E+01 \\
5.74 E+01 \\
7.18 E+01 \\
8.94 E+01\end{array}$ \\
\hline & $\begin{array}{l}21 \\
22 \\
23 \\
24 \\
25 \\
26\end{array}$ & $\begin{array}{l}6.40 E-01 \\
1.29 E+00 \\
2.59 E+00 \\
5.22 E+00 \\
1.05 E+01 \\
1.96 E+01\end{array}$ & $\begin{array}{l}2.20 \mathrm{E}+02 \\
6.82 \mathrm{E}+01 \\
7.25 \mathrm{E}+00 \\
2.83 \mathrm{E}-01 \\
5.55 \mathrm{E}-03 \\
7.73 \mathrm{E}-05\end{array}$ & $\begin{array}{l}2.87 \mathrm{E}-01 \\
1.25 \mathrm{E}-01 \\
2.35 \mathrm{E}-02 \\
1.77 \mathrm{E}-03 \\
6.87 \mathrm{E}-05 \\
1.36 \mathrm{E}-06\end{array}$ & $\begin{array}{l}6.79 \mathrm{E}-01 \\
3.67 \mathrm{E}-01 \\
7.23 \mathrm{E}-02 \\
5.75 \mathrm{E}-03 \\
2.35 \mathrm{E}-04 \\
4.89 \mathrm{E}-06\end{array}$ & $\begin{array}{l}4.56 E-01 \\
9.20 E-01 \\
1.85 E+00 \\
3.73 E+00 \\
7.50 E+00 \\
1.09 E+01\end{array}$ & $\begin{array}{l}1.00 E+02 \\
6.27 E+01 \\
1.34 E+01 \\
1.06 E+00 \\
4.16 E-02 \\
8.43 E-04\end{array}$ \\
\hline & $\begin{array}{l}\text { TOT } \\
\text { DOS } \\
\text { KER } \\
\text { ELE } \\
\text { AVE }\end{array}$ & $\begin{array}{l}\text { LUX }=6.18 \\
\text { UIVALENT } \\
\text { ATE }=2.23 \\
57 \text { DOSE } \\
\text { ENERGY }=\end{array}$ & $\begin{array}{l}\mathrm{n} / \mathrm{cm}^{2}-\mathrm{s} \\
.7146 \mathrm{E}+01 \mathrm{mrem} / \mathrm{hr} \\
\mathrm{Erg} / \mathrm{g} / \mathrm{hr} \\
.0959 \mathrm{E}-03 \mathrm{RaC} / \mathrm{hr} \\
-01 \mathrm{MeV}\end{array}$ & & & & \\
\hline
\end{tabular}


Two dosimeters mounted on water phantoms were exposed in each of storage vaults 3 and 4 . In evaluating the dosimeter results, it is important to note the positioning of the phantom and the dosimeters on the phantom (see Figure 6.D.5). In both vaults 3 and 4 , the dosimeters were placed on the right hand side of the phantom, as if an individual were facing a storage cubicle. In vault 3 , the HMPD response was 1.5 and $3.7 \mathrm{mrem} / \mathrm{hr}$. After energy response corrections this dose equivalent rate was reduced on 0.6 and 1.6 , respectively. This appears very low when compared to instrument readings. It has to be kept in mind that all three active measurement devices have a multi-directional response whereas the dosimeter is primarily a uni-directional device and requires a water phantom for the neutron albedo response function to work properly. In effect, the observed HMPD response in vault 3 was caused by the significant exposure coming from the cubicles behind the water phantom. This is an important consideration when interpreting personnel exposure. An indiviaul may recieve a significant exposure from the back of their torso which is underestimated by the HMPD.

In vault 4 , the same phenomena was observed with regards to dosimeter responses being lower than the active measurements. Before energy response corrections were made the dosimeter's response was 50.7 and $60.2 \mathrm{mrem} / \mathrm{hr}$ which was slightly higher than measurements made with active devices. After energy response corrections the dosimeters response was roughly half the active measurements, being 21.1 and 25.1 , respectively. These data reaffirm the uni-directional response of the HMPD. In this case, the exposure was roughly equal from each cubicle both in front and in the rear of the phantom. Each HMPD measured the exposure received on the side of the phantom or, in this case, about one-half the total exposure actually received.

In these particular locations, vaults 3 and 4 , dosimetry interpretation is further complicated by angular sensitivity of the HMPD. Even though the position dependence or angular response is dealt with in Study 5 of this report, Figure 6.0.7 shows why it is important. Looking at human torso $B$ in Figure 6.0.7, there is both a direct exposure from the Pu cans on the cart and a much larger $90^{\circ}$ exposure from Pu cans in storage. Torso A, in Figure 6.D.7, 


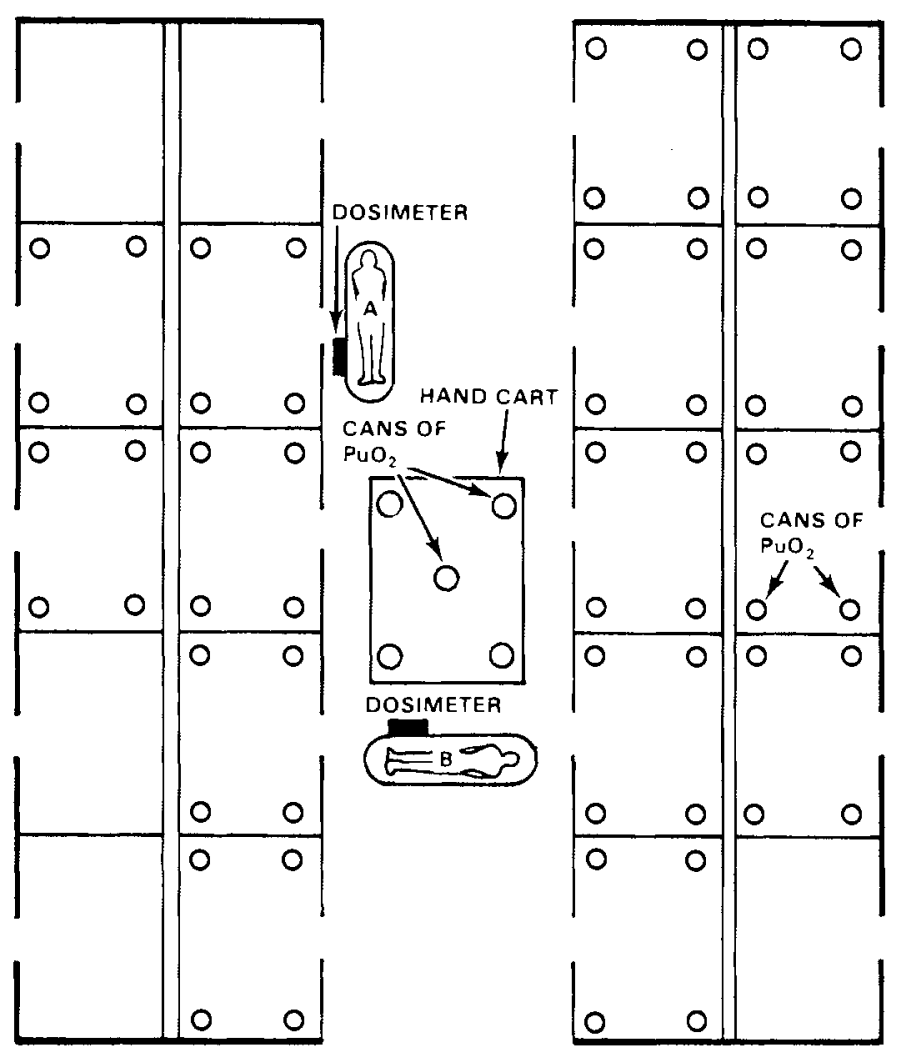

TOP VIEW

FIGURE 6.D.7. Normal Operation for Inventoring and Placement of $\mathrm{PuO}_{2}$ into the Storage Cubicles

receives primarily direct exposure but also receives an exposure from $\mathrm{Pu}$ at various angular relationships to the dosimeter. Dosimeters on both torsos $\mathrm{A}$ and $B$ miss neutron exposure from the rear.

Figure 6.D.7 illustrates the need for further investigation of dosimeter responses with different contributions of exposures from several angles at energies below $500 \mathrm{keV}$. Also, a more detailed phantom-dosimeter response study in the cubicle passageways is needed to verify the phantom shadowing effects shown in Table 6.D.1 for vaults 3 and 4 . 



\subsection{STUDY 5 - PHANTOM POSITION DEPENDENCE}

M. R. Thorson and G.W.R. Endres

\section{FOREWORD}

Sensitivity of the Hanford dosimeter response to its position relative to the phantom and the neutron source has always been recognized. A thorough investigation was performed to quantify dosimeter response according to

a) dosimeter position on phantom,

b) dosimeter distance from phantom, and

c) angular relationship of dosimeter relative to neutron source and phantom. Results were obtained for neutron irradiation at several different energies.

SUMMARY

Dependence of HMPD response upon dosimeter angle relative to the phantom and dosimeter position on the phantom adds considerably to the dosimeter inaccuracy and low precision in fast neutron fields. Angular and positional dependence cause the dosimeter to underrespond to fast neutrons by as much as $50 \%$ of a given dose equivalent. Other conclusions which can be drawn are as follows

1. Positional dependence is a function of the amount of neutron moderating material immediately behind chips 3 and 4 .

2. Positional dependence decreases considerably at high (10 MeV) neutron energies (at $100 \mathrm{keV}$ it is $45 \%$ greater than at $10 \mathrm{MeV}$ ).

3. Positional dependence of the dosimeter to ${ }^{252} \mathrm{Cf}$ can be quantified as having a multiplicative standard deviation equal to $3 \%$ of TLD chip 3 's reading and $8 \%$ of TLD chip 4 's reading.

4. Attaching a thin moderator to the back of the dosimeter considerably decreases its positional dependence. 
5. There is a depression in HMPO calculated fast neutron dose equivalent over the lungs. Values over the lungs are about $30 \%$ lower than values in the center chest region. (These values were determined on the Rando phantom.)

6. Sensitivity to fast neutrons decreases $55 \%$ when the dosimeter is at an angle of $45^{\circ}$ relative to the front plane of the phantom.

\section{INTRODUCTION}

Interest in the performance of the Hanford multipurpose dosimeter (HMPD) in field exposures involving neutron radiation has increased considerably in the past few years. The possibility that quality factors may be increased for fast neutrons and that the HMPD may be used for field exposures not considered in its initial design are two of the principle reasons for this interest. Since it was shown in previous years that the positioning of the dosimeter affected its response, we decided it was important to evaluate the dosimeter's positional dependence for several energies of neutrons.

The dosimetry technology staff at Pacific Northwest Laboratory (PNL) tested the dosimeter's response to neutrons ranging from 0.025 ev to $16 \mathrm{MeV}$ in energy. These tests were performed on a Rando phantom and were accomplished by numerous exposures with dosimeters placed at various positions in the chest region of the phantom. Also dosimeters were exposed at various angles and distances relative to the phantom.

\section{RECOMMENDATIONS}

The major recommendation which can be made from this study is that as long as an albedo dosimeter such as the HMPD is used to measure fast neutron dose equivalent, an attempt should be made to standardize the moderator behind the dosimeter. This could be accomplished by attachaing a thin, perhaps 1/4-inch, moderator to the back of the dosimeter and having the dosimeter attached flat against the body in a standardized wearing position. 
CONCEPT OF POSITIONAL DEPENDENCE, ANGLE DEPENDENCE

AND DISTANCE DEPENDENCE OF NEUTRON RESPONSES

Positional dependence, as described in this report, is the dependence of HMPD response upon the physical part of the phantom or person to which it is attached. This should be contrasted to angular dependence, which is the dependence of HMPD response upon the angle between the plane of the dosimeter and the plane of the phantom, and distance dependence, which is the dependence of the HMPD response upon the distance between the dosimeter and the phantom. In this study, only dependence to neutron irradiations--primarily fast neutron irradiations--were examined.

POSITIONAL DEPENDENCE TO A ${ }^{252}$ Cf SPECTRUM

Bare Californium-252 was used as the primary source of fast neutrons because it was readily available and was the standard fast neutron source used in calibrating the dosimeters. Its average neutron energy is $2.3 \mathrm{MeV}$. The spectrum, as shown in Appendix $A$, is a smooth spectrum with a median energy of $0.8 \mathrm{MeV}$.

To measure the positional dependence, the five chip HMPD with two TLD chips behind each filter was used. The five chip dosimeter was used in preference to the standard four chip dosimeter in order to better describe neutron dependence without confusing it with problems from inadequate gamma correction of the four chip dosimeter.

The phantoms used were the water jug and the Rando phantom. The water jug phantom is elliptical in horizontal cross section (11-5/8 inch $\times 7-7 / 8$ inch), 15-3/4 inches high, and filled with tapwater. The Rando phantom is a composite of low- and high-density polyethyelene and bone, shaped into the figure of a man. It is approximately equivalent to a "standard man" missing only legs and arms. The Rando phantom is shown in Figure 7.1 . 


\section{Evidence for Positional Dependence}

The initial evidence for positional dependence came from comparing the HMPD response when placed around the Rando phantom to that when placed around a water jug phantom. For this comparison, dosimeters were attached in a horizontal ring around the thorax region of the Rando phantom, as shown in Figures 7.1a and 7.1b. Similarly, dosimeters were attached in a ring around the water jug phantom. Each phantom was then separately exposed to ${ }^{252} \mathrm{Cf}$, one meter directly in front of the phantom. Several days after the exposures, each dosimeter was read out. From this, the fast neutron dose was calculated and is shown in Figures 7.2 and 7.3 .

Figures 7.2 shows response of dosimeters placed around the water jug phantom. These responses were corrected for distance from the source, so they are $a 11$ relative to one meter. The given dose equivalent was $1000 \mathrm{mrem}$ at the front of the phantom. Note that the thermoluminescence of TLD chips 3 and $4^{(a)}$ changes gradually from the front, at $0^{\circ}$, to the back, at $180^{\circ}$. As a result, the calculated fast neutron dose changes gradually from front to back.

In contrast, Figure 7.3 shows the HMPD response when dosimeters were placed in a horizontal ring around the Rando phantom chest and simultaneously exposed to ${ }^{252} \mathrm{Cf}$. The exposure was identical to that on the water jug. Note that the thermoluminescence of TLD chips 3 and 4 changes more abruptly from the front to the back than on the water jug. As a result, the calculated fast neutron dose changes more abruptly from front to back.

Fluctuations in calculated fast neutron dose in both Figure 7.2 and 7.3 resulted from dependence upon position of the dosimeter on the phantom, angle of the dosimeter relative to the incident radiation and shielding effect of the phantom on dosimeters between 90 and $180^{\circ}$. The physical setup was nearly identical for both exposures, and the cross sectional shape of the water jug phantom was a close approximation of that of the Rando phantom chest. Both

(a) For the 252 cf neutron dose equivalent calculations, the dose equivalent was approximately proportional to (2R4-R3); therefore, the thermoluminescent readings of chip $4(R 4)$ and the readings of chip 3 (R3) were the only important parameters in determining fast neutron dose. 


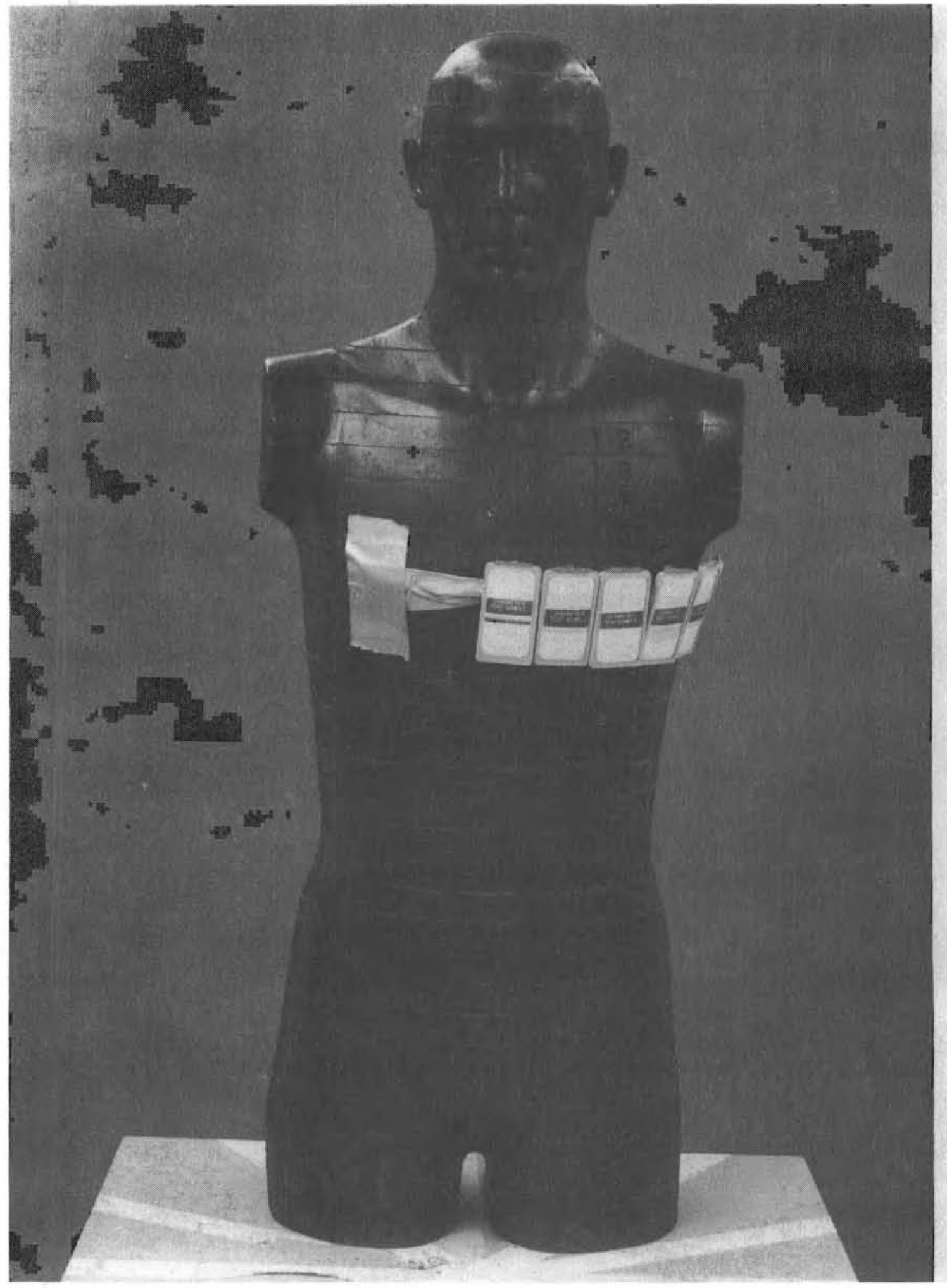

FIGURE 7.1a. Rando Phantom with Dosimeter Placement Around ThoraxAnterior 


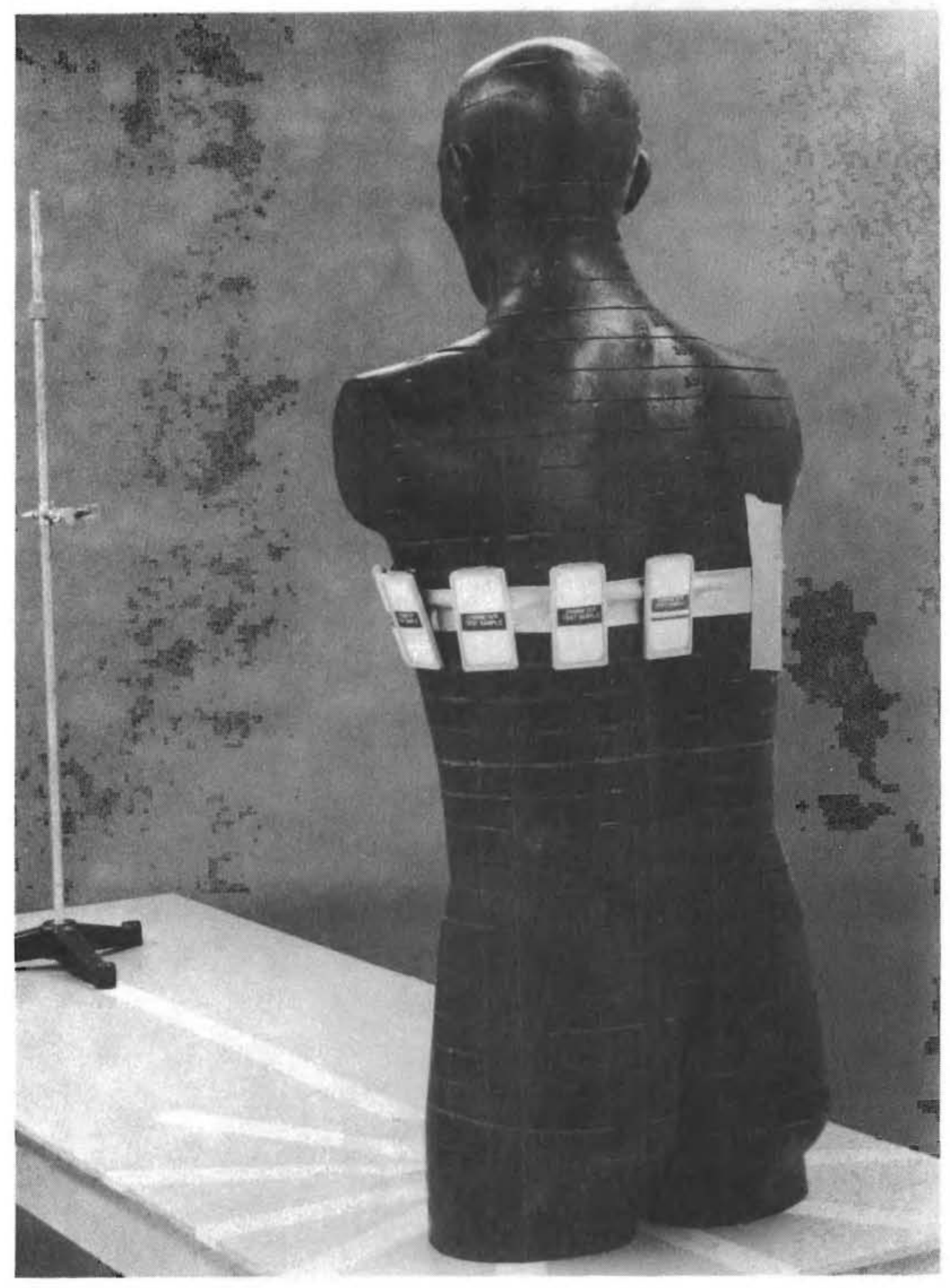

FIGURE 7.1D. Rando Phantom with Dosimeter Placement Around ThoraxPosterior 


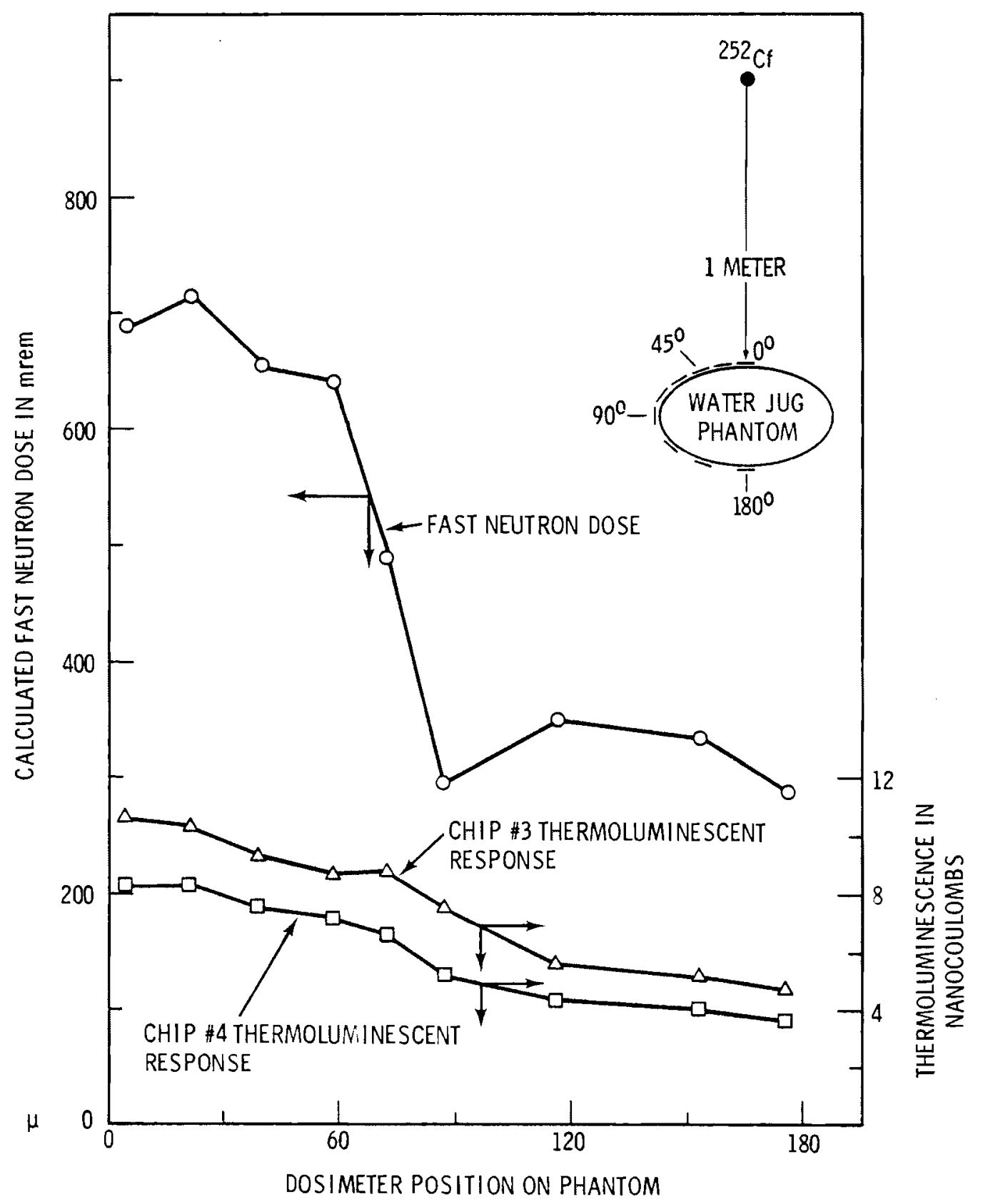

FIGURE 7.2. HMPD Response with Position on the Water Jug Phantom (Dose received is 1000 mrem at front of phantom. All values are corrected to one meter from source.) 


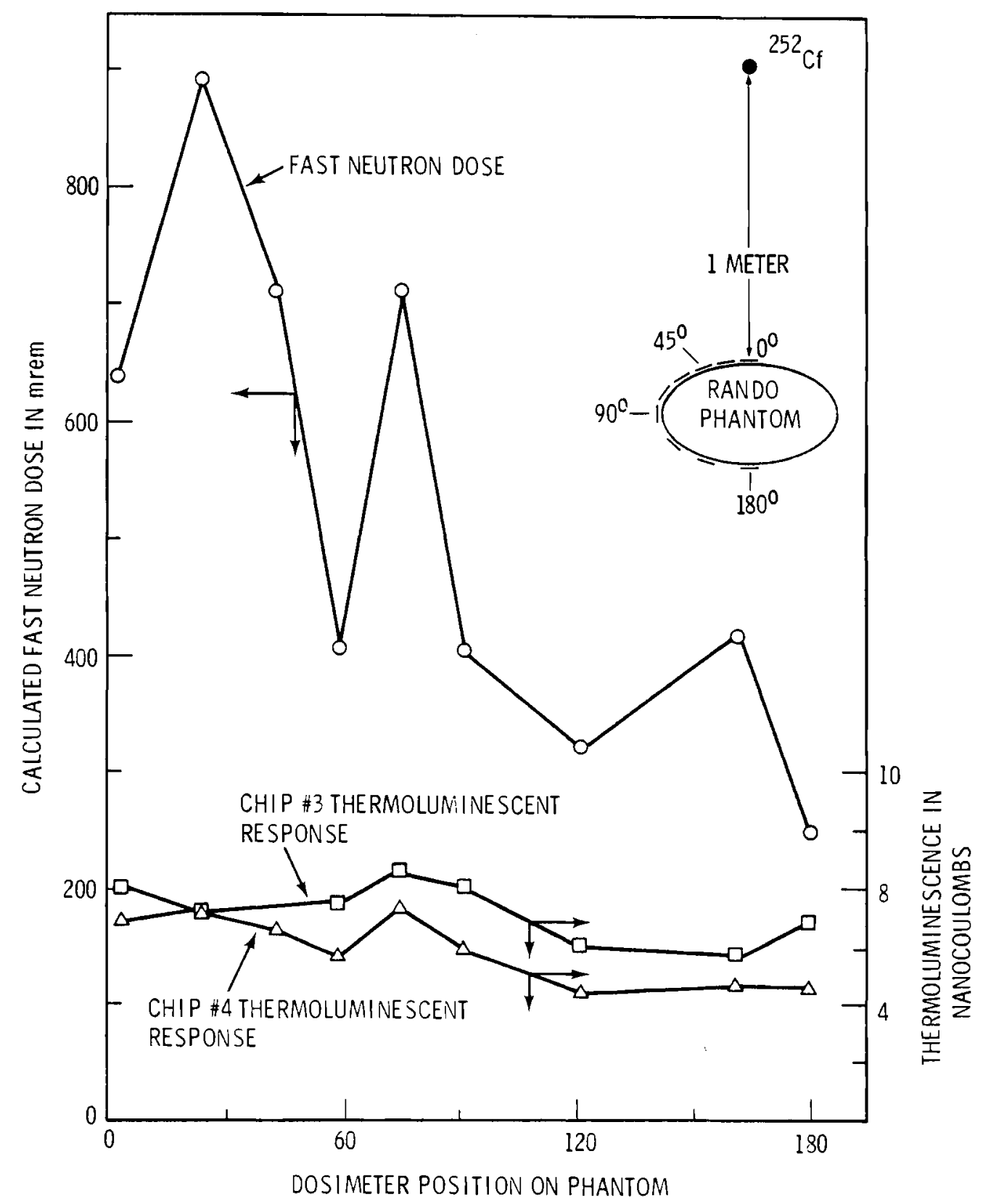

FIGURE 7.3. HMPD Response with Position on the Rando Phantom. (Dose received is $1000 \mathrm{mrem}$ at front of phantom. All values are corrected to one meter from source.) 
exposures had almost identical distance, angle, and shielding between the radiation source and the dosimeters. Therefore, the main source of difference between responses shown in the two figures, was the effect of the different neutron-moderating material behind the dosimeters (i.e., positional dependence).

Source of Positional Dependence

Positional dependence is a phenomena which results from the different neutron moderating and absorbing characteristics of material or tissue immediately behind the dosimeter. If the material is of high hydrogen density material (and therefore is a good neutron moderator), it will cause the TLD chip immediately in front of it to "see" more thermal neutrons and therefore store more thermoluminescence than a TLD chip with low hydrogen density material behind it.

In the case of the Rando phantom, the presence of bone, low-density polyethylene and high-density polyethylene in close proximity creates a composite of high- and low-neutron-moderating material. If the dosimeter is moved a few inches on the Rando phantom, its fast neutron response varies considerably. Even the one inch separating chips 3 and 4 causes them to vary somewhat independently of each other. As a result, the relative thermoluminescence of chip 3 compared to chip 4 varies considerably more on the Rando phantom than it does on the water jug phantom.

Sources of Thermoluminescence of Chips 3 and 4 on the Rando Phantom

Thermoluminescence of chip 3 in a pure neutron field is due to four main components:

A. Incident thermal neutrons,

B. Albedo thermal neutrons which are back-reflected from the phantom (i.e., albedo thermal neutrons originating from incident thermal neutrons),

C. Epicadmium (above $0.4 \mathrm{ev}$ ) neutrons which are captured by the LiF chip, and 
D. Epicadmium neutrons which are thermalized by the body, reflected back and captured by the Lif chip.

While chip 3's thermoluminescence is the sum of thermoluminescence from all four components, chip 4's thermoluminescence is the sum of thermoluminescence from on $1 y B, C$, and $D$ above. (a)

The fast neutron dose equation attempts to measure thermoluminescence from components $C$ and $D$. Roughly, this is done by measuring the ratio of thermoluminescence from component $A$ to that of component $B$ (approximately equal to one). (b) Then an equation is used to calculate the sum of thermoluminescence from components $C$ and $D$. Neglecting the gamma subtraction (R5), this equation is approximately:

$$
(2 R 4-R 3) \cdot \text { constant }=\text { fast neutron dose equivalent }
$$

This is roughly proportional to:

$$
2(B+C+D)-(A+B+C+D)
$$

Since $A \cong B$,

$$
2 \cdot(B+C+D)-(A+B+C+D) \cong 2 \cdot(B+C+D)-(2 \cdot B+C+D)=C+D
$$

In order to determine the cause of fluctuating calculated fast neutron dose and fluctuating thermoluminescence, the components of thermoluminecence for each position on the Rando phantom were determined and are shown in Figure $7.4 .(\mathrm{c})$

(a) Actually, the contribution from B is slightly less for chip 4 because of the "shadowing" effect of cadmium.

(b) The value usually used for HMPDS is $A / B=1.15$.

(c) This information was gathered by a specially built dosimeter. Basically it involved several combinations of cadmium and tin designed to el iminate thermal neutrons from selected directions. Using this dosimeter, it was possible to directly measure: $A, C$ and $B+D$. $B$ was assumed equal to $A(B=A)$, and $D$ was calculated by subtracting $A$ from $B+D$. 


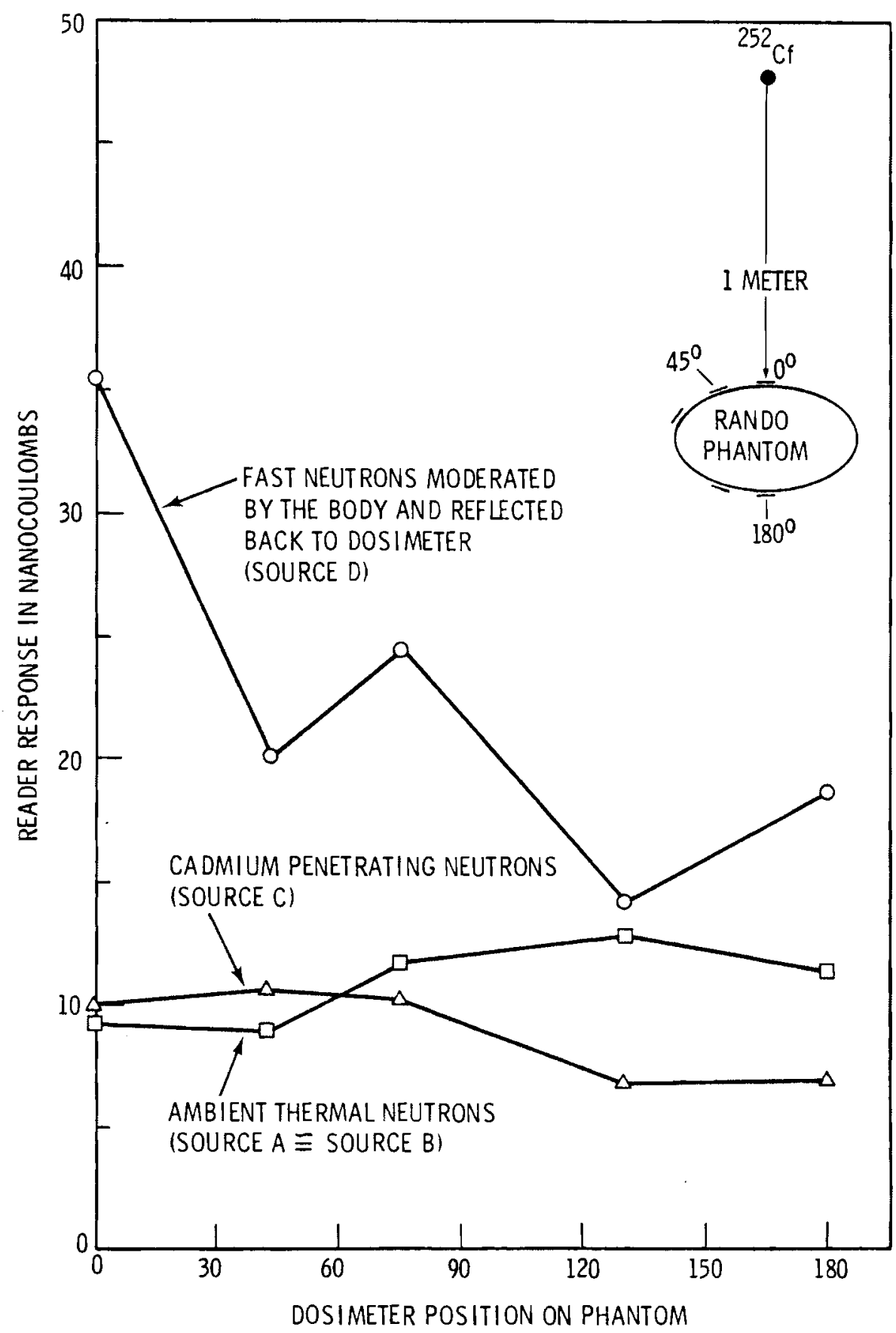

FIGURE 7.4. Components of Neutron Response. (All values are corrected to one meter from source.) 
In Figure 7.4 , components $A, B$, and $C$ do not fluctuate greatly with position, whereas component $D$ does fluctuate considerably with position on the phantom. Component $D$, fast neutrons moderated by the body and reflected back to the dosimeter, is therefore the cause of fluctuation in the readings of chip 3 and 4 . Since the dose equation involves $2 R 4-R 3$, the fluctuations of $D$ in both $R 4$ and $R 3$ are amplified in the calculated fast neutron dose.

There is a depression in component $D$ at approximately $45^{\circ}$. This corresponds to the position just over the lungs of the phantom. This same type of depression over the lungs is shown in Figures $7.3,7.5,7.6,7.9$, and 7.10 (these will be discussed later). This depression comes from the lower neutron moderating capability of low-density, lung-equivalent polyethylene just below the surface of the phantom.

Effect of Placing a Thin Neutron Moderator Behind the Dosimeter

To further demonstrate that the material immediately behind the dosimeter was the major cause of fluctuating calculated fast neutron dose, a set of HMPDS were exposed on the Rando phantom, identically as shown in Figure 7.3 except that a $3 / 8 \times 1-3 / 4 \times 2-7 / 16$ nch piece of plexiglas was attached to the back of each dosimeter as shown in Figure 7.B.1 of Appendix B. This provided a uniform $3 / 8$ inch of moderator behind the HMPD. The results are shown in Figure 7.5. Note that the thermoluminescence of chips 3 and 4 changed much more gradually than they did in Figure 7.3 . As a result, the calculated fast neutron dose fluctuated considerably less in Figure 7.5 than in Figure 7.3. This demonstrates that the moderator immediately behind the dosimeter is the major source of positional dependence.

Figure 7.5 shows a depression in response in the area over the lungs, as does Figure 7.3 and 7.4. The large deviations from a smooth curve shown in Figure 7.3 have been eliminated by attaching the plexiglas. 


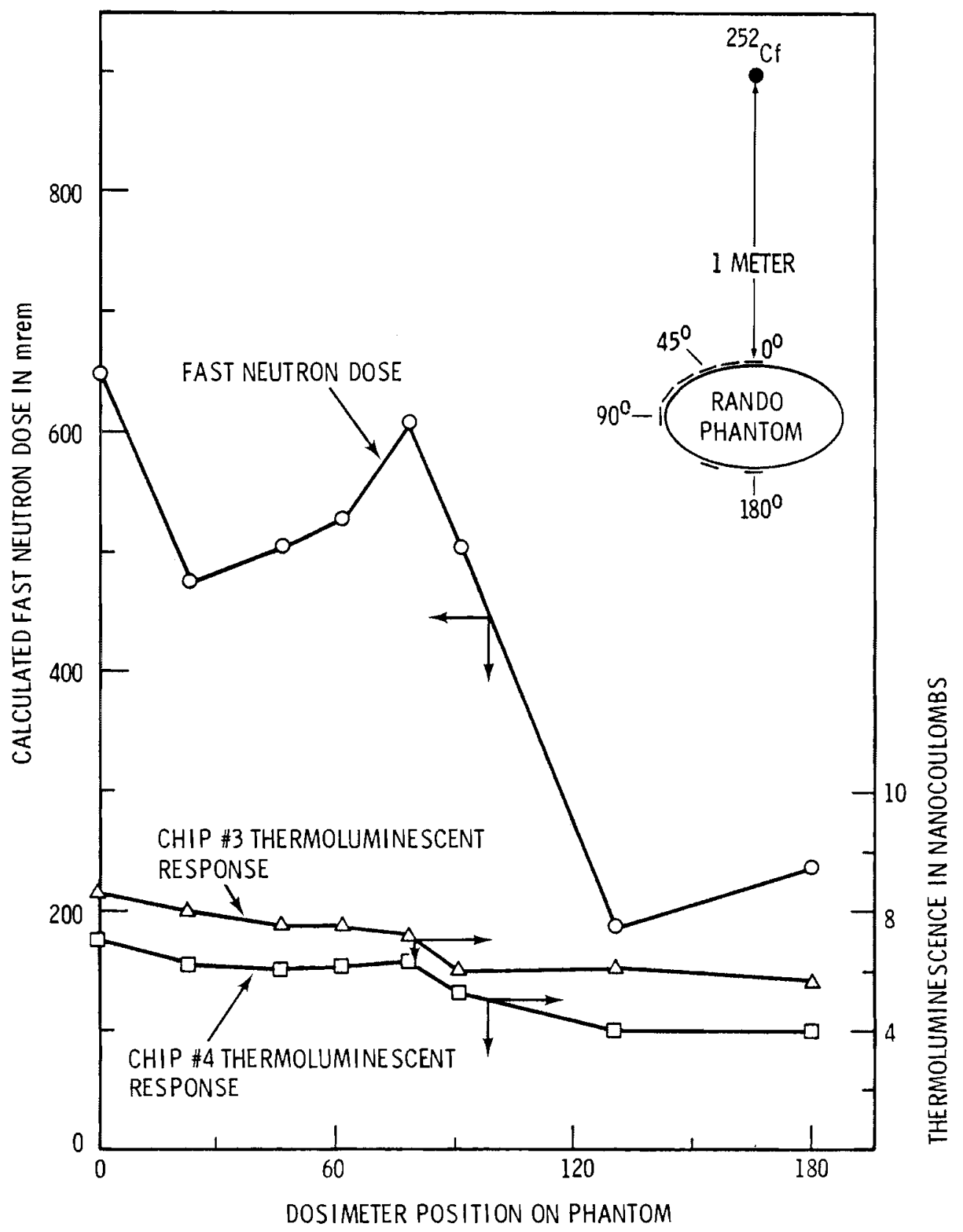

FIGURE 7.5. HMPO Response with 3/8-Inch Plexiglas Between Dosimeter and Rando Phantom. (Dose received is 1000 mrem at front of phantom. All values are corrected to one meter from source.) 


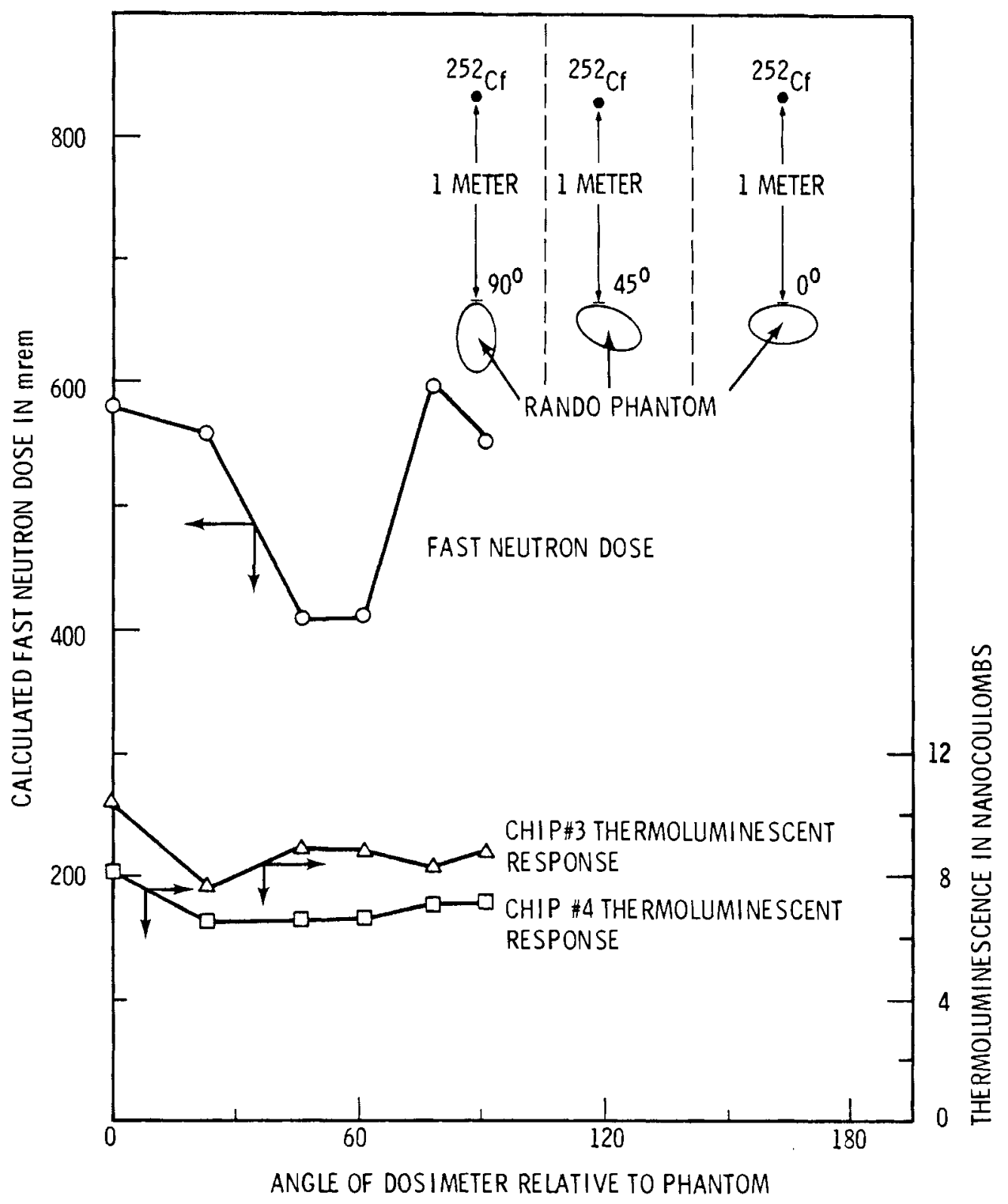

FIGURE 7.6. Rando Phantom Rotated 
Rotating the Rando Phantom

Figure 7.6 shows how the calculated dose varies with position when the dosimeter is one meter from the radiation source and directly faces the source. Since each dosimeter was at the same horizontal level at different positions of the chest region of the Rando phantom, the major factor leading to different calculated fast neutron doses was positional dependence. The positions corresponding to $45^{\circ}$ and $60^{\circ}$ indicated a fast neutron dose about $30 \%$ lower than the other positions at the front of the phantom. The lower calculated dose in these positions was believed to be due to lung equivalent polyethylene just below the surface of the phantom chest. Note that the fluctuations of thermoluminescence of chips 3 and 4 relative to each other was more abrupt in Figure 7.6 for the Rando phantom than the fluctuations in Figure 7.2 for the water jug phantom.

Quantification of Positional Dependence for ${ }^{252} \mathrm{Cf}$

To quantify the positional dependence of chip 3 and $4^{\prime} \mathrm{s}$ thermoluminescence to ${ }^{252} \mathrm{Cf}$ fast neutrons the standard deviations for chip 3 and chip 4 in Figure 7.3 and from another set of data were calculated. The other data set came from thermoluminescent data for chips 3 and 4 irradiated as shown in Figure 7.3 except that the ${ }^{252} \mathrm{Cf}$ source was at 1.5 meter instead of one meter. These standard deviation values were compared to the standard deviations of TLD chips given identical exposures in identical geometries. The difference in standard deviations was assumed to be due to positional dependence.

For values on the Rando phantom, the standard deviations of chips 3 and 4 in percent of total thermoluminescence were $4.02 \%$ and $8.81 \%$, respectively. (a) For identically exposed TLD chips, their standard deviations were $2.9 \%$ and 2.9\%. Mathematically the positional dependence for chip 3 (P3) and chip 4 (P4) were calculated as follows:

(a) This was based on an average weighted heavily towards the 1.5 meter ${ }^{252} \mathrm{Cf}$ exposure because this data was less dependent on distance from the source. The standard deviations listed are for the mean reading of two chips because two chips were used behind each filter. 


$$
\begin{aligned}
\left(\frac{4.02}{100}\right)^{2} & =\left(\frac{P 3}{100}\right)^{2}+\left(\frac{2.90}{100}\right)^{2} \\
P 3 & =2.78 \% \\
\left(\frac{8.81}{100}\right)^{2} & =\left(\frac{P 4}{100}\right)^{2}+\left(\frac{2.9}{100}\right)^{2} \\
P 4 & =8.32 \% .
\end{aligned}
$$

These values were used in Study 8.

\section{POSITIONAL DEPENDENCE AS A FUNCTION OF ENERGY}

To determine roughly how positional dependence varies as a function of neutron energy, a series of exposures were made on the Van de Graaff accelerator. Five dosimeters were placed on the Rando phantom in the arrangement shown in Figure 7.7. The phantom was placed in a known beam of monoenergetic neutrons and given a known dose. The ratio of dose calculated from HMPD response to dose given was then plotted against neutron beam energy. (a)

A linear regression best fit was made for each phantom position to see if the response for each position converged at any energy. This data is shown in Figure 7.8. Lines $A, B, C, D$, and $E$ correspond to positions $A, B, C, D$, and $E$ in Figure 7.7 .

Although the data was somewhat scattered, the general trend was that the response ratios converged somewhat at energies of $10 \mathrm{MeV}$ and above. At $10 \mathrm{MeV}$ the response ratios between positions differed by about $33 \%$ of position D's value. At $100 \mathrm{keV}$ response ratios differed by $54 \%$ of position D's value. This means that at neutron energies of $10 \mathrm{MeV}$ and above the placement of the dosimeter was less important than at energies around $100 \mathrm{keV}$. The magnitude of positional dependence is shown by the ratio between $l$ ine $D$ and $l$ ine $C$ to be about $45 \%$ greater at $100 \mathrm{keV}$ than it is at $10 \mathrm{MeV}$.

(a) This was drawn on log log paper so the data would lie in a straight line. 


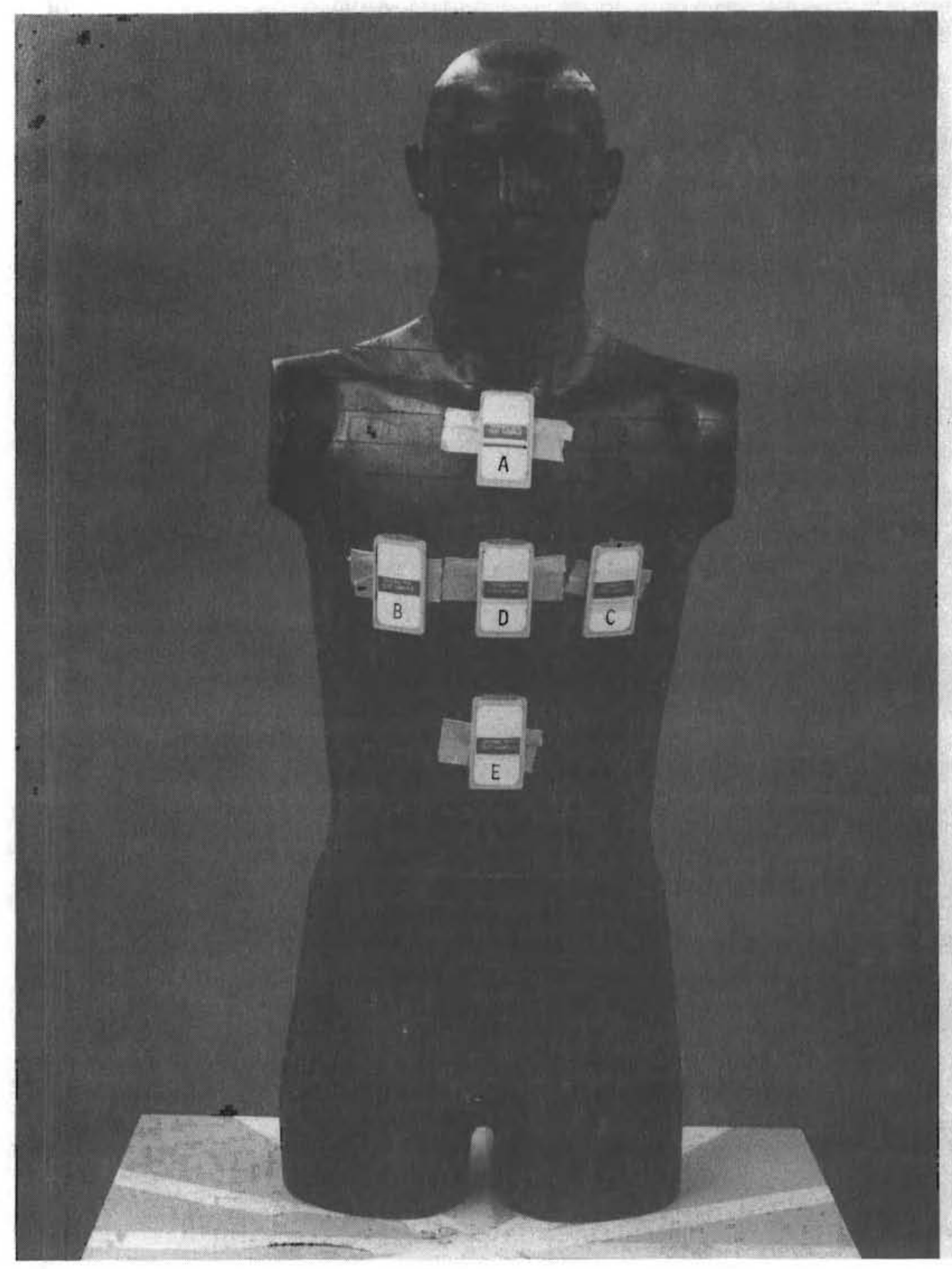

FIGURE 7.7. Dosimeter Placement for Van de Graaff Exposures 


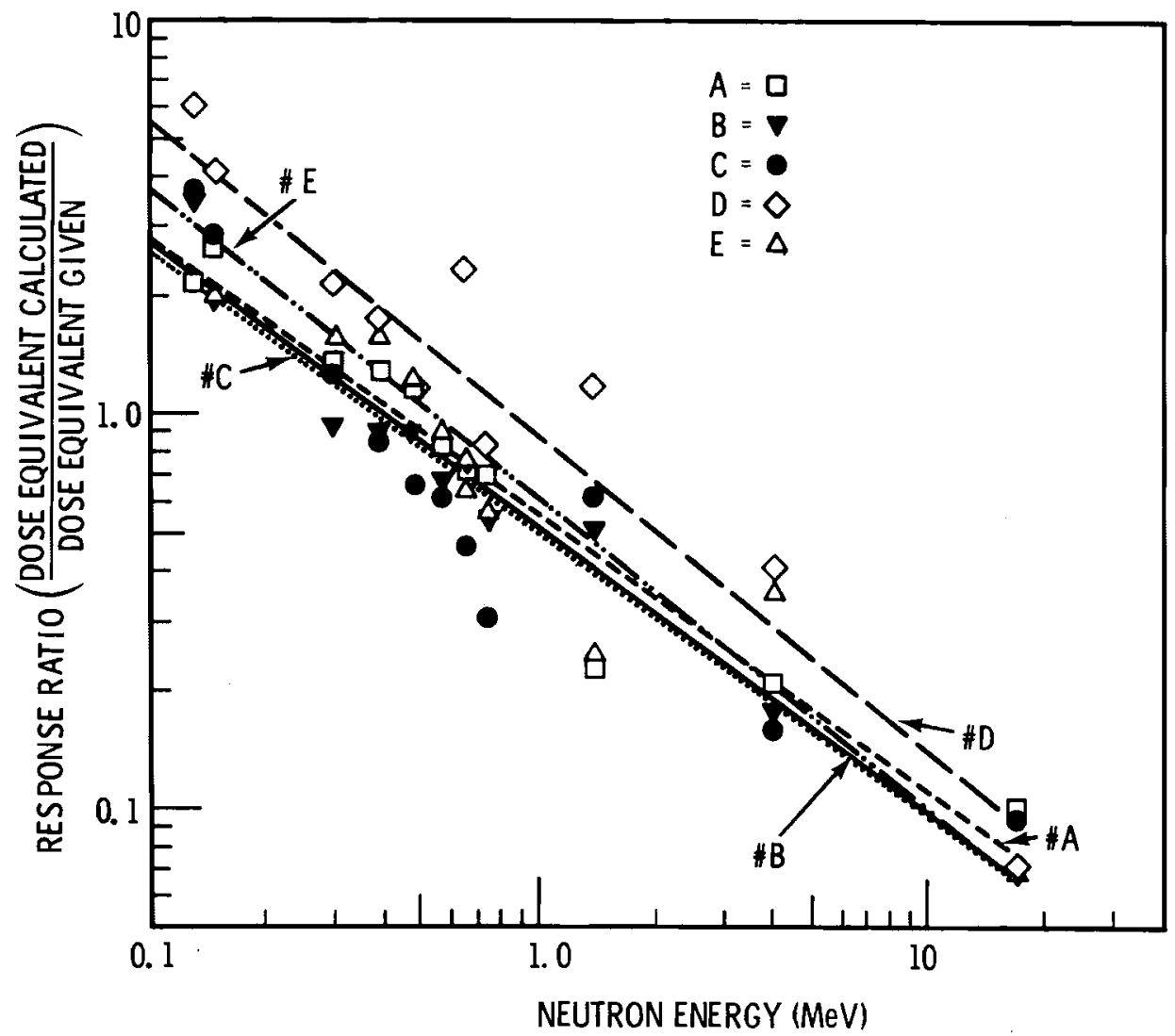

FIGURE 7.8. Positional Dependence as a Function of Energy

The reason why positional dependence (measured by the ratio of $D$ to $C$ ) tends to decrease at high neutron energies is because the cross section of hydrogen (the main moderator in both the body and the Rando phantom) decreases at high neutron energies. The cross section of hydrogen is shown in Appendix A. At high neutron energies around $10 \mathrm{MeV}$, the cross section of hydrogen is about 0.94 barns; whereas, at $100 \mathrm{keV}$ the cross section of hydrogen is 14 barns. In water this corresponds to a $50 \%$-probability path length of $11 \mathrm{~cm}$ for $10 \mathrm{MeV}$ neutrons and $0.74 \mathrm{~cm}$ for $100 \mathrm{kEV}$ neutrons. Since $10 \mathrm{MeV}$ neutrons require more collisions with hydrogen to be thermalized and their mean path length between collisions is greater, the tissue volume which is required to thermalize $10 \mathrm{MeV}$ neutrons is considerably greater than that required to thermalize $100 \mathrm{keV}$ neutrons. The result is that differences in neutron moderating ability of tissue are averaged over a larger volume for $10 \mathrm{MeV}$ 
neutrons than $100 \mathrm{keV}$ neutrons. Therefore, the specific placement of the dosimeter is less important for $10 \mathrm{MeV}$ neutrons than for $100 \mathrm{keV}$ neutrons.

POSITIONAL DEPENDENCE TO BARE PUBE AND BARE PUF

A series of dosimeters were exposed on the Rando phantom to PuBe and $\mathrm{PuF}_{4}$ sources to demonstrate positional dependence at two other energies. The average neutron energy of $\mathrm{PuBe}$ and $\mathrm{PuF}_{4}$ is 4.5 and $1.2 \mathrm{MeV}$, respectively. Their neutron spectrums are shown in Appendix $A$.

The physical set up used is diagrammed in the upper right corners of Figures 7.9 and 7.10. It was an exposure set up nearly identical to that used for Figure 7.3. The one difference was that a different batch of LiF chips were used for Figures 7.9 and 7.10 than was used for Figure 7.3 .

Comparing Figures 7.9 and 7.10 , it can be seen that the two curves fluctuated approximately the same amount in percent of calculated fast neutron dose for the front positions (between $0^{\circ}$ and $90^{\circ}$ ). Figure 7.9 shows that the PuBe response had a standard deviation of $19 \%$ for the first six positions. Figure 7.10 shows that the $\mathrm{PuF}_{4}$ response had a standard deviation of $16 \%$. They both fluctuated about the same amount because positional dependence for fast neutrons changes gradually with energy level and their energies differed by only a factor of four.

The calculated dose dropped off considerably from $90^{\circ}$ to $180^{\circ}$ because the phantom shielded these dosimeters from the neutron source. For the $\mathrm{PuF}_{4}$ source this was more pronounced than for the PuBe source because the lower energy neutrons of $\mathrm{PuF}_{4}$ were less able to penentrate through the phantom.

\section{ANGULAR DEPENDENCE}

To measure dependence of HMPD calculated dose upon angle of the dosimeter relative to the plane of the phantom, a series of exposures were made at the National Bureau of Standards (NBS) and Lawrence Livermore Laboratory (LLL). These exposures involved exposing a water jug phantom to either a neutron beam of known energy at NBS or to ${ }^{252} \mathrm{Cf}$ at LLL. 


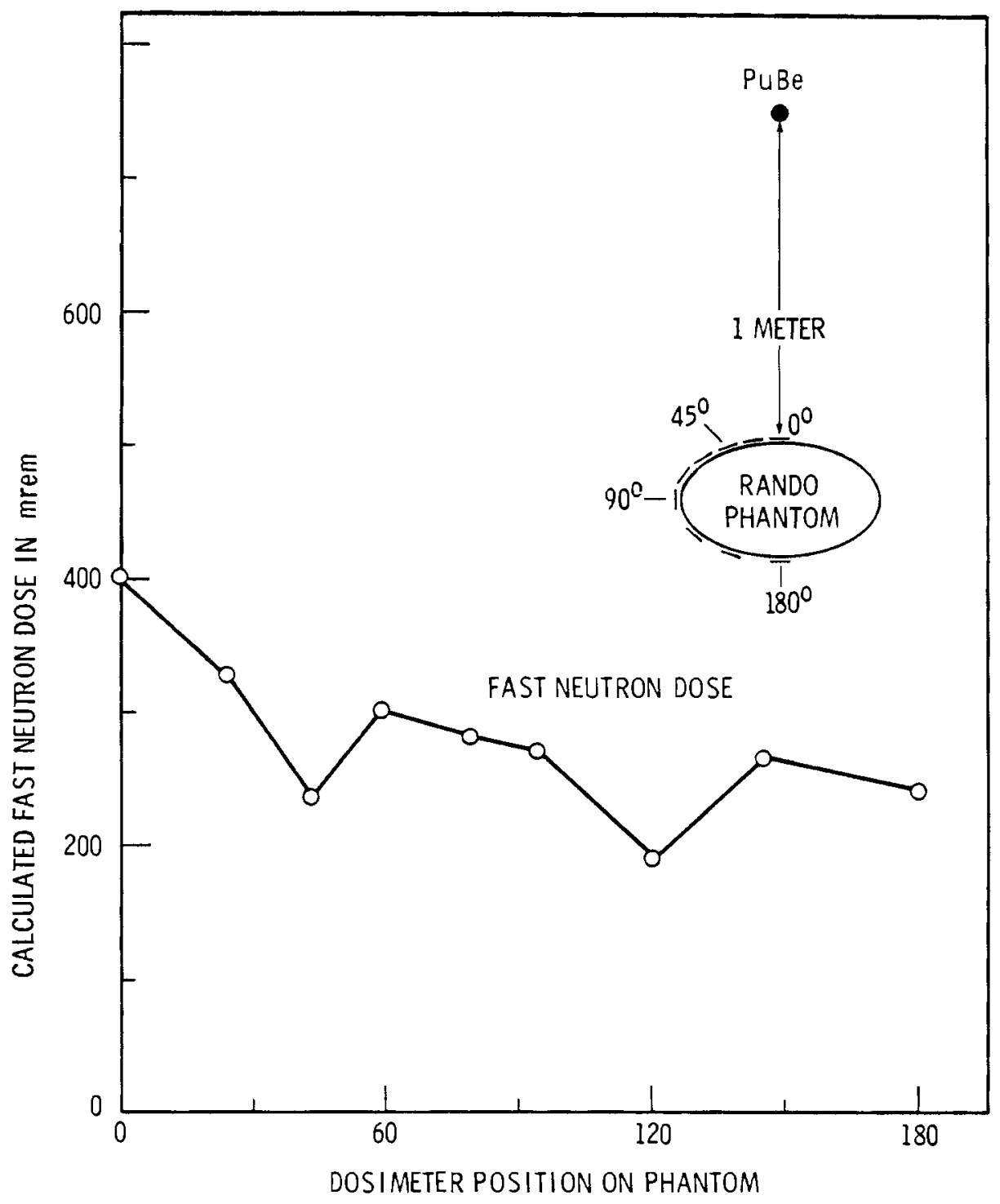

FIGURE 7.9. HMPD Response with Position on the Rando Phantom to PuBe. (Dose is 1000 mrem at front of phantom. All values are corrected to one meter from source.) 


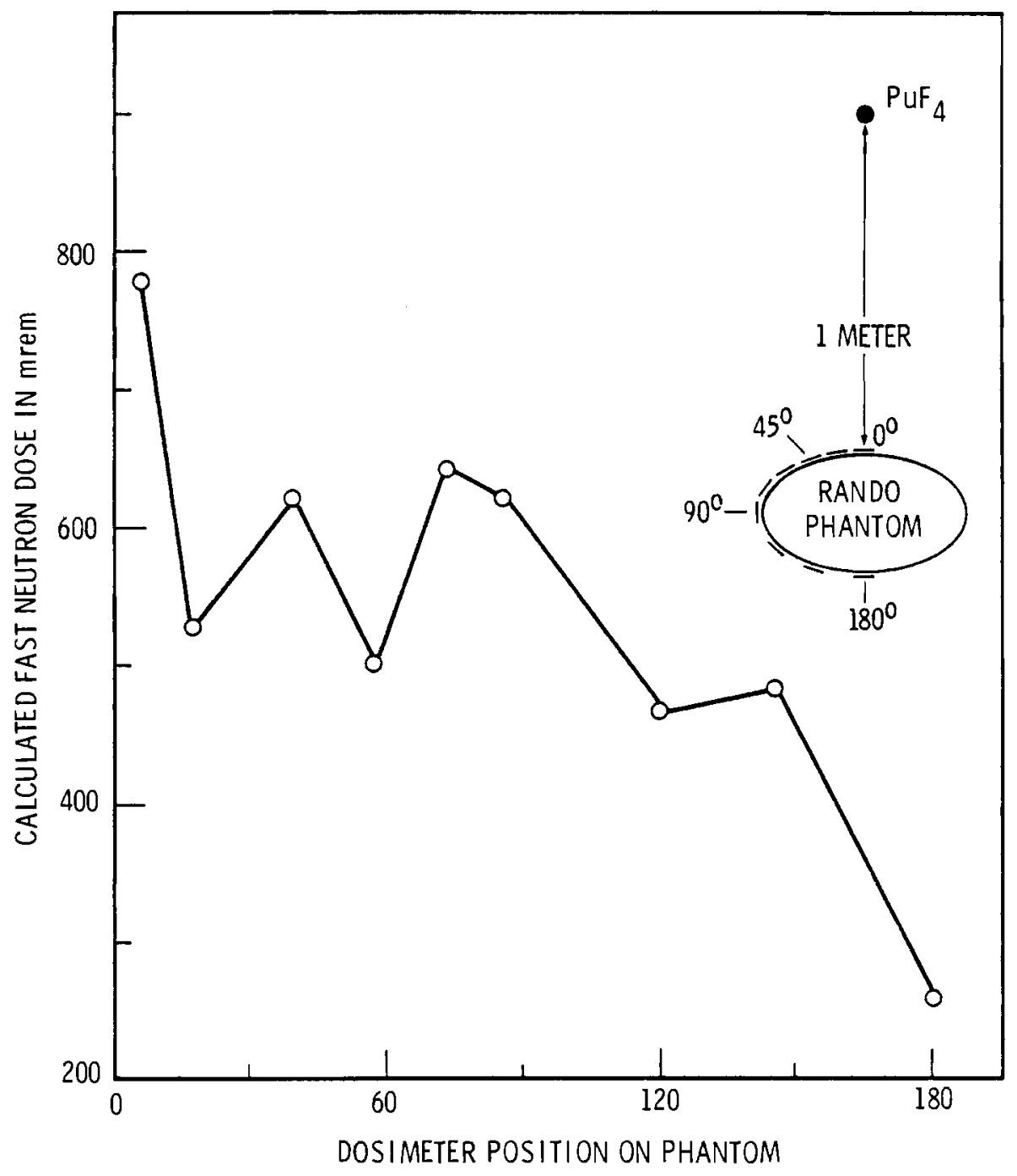

FIGURE 7.10. HMPD Response with Position on the Rando Phantom to PuF4. (Dose is $1000 \mathrm{mrem}$ at front of phantom. All values are corrected to one meter from source.) 
The exposure set up and results are shown in Figures $7.11,7.12$, and 7.13 .

\section{Fast Neutrons}

For neutrons above $1 \mathrm{keV}$, the calculated dose dropped off approximately linearly as the angle was increased from $0^{\circ}$ to $45^{\circ}$. At $45^{\circ}$ the calculated dose was about $45 \%$ of what it was at $0^{\circ}$. Beyond $45^{\circ}$, the calculated dose became a function of room geometry and varied considerably from exposure to exposure. These data are shown in Figures 7.11 and 7.12 .

\section{Thermal Neutrons}

For thermal neutrons in Figure 7.13 , the response decreased less than $10 \%$ as the angle between the plane of the dosimeter and plane of the phantom was increased from $0^{\circ}$ to $45^{\circ}$. Beyond $45^{\circ}$, the calculated thermal neutron dose dropped off dramatically to only $27 \%$ to that of the $0^{\circ}$ exposure.

RESPONSE DEPENDENCE WITH DISTANCE SEPARATING PHANTOM AND DOSIMETER

The response of the HMPO to fast neutrons as the dosimeter is held directly in front of the Rando phantom is shown in Figure 7.14. For these exposures, the plane of the dosimeters and phantom were parallel and the dosimeters were spaced from the phantom by hollow cardboard inserts.

As the distance between the dosimeter and phantom increased, the "field of view" occupied by the phantom decreased leading to the decrease in thermoluminescence of chip 3 and 4 . Somewhat counteracting this, the shadowing effect of the cadmium filter on chip 4 was reduced as the distance between the dosimeter and phantom increased. When the dosimeter was spaced $2.3 \mathrm{~cm}$ from the phantom, the calculated fast neutron dose was only $78 \%$ of that when the dosimeter rested flat on the phantom. 


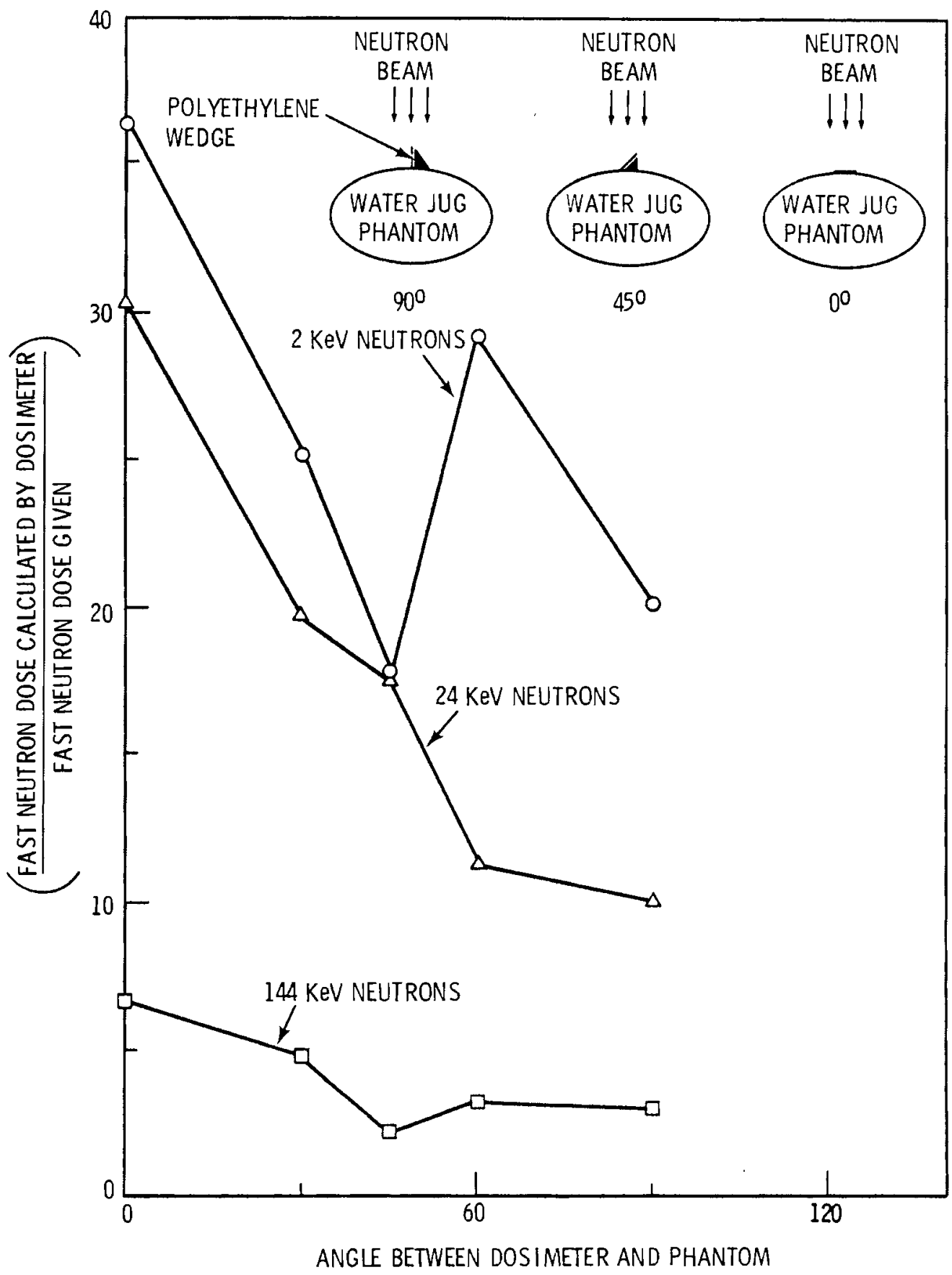

FIGURE 7.11. HMPD Response to Fast Neutrons as a Function of Angle Between Dosimeter and Phantom. 


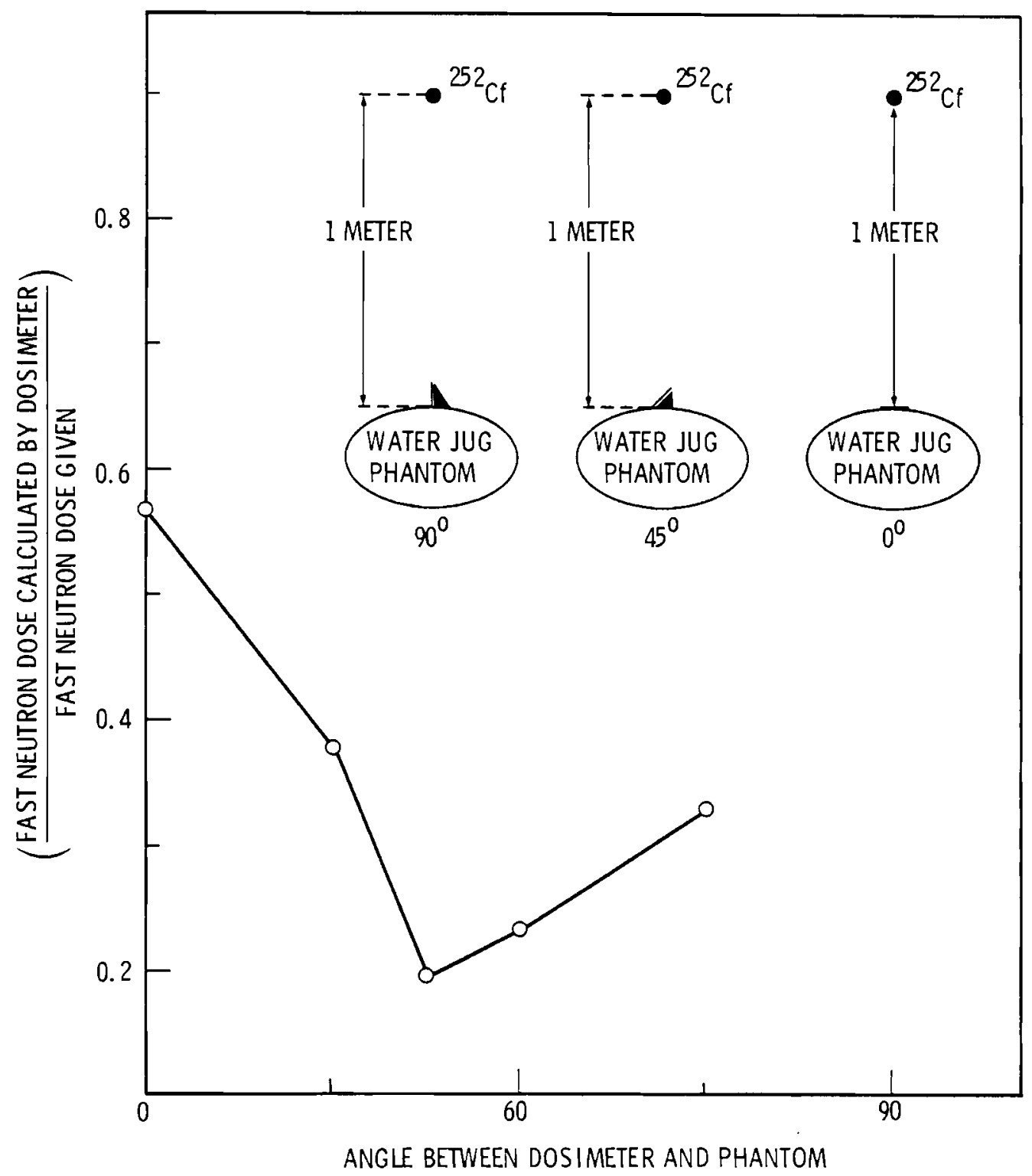

FIGURE 7.12. HMPD Response to $252 \mathrm{Cf}$ as a Function of Angle Between Dosimeter and Phantom. 


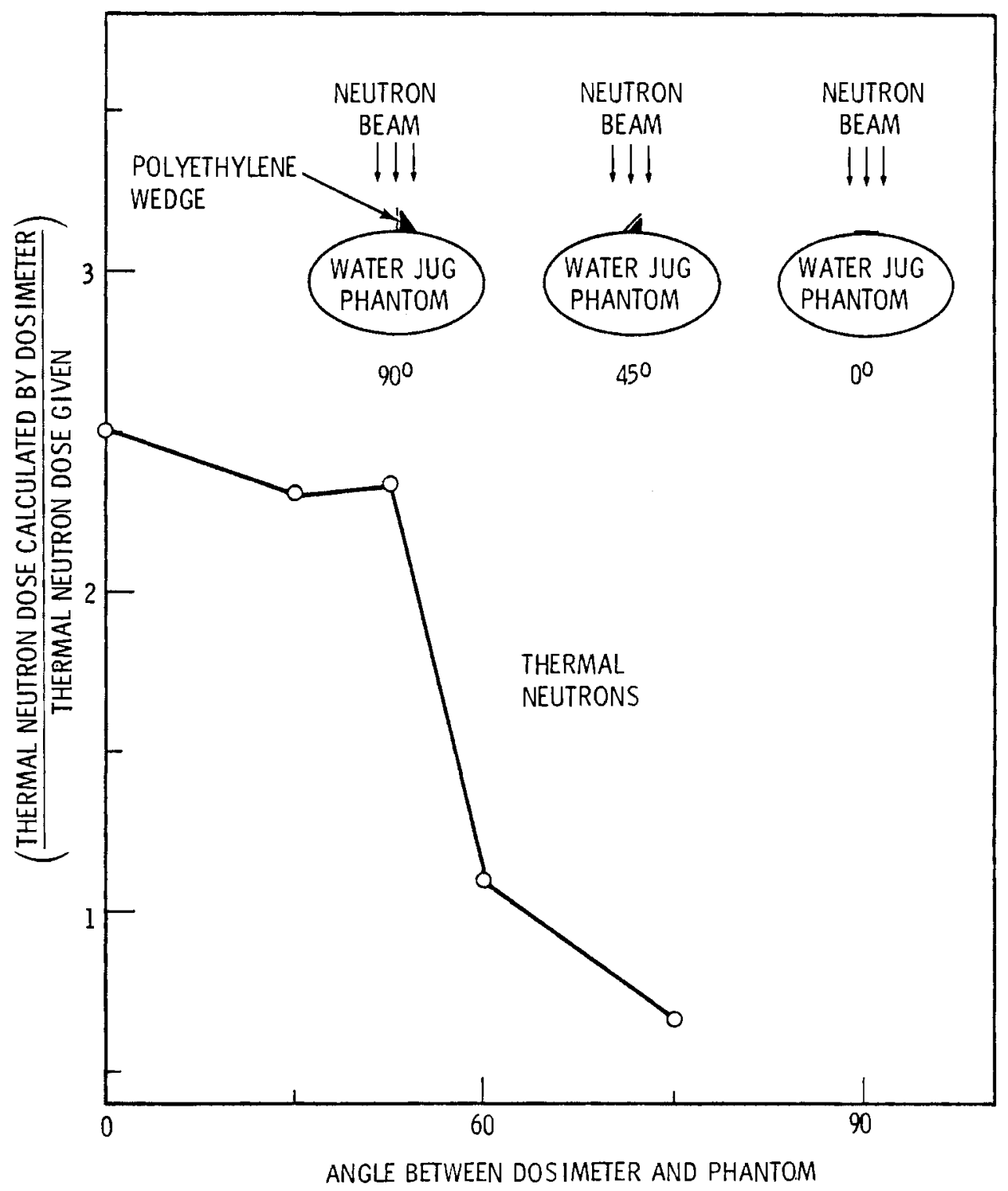

FIGURE 7.13. HMPD Response to Thermal Neutron As a Function of Angle Between Dosimeter and Phantom. 


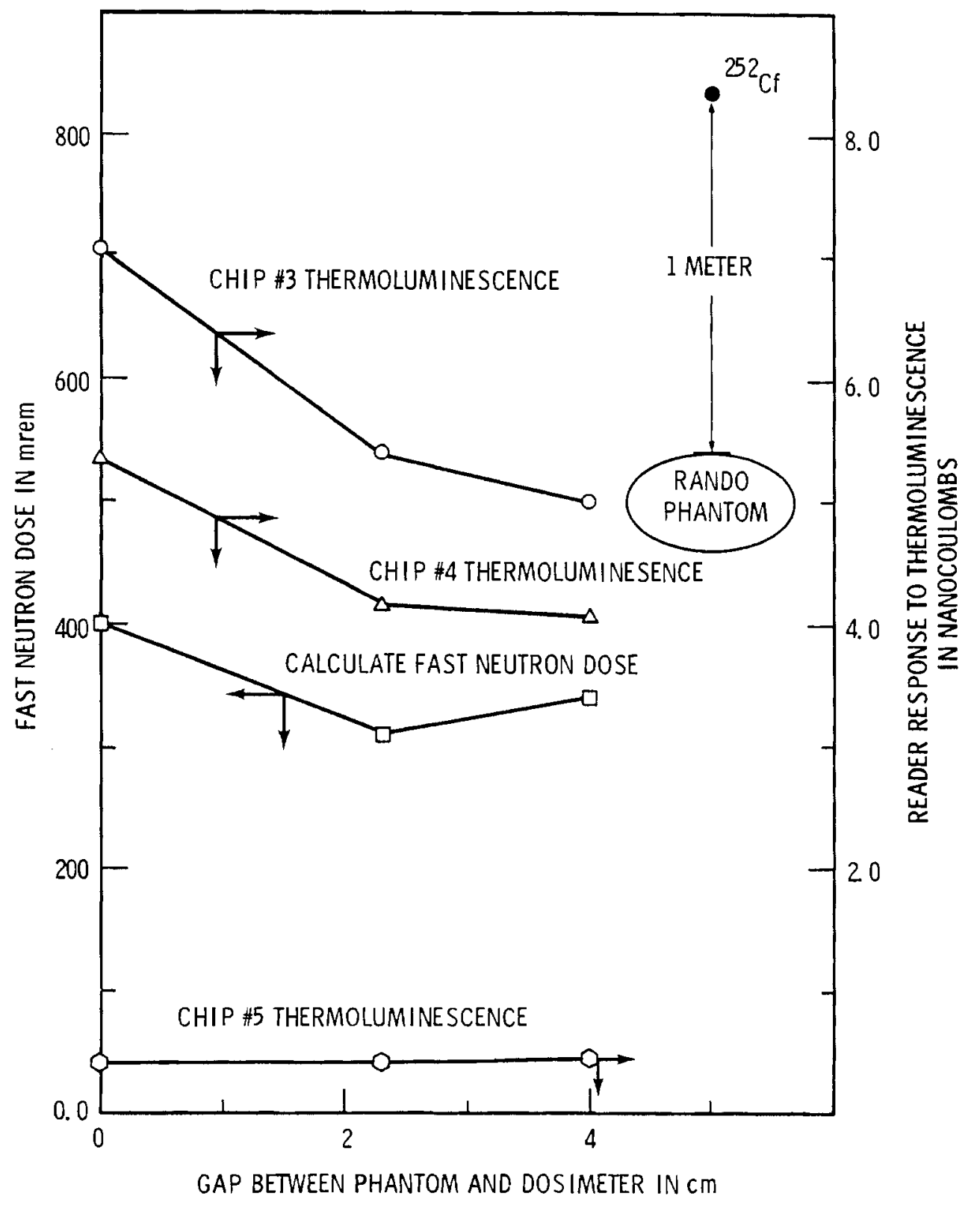

FIGURE 7.14. Response to 252Cf as a Function of Distance Between Phantom and Dosimeter. 
APPENDIX A

ENERGY SPECTRA AND CROSS SECTIONS 


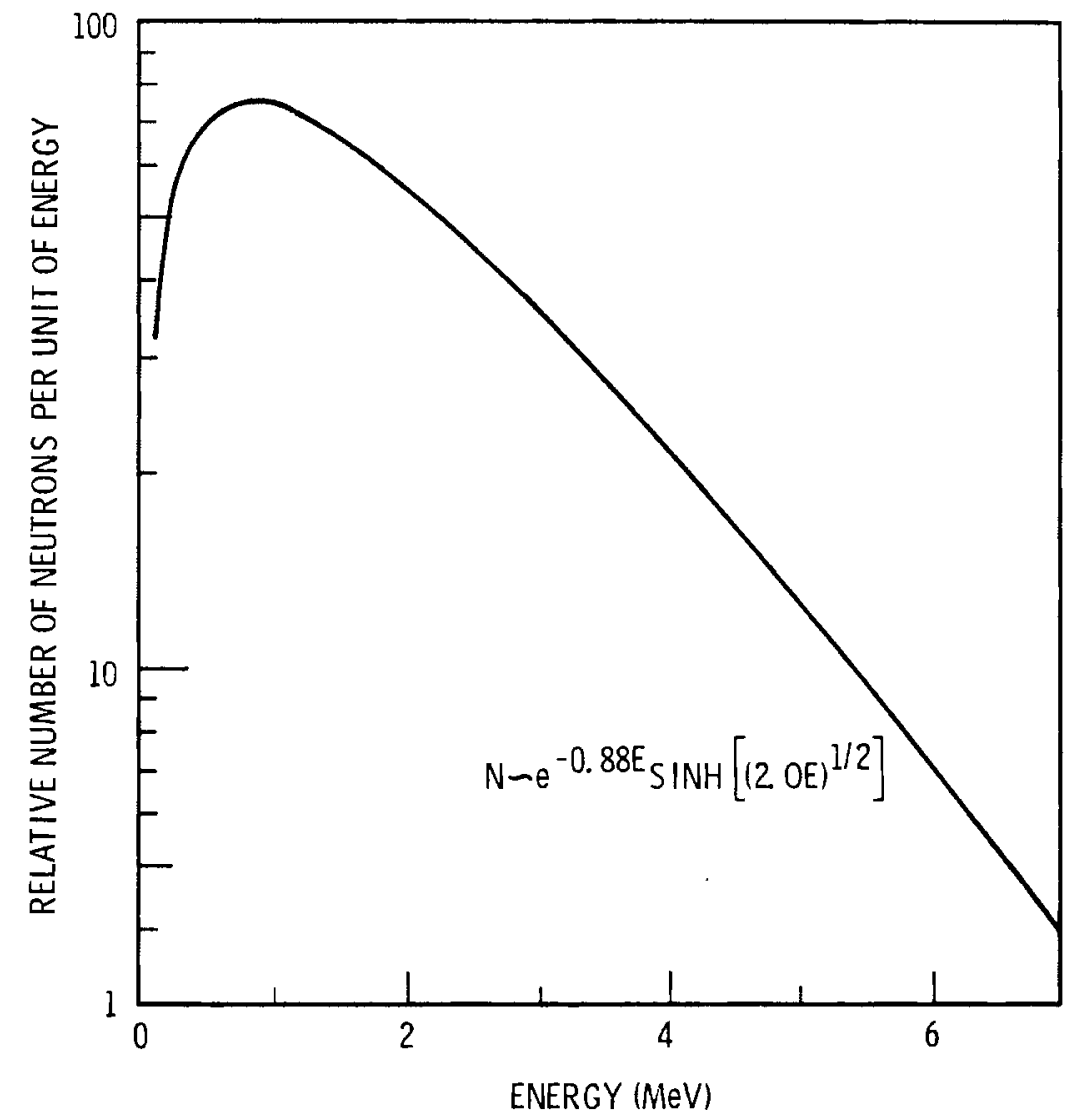

FIGURE 7.A.1. Neutron Energy Spectrum of $252 \mathrm{Cf}$ (Smith, Fields, and Roberts 1957; Fields and Diamond 1963). 


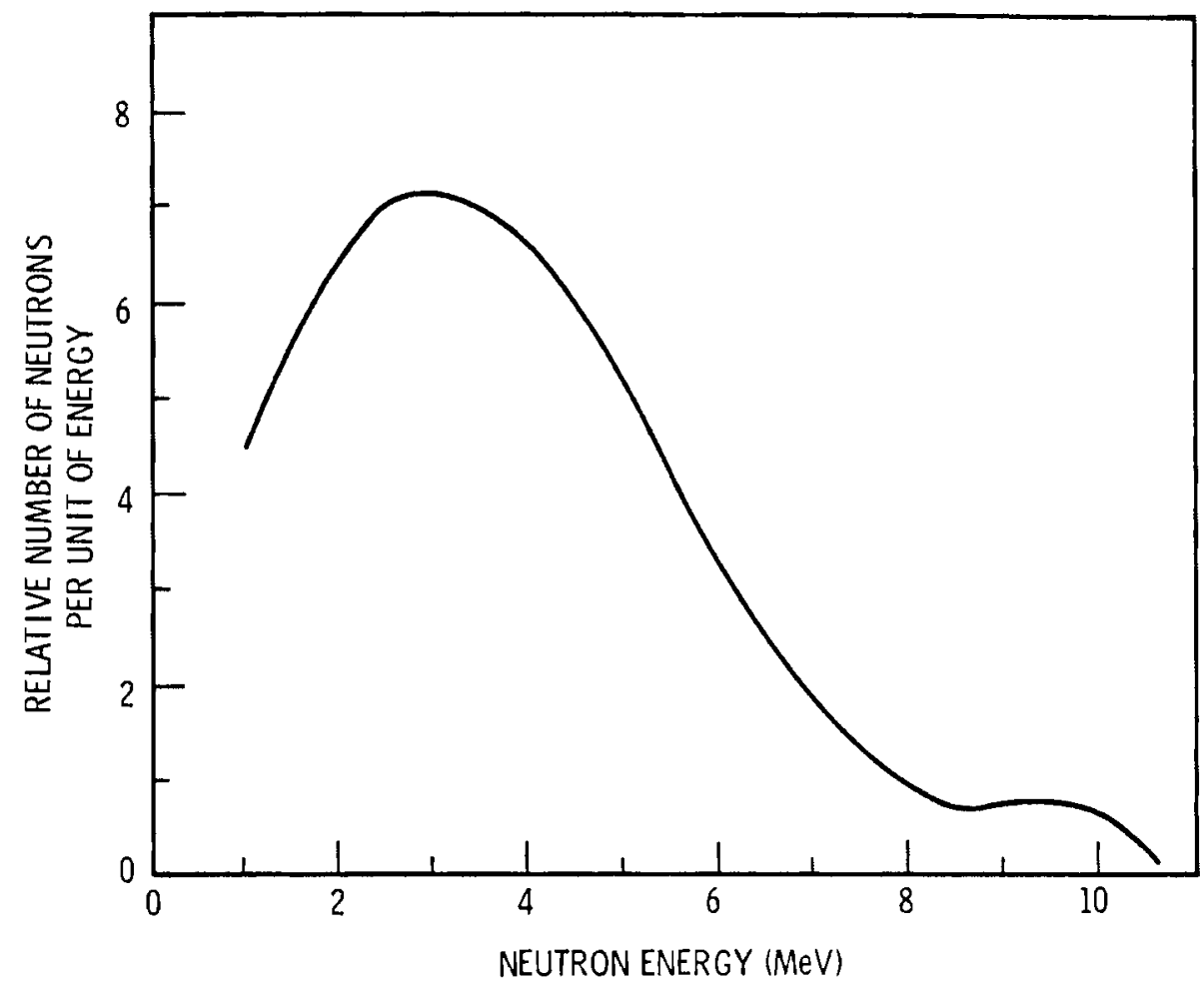

FIGURE 7.A.2. Neutron Energy Spectrum of PuBe (Tochl in 1963). 


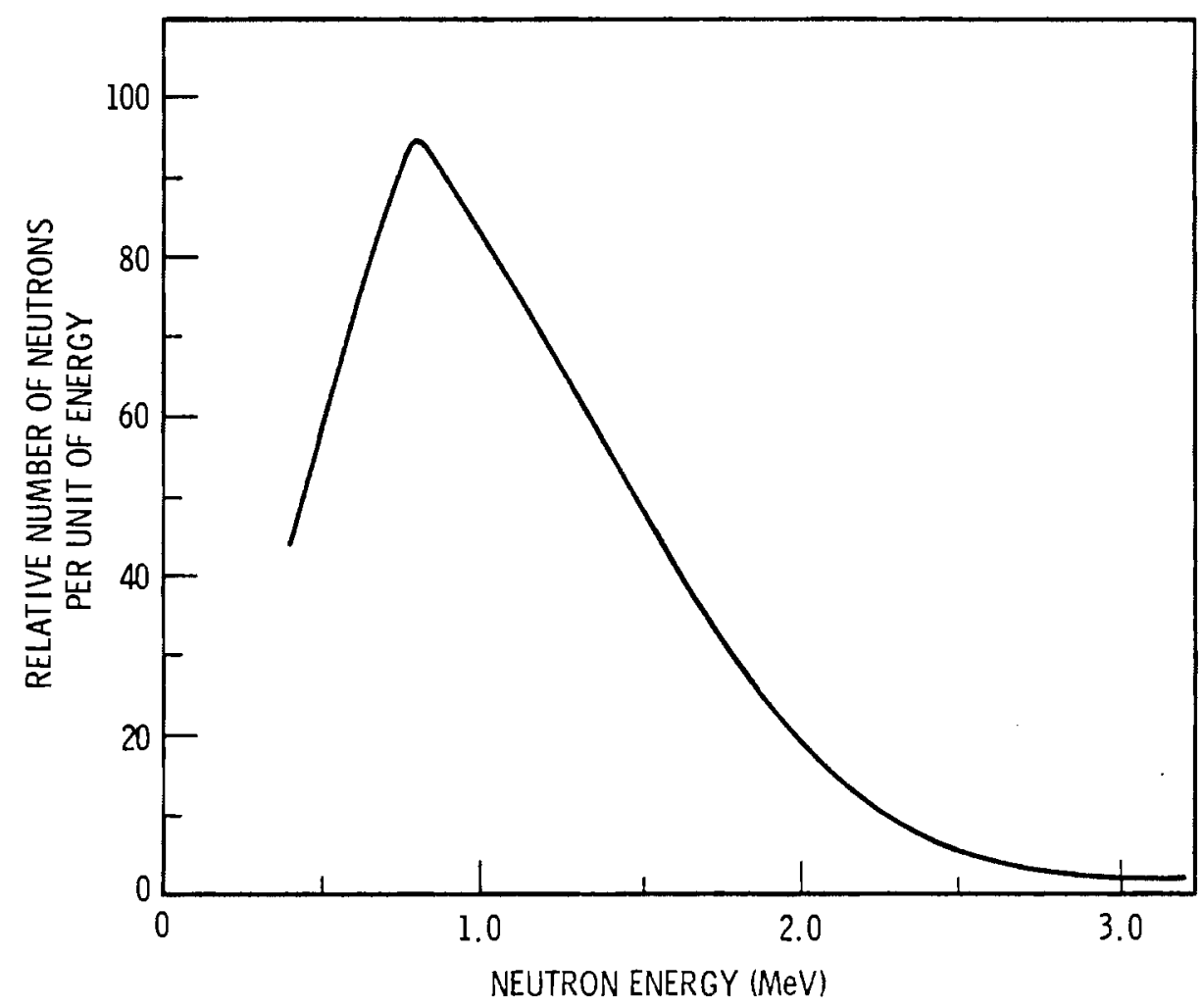

FIGURE 7.A.3. Neutron Energy Spectrum of PuF (Toch 1 in 1963). 


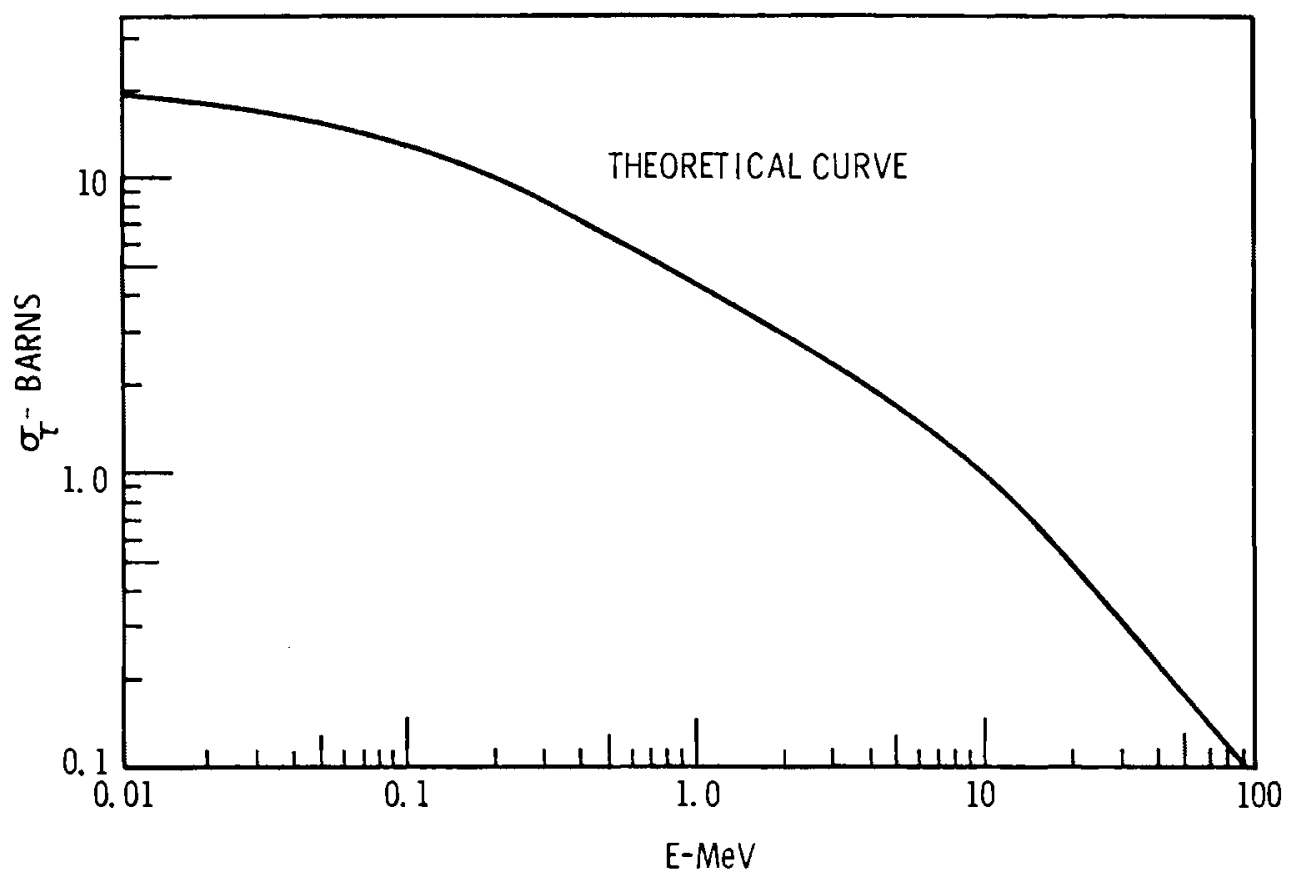

FIGURE 7.A.4. Hydrogen Cross Section

(Hughes and Harvey 1955). 


\section{REFERENCES}

Fields, Paul R. and Herbert Diamond. 1963. "Californium-252, A Primary Standard for Neutrons," In Proceedings of the Symposium on Neutron Detection, Dosimetry, and Standardization, Vol. II, pp. 581-593.

Hughes, D. J. and J. A. Harvey. 1955. Neutron Cross Sections. Brookhaven National Laboratory, U.S. Government Printing Office, Washington, D.C.

Smith, A. B., P. R. Fields, and J. H. Roberts. 1957. "Spontaneous Fission Neutron Spectrum of 252Cf." Phys. Rev. 108(411).

Toch lin, E. 1963. "Flux and Spectral Measurements of Primary and Moderated Neutron Sources," In: Proceeding of the Symposium on Neutron Detection, Dosimetry, and Standardization, Vol. I, pp. 553-563. 

APPENDIX B

DOSIMETER WITH PLEXIGLAS ATTACHED TO BACK 


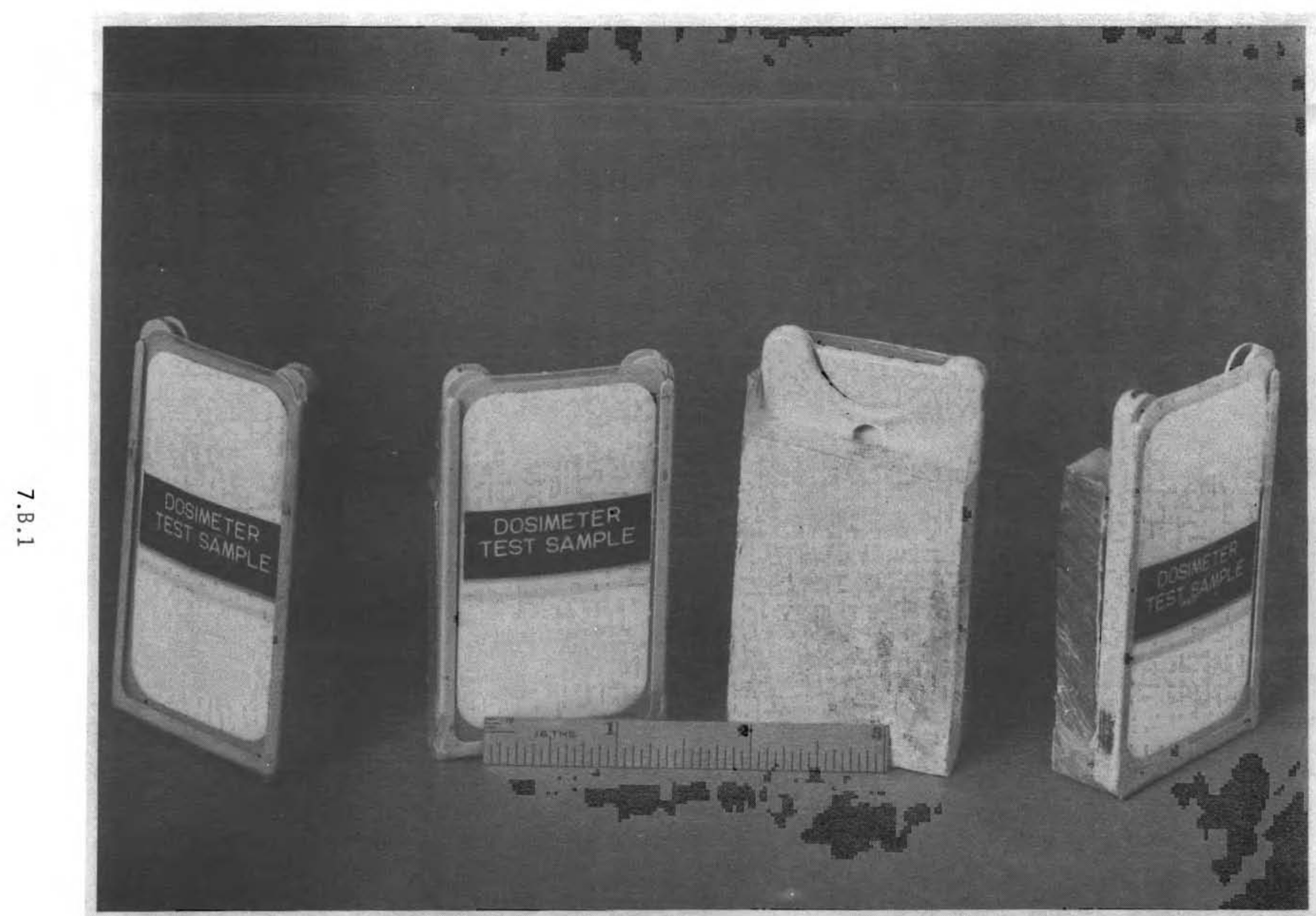

FIGURE 7.B.1. Dosimeter with 3/8-Inch Plexiglas Attached to Back 



\subsection{STUDY 6 - ENVIRONMENTAL EFFECTS ON THE HANFORD \\ MULTIPURPOSE PERSONNEL DOSIMETER}

\section{F. M. Cummings}

FOREWORD

This study examines the effects of environmental conditions on the response of TLD-700. Of particular interest is the effect of chemical contaminants, routinely encountered in the course of work, in enhancing or inhibiting the response of TLD's. The effects of contaminants on Teflon TFE tape are also studied.

Additionally, the effects of microwave irradiation and mechanical shock are investigated as well as the use of glow curve analys is to identify spurious signals.

\section{SUMMARY}

For the chemical contaminants investigated, the effect on TLD-700 was found to be slightly signal inhibitive in most cases. Some contaminants did produce a dramatic signal enhancement in Tefion tape, though. It is demonstrated that the increase in signal is primarily due to the signal enhancement from UV interaction with Teflon tape.

The effects of microwave irradiation and mechanical shock were demonstrated to be undetectable.

\section{INTRODUCTION}

In the course of routine use, a personnel dosimeter comes into contact with a wide variety of chemical substances. The effects of substances, identified in this report, on the light output from LiF were unknown. As the Hanford Multipurpose Personnel Dosimeter (MPD) utilizes a sandwich of Teflon tape and $L i F$, effects of extraneous substances on these two materials were investigated to characterize signal, collected from heated chips and tape, which was produced by substances apart from radioactivity. Glow curves are presented for 
comparison of effects and as substantiation for the recommendation of automatic glow curve analysis during TLD readout.

Additional effects from microwave irradiation and mechanical shock to the dosimeter are discussed in detail.

Temperature and humidity effects are not addressed in this study as they have already been adequately reported by Kathren (1970). Briefly, the effect of temperature and humidity on the light output of TLD-700's has been reported to be neglibible over the range including $19^{\circ} \mathrm{C}$ to $50^{\circ} \mathrm{C}$ and $10 \%$ relative humidity to $95 \%$ relative humidity (Kathren 1970 ).

\section{METHODS}

\section{Chemical Contaminants}

TLD-700 chips were screened such that all chips were within $3 \%$ of the mean sensitivity to ${ }^{137} \mathrm{Cs}$ photons (nc/mR) for the group. Ten chips were set aside as controls. The remaining 26 TLD-700 chips were divided into two groups, a pre-irradiation group and a post-irradiation group. Those chips in the preirradiation group were contaminated with the chemical agents listed in Table 8.1 and then irradiated using ${ }^{137} \mathrm{Cs}$ in a field producing $1000 \mathrm{mR}$. The chips in the post-irradiation group were irradiated to the same level, then contaminated. The chips were allowed to remain in contract with contaminant for 24 hours, then were given a superficial "dry" cleaning to remove excess agent. A 11 chips were analyzed as noted in Task II roughly 72 hours after irradiation. The raw data are listed in Table 8-1.

Additionally, small disks were punched from the Teflon TFE tape used in the Hanford MPD. These disks were contaminated in a similar manner and analyzed on the Harshaw reader in an identical manner as the chips. The Tefion tape raw data are also 1 isted in Table 8.1 .

\section{Microwave Effects}

TLD-700's were screened to with in $3 \%$ of the group mean sensitivity. Twelve of the chips were irradiated using ${ }^{137} \mathrm{Cs}$ in a field producing $100 \mathrm{mR}$ while eight were segregated as $0 \mathrm{mR}$ (unirradiated) exposures. Packets were 
TABLE 8.1. Light Output from Chemically Contaminated Teflon TFE Tape and Irradiated TLD-700's

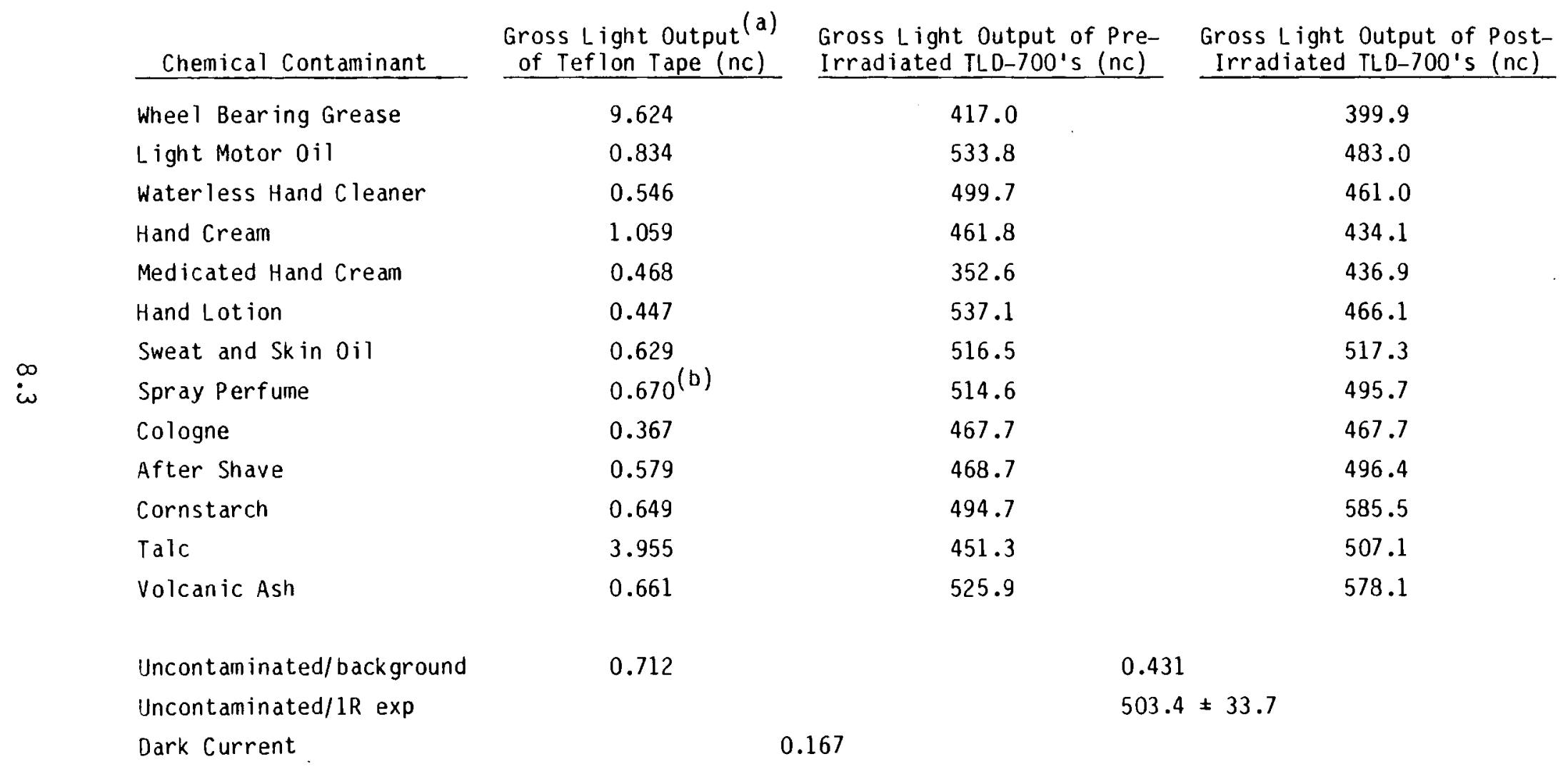

(a) Average of two samples per datum point.

(b) One sample per datum point. 
constructed of paper envelopes containing two irradiated chips and two unirradiated chips. Two packets did not contain unirradiated chips. Those packets are noted in Table 8.2. Five of the six packets were placed in a Sanyo Model 9003 microwave oven. The control was placed on high and the time was set at one minute. At the end of one minute, one packet was removed from the oven and the sequence repeated unt $i 1$ the last packet had been exposed to the microwaves for a total of five minutes. The sixth packet was used as a control group. Data are listed in Table 8.3 .

Mechanical Shock

Twenty Hanford MPO's were used in this experiment. Ten were irradiated using ${ }^{137} \mathrm{Cs}$ in a field producing $200 \mathrm{mR}$. The other ten were not irradiated. Five dosimeters from each group were dropped individually from a height of $244 \mathrm{~cm} \pm 5 \mathrm{~cm}$ onto a concrete pad. The dosimeters were than analyzed on the Harshaw reader. The raw data are listed in Table 8.4 .

\section{RESULTS}

Chemical Contaminant

Referring to Table 8.1 the exposed (1R) control TLD-700's disclosed an average light output of $503.4 \mathrm{nc}$ with a standard deviation of $33.7 \mathrm{nc}$. Two of the 26 contaminated chips had 1 ight outputs greater than one standard deviation from the mean of the controls. Those two chips were contaminated with cornstarch (585.5 nc) and volcanic ash (578.1 nc). Generally, however, the contaminants had the effect of inhibiting thermoluminescence. Upon analysis, the average light output for the pre-irradiation group was $480.1 \mathrm{nc} \pm 52.5 \mathrm{nc}$ while for the post-irradiation group, the average light output was $486.8 \mathrm{nc} \pm$ 53.2 nc.

The effect of contaminant on the TLD-700 does not appear to change the trap structure as is illustrated in Figures 8.1 through 8.4 . There is in these figures no pronounced change in the shapes of the glow curves.

While no apparent effect is produced by the contaminants on the TLD chips, there is an effect of trap restructuring in Teflon tape. As before, most of 
TABLE 8.2. Re-Read Test on Teflon Tape Contaminated with Wheel Bearing Grease

\begin{tabular}{cc}
$\begin{array}{c}\text { Analysis } \\
\text { No. }\end{array}$ & $\begin{array}{c}\text { Reader Current } \\
\text { ( } \mathrm{nc} \text { ) }\end{array}$ \\
\cline { 1 - 1 } 1 & 13.9 \\
2 & 2.77 \\
3 & 2.12 \\
4 & 1.68 \\
5 & 2.59 \\
6 & 1.44 \\
$\begin{array}{l}\text { Average of 2-5 } \\
\text { and one standard } \\
\text { deviation }\end{array}$ & \\
\hline
\end{tabular}

TABLE 8.3. Light Output from Unirradiated (0 mR) and Irradiated (100 mR) TLD-700's Exposed to Microwave

\begin{tabular}{|c|c|c|c|c|}
\hline $\begin{array}{l}\text { Microwave } \\
\text { Exposure Time } \\
\text { (min.) }\end{array}$ & $\begin{array}{l}\text { Average Gross } \\
\text { Light Output of } \\
\text { a } 0 \mathrm{mR} \text { Exposure } \\
\text { (nc) } \\
\end{array}$ & $\begin{array}{l}1 \text { SD } \\
\text { (nc) } \\
\end{array}$ & $\begin{array}{c}\text { Average Gross } \\
\text { Light Output of } \\
\text { a } 100 \mathrm{mR} \text { Exposure } \\
\text { (nc) }\end{array}$ & $\begin{array}{l}1 \text { SD } \\
\text { (nc) }\end{array}$ \\
\hline 0 & 0.97 & 0.04 & 52.2 & 2.69 \\
\hline 1 & 1.05 & 0.04 & 52.9 & 2.40 \\
\hline 2 & --- & --- & 52.9 & 1.77 \\
\hline 3 & 1.01 & 0.03 & 54.3 & 1.91 \\
\hline 4 & --- & --- & 52.1 & 1.56 \\
\hline 5 & 1.00 & 0.04 & 53.4 & 0.85 \\
\hline A11 MW Exposures & 1.02 & 0.04 & 53.1 & 1.52 \\
\hline All Chips & 1.01 & 0.04 & 53.0 & 1.63 \\
\hline
\end{tabular}


TABLE 8.4. Effects of Mechanical Shock (drop test) on the Hanford Multipurpose Personnel Dosimeter

\begin{tabular}{|c|c|c|c|c|c|}
\hline \multirow[b]{2}{*}{ Exposure Group } & \multicolumn{5}{|c|}{ Net Light Output (nc) } \\
\hline & Chip 1 & Chip 2 & Chip 3 & Chip 4 & Chip 5 \\
\hline $0 \mathrm{mR}$ Control & 0.072 & 0.020 & 0.361 & 0.049 & 0.061 \\
\hline 1 SD & 0.188 & 0.164 & 0.322 & 0.261 & 0.147 \\
\hline 0 mR Drop & 0.086 & 0.050 & 0.491 & 0.140 & 0.198 \\
\hline 1 SD & 0.164 & 0.171 & 0.337 & 0.204 & 0.301 \\
\hline $200 \mathrm{mR}$ Control & 86.89 & 86.08 & 75.98 & 74.19 & 89.47 \\
\hline $1 \mathrm{SD}$ & 2.815 & 4.079 & 1.709 & 4.095 & 2.880 \\
\hline 200 mR Drop & 86.20 & 85.52 & 79.03 & 78.51 & 91.13 \\
\hline $1 \mathrm{SD}$ & 2.815 & 3.022 & 6.360 & 3.919 & 2.454 \\
\hline $0 \mathrm{mR}$ Background & 1.924 & 1.914 & 3.192 & 2.466 & 2.377 \\
\hline 1 SD & 0.156 & 0.132 & 0.230 & 0.049 & 0.016 \\
\hline
\end{tabular}

the contaminants appear to inhibit luminescence in Teflon tape. Three contaminants significantly enhance the luminescence, through: wheel bearing grease, talc and the hand cream. The glow curves of uncontaminated Teflon tape, tape contaminated with wheel bearing grease, tape contaminated with talc, and the tape contaminated with hand cream are illustrated in Figures 8.5 through 8.8.

The re-read test performed with wheel bearing grease on Teflon is illustrated in Figures 8.9 through 8.12. Table 8.2 contains the raw data for the re-read test. The initial analysis of the contaminated tape produced a reader current of $13.9 \mathrm{nc}$. Subsequent cooling outside the reader and re-counting produced an average reader current of $2.25 \mathrm{nc} \pm 0.43 \mathrm{nc}$. The sixth re-read of the tape was performed after allowing the tape to cool in the reader. The reader current produced was $1.44 \mathrm{nc}$ and inspection of the signal shows no obvious peak when compared to the previous signals. 


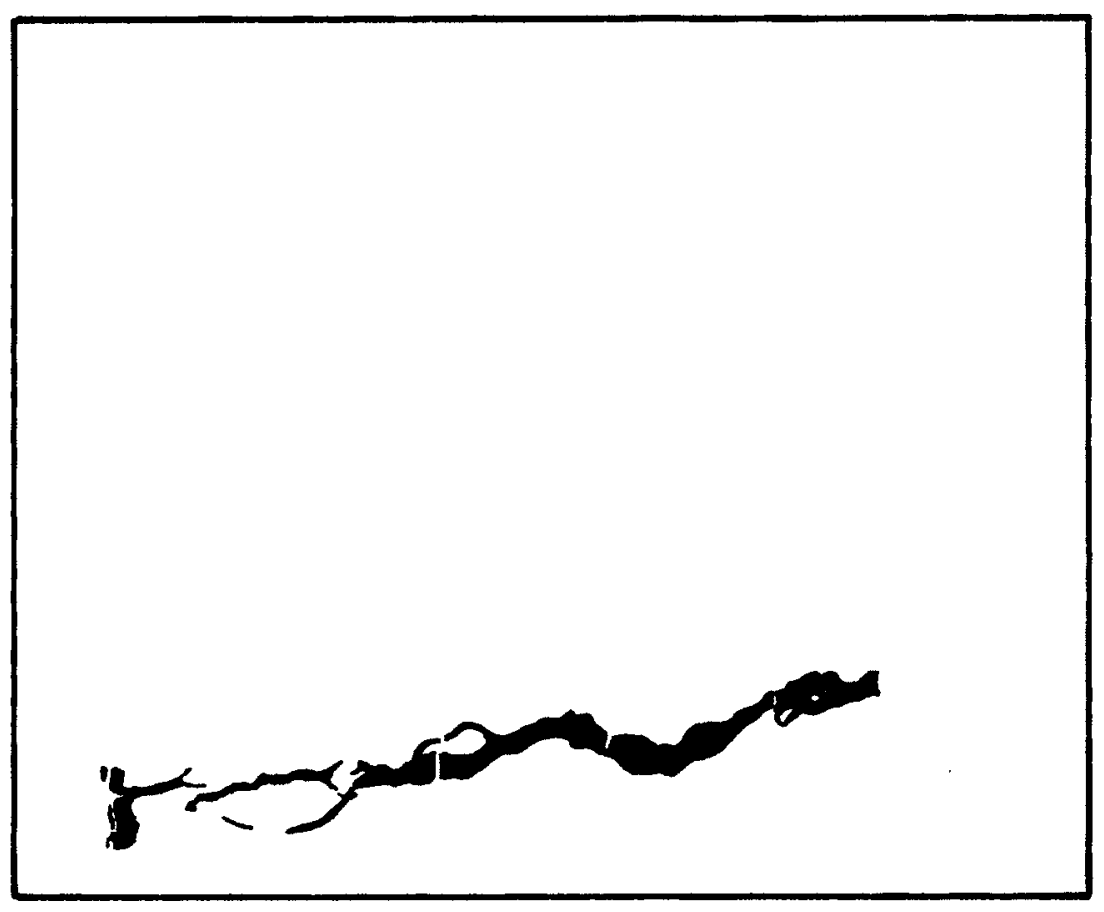

FIGURE 8.1. Glow Curve from Un irradiated Control TLD-700's

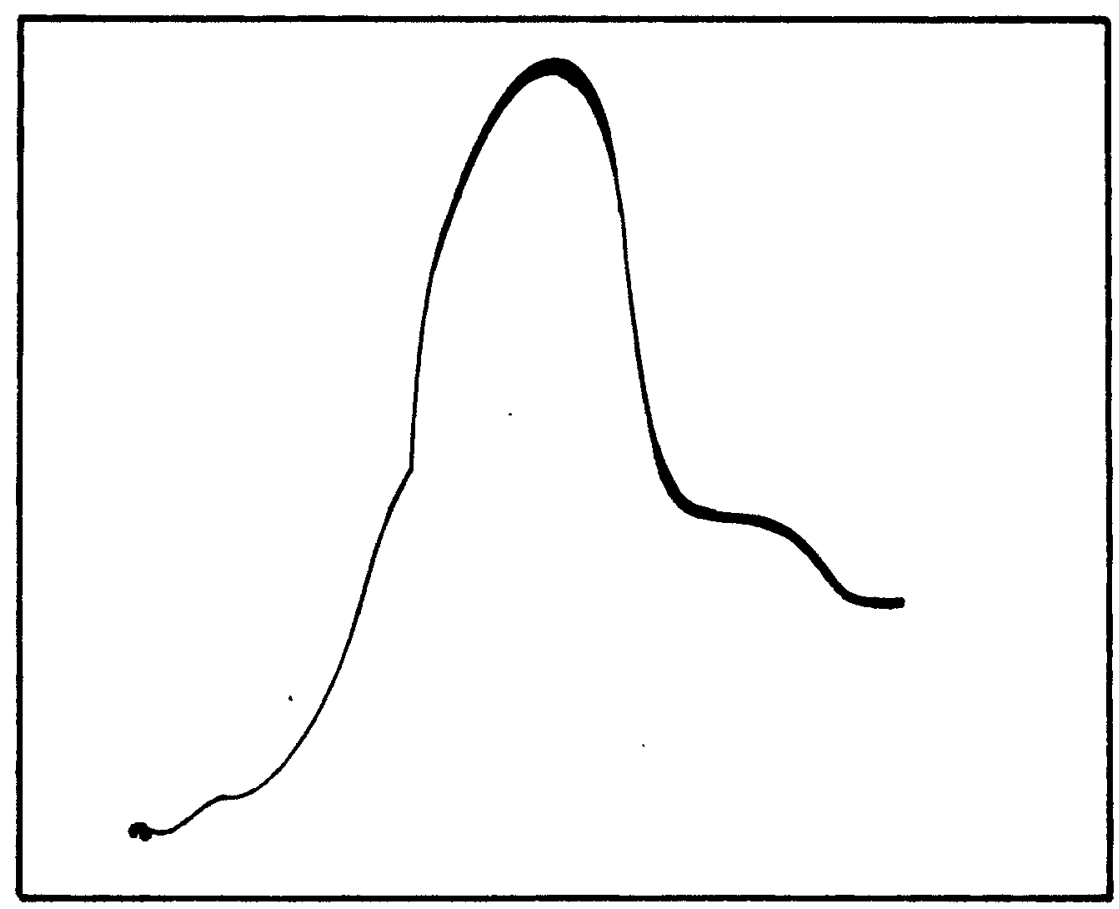

FIGURE 8.2. Glow Curve from an Irradiated $\left({ }^{137} \mathrm{Cs}\right)$ Control TLD-700

8.7 


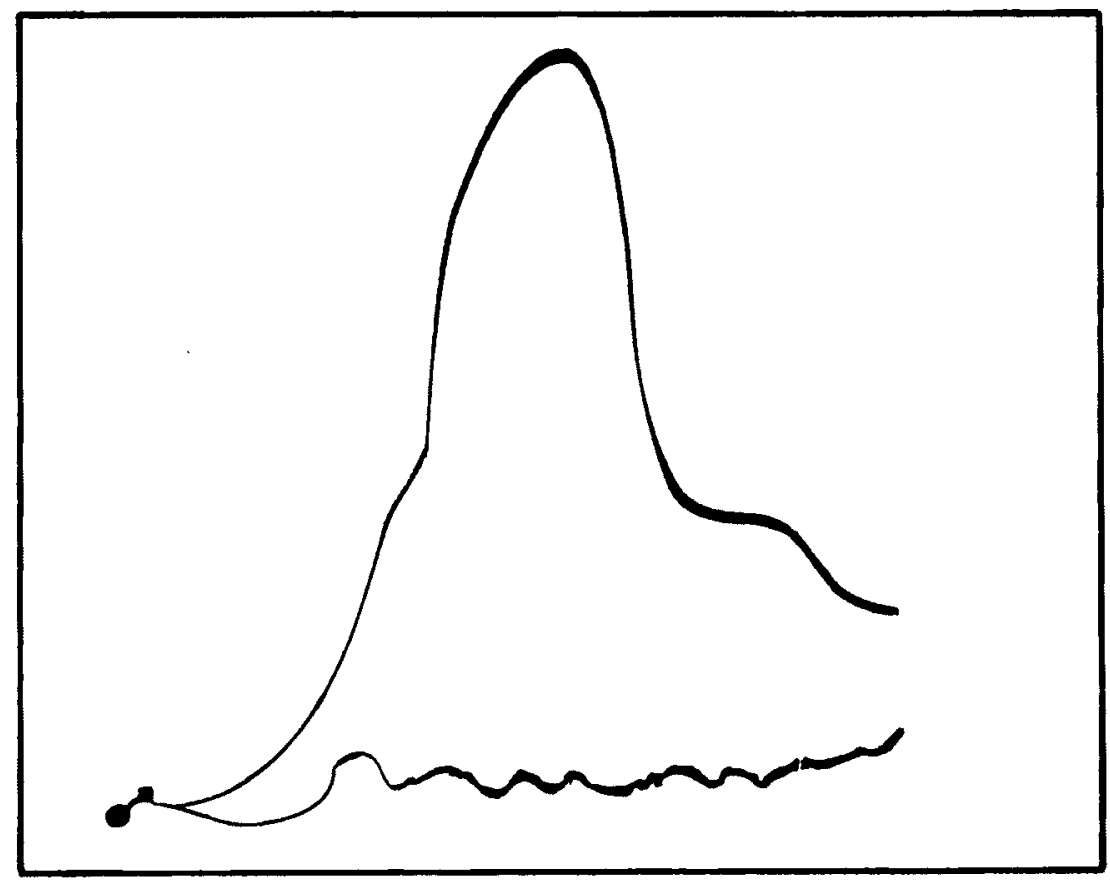

FIGURE 8.3. Glowing Curves from Irradiated and Unirradiated TLD-700's Contaminated with Spray Perfume

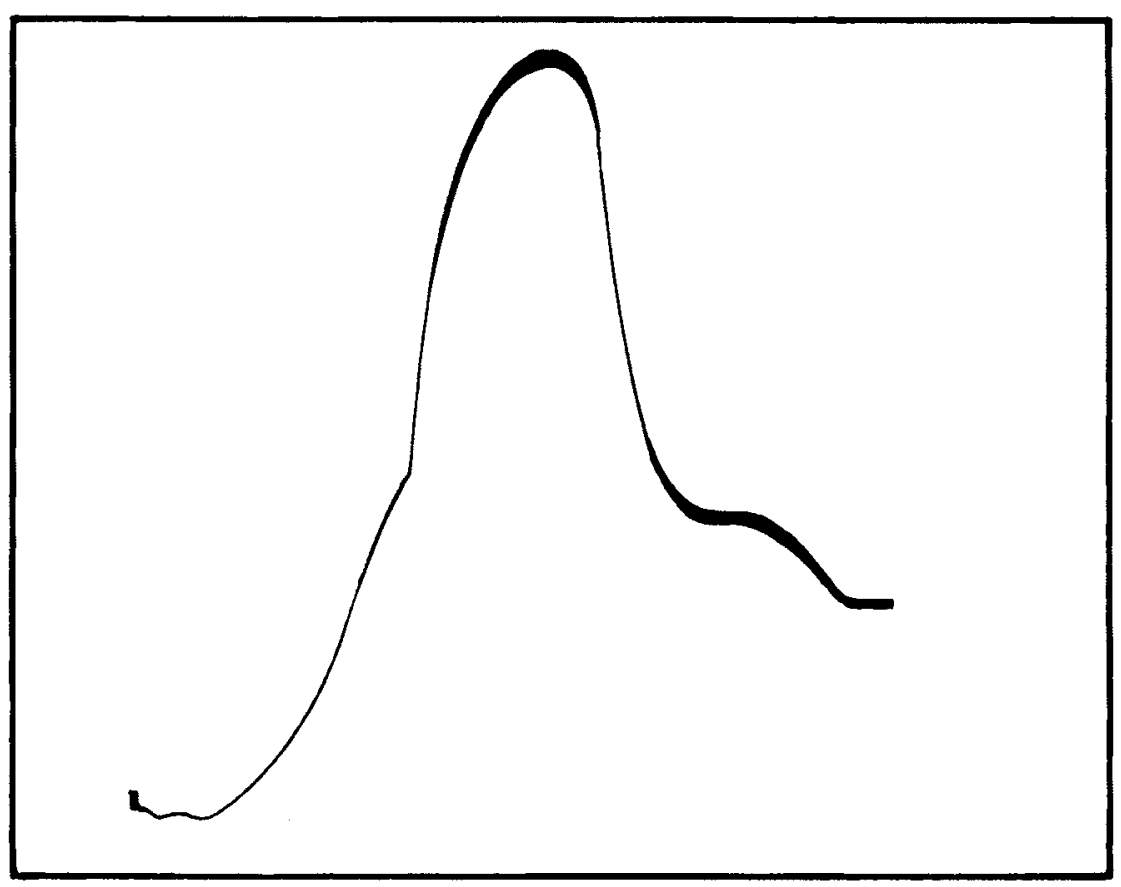

FIGURE 8.4. Glow Curve from Irradiated TLD-700 Contaminated with After Shave 


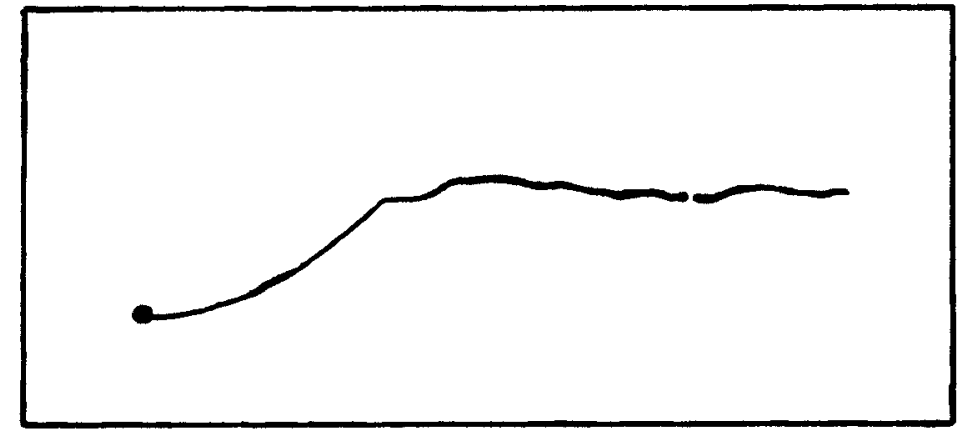

FIGURE 8.5. Glow Curve Uncontaminated Teflon Tape.

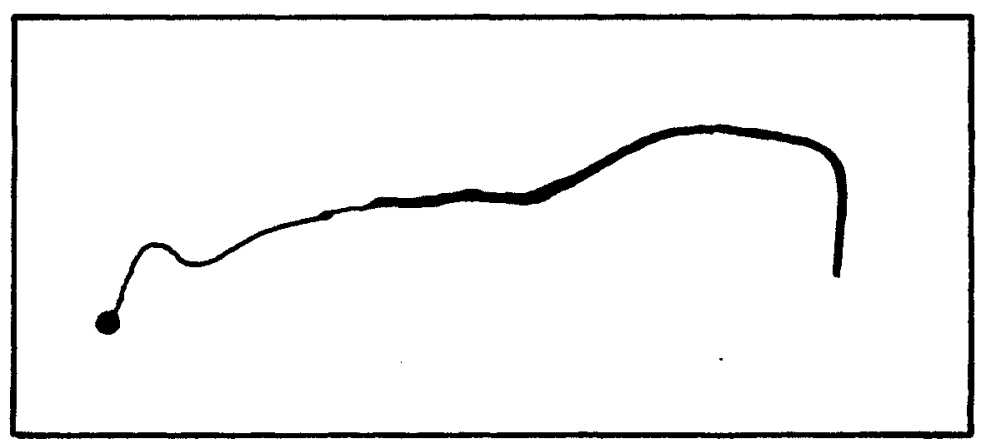

FIGURE 8.6. Glow Curve of Teflon Tape Contaminated with Talc.

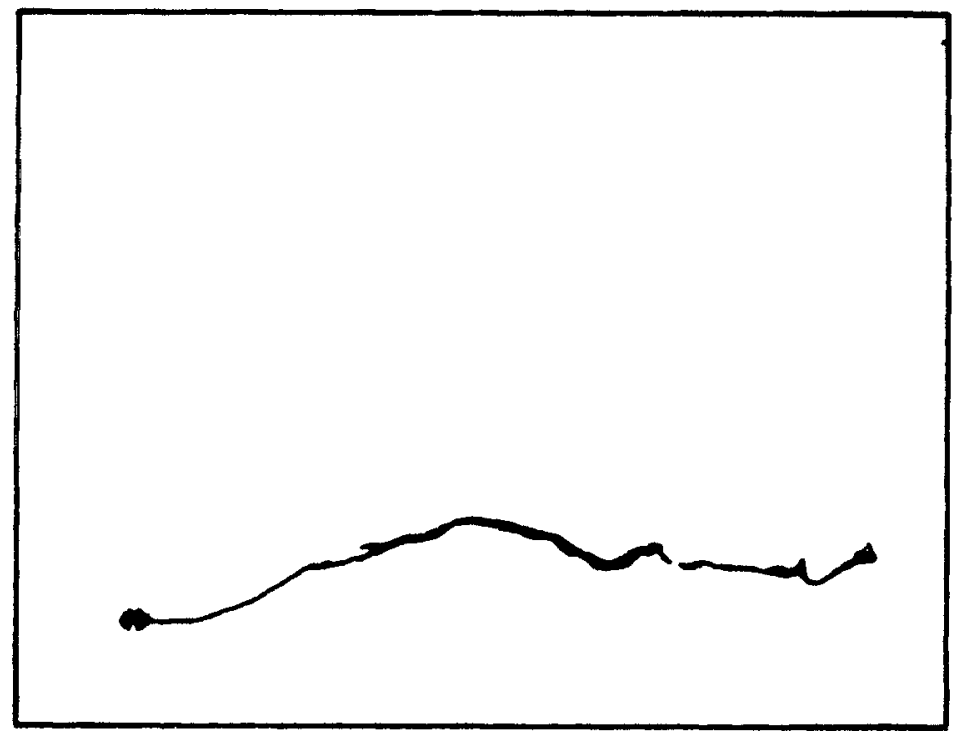

FIGURE 8.7. Glow Curve of Teflon Tape Contaminated with Volcanic Ash. 


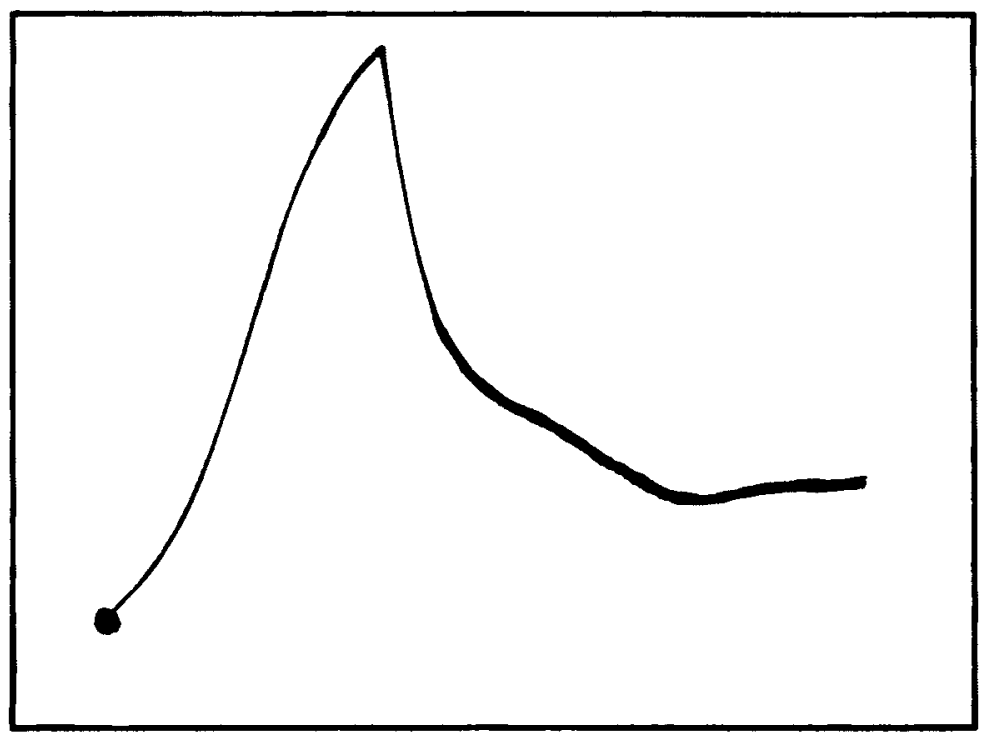

FIGURE 8.8. Glow Curve of Teflon Tape Contaminated with wheel Bearing Grease.

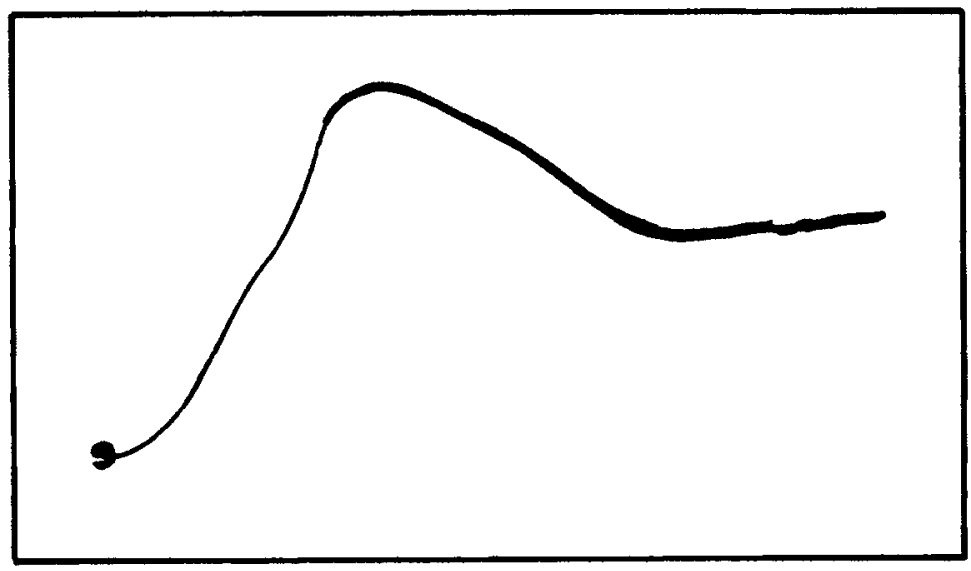

FIGURE 8.9. Glow Curve of Teflon Tape Contaminated with whee 1 Bearing Grease Analys is \#1. 


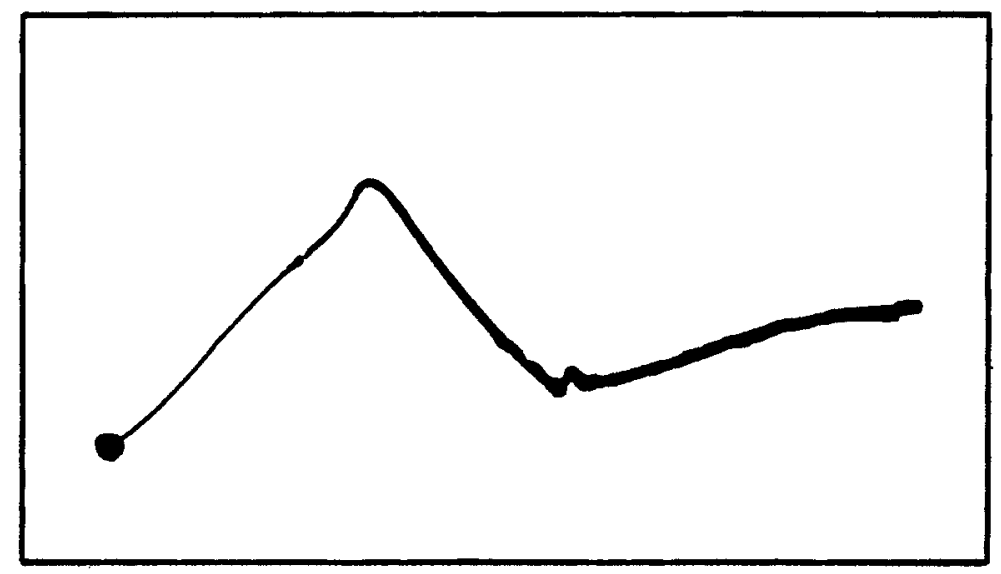

FIGURE 8.10. Glow Curve of Tefion Tape Contaminated with Wheel Bearing Grease Analys is \#2.

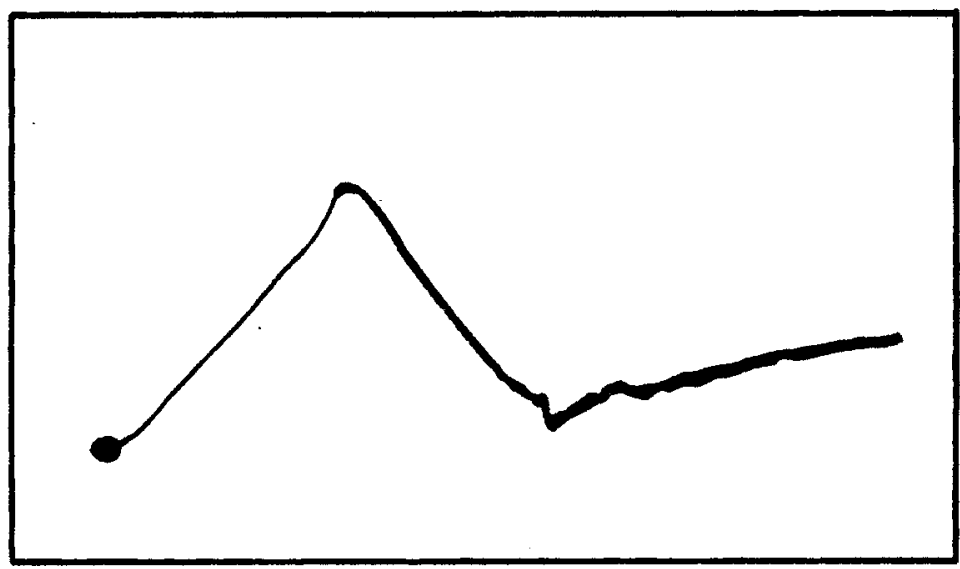

FIGURE 8.11. Glow Curve of Tefion Tape Contaminated with Wheel Bearing Grease Analysis $\# 3$.

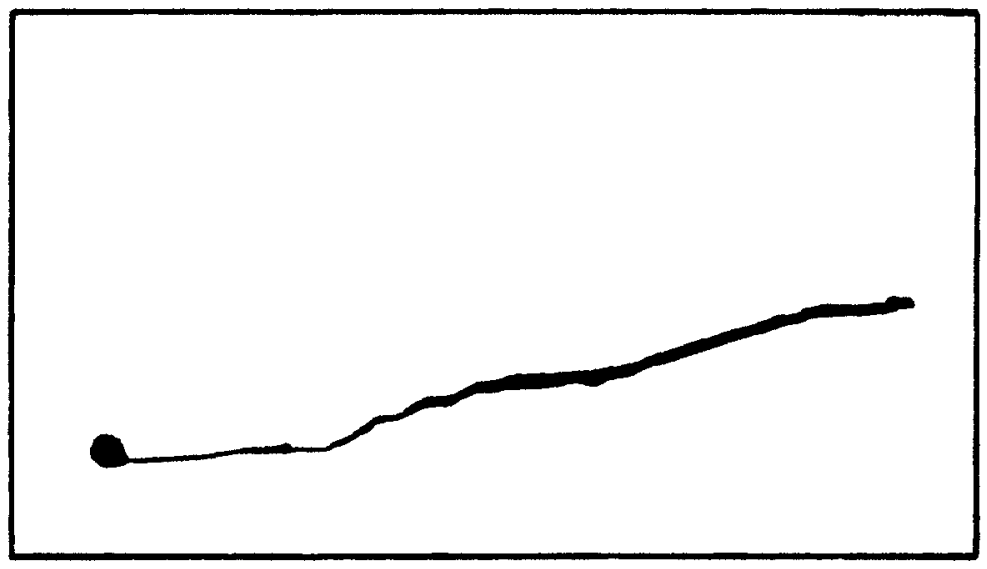

FIGURE 8.12. Glow Curve of Tefion Tape Contaminated with Wheel Bearing Grease Unirradiated by UV. 


\section{Microwaves}

Table 8.3 summarizes the raw data of TLD-700's exposed to microwaves. Of the unirradiated TLD-700's, the light output ranges from $0.97 \mathrm{nc}$ for the unirradiated chips which were not exposed to microwaves to 1.00 nc for the chips exposed to microwaves for 5 minutes with an average of $1.01 \mathrm{nc} \pm 0.04 \mathrm{nc}$ for the entire group.

The light output of TLD-700's irradiated in a field producing $100 \mathrm{mR}$ ranged from $52.1 \mathrm{nc}$ for chips exposed to microwaves for four minutes to 54.3 nc from chips exposed to microwaves for three minutes with a group average of $53.0 \mathrm{nc} \pm 1.63 \mathrm{nc}$.

Mechanical Shock

Table 8.4 summarizes the raw data from MPO's submitted to a drop test. The average net light output from each chip is the unirradiated dosimeters was consistently less than background for all dosimeters. The unirradiated controls had a dosimeter average light output of $-0.113 \mathrm{nc} \pm 0.140 \mathrm{nc}$ while the dropped, unirradiated dosimeters disclosed an average light output of $-0.193 \mathrm{nc} \pm 0.176 \mathrm{nc}$.

The average light output of the irradiated control dosimeters was $82.52 \mathrm{nc} \pm 6.928 \mathrm{nc}$ compared to an average of $84.08 \mathrm{nc} \pm 5.310 \mathrm{nc}$ from the dropped, irradiated dosimeters.

\section{DISCUSSION}

\section{Chemical Contaminants}

Investigation of light output data and glow curve characteristics of the contaminated TLD-700's suggests that the Lif crystal is relatively inert and that impurities introduced to the dosimeter extraneously have the effect of absorbing the emitted luminescence rather than changing the trap structure of the crysta1. Another effect that could be expected is inhomogenous heating of the crystal, leading to less luminescence produced over the analysis cycle. Experience at Hanford in the routine program has shown inhomogenous heating of the Lif crystal to have a more pronounced effect of ${ }_{\text {LiF }}$ (TLD-600) than on ${ }^{7}$ LiF (TLD-700). 
The dramatic results of this study 1 ie in the apparent trap restructuring of the Teflon TFE tape, used in the MPD, when brought into contact with certain substances. While the actual "trap structure" of Teflon is unknown, the sensitivity to ultraviolet light appears to be enhanced by the introduction of extraneous materials. That is best illustrated by comparing Figure 8.8 to Figures 8.9 and 8.12 . The glow peak of whee 1 bearing grease on Teflon tape occurs at a lower temperature than the ${ }^{7} \mathrm{LiF}$ glow peak, but would still contribute signal to the Lif peak during routine analysis. It is felt that the effect of sensitivity enhancement to UV is demonstrated graphically in Figure 8.12 which is the re-read of contaminated tape without exposure to UV. There exists no apparent extraneous signal in the Teflon in this re-read. As a point of perspective the result of the summation of signals from Tefion and an unirradiated TLD-700 would produce a signal equivalent to that from a TLD-700 chip irradiated in a $20 \mathrm{mR}$ field.

Microwave

The microwave oven used produces microwaves of an energy tuned to vibrate water molecules. As such, it was not expected to produce prominent loss of signal or signal enhancement in the TLD-700 due to the small amount of water of hydration present in the crystal. While there does appear to be some small signal enhancement, 0.97 nc compared to 1.02 nc from unirradiated chips, the chip statistics at background levels completely overshadow any effects from microwaves which might have been present during the study.

\section{Mechanical Shock}

Practical use of a dosimeter requires rugged construction and relative insensitivity to shock. This study nighlights the stability of the MPD when submitted to a drop test from $\sim 2.5$ meters. The reason that the net light outputs are less than zero lies in the fact that the control dosimeters (labelled background) were analyzed last and that a 11 the dosimeters were stored and analyzed in the 3717 building where there exists a small, but known, neutron field.

While there appears to be some loss of signal due to shock, the effect is too low to be of concern or consistent detection. 
CONCLUSION

Spurious flourescence in the Teflon tape caused by the introduction of extraneous materials was pronounced, while the Lif crystal was shown to be relatively inert when placed in contact with those materials. To eliminate spurious counts due to contamination of Teflon tape would require removal of each chip from the MPD and individual analysis of the chips. As this technique may not be practical, routine glow curve analysis by computer methods could alert TLD analysts of potentially contaminated dosimeters prior to complete read-out of remaining chips in the dosimeter. The dosimeter could then be disassembled and each chip analyzed individually eliminating signal enhancement from contamination of the Teflon tape.

Investigation of the data contained herein also demonstrates the insensitivity of the dosimeters to both microwave irradiation and mechanical shock. No recommendations are necessary for the protection of the dosimeter from these two external events.

\section{ACKNOWLEDGMENTS}

I wish to thank Fred Eichner, Virginia Tews and Mark Johnson for their tireless contribution of time and energy in analyzing the hundreds of samples required for this study. I also wish to thank Linda Stacy, Marianna Cross and Lor $\mathrm{i}$ Bisping who not only each had a hand in typing this report, but also in furnisining necessary substances like perfume, hand creme, etc.

\section{REFERENCES}

Kathren, R. L. 1970. "Evaluation of Hanford Basic Thermoluminescence Dosimeter," BNWL-CC-2633, Pacific Northwest Laboratory, Richland, Wash ington. 


\subsection{STUDY 7 - EXTREMITY DOSIMETER STUDIES}

R. L. Kathren, J.W. Aldrich, G. W. R. Endres, and M. K. Winegardner

\section{FOREWORD}

Finger rings employing a single TLD-700 chip have served as the routine extremity dosimeter for the past several years. The chips are read, cleaned, annealed, and loaded by hand. The response characteristics of the finger $r$ ing are described in this study. Several other areas important to the effective field use of the ring dosimeters are also discussed.

\section{SUMMARY}

The TLD rings currently in use at the Hanford site appear satisfactory for most extremity dosimetry situations. However, proper annealing is crucial to accurate and precise readout and dose assignation. The standard PNL annealing procedure of $400^{\circ} \mathrm{C}$ for one hour followed by $100^{\circ} \mathrm{C}$ for two hours appears best; reader annealing is unacceptable, showing extremely poor precision. Although the rings are in the main suitable from a human factors standpoint, adjustable size is suggested for future models. Also, it should be noted that the rings are not suitable for neutron dosimetry, but can be used for beta dosimetry with a suitable correction factor.

\section{INTRODUCTION}

Since 1974, a relatively simple finger ring has served as the standard extremity dosimeter for the Hanford site. The basic ring consists of a single size loop of flexible hypollergenic plastic flared into a small rectangular parallelopiped chamber into which a single $1 / 8 \times 1 / 8 \times 0.035-i n$. TLD-700 ch ip is inserted (Figure 9.1). A tape bearing an identification number is wrapped around the TLD chamber when the ring is used effectively keeping the TLD chip in the chamber. With the tape in place, the covering is about $25 \mathrm{mg} / \mathrm{cm}^{2}$ thick. The chamber itself is sufficiently large to hold two TLD-700 chips, but this option is not used for routine hand dosimetry. The present finger ring was designed by U.S. Testing Company and replaced an earlier model which utilized a lozenge shaped wafer of ${ }^{2}$ if impregnated Teflon. 


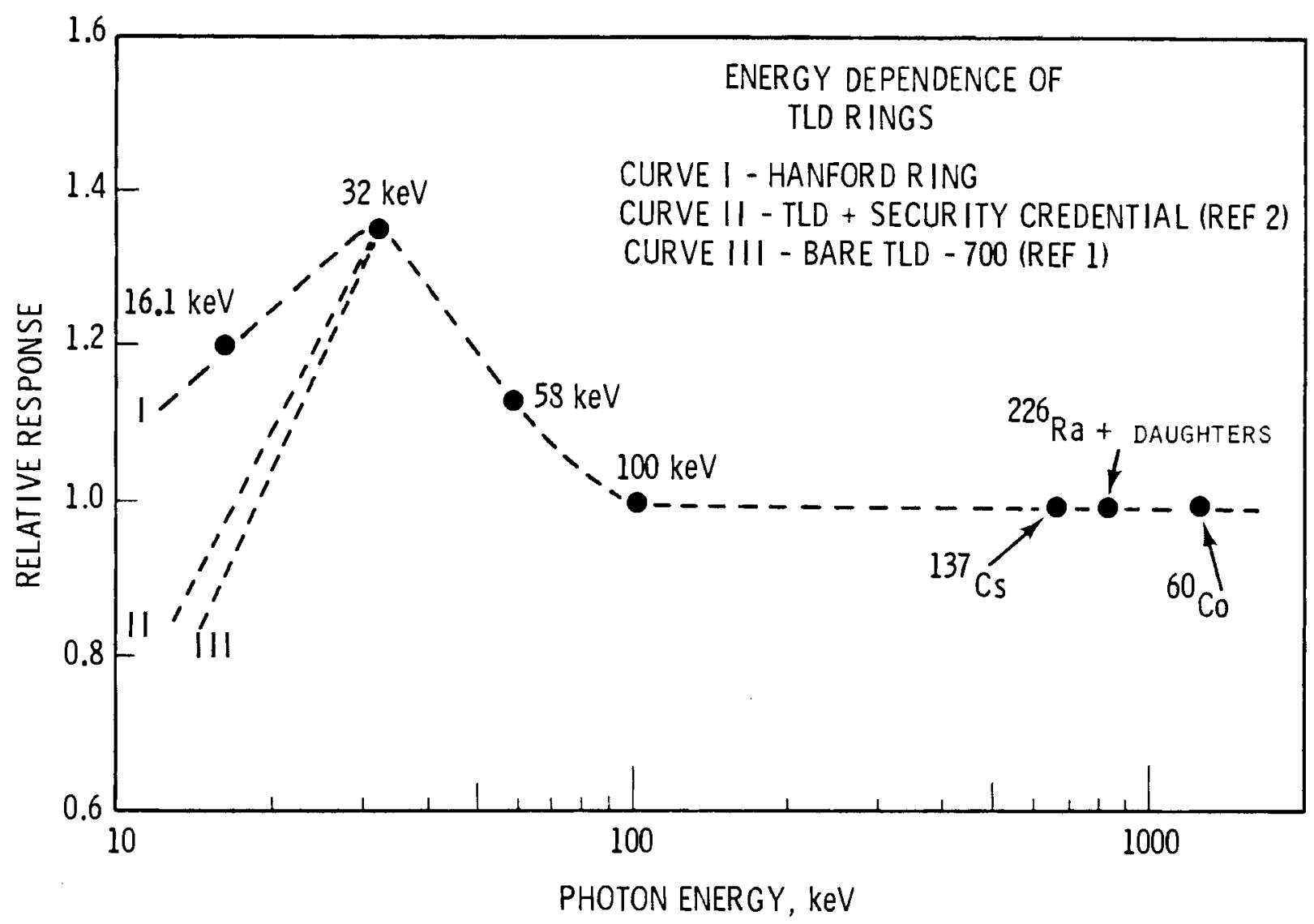

FIGURE 9.1. Photon Energy Dependence of TLD Rings

Although the rings have been used more or less satisfactorily for six years, their response characteristics have not been formally documented nor fully characterized. This study, therefore, was to provide some of the necessary documentation, and to investigate and hopefully resolve some of the problems and inconsistencies that have appeared over the years. A particularly vexing problem was related to inconsistent results between paired rings worn for a 4-week interval and 4 rings worn for consecutive 1 -week intervals on the same hand over the same time period.

Because many of the response characteristics of the TLD-700 chips are well known, studies of these were not repeated except where incorporation into the ring might presumably effect these known characteristics. Accordingly the following areas were examined: 
1. Photon energy dependence

2. Beta response

3. Effects of temperature and humidity

4. Field problems.

\section{PHOTON ENERGY DEPENDENCE}

Since the rings are to be used in field situations involving the handling of plutonium, americium-241, and other low energy photon emitters, knowledge of the energy dependence of the $T L$ chip in the assembled configuration is important. Since the covering over the TLD chip is only about $25 \mathrm{mg} / \mathrm{cm}^{2}$ of material with $z_{\text {eff }}$ close to that of air and tissue, the energy dependence of the assembled rings was not expected to be appreciably different from that observed for the bare TLD chips, and previously reported (Endres, Kathren and Kocher 1970). This was, in fact, the case.

Data points were obtained with the assembled rings at 7 energies from $16 \mathrm{keV}$ to $1.25 \mathrm{MeV}$ and are shown in Figure 9.1. Except for the single point at $16 \mathrm{keV}$, the data agree quite well with prior observations of the bare TLD chips (Endres, Kathren and Kocher 1970) and the chips exposed behind a Hanford security credential (Kocher et a1. 1971). The $16 \mathrm{keV}$ response appears somewhat greater with the rings, but not at sufficient magnitude to adversely affect field application of the rings. Indeed, the observed data point at $16 \mathrm{keV}$ is, from an operational standpoint, advantageous.

The data shown in Figure 9.1 reveal that, based on the ${ }^{137} \mathrm{Cs}$ calibration normally used at Hanford, the rings have a moderate overresponse at photon energies below about $100 \mathrm{keV}$, and are flat in response from $100 \mathrm{keV}$ to at least $1250 \mathrm{keV}$. This observed energy dependence is satisfactory for all but the most demanding measurements, and well with in acceptable levels for routine operational health physics, providing a slight degree of concentration at low photon energies. 


\section{BETA RESPONSE}

Exposures were made in the ring configuration to beta radiation from ${ }^{90} \mathrm{Sr}-\mathrm{Y}$ and from natural uranium. Light output per rad in air was compared with that from photons from ${ }^{226} \mathrm{Ra}$ in equilibrium with daughters. The data are shown in Table 9.1 below. For comparison, the beta response of the previous Hanford rings is shown. As expected the light output per rad of beta radiation (air dose) is about half that from a comparable dose of high energy photons. This should pose no significant problems for Hanford operations except in those relatively uncommon situations where beta/hand exposures predominate.

\section{TEMPERATURE AND HUMIDITY EFFECTS}

Limited studies were made of the effects of temperature and humidity on the response if the rings, but these were adequate to determine that the rings should serve satisfactorily in virtually all operational situations. No adverse effects were noted in either the TLD itself or the ring following a holding period of 1 week at $100 \%$ relative humidity and a temperature of $100^{\circ} \mathrm{F}$.

TABLE 9.1. Response of Hanford TLD Rings to Beta Radiation

\begin{tabular}{|c|c|c|c|c|}
\hline & & & $\begin{array}{l}\text { Relat } \\
\text { Outpu } \\
\end{array}$ & $\begin{array}{l}\text { e Light } \\
\text { per rad }\end{array}$ \\
\hline Source & $B(\max )$ & $E_{B}(a v)$ & $\begin{array}{l}\text { Current } \\
\text { Ring } \\
\end{array}$ & $\begin{array}{l}\text { Previous } \\
\text { Ring } \\
\end{array}$ \\
\hline $226 \mathrm{Ra}+\mathrm{dtrs}$ & $\begin{array}{l}\text { (Photons; } \\
E=830 \mathrm{keV} \text { ) }\end{array}$ & & & \\
\hline $90 S r-Y$ & $\begin{array}{ll}2.27 & (99+\%) \\
0.546 & (100 \%)\end{array}$ & $\begin{array}{l}0.93 \\
0.18\end{array}$ & 0.6 & 0.52 \\
\hline Natur + dtrs & $\begin{array}{ll}2.29 & (98 \%) \\
0.191 & (65 \%) \\
0.100 & (35 \%)\end{array}$ & $\begin{array}{l}0.72 \\
0.06 \\
0.03\end{array}$ & 0.4 & 0.39 \\
\hline
\end{tabular}

NOTES: Beta energies are in MeV. Previous ring data from Kocher, Kathren and Endres 1970. 
There was no loss of signal (i.e., decay), nor was there an adverse change in precision. Similarly, no effect was noted with TLOs held at temperatures as low as $10^{\circ} \mathrm{F}\left(-14^{\circ} \mathrm{C}\right)$.

\section{FIELD STUDIES}

Although the rings have been used successfully in the field for several years, in late 1978 a particularly vexing problem surfaced in a group of heavy users of rings. To better control hand exposures, two sets of rings were worn on each hand. One set was changed weekly, and dose information used as a sort of prompt control point. The other set was changed at 4-week intervals, and served as the basic control dose.

Excellent agreement was noted between paired rings (4-week change cycle) worn on both hands. However, agreement was poor between the four weekly changed rings and those changed on a 4-week cycle. Theoretically, the sum of doses on the four weekly rings should exactly equal the dose on the one ring worn for four weeks. Generally, the sum of the four weekly rings was consistantly greater than that of the single ring, much more than could be accounted for by normal statistical fluctuations.

After verifying that dosmieter issue, recovery and field handling procedures were satisfactory, a statistical analysis was made of the field data. The summed dose readings for the four week ly dosimeters was plotted as a function of the single 4-week ("monthly") dose. If the dosimeters were functioning as they should, these readings should have a $1: 1$ correspondence, or, in mathematical terms, be described by an equation of the form $y=x$ in which $y$ is the summed four weekly doses and $x$ is the single 4-week dose. As seen in Figure 9.2, this clearly was not the case. If the data were fitted to a straight line forced through the origin, this would be described by

$$
y=1.33 x
$$

which states that on the average, the dose obtained from the four weekly chips was about one-third greater than that obtained from the single chip worn for four weeks. 


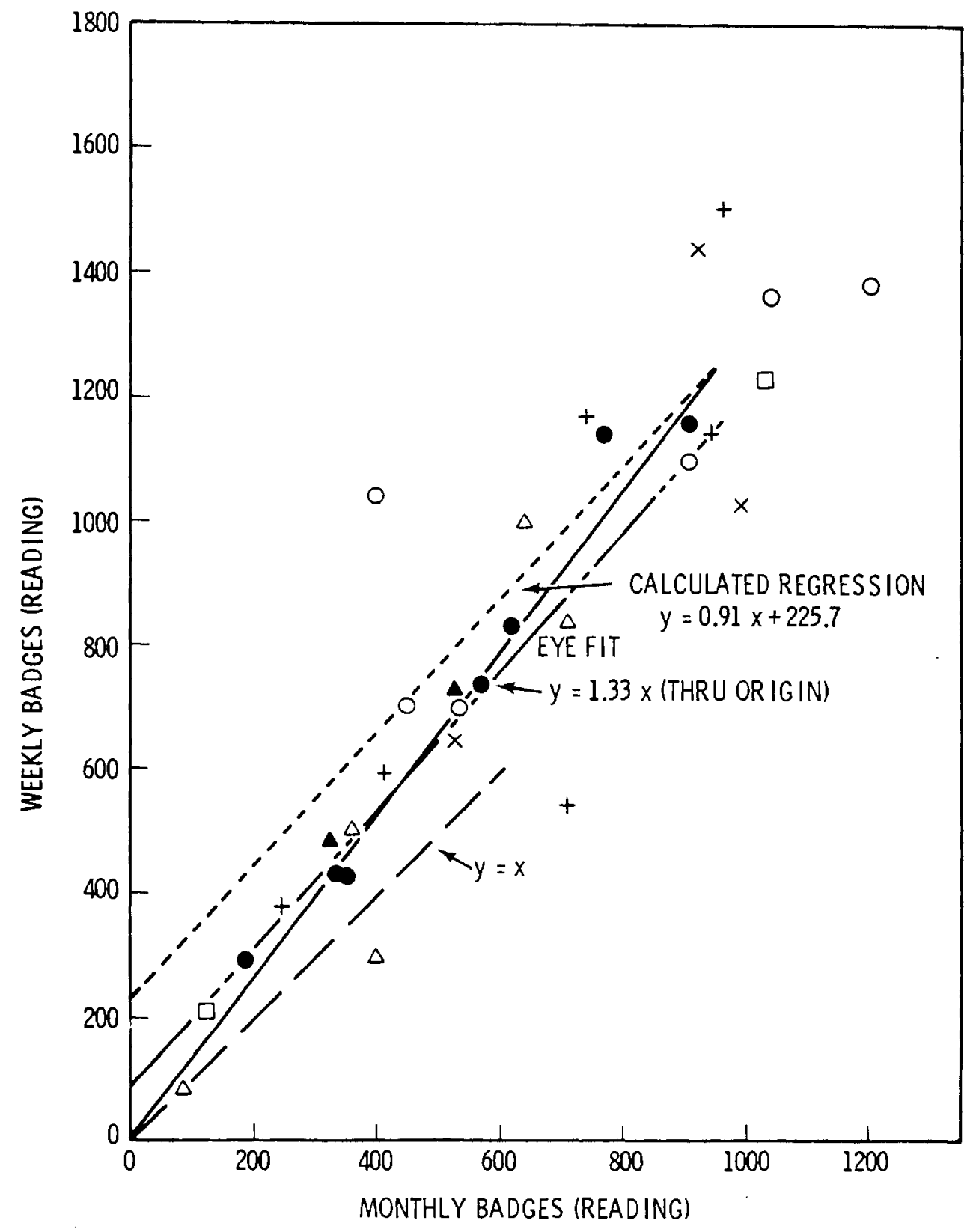

FIGURE 9.2. Comparison of Weekly and Monthly Ring Readings 
Mathematical curve fitting techniques were used to determine the best of fit for the paired data points. The analysis revealed that the relationship was best fit by a linear relationship described by Equation (2)

$$
y=0.91 x+225.7
$$

This equation had a coefficient of determination of 0.84 , suggestive of a good fit; by contrast, coefficients of determination for exponential, logarithmic, and power functons were all less than 0.35 , indicative of the fact that the data simply did not fit these forms.

Examination of Equation (2) reveals a slope of 0.91 and an intercept of 225.7. This slope of 0.91 indicates that the response per unit exposure of the paired dosimeters was with in about $\pm 5 \%$ from the mean, the positive intercept suggests that the readings from the four weekly dosimeters were generally high by a more or less constant mean amount of $225.7 \mathrm{mrem}$. This is indicative of a systematic constant error in the system.

Linear regression analysis was also done on the paired data points for each individual month, with the same general result. That the data in fact fitted a straight line was indicated by coefficients of determination of at least 0.69 , and greater than 0.94 in five of the 8 months evaluated. The slopes for the 8 months evaluated revealed excellent correlation in sensitivity (i.e., response per unit exposure); the mean of these slopes was $1.05 \pm 0.19$, very close to the value of 1.0 expected if the sensitivities of the week $1 y$ and "monthly" TLD chips were equal. The intercepts, however, were highly variable, ranging from -31 to 423; in only two of the eight months studied, the intercepts were near zero. Since all but one of the intercepts are positive, this is suggestive of an effect that somehow adds a more or less constant amount of dose to the four weekly dosimeters, or conversely, reduces the dose to the single dosimeter worn for four weeks. This amount was different each month and independent of dose--that is, it was not a certain fraction of the dose, nor did it seem to be a funcion of the dose indicated by the dosimeters. 
A logical explanation appeared to be greater fading of the TL signal in the dosimeters worn for four weeks as opposed to those worn only for one week. However, fading studies revealed that this could not be the case; indeed, no significant fading was observed over a period of one month.

The data themselves pointed to some other explanation than fading, for in some months the two sets of rings tracked together, while in others (more frequently) the discrepancy occurred. Moreover, when the weekly rings were evaluated Dy PNL instead of the dosimetry contractor, better agreement was noted between them and the singly 4-week dosimeter processed by the dosimetry contractor. Also, the intermittent nature of the problem was suggestive of some other phenomenon than fading, which would be expected to be observed consistantly.

A sample of the rings routinely used for dosimetry in the field was obtained from the dosimetry contractor and examined for dirt or other contaminants that might produce a consistant error of the type noted. In some cases, small quantities of talcum powder were observed in the rings, indicative of less than perfect cleaning. The presence of this contaminant in a few rings was, however, unlikely to adversely affect the results. Examination of rings revealed normal background levels, but in a few cases abnormal glow curves were noted. These abnormal glow curves showed that the low energy traps had been incompletely emptied, which is indicative of less than perfect annealing, and could produce changes in sensitivity.

To test this nypothesis, a group of dosimeters was obtained from the dosimetry contractor and divided into three groups, each of which was given a different annealing to procedure, as indicated:

Group 1 was given the standard contractor annealing of $400^{\circ} \mathrm{C}$ for two hours followed by $60^{\circ} \mathrm{C}$ for 24 hours,

Group 2 was reader annealed only,

Group 3 was given the PNL standard anneal of $400^{\circ} \mathrm{C}$ in a nitrogen atmosphere for one hour followed by $100^{\circ} \mathrm{C}$ for two hours. 
After annealing, the dosimeters were exposed to $500 \mathrm{mR}$ and read out. The results are shown in Table 9.2. Although only five rings were used in each group, the results are obvious and unambiguous, and show greater light output and variability than those rings given the standard PNL annealing. On the average, the reader annealed units would have shown a dose equivalent of about 70 mrem more than those given the PNL standard annealing, while those given the contractor annealing would have been interpreted as having on the order of 150 mrem (37\%) more than those given the standard annealing. If only reader annealing and the contractor annealing are compared, the contractor annealed dosimeters would have been interpreted as having, on the average, $100 \mathrm{mR}$ greater exposure.

The above data strongly underscore the need for a sound and consistantly performed annealing procedure. This conclusion is further supported by the glow curves in Figure 9.3. The bottom curve, which shows a relatively sharp, pronounced single peak is indicative of the dosimeters given the PNL standard annealing; the other four glow curves have most of their light output at lower temperatures, suggestive of inadequate trap emptying and restructuring.

TABLE 9.2. Light Output of TLD-700 Following Various Annealing Procedures

\begin{tabular}{|c|c|c|c|}
\hline & $\begin{array}{l}\text { Contractor } \\
\text { Anneal ing Cycle } \\
\left(400^{\circ} \mathrm{C} \text { for } 2 \mathrm{hrs}\right. \\
\left.+60^{\circ} \mathrm{C} \text { for } 24 \mathrm{hrs}\right) \\
\end{array}$ & Reader Annealing & $\begin{array}{l}\text { PNL Standard } \\
\text { Annealing Cycle } \\
400^{\circ} \mathrm{C} \text { for } 1 \mathrm{hr}+ \\
\left.100^{\circ} \mathrm{C} \text { for } 2 \mathrm{hr}\right) \\
\end{array}$ \\
\hline & 228.1 & 189.0 & 172.8 \\
\hline & 243.0 & 195.1 & 188.2 \\
\hline & 201.5 & 242.4 & 160.6 \\
\hline & 235.6 & 120.0 & 179.9 \\
\hline & 256.1 & 224.1 & 160.5 \\
\hline Mean \pm S.D. & $232.9 \pm 20.4$ & $194.1 \pm 46.8$ & $170.8 \pm 11.4$ \\
\hline $\begin{array}{l}\text { Light output } \\
m R \pm S . D .\end{array}$ & $0.47 \neq 88 \%$ & $0.38 \pm 24.1 \%$ & $.034 \pm 67$ \\
\hline
\end{tabular}




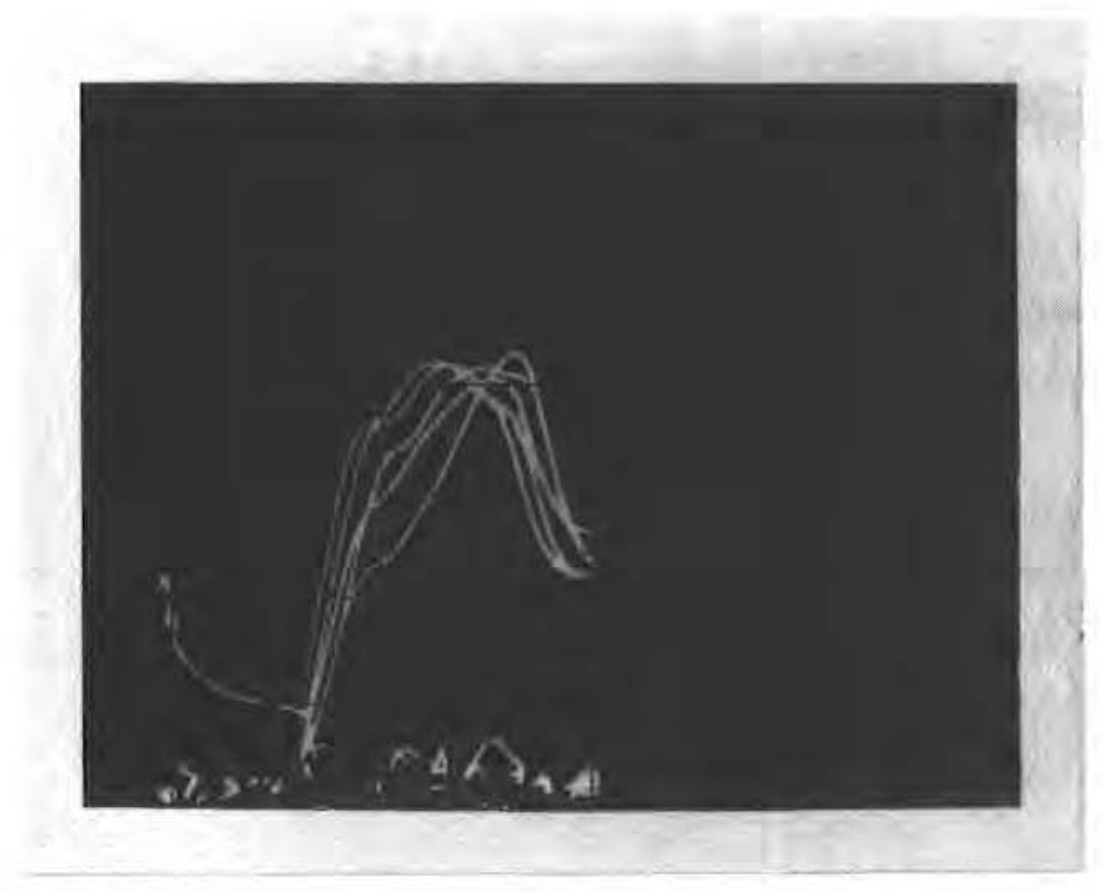

FIGURE 9.3. TLD Glow Curves for Different Annealing Procedures

A visit was made to the facilities of the dosimetry contractor to observe the complete operation of ring dosimeter readout; several items were noted which could adversely impact the precision and accuracy of the dosimeter interpretation, including

1. Heating and cooling the dosimeter chips in a rather tight mass rather than spread out during the annealing cycle; this hampers thermal transfer.

2. Readout of the weekly dosimeters without calibration standards.

3. Non-constant cooling and temperature of the reader photomultiplier tube.

4. No provision for heater temperature measurement or routine glow curve measurement during the readout cycle.

While the four factors mentioned above could contribute to readout errors, such contribution would tend to be smaller and of more random effect; thus, the use of an appropriate annealing cycle is considered vital, and $400^{\circ} \mathrm{C}$ for one hour followed by $100^{\circ} \mathrm{C}$ for two hours is recommended. 


\section{HUMAN FACTORS}

The human factors aspects of the rings were discussed with field personnel using them. In general, the rings are suitable, although some persons, particularly those with smaller hands, noted a tendency of the rings to fall off while others with larger hands were critical of the size. A variable size ring such as that in use elsewhere would seem to be indicated.

\section{REFERENCES}

Endres, G. W. R., R. L. Kathren, and L. F. Kocher. 1970. Thermoluminescence Personnel Dosimetry at Hanford. II. Energy Dependence and Application of TLD materials in Operational Health Physics. Health Phys. 18:655.

Kocher, L.F., et al. 1971. "The Hanford Thermoluminescent Multipurpose Dosimeter," BNWL-SA-3955, Pacific Northwest Laboratory, Richland, Washington.

Kocher, L.F., R. L. Kathren, and G.W.R. Endres. 1970. Thermoluminescence Personne 1 Dosimetry at Hanford. I. 7L if Extremity and Non-Radiation Worker Dosimeters. Health Phys. 18:655. 



\section{STUDY 8 - STATISTICAL AND LOW DOSE RESPONSE}

M. R. Thorson and G.W. R. Endres

\section{FOREWORD}

The low dose response and the lower limit of detection of the Hanford dosimeter depend upon many factors, including the energy of the radiation, whether the exposure is to be a single radiation or mixed fields, annealing cycles, environmental factors, and how well various batches of TLD materials are matched in the system, etc. A careful statistical study and sensitivity analys is was performed to determined how these factors influence the response of the dosimeter system. Estimates have been included in this study of the standard deviation of calculated dose for various mixed field exposures from 0 to $1000 \mathrm{mrem}$. 


\section{SUMMARY}

Values for significant sources of randomness in the Hanford multipurpose dosimetry system were determined from analysis of numerous sets of thermoluminescent data. These values were combined mathematically using the currently used dose equations to obtain the expected standard deviations of calculated dose equivalents. This was done for many combinations of mixed field exposures in the range of 0 to 1000 mrem. From this generated data, it is possible to point out some of the weakenesses and strengths of the HMP dosimetry system including the expected limits in precision.

By carefully analyzing data in this study, the following conclusions can be made:

1. It is possible to assign confidence intervals or standard deviations to calculated dose equivalents, though it should be remembered that confidence intervals shown here do not include some sources of error such as environmental factors and the effect of wearing position or angle of exposure on gamma and beta responses.

2. The lowest level of significant detection(a) in nonmixed fields for ${ }^{90} \mathrm{Sr}$ beta radiation is $11 \mathrm{mrem}$, for gamma radiation is $3.4 \mathrm{mrem}$, for thermal neutron radiation is $0.2 \mathrm{mrem}$, and for ${ }^{252} \mathrm{Cf}$ fast neutron radiation is $10 \mathrm{mrem}$.

3. The lowest dose equivalent level which has a $97 \%$ chance of being detected $(b)$ for ${ }^{90} \mathrm{Sr}$ beta radiation is $22 \mathrm{mrem}$, for gamma radiation is $7 \mathrm{mrem}$ and for thermal neutron radiation is $0.3 \mathrm{mrem}$. This level does not occur for fast neutron exposures.

4. Calculated fast neutron dose has a minimum standard deviation equal to $64 \%$ of the total fast neutron dose and, as such, is never very precise.

(a) This is arbitrarily defined as when the mean calculated dose is at least one standard deviation away from zero.

(b) The level which is two standard deviations above zero. 
5. Fast neutron dose equivalent calculations are significantly imprecise ${ }^{(a)}$ whenever the thermal neutron dose equivalent exceeds about $5 \%$ of the total dose equivalent.

6. In a high energy beta field, such as the ${ }^{90} \mathrm{Sr}$ field used for the beta exposure data, the 4-chip dosimeter consistently underestimates the fast neutron dose equivalent received. The 5-chip dosimeter does not have this problem.

7. The energy difference or scatter difference between a calibrations gamma exposure $\left({ }^{137} \mathrm{Cs}\right)$ and a field gamma exposure can lead to a determinate error $(b)$ in the calculated fast neutron dose. This error may have an order of magnitude value of about $25 \%$ of the total gamma exposure. The 5-chip dosimeter in theory should have less of a problem in this area.

8. A significant cumulative positive bias in the HMP dosimetry system will arise from the rejection of negative calculated dose readings. When the standard deviation exceeds the calculated dose, this becomes a significant problem. For example, a dosimetered person receiving 1000 mrem gamma exposure neglecting determinate error would be expected to show a calculated fast neutron dose equivalent of $0 \pm 270$ mrem. If all negative values are rejected, the average calculated dose equivalent would be $107 \mathrm{mrem}$ and one in ten persons could be expected to show a fast neutron exposure of more than $345 \mathrm{mrem}$, though they received no neutron exposure. This type of problem has shown up historically in high fast neutron personnel exposure readings during $N$ reactor outages. Problems of this nature may become considerably more serious for calculated fast neutron exposure if quality factors are greatly increased.

(a) This is arbitrarily defined as when the mean calculated dose for the specific radiation given is within one standard deviation of zero.

(b) Determinate error is a system bias as opposed to random error or indeterminate error. 


\section{RECOMMENDATIONS}

A. Calculating the fast neutron dose ${ }^{(a)}$ is by far the weakest link in the HMPD calculation of total dose received. Any overall system improvement should attempt to improve this value, especially when the fast neutron dose is calculated after a significant thermal exposure. Possible ways of improving the calculated fast neutron dose statistics are listed below:

1. Reduce the magnitude of $R 3$ in a thermal neutron field by placing a cadmium shield on the backside of chip \#3, thereby reducing the magnitude of terms used to calculate the fast neutron dose. Using the arrangement snown in Figure $10.1 \mathrm{a}$, the expected standard deviation of calculated fast neutron dose would be reduced to about $2 / 3$ of the current standard deviation values. (See Table 10.1 and Figure $10.1 \mathrm{a}$ and b.)

2. Reduce the strong positional dependence of the dosimeter for neutron exposures by placing a thin moderator behind the dosimeter. (See Study 5.) Potentially chip $\# 4$ could be reduced from $\pm 9.3 \%$ to $\pm 4 \%$ in a thermal neutron field and from $\pm 12.9 \%$ to $\pm 9.9 \%$ in a fast neutron field. This would improve statistics only from neutron exposures.

3. Integrate the second thermoluminescent peak, at $255^{\circ} \mathrm{C}$, separately for neutron calculations to calculate dose values. This might be helpful as preliminary data indicates the second glow peak is selective by a factor of ten for neutrons over gamma. That is about $20 \%$ of the total thermoluminescence for neutrons comes from the $255^{\circ} \mathrm{C}$ peak; whereas, only about $2 \%$ of the total thermoluminescence for gamma radiation comes from the $255^{\circ} \mathrm{C}$ peak. Because the total magnitude of gamma response relative to neutron response could be reduced by a factor of ten, the associated uncertainties also could be reduced (depending on dose) by up to a factor of ten.

(a) The terms dose and dose equivalent are used interchangeably in this report to mean dose equivalent in units of rem or mrem. 


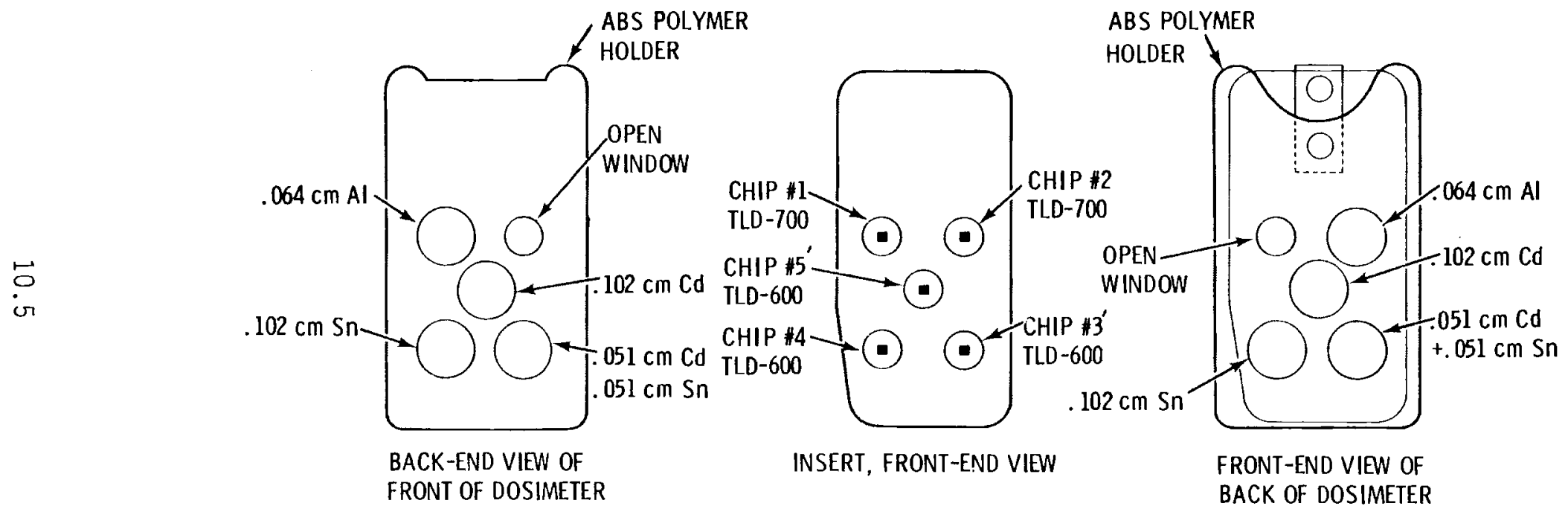

FIGURE $10.1 \mathrm{a}$. Modified Dosimeter Construction and Shielding 


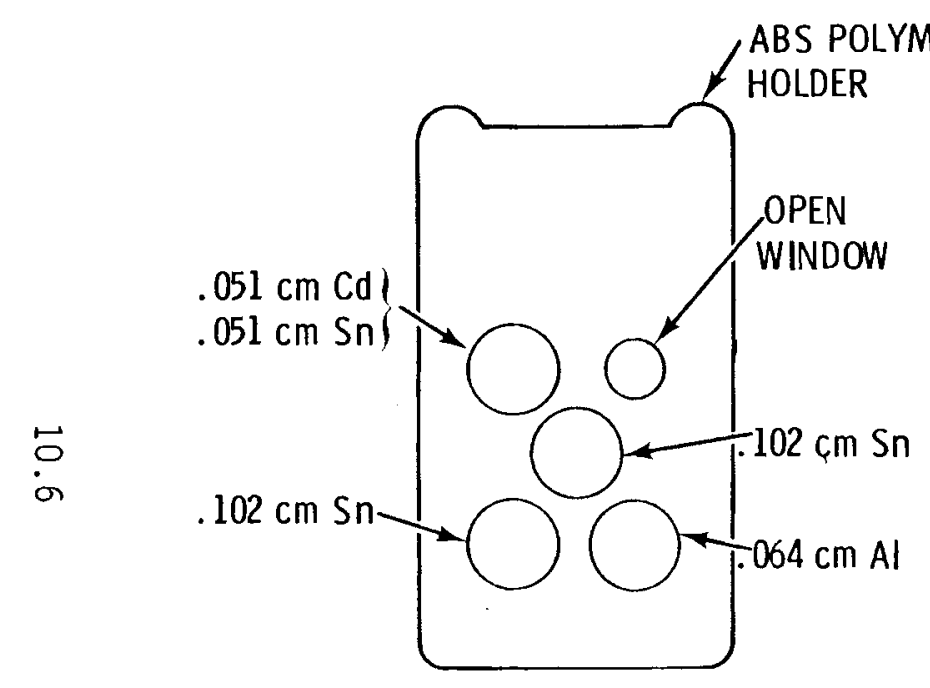

BACK-END VIEW OF FRONT OF DOSIMETER

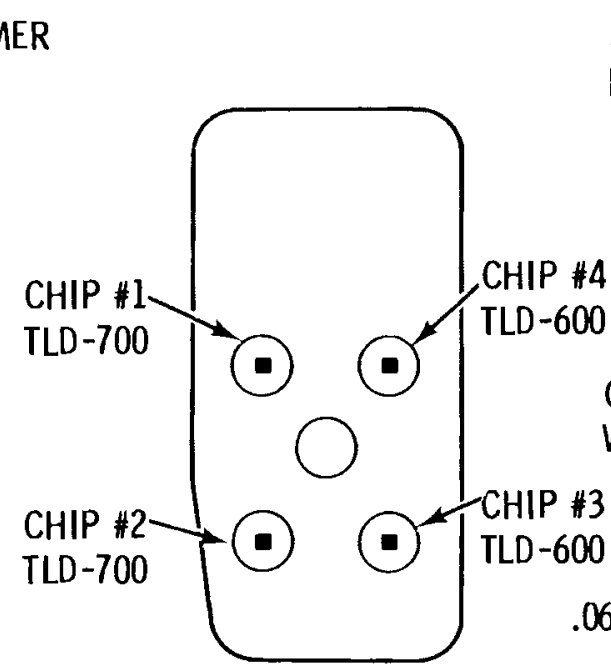

INSERT, FRONT-END VIEW
ABS POLYMER

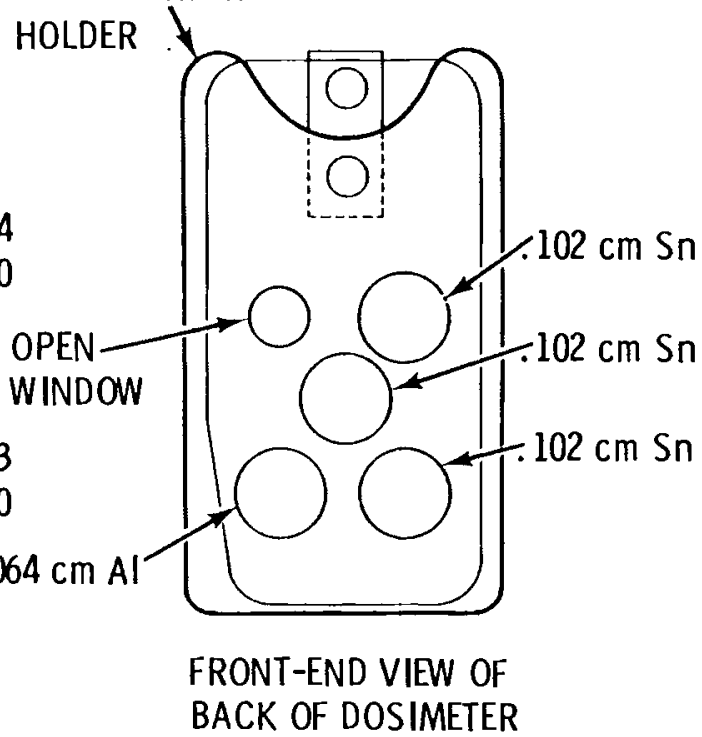

FIGURE 10.1b. Current HMP Dosimeter Construction and Shielding 


\section{TABLE 10.1. Statistical Comparison of Current Dosimeter with Modified Dosimeter}

Equations Used to Calculate Dose

\begin{tabular}{|c|c|}
\hline Current Dosimeter $(\mathrm{d})$ & Modified Dosimeter $(b)$ \\
\hline$N P=C 2 \quad(R 1-K 2 \cdot R 2)$ & (same) \\
\hline$P E N=C 1 \cdot R 2$ & (same) \\
\hline$S L O-N=C 4 \cdot(R 3-R 4)$ & $S L O-N=C 4^{\prime} \cdot\left(R 3^{\prime}-R 5^{\prime}\right)$ \\
\hline where, & where, \\
\hline$C 4=\frac{50 \mathrm{mrem}}{(R 3-R 4)} 50$ mrem thermal neutrons & 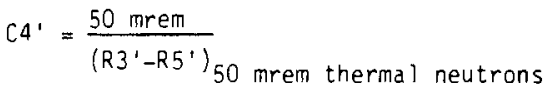 \\
\hline$F N=C 5 \cdot(R 4-K 6 \cdot R 2-K 5 \cdot(R 3-R 4))$ & $F N=C_{A} \cdot\left(R 4-R 5^{\prime}-K_{A} \cdot\left(R 3^{\prime}-R 5^{\prime}\right)\right)$ \\
\hline where, & where, \\
\hline$C 5=\frac{1000 \text { mrem }}{\left(R 4-K 6 \cdot R 2-K 5 \cdot\left(\begin{array}{c}(R 3-R 4) ! \\
1000^{\circ} \\
P_{u F}\end{array} \text { mrem }\right.\right.}$ & $C_{A}=\frac{1000 \text { mrem }}{\left(R 4-R 5^{\prime}-K_{A} \cdot\left(R 3^{\prime}-R 5^{\prime}\right)\right)_{\substack{1000^{\circ} \\
P_{4 F} \text { mrem }}}}$ \\
\hline $\begin{aligned} & K 6=\frac{R 4}{R 2} 1000 \text { mrem } 137 \mathrm{Cs} \\
& K 5=\left(\frac{R 4-K 6 \cdot R 2}{R 3-R 4}\right)_{50 \text { mrem thermal neut }} \\
& \text { Equation Used to Approximat }\end{aligned}$ & $K_{A}=\left(\frac{R 4-R 5^{\prime}}{R 3^{\prime}-R 5^{\prime}}\right) 50$ mrem thermal neutrons \\
\hline
\end{tabular}

$$
\begin{aligned}
\frac{S F N_{\text {modified }}}{\text { SFN }_{\text {current }}} & \cong\left(\frac{(S R 4)^{2}+\left(\left(1-K_{A}\right) \cdot S R 5^{\prime}\right)^{2}+\left(K_{A} S R 3^{\prime}\right)^{2}}{(1+K 5) \cdot S R 4)^{2}+(K 6 \cdot S R 2)^{2}+(K 5 \cdot S R 5)^{2}}\right)^{1 / 2} \cdot \frac{C_{A}}{C 5} \\
& \cong\left(\frac{(S R 4)^{2}+\left(.2 \cdot S R 5^{\prime}\right)^{2}+\left(.8 \cdot S R 3^{\prime}\right)^{2}}{(1.9 \cdot S R 4)^{2}+(1.0 \cdot S R 2)^{2}+(.9 \cdot S R 3)^{2}}\right)^{1 / 2} \cdot 1.37
\end{aligned}
$$

\begin{tabular}{ll} 
Relative Standard Deviation $(c)$ & \\
\hline TFN modifed & SFN
\end{tabular}

Pure Gamma

0.8

Pure Thermal Neutron

0.7

Pure Fast Neutron

0.7

Pure Beta

0.1

Half Gamma, Half Fast Neutron

0.7

Half Beta, Half Fast Neutron

0.6

Ha if Gamma, Ouarter FN, Quarter $S_{L} O-N$

0.8

Half Beta, Quarter FN, Quarter SLO-N

0.6

Quarter Gamma, Quarter FN, Ouarter SLO-N, Quarter Beta

$\underline{0.7}$

Average: $\quad 0.65$

(a) See Fiaure $10.1 b$

(b) See Figure $10.1 \mathrm{a}$

(c) These values are based upon the assumption that all TLO chips have the same standard deviation values by position when expressed as percent of total thermoluminescence. They have not been verified experimentally. 
If all these recommendations were feasible and were implemented, the standard deviation of calculated fast neutron dose after a neutron exposure might be reduced by a factor of two or three, and the standard deviation of calculated fast neutron dose after a gamma or beta exposure might be reduced by a factor of 10 . (These values are based upon rough estimates from preliminary data and should be considered as such until further investigated).

B. A11 personnel dose calculations could include a confidence bracketing on the basis of each calculated standard deviation value. Using the equations in this study, a computer program could be written which would give one standard deviation of the total calculated dose a person received in say, one year. This value would not include all sources of variance but would give a rough estimate of the limitations in precision of a specific calculated dose.

C. Personnel dose calculations which have a high level of uncertainty would be more accurate in the long run if negative calculated dose values were not "zeroed", but were summed over a period of one or more years with other highly uncertain calculated dose values. Then every year or every few years, the sum could be "zeroed" if it were negative or accepted if positive. Any such accepted values would then be added to the previously calculated dose. Such a procedure would greatly reduce the statistical bias towards positive dose values. 


\section{INTRODUCTION}

Statistical fluxuations in the dosimeter (HMPD) and reader system are the main limitations to meaningful measurement of low doses. This task, therefore, was designed to better describe the precision of the HMPD over the range of 0 to $1000 \mathrm{mrem}$ and to better define the lowest level of significant dose detection. Both mixed and nonmixed exposures were covered.

\section{IMPORTANCE OF STANDARD DEVIATION}

It was shown experimentally that the dose calculated from a set of identically exposed dosimeters followed a normal distribution. As such the precision could be described by the standard deviation value. The standard deviation value, therefore, was the key quantity derived in this task.

\section{SOURCES FOR CALCULATING STANDARD DEVIATIONS}

To calculate the standard deviation values for all combinations of gamma, thermal neutron, fast neutron and beta radiation, it was necessary to analyse each separate source of variance and combine each mathematically to determine the calculated dose standard deviation. Each separate source of variance is listed below with a brief explanation of how it was determined:

1. General HMPD response and variability
The general HMPD response and variability is a function of the type of radiation involved. Values for reader response and standard deviation were determined for each position of the dosimeter for each type of radiation. Specific values were determined by comparing LiF chip thermoluminescense readings from sets of identically exposed dosimeters.

2. Calibration dosimeter Calibration dosimeter response and response and variability variability was similarly determined for each of the four standard calibration 
exposures. For each position of the dosimeter, values were determined for reader response and standard deviation. Specific values were determined by comparing sets of identically exposed calibration dosimeters. The final standard deviation values used were standard deviation values for the mean calculated reader response, rather than values for individual reader response.

3. Lithium floride--reader background variability

4. Reader response variability

5. Calibration exposure variability

6. Positional response variability
Lithium floride--reader background variability was calculated from reread " $1 T$ " dosimeters. The actual values were the standard deviations of Lif chips with no exposure when read on the Hanford reader. Reader response variability is a measure of how much the reader heat contact and light sensitivity change during a monthly run. The value was determined by comparing consecutively read "IT" dosimeters with intermittently read "IT" dosimeters.

Calibration exposure variability is a measure of how much the calibrations' exposures fluxuated between separate calibrations. It was determined by comparing IT. with PT dosimeters.

Positional response variability was determined in Study 5. It is a measure of how much the placement of the dosimeter on a person affects its neutron response. 
COMBINING SOURCES OF VARIANCE

The preceeding six sources of standard deviations were combined to give a calculated dose and standard deviation as diagrammed in Figure 10.2. The values were combined mathematically using standard equations for combining standard deviations. These equations are covered in the theory section. Basic assumptions also involved are covered in the assumptions section. 


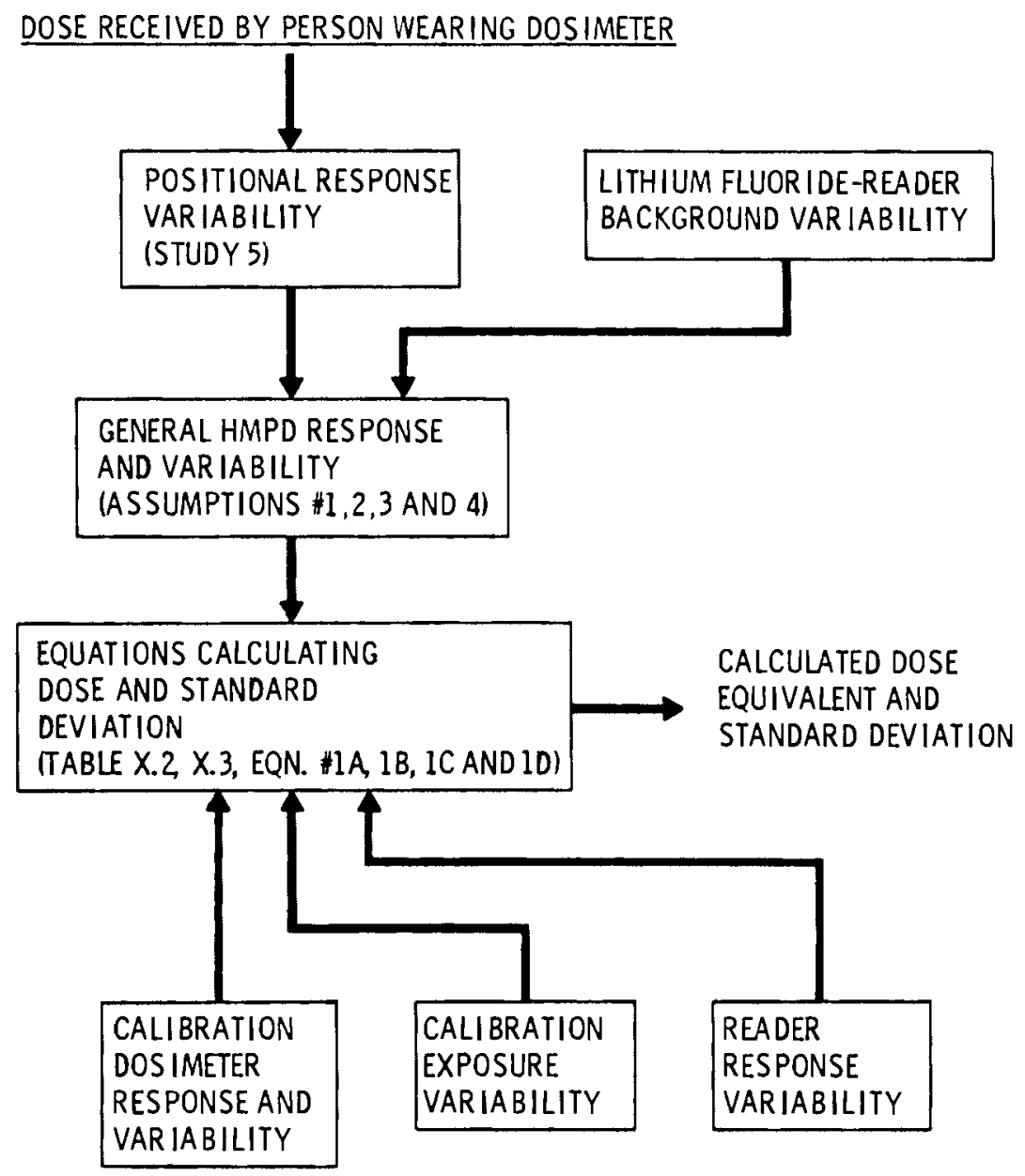

FIGURE 10.2. Schematic for Calculating Dose Standard Deviations 


\section{DISCUSSION}

\section{LIMITATIONS}

The calculated standard deviations and dose equivalents in this study were designed to be reasonable approximations of values which could be expected from personnel receiving radiation exposure while wearing the HMPD. Fluxuations of the LiF chip population response, reader system response and calibrations factors were the primary factors considered in calculating standard deviations. It was assumed that the background subtraction on the average was correct and therefore contributed no determinate error. The effect of positioning of the HMPD on the exposed person and the angle of exposure were not considered except for neutron exposures. Also the effect of environmental factors such as humidity, physical shock, etc. were not considered.

Since only one source was used for each type of radiation, the calculated standard deviations are best approximations only for spectrums resembling a combination of these four sources $\left({ }^{60} \mathrm{Co}, \mathrm{PuBe}-\mathrm{D}_{2} \mathrm{O},{ }^{252} \mathrm{Cf},{ }^{90} \mathrm{Sr}\right)$. However, since $L$ if response to gamma and thermal neutron sources does not vary greatly from source to source, $(a)$ these approximations should be good for most gamma and thermal neutron exposures. The HMPD-LiF response to fast neutron and beta exposures does vary significantly from source to source, but the calculated standard deviations should still give a good first approximation value. A significant difference in HMPD-Lif response per unit dose results from beta exposures where only radiation of sufficient energy to pass through the security credential can be detected. The relative response of the HMPO to beta radiation can be corrected for by using the ratio of R1-K2-R2 of the actual field to that of ${ }^{90} \mathrm{Sr}$. For example if the HMPD is one half as sensitive to field beta as ${ }^{90}$ Sr beta,

$$
\left(\frac{(R 1-K 2 \cdot R 2) \text { Fie ld }}{(R 1-K 2 \cdot R 2){ }_{90 S r}}=\frac{1}{2}\right),
$$

(a) For gamma radiation this is true if most of the radiation is above $100 \mathrm{KeV}$. For thermal neutrons this is true if the neutron spectrum is at equilibrium with room temperature $\left(70^{\circ}\right)$. 
then a 100 mrem ${ }^{90} \mathrm{Sr}$ exposure with a standard deviation of 12.7 would be approximately equal to a $200 \pm 25.4$ mrem field exposure.

USE OF DATA IN TABLES AND FIGURES

The body of data describing the performance of the general HMPD is given in Table A.10.1 and Figures 10.3 through 10.6 .

First Table A.10.1(a) lists the mean calculated dose equivalent and standard deviation for numerous combinations of mixed field exposure. This table has five columns. The first four are for each labeled radiation measured by the standard 4-chip HMPD. The fifth is for fast neutron radiation measured by the 5-chip HMPD. Each column contains sets of three lines. The first lists the amount of radiation given to a dosimeter placed on a phantom. The second gives the average dose calculated from dosimeter response. (b) The third gives the standard deviation of calculated dose.

The table lists standard deviations only for irradiations having a total dose equivalent of $100 \mathrm{mrem}$. That is, the sum of the given dose equivalents for nonpentrating, penetrating, slow neutron, and fast neutron radiation equals 100 mrem for all values listed.

As an illustration of the use of Table A.10.A, if a person receives $33 \mathrm{mrem}$ gamma radition and $67 \mathrm{mrem}$ fast neutron radiation, his expected average calculated dose equivalent and standard deviation is shown at the bottom of the first page of the table. This expected standard deviation would be 11.7 mrem nonpenetrating, 4.2 mrem penetrating, 0.7 mrem slow neutrons, and 44.9 mrem fast neutrons. His mean calculated dose is shown just above this line as 0.1 mrem nonpenentrating, 34.4 mrem penetrating, 2.2 mrem therma 1 neutrons, and 58.3 mrem fast neutrons.

(a) All standard deviation values in Table A.10.1 were calculated using the scheme shown in Figure 10.2 of the Introduction. The specific equations used are listed in the Theory and Equations section. Assumptions needed for mixed field calculations are in the Assumptions section.

(b) Asterisks are placed around the average calculated dose if the standard deviation exceeded this value. 
If the total dose equivalent received is not equal to $100 \mathrm{mrem}$, Table A.10.1 can still be used to predict the standard deviations. To do this, locate the listed exposure in Table A.10.1 which has the most similar percentage contribution from each radiation. Then for the standard deviation of interest, say the standard deviation of penetrating dose equivalent, solve the following equations:

$$
\begin{aligned}
S_{100 \text { mrem }} & =\left[S_{\min }^{2}+\left(100 \cdot\left(\frac{S}{m r e m}\right)\right)^{2}\right]^{1 / 2} \\
S & =\left[S_{\text {min }}^{2}+\left(D E \cdot\left(\frac{S}{\text { mrem }}\right)\right)^{2}\right]^{1 / 2}
\end{aligned}
$$

where,

$$
\begin{aligned}
S_{100 \text { mrem }}= & \text { standard deviation from Table A.X.1 } \\
S_{\min }= & \text { minimum standard deviation from Figure X.3, X.4, X.5 (a) } \\
& \text { or } X .6 \\
\left(\frac{S}{m r e m}\right)= & \text { calculated constant } \\
D E= & \text { total dose equivalent of interest in mrem } \\
S= & \text { standard deviation of interest. }
\end{aligned}
$$

Figures 10.3 Through 10.6

Figures 10.3 through 10.6 give expected standard deviation values for nonmixed exposures ranging from $1 \mathrm{mrem}$ to $1000 \mathrm{mrem}$. They also help illustrate the effect of each radiation type and exposure level on the standard deviations of calculated exposures. To use these figures, move vertically from the dose equivalent value on the abscissa to the line corresponding to the type of radiation involved. The value for the expected standard deviation is shown directly across on the ordinate.

(a) If the standard deviation of interest was for penetrating radiation, Figure 10.3 would be used. $S_{\min }$ would, therefore, be $3.4 \mathrm{mrem}$. 


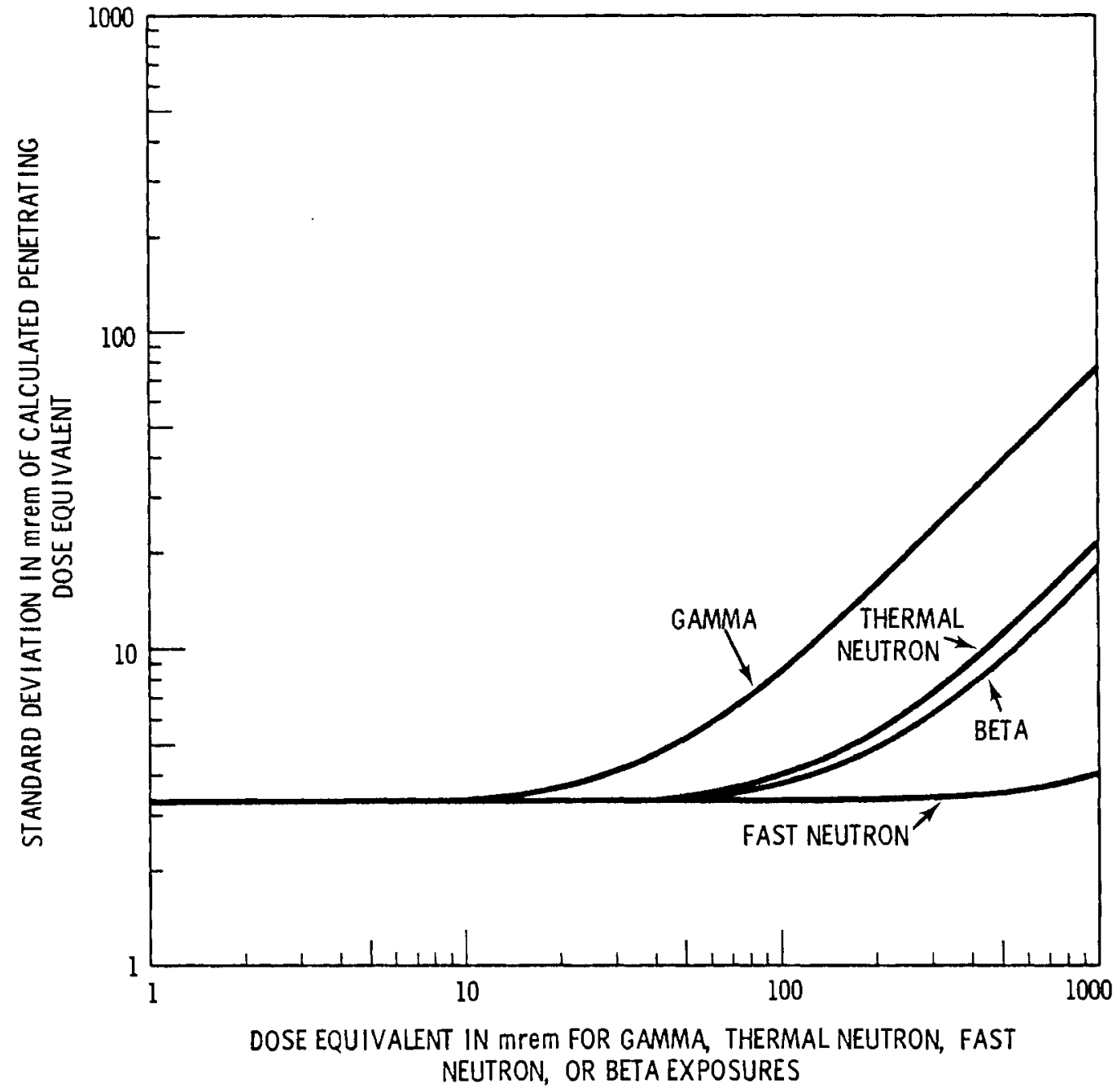

FIGURE 10.3. Effect of Each Type of Radiation on Calculated Penetrating Standard Deviation

The minimum standard deviation values for each type of radiation are the values which are asymptotically approachedas the dose equivalent changes from 1000 to 0 mrem. The minimum standard deviation for penetrating raidation is shown in Figure 10.3 to be $3.4 \mathrm{mrem}$. For thermal neutron radiation in Figure 10.4 it is $0.14 \mathrm{mrem}$. For fast neutron radiation in Figure 10.5 it is 10 mrem. For nonpenetratging radiation in Figure 10.6 it is 11 mrem. 


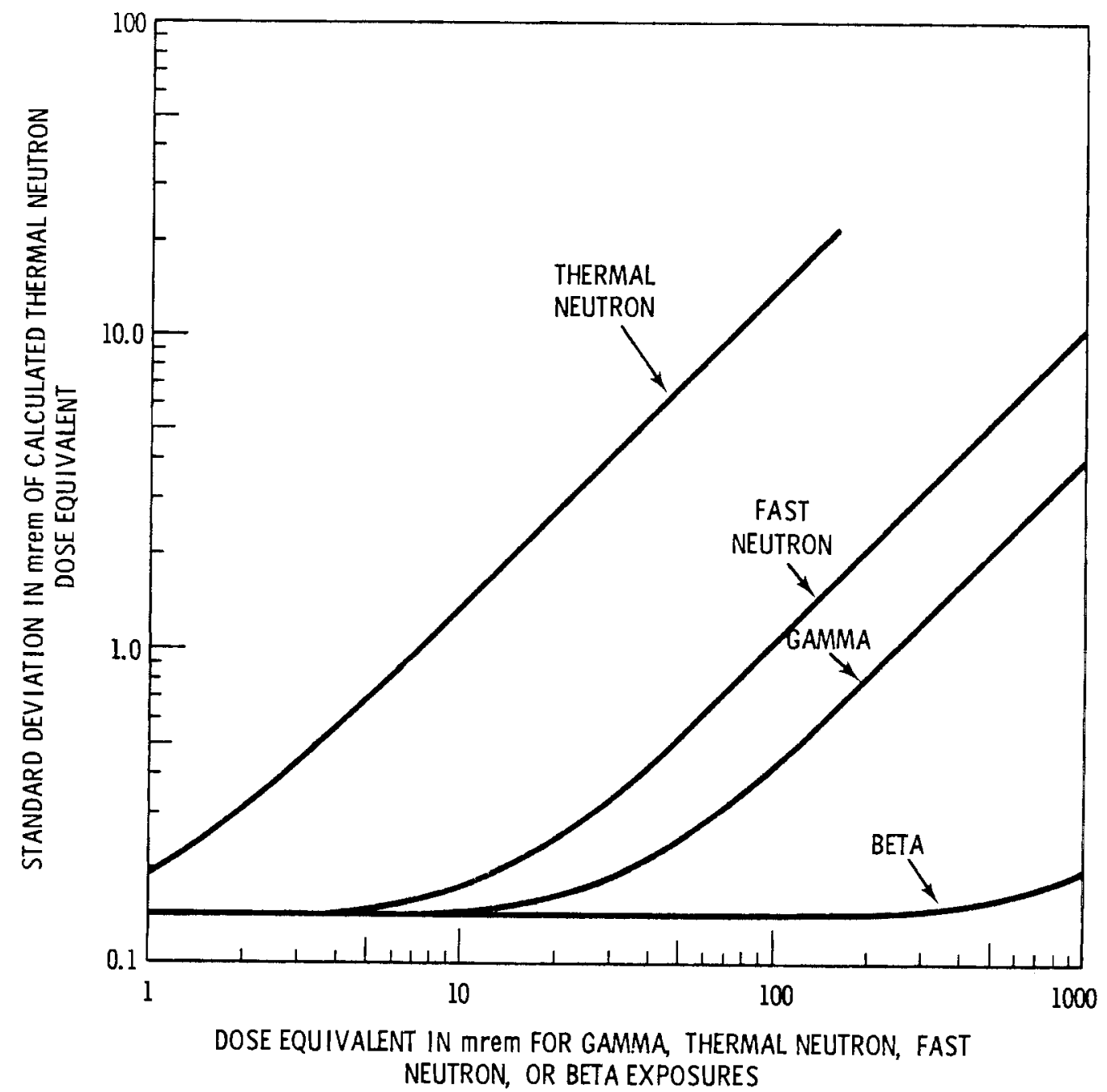

FIGURE 10.4. Effect of Each Type of Radiation on Calculated Thermal Neutron Standard Deviation

The lowest level of significant detection in nonmixed fields is determined by determining what dose of a specific type of radiation would have a standard deviation equal to the amount of radiation received. For example, in Figure 10.3 the standard deviation of a $3.4 \mathrm{mrem}$ gamma dose is $3.4 \mathrm{mrem}$; therefore, the lowest level of significant detection for gamma radiation is 3.4 mrem.

The level of dose which has a $97 \%$ chance of being detected (two standard deviations above zero) is determined similarly. In this case, the dose equivalent on the abcissa must be twice the standard deviation on the ordinate. 


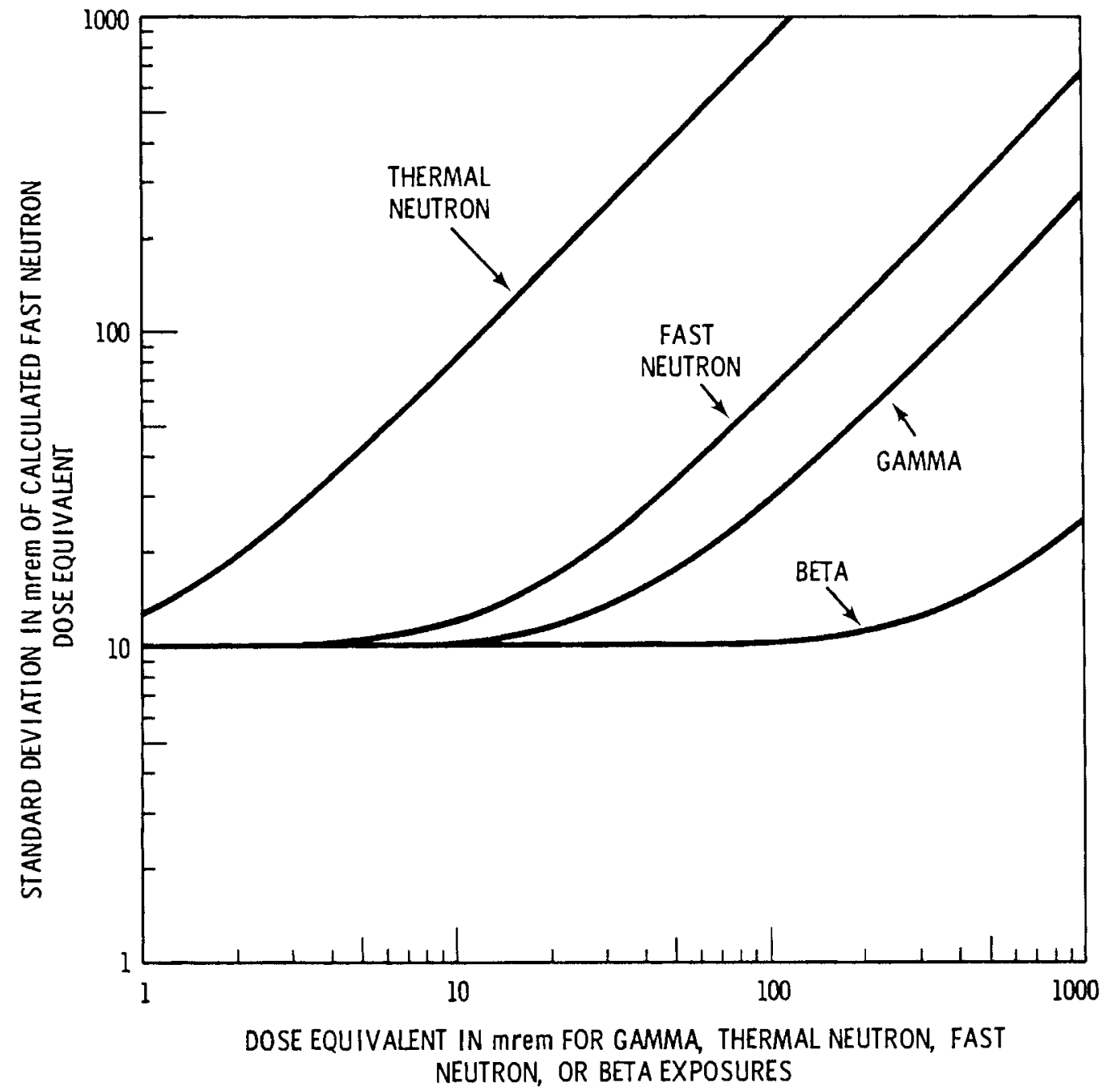

FIGURE 10.5. Effect of Each Type of Radiation on Calculated Fast Neutron Standard Deviation

The most accurate description of standard deviations for mixed field exposures comes from Table A.10.1; however, Figures 10.3 through 10.6 give quick and easy approximations of standard deviations. For example, using Figure 10.3 exposures which give statistically significant penetrating dose values can be determined. There is no easy way of describing the information in Figure 10.3, but an approximation would be to say that the gamma dose will be statistically significant if it is more than $5 \mathrm{mrem}$ and more than $3 \%$ of the total exposure given. In a similar manner statistically significant dose values for the other radiation types are determined from Figures 10.4 through 10.6 . 


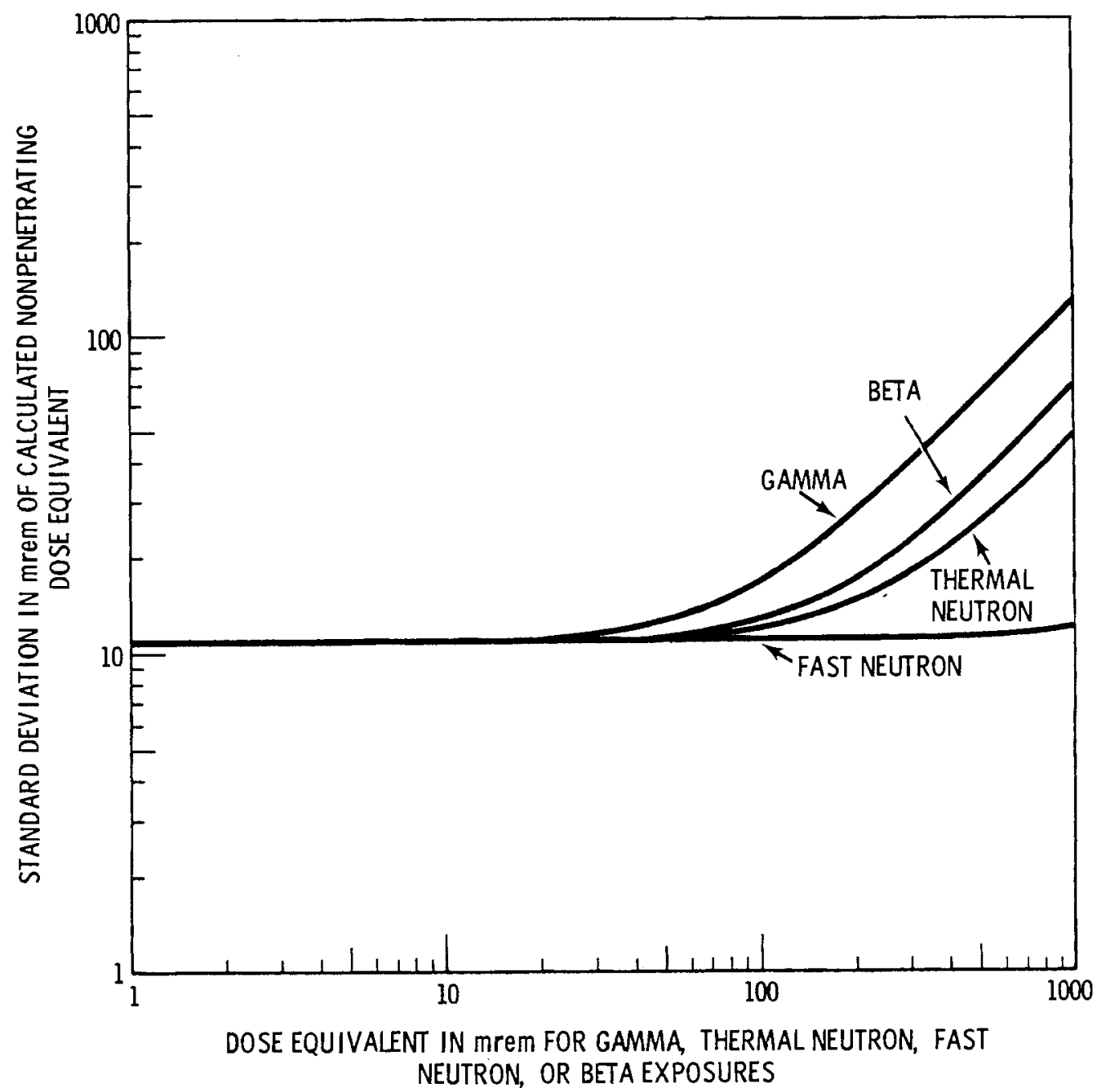

FIGURE 10.6. Effect of Each Type of Radiation on Calculated Nonpenetrating Standard Deviation

DESCRIPTION OF PRECISION, PROBLEMS, AND DETERMINATE ERROR

Data in Table A.10.1 and Figures $10.3,10.4,10.5$, and 10.6 can be used to delineate the weaknesses and strengths of the HMPD.

\section{Gamma (Penetrating)}

Starting with calculated gamma exposure, the calculated dose equivalent values are shown in Figure 10.3 to be quite precise under almost all conditions of mixed field exposure. As mentioned previously, gamma calculated dose values 
are statistically significant ${ }^{(a)}$ if the gamma dose is both more than 5 mrem and more than $3 \%$ of the total exposure given. In general if the total exposure received is more than $100 \mathrm{mrem}$, the standard deviation of calculated gamma dose equivalent will be less than $8.6 \%$ of the total exposure received. If the exposure is pure gamma, the lowest level of significant detection is 3.4 mrem and the two standard deviation level of detection(b) is 7 mrem.

Thermal Neutron

For the thermal neutron calculated exposure, the calculated dose equivalent values are also showr. in Figure 10.4 to be fairly precise under almost all conditions. Thermal neutron calculated dose values are statistically significant if the thermal neutron dose is both more than 0.2 mrem and more than $2 \%$ of the total exposure. In general if the total exposure is more than 2 mrem, the standard deviation of calculated thermal neutron dose equivalent will be less than $16 \%$ of the total exposure received. If the exposure is pure thermal neutrons, the lowest level of significant detection is $0.14 \mathrm{mrem}$ and the two standard deviation level is $0.3 \mathrm{mrem}$.

Fast Neutron

The fast neutron calculated exposure is by far the least precise (see Figure 10.5). The standard deviation of calculated fast neutron dose will be at least eight times the magnitude of the thermal neutron dose given.

(a) This is defined as when the mean calculated dose is at least one standard deviation away from zero. At this level, one in six dosimeters would indicate no exposure assuming the background subtraction was correct.

(b) This is the level where there is a $97 \%$ chance of the dose being detected, that is, when the calculated dose is two standard deviations above zero. 
(SFN $\geq 8$ - THN.) The lowest level of significant detection for a pure fast neutron exposure is $10 \mathrm{mrem}$. There is no two standard deviation level.

Figure 10.7 illustrates the effect of thermal neutron exposure on calculated fast neutron exposure when the remainder of the exposure comes from gamma radiation. Note that increasing the percentage thermal neutron dose equivalent from $0 \%$ to $16 \%$ completely destroys the fast neutron precision.

If there is very little thermal neutron exposure, the calculated fast neutron dose is much more precise but still has significant statistical problems. For example if a group of workers are each exposed to 500 mrem gamma (including background) and $100 \mathrm{mrem}$ beta, their expected calculated fast neutron dose equivalent would, assuming no determinate error, be $0 \pm 130 \mathrm{mrem}$.

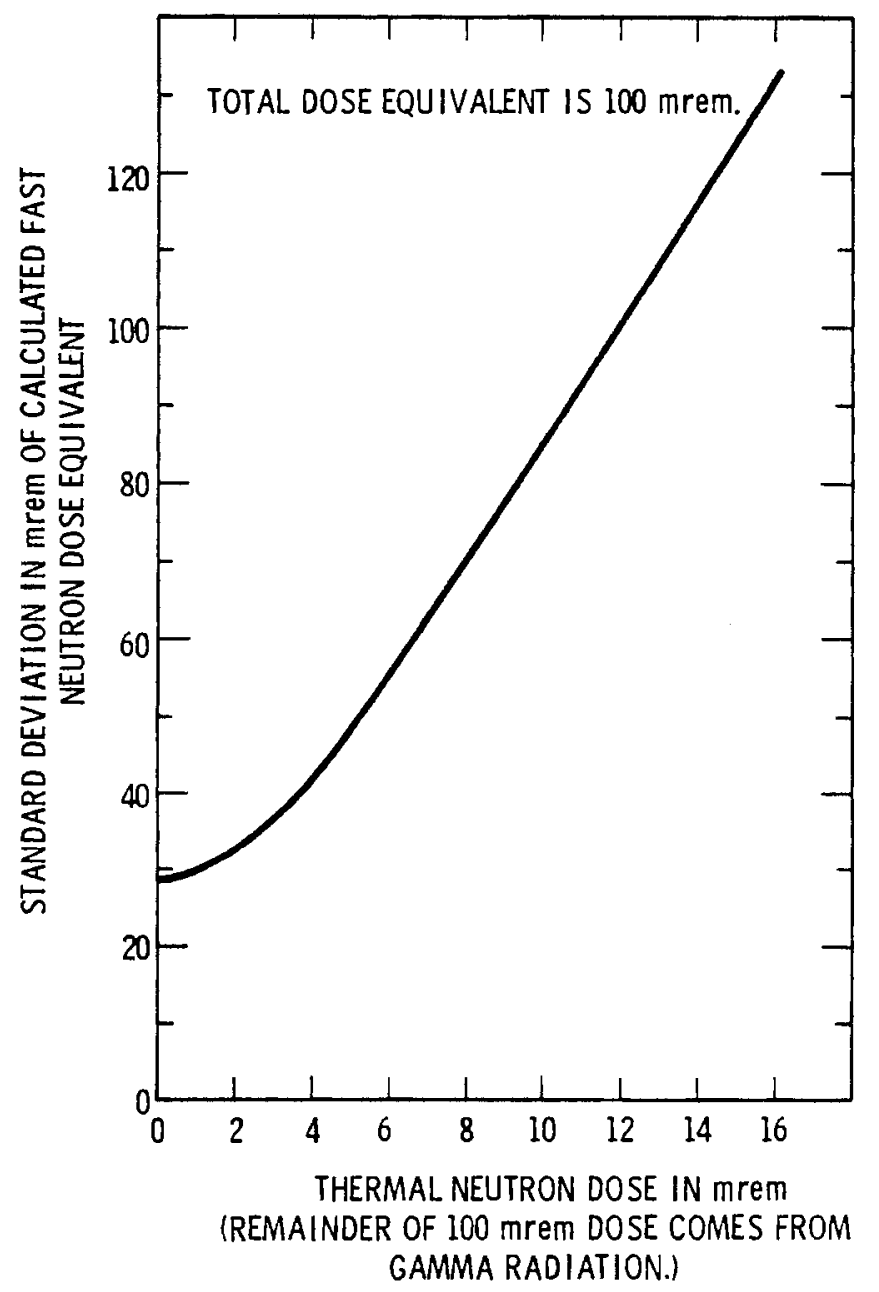

FIGURE 10.7. Effect of Thermal Neutron Exposure on Calculated Fast Neutron Standard Deviation 
If all negative calculated dose values are assumed zero, half of these workers would show no fast neutron dose. Assuming a normal distribution, $25 \%$ would show a fast neutron dose between 0 and 90 mrem; 15\% would show between 90 and 170 mrem; 9\% would show between 170 and 305 mrem; and 1\% would show a fast neutron dose above 305 mrem.

This kind of problem has occurred historically at $N$ reactor during summer outages. Common dose values for maintenance personnel are 500 mrem gamma and 100 mrem beta. They receive no significant fast neutron exposure, yet a significant fraction of their dosimeters indicate a fast neutron dose. For example, one population of 44 dosimeters for June ' 80 indicated a mean population fast neutron dose and standard deviation of $-59 \pm 107$ mrem and another population of 21 indicated $-101 \pm 144$ mrem. Of the 44 dosimeters, $27 \%$ indicated a fast neutron dose between -59 and 13 mrem (equivalent to $25 \%$ for 0 to 90 mrem in example above), $11 \%$ indicated between 13 and 78 mrem (equivalent to $15 \%$ for 90 to 170 mrem above), and $9 \%$ indicated a dose between 78 and 190 mrem (equivalent to $9 \%$ for 170 to $305 \mathrm{mrem}$ above). As can be seen here, the calculated dose values closely follow a normal distribution. Also, the predicted standard deviation of 130 mrem was quite close to the observed values of 107 and 144 mrem.

A determinate error was observed illustrating the expected effect of a beta field exposure on the calculated fast neutron dose. For the group of 44 dosimeters in the example above, their average calculated fast neutron dose was -59 mrem instead of zero. This negative value was probably due to the presense of a 100 mrem beta dose. In high energy beta fields, the four-chip HMPD consistently underestimates the fast neutron dose because the gamma subtraction (R2) includes too much beta response. As shown in Table A.10.1 the five-chip dosimeter does not have this problem.

Careful analysis of Figure 10.5 also shows that the standard deviation of a calculated fast neutron dose will be at least equal to $64 \%$ of the given fast neutron dose. From this it can be shown that there is at least a $6 \%$ chance of any fast neutron dose being calculated as a negative value. In other words, 1 in 17 people who receive an exposure of 1000 mrem fast neutrons can expect 
to have a calculated fast neutron dose of zero or less. (Those people would most likely show a thermal neutron dose of about 40 mrem.)

Beta (Nonpenetrating)

The beta dose values are much more precise than the fast neutron dose values but not as precise as gamma values. Figure X.6 shows the effect of each type of radiation on the calculated beta dose equivalent values. The minimum standard deviation is shown to be $11 \mathrm{mrem}\left({ }^{90} \mathrm{Sr}\right.$ equivalent). A beta calculated dose value will be statistically significant if it is greater than $11 \mathrm{mrem}$ and greater than $13 \%$ of the total exposure. If the dose is from a pure beta exposure, the lowest level of significant detection will be 11 mrem and the two standard deviation level will be 22 mrem.

\section{EFFECT OF "ZEROING" ALL NEGATIVE VALUES}

Since each calculated dose has an associated standard deviation, often significant relative to the dose, the rejection of all negative calculated dose values will lead to a cumulative inaccurracy. For dose calculations whose standard deviation exceeds the given dose, zeroing all negative dose values will result in a significant average overcalculation of the dose given. Figure 10.8 illustrates this. Figure $10.8 \mathrm{~b}$ shows that if the mean is one standard deviation above zero, considering all negative values equal to zero will result in an average overestimation of the dose by $24 \%$. If the mean is two standard deviations above zero the dose will be overestimated by only $2.6 \%$, but if the mean is only one half of a standard deviation above zero the dose will be overestimated by $70 \%$. 


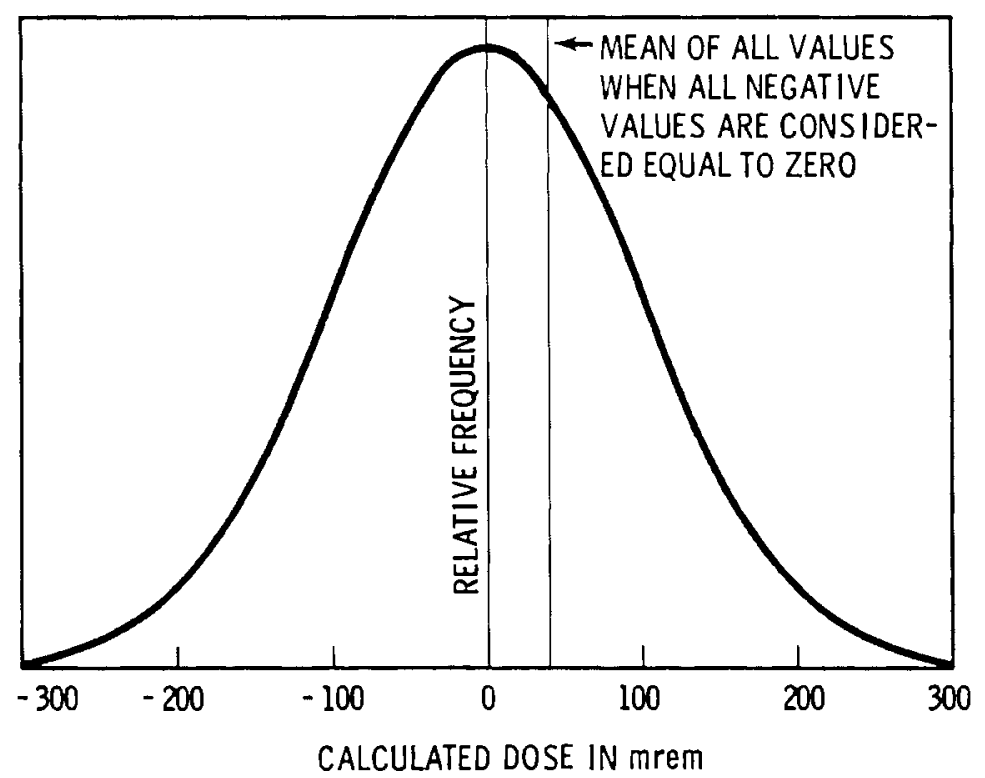

FIGURE 10.8a. Normal Frequency Distribution for a Calculated Dose of $0 \pm 100 \mathrm{mrem}$

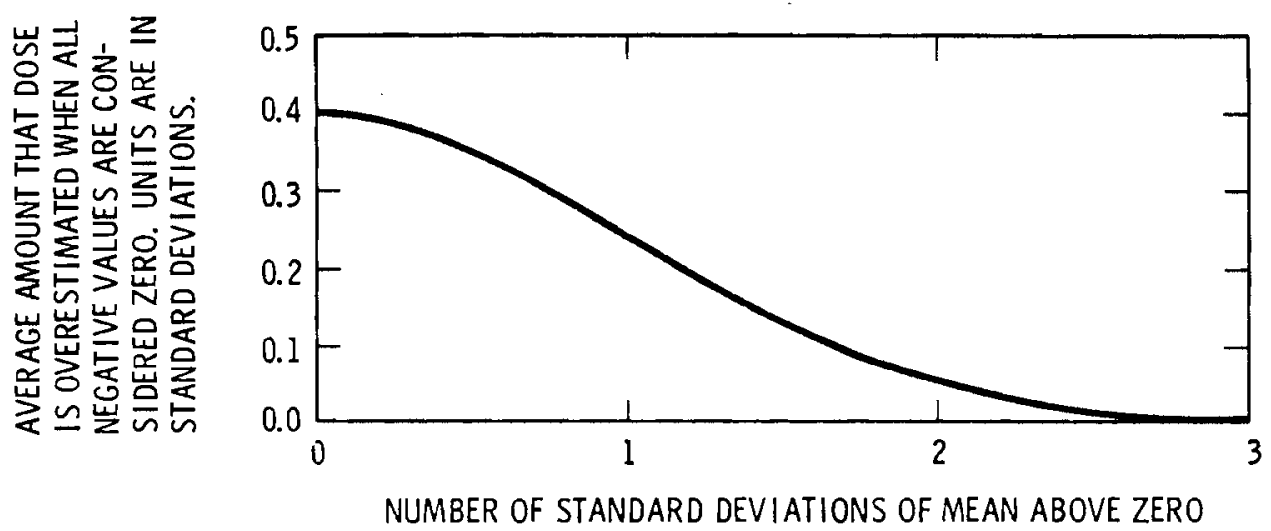

FIGURE 10.8b. Effect of "Zeroing" All Negative Vaiues 


\section{THEORY AND EQUATIONS}

The equations used in calculating dose ${ }^{(a)}$ with the 4-chip and 5-chip dosimeter are shown in Table 10.2. The expected standard deviations of calculated dose were calculated by reducing each equation to only independent variables; then the linear terms of a Taylor series expansion about the mean were used to obtain an approximate average exposure and standard deviation. This is further explained in Bennett and Franklin, Statistical Analys is in Chemistry and the Chemical Industry, pages 51 to 53. The mathematical methodology used is shown below:

$$
\begin{array}{ll}
\text { Case I: } \quad & Z=A+B \\
& S_{Z} \cong\left(S_{A}^{2}+S_{B}{ }^{2}\right)^{1 / 2}
\end{array}
$$

Case II: $\quad Z=A \cdot B$

$$
S_{z} \cong z \cdot\left(\left(\frac{S_{A}}{A}\right)^{2}+\left(\frac{S_{B}}{B}\right)^{2}\right)^{1 / 2}
$$

Case III: $z=f(A, B, C$, etc. $)$

$$
\begin{aligned}
S_{2} \equiv & \left(f_{A}^{2}\left(\mu_{A}, \mu_{B}, \mu_{C}, \text { etc. }\right) \cdot S_{A}^{2}+f_{B}^{2}\left(\mu_{A}, \mu_{B}, \mu_{C}, \text { etc. }\right) \cdot S_{B}{ }^{2}\right. \\
& \left.+f_{C}^{2}\left(\mu_{A}, \mu_{B}, \mu_{C} \text {, etc. }\right) \cdot S_{C}^{2}+\text { etc. }\right)^{1 / 2}
\end{aligned}
$$

where,

$S_{A}=$ standard deviation of variable $A$

$f_{A}=$ partial deviation of $f(A, B, C$, etc. $)$ with respect to $A$ evaluated at ${ }_{A}, \mu_{B}, \mu_{C}$, etc.

(a) The terms dose and dose equivalent are used interchangeably in this report to mean dose equivalent in units of rem or mrem. 
TABLE 10.2. Equations Used in Calculating Dose Equivalent

\begin{tabular}{|c|c|c|}
\hline \multirow[b]{2}{*}{ Constant } & \multicolumn{2}{|c|}{ Calibration Equations } \\
\hline & 4-Chip Badge & 5-Chip Badge \\
\hline K2 & RICS/R2CS & (Same) \\
\hline K6 & R4CS/R2CS & R4CS/R5CS \\
\hline $\mathrm{C} 1$ & $1000 \mathrm{mR} / \mathrm{R} 2 \mathrm{CS}$ & (Same) \\
\hline C2 & $\frac{2000 \mathrm{mRad}}{\mathrm{R} 1 \mathrm{~B}-\mathrm{K} 2 \cdot \mathrm{R} 2 \mathrm{~B}}$ & (Same) \\
\hline C3 & $\mathrm{C} 2 \cdot \mathrm{K} 2$ & (Same) \\
\hline C4 & $\frac{50 \mathrm{mrem}}{\mathrm{R} 3 \mathrm{THN}-\mathrm{R} 4 \mathrm{THN}}$ & (Same) \\
\hline K5 & $\frac{\text { R4THN-K6 } \cdot \text { R2THN }}{\text { R3THN-R4THN }}$ & $\frac{\text { R4THN-K6 } \cdot \text { R5THN }}{\text { R3THN-R4THN }}$ \\
\hline K7 & $\frac{\text { R4FN-K6 } \cdot \text { R2FN-K5 } \cdot(R 3 F N-R 4 F N)}{1000 \mathrm{mrem}}$ & $\frac{R 4 F N-K 6 \cdot R 5 F N-K 5 \cdot(R 3 F N-R 4 F N)}{1000 \mathrm{mrem}}$ \\
\hline $\mathrm{C} 5$ & $1 / \mathrm{K} 7$ & $1 / K 7$ \\
\hline C6 & $\mathrm{K} 6 \cdot \mathrm{C} 5$ & $\mathrm{~K} 6 \cdot \mathrm{C} 5$ \\
\hline$C 7$ & $\mathrm{~K} 5 \cdot \mathrm{C} 5$ & $\mathrm{~K} 5 \cdot \mathrm{C} 5$ \\
\hline
\end{tabular}

\begin{tabular}{|c|c|c|}
\hline \multirow[b]{2}{*}{ Type of Radiation } & \multicolumn{2}{|c|}{ Dose Equivalent Equations } \\
\hline & 4-Chip Badge & 5-Chip Badge \\
\hline Nonpenetrating (NP) & $C 2 \cdot(R 1-B 1)-C 3 \cdot(R 2-B 2)$ & (Same) \\
\hline Penetrating (PEN) & $\begin{array}{l}\mathrm{C} 1 \cdot(\mathrm{R} 2-\mathrm{B} 2)-\mathrm{E} \cdot(\# \text { of days } \\
\text { between annealings) }\end{array}$ & (Same) \\
\hline Slow neutrons (SLO) & $C 4 \cdot(R 3-B 3-R 4+B 4)$ & (Same) \\
\hline Fast neutrons (FN) & $\begin{array}{l}C 5 \cdot(R 4-B 4)-C 6 \cdot(R 2-B 2) \\
-C 7 \cdot(R 3-B 3-R 4+B 4)\end{array}$ & $\begin{array}{l}C 5 \cdot(R 4-B 4)-C 6 \cdot(R 5-B 5) \\
-C 7 \cdot(R 3-B 3-R 4+B 4)\end{array}$ \\
\hline
\end{tabular}

(a) RX__ refers to the thermoluminescent reading in total counts for a TLD chip located in position \#X. For a calibration exposure _- gives the type of radiation involved, i.e., CS means ${ }^{137} \mathrm{Cs}$ gamma. $\overline{\mathrm{B}}$ means beta from natural uranium, THN means thermal neutrons from the Sigma Pile, and FN means fast neutrons from PuF 4 .

(b) $\mathrm{BX}$ refers to the thermoluminescent reading in total counts for a control TLD chip in position \#X.

(c) E refers to the rate of background radiation accumulation of $1 \mathrm{~cm}$ deep exposure. This is approximately equal to $0.18 \mathrm{mR}$ per day. 
$\mu_{A}=$ mean value of $A$,

etc.

Applying these methods to the current dose equations shown in Table 10.2, equations approximating standard deviations of calculated exposure were generated and are listed in Table 10.3. Due to the complexity of these equations they have been separated into several separate equations.

Use of the equations in Table 10.3 allows a calculation of expected standard deviations due just to TLD-reader variability. The assumption was made that each HMPD-Lif chip response by position was independent of the other responses by position (in other words, that the covariance between positions was zero). Therefore care must be taken to assure that only position independent TLD-reader variability is included in the input standard deviation values.

Since the equations in Table 10.3 do not include the factor of calibration exposure variability nor of reader response variability, (a) these values had to be added in separately. They were included as multiplicative errors in the final calculated exposure values. Mathematically they were combined as follows:

$$
\begin{aligned}
& S N P_{\text {tot }}=N P \cdot\left(\left(\frac{S N P \text { TLD-Reader }}{N P}\right)^{2}+R E R^{2}+C E R^{2}\right)^{1 / 2} \\
& \text { SPEN }_{\text {tot }}=P E N \cdot\left(\left(\frac{\text { SPEN TLD-Reader }}{P E N}\right)^{2}+\operatorname{RER}^{2}+C E R^{2}\right)^{1 / 2} \\
& \text { STHN }_{\text {tot }}=\operatorname{THN} \cdot\left(\left(\frac{\text { STHN TLD-Reader }}{\text { PEN }}\right)^{2}+R E R^{2}+C E R^{2}\right)^{1 / 2} . \\
& S F N_{\text {tot }}=F N \cdot\left(\left(\frac{S F N \text { TLD-Reader }}{F N}\right)^{2}+R E R^{2}+C E R^{2}\right)^{1 / 2}
\end{aligned}
$$

(a) See Figure 10.2. 
TABLE 10.3. Equations Used in Calculating Standard Deviations of Calculated Exposure Due to Independent Chip Variability

Nonpenetrating exposure:

$$
\begin{aligned}
S K 2= & K 2 \cdot\left(\left(\frac{S R 1 C S}{R 1 C S}\right)^{2}+\left(\frac{S R 2 C S}{R 2 C S}\right)^{2}\right)^{1 / 2} \\
G= & R 2-B 2 \\
H= & R 1 B-K 2 \cdot R 2 B \\
W= & R 1-B 1-K 2 \cdot G \\
S N P= & 2000 \cdot\left(\frac{S R 1^{2}+S B 1^{2}+(S R 2 \cdot K 2)^{2}+(S B 2 \cdot K 2)^{2}}{H^{2}}+\right. \\
& \left.\frac{((W \cdot R 2 B-H \cdot G) \cdot S K 2)^{2}+(S R 1 B \cdot W)^{2}+(S R 2 B \cdot W \cdot K 2)^{2}}{H^{4}}\right)^{1 / 2}
\end{aligned}
$$

Standard deviation of penetrating exposure:

SC1 $=$ C1 $\cdot($ SR2CS/R2CS $)$

$$
\text { SPEN }=C 1 \cdot(R 2-B 2) \cdot\left(\left(\frac{S C 1}{C 1}\right)^{2}+\frac{S R 2^{2}+S B 2^{2}}{(R 2-B 2)^{2}}\right)^{1 / 2}
$$

Standard deviation of slow neutron exposure:

$$
\begin{aligned}
\text { SC4 } & =C 4 \cdot \frac{\left(S R 3 T H N^{2}+S R 4 T H N^{2}\right)^{1 / 2}}{R 3 T H N-R 4 T H N} \\
S S L O & =S L O \cdot\left(\left(\frac{S C 4}{C 4}\right)^{2}+\frac{S R 3^{2}+S B 3^{2}+S R 4^{2}+S B 4^{2}}{(R 3-B 3-R 4+B 4)^{2}}\right)^{1 / 2}
\end{aligned}
$$

Standard deviation of fast neutron exposure:

$$
\begin{aligned}
\text { SK6 } & =K 6 \cdot\left(\left(\frac{\text { SR4CS }}{R 4 C S}\right)^{2}+\left(\frac{\text { SR2CS }}{R 2 C S}\right)^{2}\right)^{1 / 2} \\
V & =\text { R3THN }- \text { R4THN } \\
Z R & =\text { R3FN }- \text { R4FN } \\
Z F & =\text { R3THN }-K 6 \cdot \text { R2THN } \\
T & =\text { R4THN }-K 6 \cdot \text { R2THN } \\
G 2 & =\text { R2-B2 } \\
G 3 & =\text { R3-B3 } \\
G 4 & =\text { R4-B4 }
\end{aligned}
$$




\section{TABLE 10.3. (Contd)}

$$
\begin{aligned}
& D 1=R 4 F N-K 6 \cdot \cdot R 2 F N \\
& D E N=D 1 \cdot V-T \cdot Z R \\
& N U M=Z F \cdot G 4-V \cdot K 6 \cdot G 2-T \cdot G 3 \\
& A A=([D E N \cdot(G 4-K 6 \cdot G 2)-N U M \cdot D 1] \cdot S R 3 T H N)^{2} \\
& A B=[(D E N \cdot(R 2 T H N \cdot G 3-V \cdot G 2-R 2 T H N \cdot G 4)-N U M \cdot R 2 T H N \cdot Z R+ \\
& \text { NUM } \cdot R 2 F N \cdot V) \cdot S K 6]^{2} \\
& A C=([D E N \cdot(K 6 \cdot G 3-K 6 \cdot G 4)-N U M \cdot K 6 \cdot Z R] \cdot S R 2 T H N)^{2} \\
& A D=[(D E N \cdot(K 6 \cdot G 2-G 3)+N U M \cdot Z R+N U M \cdot D 1) \cdot S R 4 T H N]^{2}+ \\
& \text { (NUM } \cdot T \cdot S R 3 F N)^{2} \\
& A E=[(N U M \cdot T+N U M \cdot V) \cdot S R 4 F N]^{2} \\
& A F=\left(\frac{Z F \cdot S R 4}{D E N}\right)^{2} \\
& A G=\left(\frac{Z F \cdot S B 4}{D E N}\right)^{2} \\
& A \dot{H}=\left(\frac{V \cdot K \sigma \cdot S R 2}{D E N}\right)^{2} \\
& A I=\left(\frac{V \cdot K 6 \cdot S B 2}{D E N}\right)^{2} \\
& A J=\left(\frac{T \cdot S R 3}{D E N}\right)^{2}+\left(\frac{T \cdot S B 3}{D E N}\right)^{2} \\
& A K=\left(\frac{N U M \cdot K 6 \cdot V \cdot S R 2 F N}{D E N^{2}}\right)^{2} \\
& S F=1000 \cdot\left(\frac{A A+A B+A C+A D+A E}{D E N^{4}}+A F+A G+A H+A I+A J+A K\right)^{1 / 2}
\end{aligned}
$$

NOTES: Variables and constants are the same in this table as those defined in Table 10.2. The only major addition is that an $S$ is put in front of the variable or constant name to indicate this is a standard deviation value. 
where,

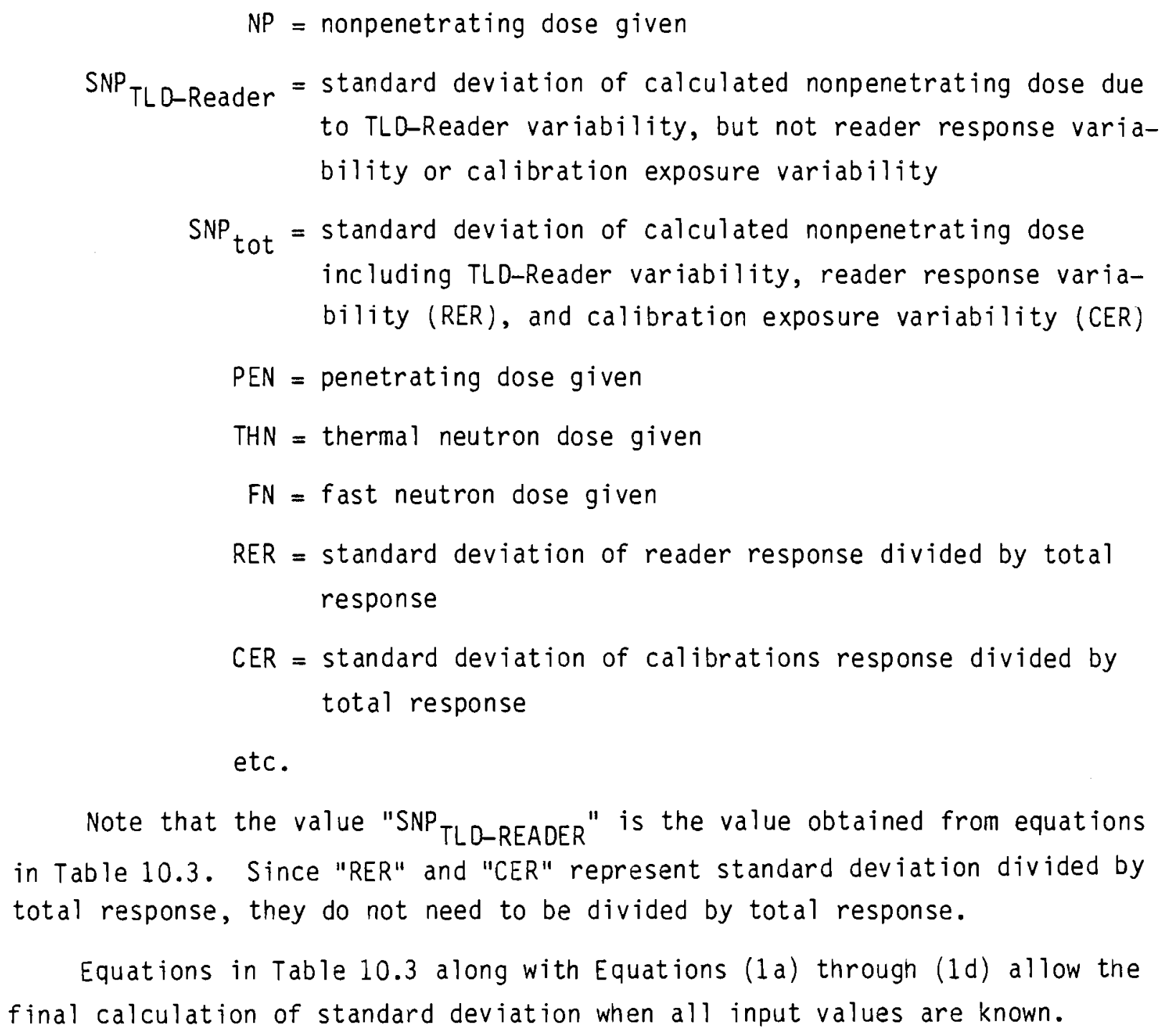

Equations in Table 10.3 along with Equations (1a) through (1d) allow the final calculation of standard deviation when all input values are known. 


\section{ASSUMPTIONS}

Several assumptions on TLD variability were made so that statistical data obtained from specific nonmixed fields could be used to predict statistical responses in mixed field exposures of various magnitudes. These assumptions are listed below:

1. For a qualitatively constant radiation exposure, TLD thermoluminescence is directly proportional to the quantity of radiation received:

$$
R=Q \cdot C_{R}+B
$$

where,

$$
\begin{aligned}
R= & \text { thermoluminescent response } \\
Q= & \text { quantity of radiation received } \\
C_{R}= & \text { chip response in thermoluminescence per quantity of radiation } \\
B= & \text { thermoluminescent response of control chip due to inherent TLD } \\
& \text { "noise" }
\end{aligned}
$$

2. For a qualitatively constant radiation exposure (i.e., $S_{Q}=0$ ), the standard deviation of thermoluminescent response equals:

$$
S_{R}=\left[\left[Q \cdot C_{R} \cdot\left(\frac{S \%}{100}\right)\right]^{2}+S_{B}^{2}\right]^{1 / 2}
$$

where,

$S_{R}=$ standard deviation of thermoluminescence response

$S \%=$ standard deviation in percent due to this radiation

$S_{B}=$ standard deviation of control chips with no exposure

3. When radiation fields are mixed, the total thermoluminescent response is equal to the sums of the individual thermoluminescent responses:

$$
\begin{aligned}
R_{T}= & R_{\gamma 1}+R_{\gamma 2}+\ldots+R_{B 1}+R_{B 2}+\ldots+R_{T H N 1}+R_{T H N 2}+\ldots \\
& +R_{F N 1}+R_{F N 2}+\ldots
\end{aligned}
$$


where,

$$
\begin{aligned}
R_{T} & =\text { total thermoluminescent response } \\
R_{Y 1} & =\text { response due to gamma radiation } \# 1 \\
R_{B 1} & =\text { response due to beta radiation } \# 1 \\
R_{T H N 1} & =\text { response due to thermal neutron radiation } \# 1 \\
R_{F N 1} & =\text { response due to fast neutron radiation } \# 1 \\
R_{Y 2} & =\text { response due to gamma radiation } \# 2 \\
\text { etc. } &
\end{aligned}
$$

4. When radiation fields are mixed, the standard deviation of TLD thermoluminescent response equals:

$$
\begin{aligned}
S_{T}= & \left(\left(S_{Y 1}+S_{\gamma 2}+\ldots+S_{B 1}+S_{B 2}+\ldots\right)^{2}+\left(S_{T H N 1}+S_{T H N 2}+\ldots\right.\right. \\
& \left.\left.+S_{F N 1}+S_{F N 2}+\ldots\right)^{2}\right)^{1 / 2}
\end{aligned}
$$

where,

$$
\begin{aligned}
S_{T} & =\text { standard deviation of } R_{T} \\
S_{Y 1} & =\text { standard deviation of } R_{Y 1} \\
S_{B 1} & =\text { standard deviation of } R_{B 1} \\
S_{T H N 1} & =\text { standard deviation of } R_{T H N 1} \\
S_{F N 1} & =\text { standard deviation of } R_{F N 1} \\
\text { etc. } &
\end{aligned}
$$

\section{SUPPORTING EVIDENCE}

Assumptions \#1 and $\# 3$ are well established as valid at low exposure levels (below 1 rem) and are not dealt with here.

Assumption \#2 follows directly from assumption \#1 when it is realized that the standard deviation of a quantitatively constant exposure equals zero $\left(S_{Q}=0\right)$ and the chip response per quantity of radiation is assumed to be constant $\left(S_{C R}=0\right)$.

Assumption 2 is shown in Figure $X .9$ to be quite reasonable in the range of $5 \mathrm{mrem}$ to $1000 \mathrm{mrem}$. Also data in Figure $x .10$ indicates this assumption is 


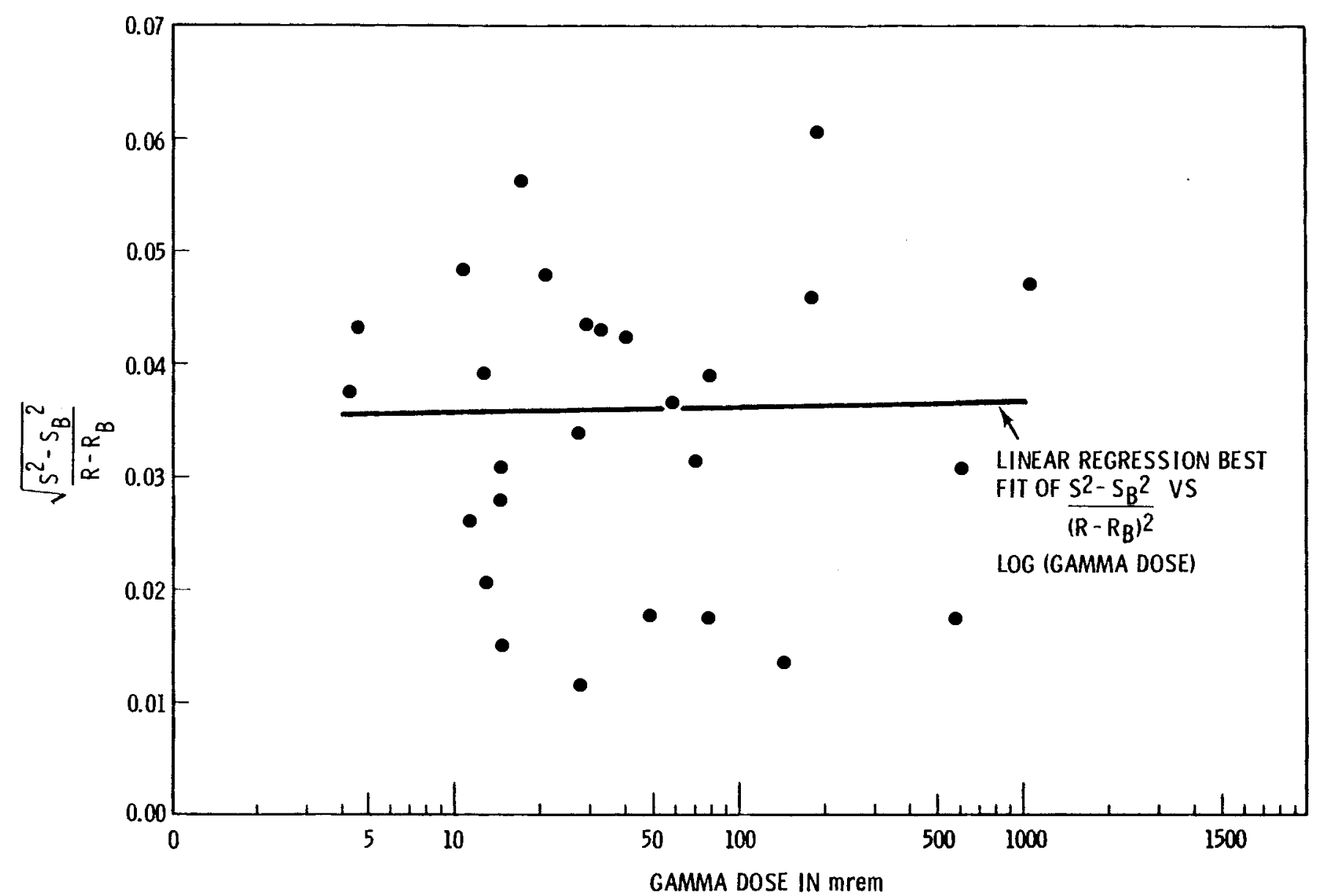

FIGURE 10.9. Low Dose Statistics of LiF, Batch A 


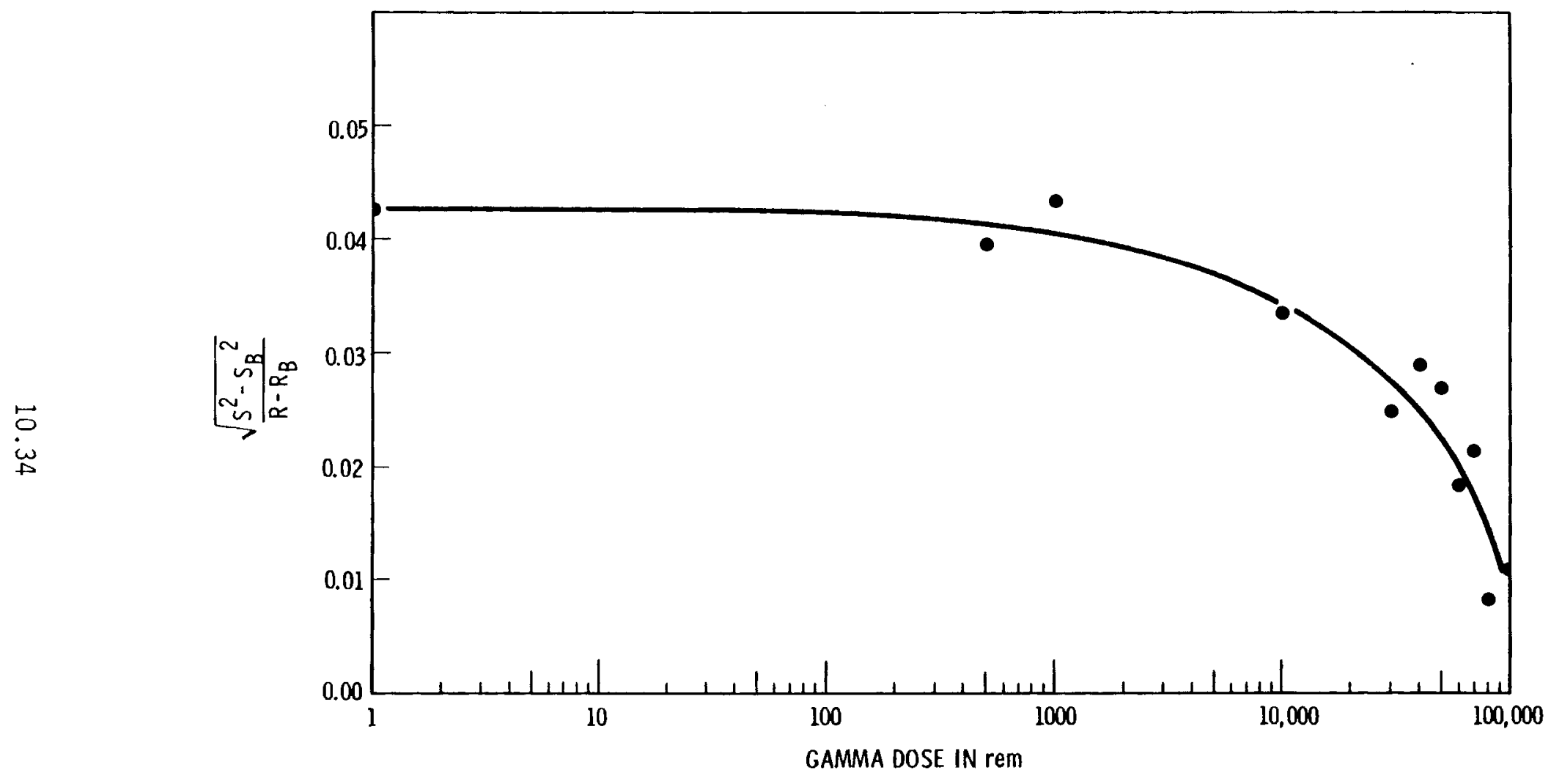

FIGURE 10.10. High Dose Statistics of LiF, Batch B 
reasonable for exposures up to 1000 rem. Though these two figures deal primarily with gamma radiation, it is reasonable to assume that a similar response occurs for beta and neutron fields.

Assumption \#4 has not been vigorously verified experimentally, but rather is a best guess based upon the physics of trap deposition in Lithium TLD materials. Since the mechanisms of energy deposition are quite different for neturon absorption compared to gamma-beta absorption, (a) they can reasonably be considered independent variables (covariance equals zero). As such, their standard deviations should be added as rms (root mean square) values.

Data which helps support assumption \#4 is shown in Figure 10.11. The predicted curve for standard deviations shown here is reasonably close to the data pattern. Though the data points are quite scattered, this graph does show that increasing the percent thermoluminescence coming from neutron exposure to $40 \%$ decreases the percent standard deviation, which is in agreement with predictions made using assumption \#4.

The predicted curve in Figure 10.11 comes from independent data on the standard deviations of this specific TLD material for a pure gamma dose of 1000 mrem and a pure thermal neutron dose of 50 mrem. The actual data points in Figure 10.11 come from thermoluminescent data from doses ranging from 2.5 mrem to $270 \mathrm{mrem}$. The approximate agreement between the predicted curve, using assumptions \#2 and \#4, and the actual data indicates that assumptions $\# 2$ and \#4 are fairly good approximations of actual TLD behavior.

(a) Neutron absorption by Lithium-6 leads to creation of a $4.8 \mathrm{MeV}$ triton and an alpha particle which dissipate their energy by physically bombarding the nearby crystal lattice. Whereas, gamma and beta trap deposition have a completely different primary mechanism envolving electron cloud interaction with ionizing radiation. 


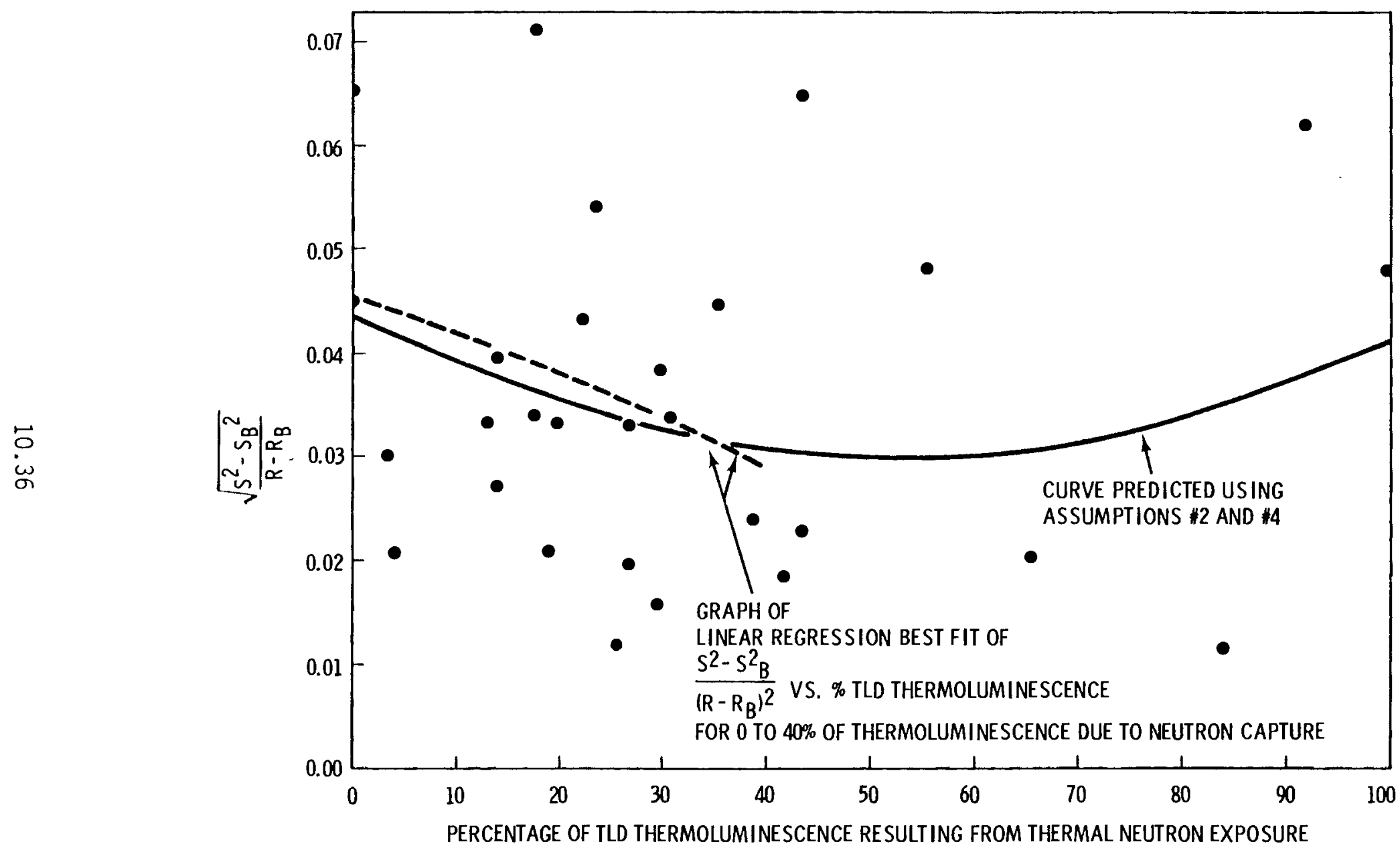

FIGURE 10.11. Mixed Field Statistics of LiF, Batch C 


\section{EXPERIMENTAL AND CALCULATION METHOD}

The values listed in Table 10.4 are parameters used to predict calculated dose standard deviations. They are approximations obtained from analysing data from specifically designed experiments as well as data from calibration exposures. The specific values determined are:

1. the general HMPD response and variability

2. the calibration dosimeter response and variability

3. the LiF background variability

4. the reader response variability

5. the calibration exposure variability.

How each value was determined is briefly described here.

GENERAL HMPO RESPONSE AND VARIABILITY

First, experiments were specifically designed to give nearly identical exposures to groups of 12 badges simultaneously exposed to one source. For beta, gamma and fast neutron exposures 12 HMPDs were symmetrically attached to the base of a 50 liter tap water filled carboy. The base of the carboy directly faced the radiation source, $70 \mathrm{~cm}$ away. The arrangement is pictured in Figure 10.12a, b, and $c$. Radiation sources used were ${ }^{90} \mathrm{Sr},{ }^{60} \mathrm{Co}$ and ${ }^{252} \mathrm{Cf}$. For each source, 12 standard Hanford four-chip dosimeters with sample security credentials were exposed to the doses listed in Table 10.4. In a similar manner, 12 standard Hanford dosimeters (randomly selected form the Hanford dosimeter p001) were exposed to thermal neutrons from a PuBe source surrounded by a cylindrical shell of $\mathrm{D}_{2} \mathrm{O}$. Dosimeters were placed symmetrically arround the PuBe-- $\mathrm{D}_{2}$ source as shown in Figure 10.13. A second shell of $\mathrm{D}_{2} \mathrm{O}$ surrounded the dosimeters. The thermal neutron dose equivalent was $280 \mathrm{mrem}$.

After a holding time ranging from 2 days to one month, the dosimeter cards were read on Hanford reader \#1. The reader count data were analysed to determine the expected standard deviation of each chip position from a population of dosimeters given the same dose. For thermoluminescent data, it was assumed that certain TLD-700 chips had the same standard deviations expressed as percent of total thermoluminescence. These were: 


\section{TABLE 10.4. Values Used in Calculating Standard Deviations}

Reader Response Variability $=4.4 \%$ for one standard deviation (reader \#1)

Calibrations Exposure Variability $=2.2 \%$ for one standard deviation

Reader Counts for Each Position (based on a 100 prgm exposure) and

\begin{tabular}{|c|c|c|c|c|c|c|c|}
\hline Radiation & & & HMPD POS & & & Actual instrument & Calibration \\
\hline (Source Used) & $\$ 1$ & $\# 2$ & $\$ 3$ & $\# 4$ & $\# 5$ & Measured Dose & Factor \\
\hline $\begin{array}{l}\text { Gamma } \\
\left({ }^{60} \mathrm{Co}\right)\end{array}$ & $\begin{array}{l}140.3 \\
+5.8 \%\end{array}$ & $\begin{array}{l}146.3 \\
+5.8 \%\end{array}$ & $\begin{array}{l}168.4 \\
+11.7 \%\end{array}$ & $\begin{array}{l}140.8 \\
+12.7 \%\end{array}$ & $\begin{array}{l}141.1 \\
+5.8 \%\end{array}$ & $90.4 \mathrm{mR}$ & 1.04 \\
\hline $\begin{array}{l}\text { Themmal Neutrons }(b) \\
\left(\mathrm{PuBe}-\mathrm{D}_{2} \mathrm{O}\right)\end{array}$ & $\begin{array}{l}68.3 \\
+2.6 \%\end{array}$ & $\begin{array}{l}58.8 \\
+2.6 \%\end{array}$ & $\begin{array}{l}11923 \\
+4.0 \% \\
\pm 4.9(\mathrm{c})\end{array}$ & $\begin{array}{l}5585 \\
+4.0 \% \\
\pm 9.3(\mathrm{c})\end{array}$ & $\begin{array}{l}71.9 \\
+2.6 \%\end{array}$ & 280 mRem & 0.91 \\
\hline $\begin{array}{l}\text { Fast Neutrons (d) } \\
(252 \text { Cf })\end{array}$ & $\begin{aligned} & 2.7 \\
+ & 12.6 \%\end{aligned}$ & $\begin{aligned} & 2.4 \\
+ & 12.6 \%\end{aligned}$ & $\begin{array}{r}503.4 \\
+9.9 \% \\
+10.3(\mathrm{c})\end{array}$ & $\begin{array}{r}308.6 \\
+9.9 \% \\
+12.9(\mathrm{c})\end{array}$ & $\begin{aligned} & 2.8 \\
+ & 12.6 \%\end{aligned}$ & 109 mRem & 0.92 \\
\hline $\begin{array}{l}\text { Beta } \\
\left(900_{S r}\right)\end{array}$ & $\begin{array}{l}123.8 \\
+2.4 \%\end{array}$ & $\begin{array}{l}28.5 \\
+7.4 \%\end{array}$ & $\begin{aligned} & 2.2 \\
&+14.8 \%\end{aligned}$ & $\begin{aligned} & 1.6 \\
&+14.8 \%\end{aligned}$ & $\begin{array}{l}1.4 \\
9.3 \%\end{array}$ & $260 \mathrm{mRad}$ & \\
\hline
\end{tabular}

One Standard Deviation in Reader Counts of Control TLD's With No Exposure Since Last Anneal

2 nd Reading

$\begin{array}{llll}\text { of } 1 T \text { Badges } \quad+9.44 \pm 4.85 & +6.55 \quad \pm 6.08 \quad \pm 4.85\end{array}$

Reader Counts for Calibration Exposures and Expected Standardepeviation of Mean Due Only to TLD Consecutive Reading Variance

\begin{tabular}{|c|c|c|c|c|c|}
\hline $\begin{array}{l}1-R \text { Gamma } \\
(137 \mathrm{Cs})\end{array}$ & $\begin{array}{l}1408.8 \\
+2.09 \%\end{array}$ & $\begin{array}{l}1462.8 \\
+1.86 \%\end{array}$ & $\begin{array}{l}1678.6 \\
+0.91 \%\end{array}$ & $\begin{array}{l}1520.9 \\
+1.05 \%\end{array}$ & $\begin{array}{l}1499.3 \\
+2.13 \%\end{array}$ \\
\hline $\begin{array}{l}50 \text { mRem Thermal } \\
\text { Neutrons } \\
\text { (Sigma Pile) }\end{array}$ & & $\begin{array}{l}18.8 \\
+6.4 \%\end{array}$ & $\begin{array}{l}5945 \\
+1.29 \%\end{array}$ & $\begin{array}{l}2775 \\
\quad+1.29 \%\end{array}$ & $\begin{array}{l}24.7 \\
+6.2 \%\end{array}$ \\
\hline $\begin{array}{l}1 \text { Rem Fast } \\
\text { Neutrons } \\
\left(\mathrm{PuF}_{4}\right)\end{array}$ & & $\begin{array}{l}289.3 \\
+2.19 \%\end{array}$ & $\begin{array}{l}2562.3 \\
+0.93 \%\end{array}$ & $\begin{array}{l}2080.8 \\
+1.46 \%\end{array}$ & $\begin{array}{l}288.6 \\
+2.22 \%\end{array}$ \\
\hline $\begin{array}{l}2 \text { Rad } 90 \mathrm{Sr} \\
\text { Equivalent Beta(f) } \\
\text { (u) }\end{array}$ & $\begin{array}{l}2001 \\
+2.18 \%\end{array}$ & $\begin{array}{l}76.8 \\
+3.3 \%\end{array}$ & & & $\begin{array}{r}1.9 \\
+53.4 \%\end{array}$ \\
\hline
\end{tabular}

(a) Actual reader counts were corrected to a 100 mrem exposure, then multiplied by the calibration factor given so that the HMPD dose equation calculated 100 mrem for the type of radiation involved.

(b) Reader counts for HMPD Positions 1,2 , and 5 were calculated as shown on page B.12 of appendix B for a pure thermal neutron exposure with the dosimeter on a cylindrical phantom.

(c) These standard deviation percentage values include a $2.8 \%$ multilicative standard deviation value for HMPD position 3 and an $8.3 \%$ multiplicative value for HMPD position 4 . See Study 5 on positional dependence.

(d) Reader counts for HMPD Positions 1, 2, and 5 were calculated as shown on page B.13 of appendix $B$ for a pure fast neutron exposure on a cylindrical phantom.

(e) This is mathematically equal to the standard deviation of individual values divided by the mean value divided by the square root of the number of measurements:

$$
\frac{s}{\sqrt{x} n}
$$

(f) $2 \mathrm{Rad} 90 \mathrm{Sr}$ equivalent radiation equals 4 Rad $U$ radiation. 


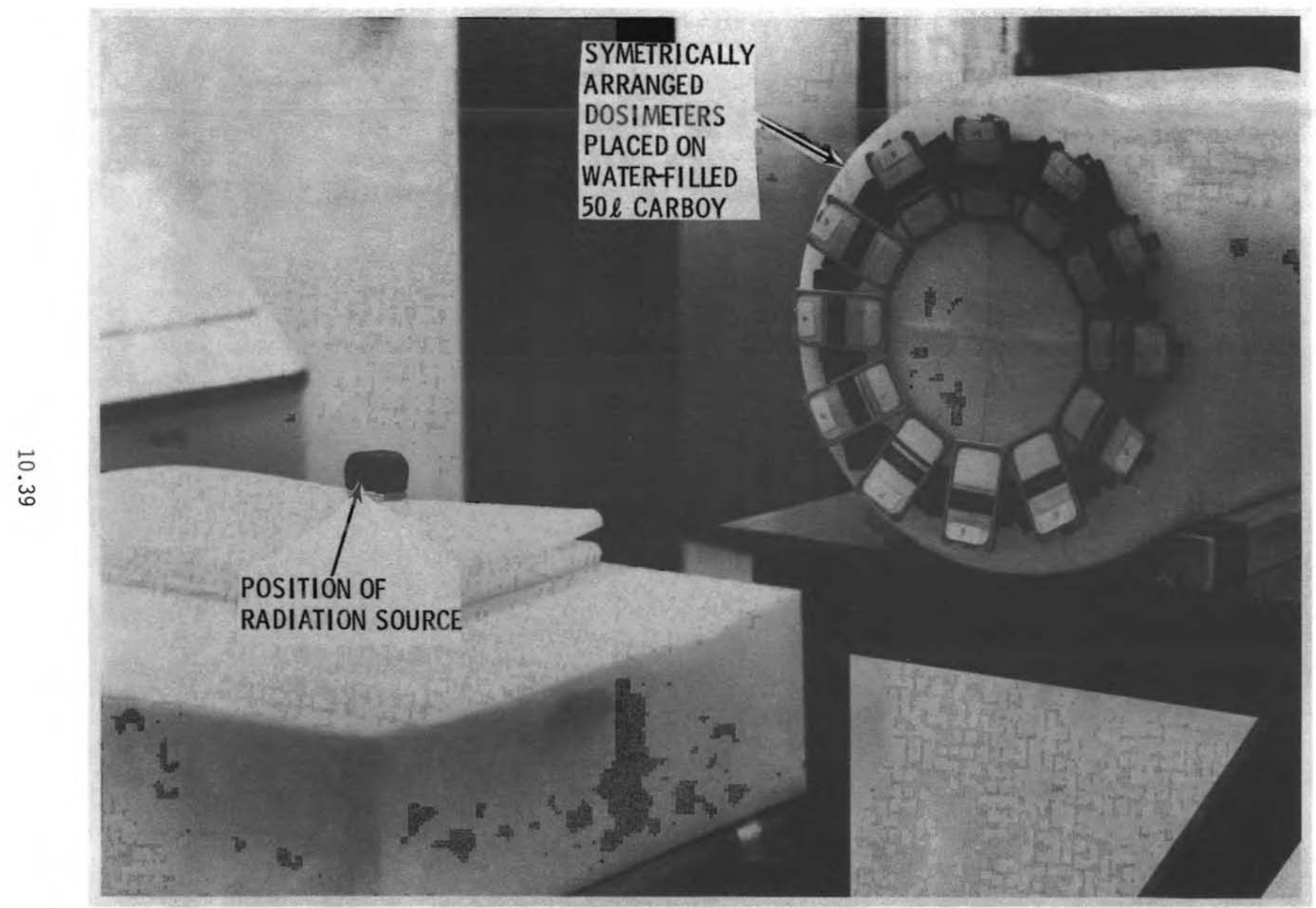

FIGURE 10.12a. Skewed View of Exposure Setup 


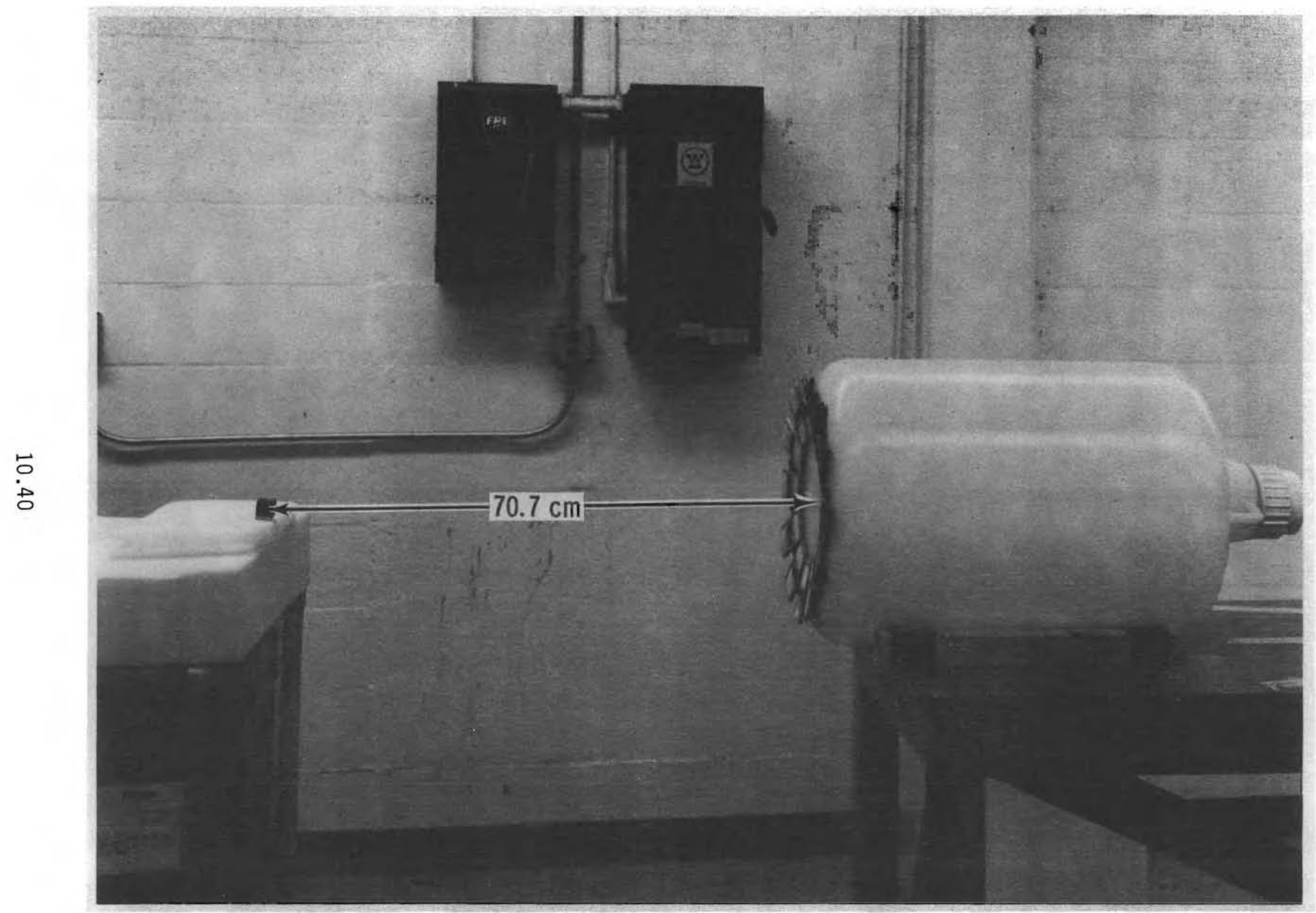

FIGURE 10.12b. Side View of Exposure Setup 


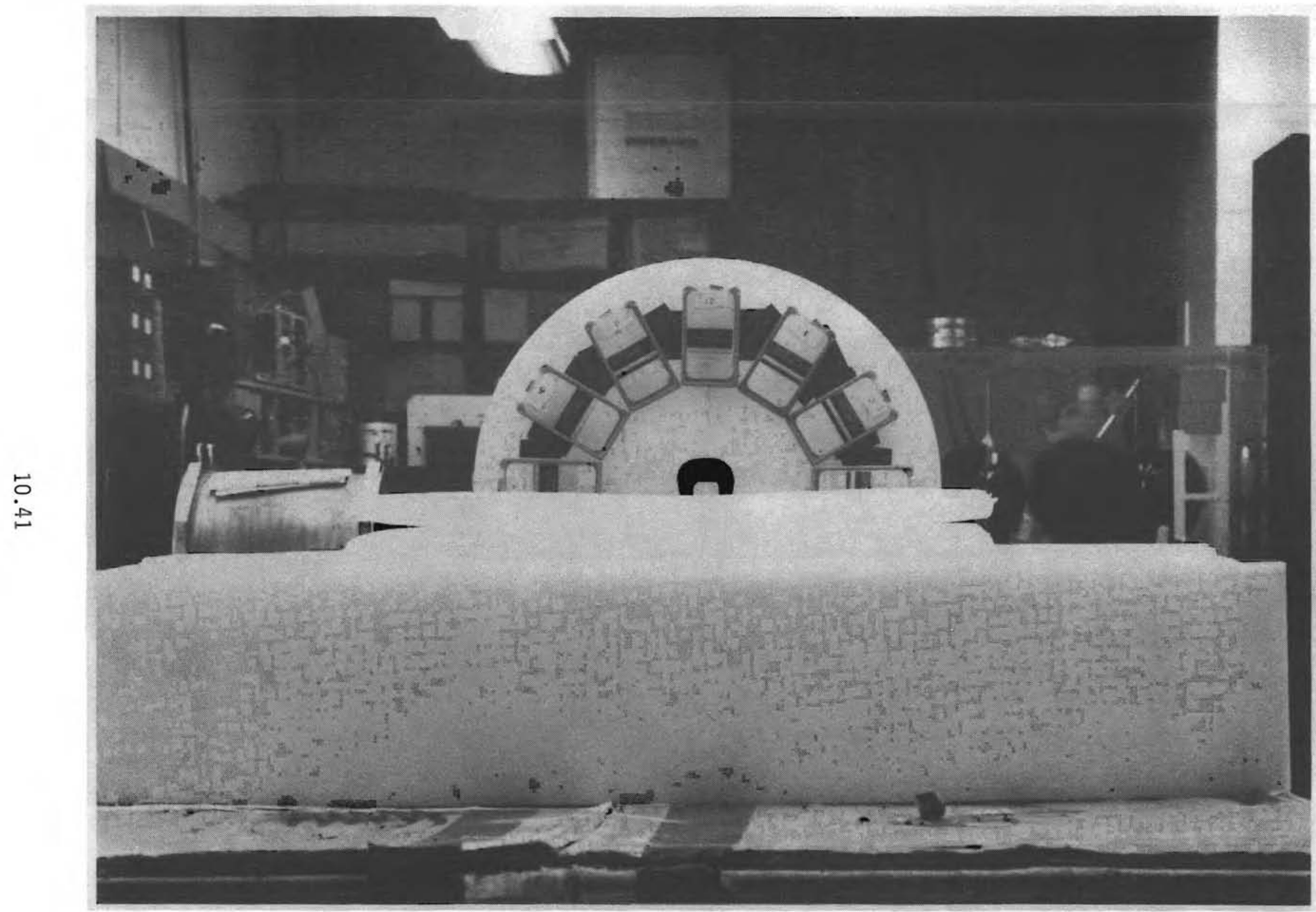

FIGURE 10.12c. Front-End View of Exposure Setup 

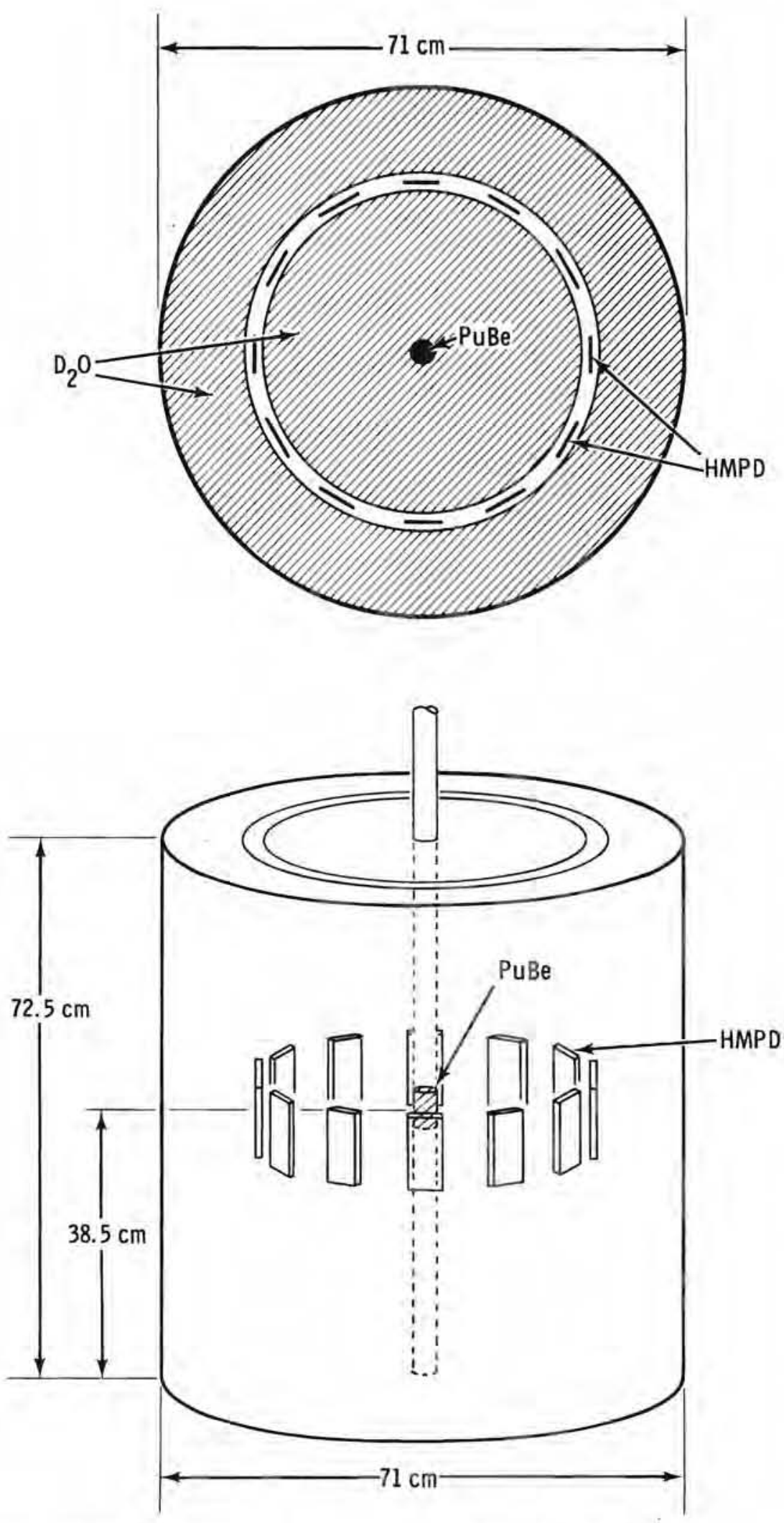

FIGURE 10.13. Top and Side V iew of Thermal Neutron Exposure 
A. Thermoluminesescence of TLD-600 chips in positions 3 and 4 resulting from either a gamma, thermal neutron or fast neutron exposure.

B. Thermoluminescence of TLD-700 chips in positions 1,2 and 5 resulting from either a gamma thermal neutron or fast neutron exposure.

To determine the independent variability (no covariance) of reader count measurement by HMPD position, the standard deviations of the difference between two similar TLD position readings were calculated. From this the independent standard deviation of each TLO reading was calculated. As an illustration, for the gamma exposure the percent standard deviation for positions 1 and 2 was determined as follows: (100 mrem exposure)

$$
\begin{aligned}
S(R 1-R 2) & = \pm 11.99 \\
S(R 1-R 2) & =\left(\frac{\sum_{i=1}^{i=12}\left((R 1-R 2)_{j}-(\overline{R 1-R 2})\right)}{12-1}\right)^{1 / 2}=11.99 \\
11.99 & =\left(\left(\frac{S \%}{100} \cdot R 1\right)^{2}+(.84)^{2}+\left(\frac{S \%}{100} \cdot R 2\right)^{2}+(1.64)^{2}\right)^{1 / 2} \\
S \% & =5.84
\end{aligned}
$$

where,

$$
\begin{aligned}
S(R 1-R 2)= & \text { standard deviation of the value }(R 1-R 2) \text { for } 12 \text { identically } \\
& \text { exposed dosimeters } \\
S \%= & \text { standard deviation in percent of } R 1 \text { and } R 2 \text { without the control } \\
& \text { reading contribution } \\
R 1= & \text { themoluminescent reading of TLD chip in position \#1 from a }{ }^{60} \text { Co } \\
& \text { exposure }
\end{aligned}
$$


R2 = thermoluminescent reading of TLD chip in position \#2 from a ${ }^{60}$ Co exposure

$0.84=$ standard deviation of control TLD chips in position \#1

1.64 = standard deviation of control TLD chips in position \#2

The actual calculations involved in determining the standard deviations by TLD position for each source are shown in more detail in the addendum to Table 10.4 in Appendix B.

\section{$\underline{\mathrm{R} 5}$}

After each set of 12 standard HMPDs was exposed, a set of 12 handloaded multpurpose dosimeters was identically exposed to the same approximate dose. Data from these hand read 5 chip dosimeters were used to predict values of R5 and SR5 in the HMPD for each type of radiation. Also these data were used to verify the accuracy of the equations calculating standard deviation values in Table 10.3.

\section{LiF--READER BACKGROUND VARIABILITY}

Next, the reader values for control TLD's given no dose were approximated by computing the standard deviations by position of HMP control dosimeters given no exposure other than background for about four months. These standard deviations were compared to standard deviation values from TLD's reread immediately after reader anneal. Reread HMP TLDs had a slightly lower standard deviation than control dosimeters, and since they had no background accumulation the reread values were taken as the best values for control TLD chips with no exposure. These values are listed in Table 10.4 under the heading " 2 nd reading of $1 T$ bades."

\section{CALIBRATION DOSIMETER RESPONSE AND VARIABILITY}

The standard deviation of calibrations' data was calculated by position for TLD chip populations using the standard deviation of the difference between two similar positions as done previously for the general HMPD response and variability. The expected standard deviation of mean values used in dose 
calculations were calculated by dividing the population standard deviation by the square root of the number of measurements involved in obtaining the mean. As an example, the calculations for gamma calibrations data in position \#1 and \#2 are shown below:

A. Twelve groups of ten calibrations' dosimeters were each simultaneously exposed to $1 R$ ( $=1 \mathrm{rem}){ }^{137} \mathrm{Cs}$ and each group was consecutively read on Hanford reader \#1. The consecutive thermoluminescent readings were analyzed to determine the standard deviation of $R 1-R 2, S(R 1-R 2)$, as follows.

$$
\begin{aligned}
x_{i} & =(R 1-R 2) \\
\bar{x}_{10, j} & =\frac{\sum_{i=1}^{i=10} x_{i, j}}{10} \\
S(R 1-R 2)_{10, j} & =\left(\frac{\sum_{j=1}^{j=10}\left(x_{i, j}-\bar{x} 10, j\right.}{10}\right)^{2} 1 / 2 \\
S(R-R 2)_{120} & =\left(\frac{\sum_{j=1}^{j=12}\left(S(R 1-R 2)_{10, j}\right.}{10-1}\right)^{2} \\
S(R 1-R 2)_{120} & =126.96 \\
S(R 1-R 2)_{120} & \cong S(R 1-R 2) \\
S(R 1-R 2) & \cong 126.96
\end{aligned}
$$

where,

$$
\begin{aligned}
S(R 1-R 2)_{120}= & \text { The standard deviation of } R 1-R 2 \text { determined from } \\
& 120 \text { calibration HMPD exposures. } \\
R 1= & \text { thermoluminescent reading of TLD chip \#1 }
\end{aligned}
$$




$$
\begin{aligned}
R 2 & =\text { thermoluminescent reading of TLD chip \#2 } \\
i & =\text { dosimeter number }(1 \text { to } 10) \\
j & =\text { set number }(1 \text { to } 12)
\end{aligned}
$$

B. From this standard deviation value, $S(R 1-R 2)$, the expected standard deviations (with no covariance) of the mean values were calculated:

$$
\begin{aligned}
\overline{R I}_{10, j} & =\frac{\sum_{i=1}^{i=10} R 1_{i, j}}{10} \\
\overline{R I}_{120}= & \sum_{j=1}^{j=12} \overline{R I}_{10, j} \\
S R 1_{10, j} \% & =\frac{\left(\sum_{i=1}^{i=10}\left(\frac{R 1_{i, j}-}{R I_{10, j}}\right)^{2}\right)^{1 / 2}}{\overline{R I}_{10,1}} \\
S R 1_{120} \% & =\left(\sum_{j=1}^{j=12}\left(\frac{\left.S R 1_{10, j}\right)^{2}}{12}\right)^{1 / 2}\right.
\end{aligned}
$$

(In a similiar manner, SR $2{ }_{120} \%$ was calculated. These values include covariance. They were used just to determine the ratio of standard deviations.) 


$$
\begin{aligned}
& \frac{\mathrm{SR} 1120 \%}{\mathrm{SR2} 120 \%}=\frac{7.92 \%}{7.04 \%}=1.125 \cong \frac{\mathrm{SR} 1 \%}{\mathrm{SR} 2 \%} \\
& \overline{R I}_{120}=1408.8 \cong \overline{R I} \\
& \overline{\mathrm{R}}_{120}=1462.8 \cong \overline{\mathrm{R} 2} \\
& S(R 1-R 2)=126.96=\left(\left(\frac{S R 1 \%}{100} \cdot \overline{R 1}\right)^{2}+\left(\frac{1}{1.125} \cdot \frac{S R 1 \%}{100} \cdot \overline{R 2}\right)^{2}\right)^{1 / 2} \\
& \text { SR1\% (population) }=6.62 \% \\
& \text { SR2\% (population) }=5.88 \% \\
& \overline{S R 2} 10 \%(\text { mean of } 10)=\frac{S R 1 \%}{\sqrt{10}}=2.09 \% \\
& \overline{\mathrm{SR}} 210 \%(\text { mean of } 10)=\frac{\mathrm{SR} 1 \%}{\sqrt{10}}=1.86 \%
\end{aligned}
$$

where,

$$
\begin{aligned}
R 1_{i, j}= & \text { reading } i \text { in set } j \\
\overline{R 1}_{10, j}= & \text { mean of } 10 \text { readings in set } j \\
\bar{R}_{120}= & \text { mean of a11 } 120 \text { readings in sets } 1 \text { through } 12 \\
S R 1_{10, j \%=} & \text { standard deviation of } R 1 \text { in set } j \text { in percent } \\
S R 1_{120}= & \text { standard deviation of } R 1 \text { in percent determined from } \\
& 120 \text { calibration HMPD readings } \\
S R 2 & \text { standard deviation of } R 2 \text { in percent determined from } 120 \\
& \text { calibration HMPD readings }
\end{aligned}
$$




$$
\begin{aligned}
\text { SR1\% }= & \text { population standard deviation of } R 1 \text { with no covariance in } \\
& \text { percent } \\
\text { SR2\% = } & \text { population standard deviation of } R 2 \text { with no covariance in } \\
& \text { percent } \\
\mathrm{SR}_{1} 10 \%= & \text { standard deviation of mean of } 10 \text { readings of } \mathrm{R} 1 \text { with no } \\
& \text { covariance in percent } \\
\mathrm{SR} 210 \%= & \text { standard deviation of mean of } 10 \text { readings of } \mathrm{R} 2 \text { with no } \\
& \text { covariance in percent }
\end{aligned}
$$

The reason for these lengthy calculations is to eliminate all covariance between positions in the HMPD data which might result from differences in distance from the source, differences in room scatter, etc. Note that SR $120 \%$ (7.92\%) was slightly greater than SR1\% (6.62\%). This is because the SR1 $120 \%$ value included the covariance contribution and the SR1\% value did not.

$\underline{R 5}$

Values for each calibration mean and standard deviation reading used in dose calculations are shown in Table 10.4. Deviation values were calculated in a similar manner as the example given above. The 5 th chip response values were added by comparing chip response values using 5-chip, hand-loaded and handread dosimeters with standard 4-chip HMPD response values.

\section{CALIBRATION EXPOSURE VARIABILITY}

Calibration exposure variability as shown in Table X.4 is a measure of how much one calibration exposure varies from another calibration exposure due to the exposure rather than TLD-reader sources. This value is expressed as fraction of total exposure. To determine this value, $1 R{ }^{137} \mathrm{Cs}$ calibration exposure data were analyzed. For each calibration there are 10 " $1 T$ " dosimeters consecutively read followed by 10 "PT" dosimeters. These dosimeters are exposed separately to $1 R{ }^{137} \mathrm{CS}$ in near identical geometries. The variance of the ratio of the mean $1 T$ reading to the mean $\mathrm{PT}$ reading was compared to the predicted variance using population standard deviations. The difference between the predicted variance and the actual variance was assumed to be due 
to variability in calibration exposure. This was the only reasonably accurate measure of variance of calibration exposure; therefore, this value was used for gamma, beta, fast neutron and slow neutron exposures.

The calibration exposure variability was calculated mathematically as follows:

$$
\begin{aligned}
& S\left(\frac{\bar{R}_{Y, 1 T, 10}}{\bar{R}_{\gamma, P T, 10}}\right)_{\text {predicted } w / 0}=\left(\left(\frac{S R i_{120} \%}{(10)^{1 / 2}}\right)^{2} \times 2\right)^{1 / 2} \\
& \text { CER, } i \\
& \mathrm{CER}_{i}^{2}=S\left(\frac{\bar{R}_{\gamma, 1 T, 10}}{\bar{R}_{\gamma, \text { PT }, 10}}\right)_{\text {actua } 1, i}^{2}-S\left(\frac{\bar{R}_{\gamma, 1 T, 10}}{\bar{R}_{\gamma, \text { PT, 10 }}}\right)_{\text {predicted } w / 0 \text { CER, } i}^{2} \\
& \operatorname{CER}=\left(\frac{\sum_{i=1}^{i=4}(\text { CER } i)^{2}}{4}\right)^{1 / 2} \\
& =0.02 \text { or } 2 \%
\end{aligned}
$$

where,

$$
\begin{aligned}
\bar{R}_{\gamma, 1 T, 10}= & \text { mean of position } i \text { in } 10 \text { calibration HMPDs when given } 1 R{ }^{137} \mathrm{CS} . \\
\bar{R}_{Y P T, 10}= & \text { mean of position } i \text { in } 10 \text { calibration HMPDs when given } 1 R{ }^{137} \mathrm{Cs} . \\
\mathrm{SR}_{120}= & \text { standard deviation of } \mathrm{R} i \text { in percent of total response deter- } \\
& \text { mined from } 120 \text { calibration HMPD readings } \\
\mathrm{S}()_{i=} & \text { standard deviation of quantity in parenthesis, predicted or } \\
& \text { actually calculated for position } i \\
10= & \text { number of dosimeters used in calculating mean }
\end{aligned}
$$




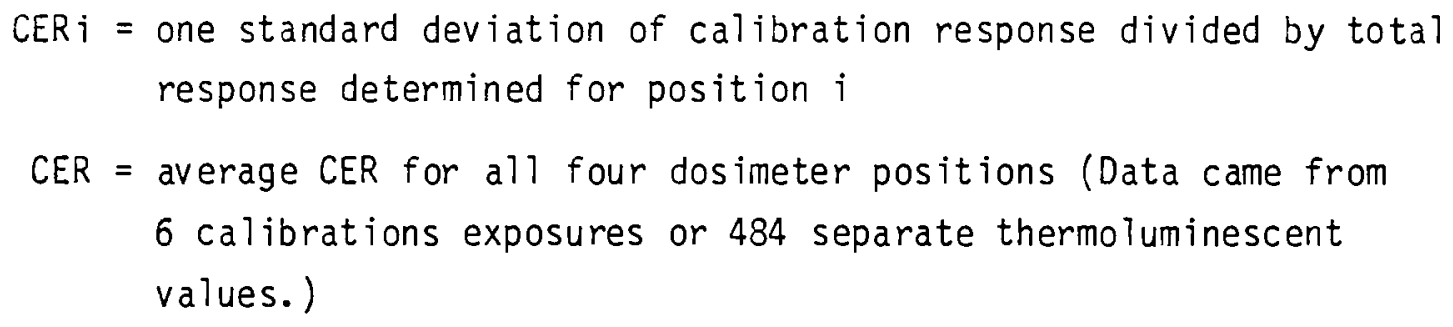

\section{READER RESPONSE VARIABILITY}

The final value which was calculated in Table 10.4 is the reader response variability, which is one standard deviation of reader drift or cycling during an average run expressed as fraction of total readout. To determine this value, the standard deviation of consecutively read $1 T$ dosimeters (exposed to $1 R^{137} \mathrm{Cs}$ ) was compared to the standard deviation of $1 T$ dosimeters read intermittently throughout three complete runs. (The larger standard deviation of intermittent readings was assumed to be due to reader response variability.) The equations used in calculating reader response variability are:

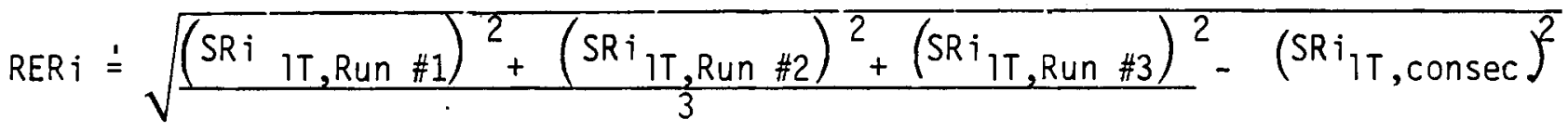

$$
\begin{aligned}
& \text { RER }=\sqrt{\frac{\sum_{i=1}^{i=4}(R E R i)^{2}}{4}}-C^{2} R^{2}=.044=4.4 \%
\end{aligned}
$$

where,

$$
\begin{aligned}
\text { RERi }= & \text { one standard deviation of reader response calcu- } \\
& \text { lated as fraction of total response for TLD chips } \\
& \text { in position } i . \\
\mathrm{SRi}_{1 T, \text { Run \#1 }=} & \text { one standard deviation of } 1 T \text { TLD response in } \\
& \text { fraction of total response in position } i \text { for Run \#1. } \\
\mathrm{SRi} 1 T, \text { consec. }= & \text { one standard deviation of } 1 T \text { TLD response in } \\
& \text { fraction of total response in position } i \text { when read } \\
& \text { consecutively. }
\end{aligned}
$$




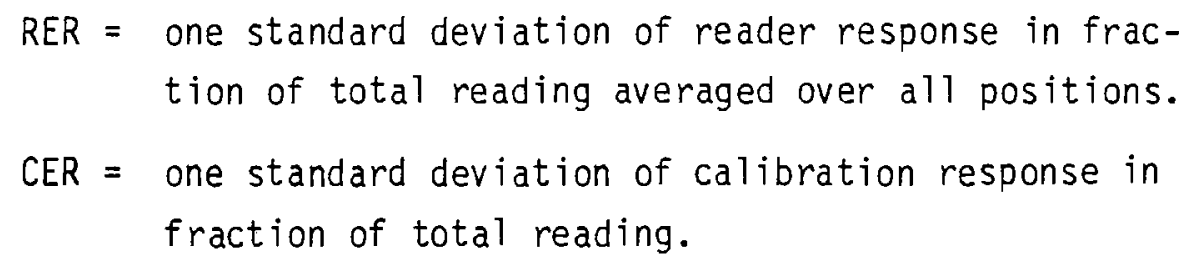




\section{VERIFICATION OF STANDARD DEVIATION EQUATIONS AND TABULATED VALUES}

To verify the standard deviation equations in Table 10.3 , sets of twelve hand-loaded and hand-read dosimeters were exposed to either ${ }^{60} \mathrm{Co}, \mathrm{PuBe}-\mathrm{D}_{2} \mathrm{O}$, ${ }^{252} \mathrm{Cf}$ or ${ }^{90} \mathrm{Sr}$ as shown in Figures 10.12 and 10.13 . Using the same methodology used deriving the standard deviation values for the Hanford reader-dosimeter system, the predicted values were computed and compared to the actual values for standard deviation. Only one set of calibration constants was used.

Results are shown in Table 10.5. In general the equations are shown to be very accurate in predicting the standard deviation values.

In a similar manner, the variability of hand read calibration constants were used to test the equations in Table X.3. Results are also shown in Table 10.5. The agreement between predicted and actual standard deviation values is again quite good (90\% of the predicted values in Table 10.5 are with in $25 \%$ of actual values).

In general, Table 10.5 shows that when the correct values for standard deviation and total thermoluminescence are input, the equations in Table 10.3 will calculate good first approximations of standard deviations. The question then is, "How accurate are the standard deviation and total thermoluminescence values in Table 10.4 and how accurate are the calibration exposure variability and reader response variability values?" To answer this, sets of Hanford calibrations data over several months were analysed to determine their standard deviations. Then these values were compared to general HMPD predicted values using Table 10.4 and Figures 10.3 through 10.6. (a) The results are tabulated in Table 10.6 .

In general, the predicted and actual standard deviations are fairly close ( $40 \%$ of the predicted values are within $25 \%$ of actual values). The largest differences occur when calculating the standard deviation of neutron doses following a neutron exposure. This is because the calibration exposure is controlled to assure nearly identical phantom dosimeter placement,

(a) The drawback of this procedure was that calibrations TLD chips do not have the same statistical repsonse as do general HMPD TLD chips, though they are similar. 
TABLE 10.5. Verification of Standard Deviation Equations (All data here came from hand-loaded and read dosimeters.)

$\begin{array}{ll} & \text { Dose Calculated } \\ & \\ & \text { SNP predicted } \\ & \text { SNP actual } \\ & \text { SPEN predicted } \\ & \text { SPEN actual } \\ 5 & \text { SSLO-N predicted } \\ \text { in } & \text { SSLO-N actual } \\ \omega & \text { SFN }\end{array}$

SFN (4 chip eqn) predicted

SFN (4 chip eqn) actual

SFN ( 5 chip eqn) predicted

SFN ( 5 chip eqn) actual
Standard deviation due to TLD reader variability

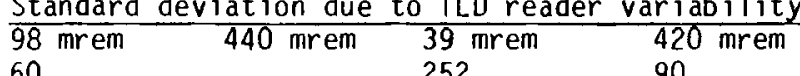
${ }^{60} \mathrm{CO}$

$\frac{\mathrm{CO}}{ \pm 17.5}$ PuBe-D20

$\pm 14$

\pm 4.7
\pm 4.7$$
\begin{aligned}
& \pm .16 \\
& \pm .17
\end{aligned}
$$

$\pm 13$

$+13.8$

$\pm 14.3$

$\pm 14.6$
${ }^{252} \mathrm{Cf}$

\pm 72
\pm 85

\pm 72
\pm 85

\pm 3.3
\pm 3.2

$90_{\mathrm{Sr}}$

$\pm 37.6$

$\pm 37.6$

$\begin{array}{lll} \pm 29 & \pm 1.1 & \pm 3.2 \\ \pm 29 & \pm 1.1 & \pm 3.2\end{array}$

$\pm 19 \quad \pm .45 \quad \pm .03$

$\pm .44$

$\pm .02$

$\pm 4.7$

$\pm 1430$

\pm 1430
\pm 1130

\pm 41
\pm 35

$\pm 1417$

$\pm 1226$ $\pm 41$

$\pm 34$
Standard deviation due just to variations of cal ibrations constants

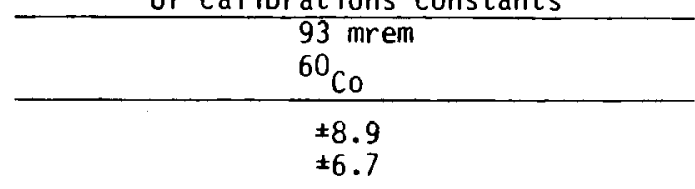

$\pm 3.8$

$\pm 3.8$

$\pm .019$

$\pm .020$

$\pm 11.8$

$\pm 11.7$

$\pm 11.8$

where,

SNP = standard deviation of calculated nonpenetrating dose

SPEN = standard deviation of calculated penetrating dose

SSLO-N = standard deviation of calculated slow neutron dose

SFN = standard deviation of calculated fast neutron dose 
TABLE 10.6. Comparsion of Predicted General HMPD Standard Deviations with Actual Calibrations HMPD Standard Deviations

Calibration Dose Given

\begin{tabular}{|c|c|c|c|c|}
\hline & $\begin{array}{l}1000 \mathrm{mrem} \\
137 \mathrm{Cs} \\
\end{array}$ & $\begin{array}{l}50 \text { mrem } \\
\text { thermal neutrons }\end{array}$ & $\begin{array}{l}1000 \text { mrem } \\
\mathrm{PuF}_{4}^{(\mathrm{a})} \\
\end{array}$ & $2000 \operatorname{mrem}\left({ }^{90} S R\right.$ eq $)$ \\
\hline $\begin{array}{l}\text { SNP predicted } \\
\text { SNP actual }\end{array}$ & $\begin{array}{l} \pm 127.4 \\
\pm 119.0\end{array}$ & $\begin{array}{l} \pm 11 \\
\pm 6.3\end{array}$ & $\begin{array}{l} \pm 26 \\
\pm 26.4\end{array}$ & $\begin{array}{l} \pm 132.8 \\
\pm 158.1\end{array}$ \\
\hline $\begin{array}{l}\text { SPEN predicted } \\
\text { SPEN actual }\end{array}$ & $\begin{array}{l} \pm 78.5 \\
\pm 79.8\end{array}$ & $\begin{array}{l} \pm 3.4 \\
\pm 6.6\end{array}$ & $\begin{array}{l} \pm 15.3 \\
\pm 15.6\end{array}$ & $\begin{array}{l} \pm 5.9(b) \\
\pm 7.2\end{array}$ \\
\hline $\begin{array}{l}\text { SSLO-N predicted } \\
\text { SSLO-N actual }\end{array}$ & $\begin{array}{l} \pm 4.1 \\
\pm 1.6\end{array}$ & $\begin{array}{l} \pm 6.7(c) \\
\pm 2.6\end{array}$ & $\begin{array}{l} \pm 10.4(\mathrm{c}) \\
\pm 2.2\end{array}$ & $\begin{array}{l} \pm .3 \\
\pm .2\end{array}$ \\
\hline $\begin{array}{l}\text { SFN predicted } \\
\text { SFN actual }\end{array}$ & $\begin{array}{l} \pm 268.6 \\
\pm 134.6\end{array}$ & $\begin{array}{l} \pm 400(c) \\
\pm 122\end{array}$ & $\begin{array}{l} \pm 640(c) \\
\pm 127\end{array}$ & $\begin{array}{l} \pm 46 \\
\pm 17.4\end{array}$ \\
\hline
\end{tabular}

where,

$$
\begin{aligned}
\text { SNP } & =\text { standard deviation of calculated nonpenetrating dose } \\
\text { SPEN } & =\text { standard deviation of calculated penetrating dose } \\
\text { SSLO-N } & =\text { standard deviatin of calculated slow neutron dose } \\
\text { SFN } & =\text { standard deviation of calculated fast neutron dose }
\end{aligned}
$$

(a) These actual values include the contribution from 180 mrem gamma radiation.

(b) This value has been corrected for the relative response of chip \#2 to $U$ beta compared to $90 \mathrm{Sr}$ beta.

(c) These predicted valves include the effect of positional dependence, whereas the calibrations exposure did not. Therefore they would be expected to overestimate calibration standard deviations by about a factor of two.

and as such does not include the contribution from positional dependence. Also the calibrations TLD chips are more precise then then general HMPD TLD chips for neutron exposures. (The general HMPD TLD population was shown to be $\pm 4 \%$. and $\pm 10 \%$ for thermal and fast neutrons respectively, whereas the calibrations TLD population was shown to be $\pm 3.2 \%$ and $\pm 3 \%$ for thermal and fast neutrons.)

Within the expected limitations of accuracy of predicting standard devjations and the limitation resulting from comparing the predicted field HMPD standard deviations with calibrations standard deviations, Table 10.6 verifies the predicted values as being reasonably close to acutual values. 
As a further test of the predicted standard deviations, Table 10.7 compares the predicted values with values for control TLDs. Since the control TLDs come from the general HMPD pool, they provided a better test. In general, the agreement between predicted and actual standard deviations is quite good over the dose range covered. (45\% of the predicted values are within 25\% of the actual value, $100 \%$ are within a factor of 2.2.)

TABLE 10.7. Comparison of Predicted General HMPD Standard Deviations with Actual Control HMPD Standard Deviations.

$\begin{array}{llll}\text { Beta dose given } & 50 \mathrm{mrem} & 400 \mathrm{mrem} & 1000 \mathrm{mrem} \\ \text { SNP predicted } & \pm 11.2 & \pm 28.7 & \pm 67.1 \\ \text { SNP Actual } & \pm 5.6 & \pm 53.8 & \pm 144.4 \\ & & & \\ \text { Gamma dose given } & 50 \mathrm{mrem} & 400 \mathrm{mrem} & 1000 \mathrm{mrem} \\ \text { SPEN predicted } & \pm 5.2 & \pm 32 & \pm 78.5 \\ \text { SPEN actual } & \pm 5.3 & \pm 39.3 & \pm 90.2 \\ \text { Slow neutron doseggiven } & & 40 \mathrm{mrem} & \\ \text { SSLO-N predicted(a) } & & \pm 5.6 & \\ \text { SSLO-N actual } & & \pm 7.1 & \\ & & & \\ \text { Fast neutron dose given } & 100 \mathrm{mrem} & 400 \mathrm{mrem} & 1000 \mathrm{mrem} \\ \text { SFN predicted(a) } & \pm 33 & \pm 250 & \pm 640 \\ \text { SFN actual } & \pm 33.9 & \pm 155 & \pm 311\end{array}$

(a) These predicted values include the effect of positional dependence, whereas the control exposures did not. Therefore they would be expected to overestimate control standard deviations by almost a factor of two at high dose levels. 


\section{REFERENCES}

1. Bennett, C. A. and N. L. Franklin. 1974. Statistical Analys is in Chemistry and the Chemical Industry. John Wiley and Sons, Inc., New York.

2. Selby, S. M., ed. 1970. Standard Mathematical Tables. 18th ed. The Chemical Rubber Co., CleveTand, Ohio.

3. Attix, F. H., Roesch, W. C. and E. Tochilin. 1968. Radiation Dosimetry. 2nd ed. Academic Press, Inc., New York.

4. Shoemaker, D. P., C. W. Garland, and J. I. Steinfeld. 1974. Experiments in Physical Chemistry. 3rd ed. McGraw Hill, Inc., New York.

5. Dick, J. G. 1973. Analytical Chemistry, McGraw Hill, Inc., New York. 
APPENDIX A

TABLE A.10.1.

CALCULATED STANDARD DEVIATIONS FOR 100 MREM MIXED FIELD EXPOSURES 
GIVEN IIOSE EQUIVALENT, CALCULATEII IOSE EQUIV ANII STANIIAFII IIEUIATION IN. UNITS OF MFEM

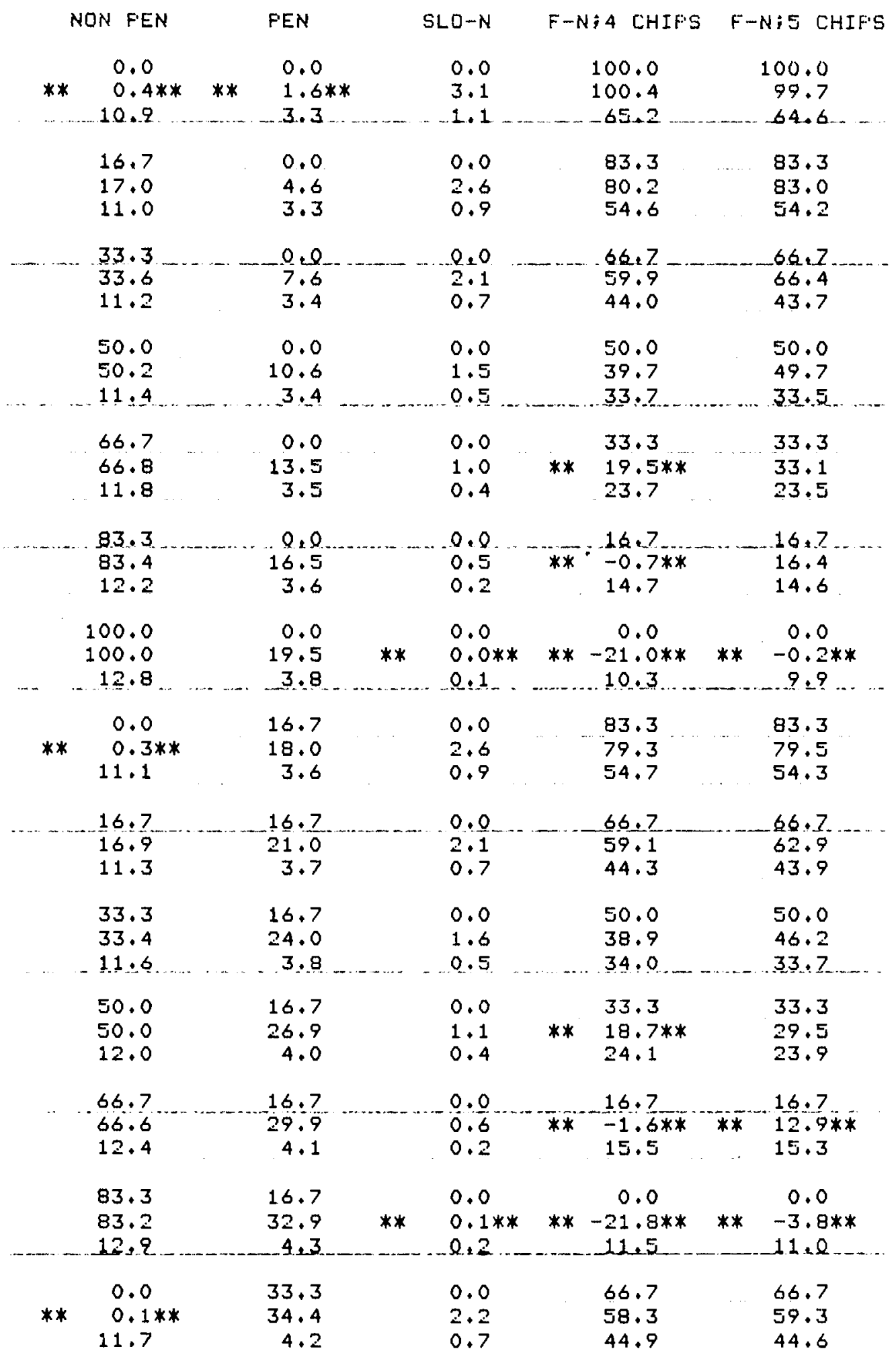




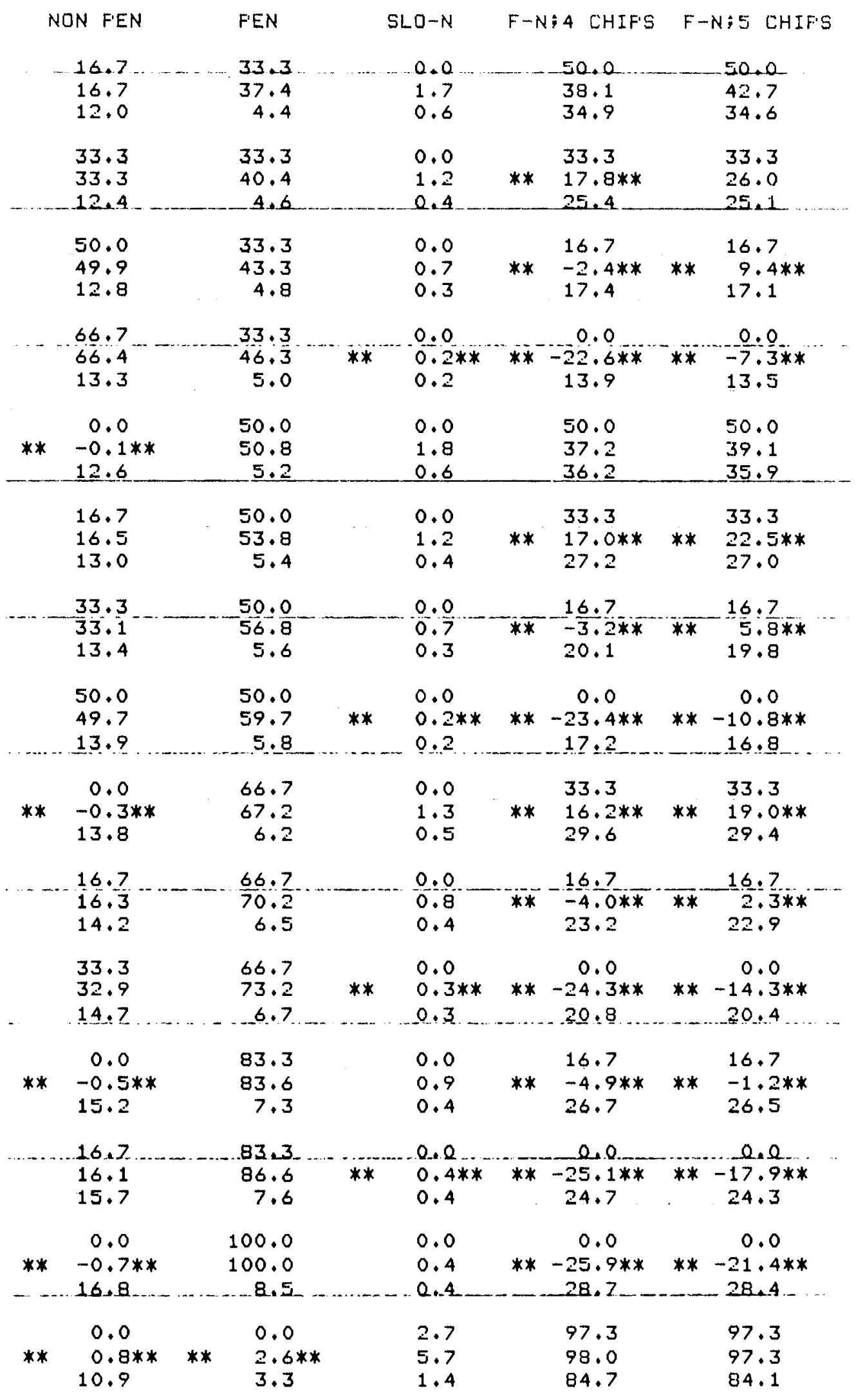

10.A. 2 


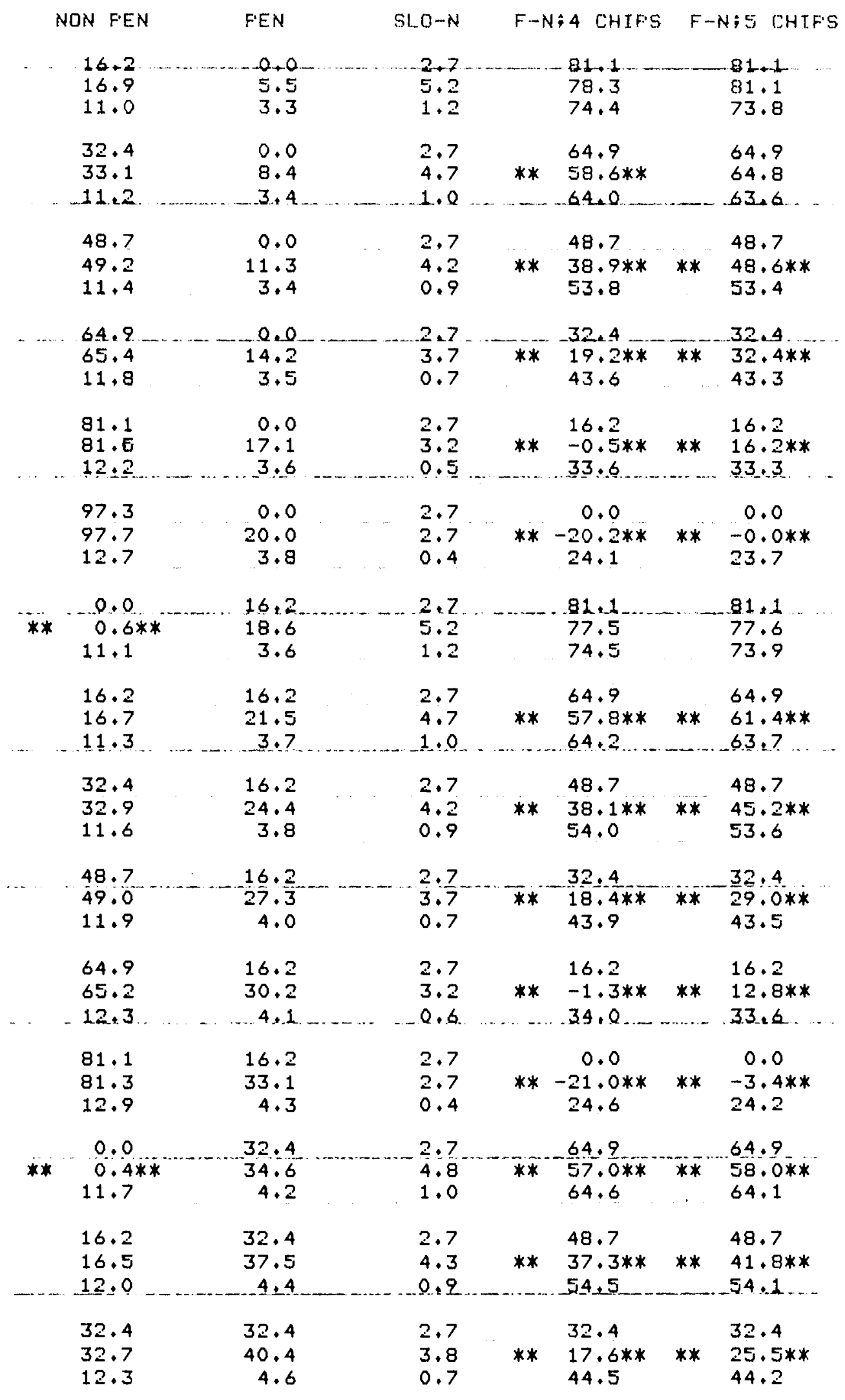

10.A. 3 


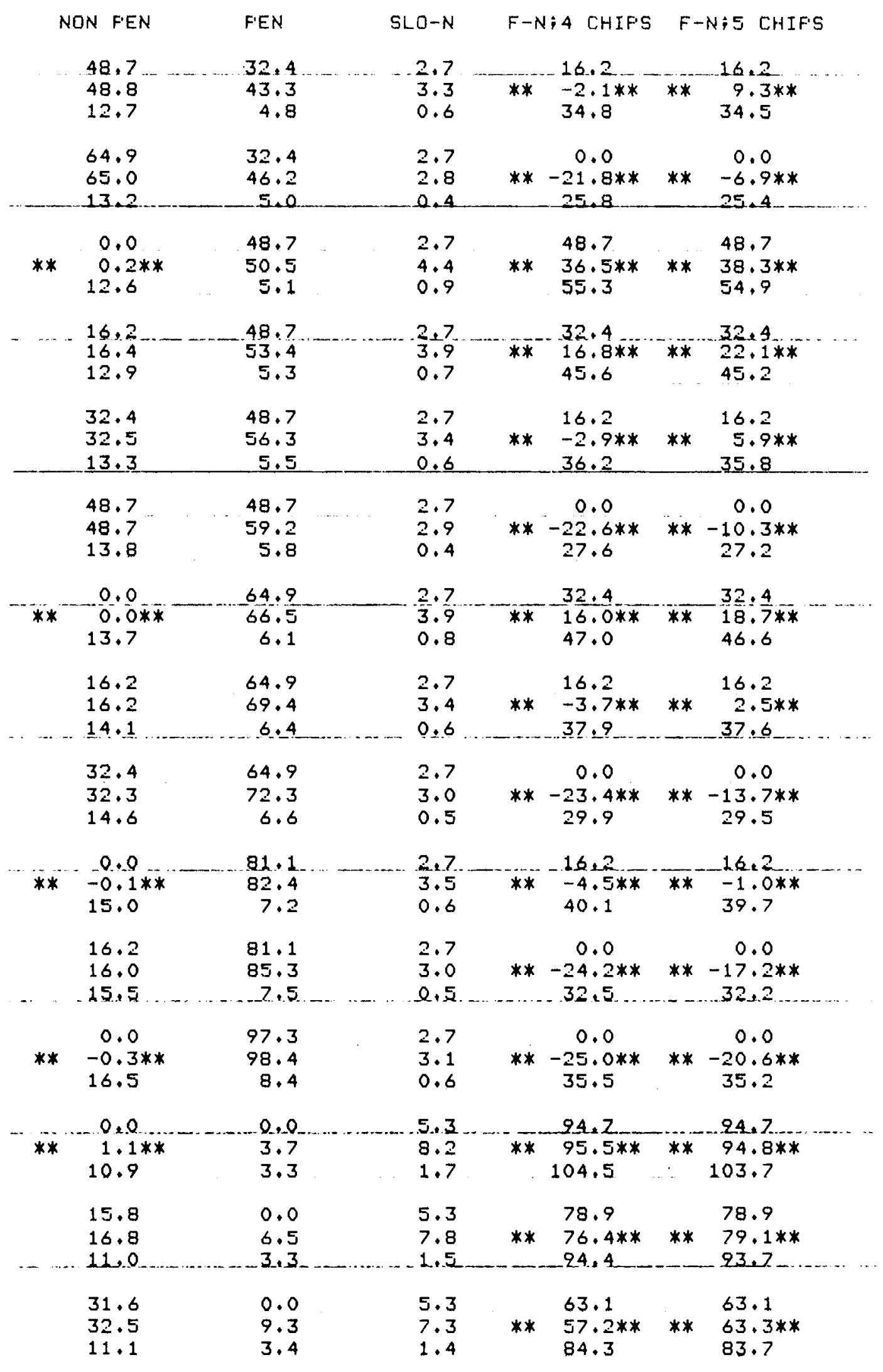

10.A. 4 


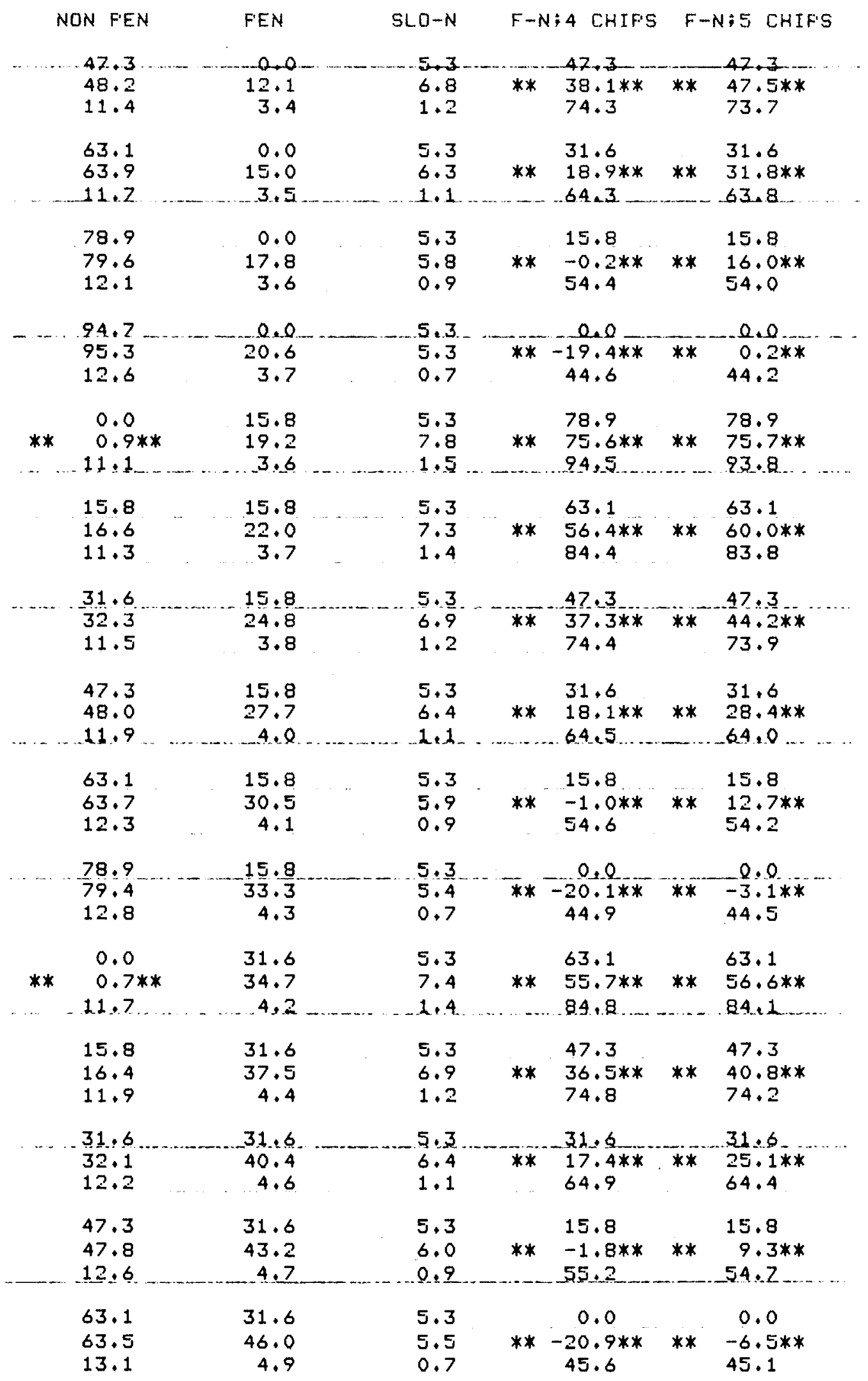

10.A. 5 


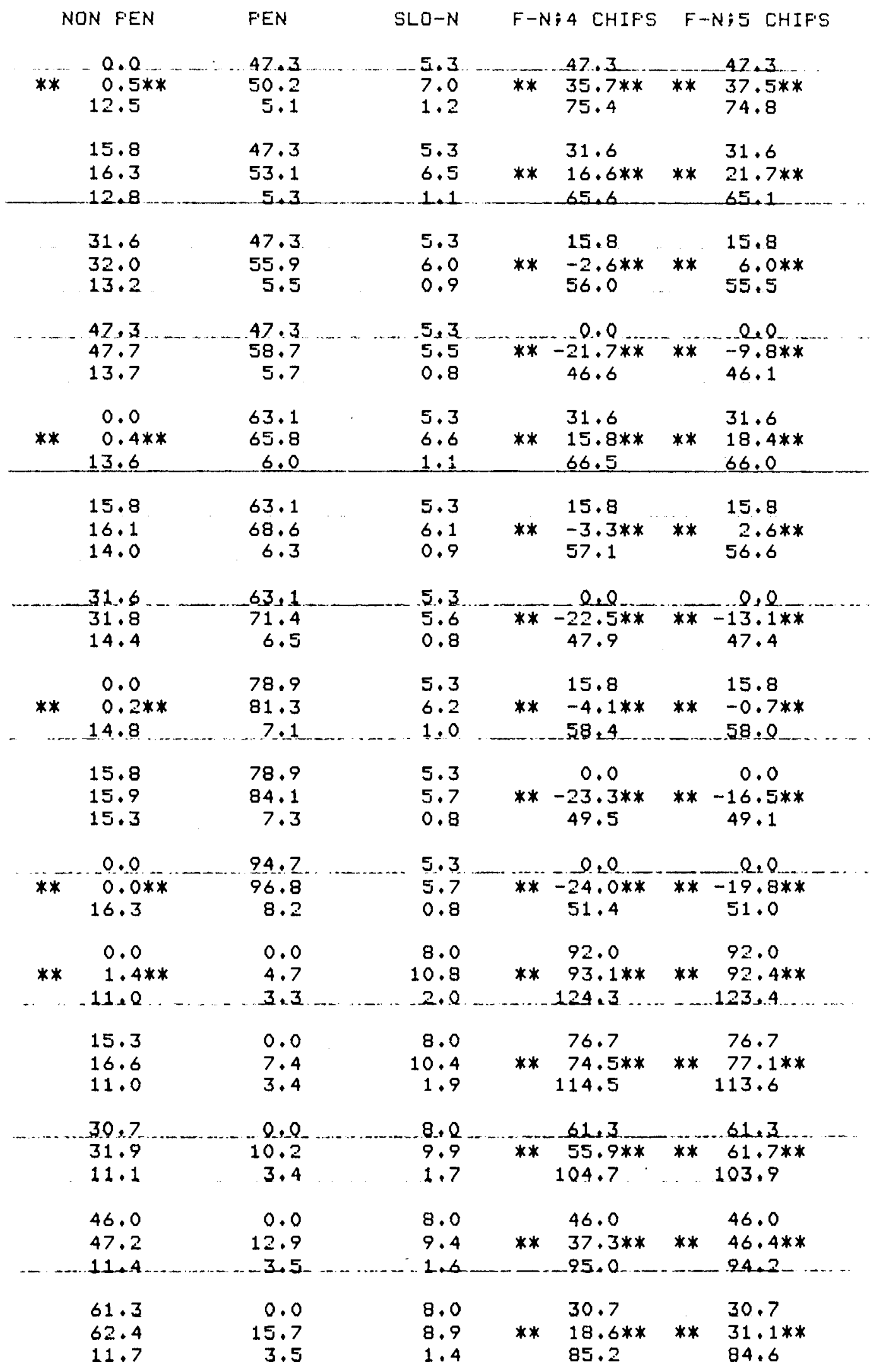

10.A. 6 


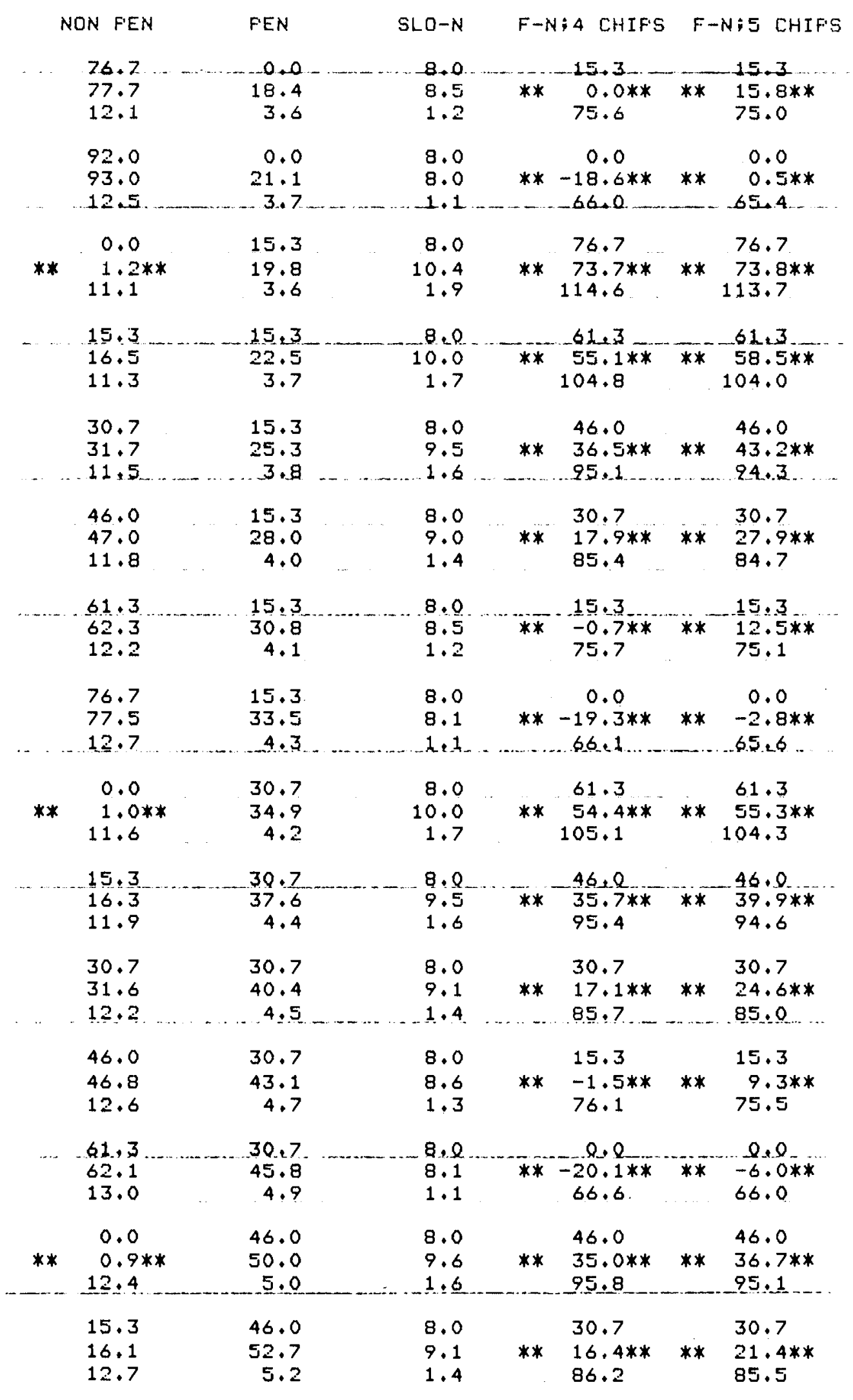

10.A. 7 


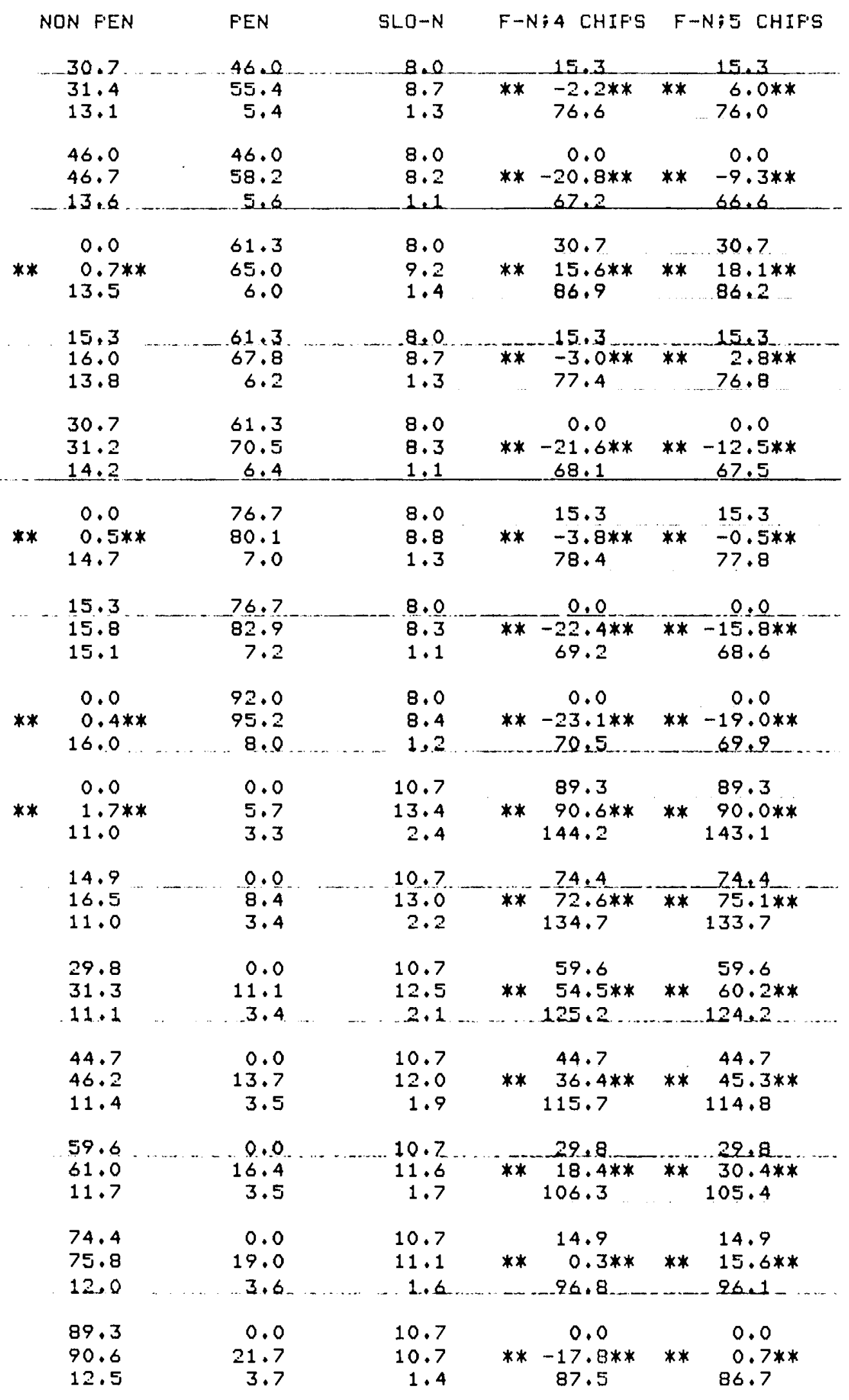

10.A. 8 


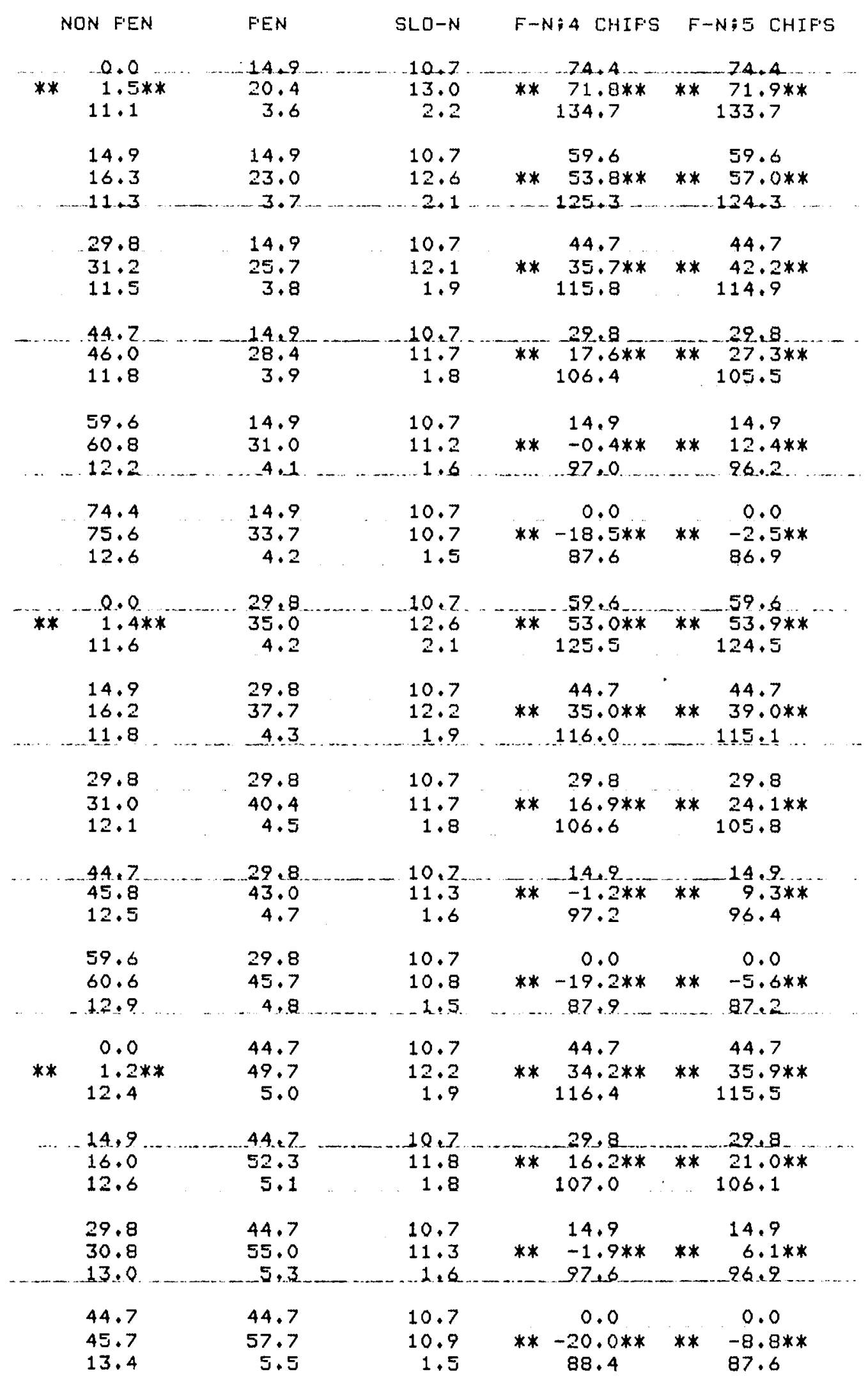

10.A.9 


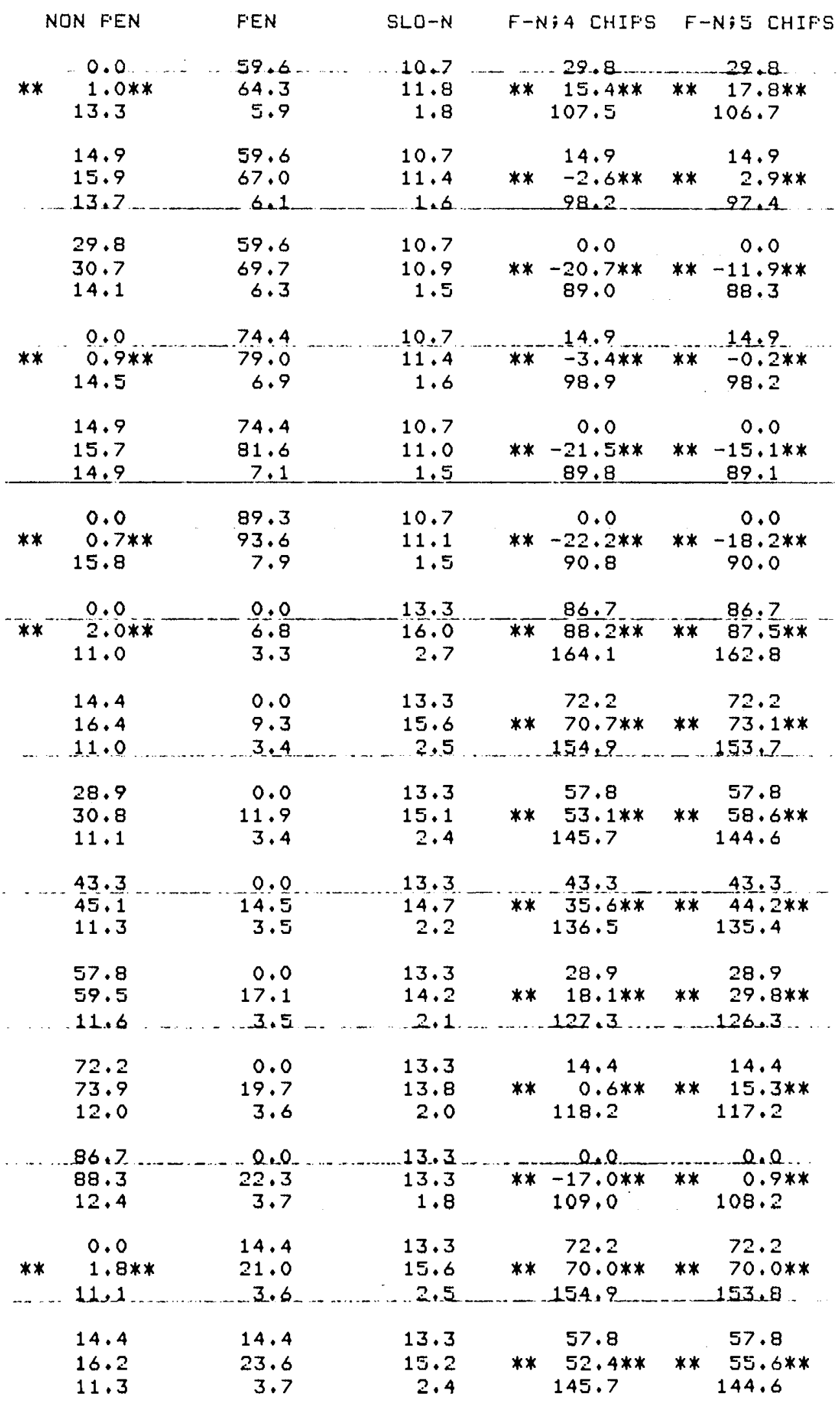




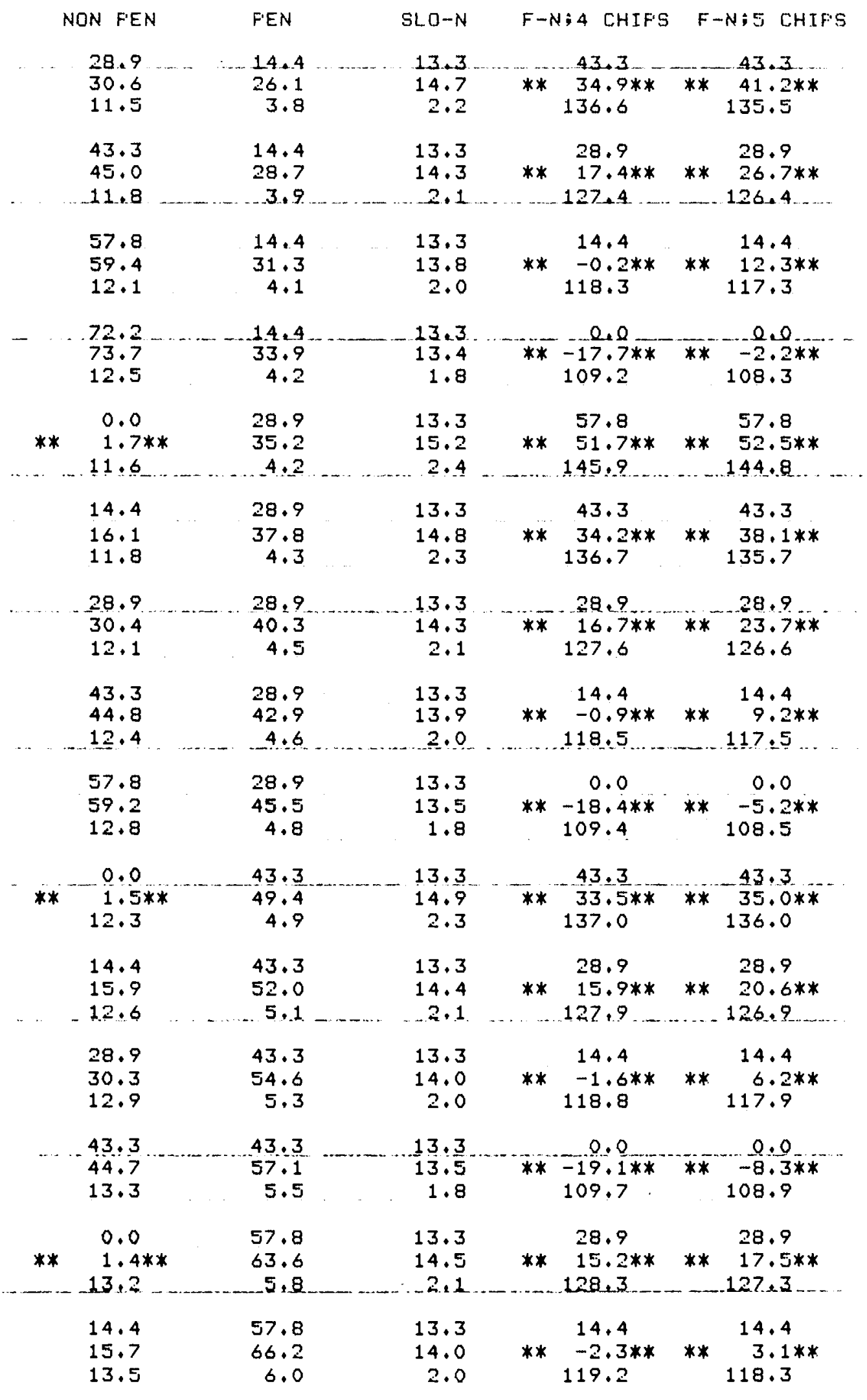




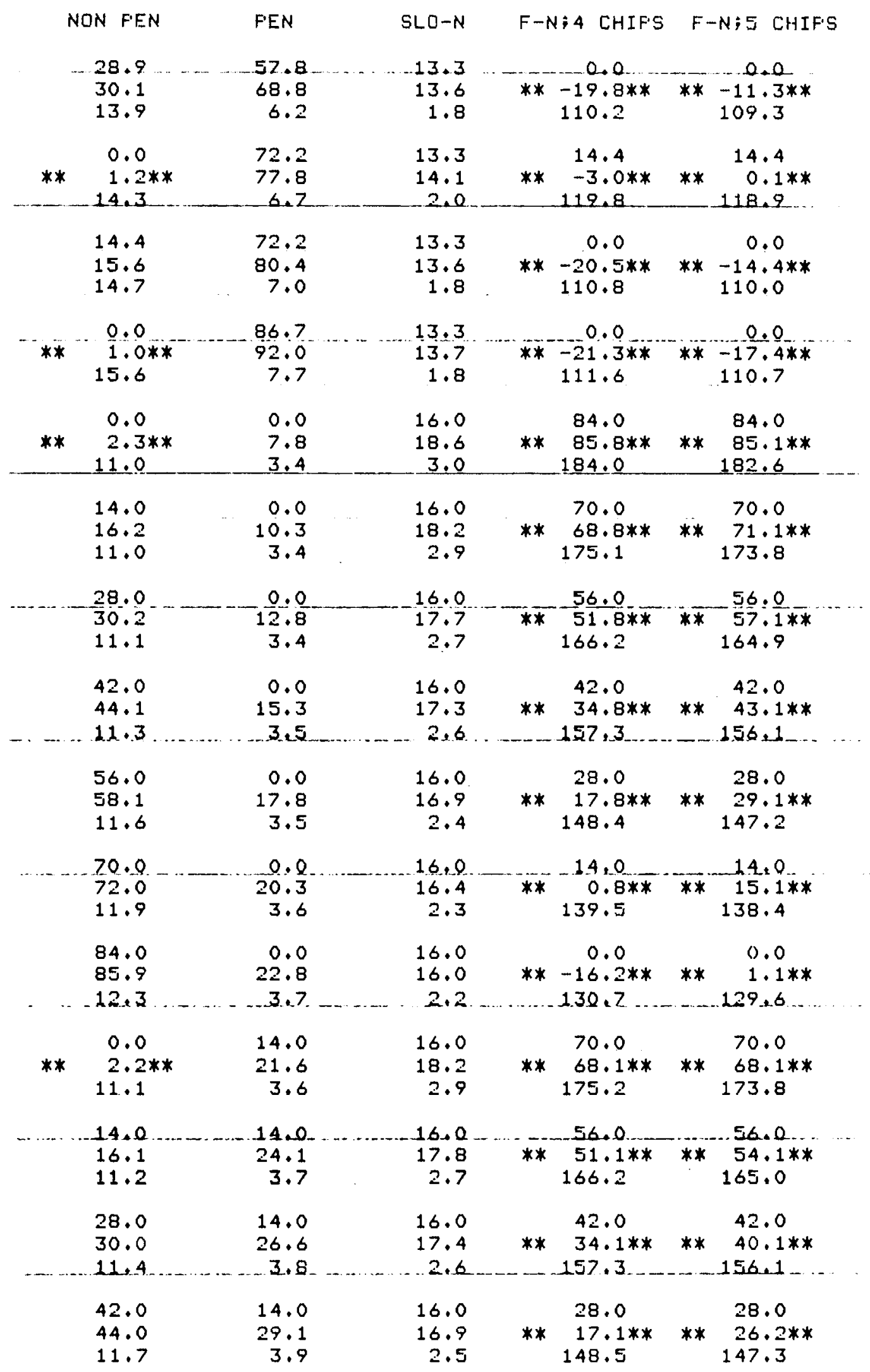

10.A. 12 


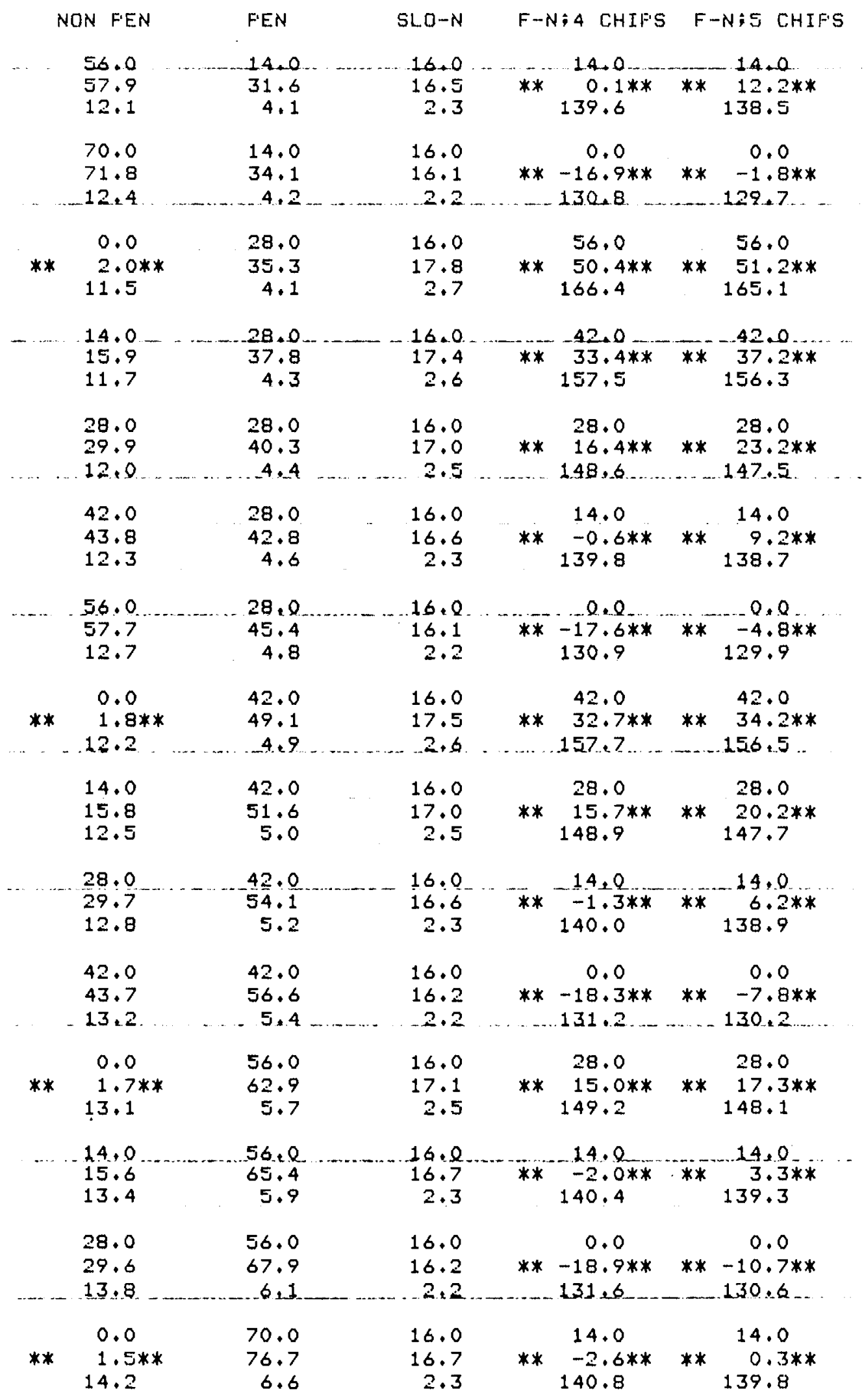




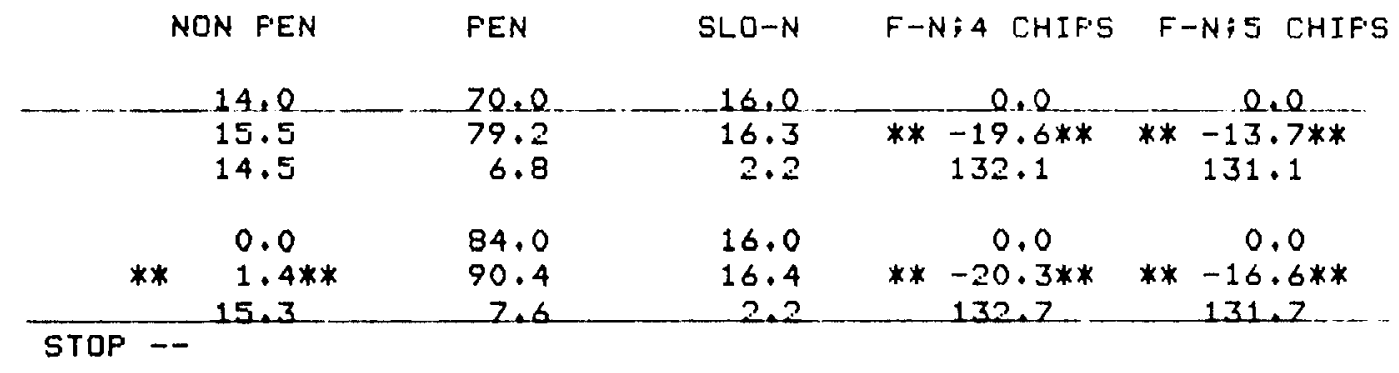

10.A. 14 
$000056 \quad 152546 \quad 140714000030$

$\$ I 1 \times 0$

RT-11SJ V02C-02

RUN IIXI:IIISST8

CALIB CONSTS AND STD DEV

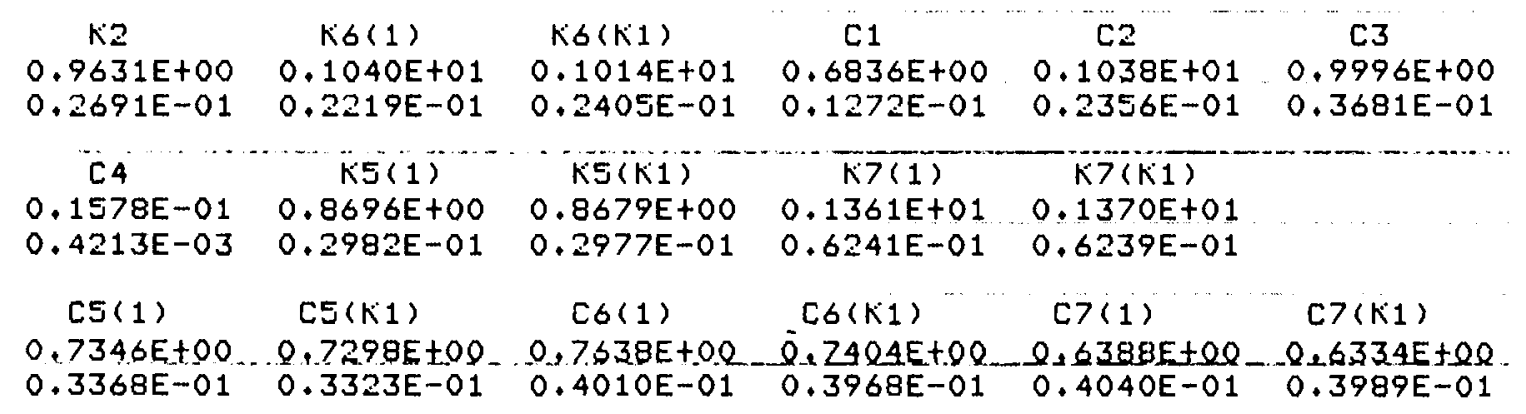

10.A.15 

APPENDIX B

CALCULATIONS FOR TABLE 10.4 
ADDENDUM TO TABLE 10.4:

GAMMA EXPOSURE

$$
\begin{aligned}
\text { Dose }=90.4 \mathrm{mR}= & 90.4 \text { mrem }{ }^{60} \mathrm{CO} \\
\bar{R} 1 & =122.12 \\
\overline{\mathrm{R}} 2 & =127.37 \\
\mathrm{~S}(\mathrm{R} 1-\mathrm{R} 2)_{\text {HMPD } 1 \rightarrow 12} & = \pm 10.45 \\
\mathrm{SB1} & =.84 \\
\mathrm{SB2} 2 & =1.64
\end{aligned}
$$

$$
S(R 1-R 2)=\sqrt{\left(\frac{S \%}{100} \cdot \bar{R} 2\right)^{2}+S B 1^{2}+\left(\frac{S \%}{100} \cdot \bar{R} 2\right)^{2}+S B 2^{2}}
$$

$S \%=5.829 \%$

$$
\begin{aligned}
& \overline{\mathrm{R}} 3=146.65 \quad \mathrm{SB3}=2.96 \\
& \bar{R} 4=122.62 \quad \mathrm{SB} 4=3.42 \\
& S(R 3-R 4) \text { HMPD } 1 \rightarrow 12= \pm 22.79 \\
& S(R 3-R 4)=\sqrt{\left(\frac{S \%}{100} \cdot R \overline{3}\right)^{2}+S B 3^{2}+\left(\frac{S \%}{100} \cdot \bar{R} 4\right)^{2}+S B 4^{2}} \\
& \mathrm{~S} \%=11.68 \%
\end{aligned}
$$




$$
\begin{aligned}
& 100 \text { mR Data Without Correction Factor } \\
& \text { Mean Standard Deviation } \\
& \begin{array}{lll}
\text { R1 } & 135.09 & 7.87
\end{array} \\
& \begin{array}{lll}
\text { R2 } & 140.90 & 8.21
\end{array} \\
& \begin{array}{lll}
\text { R3 } & 162.22 & 18.96
\end{array} \\
& \begin{array}{lll}
\text { R4 } & 135.64 & 15.84
\end{array} \\
& \begin{array}{lll}
\text { R5 } & 138.82 & 8.902
\end{array} \\
& R 5=\left(\frac{R 5}{R 1+R 2}\right) \underbrace{60}_{\substack{\text { Dosimeters } \\
\text { Dond-Loaded }}} \times(R 1+R 2)^{60} \begin{array}{c}
\text { Co, Hanford MP } \\
\text { Dosimeters }
\end{array}=138.82
\end{aligned}
$$




$$
\begin{aligned}
& \text { Dose }=109.07 \mathrm{mrem}{ }^{252} \mathrm{Cf} \\
& \bar{R} 1=30.76 \\
& \bar{R} 2=32.87 \\
& \mathrm{SB1}=.84 \\
& S B 2=1.64 \\
& S(R 1-R 2)_{H M P D} 1 \rightarrow 12= \pm 5.982 \\
& \text { Eqn. } 1 \\
& S \%=12.65 \% \\
& \bar{R} 3=626.07 \\
& \overline{\mathrm{R}} 4=395.28 \\
& \mathrm{SB} 3=2.96 \\
& S B 4=3.42 \\
& S\left(R 3-\left(\frac{\overline{R 3}}{\overline{R 4}}\right) \cdot R 4\right) \text { HMPD } 1 \rightarrow 12= \pm 87.79 \\
& S\left(R 3-\left(\frac{\bar{R} 3}{\bar{R} 4}\right) \cdot R 4\right)=\sqrt{2 \cdot\left(\frac{S \%}{100} \cdot \bar{R} 3\right)^{2}+S B 3^{2}+\left(S B 4 \cdot \frac{\overline{R 3}}{\overline{R 4}}\right)^{2}} \\
& S \%=9.891
\end{aligned}
$$

Eq. 3 (using hand loaded, 1 TLD per position dosimeters)

$$
R 5=33.08
$$

For Pure Fast Neutron Exposure $\left({ }^{252} \mathrm{Cf}\right.$ is about $6 \%$ gamma)

The four sources of TLD-700 response to a pure fast neutron exposure would be: 
(a) Thermoluminescense due to capture $\gamma$ rays in phantom

(b) Thermoluminescense due to ${ }^{6} \mathrm{Li}(0.07 \%)$ impurity in TLD-700 material

(c) Thermoluminescense due to capture $r$ rays in Cadmium filter

(d) Thermoluminescense due to ${ }^{7} \mathrm{Li}$ capture of neutrons

(a) $109.07 \mathrm{mrem}{ }^{252} \mathrm{Cf} \times\left(\frac{.009063 \mathrm{rad} \gamma}{\text { rem neutrons }}\right)^{(*)}=.9885 \mathrm{rad} \gamma$

$$
\begin{aligned}
& R 1 \rightarrow \frac{.99 \mathrm{rad}}{100} \cdot 140.3=1.386 \text { reader counts } \\
& R 2 \rightarrow \frac{.99 \mathrm{rad}}{100} \cdot 146.28=1.446 \text { reader counts } \\
& R 3 \rightarrow \frac{.99 \mathrm{rad}}{100} \cdot 144.12=1.425 \text { reader counts }
\end{aligned}
$$

(b) $(.0007)^{(* *)} \cdot(593)=.415$ reader counts

$\mathrm{R} 1=\mathrm{R} 2=\mathrm{R} 5=.415$ reader counts.

(c) $4.68 \%$ of neutron response absorbed by $\mathrm{Cd}$ in $180^{\circ}$ of view was shown experimentally to lead to generation of radiation which lead to gamma thermoluminescent response. From this:

$$
\begin{aligned}
& R 2 \rightarrow(.007801)^{(\ddagger)} 487 \cdot .0468=.178 \\
& R 1 \rightarrow(.02847) \cdot 487 \cdot .0468=.649 \\
& R 5 \rightarrow(.03264) \cdot 487 \cdot .0468=.744 \\
& \frac{1.2}{170} \cdot(0.179) \cdot(593)=0.75 \leftarrow R 1=R 2=R 5
\end{aligned}
$$

(d)

(*) From data in Attrix, Roesch, and Tochilin, Radiation Dosimetry I, pp. 297, 298.

(**) This vaiue is cited by Oak Ridge National Laboratorys Spectrographic analys is data for the lithium metal used to make TLD-700.

$(\neq)$ Field of view as fraction of hemisphere (or $180^{\circ}$ ) occupied by cadmium. 


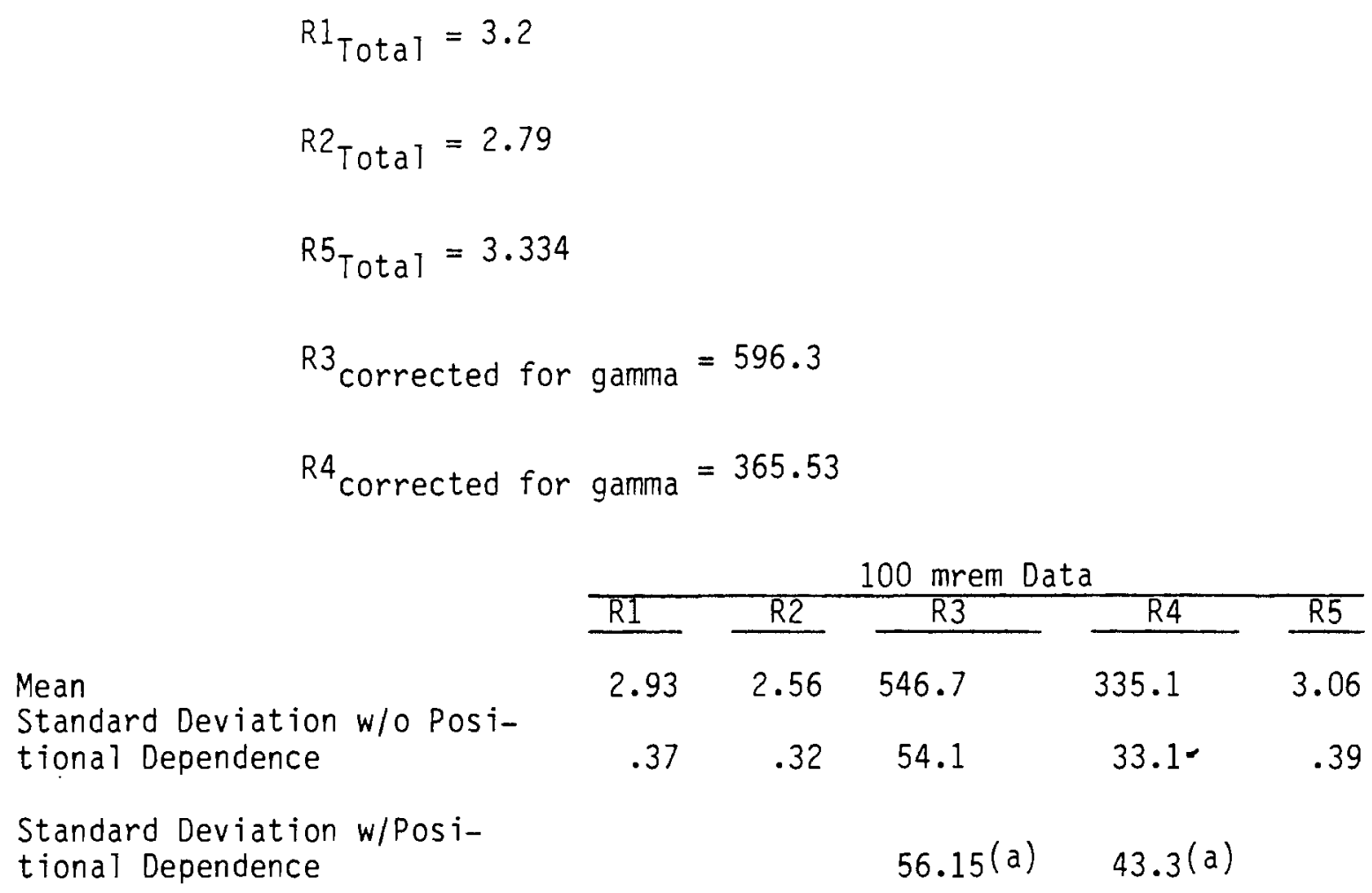

(a) With radiation positional dependence of 0.0275 and 0.0833 . 


\section{BETA EXPOSURE}

$$
\text { dose } \simeq 260 \text { mrem }
$$

$$
\begin{aligned}
& \overline{\mathrm{RI}}=319.7 \\
& \overline{\mathrm{R} 2}=73.63
\end{aligned}
$$

$\frac{S 2 \% \text { HMPD } 1 \rightarrow 12}{S 1 \% \text { HMPD } 1 \rightarrow 12}=3.09$

$S\left(R 1-\left(\frac{\overline{R I}}{\overline{R 2}}\right) \cdot R 2\right)$ NMPD $1 \rightarrow 12= \pm 28.03$

$S\left(B 1-\left(\frac{\bar{R} 1}{\overline{R 2}}\right) \cdot B 2\right)= \pm 12.67$

$S\left(R 1-\left(\frac{\overline{R 1}}{\overline{R 2}}\right) \cdot R 2\right)=\sqrt{\left(\frac{S 1 \%}{100} \cdot \overline{R 1}\right)^{2}+\left(\frac{\overline{R 1}}{\overline{R 2}} \cdot \frac{3.09 \cdot S 1 \%}{100} \cdot \overline{R 2}\right)^{2}+S\left(B 1-\left(\frac{\overline{R 1}}{\overline{R 2}}\right) \cdot B 2\right)^{2}}$

$\mathrm{S} 1 \%=2.41 \%$

$\mathrm{S} 2 \%=7.44 \%$ 
UST $=$ U.S. Testing dosimeters read bv U.S. Testina

$H L=$ Hand loaded and read dosimeters

(-all readings come from beta exposures unless listed otherwise)

$$
R_{5 \text { UST }}=(R 1+R 2)_{U S T} \cdot\left(\frac{R 5}{R I+R 2}\right)_{H L}
$$

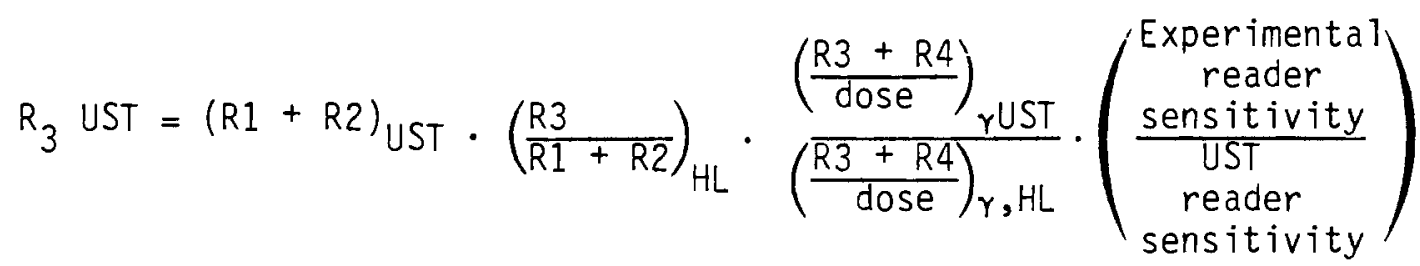

$R_{4 U S T}=(R 1+R 2)_{U S T} \cdot\left(\frac{R 4}{R 1+R 2}\right)_{H L} \cdot \frac{\left(\frac{R 3+R 4}{d o s e}\right)_{Y, U S T}}{\left(\frac{R 3+R 4}{\text { dose }}\right)_{Y, H L}} \cdot\left(\begin{array}{l}\text { Experimental } \\ \text { reader } \\ \text { sensitivity } \\ \text { UST reader } \\ \text { sensitivity }\end{array}\right)$

$\mathrm{SR} 5 \%=(\mathrm{SR} 1 \%+\mathrm{SR} 2 \%)_{\mathrm{UST}} \cdot\left(\frac{\mathrm{SR} 5 \%}{\mathrm{SR} 1 \%+\mathrm{SR} 2 \%}\right)_{\mathrm{HL}}$

$\mathrm{SR} 3 \%=(\mathrm{SR} 1 \%+\mathrm{SR} 2 \%)_{\text {UST }} \cdot\left(\frac{\mathrm{SR} 3 \%}{\mathrm{SR} 1 \%+\mathrm{SR} 2 \%)_{H L}} \cdot \frac{(\mathrm{SR} 3 \%+\mathrm{SR} 4 \%)_{\gamma}, \mathrm{UST}}{(\mathrm{SR} 3 \%+\mathrm{SR} 4 \%)_{\gamma}, \mathrm{HL}}\right.$

$\mathrm{SR} 4 \%=(\mathrm{SR} 1 \%+\mathrm{SR} 2 \%)_{U S T} \cdot\left(\frac{\mathrm{SR} 4 \%}{(S R 1 \%+\mathrm{SR} 2 \%)_{H L}} \cdot \frac{(\mathrm{SR} 3 \%+\mathrm{SR} 4 \%)_{\gamma}, \mathrm{UST}}{(\mathrm{SR} 3 \%+\mathrm{SR} 4 \%)_{\gamma}, \mathrm{HL}}\right.$ 
Using Equations $6,7,8,9,10$, and 11 :

$$
\begin{aligned}
& R 5=(319.7+73.63) \cdot\left(\frac{1.243}{111.22+23.79}\right)=3.621 \\
& R 3=(393.3) \cdot\left(\frac{2.088}{135.01}\right) \cdot\left(\frac{3.4658}{3.676}\right)=5.735 \\
& R 4=(393.3) \cdot\left(\frac{1.526}{135.01}\right) \cdot\left(\frac{3.4658}{3.676}\right)=4.191
\end{aligned}
$$

\begin{tabular}{lcc} 
& \multicolumn{2}{c}{100 mrem data } \\
\cline { 2 - 3 } & mean & standard deviation \\
R1 & 123.803 & 2.984 \\
R2 & 28.51 & 2.121 \\
R3 & 2.221 & .33 \\
R4 & 1.623 & .24 \\
R5 & 1.402 & .13
\end{tabular}

$$
\left.\begin{array}{l}
\text { SR5 }=(2.41+7.44) \cdot\left(\frac{11.18}{12.02}\right)=9.162 \% \\
\text { SR3 }=(2.41+7.44) \cdot\left(\frac{10.68}{12.02}\right) \cdot 3.337=29.21 \% \\
\text { SR4 }=(2.41+7.44) \cdot\left(\frac{11.21}{12.02}\right) \cdot 3.337=30.65 \%
\end{array}\right\} \begin{aligned}
& \text { this looks too high so } \\
& \text { decreased arb itrarily to } 15 \%
\end{aligned}
$$


THERMAL NEUTRON EXPOSURE

dose $=280$ mrem $P$ uBe $-D_{2} \mathrm{O}$

$$
\begin{aligned}
& \overline{R I}=471.7 \\
& \overline{R 2}=472.8 \\
& S(R 1-R 2)=18.25 \\
& S(B 1-B 2)=4.56 \\
& 18.25=\sqrt{\left(471.7 \cdot \frac{5 \%}{100}\right)^{2}+\left(472.8 \cdot \frac{5 \%}{100}\right)^{2}+4.56^{2}} \\
& \underline{S}=2.64 \% \\
& \overline{R 3}=36908 \\
& \overline{\mathrm{R} 4}=17461 \\
& S\left(B 3-\left(\frac{\overline{R 3}}{\overline{R 4}}\right) \cdot B 4\right)= \pm 15.03 \\
& S\left(R 3-\left(\begin{array}{l}
\overline{R 3} \\
R 4
\end{array}\right) \cdot R 4\right)= \pm 1651.6 \\
& 1651.6=\sqrt{\left(36908 \cdot \frac{S \%}{100}\right)^{2}+\left(17461 \cdot \frac{S \%}{100}\right)^{2}+15.03^{2}} \\
& S=4.045 \%
\end{aligned}
$$


For a Pure Thermal Neutron Exposure

Four sources of TLD-700 response to a pure thermal neutron exposure would be:

(a) Thermoluminescense due to capture $\gamma$ rays in phantom.

(b) Thermoluminescense due to ${ }^{6} \mathrm{Li}$ (0.07\%) impurity in TLD-700 material.

(c) Thermoluminescense due to capture yrays from cadmium filter.

(d) Thermoluninescense due to ${ }^{7} \mathrm{~L} i$ capture of neutrons.

(a) $280 \mathrm{mrem}$ (thermal neutrons) $\times \frac{0.347 \mathrm{mrad}}{\mathrm{mrem} t h-\mathrm{n}}=97.15 \mathrm{mrad} \gamma$

$\mathrm{R} 1 \rightarrow\left(\frac{97.16 \mathrm{rad}}{100 \mathrm{rad}}\right) \times 140.3=136$

$R 2 \rightarrow\left(\frac{97.16 \mathrm{rad}}{100 \mathrm{rad}}\right) \times 146.28=142$

$R 5=\left(\frac{97.16 \mathrm{rad}}{100 \mathrm{rad}}\right) \times 144.12=140$

assume $R 3=R 4=R 5$

(b) $.0007 \cdot 36432=25.5=\mathrm{R} 1=\mathrm{R} 2=\mathrm{R} 5$

(c) $4.68 \%$ of neutron response absorbed by $\mathrm{Cd}$ in $180^{\circ}$ view was shown experimentally to lead to generation of $y$ radiation which lead to gamma thermolunimescent response. From this:

$R 2 \rightarrow(.007801) \cdot 36432 \cdot .0468=13.3$

$R 1 \rightarrow(.02847) \cdot 36432 \cdot .0468=48.5$

$R 5 \rightarrow(.03268) \cdot 36432 \cdot .0468=55.7$

(d) -not calculated.

R1 total $=210$

R2 total $=181$ 


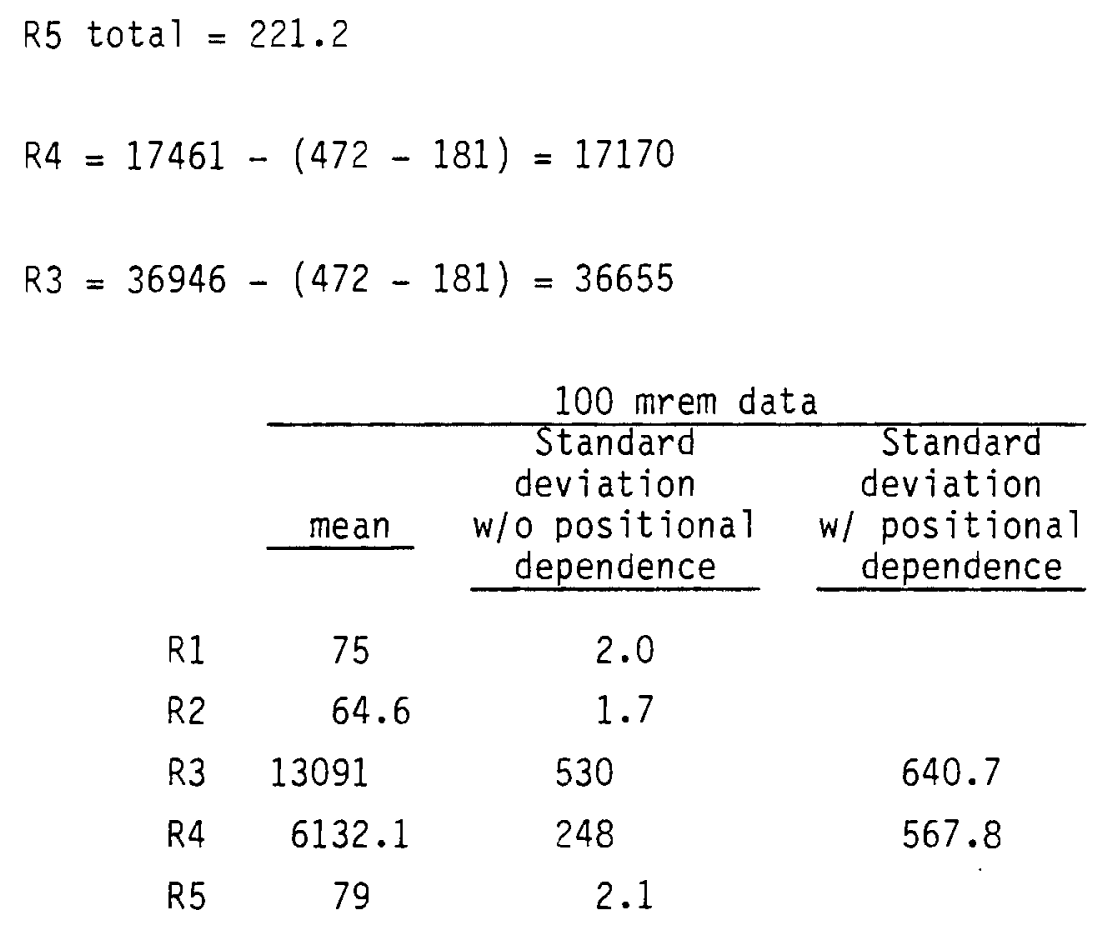

10.B. 11 



\section{DISTRIBUTION}

No. of

Copies

OFFSITE

A. A. Churm

DOE Patent Division

9800 S. Cass Avenue

Argonne, IL 60439

E. J. Vallario

Assistant Chief/Manager

Health Physics Programs

Operations and Environmental

Safety Division

U.S. Department of Energy

Washington, D.C. 20545

W. V. Baumgartner

United States Testing Company

2800 George Washington Way

Richland, WA 99352

27 DOE Technical Information Center

\section{ONSITE}

7 DOE Richland Operations Office

M. S. Mills

H. E. Ransom

J. L. Rhoades

M. W. Tiernan

M. G. White

G. R. Yesberger (2)

1 FFTF Project Office

J. R. Patterson

3 Rockwe 11 Hanford Operations

W. A. Decker

E. N. Dodd, Jr.

P. G. Lorenzini
No. of

Copies

3 UNC Nuclear Industries

P. A. Carlson

L. K. Poppe

W. G. Westover

1 Hanford Engineering Development Laboratory

G. P. Carpenter

34 Pacific Northwest Laboratory

J. M. Aldrich

G. E. Backman

F. M. Cummings

F. N. Eichner

G. W. R. Endres

L. G. Faust

J. J. Fix

W. A. Glass

D. L. Haggard

J. J. Jech (7)

R. L. Kathren

H. V. Larson

L. L. Nichols

N. P. Nisick

C. R. Richey

M. R. Thorson

C. M. Unruh

R. H. Wilson

M. K. Winegardner

R. C. Yoder

Hea1th Physics Technology Library

Technical Information Library (5)

Publishing Coordination (2) 
